Universidad Politécnica de Madrid

Escuela Técnica Superior de Ingeniería Aeronáutica y del Espacio

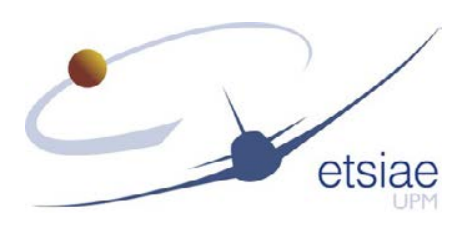

\title{
Modelización del proceso de laminación automática y consolidación in-situ con materiales compuestos termoplásticos $\mathrm{APC} 2 / \mathrm{AS} 4$
}

\section{TESIS DOCTORAL}

María Isabel Martín Hernando

Ingeniero Aeronáutico

2019 
Documento maquetado con $\mathrm{T}_{\mathrm{E}} \mathrm{XIS}$ v.1.0+. 
Departamento de Materiales y Producción Aeroespacial Escuela Técnica Superior de Ingeniería Aeronáutica y del Espacio

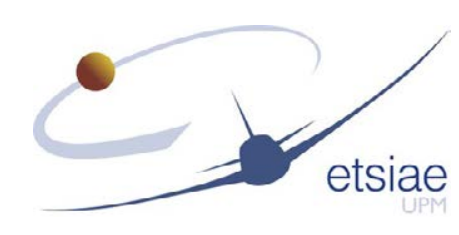

Modelización del proceso de laminación automática y consolidación in-situ con materiales compuestos termoplásticos $\mathrm{APC} 2 / \mathrm{AS} 4$

Memoria que presenta para optar al título de Doctor en Ingeniería Aeronáutica y del Espacio María Isabel Martín Hernando Ingeniero Aeronáutico Dirigida por el Doctor Jesús Alfredo Güemes Gordo 
Copyright (c) María Isabel Martín Hernando 
A mis padres, por inculcarme que en la vida vale más envidiar al inteligente que al que más tiene 



\section{Agradecimientos}

Elogia el puente que te llevó encima.

George Colman

No querría dejar escapar la oportunidad de dar las gracias en dos breves párrafos a todas las personas que en el transcurso de esta tesis me han servido de apoyo. Familiares, pareja, amigos y compañeros que no han cesado de animar y de impulsar mis ganas por terminar un trabajo que acepté con muchos miedos.

Debo incluir una mención importante hacia FIDAMC, el centro que me ha permitido hacer este trabajo. En varios momentos del desarrollo de la tesis, me encontré pensando en FIDAMC como un punto en el centro del mapa de nuestro país con un sistema prácticamente único para el encintado de termoplásticos. ¿Cómo podría desaprovechar la oportunidad de trabajar en algo en lo que tan poca gente podía?, ¿cómo podía no intentar encontrar alguna aportación?, tenía que intentarlo, siempre intentarlo. De ahí que nunca parara de buscar información y que vaya a seguirla buscando siempre de aquí en adelante. Este trabajo irá conmigo siempre a pesar del futuro que se presente.

Finalmente, querría incluir un agradecimiento a la comunidad científica mundial. Durante el desarrollo de la tesis, he enviado consultas a personas de diferentes lugares del mundo: Rusia, Australia, Estados Unidos...y todos ellos contestaron a las preguntas que les formulaba. Debo decir que cuando mandé los correos jamás pensé que fueran a prestarme ninguna atención y sin excepción, recibí siempre sus aportaciones. En este punto querría destacar la ayuda que compañeros de IMDEA Materiales y de CSIC (centros de Madrid y de Sevilla) han prestado a mi trabajo, sin ellos nunca jamás habría llegado a este punto. Ojalá mis conocimientos y mi trabajo puedan proporcionarles pronto toda la ayuda que ellos me prestaron a mí. 



\section{Resumen}

Este trabajo doctoral, se focaliza en el análisis del proceso de encintado en automático y consolidación in-situ con material reforzado termoplástico tipo APC2/AS4. Dadas las limitaciones encontradas para combinar resultados de calidad y capacidades productivas en este proceso de fabricación, ejecutar un estudio detallado de cada uno de los elementos que interaccionan en el proceso, se presenta como la clave para introducir mejoras.

En el proceso, el material debe calentarse para permitir la adhesión entre el elemento aportado y el sustrato. Tratando de analizar ese proceso de calentamiento, se presenta en este trabajo un modelo numérico que permite extraer información de la evolución de los perfiles temperatura-tiempo en el material durante su calentamiento y durante la etapa de enfriamiento posterior. Sus resultados han sido correlados con medidas experimentales sobre paneles laminados.

Tratando de evitar efectos de degradación por calentamiento sobre el material, se estudia en este trabajo la cinética de degradación del polímero PEEK. El análisis permitirá proponer una representación matemática a la evolución de la degradación bajo unos valores de temperatura-tiempo cualesquiera, fundamentándose en degradaciones monitorizadas a través de pérdida de masa en el material o variaciones ocasionadas sobre su viscosidad por efecto de la temperatura. Asimismo, se emplearán diferentes técnicas de análisis para determinar la existencia de indicios de degradación sobre el material encintado.

Una vez calentado el material, el sistema de encintado pone en contacto las superficies de material bajo la acción de un rodillo de compactación. Buscando modelar esa etapa, se analizará el porcentaje de unión alcanzado entre las capas de material encintado en base a la evolución del grado de contacto íntimo (entendido como la eliminación de la rugosidad superficial del material) y a la difusión de las cadenas poliméricas. Para ello, el estudio elaborado tratará de describir las heterogeneidades de la superficie del material, modelizando la evolución de su destrucción como función de su estado 
irregular inicial, de la presión aplicada y del perfil tiempo-temperatura aplicado. El movimiento de las cadenas poliméricas, asociado con la difusión, se estudiará mediante ensayos de reología que permiten extraer una ecuación matemática relacionando el tiempo de relajación frente a la temperatura.

En el momento en que el rodillo pone en contacto las superficies de los materiales aporte y sustrato, punto justo tras el cese del calentamiento, tiene lugar una brusca caída de la temperatura. La caída de temperatura, inicia el proceso cinético de cristalización en el material. En este trabajo se han ejecutado diversos análisis para conocer con más detalle cómo tiene lugar la cristalización en un polímero como el PEEK y cómo esta se ve afectada en las condiciones de procesado de la laminación automática y consolidación in-situ. Se propondrá, tal como se hiciera con los anteriores mecanismos, un modelo matemático representativo de la evolución de la cristalización en el proceso, de modo que, considerando un perfil temperatura-tiempo pueda valorarse el grado de cristalización obtenido.

Los análisis de grado de unión y cristalización, son ejecutados bajo la consideración de una única etapa de encintado (es decir, en el encintado de capa 2 sobre capa 1 , sin considerar las sucesivas etapas en el encintado del resto de capas). En varios puntos del trabajo se efectuarán aclaraciones sobre cómo debería continuarse dicho análisis para estimar su impacto en la laminación de un panel completo.

En la parte final del trabajo, se han incluido los resultados de diferentes ensayos mecánicos sobre paneles fabricados por la tecnología de encintado automático y consolidación in-situ, siendo comparados con una referencia obtenida en prensa de platos calientes. Se analizarán las diferencias fundamentales entre ellos, no sólo respecto a los valores numéricos reportados por los ensayos, sino también mediante la aplicación de microscopia electrónica de barrido en algunas de las entrecaras de fractura, buscado obtener información de los distintos modos de fallo. 


\section{Abstract}

This work is focused on the analysis of one manufacturing process: Automatic Lamination and In-Situ Consolidation with Thermoplastic Composite Materials, with APC2/AS4 being the material considered for the experiments and models. Due to the limitations associated with obtaining good quality and high productivity simultaneously, a detailed analysis of the process is evidenced as a requirement. This analysis needs to take into account each of the individual elements that interact, being its knowledge the only way to improve the process.

During the process, the material is heated to generate the adhesion between the incoming element and the substrate. In order to analyze the previously mentioned heating, a numerical model is presented in this work. The model permits to extract the information of the time-temperature evolution whilst heating the material and in the later stage of cooling.

Trying to avoid degradation effects derived from heating, a control of the temperature thresholds is required. This document includes a kinetic analysis of the thermal degradation of the polymer (PEEK), which has allowed to obtain a mathematical equation that represents the evolution of thermal degradation and its dependence on temperature-time profiles. The evolution of thermal degradation is presented by considering two parameters: the mass loss and viscosity variations. Moreover, different techniques of analysis have been used to determine the existence of thermal degradation in the material after being laminated.

After heating, the incoming material makes contact with the substrate by the interaction of a compaction roller. With the goal of modeling this stage, the percentage of bonding between the layers was analyzed. The evolution of the degree "intimate contact" and the degree of "healing" has been considered to develop this analysis. The heterogeneous material surface has been measured, modelling the evolution during the process as a mathematical function of the initial roughness state, the applied pressure and the temperature-time profiles. The polymer chains movement, associated with healing, has been 
followed by rheological testing. For both cases, equations are proposed.

When the compaction roller contacts with the material, a sharp temperature drop appears. During cooling, the polymer develops crystallization. In this work, several studies were done in order to determine how the crystal structure is created and the impact on crystallization of this manufacturing process conditions in comparison with other processes as oven or press. As with the other elements under analysis, a mathematical equation is proposed to predict the evolution of crystallization whilst lamination.

Adhesion and crystallization were studied by considering the first lamination stage, laminating the second layer over the first. These analyses should be continued taking into account the deposition of multiple layers in a real structure.

At the end of the work, the results of several mechanical tests are included, with the subject being samples coming from automatic lamination and in-situ consolidation and press, trying to compare their differences. Scanning electron microscopy was applied to obtain visual information of the fracture mode. 


\section{Índice}

\begin{tabular}{lll}
\hline Agradecimientos & VII
\end{tabular}

Resumen IX

$\begin{array}{ll}\text { Abstract } & \text { XI }\end{array}$

1. Introducción 1

1.1. Introducción . . . . . . . . . . . . . . . . . . . 1

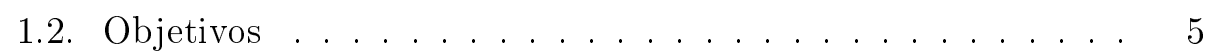

\begin{tabular}{lr}
\hline 2. Estado del arte & 9
\end{tabular}

2.1. Materiales termoplásticos . . . . . . . . . . . . . 11

2.2. Laminación automática y consolidación in-situ. . . . . . . . . 13

2.2.1. Mejoras al proceso de ISC . . . . . . . . . . . . 16

2.3. Transferencia térmica y medidas . . . . . . . . . . . 18

2.3.1. Sistemas de calentamiento . . . . . . . . . . . . 18

2.3.2. Modelos de transferencias de calor . . . . . . . . . . 21

2.3.3. Determinación experimental de la temperatura . . . . 41

2.3.4. Sistemas de control . . . . . . . . . . . . . . 43

2.4. Degradación térmica . . . . . . . . . . . . . . . . 45

2.4.1. Determinación experimental de la degradación térmica 49

2.4.2. Cinética de degradación térmica . . . . . . . . . 51

2.5. Adhesión . . . . . . . . . . . . . . . . . . . . 59

2.5.1. Teoría del contacto íntimo . . . . . . . . . . . 59

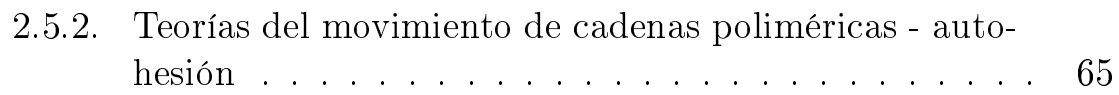

2.5.3. Teoría de unión . . . . . . . . . . . . . . . 72

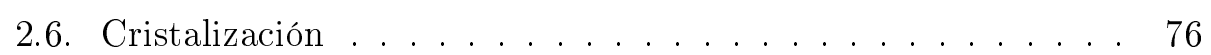

2.6.1. Termodinámica en la cristalización de polímeros. . . . 76

2.6.2. Teoría cinética . . . . . . . . . . . . . 79

2.6.3. Transcristalización . . . . . . . . . . . . . 86

2.6.4. Estudios de cristalización en el PEEK . . . . . . . 87 
2.6.5. Cristalización y propiedades mecánicas . . . . . . . . 98

\begin{tabular}{ll}
\hline 3. Procedimiento Experimental & 103
\end{tabular}

3.1. Materiales . . . . . . . . . . . . . . . . . . . 103

3.2. Fabricación de paneles . . . . . . . . . . . . . . 105

3.2.1. Paneles fabricados en máquina de encintado automático (ISC) $\ldots \ldots \ldots \ldots$. . . . . . . . . . . . . . 105

3.2.2. Paneles fabricados en prensa de platos calientes . . . . 107

3.2.3. Inspección no destructiva de los paneles . . . . . . . . 108

3.3. Monitorización de temperatura . . . . . . . . . . . . . 110

3.4. Técnicas de ensayo . . . . . . . . . . . . . . . . . . 110

3.4.1. Propiedades térmicas y termomecánicas . . . . . . . 110

3.4.2. Propiedades mecánicas . . . . . . . . . . . . . 116

3.4.3. Análisis superficial . . . . . . . . . . . . . . . . 118

3.4.4. Espectroscopía . . . . . . . . . . . . . . . . 118

3.4.5. Difracción de rayos X (XRD) . . . . . . . . . . . . 119

3.4.6. Análisis óptico . . . . . . . . . . . . . . . . 120

4. Discusión de resultados 123

4.1. Transferencia de calor . . . . . . . . . . . . . . 125

4.1.1. Determinación experimental de la transferencia de calor 125

4.1.2. Simulación térmica . . . . . . . . . . . . . . 146

4.1.3. Simulación térmica vs. experimental . . . . . . . . 155

4.2. Degradación térmica . . . . . . . . . . . . . . 165

4.2.1. Determinación experimental de degradación térmica .165

4.2.2. Modelos de degradación térmica . . . . . . . . . . 177

4.3. Adhesión . . . . . . . . . . . . . . . . . 192

4.3.1. Contacto íntimo . . . . . . . . . . . . 193

4.3.2. Difusión - Autohesion - Healing . . . . . . . . . . . . . . . . . . . . . . . . . . . . . . .

4.3 .3$. Unión . . . . . . . . . . . . . . . . . 230

4.4. Cristalización . . . . . . . . . . . . . . . . . . . . 232

4.4.1. Determinación experimental de cristalinidad . . . . . . 233

4.4.2. Modelos de cristalización. . . . . . . . . . . . . 254

4.5. Caracterización de laminados fabricados . . . . . . . . . . 285

4.5.1. Caracterización termo-mecánica de laminados fabricados por ISC . . . . . . . . . . . . . . . . 285

4.5.2. Caracterización mecánica de laminados. . . . . . . . . 289

5. Conclusiones 303

5.1. Conclusiones . . . . . . . . . . . . . . . 303

\begin{tabular}{|ll}
\hline A. Ejecuciones de medida de temperatura con termopares & 311
\end{tabular} 
A.1. Encintado con todas las capas a 0 . . . . . . . . . . 311

A.2. Encintado con capas a $0-90 \ldots \ldots 318$

A.3. Encintado con doble láser . . . . . . . . . . . . . . . . . . 334

B. Capacidad calorífica Zafiro 339

\begin{tabular}{ll}
\hline C. Calorimetría diferencial de barrido & 341
\end{tabular}

C.1. Calorimetría en el análisis de la degradación térmica . . . . . 341

C.2. Calorimetría en el análisis de la estructura del PEEK . . . . . 345

C.3. Morfología del pico de fusión . . . . . . . . . . . . . 352

C.4. Efecto del utillaje calefactado . . . . . . . . . . . . . . 354

C.5. Efecto del calentamiento secuencial en ISC. . . . . . . . . . . 357

C.5.1. Utillaje no calefactado - probeta escalón . . . . . . . . 358

C.5.2. Utillaje calefactado - probeta escalón . . . . . . . . . 367

D. Deconvolución en cristalización: enfriamientos a mayor velo$\begin{array}{ll}\text { cidad } & 377\end{array}$

\begin{tabular}{ll}
\hline Bibliografía & 379
\end{tabular} 



\section{Índice de figuras}

2.1. Croquis del proceso de laminación automática y consolidación in-situ ....................... 14

2.2. Máquinas de encintado con doble sistema de compactación a)(Tierney y Gillespie [2006) y b)(Barasinski et al.] 2011b)] . . 19

2.3. Tiempo de mantenimiento para el comienzo de la degradación en APC2 bajo atmósfera inerte (Dolo et al.[ 2017)] . . . . . . 49

2.4. Teoría de reptación de De Gennes, movimiento de cadenas menores $($ Wool $[2002)] \ldots \ldots \ldots \ldots 68 \ldots \ldots \ldots$

2.5. Estructura de formación del cristal (Hynstová [2010) . . . . . 77

2.6. Celdilla unidad del PEEK (Kumar et al., 1986) . . . . . . . . 89

2.7. SEM sobre muestras de etching de PEEK/FC a) Enfriada lentamente desde fundido y b) Recocida desde un estado amorfo por debajo de la fusión y sobre la transición vítrea (Blundell et al. $[1989) \ldots \ldots \ldots \ldots \ldots$. . . . . . . . . . . . . 92

3.1. Unidad monomérica del PEEK . . . . . . . . . . . . . . . . 105

3.2. Máquina Unitow . . . . . . . . . . . . . . . . . 106

3.3. Ciclo Cytec/Solvay prensa . . . . . . . . . . . . . . . 108

3.4. Ciclo real prensa FIDAMC . . . . . . . . . . . . . . . . . . 109

3.5. Unidad de escaneo por NDT automático - placa reflectante . 110

3.6. Fundamento de la metodología de ensayo tipo CRTA . . . . . 114

4.1. Termografía durante el encintado con APC2/AS4 . . . . . . . 126

4.2. Perfil Temperatura-Longitud en el encintado de APC2/AS4 Lectura de cámara termográfica . . . . . . . . . . . . . . . 127

4.3. Marcados láser en la búsqueda de determinar posibles efectos de sombra generada por el rodillo de compactación . . . . . . 130

4.4. Perfil temperatura vs tiempo punto entre capas 1 y 2 encintando capa 3 con útil frío - Lectura con OMEGA CHAL-002 . 131

4.5. Perfil temperatura vs tiempo punto entre capas 1 y 2 encintando capa 4 con útil frío - Lectura con OMEGA CHAL-002. 132 
4.6. Perfil temperatura vs tiempo punto entre capas 1 y 2 encintando capa 5 con útil frío - Lectura con OMEGA CHAL-002. 133

4.7. Perfil temperatura vs tiempo punto entre capas 1 y 2 encintando capa 6 con útil frío - Lectura con OMEGA CHAL-002 . 134

4.8. Perfil temperatura vs tiempo punto entre capas 1 y 2 encintando capa 7 con útil frío - Lectura con OMEGA CHAL-002. 135

4.9. Perfil temperatura vs tiempo punto entre capas 1 y 2 encintando capa 8 con útil frío - Lectura con OMEGA CHAL-002 . 135

4.10. Perfil temperatura vs tiempo punto entre capas 1 y 2 encintando capa 9 con útil frío - Lectura con OMEGA CHAL-002. 136

4.11. Perfil temperatura vs tiempo punto entre capas 1 y 2 encintando capa 10 con útil frío - Lectura con OMEGA CHAL-002 137

4.12. Perfil temperatura vs tiempo punto entre capas 1 y 2 encintando capa 11 con útil frío - Lectura con OMEGA CHAL-002 138

4.13. Perfil temperatura vs tiempo punto entre capas 1 y 2 encintando capa 12 con útil frío - Lectura con OMEGA CHAL-002 138

4.14. Perfil temperatura vs tiempo punto entre capas 1 y 2 encintando capa 13 con útil frío - Lectura con OMEGA CHAL-002 139

4.15. Perfil temperatura vs tiempo punto entre capas 1 y 2 encintando capa 14 con útil frío - Lectura con OMEGA CHAL-002 139

4.16. Perfil temperatura vs tiempo punto entre capas 1 y 2 encintando capa 15 con útil frío - Lectura con OMEGA CHAL-002 140

4.17. Perfil temperatura vs tiempo punto entre capas 1 y 2 encintando capa 16 con útil frío - Lectura con OMEGA CHAL-002 140

4.18. Perfil temperatura vs tiempo punto entre capas 1 y 2 reprocesando sobre la capa 16 sin aporte de material con útil frío Lectura con OMEGA CHAL-002 . . . . . . . . . . . . . . . . 141

4.19. Perfil temperatura vs tiempo punto entre capas 1 y 2 tras el encintado de 16 capas con útil frío - Lectura con OMEGA CHAL-002 . . . . . . . . . . . . . . . . 142

4.20. Evolución de los máximos registrados por el termopar durante el encintado - Lectura con OMEGA CHAL-002 . . . . . . . . 142

4.21. Perfil temperatura vs tiempo punto entre capas 1 y 2 encintando capa 3 con útil frío con rodillos diferentes - Lectura con OMEGA CHAL-002, los rectángulos incluidos tratan de aproximar las áreas de compactación de cada uno de los rodillos considerados . . . . . . . . . . . . . . . . 144

4.22. Perfil temperatura vs tiempo, punto entre capas 1 y 2 encintando capa (a) 5, (b) 8, (c) 11 y (d) 16, con útil frío y rodillo cerámico - Lectura con OMEGA CHAL-002 . . . . . . . . . . 145

4.23. Perfil simulado T-t en un punto situado entre capas 1 y 2 encintando 16 capas, con útil frío y útil calefactado . . . . . . 152 
4.24. Ensayo DSC a $373 K$ para determinación de Cp en APC2/AS4 154

4.25. Cp vs. temperatura para PEEK 150G y APC2/AS4 . . . . . 155

4.26. Perfil temperatura vs tiempo, punto entre capas 1 y 2 encintando capa 3 con útil frío - Simulación vs. experimental . . . 156

4.27. Perfil temperatura vs tiempo punto entre capas 1 y 2 encintando capa 3 con útil frío - Simulación vs. experimental con factores multiplicativos en la potencia . . . . . . . . . 157

4.28. Barrido paramétrico en $h_{\text {rodillo }}$ laminando capa 2 con punto de muestreo sobre capa 1 . . . . . . . . . . . . 158

4.29. Barrido paramétrico en la longitud de compactación de rodillo laminando capa 2 con punto de muestreo sobre capa 1 . . . . 159

4.30. Simulación de calentamiento con barrido paramétrico en variación de distancia entre láser y entrada de rodillo . . . . . . 160

4.31. Simulación de calentamiento con barrido paramétrico en tem-

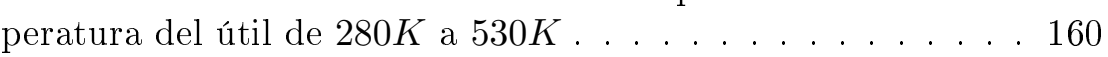

4.32. Simulación de calentamiento con barrido paramétrico en velocidad de encintado 1 a $10 \mathrm{~m} / \mathrm{min}$. . . . . . . . . . 161

4.33. Simulación de calentamiento con barrido paramétrico en velocidad de encintado 11 a $19 \mathrm{~m} / \mathrm{min}$. . . . . . . . . . 162

4.34. Efecto de la resistividad térmica entre capas . . . . . . . . . 163

4.35. Efecto de la potencia recibida por el material de aporte. . . . 164

4.36. Efecto de la potencia recibida por el material de aporte con \begin{tabular}{|c|c|}
\hline condición de sombra generada por el rodillo de compactación 164 & 16 \\
\hline
\end{tabular}

4.37. Comparativa ensayo TGA para panel en prensa y panel en ISC, rampa de calentamiento $10 \mathrm{~K} / \mathrm{min}$ y atmósfera oxidativa 167

4.38. Ensayo CRTA con velocidad de reacción igual a $0,004 \mathrm{~min}^{-1}$ para PEEK 450G (C1) en atmósfera oxidativa . . . . . . . . . 168

4.39. Comparativa del valor onset extrapolado y pico de fusión en ciclo 1 sobre tres muestras procedentes de un panel de prensa y otras tres de un panel de ISC . . . . . . . . . . . . . . . 169

4.40. Comparativa del valor onset extrapolado y pico de cristalización en ciclo 2 sobre tres muestras procedentes de un panel de prensa y otras tres de un panel de ISC . . . . . . . . . . . 170

4.41. Comparativa del valor onset extrapolado y pico de fusión en ciclo 3 sobre tres muestras procedentes de un panel de prensa y otras tres de un panel de ISC . . . . . . . . . . . . . 170

4.42. Espectro FTIR-ATR para (a) PEEK 450G (C1) y (b) PEEK 450G (C2) tras una degradación de un 2\% en ensayo de TGA 173

4.43. Espectro FTIR-ATR para (a) APC2/AS4 (C3) (suministrador), (b) APC2/AS4 tras calentamiento con la fuente láser (C4), (c) APC2/AS4 tras calentamiento con la fuente láser (C5) 173

4.44. Principio general del XPS . . . . . . . . . . . 174 
4.45. Consideraciones espectrales en el monómero del PEEK . . . . 175

4.46. Espectro de XPS obtenido sobre (a) Muestra de APC2/AS4 (C3) y muestra de APC2/AS4 tras irradiación láser en condiciones normales de laminación en ISC (C4) $\ldots$. . . . . . . 176

4.47. Ensayos experimentales sobre PEEK 450G a diferentes programas de calentamiento a) Conversión frente a temperatura y b) Derivada de la conversión con el tiempo frente a la tem-

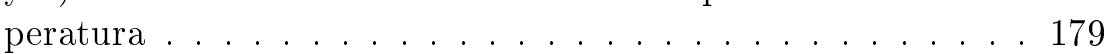

4.48. Deconvolución aplicada al ensayo sobre PEEK 450G en atmósfera oxidativa a $10 \mathrm{~K} / \mathrm{min}$. . . . . . . . . . . 180

4.49. Curvas de deconvolución aplicadas al primer pico . . . . . . . 181

4.50. Curvas de deconvolución aplicadas al segundo pico . . . . . . 181

4.51. Curvas de deconvolución aplicadas al tercer pico. . . . . . . . 182

4.52. Energía de activación frente a conversión para los 3 mecanismos iniciales del proceso en PEEK 450G . . . . . . . . . . . 182

4.53. Ajuste lineal tras la aplicación de la optimización mediante el empleo de Sestak-Berggren (a) Pico 1, (b) Pico 2, (c) Pico 3] . 184

4.54. Comprobación ensayo vs. simulación en la degradación oxidativa del PEEK 450G a $10 K / \min \ldots \ldots \ldots$. . . . . . . 186

4.55. Comparativa entre los modelos de reacción obtenidos para PEEK 450G y los modelos teóricos de la bibliografía . . . . . 187

4.56. Comprobación ensayo vs. simulación en la degradación oxidativa del PEEK 450G a diferentes isotermas de calentamiento. 188

4.57. Variación de $\eta^{\prime}$ con el tiempo para diferentes programas isotermos en PEEK 450G . . . . . . . . . . . . . . . . . . . . 189

4.58. Variación de $n$ (actos de reticulación) con el tiempo para diferentes programas isotermos en PEEK 450G . . . . . . . . . 192

4.59. Micrografías (20x) en muestra 1 del material APC2/AS4 tras ser recibido por el suministrador $\ldots \ldots \ldots$. . . . . . . 195

4.60. Micrografías (20x) en muestra 2 del material APC2/AS4 tras ser recibido por el suministrador $\ldots \ldots \ldots$. . . . . . 196

4.61. Micrografías (20x) en muestra 3 del material APC2/AS4 tras ser recibido por el suministrador . . . . . . . . . . . . . 197

4.62. Perfiles de rugosidad medidos en muestras de APC2/AS4 sin tratamiento, estado de recepción por el suministrador. . . . . 198

4.63. Análisis por imagen del grado de contacto entre superficies con tiempos de mantenimiento (a) $3 \mathrm{~min}$, (b) $2 \mathrm{~min}$, (c) 1 min, (d) $20 \mathrm{~s},(\mathrm{e}) 10 \mathrm{~s},(\mathrm{f}) 5 \mathrm{~s} \ldots \ldots \ldots 20 \ldots \ldots$

4.64. Análisis de la evolución del grado de contacto íntimo con el tiempo en condiciones isotermas (a) $623 K$, (b) $648 K$, (c) $673 K$ y (d) $698 K$ para diferentes valores de presión aplicada|. 202 
4.65. Análisis de la evolución del grado de contacto íntimo con el tiempo en condiciones de presión constante e igual a (a) 0,1MPa, (b) 0,5MPa, (c) 0,9MPa, (d) 1,3MPa, (e) 1,7MPa y (f) $2,1 M P a$ para diferentes valores de temperatura isoterma 203

4.66. Análisis de la evolución del grado de contacto íntimo con el tiempo en (a) Integrando con el perfil de enfriamiento bajo el efecto del rodillo en el proceso de laminación a $1 \mathrm{~m} / \mathrm{min}$ y (b) Variando la velocidad de encintado bajo la suposición de misma tendencia de enfriamiento . . . . . . . . . . . . 205

4.67. Análisis de la evolución del grado de contacto íntimo con el tiempo en la segunda pasada de calentamiento (a) Integrando con el perfil de enfriamiento bajo el efecto del rodillo en el proceso de laminación a $1 \mathrm{~m} /$ min y (b) Variando la velocidad de encintado estimando la misma tendencia de enfriamiento . 206

4.68. Comparativa viscosidades entre PEEK150G y PEEK450G . . 207

4.69. Ensayo oscilatorio y transformación de Cox-Merz. Isoterma a

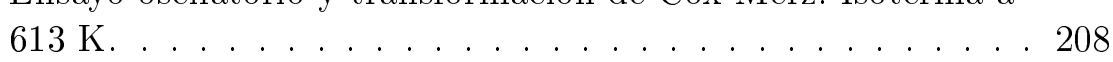

4.70. Ensayo oscilatorio y transformación de Cox-Merz. Isoterma a

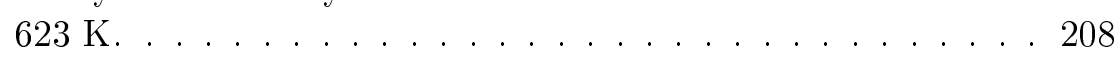

4.71. Ensayo oscilatorio y transformación de Cox-Merz. Isoterma a

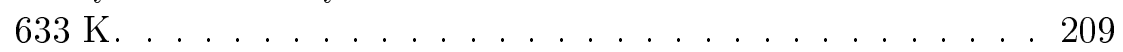

4.72. Ensayo oscilatorio y transformación de Cox-Merz. Isoterma a $643 \mathrm{~K}$. . . . . . . . . . . . . . . . . 209

4.73. Ensayo oscilatorio y transformación de Cox-Merz. Isoterma a

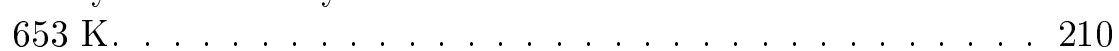

4.74. Ensayo oscilatorio y transformación de Cox-Merz. Isoterma a $673 \mathrm{~K}$. . . . . . . . . . . . . . . . . . 210

4.75. Comparativa viscosidades a diferentes isotermas, PEEK 450G 211

4.76. Comparativa viscosidades flujo vs. oscilatorio a $673 \mathrm{~K}$, PEEK $450 \mathrm{G}$.................... 212

4.77. Ajuste Arrhenius viscosidad vs. temperatura valores primer plateau newtoniano de ensayos en flujo y oscilatorio transformado por Cox-Merz . . . . . . . . . . . . . . . 213

4.78. Ajuste Arrhenius viscosidad vs. temperatura valores en shear thinning $100[1 / s]$ de los ensayos oscilatorios . . . . . . . . . . 214

4.79. Viscosidad del material compuesto APC2/AS4 según diferentes modelos (a) Longitudinal a la fibra y (b) Transversal a la fibra ..................... 217

4.80. (Viscosidad de (a) APC2/AS4 según (Levy et al., 2014) y (b) PEEK450G en "zero shear rate" y "shear thinning" . . . . . . 217 
4.81. Análisis de la evolución del grado de contacto íntimo con el tiempo en condiciones isotermas con viscosidad longitudinal de Binding (a) $623 K$, (b) $648 K$, (c) $673 K$ y (d) $698 K$ para diferentes valores de presión aplicada . . . . . . . . . . . 219

4.82. Análisis de la evolución del grado de contacto íntimo con el tiempo en condiciones de presión constante e igual a (a) $0,1 M P a$, (b) $0,5 M P a$, (c) $0,9 M P a$, (d) $1,3 M P a$, (e) $1,7 M P a$ y (f) $2,1 M P a$ para diferentes valores de temperatura isoterma y viscosidad según modelo longitudinal de Binding . . . . . . 220

4.83. Análisis de la evolución del grado de contacto íntimo con el tiempo y modelo de viscosidad longitudinal de Binding en (a) Integrando con el perfil de enfriamiento bajo el efecto del rodillo en el proceso de laminación a $1 \mathrm{~m} / \mathrm{min}$ y (b) Variando la velocidad de encintado bajo la suposición de la misma tendencia de enfriamiento . . . . . . . . . . . . . . . . 221

4.84. Vías para la determinación de los tiempos de relajación en el polímero (Regnier y Le Corre $[2016)]$. . . . . . . . . . . . . . 223

4.85. Tiempo de healing obtenido según el cruce de las rectas tangentes a $G^{\prime}$ y $G^{\prime \prime}$ cuando $\omega \longrightarrow 0$. . . . . . . . . . . 224

4.86. Tiempo healing vs. temperatura G'-G" cross-point . . . . . . 226

4.87. Tiempo healing vs. temperatura a través del parámetro de consistencia de Carreau en ensayos en flujo y oscilatorio trasformado por Cox-Merz . . . . . . . . . . . . . . . 227

4.88. Análisis de la evolución del grado de healing con el tiempo en (a) Integrando con el perfil de enfriamiento bajo el efecto del rodillo en el proceso de laminación a $1 \mathrm{~m} / \mathrm{min}$ y (b) Variando la velocidad de encintado estimando la misma tendencia de enfriamiento . . . . . . . . . . . . . . . . . . 230

4.89. Termograma APC2/AS4 tras ser calentado por el láser a $473 K$ d consigna, rampa de calentamiento en DSC $10 K / \mathrm{min} / \ldots .236$

4.90. Esquema de probeta escalón encintada con útil frío . . . . . . 241

4.91. Evolución de la cristalinidad en probeta escalón encintada en útil frío . . . . . . . . . . . . . . . 243

4.92. Evolución de la cristalinidad en probeta escalón encintada en útil frío, ajuste asintótico . . . . . . . . . . . 243

4.93. Esquema de probeta escalón encintada con útil caliente. . . . 244

4.94. Diagrama progreso de cristalización en ISC con útil calefactado 246

4.95. Evolución de la cristalinidad en probeta escalón encintada en útil caliente . . . . . . . . . . . . . . 246

4.96. Espectros WAXS de a) PEEK 450G amorfo y b) PEEK 450G cristalizado lentamente en prensa . . . . . . . . . . . . 248

4.97. Espectros WAXS de AS4. . . . . . . . . . . . . . . . 248 
4.98. Espectros brutos WAXS de a) APC2/AS4 as received y b)

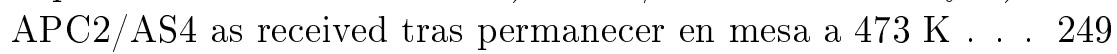

4.99. Espectros brutos WAXS de a) APC2/AS4 as received y b) APC2/AS4 as received tras permanecer en mesa a $473 \mathrm{~K}$. . . 250

4.100Espectros WAXS PEEK 450G sustracción de halo amorfo . . 251

4.101.Ajuste gaussianas en PEEK 450G semicristalino. . . . . . . . 252

4.102.Comparativa dimensiones de cristales . . . . . . . . . . . 253

4.103Evolución de la cristalinidad relativa en PEEK 150G en su enfriamiento isotermo a $@ 593 K\left(320^{\circ} \mathrm{C}\right) \ldots . . . . .256$

4.104Evolución de la cristalinidad relativa con el tiempo enfriando bajo diferentes programas isotermos (a) PEEK 150G y (b) PEEK 450G . . . . . . . . . . . . . . . . 257

4.105.Obtención del índice de Avrami en ensayos isotermos sobre (a) PEEK 150G y (b) PEEK 450G . . . . . . . . . . . . . . 258

4.106Evolución de la cristalinidad relativa en PEEK 450G en su enfriamiento dinámico a $2 K / \min$. . . . . . . . . . . . . . . 259

4.107Evolución de la cristalinidad relativa con la temperatura enfriando con diferentes programas dinámicos (a) PEEK 150G y (b) PEEK 450G . . . . . . . . . . . . . . . 260

4.108.Obtención del índice de Avrami modificado en ensayos dinámicos sobre PEEK 150G y PEEK 450G . . . . . . . . . 260

4.109Evolución de la cristalización relativa en enfriamientos (a) isotermos y (b) dinámicos en APC2/AS4 . . . . . . . . . . . 261

4.110Tiempos para alcanzar el 50\% de la cristalización en PEEK 150G, PEEK 450G y APC2/AS4 con (a) condiciones isotermas y (b) condiciones dinámicas $\ldots \ldots \ldots 26$. . . . . . 262

4.111Evolución de la cristalinidad relativa en APC2/AS4 en su calentamiento dinámico . . . . . . . . . . . . . . . 263

4.112Deconvolución del pico exotermo de cristalización en PEEK 450G enfriando a $15 \mathrm{~K} / \mathrm{min} \ldots \ldots \ldots 6$

4.113Deconvolución aplicada a PEEK 450G, (a) Primer pico - nucleación y crecimiento esferulítico y (b) Segundo pico - cristalización tras el choque de esferulitas . . . . . . . . . 266

4.114Factores de peso asociados a la deconvolución del PEEK 450G 267

4.115Factores de peso asociados a la deconvolución del PEEK 450G, programas de enfriamiento a mayor velocidad . . . . . . . . 268

4.116Deconvolución del pico exotermo de cristalización en APC2/AS4 enfriando a $10 K / \min \ldots \ldots \ldots \ldots \ldots$. . . . . . . . . . 269

4.117Deconvolución aplicada a APC2/AS4, (a) Primer pico - efectos de cristalización sobre AS4, (b) Cristalización esferulítica en el bulk, (c) Cristalización tras el choque de esferulitas . . . 270

4.118Factores de peso asociados a la deconvolución del APC2/AS4 271 
4.119Ajuste lineal tras la aplicación de la optimización mediante el empleo de Sestak-Berggren Pico 1 en cristalización de

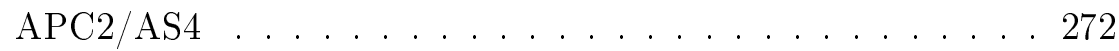

4.120Ajuste lineal tras la aplicación de la optimización mediante el empleo de Sestak-Berggren Pico 2 en cristalización de

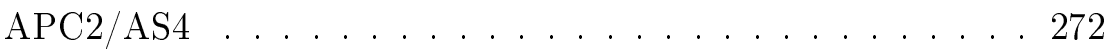

4.121Ajuste lineal tras la aplicación de la optimización mediante el empleo de Sestak-Berggren Pico 3 en cristalización de APC2/AS4 . . . . . . . . . . . . . . . . . 273

4.122: $\frac{\chi_{v c}}{\chi_{v c}}$ vs. Temperatura en APC2/AS4 para distintos progra$\chi_{v c \infty}$ mas de enfriamiento dinámico $\ldots \ldots \ldots \ldots$. . . . . . . 278

4.123Aplicación al resultado experimental de $10 \mathrm{~K} / \mathrm{min}$ en APC2/AS4 de los modelos teóricos bibliográficos - Cebe . . . . . . . . . 279

4.124Aplicación al resultado experimental de $10 \mathrm{~K} / \mathrm{min}$ en APC2/AS4 de los modelos teóricos bibliográficos - Velisaris . . . . . . . . 279

4.125Aplicación al resultado experimental de $10 \mathrm{~K} / \mathrm{min}$ en APC2/AS4 de los modelos teóricos bibliográficos - Tierney $\ldots$. . . . . 280

4.126Comparativa del ensayo a $10 \mathrm{~K} / \mathrm{min}$ y el modelo de Tierney con parámetros obtenidos tras el ajuste no lineal . . . . . . . 281

4.127Comparativa del ensayo a $30 \mathrm{~K} / \mathrm{min}$ y el modelo de Tierney con parámetros obtenidos tras el ajuste no lineal . . . . . . . 282

4.128Comparativa del ensayo a $30 \mathrm{~K} / \mathrm{min}$ y el modelo de Velisaris con parámetros obtenidos tras el ajuste no lineal . . . . . . . 284

4.129DMA Single Cantilever panel prensa . . . . . . . . . . . . . . . 286

4.130DMA Single Cantilever panel ISC . . . . . . . . . . . . . . 286

4.131DMA fibra a $90^{\circ}$ en (a) Panel de prensa y (b) Panel de ISC

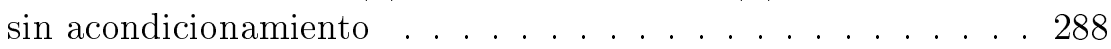

4.132DMA fibra a $90^{\circ}$ en (a) Panel de prensa y (b) Panel de ISC acondicionados a $323 K \ldots \ldots \ldots$. . . . . . . . . . 289

4.133DMA fibra a $90^{\circ}$ en (a) Panel de prensa y (b) Panel de ISC

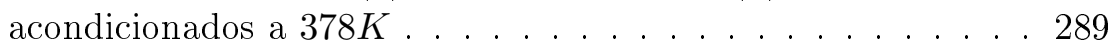

4.134SEM entrecara pelado (a) Prensa y (b) Consolidación in-situ 290

4.135SEM entrecara prensa frontera zonas fractura . . . . . . . . 291

4.136Probeta de prensa tras ensayo de pelado a) Zona blanca y b)

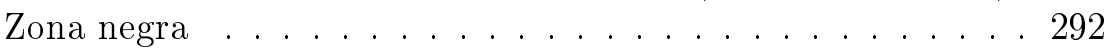

4.137IPSS sobre paneles fabricados en (a) Prensa y (b) ISC sin tacones, modo de fallo . . . . . . . . . . . . . . 293

4.138IPSS sobre paneles fabricados en (a) Prensa y (b) ISC . . . . 294

4.139Resultado del ensayo de IPSS sobre panel fabricado en prensa y por ISC (a) Resistencia y (b) Módulo . . . . . . . . . . . . 294

4.140SEM en probetas de IPSS tras fallo, fabricadas (a) Prensa y

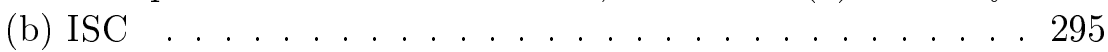


4.141Fuerza frente a deformación en un ensayo a flexión de laminados fabricados (a) Prensa y (b) ISC . . . . . . . . . . . 296

4.142.Valores de (a) resistencia y (b) módulo a flexión para paneles de prensa e ISC ensayados a flexión . . . . . . . . . . . . . 297

4.143Fuerza frente a deformación en un ensayo a flexión de laminados fabricados por laminación automática y consolidación in-situ con a) Cara útil abajo y b) Cara útil arriba . . . . . . 297

4.144.Valores de (a) Resistencia y (b) Módulo a flexión para paneles de ISC ensayados a flexión alternando la posición de la cara en contacto con el útil en el set-up del ensayo . . . . . . . . . 298

4.145SEM en probetas de flexión tras fallo, fabricadas (a) Prensa y (b) ISC . . . . . . . . . . . . . . . . . . . 298

4.146Carga vs deformación ILSS . . . . . . . . . . . . . . . 299

4.147Curvas de ensayo para las probetas de (a) Prensa e (b) ISC . 300

4.148 Modo de fallo ILSS (a) Prensa y (b) ISC . . . . . . . . . . . . 301

4.149Resistencia en ILSS en laminado fabricado en prensa y por ISC 301

A.1. Croquis de posicionado de termopares en un encintado a $0^{\circ}$. 312

A.2. Encintado de la capa 6, lecturas de los termopares TC1-TC2TC3 (entre 4-5) . . . . . . . . . . . . . 313

A.3. Encintado de la capa 8, lecturas de los termopares TC1-TC2-

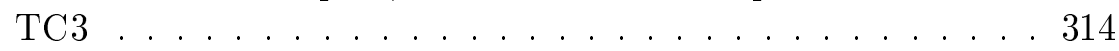

A.4. Encintado de la capa 8, lecturas de los TC4-TC5 . . . . . . . 314

A.5. Encintado de la capa 12, lecturas de los termopares TC1-TC2 315

A.6. Encintado de la capa 12, lectura del termopar TC4 . . . . . . 315

A.7. Encintado de la capa 12, lectura de los termopares TC9-TC10 316

A.8. Encintado de la capa 15, lecturas de los TC1-TC2-TC3 . . . . 316

A.9. Encintado capa 15 (a) TC4, (b) TC7, (c) TC9 y (d) TC11 . . 317

A.10.Croquis de posicionado de termopares en un encintado a 0-90 318

A.11.Croquis de posicionado de termopares en un encintado a 0-90, encintado capa 3 - lecturas de TC1-TC2-TC3 . . . . . . . . 319

A.12.Registro en un instante temporal de la termografía durante el encintado de capa 3 . . . . . . . . . . . . . 320

A.13.Encintado capa 5 (a) TC1-TC3 y (b) TC4-TC5 . . . . . . . . 320

A.14.Encintado capa 7 (a) TC1-TC3, (b) TC4 y (c) TC6-TC7. . . 322

A.15.Encintado capa 9 (a) TC1-TC3, (b) TC4 y (c) TC6-TC7. . . 324

A.16.Encintado capa 11 (a) TC1-TC3, (b) TC4, (c) TC6-TC7 y (d)

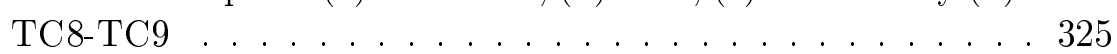

A.17.Encintado capa 13 (a) TC1-TC3, (b) TC4, (c) TC6-TC7 y (d)

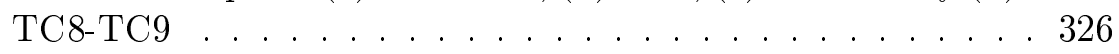

A.18.Encintado capa 15 (a) TC1-TC3, (b) TC4, (c) TC6-TC7, (d) TC8-TC9 у (e) TC10-TC11-TC12 . . . . . . . . . . 328 
A.19.Encintado capa 20 (a) TC1-TC3, (b) TC4, (c) TC6-TC7 y (d)

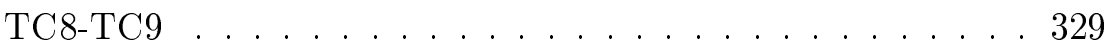

A.20.Encintado capa 20 (e) TC10-TC11-TC12, (f) TC13-TC14 y

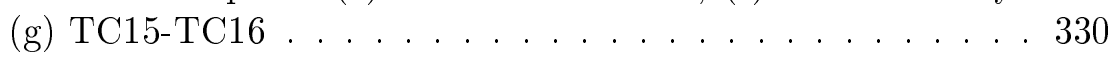

A.21.Encintado capa 30 (a) TC15, (b) TC17-TC18 y (c) TC20 . . 331

A.22.Croquis de posicionado de termopares en un encintado a 0-90 332

A.23.Registro de termopares TC2-TC3 en el encintado con doble láser entre capas 1 y 2 (a) Laminando capa 3, (b) Laminando capa 4 y (c) Laminando capa $5 \ldots \ldots 336$

B.1. Valor teórico de la $C_{p}$ del Zafiro . . . . . . . . . . . . . . 339

C.1. DSC panel prensa ciclo 1 - estudio de degradación por intercomparación entre procesos de fabricación . . . . . . . . 342

C.2. DSC panel prensa ciclo 2 - estudio de degradación por intercomparación entre procesos de fabricación . . . . . . . . . 343

C.3. DSC panel prensa ciclo 3 - estudio de degradación por intercomparación entre procesos de fabricación . . . . . . . . . 343

C.4. DSC panel ISC ciclo 1 - estudio de degradación por intercomparación entre procesos de fabricación . . . . . . . . . . . 344

C.5. DSC panel ISC ciclo 2 - estudio de degradación por intercomparación entre procesos de fabricación . . . . . . . . . . 344

C.6. DSC panel ISC ciclo 3 - estudio de degradación por intercomparación entre procesos de fabricación . . . . . . . . . 345

C.7. DSC PEEK 450G amorfo tras quenching . . . . . . . . . . . . 346

C.8. DSC PEEK 450G cristalizado tras ciclo en prensa de platos

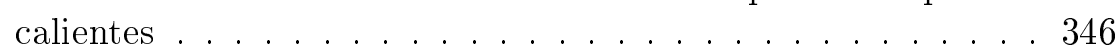

C.9. DSC APC2/AS4 as received - primer ciclo calentammiento. . 347

C.10.DSC PEEK $150 \mathrm{G}$ vs $450 \mathrm{G}$ enfriando a $20 \mathrm{~K} / \mathrm{min}$ tras fusión

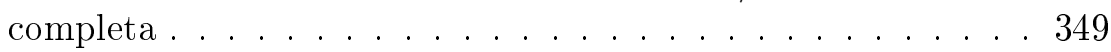

C.11.DSC APC2/AS4 as received sometido a distintas velocidades

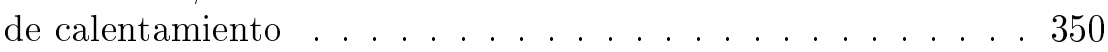

C.12.DSC APC2/AS4 fundido y sometido a distintas velocidades de enfriamiento; $2,5,10,15,20,30 K / \min . \ldots \ldots 351$

C.13.DSC PEEK 450G distintas velocidades de enfriamiento; 2, 5, $10,15,20,30 \mathrm{~K} / \mathrm{min} \ldots \ldots \ldots \ldots \ldots \ldots$

C.14.Comparativa entre paneles en prensa e ISC, ciclo calentamiento $1 \ldots \ldots \ldots \ldots \ldots \ldots \ldots \ldots \ldots$

C.15.Comparativa entre paneles en prensa e ISC, ciclo calentamien-

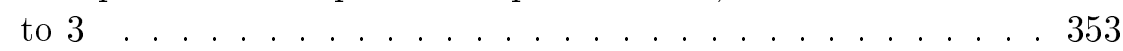

C.16.DSC APC2/AS4 tras posicionarlo en mesa calefactada . . . . 355

C.17.DSC APC2/AS4 simulación del proceso de colocación de primera capa en útil calefactado a $473 K \ldots \ldots$. . . . . . . 355 
C.18.DSC APC2/AS4 simulación del proceso de colocación de primera capa en útil calefactado a $473 K$ - isoterma a $473 K$. . . 356

C.19.DSC APC2/AS4 simulación del proceso de colocación de primera capa en útil calefactado a $473 K$ - fusión . . . . . . . . 356

C.20.DSC APC2/AS4 probeta escalón encintada sobre útil frío -

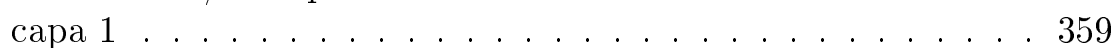

C.21.DSC APC2/AS4 probeta escalón encintada sobre útil frío -

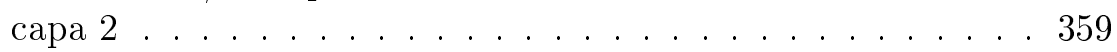

C.22.DSC APC2/AS4 probeta escalón encintada sobre útil frío $\begin{array}{r}\hline \text { capa } 3 \ldots \ldots \ldots \ldots \ldots \ldots \\ \hline\end{array}$

C.23.DSC APC2/AS4 probeta escalón encintada sobre útil frío -

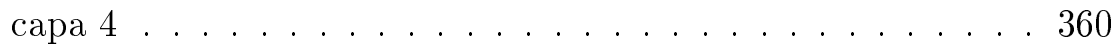

C.24.DSC APC2/AS4 probeta escalón encintada sobre útil frío -

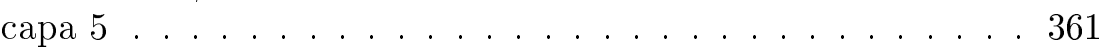

C.25.DSC APC2/AS4 probeta escalón encintada sobre útil frío -

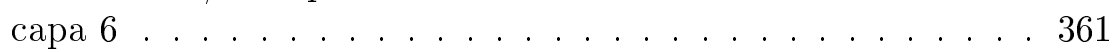

C.26.DSC APC2/AS4 probeta escalón encintada sobre útil frío -

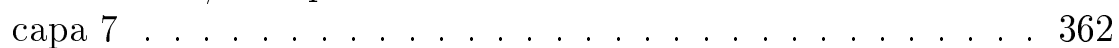

C.27.DSC APC2/AS4 probeta escalón encintada sobre útil frío -

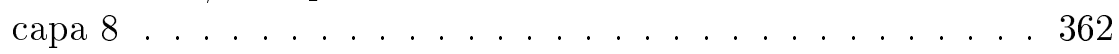

C.28.DSC APC2/AS4 probeta escalón encintada sobre útil frío -

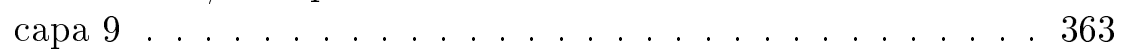

C.29.DSC APC2/AS4 probeta escalón encintada sobre útil frío -

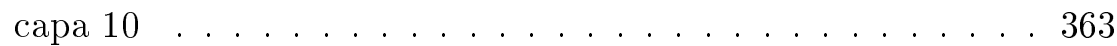

C.30.DSC APC2/AS4 probeta escalón encintada sobre útil frío -

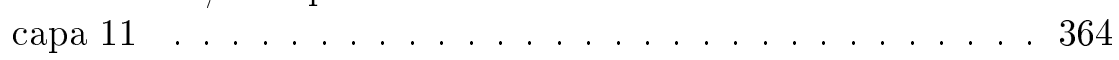

C.31.DSC APC2/AS4 probeta escalón encintada sobre útil frío capa $12 \ldots \ldots \ldots \ldots 64 \ldots \ldots \ldots \ldots$

C.32.DSC APC2/AS4 probeta escalón encintada sobre útil frío capa $13 \ldots \ldots \ldots \ldots \ldots \ldots \ldots$

C.33.DSC APC2/AS4 probeta escalón encintada sobre útil frío capa $14 \ldots \ldots \ldots \ldots \ldots \ldots \ldots \ldots$

C.34.DSC APC2/AS4 probeta escalón encintada sobre útil frío -

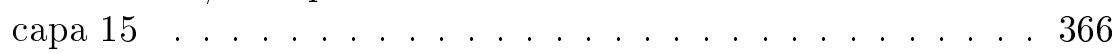

C.35.DSC APC2/AS4 probeta escalón encintada sobre útil frío -

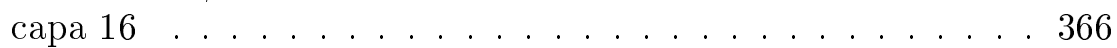

C.36.DSC APC2/AS4 probeta escalón encintada sobre útil caliente

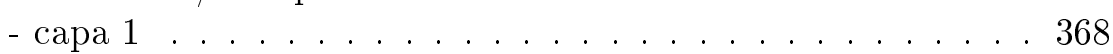

C.37.DSC APC2/AS4 probeta escalón encintada sobre útil caliente - capa $2 \ldots \ldots \ldots \ldots \ldots \ldots \ldots$

C.38.DSC APC2/AS4 probeta escalón encintada sobre útil caliente 
C.39.DSC APC2/AS4 probeta escalón encintada sobre útil caliente

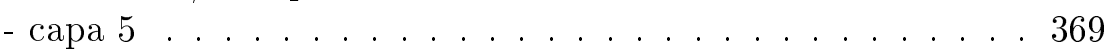

C.40.DSC APC2/AS4 probeta escalón encintada sobre útil caliente

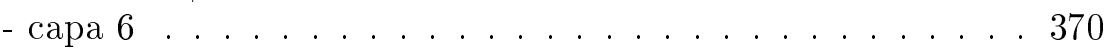

C.41.DSC APC2/AS4 probeta escalón encintada sobre útil caliente

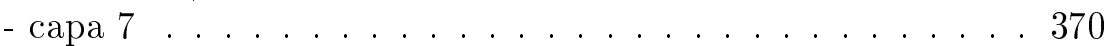

C.42.DSC APC2/AS4 probeta escalón encintada sobre útil caliente

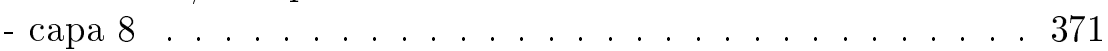

C.43.DSC APC2/AS4 probeta escalón encintada sobre útil caliente

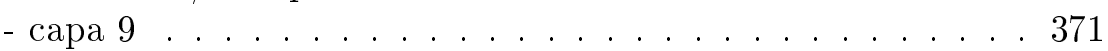

C.44.DSC APC2/AS4 probeta escalón encintada sobre útil caliente - capa 10. . . . . . . . . . . . . . . 372

C.45.DSC APC2/AS4 probeta escalón encintada sobre útil caliente

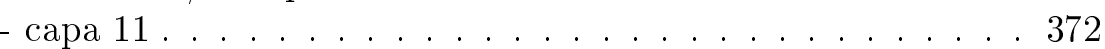

C.46.DSC APC2/AS4 probeta escalón encintada sobre útil caliente - capa 12. . . . . . . . . . . . . . . . 373

C.47.DSC APC2/AS4 probeta escalón encintada sobre útil caliente - capa 13. . . . . . . . . . . . . . . . . 373

C.48.DSC APC2/AS4 probeta escalón encintada sobre útil caliente

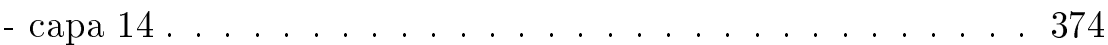

C.49.DSC APC2/AS4 probeta escalón encintada sobre útil caliente - capa 15. . . . . . . . . . . . . . . . 374

C.50.DSC APC2/AS4 probeta escalón encintada sobre útil caliente - capa 16. . . . . . . . . . . . . . . 375

D.1. Deconvolución del pico exotermo de cristalización en PEEK 450G enfriando a $30 \mathrm{~K} / \mathrm{min} . \ldots \ldots \ldots . \ldots . \ldots . \ldots 378$

D.2. Deconvolución aplicada a PEEK 450G, (a) Primer pico - nucleación y crecimiento esferulítico y (b) Segundo pico - cristalización tras el choque de esferulitas, incrementando las velocidades de enfriamiento . . . . . . . . . . . . 378 


\section{Índice de Tablas}

2.1. Propiedades térmicas del material compuesto PEEK-FC . . . 30

2.2. Propiedades térmicas del utillaje . . . . . . . . . . 31

2.3. Propiedades térmicas para condiciones de contorno . . . . . . 32

2.4. Propiedades térmicas para condiciones de contorno . . . . . . 33

2.5. Velocidades de encintado para PEEK-FC y otros termoplásticos en procesos de laminación y consolidación in-situ . . . . 34

2.6. Propiedades ópticas del material compuesto PEEK-FC . . . . 35

2.7. Modelos isoconversionales . . . . . . . . . . . 55

2.8. Definición de parámetros bibliográficos para las ecuaciones del grado de contacto íntimo . . . . . . . . . . . . 64

2.9. Parámetros de la celdilla unidad . . . . . . . . . 88

3.1. Propiedades APC2/AS4 . . . . . . . . . . . . . . . . . 104

3.2. Propiedades mecánicas PEEK y APC2/AS4 . . . . . . . . . . 104

3.3. Propiedades de la fuente térmica . . . . . . . . . . 106

3.4. Parámetros de encintado . . . . . . . . . . . . . . . 107

4.1. Valores simulación - proceso ． . . . . . . . . . . . . . . 149

4.2. Parámetros de los materiales utilizados . . . . . . . . . 150

4.3. Coeficientes convección térmica - proceso . . . . . . . . . 150

4.4. Codificación muestras FTIR-ATR . . . . . . . . . . . . 172

4.5. Tabla espectral para el PEEK . . . . . . . . . . . . . . . 175

4.6. Energías de activación por Friedman tras deconvolucionar . . 183

4.7. Triplete cinético tras optimización lineal . . . . . . . . . . 185

4.8. Relación viscosidad vs. temperatura PEEK 450G . . . . . . . 213

4.9. Parámetros de ajuste por Arrhenius de las curvas viscosidad vs. temperatura PEEK 450G . . . . . . . . . . . . . . . 214

4.10. Tiempos de relajación en el cruce G'y G' . . . . . . . . . . . 225

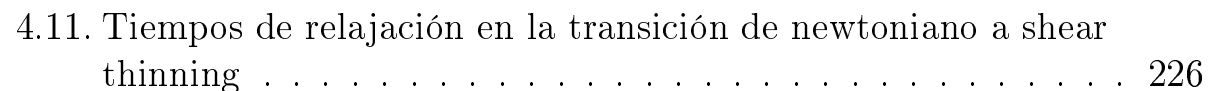


4.12. DSC sobre PEEK 450G amorfo, cristalizado, APC2/AS4 as received, laminado de APC2/AS4 procesado en prensa y procesado por ISC con mesa calefactada a $473 K \quad \ldots . . .235$

4.13. Onset extrapolado de cristalización en el enfriamiento a $20 \mathrm{~K} / \mathrm{min}$ tras fusión completa para PEEK 150G, PEEK 450G y APC2/AS4255

4.14. Índice-k de Avrami y $t_{1 / 2}$ en PEEK 150G . . . . . . . . . 257

4.15. Índice-k de Avrami y $t_{1 / 2}$ en PEEK 450G . . . . . . . . . . . . 258

4.16. $t_{1 / 2}$ en PEEK $150 \mathrm{G}$ y PEEK $450 \mathrm{G}$. . . . . . . . . . . . . 261

4.17. $t_{1 / 2}$ en ensayos isotermos sobre APC2/AS4 . . . . . . . 262

4.18. $t_{1 / 2}$ en ensayos dinámicos sobre APC2/AS4 . . . . . . . . . . 262

4.19. Parámetros del ajuste lineal para APC2/AS4 . . . . . . . . . 273

4.20. Parámetros de la ecuación de doble Avrami paralelo para APC2/AS4 según referencia bibliográfica . . . . . . . . . . . 276

4.21. Parámetros de la ecuación de doble Avrami paralelo para APC2/AS4 según referencia . . . . . . . . . . . . . 277

4.22. Cristalización desarrollada en APC2/AS4 según el programa de enfriamiento dinámico . . . . . . . . . . . . 277

4.23. Parámetros del ajuste no lineal con el modelo de Tierney para ensayo a $10 K / \min \ldots \ldots \ldots \ldots . \ldots . \ldots . \ldots 281$

4.24. Parámetros del ajuste no lineal con el modelo de Tierney para ensayo a $30 \mathrm{~K} / \mathrm{min}$. . . . . . . . . . . . . . . . 282

4.25. Parámetros del ajuste no lineal con el modelo de Velisaris para ensayo a $30 \mathrm{~K} / \mathrm{min} \ldots \ldots \ldots \ldots \ldots 283$

4.26. Codificacion paneles de ensayos mecánicos . . . . . . . . . 285

4.27. Promedios DMA - Storage Modulus y $T_{g} \ldots$. . . . . . . . 287

4.28. Promedios DMA - Storage Modulus y $T_{g}$ a $90^{\circ} \ldots$. . . . . 288

4.29. Promedios DMA - Storage Modulus y $T_{g}$ a $90^{\circ}$ acondicionado a $323 \mathrm{~K} \ldots \ldots \ldots \ldots \ldots \ldots \ldots$

\begin{tabular}{|l} 
4.30. Promedios DMA - Storage Modulus y $T_{g}$ a $90^{\circ}$ acondicionado \\
\hline a $378 K$ \\
\hline$\ldots \ldots \ldots \ldots$
\end{tabular}

A.1. Posiciones termopares en el encintado 0-90 . . . . . . . . . . . 318

A.2. Posiciones termopares en el encintado con doble láser . . . . . 334

C.1. Masas de las probetas ensayadas . . . . . . . . . . . . 342

C.2. Masas de las probetas ensayadas . . . . . . . . . . . . . 345

C.3. Masas de las probetas ensayadas . . . . . . . . . . . . . 348

C.4. Masas de las probetas ensayadas . . . . . . . . . . . . . . 349

C.5. Masas de las probetas ensayadas . . . . . . . . . . . . . . . . . . . . . . . . . . . . .

C.6. Masas de las probetas ensayadas . . . . . . . . . . . . . 351

C.7. Masas de las probetas ensayadas . . . . . . . . . . . . 352

C.8. Masas de las probetas ensayadas . . . . . . . . . . . . . 354 
C.9. Masas de las probetas ensayadas . . . . . . . . . . . . . 358

C.10.Masas de las probetas ensayadas . . . . . . . . . . 367 



\section{Capítulo 1}

\section{Introducción}

\subsection{Introducción}

En (Dutton et al. 2004$)$ se incluyen las propiedades claves que han posibilitado la aplicación de los materiales compuestos en la industria aeronáutica, entre ellas aparecen como principales el ahorro en peso acompañado por incrementos en resistencia específica y rigidez, que llevan aparejadas reducciones de consumo de combustible permitiendo incrementar la carga de pago en las aeronaves. Además, para garantizar la posibilidad de ser utilizados, los materiales requieren demostrar cómo de asequible es su empleo, su obtención, su coste y el futuro mantenimiento a lo largo de la vida de pieza. Todo material seleccionado debe asegurar también la capacidad de soportar esfuerzos en presencia de daños típicos, la durabilidad, la resistencia a esfuerzos cíclicos y a degradación ambiental.

El material compuesto fibra de carbono-matriz polimérica termoestable, ha demostrado cumplir la gran mayoría de los requisitos descritos anteriormente, mejorando incluso el comportamiento de aleaciones metálicas típicas. A pesar de su potencial de mejora, la aplicación de este material a piezas aeronáuticas ha sido muy progresiva a causa del coste inicial y de las necesidades de certificación de las nuevas estructuras desarrolladas.

Por su parte, la aplicación de los materiales con matriz polimérica termoplástica no ha alcanzado en la actualidad los mismos niveles de desarrollo que los ya obtenidos con los termoestables. Entre las posibles causas, los elevados requisitos de temperatura de proceso que presentan los termoplásticos y las inferiores productividades conseguidas. En los materiales reforzados termoplásticos, al presentarse la matriz en su estado ya polimerizado, los valores de viscosidad son muy elevados, haciendo necesarios procesos donde se apliquen mayores temperaturas y presiones y por tanto, procesos con costes asociados superiores. 
Los termoplásticos, parecen mantenerse periodo tras periodo, a cinco años de la madurez industrial, tal y como se expone en una publicación de CompositesWorld de 2015 "Thermoplastic composites technology: A view from Europe". La causa de ello puede asociarse con la falta de conocimiento existente sobre estos materiales. Tras años de estudio, algunos centros parecen ya encontrarse en la posición de presentar resultados sobre los potenciales beneficios obtenidos del uso de estos materiales, guiados también por la premisa de ejecutar diseños de vehículos con objetivos "end-of-life", que está empujando a las industrias a localizar materiales capaces de garantizar reciclabilidad.

En los termoplásticos, para lograr los mismos o similares niveles de aplicación frente a los termoestables en la industria aeronáutica, se requiere localizar procesos que consigan simplificar o abaratar costes respecto a los procesos típicos de fabricación. Actualmente, en la fabricación de estructuras de gran tamaño con material termoestable, se emplean procesos donde el encintado está automatizado, con velocidades de encintado del orden de 50 $\mathrm{m} / \mathrm{min}$. Al encontrarse el material parcialmente curado, preserva su adhesividad posibilitando la unión entre las diferentes capas. Tras el encintado, los apilados requieren la preparación de conformados y/o bolsas de vacío para una subsiguiente etapa de curado en autoclave. Por su parte, los materiales reforzados termoplásticos no han podido experimentar la misma secuencia evolutiva a causa de las importantes diferencias que los procesos automáticos de encintado presentan entre unos y otros.

En un material reforzado termoplástico, los cortos ciclos requeridos para su conformado se presentan como una ventaja mientras que la adhesividad entre capas de material a temperaturas en el entorno de la temperatura ambiente es inexistente, partiéndose de láminas que requieren de un calentamiento sobre la transición vítrea o fusión para provocar un desplazamiento de las cadenas poliméricas y posibilitar esa unión. Este aspecto, que podría aparecer como un punto en contra de la aplicación de estos materiales, ha abierto el camino al desarrollo de un proceso que permite simultáneamente adherir las láminas y alcanzar el estado final requerido de pieza sin necesidad de ciclos de autoclave posteriores, con el consiguiente ahorro energético y económico que resulta de su supresión.

Bajo esa idea, se establecen los desarrollos que conducirán al proceso de encintado en automático y consolidación in-situ, donde una fuente calefactora calienta superficies de material termoplástico poniéndolas posteriormente en contacto bajo la acción de un elemento compactador. Este proceso conlleva asociadas múltiples físicas que tienen lugar de manera simultánea y cuyo 
control es imprescindible para posibilitar la aplicación de mejoras en el proceso. Para poder aplicar este proceso de un modo rentable para la industria, es preciso asegurar que es posible alcanzar altos grados de consolidación sin la necesidad de un segundo ciclo de re-consolidación en estufa o autoclave, referencias como (Campbell, 2004) reportan grados de consolidación en el entorno de un $80 \%$ - 90\%, sin embargo resultados actuales de la empresa Automated Dyamics, afirman la posibilidad de alcanzar niveles comparables a los obtenidos en ciclos de estufa y autoclave con velocidades adecuadas a la producción industrial.

Otros puntos positivos en los desarrollos con material termoplástico incluyen: posibilidad de generar estructuras con grandes niveles de integración, evitando la necesidad de efectuar procesos posteriores de encolado, vida prácticamente ilimitada sin necesidad de refrigeración y bajo riesgo de contaminación o toxicidad en la manipulación por el ser humano por encontrarse ya reaccionado el polímero (Campbell, 2004). Actualmente cobran importancia aspectos como la sostenibilidad y la conservación medioambiental (Biron, 2018b a), los materiales termoplásticos, por sus características presentan capacidad de ser reciclados. La posibilidad de efectuar una futura re-utilización de las piezas de las subsecuentes flotas de aviones supone un punto en favor de la incorporación de este tipo de materiales.

En la aplicación a piezas aeronáuticas de los termoplásticos reforzados, (Hoa, 2009) puntualiza la necesidad de utilizarlas en aplicaciones donde los límites de temperatura sean próximos a su transición vítrea menos $30 \mathrm{~K}$, pues en el entorno de dicha temperatura es donde tiene lugar el reblandecimiento del material modificando sus propiedades mecánicas.

A pesar de las limitaciones expuestas al uso de los termoplásticos en piezas aeronáuticas, es una realidad que la industria sigue interesada en evolucionar esa tecnología, continuar estudiándola hasta que se demuestre su aplicación mediante la inclusión de piezas avionables desarrolladas de este modo. Existen múltiples patentes, destinadas a proteger los desarrollos de equipos y también de los procesos cuyos cesionarios son en su mayoría los principales fabricantes de aviones mundiales o centros asociados a ellos, hecho manifiesto del interés de la industria por el proceso de encintado automático y consolidación in-situ.

La primera patente localizada aludiendo a este proceso data de 1986, asociada a DuPont (Segal y Testa, 1984) (patente de método de encintado y equipo), donde el punto destacable es el planteamiento de un encintado en automático aplicado a un material termoplástico empleando una fuente secundaria de pre-calentamiento sobre el sustrato y una fuente principal 
que actúa entre dicho sustrato y el material que está siendo aportado, con una distribución de energía entre sustrato y material de aporte de 20-80\%. Northrop Corporation, la fabricante americana de aeronaves, lanzó una patente en relación con esta temática en 1991 (Brown et al., 1991) (patente de método de encintado y equipo). Entre las particularidades de su propuesta, presenta el empleo de un rodillo calefactado, un sistema de refrigeración justo en la salida del rodillo (pie compactador) y la interposición de una lámina de material entre rodillo y material objeto del encintado para evitar la adhesión entre ellos. La patente presenta también un sistema de trabajo para el encintado de primera capa basado en el uso de un útil perforado desde donde se aplicará vacío sobre el material encintado, entre el útil y pieza se interpondrán una capa de aislante fibra de vidrio y un film de kapton.

En 1997, es The Boeing Company el cesionario de una patente sobre una máquina de encintado multimecha (al menos dos mechas de material). En la patente se reporta una descripción detallada de cada uno de los componentes del equipo, dando detalles específicos sobre el rodillo de compactación. El sistema que se propone, consta de unas cavidades por donde se hace circular aire para su refrigeración, estando dotado de un componente que le permite inclinarse (eje de giro en sentido del encintado) para posibilitar la aplicación de de presión sobre todas las mechas en condiciones no planas de encintado. The Boeing Company protege también en 2002 sus trabajos sobre el método de calentamiento y el sistema de control de calentamiento en el proceso de encintado de materiales compuestos, sin especificar el tipo (Holmes et al. 2002). En la anterior patente, el sistema de calentamiento empleado es un agrupamiento de láseres de diodo que permiten controlar la energía suministrada en dirección longitudinal y transversal al encintado, favoreciendo los encintados cóncavo-convexo y con diferentes inclinaciones del sustrato. Como sistema de control consideran el empleo de un sistema de medida tipo termografía.

Aerospatiale, la empresa aeroespacial francesa fundada en 1970 y que posteriormente pasaría a conformar parte del conglomerado de empresas europeas, Airbus, presenta una patente donde protege el desarrollo de un encintado con integración, con una tecnología conocida como co-consolidación (Maison et al. 2003). La patente considera la laminación de una piel sobre los rigidizadores, quedando la piel consolidada y los rigidizadores unidos por soldadura por difusión/conducción, indicándose una aplicación preferente de este sistema en la fabricación de segmentos del fuselaje o cubiertas del motor.

La ya formada Airbus, patenta en 2011 otra metodología para el encintado de termoplásticos (Burchell 2011), en la cual se requiere que una parte del útil de encintado se fabrique con un material poroso. Como propuesta 
se indica el uso de un aluminio microporoso posicionado en la superficie de un útil mayor no poroso, el tamaño de las cavidades es lo suficientemente pequeño para que en conjunción con la viscosidad del polímero, éstas no puedan bloquearse ni afectar a los acabados superficiales de pieza. Ese sistema puede ayudar también en la etapa del desmoldeo, si se ejecuta el cambio de presión negativa a positiva sobre pieza.

Los fabricantes de máquinas también han protegido sus avances con patentes, Cincinnati Milacron, Inc. protegiendo el control del calentamiento en el proceso de encintado con termoplásticos (Zaffiro, 1993), Automated Dynamics contando con diversas patentes, (Hauber et al., 2006 Martin, 2007. Langone et al. 2013, Langone y Becker, 2015 Langone et al. 2016), relacionadas con el equipo de encintado, el material de encintado y la tecnología de fabricación para la incorporación de sistemas de protección frente a rayo. Por su parte, en 2008 Accudyne Systems, Inc. lanzó una patente de equipo y de proceso para el encintado de material compuesto termoplástico Cope et al. 2008), donde destaca la propuesta de empleo de un sistema flexible de compactación compuesto por segmentos que aplican la presión de modo independiente. La empresa productora de células robóticas para el encintado de materiales compuestos, Coriolis Composites, patentó en 2016 (Caffiau et al. 2016) una solución innovadora para el rodillo de compactación, en línea con la solución propuesta por Accudyne. La solución se basa en que cada uno de los segmentos que componen el rodillo sean a su vez cilindros con un interior compuesto por elementos con curvaturas que le dotan de una mayor flexibilidad.

\subsection{Objetivos}

A lo largo de la introducción se ha mencionado la necesidad de asegurar la "asequibilidad" para el uso de los materiales compuestos en la industria aeronáutica. Entendiendo asequibilidad como un concepto relacionado con distintos factores, entre ellos, los costes de material y también de proceso de fabricación. (Soutis, 2005), ya en 2005 indicaba que la única vía para conseguir una aplicación prolífica de los materiales compuestos pasaba por desarrollar análisis y simulaciones por ordenador tanto de la fabricación como del comportamiento posterior de la estructura.

Teniendo en cuenta la necesidad de ejecución de modelos predictivos o simulaciones de procesos, en esta tesis doctoral se ha perseguido estudiar algunas de las físicas implicadas en el proceso de encintado automático y consolidación in-situ con material compuesto termoplástico, tratando de obtener una representación matemática de su evolución bajo unas condiciones 
de proceso cualesquiera, abriendo la posibilidad de actuar de modo predictivo para adecuar el resultado final de la pieza fabricada a los requisitos establecidos. El trabajo se ha focalizado en el estudio de la respuesta en este proceso del material APC2/AS4, suministrado por Solvay-Cytec. Este material consiste en una matriz tipo poli-éter-éter-cetona (PEEK) reforzada con fibra continua de carbono, material de altas prestaciones, reconocido y certificado por la industria aeronáutica para su aplicación en otro tipo de procesos de fabricación.

El PEEK es un termoplástico aromático semicristalino, cuya obtención tiene como antecesora la síntesis de la poli-éter-cetona (PEK) en 1960. La primera versión comercial del PEK desarrollada por Raychem Corporation fue preparada y patentada en 1976. Por su parte, fue Imperial Chemicals Industries Limited (ICI) el primero en obtener una patente para el desarrollo de PEEK (VICTREX PEEK) en 1982. La comercialización de los productos de la familia del PEEK, incluyendo los reforzados con fibra de vidrio y de carbono, comenzó en 1981. En 1993, el desarrollo comercial del PEEK se aleja de ICI, constituyéndose Victrex Polymer Solutions. Este polímero, se presenta como una alternativa para la industria aeronáutica con aplicaciones tanto para interiores como exteriores, para automoción, para la industria alimentaria e incluso en aplicaciones médicas (Fink, 2010).

Conviene precisar aquí que, la selección de un material u otro no solo condiciona los parámetros de trabajo a emplear, sino que también puede suponer un límite sobre la perfección del resultado obtenido (por ejemplo en términos de máxima velocidad de encintado). En base a la anterior afirmación, la comparación de desarrollos con máquinas idénticas pero distintos materiales no es rigurosa, pues una simple modificación tal como un cambio de peso molecular del polímero, impacta en aspectos tan relevantes como los tiempos necesarios para permitir una buena adhesión en las entre-caras.

Asimismo, en consonancia con la afirmación anteriormente ejecutada sobre las variaciones ocasionadas por los cambios de material, también se debe precisar que pequeñas variaciones entre equipos de encintado trabajando con idéntico material repercute en resultados completamente diferentes. Como ejemplo, el trabajo con equipos de calentamiento que consigan huellas de acción superiores, puede producir resultados finales similares pero con niveles de productividad superiores.

Dada la gran sensibilidad de este proceso de fabricación a pequeñas variaciones, este estudio ha tratado de aproximarse a cada uno de los efectos que impactan en el encintado para, o bien modelizarlo o bien conocer todas las variables de las que depende, teniendo de este modo un mayor control 
sobre los trabajos de encintado a ejecutar y un criterio más estricto a la hora de valorar ejecuciones semejantes.

La metodología aplicada para estudiar este proceso de encintado ha tratado de seguir la secuencia evolutiva del proceso y de ese modo han sido organizadas cada una de las sub-secciones de los distintos capítulos que componen el documento.

Inicialmente, el material requiere ser calentado para superar la temperatura de fusión y permitir así el movimiento de cadenas poliméricas en la entrecara. El principal objetivo de este trabajo será simular los perfiles tiempotemperatura generados sobre el material por la actuación de una fuente de calentamiento tipo láser y validar los resultados con medidas experimentales.

Durante el calentamiento del material, éste puede verse sometido a picos de temperatura que excedan los límites que marcan el comienzo de su degradación térmica. En este trabajo se tratará de determinar la posible existencia de efectos de degradación en el material encintado, aplicando para ello diversas técnicas experimentales de medida. Asimismo, persiguiendo conocer de modo predictivo como tiene lugar la de degradación con la temperatura en el polímero, se buscará proponer un modelo matemático de evolución de la degradación que prediga dicho efecto bajo la imposición de perfiles térmicos cualesquiera sobre el material.

Justo tras el calentamiento impuesto por la fuente láser, el material de aporte y el sustrato son puestos en contacto bajo la acción de un rodillo de compactación elastomérico de dureza Shore A 70. El perfil de aplicación de presión varía en relación con la huella del rodillo empleado y con la velocidad de encintado. Al poner sendas partes del material en contacto bajo la acción de la presión, el primer mecanismo que interviene es la eliminación de la irregularidad superficial presente en el material (fenómeno referenciado en la bibliografía como contacto íntimo). Para evaluar los requisitos para una correcta eliminación de rugosidad en el material, éste deberá ser caracterizado superficialmente y utilizando los datos obtenidos, se buscará plantear una ecuación que prediga en base a su estado inicial, a la presión aplicada y al perfil tiempo-temperatura aplicado la evolución del grado de contacto entre las partes.

En el desarrollo del grado de contacto íntimo, la viscosidad jugará un papel importante, condicionando la capacidad del material para fluir. Su valor deberá ser obtenido experimentalmente y representado matemáticamente como una función dependiente de la temperatura aplicada. 
Cuando las dos superficies que van a ser unidas logran contactar entre sí, las cadenas poliméricas se desplazan por reptación para generar una entrecara indistinguible. El desplazamiento de las cadenas responde al mecanismo conocido como difusión y se encuentra relacionado con los tiempos característicos del espectro de relajación del polímero. Este trabajo tiene como objetivo analizar el comportamiento reológico del material a diferentes temperaturas, posibilitando estimar los tiempos requeridos para el movimiento de las cadenas del polímero como función matemática de la temperatura y tiempo a la que es sometido.

Tras la entrada en contacto de las superficies de material de aporte y material sustrato, la temperatura comienza a descender iniciándose el proceso de solidificación del polímero, cuyas cadenas se empaquetarán parcialmente a causa de la naturaleza semicristalina del PEEK. Los abruptos perfiles tanto de calentamiento como de enfriamiento experimentados con esta técnica de fabricación, impiden reproducir a escala de laboratorio las condiciones exactas obtenidas en la fabricación. Con el fin de comprender qué ocurre en el proceso de cristalización de este material, se tratará de caracterizar la morfología del cristal desarrollado, localizando diferencias respecto a procesos de fabricación convencionales fuera de autoclave. Asimismo, se aplicarán teorías y ecuaciones bibliográficas para la predicción de la cristalización bajo perfiles de temperatura y tiempo cualesquiera.

Para evaluar el efecto de la conjunción de todas esas físicas en el resultado del proceso, se buscará analizar la respuesta de este material sometido a diferentes solicitaciones mecánicas, comparando su resultado con el que se obtendría en paneles fabricados en prensa. 


\title{
Capítulo 2
}

\section{Estado del arte}

\author{
En cuestiones de ciencia, la autoridad de \\ miles, no vale más que el humilde \\ razonamiento de un único individuo.
}

Galileo Galilei

ReSUMen: Este capítulo contiene una revisión de los trabajos precedentes en los se han evaluado diferentes metodologías de análisis para los polímeros termoplásticos y los materiales compuestos fibra de carbono-termoplástico. La aplicación de estas metodologías ha permitido a cada uno de los citados autores, obtener información sobre el material desde un punto de vista físico (propiedades térmicas y ópticas, propiedades geométricas/superficiales, desarrollo de cristalización y respuesta a la degradación térmica).

El capítulo se estructura del siguiente modo: una primera parte donde se presenta información sobre el material termoplástico y también sobre generalidades al proceso de laminación automática y consolidación in-situ junto con las ya detectadas necesidades de mejora. En esta parte se incluye por tanto información considerada de utilidad en el conocimiento del proceso, pero sin conexión directa con los diferentes aspectos ligados con la modelización del sistema.

A continuación, se divide el capítulo en subsecciones con los trabajos localizados sobre las modelizaciones del proceso de transferencia de calor, de degradación térmica, de adhesión y de cristalización.

En el recorrido bibliográfico, que ha tratado de hacerse de un modo cronológico, desde las referencias más antiguas a las más actuales, se analizará también la evolución de los sistemas de calentamiento empleados por esta tecnología.

Entre las referencias incluidas, se encuentran estudios que proponen modelos considerando sólo algunas de las físicas implicadas y otras 
en los que los autores dan una visión global analizando cómo éstas interactúan entre sí. Aquellas referencias que hagan alusión a diversos mecanismos implicados se citarán en varios de los subapartados del capítulo con la finalidad de agrupar entre sí, trabajos asociados con los mismos mecanismos.

La búsqueda de trabajos previos no va a centrarse únicamente en aquéllos directamente asociados al proceso de fabricación bajo estudio, sino que se persigue encontrar explicaciones a efectos básicos que pudieran ser posteriormente extrapolados al mismo. Los desarrollos elaborados por grupos expertos en temas particulares como por ejemplo, la degradación térmica, han permitido conocer con mayor exactitud la explicación real a este fenómeno, aunque las explicaciones procedan de trabajos donde la aplicación se ejecute en campos de trabajo completamente alejados del foco de estudio de esta tesis doctoral.

El análisis bibliográfico con el propósito de ejecutar una modelización/simulación de mecanismos experimentados por el material, ha perseguido conocer la física implicada antes de aplicar tratamientos matemáticos que, aun pudiendo reproducir el mecanismo, se encuentren lejos del sentido físico real del proceso. 


\subsection{Materiales termoplásticos}

Los orígenes de los materiales plásticos, tal y como se describe en Feldman, 2008), datan de 1862 con el primer desarrollo basado en la nitrocelulosa, que conduciría a la obtención del primer termoplástico conocido como "celuloide". El primer polímero sintético termoestable, Bakelita, se obtuvo en 1907, mediante la reacción de policondensación del fenol con formaldehido. Estos materiales fueron el mayor sector de crecimiento en la industria química norteamericana tras la Segunda Guerra Mundial (Brazel y Rosen, 2012).

Fue en 1920 cuando emergió el concepto de "polímero" para definirlos. El concepto polímero hace alusión a la presencia de "múltiples-miembros", por el hecho de conformarse por la repetición de una unidad (unidad monomérica) un número elevado de veces. La estructura básica de un polímero consta de un esqueleto principal y de grupos laterales, donde las fuerzas que puede aparecer interactuando son: enlaces covalentes primarios, enlaces de hidrógeno, interacciones tipo dipolo, fuerzas de Van der Waals y enlaces iónicos. Todos ellos, salvo los enlaces covalentes, son secundarios y débiles. Los átomos unidos covalentemente se extienden de un extremo a otro de la cadena principal del polímero conformando su esqueleto, mientras que, todos los demás átomos forman parte de los ya mencionados grupos laterales.

Los materiales poliméricos suelen clasificarse atendiendo a respuesta a la temperatura. La clasificación permite distinguir entre polímeros termoestables y termoplásticos. Los materiales termoplásticos experimentan un reblandecimiento cuando son sometidos a temperatura y pueden fluir bajo esfuerzo, de forma inversa, cuando la temperatura se reduce recuperan su estado sólido o vítreo. En el caso de los termoestables, el comportamiento no es reversible pues experimentan una reacción química con la temperatura conocida como curado que deja congelada su estructura.

Analizando los materiales poliméricos desde el punto de vista de su organización estructural, es posible diferenciar entre lineales, ramificados y entrecruzados. Un polímero lineal es aquel que procede de monómeros difuncionales, generando cadenas lineales, por su parte, un polímero ramificado resulta de la unión de moléculas tri-funcionales o funcionales en mayor número a tres. Cuando la longitud y número de ramificaciones de las cadenas poliméricas crece, se incrementa la probabilidad de que las ramas de una cadena principal a otra se alcancen, dando lugar a las estructuras entrecruzados.

A nivel de producción y empleo, los materiales plásticos pueden dividirse en dos sub-grupos, los conocidos como "commodity" (alto volumen y bajo 
coste) y los polímeros ingenieriles (alto coste y bajo volumen).

Respecto a los polímeros ingenieriles, las necesidades en el campo de la ingeniería condujeron a su empleo mediante el desarrollo de plásticos reforzados. Los primeros elementos consistieron en matrices poliméricas reforzadas con fibra de vidrio fundamentalmente para aplicaciones marítimas pero, en 1960 aparecieron nuevas necesidades promovidas por los programas espaciales militares que requerían el empleo de fibras de alto módulo. La carrera espacial impulsó de manera definitiva los desarrollos de los refuerzos de fibra de carbono, que condujeron a la elaboración de materiales como el que supone el foco del estudio de este documento.

Como ya se indicó en la introducción, estos materiales se encuentran aún lejos de su aplicación industrial al mismo nivel del ya existente en los reforzados termoestables. Se incluyen a continuación las principales ventajas e inconvenientes reportadas sobre los materiales reforzados termoplásticos (Vaidya y Chawla, 2008, Marsh, 2010, August et al., 2014).

- Mejora en propiedades mecánicas como impacto y erosión.

- Mejora de resistencia ambiental, a la humedad y a corrosión.

- Vida ilimitada sin requisitos de almacenaje.

- Los productos y los procesos de fabricación pueden diseñarse a medida para cada necesidad particular.

- Ambientalmente benignos porque no experimentan reacciones exotérmicas ni emiten tóxicos ni volátiles.

- Propiedades FST (Fire Smoke Toxicity) favorables.

- Adaptables a la producción a bajo y alto volumen.

- Coste bajo de utillaje y ciclos de "curado" rápidos.

- Reciclables.

- Métodos mejorados de adhesión y unión aplicables.

- Posibilidad de moldear elementos complejos y completamente integrados en una única operación.

- Propagación de grietas más lenta.

- En caso de fallo, las grietas tienden a ser visibles (detectables), a diferencia de lo que ocurre en termoestables. 
- Baja absorción de agua.

- Temperatura de transición vítrea estable incluso en condiciones de calor y humedad.

Por contra, entre las desventajas pueden citarse:

- Mal comportamiento a fatiga a causa de la mala adhesión fibra-resina.

\subsection{Laminación automática y consolidación in-situ}

El proceso de laminación automática y consolidación in-situ con material reforzado termoplástico, viene siendo estudiado desde los años 80 (Woo Il Lee y Springer 1987). Gran parte de las primeras referencias basadas en este proceso aluden al desarrollo de encintados donde no es posible obtener un grado total de unión entre las partes, haciéndose necesaria una segunda etapa de consolidación (Cogswell, 2013), estimándose que las velocidades requeridas para poder hablar de una consolidación in-situ real, están en el entorno de $0,5 \mathrm{~m} / \mathrm{s}$. Estudios más actuales plantean la posibilidad de ejecutar encintados más rápidos justificando las consideraciones pasadas basadas en errores en la interpretación de los modelos teóricos.

Las múltiples variaciones que pueden aplicarse sobre el equipo de encintado impactan radicalmente en el resultado obtenido, de ahí que tal como ya se planteaba en (Funck y Neitzel, 1995), la tecnología exacta para la mejora absoluta de este proceso aún podría continuar desarrollándose.

Las razones que llevan a considerar este proceso de fabricación ventajoso son: la reducción de costes por una limitada cantidad de residuo o material sobrante en los encintados, mejoras en el posicionado del material, repetitividad en los resultados y menores costes de mano de obra. Constituye además una herramienta esencial para el desarrollo de estructuras de gran tamaño (Mallick, 2001, Kozaczuk, 2016).

El esquema básico de este proceso se incluye en la Figura 2.1. Capas de material reforzado termoplástico se adhieren entre sí tras incrementarse su temperatura por del calentamiento generado por una fuente térmica (tipo láser u otra) y por su puesta en contacto con la aplicación de presión mediante un rodillo compactador.

Aunque en la mayoría de los trabajos localizados sobre laminación automática y consolidación in-situ se emplean materiales termoplásticos de tipo semicristalino, entre otras razones, por ofrecer estos materiales las mayores 


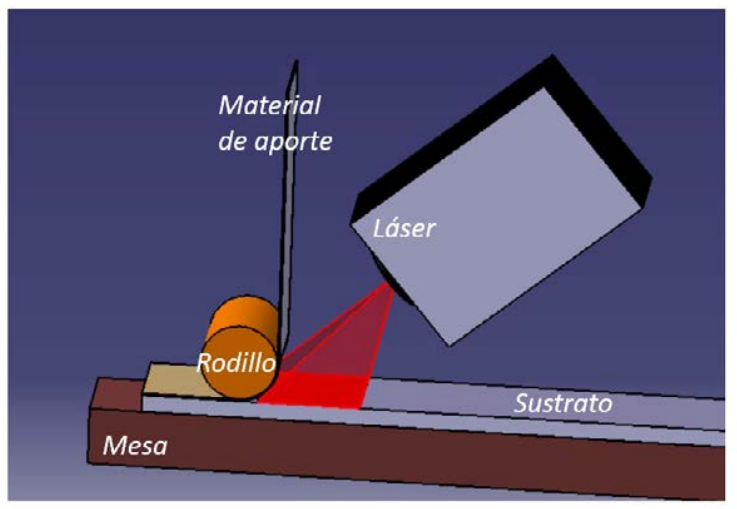

Figura 2.1: Croquis del proceso de laminación automática y consolidación in-situ

prestaciones, el proceso no presenta restricción alguna al encintado con materiales termoplásticos amorfos. De hecho, en (Dai y Ye, 2002) se analiza la aplicación de este proceso al encintado de fibra de carbono y polieterimida en un proceso de encintado con geometría de revolución.

En 2016, se localiza el primer estudio donde se efectúa la aplicación de este proceso de fabricación al encintado de fibras flax con polímero polipropileno (Baley et al. 2016). También en (McGregor et al. 2017) se investiga sobre el encintado de poliamida reforzada con fibra flax. Dichos encintados manifiestan la posible aplicación del proceso de fabricación a materiales reforzados con fibras naturales.

El aspecto crítico de la productividad, considerado una necesidad de mejora de este proceso para su escalado industrial ha sido tratado por diferentes autores y atendiendo a diferentes aspectos. Entre ellos, la reducción de los precios prohibitivos de materiales (Lefebure y Lang, 2007) y de los elementos auxiliares ha ayudado a potenciarlo como alternativa a considerar en su aplicación a la producción de piezas aeronáuticas.

En relación con las características y físicas del encintado, en (Khan et al. 2013) se hace un análisis bastante completo sobre cómo diferentes condiciones/aspectos de encintado afectan al nivel de porosidad y al grado de unión entre las capas y la relación que presentan con la velocidad de procesado. El siguiente listado contiene sus principales conclusiones, de todas ellas puede hacerse visible que, la mejora de alguna de las condiciones normalmente impacta negativamente sobre otra, hecho donde radica la especial complejidad de este proceso de fabricación. 
- Temperatura de utillaje. La tendencia en el volumen de huecos a disminuir con menor velocidad de encintado se invierte cuando las temperaturas del útil se aproximan a la temperatura de fusión del polímero que está siendo encintado. Por su parte, el grado de unión en relación con la temperatura de utillaje, es tal que, cuando la temperatura es baja, el útil suele actuar como un sumidero de calor llevando a una viscosidad que impide un buen desplazamiento de las cadenas e impactando e un grado de unión bajo, haciendo necesario disminuir la velocidad de encintado. Por contra, teniendo el útil a alta temperatura (entorno de $573 \mathrm{~K}$ con PEEK), se obtienen buenos grados de unión incluso en el entorno de $10 \mathrm{~m} / \mathrm{min}$.

- Fuerza de compactación. Si ésta crece, crece el grado de unión y también decae el contenido en huecos, siendo su efecto más marcado con el incremento de velocidad de encintado (a más velocidad más fuerza requerida). Respecto a la velocidad de encintado, el nivel de porosidad debería bajar con el incremento de la fuerza e incremento de la velocidad, por su parte, el grado de unión, a pesar de subir con la fuerza, decae con la velocidad.

- Número de capas. Cuando el número de capas de un laminado es elevado ocurre un doble efecto, las inferiores reciben más etapas de reconsolidación pero las superiores se encuentran más aisladas del sumidero de calor-utillaje, esto hace que experimenten calentamientos mayores y que por tanto se contribuya a incrementar el tamaño de los poros. Ese efecto de desconsolidación por huecos de las capas superiores baja a mayor velocidad de encintado.

- Longitud de calentamiento. Mayores longitudes de calentamiento contribuyen a incrementar el nivel de porosidad. Por su parte, el grado de unión sí se mejora, pudiendo desarrollarse el proceso a mayores velocidades.

- El empleo de varios rodillos contribuye a mejorar el grado de unión, que puede pasar de variar entre 20-95\% a un rango entre $70-95 \%$. A pesar de la ventaja de tener varios rodillos sobre la compactación, incrementar su número tiene un efecto perjudicial sobre la máquina de encintado, haciendo necesario más componentes (más volumen ocupado) e imposibilitando el encintado de geometrías complejas.

A pesar de todas las problemáticas presentes en este sistema de fabricación, ya han sido ejecutadas piezas de relativa complejidad empleando esta tecnología, a continuación se enumeran algunas de ellas: tubos del tren de 
aterrizaje de un helicóptero (Derisi et al. 2011; Hoa, 2017), cono de cola de un helicóptero (LeGault, 2013), coberturas de motores cohete (Henne et al. 2014), tanques criogénicos para espacio (tecnología AFP acoplada a rotomoldeo) (Murray et al. 2017) y cajones de torsión del ala (Oliveri et al. 2018, Peeters et al. 2018).

En la fabricación del cajón de torsión, los rigidizadores diseñados con geometría cerrada en omega, también han sido ejecutados con laminación automática y consolidación in-situ. Para posibilitar su desarrollo fueron empleados útiles fabricados con aleaciones metálicas, cuyo punto de fusión es $75^{\circ}$, bajo la temperatura de transición vítrea del PEEK, facilitando así su extracción por fusión una vez concluído el encintado.

\subsubsection{Mejoras al proceso de ISC}

Existen diversas fuentes de distorsión del proceso que se encuentran localizadas y cuya mejora/resolución implicaría, entre otros aspectos, mejorar la productividad. El encintado y fijación de primera capa es una de ellas; soluciones bibliográficas localizadas pasan por: encintados sobre láminas de polímero sin reforzar (Di Francesco et al., 2017), utillajes con aplicación de vacío o adhesivos de fijación (Lefebure y Lang, 2007; Hoang, 2015) o con el empleo de útiles microporosos (Burchell, 2011).

Las mejoras al proceso no se limitan a componentes físicos de la máquina, sistemas de control o consideraciones del encintado, el material objeto de la laminación tiene también un papel dominante en el resultado (metodologías para la fabricación del mismo recogidas en (Vaidya y Chawla, 2008)). Por la anterior afirmación, muchos trabajos concluyen que los resultados podrían ser mejores con desarrollos implementados sobre la calidad del material encintado (Dai y Ye, 2002), reportándose en otros las características a considerar para evaluarlo (Schaefer, 2015): rugosidad superficial, viscosidad y distribución de fibra y resina.

Otro de los problemas y que es además extensible a todo proceso de fabricación con material compuesto es el desarrollo de tensiones residuales (Parlevliet et al. 2006, 2007a b). Su desarrollo es inherente a las diferencias en los coeficientes de expansión térmica entre fibra y resina, pero además los grandes saltos térmicos de este proceso suponen un problema mayor. El proceso de encintado tiene otro elemento penalizador asociado, el incremento secuencial de capas del material, dejando el material en estados no favorables desde el punto de vista de tensiones. Las tensiones residuales pueden llegar a ser lo suficientemente grandes como para provocar micro-grietas en la resina. $\mathrm{Su}$ análisis se recoge en (Sonmez et al., 2002), donde se tienen en cuenta 
ciertos aspectos de mejora para reducir estas tensiones residuales térmicas:

- Precalentar el material de aporte, impacta en una caída más progresiva de la temperatura cuando aporte y sustrato entran en contacto, resultando en enfriamiento más progresivo y reduciendo por tanto la tensión residual.

- Trabajar con mayor velocidad de encintado incrementa las tensiones residuales. La causa es la existencia de zonas puntuales que están experimentando mayores gradientes térmicos.

- El tamaño de la superficie calentada también influye sobre las tensiones residuales. A menor superficie calentada más bruscos son los perfiles de calentamiento-enfriamiento. Observándose mejores resultados cuando la superficie calentada del sustrato tiene mayor tamaño que la del aporte.

En (August et al., 2014), se indica que la necesidad de emplear velocidades bajas de encintado procede de una mala interpretación ejecutada de la teoría de reptación de De Gennes, al entrar el material en la región del "shear thinning" la viscosidad se reduce y por tanto el tiempo para la relajación de cadena es menor. De hecho, Automatic Dynamics, productora de máquinas asociada al trabajo de la referencia citada, indica que es real la posibilidad de producir piezas con esta tecnología, indicando que generan piezas equivalentes a $5000 \mathrm{~kg}$ de material compuesto por esta tecnología cada año.

Del trabajo de (Hoang, 2015), se deduce como el efecto de porosidades intercapa se elimina por las sucesivas pasadas de máquina en la colocación del material subsiguiente, no obstante las 3 últimas entrecaras son las más afectadas, indicando que 3 pasadas sobre el material no son suficientes para alcanzar la unión perfecta, con una velocidad de encintado de $1,5 \mathrm{~m} / \mathrm{min}$ y con un calentamiento proporcionado por una antorcha de gas caliente. Además, en el trabajo se argumenta que según la secuencia de encintado la necesidad de pasadas de reconsolidación es diferente, con diferentes requerimientos para paneles donde todas las capas son $0^{\circ} \mathrm{o}+/-45^{\circ}$. Se solventa la problemática con pasadas de reconsolidación sin aporte de material desde diferente número de capa según la secuencia que esté siendo encintada. En algunos laminados también utiliza sistemas de refrigeración cuando sus espesores son tales que todo el laminado inferior puede actuar como aislante respecto a la superficie del útil y generar un efecto de sobrecalentamiento. La anterior mejora carece de sentido cuando sistemas de control activo son capaces de actuar sobre la potencia suministrada por la fuente de calentamiento. 
El rodillo de compactación se presenta también como un elemento de mejora para el proceso. Algunos autores defienden la postura de trabajar con rodillos calefactados (fundamentalmente propuesto cuando son metálicos), mientras que otros plantean soluciones en las que el rodillo requiere sistemas de refrigeración que eviten un deterioro excesivo de la goma constituyente (elastómeros o siliconas). Las propuestas de sistemas de refrigeración de los rodillos suelen fundamentarse en el hecho de que la compactación debe coincidir con la etapa de solidificación del material para evitar el desarrollo de porosidad en los laminados. El rodillo también tiene un papel relevante sobre el acabado superficial de pieza, en (Henne et al. 2014) se presentan los resultados de acabado superficial obtenidos con diferentes soluciones de enfriamiento en el rodillo (por chorro de aire externo, por conducción contra un rodillo más frío con el que contacta o por flujo de agua interior) siendo el refrigerado por chorro de agua interior la solución más prometedora.

\subsection{Transferencia térmica y medidas}

En el procesado de los materiales compuestos poliméricos, considerando de modo general termoestables y termoplásticos, el perfil térmico aplicado condiciona radicalmente el resultado en la pieza obtenida. En el caso particular de los materiales termoplásticos, al presentar un comportamiento dependiente y no estable con la temperatura, se hace de gran interés conocer con precisión la historia térmica a la que se somete el material. Más particularmente, para el proceso de encintado automático y consolidación in-situ, los perfiles térmicos aplicados serán los que condicionen el desarrollo de variaciones en el material como la fusión, la difusión de cadenas, la cristalización, la posible degradación térmica y el desarrollo de tensiones residuales.

\subsubsection{Sistemas de calentamiento}

El sistema de calentamiento en las máquinas de encintado es uno de los elementos más cuestionados en las referencias, como reportan (Funck y Neitzel, 1995, Lee, 2004, Haake, 2005, Schledjewski y Miaris, 2009), pudiendo verse la evolución de estos equipos con el transcurso del tiempo. Inicialmente, el sistema se basaba en el uso de antorchas de gas caliente, evolucionando posteriormente al uso del láser, comenzándose con láseres de $\mathrm{CO}_{2}$, pasando por los Nd:YAG y llegando al diodo láser como la mejor alternativa en tiempos más recientes. Esta diversidad de soluciones para el calentamiento han sido implementadas con diferentes resultados: los infrarrojos, que no han permitido alcanzar la gran intensidad demandada por el calentamiento del NIP o la antorcha de gas caliente, que a pesar de su bajo coste y flexibilidad de diseño, pone de manifiesto una baja eficiencia energética y lentitud en su 
tiempo de respuesta. El láser ha resultado ser la primera opción en base a su buena eficiencia energética y rapidez de respuesta. Además, en el caso del láser, en la decisión sobre el empleo de una fuente u otra se hace vital conocer la interacción con el material, en especial, la capacidad del material para absorber la radiación. En el caso de los láseres de tipo $\mathrm{CO}_{2}(\lambda=10600 \mathrm{~nm})$, la resina manifiesta una alta absorbancia, por contra en la longitud de onda del Nd:YAG y diodo ( $\lambda=1064$ y $805-940-980 \mathrm{~nm}$ respectivamente), la resina es transparente a la radiación, transmitiéndose y reflejándose toda la energía.

En relación con el calentamiento, en ciertas referencias se alude a la posibilidad de ejecutarlo con el empleo de dos fuentes de calentamiento en lugar de una única. (Tierney y Gillespie, 2006) indica que la existencia de un sistema de calentamiento previo no busca la consolidación sino un primer efecto de adhesión entre las partes, ayudando a evitar efectos perjudiciales derivados del corte del material (falta de tensión en la cinta posicionada, desalineamiento de fibras, etc.), equipo mostrado en la Figura 2.2 a. También se reporta la posibilidad de conseguir esa mejora en (Barasinski et al. 2011a b), con una estructura de máquina donde existe únicamente una fuente térmica tipo láser y dos sistemas de compactación tipo rodillo, como muestra la Figura $2.2 \mathrm{~b}$.

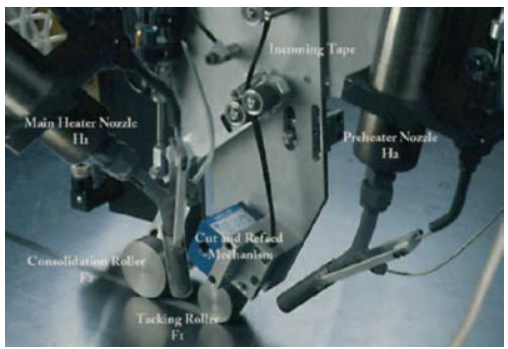

(a)

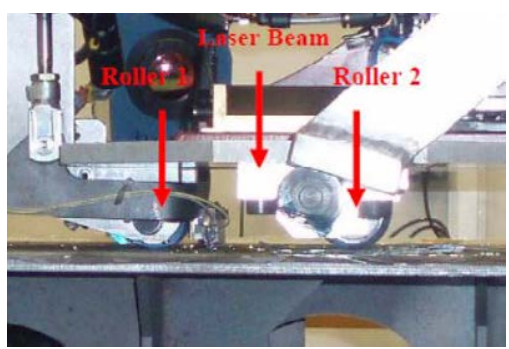

(b)

Figura 2.2: Máquinas de encintado con doble sistema de compactación a) (Tierney y Gillespie, 2006) y b) (Barasinski et al. 2011b)

(Maurer y Mitschang, 2015; Stokes-Griffin et al. 2015, Di Francesco et al. 2017) estudian el proceso de encintado con máquinas portando láseres adquiridos a Laserline, siendo el equipo de calentamiento el modelo Laserline GmbH LDF 6000-100 6kW con dos agrupaciones de diodo láser de longitud de onda $\lambda=975 \pm 10 \mathrm{~nm}$ y otras dos con $\lambda=1025 \pm 10 \mathrm{~nm}$ ). La incorporación del láser de diodo tipo NIR (near-infrared), ha permitido trabajar con distancias focales mayores a las fuentes láser de dióxido de carbono, $127 \mathrm{~mm}$ (Stokes-Griffin et al., 2015) o $250 \mathrm{~mm}$ en (Schaefer et al. 2017a).

El láser de diodo es la solución más comúnmente empleada, no obstante, 
en (Köhler et al. 2007) se muestran las posibles desventajas de emplear este tipo de sistema, principalmente a causa de la falta de una distribución homogénea de la intensidad. El empleo de homogeneizadores puede paliar este efecto, pudiéndose ejecutar esa homogeneización mediante diferentes alternativas, una de ellas es la superposición de haces del propio láser obtenidos mediante la construcción de un equipo con diferentes líneas láser (quedando el resultado condicionado por la posición a la que se localice el láser respecto al cuerpo de actuación y a posibles fallos de cada una de las líneas independientes), otro sistema consiste en incorporar un equipo de guía de onda, también puede ejecutarse mediante un conjunto de lentes micro-ópticas como se presenta en el trabajo de (Homburg et al. 2008).

En (Brecher et al. 2013) se muestra el empleo de láseres de $\mathrm{CO}_{2}$ como alternativa para los calentamientos de superficies sin color como polímeros sin refuerzo o con refuerzo de fibra de vidrio. La solución que se propone tiene una aplicación directa a problemas de fijación de primeras capas o el empleo de láminas como superficies funcionalizadas, así como en el desarrollo de componentes híbridos.

Actualmente, existen también máquinas donde se están probando sistemas alternativos de calentamiento, como es el caso de (Rizzolo y Walczyk, 2016. Chu et al. 2018) con el empleo de una fuente de calentamiento por ultrasonidos. El calentamiento por ultrasonidos consiste en una exitación y fricción de las moléculas del polímero por la baja amplitud y gran frecuencia de vibración de las ondas ultrasónicas. Las ventajas de emplear fuentes de calentamiento por ultrasonidos que aparecen reportadas en los trabajos consultados son: calentamiento focalizado reduciendo la cantidad de energía requerida y permitiendo incrementar la velocidad de soldadura. Su uso ha permitido el encintado en automático con materiales de polietileno y fibra de vidrio y polietilentereftalato con fibra de carbono dando resultados inferiores a los obtenidos por el procesado en prensa del mismo material.

(Lichtinger et al. 2015) también reporta el uso de un sistema de calentamiento diferente, unas lámparas de cuarzo que aplican un calentamiento infrarrojo desarrolladas por Heraeus Noblelight. Este sistema presenta como desventaja la necesidad de localizarse casi en contacto con el material sustrato y aporte.

Otro sistema alternativo referenciado en varios estudios es el "VerticalCavity Surface-Emitting Laser (VCSEL)" (Weiler et al. 2016a). Este sistema, compuesto por microlentes dispuestas en serie, permite un control en líneas independientes de la potencia de emisión láser. Entre las ventajas de usar sistemas de este tipo se encuentran: posible calentamiento diferencial 
para unir superficies de materiales diferentes, compensación de zonas con pérdidas de calor/zonas con acumulación de calor (homogeneizar la huella de calentamiento), control de distribuciones de temperatura en encintados complejos (curvaturas) o control de los perfiles de enfriamiento. Considerando zonas complejas como cambios en curvaturas o rampas, los efectos que se producen suelen corresponderse con sobrecalentamientos, relacionados con la posición láser respecto al laminado, donde la irradiación resulta de una relación entre la potencia suministrada y la superficie que está siendo irradiada, la disminución de la superficie genera una mayor irradiación para un mismo nivel de potencia aplicado.

Las ventajas de las VCSEL tienen también una aplicación directa a los efectos de subcalentamientos en las entradas del láser o posibles sobrecalentamientos experimentados en las salidas. Por contra, este sistema no consta de un sistema que homogeneice el haz láser, haciendo preciso su posicionado muy próximo al área de encintado y dificultando el posicionado de sistemas de lectura y control de la temperatura.

\subsubsection{Modelos de transferencias de calor}

Con el objetivo de poder controlar el proceso de laminación automática y consolidación in-situ, muchos han sido los grupos de investigación que han tratado de simular la evolución de los perfiles térmicos en el material calentado bajo la acción de diversas fuentes térmicas, (Grove, 1988, Saliba et al. 1989, Ghasemi Nejhad et al., 1991, Pitchumani et al., 1996, Toso, 2003 Kim et al., 1996; Sonmez y Hahn, 1997; Tumkor et al., 2001; Heider et al. 2002, Dai y Ye, 2002, Tierney y Gillespie, 2003; Schlottermuller et al., 2003 Barasinski et al., 2011a; Li et al., 2011, Grouve, 2012; Duhovic et al., 2014 Han et al. 2014, Li et al. 2015, Kergomard, 2016). Para dicha tarea, se han basado en la aplicación de diversas metodologías y simplificaciones.

Los primeros estudios encontrados a este respecto datan de los años 80 , con los trabajos de (Grove, 1988) que utiliza el método de los elementos finitos para resolver el problema de transferencia térmica en APC2 con una simplificación bidimensional de la geometría del proceso de calentamiento mediante el empleo de una fuente láser. No obstante, no se reportan validaciones experimentales de los resultados obtenidos.

Algunos de los trabajos muestran también el acoplamiento del modelo térmico con otros, como los de consolidación o degradación, para determinar así las condiciones óptimas de procesado, como (Sonmez y Hahn, 1997. Toso, 2003). (Sonmez y Hahn, 1997) destacan los beneficios de efectuar precalentamientos del sustrato y no del material de aporte sobre la optimización 
del grado de unión (las distribuciones entre \% de calentamiento en material de aporte y sustrato también se discuten en (Schledjewski y Miaris, 2009), determinándose un valor alto y estable de fuerza de pelado entre capas, cuando la distribución de área de calentamiento es 60-material de aporte/40-sustrato), asimismo también reconocen la necesidad de ejecutar los encintados de las últimas capas a menor velocidad para compensar la disminución de tiempos de consolidación.

(Toso, 2003) resuelve el problema del calentamiento con una antorcha de gas caliente en un encintado para la obtención de una geometría de revolución. Para ello, utiliza un sistema de coordenadas cilíndricas en el material sustrato y un sistema cartesiano en el material de aporte. En este estudio, se desprecia la contribución de los flujos de calor procedentes de la exoterma de cristalización y la endoterma de fusión basándose en resultados experimentales obtenidos por calorimetría. Sus análisis determinan que se produce una sobre-estimación del valor de temperatura al considerar dichos efectos, sobre-estimación que se multiplicará con los perfiles reales de enfriamiento del proceso de fabricación (hipótesis también encontrada en (Shih, 1997; Grouve, 2012, Weiler et al. 2018)). Además, esta referencia tampoco considera el término de radiación, mostrando un error cometido inferior al $6 \%$ al despreciarlo.

$\mathrm{Al}$ contrario de lo hipotetizado anteriormente por (Toso, 2003), en el caso de la modelización de un problema térmico semejante en materiales termoestables, (Hassan et al. 2005) tiene en cuenta la exoterma del curado en la modelización como una fuente de calor añadida. En su trabajo, contabiliza el efecto del encintado añadiendo nuevos elementos al mallado en cada paso de iteración. (Nicodeau, 2005) efectuará la modelización del problema térmico en el encintado con APC2 incluyendo en las ecuaciones los términos relativos a la fusión y la cristalización del material. En el trabajo se hace una resolución del problema de modo numérico con una simplificación geométrica bidimensional. Para contabilizar el efecto de ir depositando nuevas capas de material, se actúa sobre los elementos de las entrecaras modificando sus condiciones de contorno, antes de la actuación del rodillo serán elementos aislados entre sí y tras el paso del rodillo se impondrá igualdad de temperatura entre esos elementos pero no igualdad de flujo de calor. Es de destacar en esta referencia la simplificación que se ejecuta del utillaje, que se tendrá en cuenta en la simulación como una condición de contorno y no como un elemento físico, impactando por tanto en los tiempos de cálculo. Esta simplificación también se ejecuta en otras referencias y de ahí que se incorporen diferentes valores para $h_{\text {Utillaje }}$, utilizándose también en los casos en los que se estima que no existe un contacto perfecto material-utillaje. 
(Ghasemi Nejhad et al. 1991) ejecuta una inter-comparación para la resolución del problema térmico empleando una solución numérica basada en elementos finitos y también aplicando una solución analítica por medio de un desarrollo basado en separación de variables. En su trabajo se demuestra que existe un buen acoplamiento en las soluciones reportadas por ambas metodologías de cálculo.

Por su parte, (Pitchumani et al. 1996), propone ejecutar el proceso de encintado mediante el empleo de dos fuentes de calentamiento, siendo la primera de ellas un sistema de "precalentamiento" del material. Entre las hipótesis elaboradas en este trabajo se destacan: se desprecia el flujo de calor de la cristalización por ser muy inferior a los demás implicados en el proceso y la primera fuente de calentamiento ejerce su efecto sobre la superficie superior del material de aporte. El trabajo emplea el modelo térmico para alimentar su estudio sobre el grado de consolidación y la evolución de la porosidad en el conjunto laminado. Reporta mejoras sobre el grado de unión con incrementos de la fuerza de compactación, con incrementos en la temperatura del aire de la antorcha de calentamiento, con la incorporación de un sistema de compactación entre ambas fuentes de calor y con un enfriamiento posterior forzado (por reducción de la porosidad al compactarse durante la solidificación).

Esta solución basada en dos fuentes de calentamiento ha sido también utilizada por (Heider et al. 2002), con dos antorchas de nitrógeno caliente.

Perteneciente al mismo grupo de investigación de los autores mencionados en el párrafo previo, (Tierney y Gillespie, 2003), desarrollan un trabajo en el que se presentan conjuntamente la simulación numérica del modelo térmico en un proceso de laminación automática y las formulaciones matemáticas que aplican a la dinámica en la formación de huecos. La formulación de su modelo térmico considera una simplificación en una única dimensión y bajo un estado estacionario.

Como se ha mostrado anteriormente, son varios los grupos de trabajo donde se emplean dobles fuentes de calentamiento en el proceso para mejorar la consolidación. Con un propósito similar pero una arquitectura diferente (Li et al. 2011) alude al empleo de un sistema de precalentamiento por infrarrojos en material alimentado por la máquina. A parte de modelizar térmicamente ese efecto de pre-calentamiento, también estima las disminuciones en tiempo de encintado por el pre-calentamiento, reportando mejoras en la productividad obtenida bajo el empleo de esta solución.

Para (Schlottermuller et al. 2003), el modelo térmico forma parte de 
una simulación general para predecir las deformaciones térmicas en un proceso tipo "filament winding" con polipropileno reforzado con fibra de vidrio (GF/PP). Entre los aspectos diferenciales de este trabajo destaca la incorporación del flujo de calor de salida desde el material al ambiente por radiación.

Respecto al sistema de calentamiento, (Lee, 2004) presenta las diferencias a imponer en la ecuación de transferencia térmica en función de qué tipo de fuente de calentamiento se esté empleando, contemplando calentamientos con un gas caliente, con aire caliente y con un elemento rígido, en el análisis de un proceso de encintado con material compuesto termoestable. Para el caso de calentamiento con un fluido/líquido caliente, se estima que el coeficiente de convección térmica debe ser al menos dos veces el considerado al emplear una fuente de gas caliente. En un calentamiento con un sistema rígido, la condición de contorno en convección se sustituye por una condición en temperatura constante en la entrecara entre este elemento y pieza, siendo éste el sistema que permite los menores tiempos de respuesta y también el que menores riesgos ofrece a posibles efectos de degradación en el material. La única desventaja que manifiesta sobre el uso de este tipo de sistemas es la necesidad de generarlos como rodillos calefactados portantes de un sistema de control de la temperatura.

En los trabajos de (Lamèthe et al., 2005), se ejecutan simulaciones térmicas mediante el uso del software FlexPDE, contabilizando el flujo de calor de salida del material por radiación. La simulación térmica permite dar explicaciones a variaciones en las propiedades mecánicas de fractura entre probetas fabricadas de diferente modo mediante el análisis del tiempo de mantenimiento sobre la temperatura de fusión del polímero.

Otras metodologías empleadas en la resolución del problema térmico pueden encontrarse en (Barasinski et al., 2011a b, 2014, Bur et al., 2016, Perez et al. 2017), con el empleo del método numérico de la descomposición propia generalizada (PGD), que resuelve la ecuación del calor mediante separación de variables y con una metodología fundamentada en la aplicación del principio de los trabajos virtuales. Asimismo, en estos trabajos se contabiliza el efecto de la resistencia térmica entre capas (también empleado por Grouve, 2012)). Tener en cuenta que no existe un contacto perfecto entre las capas para la transmisión de calor genera resultados más precisos del perfil de temperatura experimentado por el material, mejorándose especialmente la precisión del ajuste en la fase de enfriamiento. La condición de resistividad entre las capas actúa de tal modo que considera que existe un bloqueo a la transmisión de calor hacia las capas inferiores y por tanto el enfriamiento está más impedido y es, por tanto, más progresivo. En otros estudios, por contra, este efecto se considera despreciable para la simulación (Schaefer et 
al. 2017a).

En el trabajo de (Barasinski et al., 2011a) se presenta también una correlación entre la transmisión de calor y los mecanismos de difusión y de degradación por entrecruzamiento (cross-link) en el material (sin considerarse el efecto del contacto íntimo - estimando contacto perfecto), reportándose un efecto beneficioso por mantener el utillaje calefactado a una temperatura de $473 \mathrm{~K}$, condición en la que se obtiene un $100 \%$ de adhesión con un valor de cross-link en el mínimo reportado como perjudicial por (Nicodeau, 2005).

Aplicado a un proceso de encintado con una fuente de calentamiento tipo inductor electromagnético, (Duhovic et al. 2014) presenta una resolución del modelo térmico mediante el método de los elementos finitos. En su estudio destaca la posibilidad de ejecutar uniones híbridas metal-material compuesto de fibra de carbono o de material compuesto fibra de carbono contra otro homólogo mediante un susceptor intermedio. La característica especial de esta simulación es la necesidad de acoplar también un flujo de enfriamiento aplicado a la superficie superior para evitar un excesivo calentamiento cuando el objetivo es la unión de una interfaz alejada de este área superficial. La simulación ha permitido llegar también a conclusiones relativas a la correcta adhesión de los elementales, indicándose que para conseguir una correcta unión, la etapa de compactación debe tener lugar en el rango de temperaturas de $653 \mathrm{~K}$ a $553 \mathrm{~K}$, pues se corresponde con el intervalo en el que tiene lugar la re-cristalización/solidificación del polímero.

En el modelo de (Li et al. 2015) la novedad estriba en la metodología empleada para simular la adición secuencial de capas al laminado, en un encintado con antorcha de gas caliente. La estrategia se basa en la programación de un algoritmo en ANSYS que va activando los elementos progresivamente con la evolución del encintado. No significa que los elementos del modelo aparezcan y desaparezcan sino que se multiplican por ciertos factores de modo que durante el encintado de la capa 1, las capas más altas no tienen influencia para el modelo, su contribución aparece al llegar al encintado de las mismas y así sucesivamente con todas ellas. Entre sus hipótesis destaca despreciar el efecto de la disipación del calor hacia el rodillo, simplificación no ejecutada por la mayoría de los trabajos consultados. En una de sus conclusiones se indica que aumentando la velocidad de encintado, disminuye la temperatura en el NIP, presentándose una tendencia que no es lineal entre ambos parámetros.

Contrario a despreciar el rodillo como elemento participante en la simulación, (Kergomard, 2016), plantea el desarrollo de una simulación mecánica que permita previamente conocer la deformación de rodillo bajo el estado 
de cargas al que se somete y una vez con dicho resultado evaluar el modelo térmico. De este modo, se genera una menor incertidumbre sobre la zona de actuación del rodillo en el modelo térmico.

En el estudio térmico efectuado por (Stokes-Griffin et al. 2015, StokesGriffin y Compston, 2015a) se alude a un efecto penalizando el calentamiento en laminación automática frente a los calentamientos obtenidos por "filament winding"; la sombra del rodillo, efecto a considerar en las simulaciones. A causa de las posiciones que deben ocupar cada uno de los elementos en el conjunto y con la deformación obtenida con el uso de rodillos elastoméricos, se genera un área reducida donde el láser no es capaz de actuar unos milímetros antes de la entrada en contacto del material de aporte con el sustrato (NIP). Las validaciones experimentales así como los modelos desarrollados demuestran que esa caída supone un incremento mayor en el sustrato que en el material de aporte por la mayor capacidad del material de aporte para retener el calor. El autor del trabajo indica que dicho efecto de sombra afecta al área de consolidación posterior (iniciada desde el NIP) y por tanto, cada máquina será objeto de resultados muy dispares sólo por diferencias en este simple elemento del conjunto. En su desarrollo se contabiliza el rodillo como un cuerpo físico, incluyendo su geometría en el modelo de elementos finitos aplicado para la resolución de la ecuación del calor, a diferencia de la gran mayoría de las referencias previas donde el rodillo se considera como una condición de contorno. La condición que aplica entre rodillo y laminado es una condición de conducción térmica en la que se incluye la posibilidad de considerar un efecto de resistencia térmica, cuanto mayor es esa resistencia térmica, menor es el efecto de sumidero de calor del rodillo. El valor que mejor ajusta la resistencia térmica rodillo-laminado en esta investigación se corresponde con: $1-2\left[m^{2} K / k W\right]$, valor típico en las interacciones acero inoxidable-silicona.

En la propuesta de modelo térmico de la referencia anterior, destaca el hecho de que se contabiliza un término más en la ecuación del calor normalmente no considerado; proponiéndose la Ecuación 2.1. Se trata de un vector velocidad que tiene en cuenta el transporte másico del calor.

$$
\rho c\left(\frac{\partial T}{\partial t}+v_{x} \frac{\partial T}{\partial x}+v_{y} \frac{\partial T}{\partial y}\right)=\ddot{q}+\frac{\partial}{\partial x}\left(K_{x} \frac{\partial T}{\partial x}\right)+\frac{\partial}{\partial y}\left(K_{y} \frac{\partial T}{\partial y}\right)
$$

Además, en este estudio se analiza la necesidad de refinamiento en la malla para la validez de la simulación. Para ello, reporta valores de difusividad térmica de los difentes componentes de la geometría modelizada, empleando dicho parámetro para calcular el número de Peclet, que establece el límite en 
el tamaño de los elementos de la malla. Por los resultados, el mayor número de elementos se requiere localizar en el área del rodillo directamente en contacto con el material laminado.

En (Tierney y Gillespie, 2006; Stokes-Griffin y Compston, 2015b) se considera el efecto de las múltiples pasadas experimentadas por una capa de material en el resultado final de los laminados. (Tierney y Gillespie, 2006) considera que, aproximadamente dos capas por debajo del área de encintado verán la fusión del material mientras que son varias más las que experimentarán temperaturas entre la transición vítrea y la fusión (considerándose velocidades de encintado de 1,2 a $4,8 \mathrm{~m} / \mathrm{min}$ ). Ese efecto implica, según los autores, un incremento del grado de contacto entre las partes que evoluciona de 0,75 a 0,9 en la línea de unión tras sólo 3 pasadas de encintado, haciéndose por tanto necesarias las pasadas de re-consolidación de las capas superiores para obtener un laminado homogéneo. (Stokes-Griffin y Compston, 2015b) reporta que a velocidades de 6 y $24 \mathrm{~m} / \mathrm{min}$ con AS4/PEEK150, únicamente la capa que es directamente laminada con consigna de $673 \mathrm{~K}$ experimenta fusión, quedando los procesos de unión condicionados por estos perfiles térmicos.

El mismo autor del artículo anterior, publica en el estudio (Stokes-Griffin y Compston, 2016a) una nueva metodología que busca obtener los requisitos de flujo de calor sobre el laminado imponiendo la temperatura que se desea que gobierne la entre-cara objeto de laminación, de este modo se pueden estimar las potencias que serían requeridas para ese resultado concreto. En el trabajo se destacan las afirmaciones ejecutadas sobre el "heat soak", que es una nomenclatura usada por el autor para referirse al tiempo de mantenimiento del material a la temperatura consignada; cuando el valor del "heat soak" se reduce, el material está menos tiempo a la temperatura máxima y los perfiles de enfriamiento son más lentos, luego afectan positivamente a la cristalización.

(Pignon et al., 2017) acopla en el modelo térmico la contribución del flujo de calor generado por la cristalización del material en un proceso de moldeo por inyección. Aplica el modelo de Nakamura, descrito en las próximas secciones, para el proceso de cristalización.

(Di Francesco et al. 2017), propone una resolución analítica del problema térmico, aplicado a una máquina con capacidad para encintar material preimpregnado termoestable, termoplástico y fibra seca. En su trabajo se presenta una ecuación que estima la temperatura del punto que referencia como NIP visible, punto más próximo a la entrada en contacto entre aporte y sustrato y en el que es posible medir la temperatura. Dicha temperatura, 
estimada como una función dependiente de la velocidad de encintado (V), la potencia $(\mathrm{P})$, parámetros del material $(\mathrm{K})$ y del set-up de máquina $(\mathrm{K})$ (huella de calentamiento), presenta una aparente tendencia lineal con la variación de la potencia, según muestra la Ecuación 2.2. Dicha tendencia lineal no se demuestra experimentalmente y se concluye que la causa para ese efecto es la dependencia existente entre las propiedades del material y la temperatura. Su desarrollo ha permitido establecer un ciclo abierto de control para ajustar los parámetros potencia-velocidad-temperatura de laminación.

$$
T_{V N P}=K V^{-0,5} P+T_{0}
$$

(Weiler et al. 2018) propone una resolución analítica de la ecuación considerando que es el método más efectivo/rápido para establecer un control en línea del proceso de encintado automático y consolidación in-situ. Entre las hipótesis y consideraciones novedosas que figuran en este trabajo se encuentran las listadas a continuación.

- Se determina que la resistencia térmica al calentamiento de la fuente láser es de valor infinitamente pequeño, de ahí la ventaja de este tipo de calentamientos frente a otros.

- Las propiedades del material dependientes de la temperatura se simplifican utilizando su valor medio en el rango de temperaturas considerado.

- Aun ejecutando un análisis del proceso de encintado de una geometría curva, el autor propone simplificar el material como una geometría de placa.

- Se considera que la profundidad de penetración del láser es inferior a la profundidad de penetración del flujo de calor.

- A diferencia de otros autores, no considera que las capas del material puedan aproximarse por elementos de espesor semi-infinito. Analizando su capacidad de almacenamiento de calor a través del estudio del número de Fourier (relación entre la velocidad de difusión y de almacenamiento del calor) proponen una solución válida para variaciones de este número entre 0 e infinito. Se estima que el valor límite de este número corresponde con un valor de 0,2 para que las aproximaciones de espesor semi-infinito y con espesor finito se alejen entre sí.

- Propone dos modelos de control para el proceso, uno basado en un sistema de bucle abierto (un sistema que no se basa en ninguna lectura externa sino en soluciones previamente calculadas) y otro cerrado (empleando lecturas sobre la parte posterior del material alimentado obtenidas con pirómetros). 
En la simulación, la potencia suministrada por la fuente se incluirá en los modelos como un flujo estimado a partir del valor de la potencia en [W] y del área de aplicación de la misma.

Para el correcto funcionamiento de las simulaciones presentadas por los diferentes autores, ésta requieren alimentarse con los valores de las diferentes propiedades térmicas del material, propiedades que en el caso de los materiales compuestos son anisotrópicas y que en muchos casos son también dependientes de la temperatura. Para arrojar más claridad a este respecto, la Tabla 2.1 contiene una compilación de los valores bibliográficos de diferentes parámetros requeridos para la modelización térmica junto con la información aportada sobre el material bajo estudio.

También es posible localizar algún trabajo (Romoli et al. 2012) donde se presentan de modo independiente las propiedades térmicas de la fibra y la resina, permitiendo aplicar la ley de mezclas para la obtención de valores en el material compuesto. Los valores reportados son, en conductividad de 0,25 $W /(m K)$ y $50 \mathrm{~W} /(\mathrm{mK})$. Densidades de 1,32 y $1,85 \mathrm{~g} / \mathrm{m}^{3}$ y calor específico 320 y $710[\mathrm{~J} / \mathrm{kgK}]$. 


\begin{tabular}{|c|c|c|c|c|c|}
\hline [Ref.] & Material & $\begin{array}{c}c_{p} \\
{[J /(k g K)]}\end{array}$ & $\begin{array}{c}k_{11} \\
{[W /(m K)]}\end{array}$ & $\begin{array}{c}k_{22} \\
{[W /(m K)]}\end{array}$ & $\begin{array}{c}\rho \\
{\left[k g / m^{3}\right]}\end{array}$ \\
\hline (Grove, 1988) & APC2 ICI & $a$ & $a$ & $a$ & - \\
\hline (Ghasemi Nejhad et al., 1991) & APC2 & $10^{b}$ & $6^{b}$ & $0,72^{b}$ & $1560^{b}$ \\
\hline$(\overline{\text { Phillips et al., } 1994)}$ & APC2 & 1700 & 5,9 & $0,7^{b}$ & 1600 \\
\hline (Kim et al., 1996) & APC2 ICI & - & $10 \cdot k_{22}^{a}$ & $a$ & - \\
\hline$(\overline{\text { Shih }}, \overline{19} \overline{97})$ & $\begin{array}{c}\mathrm{APC} 2 / \mathrm{AS} 4 \\
\text { Fiberite Inc. }\end{array}$ & $\begin{array}{c}1425[\mathrm{~J} / \mathrm{K}] \\
\text { Capacidad calorífica }\end{array}$ & 6,0 & 0,72 & 1562 \\
\hline (Tumkor et al., 2001) & APC2 & $a$ & $a$ & $a$ & - \\
\hline$(\overline{\text { Toso }}, \sqrt{2003)}$ & PEEK/FC & $969,32+5,0244 T-0,0097944 T^{2}$ & 0,55 & 0,41 & 1640 \\
\hline (Tierney y Gillespie, 2003) & APC2 & 1370 & - & 0,34 & 1584 \\
\hline (Lamèthe et al., 2005 & $\mathrm{APC} 2$ & $1300[J / g K]^{c}$ & - & $0,70^{c}$ & $1575^{c}$ \\
\hline (Talbot et al., 2005) & $\mathrm{APC} 2 / \mathrm{AS} 4$ & 930 & 6,8 & 0,658 & 1598 \\
\hline (Tierney y Gillespie, 2006) & APC2 & 1370 & 3,5 & 0,34 & 1584 \\
\hline (Lemarchand, 2008) & $\mathrm{APC} 2$ & 1425 & 6 & 0,72 & 1560 \\
\hline Barasinski et al., 2011b & $\mathrm{APC} 2$ & $1700[\mathrm{~J} / \mathrm{gK}]$ & 5 & 0,5 & 1560 \\
\hline$($ Li et al. $201 \overline{1})$ & APC2 & 1425 & - & 0,72 & 1560 \\
\hline$($ Li et al. 2015$)$ & APC2 ICI & $1124[W / m K]^{d}$ & $7,5^{d}$ & $0,75^{d}$ & 1562 \\
\hline (Maurer y Mitschang, 2015) & $\mathrm{APC} 2$ & $\begin{array}{c}886(298 \mathrm{~K}) \\
1803(573 \mathrm{~K})\end{array}$ & $\begin{array}{l}5,542(298 \mathrm{~K}) \\
9,364(573 \mathrm{~K}) \\
\end{array}$ & $\begin{array}{l}0,813(298 \mathrm{~K}) \\
1,188(573 \mathrm{~K}) \\
\end{array}$ & 1540 \\
\hline (Stokes-Griffin et al., 2015) & $\begin{array}{c}\text { AS4-PEEK150 } \\
\text { Suprem }\end{array}$ & $1300^{e}$ & $5,9^{e}$ & $0,7^{e}$ & $1575^{e}$ \\
\hline (Lionetto et al. 2017) & $\mathrm{PEEK} / \mathrm{FC}$ & 1088 & 5,4 & 0,5 & 1532 \\
\hline (Weiler et al., 2018, & $\mathrm{PEEK} / \mathrm{FC}$ & 1425 & - & 0,72 & 1560 \\
\hline
\end{tabular}

${ }^{d}$ Valores para $453 \mathrm{~K}$, consultar referencia para valores intercalados $60 \mathrm{~K}$ entre sí, desde 273 a $753 \mathrm{~K}$

e Valor a $473 \mathrm{~K}$, más valores en la referencia.

Tabla 2.1: Propiedades térmicas del material compuesto PEEK-FC 


\begin{tabular}{|c|c|c|c|c|}
\hline [Ref.] & $\begin{array}{c}\text { Material } \\
\text { de utillaje }\end{array}$ & $\begin{array}{c}c_{p} \\
{[J /(k g K)]}\end{array}$ & $\begin{array}{c}k \\
{[W /(m K)]}\end{array}$ & $\begin{array}{c}\rho \\
{\left[\mathrm{kg} / \mathrm{m}^{3}\right]}\end{array}$ \\
\hline (Tumkor et al. 2001) & Acero & 480 & 15 & 8055 \\
\hline (Ghasemi Nejhad 1993) & Acero & 473 & 43 & 7800 \\
\hline$(\overline{\text { Shih }} 1$ 1997) & Acero & $473[\mathrm{~J} / \mathrm{K}]$ & 43 & 7800 \\
\hline (Shih 1997$)$ & Aluminio & $905[\mathrm{~J} / \mathrm{K}]$ & 237 & 2700 \\
\hline (Han et al. 2014) & Acero & 460 & 45 & 7600 \\
\hline Li et al. 2015) & - & 905 & 237 & 2700 \\
\hline (Maurer y Mitschang 2015) & Aluminio & 875 & 170 & 2800 \\
\hline (Stokes-Griffin et al. 2015$)$ & Aluminio & 951 & 237,5 & 2689 \\
\hline
\end{tabular}

Tabla 2.2: Propiedades térmicas del utillaje

En la simulación, no solo intervendrán parámetros propios del material sino que también la transmisión de calor hacia el ambiente, con el utillaje o con el rodillo de compactación implica alimentar el modelo con una serie de valores numéricos. En el caso del utillaje empleado para la laminación, es posible encontrar variedad de parámetros según la referencia, en la Tabla 2.2 se incluyen algunos de ellos. El resto de transferencias térmicas, se modelarán en base a unas condiciones de contorno, los parámetros que aplican han sido reportados por varias referencias bibliográficas y se recopilan en la Tablas 2.3 y 2.4

Junto con los valores anteriormente reportados para contabilizar las transferencias con el rodillo y con el aire, algunas referencias tienen en cuenta la transferencia hacia el utillaje o en el área de actuación de la antorcha de calentamiento, con un coeficiente de convección térmica. En (Ghasemi Nejhad et al. 1991 se reporta un valor de $h_{\text {Utillaje }}=1000 \mathrm{~W} / \mathrm{m}^{2} \mathrm{~K}$, para contabilizar la posible resistencia a la transmisión de calor entre el material de primera capa y el utillaje de laminación, valor utilizado también por (Kim et al. 1996). Este último, también reporta la complejidad para establecer el valor de ese coeficiente de convección en el área de actuación de la antorcha, adoptando valores tan alejados como 250 o $900 \mathrm{~W} / \mathrm{m}^{2} \mathrm{~K}$ en relación con la distancia respecto al punto NIP, esta distribución de valores también fue empleada en (Tumkor et al. 2001), donde además se reporta $\left.h_{\text {Utillaje }}=h_{\text {Aire }}=5 \mathrm{~W} / \mathrm{m}^{2} \mathrm{~K}\right)$. En el análisis de este coeficiente de convección térmica, (Shih, 1997) establece que el único modo para la determinación es intercomparar con un caso real de estudio, adaptando el coeficiente en el modelo al resultado real, se propone un valor de $260 \mathrm{~W} / \mathrm{m}^{2} K$. (Li et al. 2015) ejecuta un estudio basado en la evolución del número de Nusselt, representando el flujo evacuado por la fuente de calentamiento. Para (Nicodeau, 2005) el coeficiente de convección térmica en la zona de la antorcha adopta un valor 


\begin{tabular}{|c|c|c|c|}
\hline [Ref.] & Material rodillo & $\begin{array}{c}h_{\text {Rodillo }} \\
{\left[W /\left(m^{2} K\right)\right]}\end{array}$ & $\begin{array}{c}h_{\text {Aire }} \\
{\left[W /\left(m^{2} K\right)\right]}\end{array}$ \\
\hline (Grove, 1988) & - & 500 & 7 \\
\hline$(\overline{\text { Pitchumani et al. }}$ 1996) & - & $\infty$ & - \\
\hline$($ Shih 1997) & - & - & 10 \\
\hline Kim et al. 1996) & - & 1000 & 5 \\
\hline (Tumkor et al. 2001) & - & 1000 & 5 \\
\hline (Toso 2003$)$ & - & - & 21 \\
\hline (Lamèthe et al. 2005$)$ & - & - & 2 \\
\hline$(\overline{\text { Nicodeau }} 20 \overline{205})$ & Metal & 1000 & 13 \\
\hline Li et al. 2011) & - & - & 12,5 \\
\hline (Grouve, 2012) & - & 100 & 10 \\
\hline (Duhovic et al. 2014) & Metal & 300 & - \\
\hline (Han et al. $\overline{2014})$ & Metal & 400 & 10 \\
\hline (Stokes-Griffin et al. 2015$)$ & Elastómero & 1000 & $5-17,1$ \\
\hline$(\overline{\text { Lionetto et al. }}$ 2016) & - & - & 5 \\
\hline (Schaefer et al. 2017a) & Elastosil M4641 & $2\left[\left(m^{2} K\right) / k W\right]$ & $8,8-11,4^{a}$ \\
\hline (Weiler et al. 2018$)$ & - & 300 & $40-10^{b}$ \\
\hline
\end{tabular}

${ }^{a}$ En la referencia se aportan valores dependientes de la temperatura

${ }^{b}$ Se considera un valor de 40 para la convección al ambiente y 10 para la radiación.

Tabla 2.3: Propiedades térmicas para condiciones de contorno

de $1500 W / m^{2} K$ y el $h_{\text {Utillaje }}=1000 W / m^{2} K$. Para (Grouve, 2012) el valor de $h_{\text {Utillaje }}$ varía en un rango entre 400 y $1000 W / m^{2} K$.

En (Stokes-Griffin et al. 2015), se emplean diferentes valores del coeficiente en función de la temperatura, variando $h_{\text {Utillaje }}$ de 5 a $17,1 \mathrm{~W} / \mathrm{m}^{2} \mathrm{~K}$. En su simulación térmica destaca la simplificación bidimensional ejecutada donde el rodillo se modela como una sección de lámina de $1 \mathrm{~mm}$ de espesor en la zona del contacto del material de aporte y el sustrato.

(Schaefer et al. 2017a) reporta el coeficiente convectivo con el utillaje como una resistencia térmica de contacto en la entrecara, considerando $R_{\text {Utillaje }}=0,71\left(\mathrm{~m}^{2} \mathrm{~K}\right) / \mathrm{kW}$.

En línea con este aspecto de resistencia en la entre-cara material-útil, (Dai y Ye, 2002) desarrolla un análisis sobre la relación existente entre temperatura de encintado, velocidad de encintado y utilización o no de un elemento aislante interpuesto entre el material laminado y el utillaje. Sus investigaciones sobre el aislamiento del utillaje de encintado llevan a concluir que una baja temperatura en el mismo es la causa de desconsolidaciones entre las capas primera y segunda del laminado. 


\begin{tabular}{|c|c|c|c|}
\hline [Ref.] & $h_{\text {Rodillo }}$ & Material rodillo & $h_{\text {Aire }}$ \\
\hline & {$\left[W /\left(m^{2} K\right)\right]$} & & {$\left[W /\left(m^{2} K\right)\right]$} \\
\hline (Grove, 1988$)$ & 500 & & 7 \\
\hline (Pitchumani et al. 1996) & $\infty$ & & - \\
\hline$(\overline{\text { Shih }} \overline{1997)}$ & - & - & 10 \\
\hline (Kim et al. 1996$)$ & 1000 & & 5 \\
\hline (Tumkor et al. 2001) & 1000 & & 5 \\
\hline$(\overline{\text { Toso }}, \overline{2003})$ & - & & 21 \\
\hline (Lamèthe et al. 2005) & - & & 2 \\
\hline$($ Nicodeau $] 2005)$ & 1000 & Metal & 13 \\
\hline Li et al. 2011) & - & & 12,5 \\
\hline (Grouve, 2012) & 100 & & 10 \\
\hline$(\overline{\text { Duhovic et al. }} 2014)$ & 300 & Metal & - \\
\hline (Han et al. 2014) & 400 & Metal & 10 \\
\hline (Stokes-Griffin et al. 2015$)$ & 1000 & Elastómero & $5-17,1$ \\
\hline (Lionetto et al. 2016) & - & - & 5 \\
\hline Schaefer et al. 2017a) & $2\left[\left(m^{2} K\right) / k W\right]$ & Elastosil M4641 & $8,8-11,4^{a}$ \\
\hline (Weiler et al. 2018$)$ & 300 & & $40-10^{b}$ \\
\hline
\end{tabular}

${ }^{a}$ En la referencia se aportan valores dependientes de la temperatura

${ }^{b}$ Se considera un valor de 40 para la convección al ambiente y 10 para la radiación.

Tabla 2.4: Propiedades térmicas para condiciones de contorno

En las simulaciones, los resultados están totalmente ligados a la velocidad de encintado considerada (que condicionará el tiempo de calentamiento, entre otros), de ahí que resulte de interés conocer los valores reportados en los distintos trabajos, los cuales han sido recogidos en la Tabla 2.5.

Simulaciones más actuales, basadas en sistemas con fuentes de calentamiento láser, tienen en cuenta el comportamiento óptico del material para los cálculos. En los anteriores casos, se hace preciso conocer también propiedades ópticas de los materiales, las cuales, se recopilan en la Tabla 2.6 . Tal y como propone (Nichelatti 2002), la obtención de la reflectancia y la transmitancia de un material de espesor delgado se puede ejecutar utilizando medidas experimentales con un espectrofotómetro, posteriormente, mediante el uso de expresiones matemáticas se podrá extraer el valor del índice de reflexión (componentes real y compleja). 


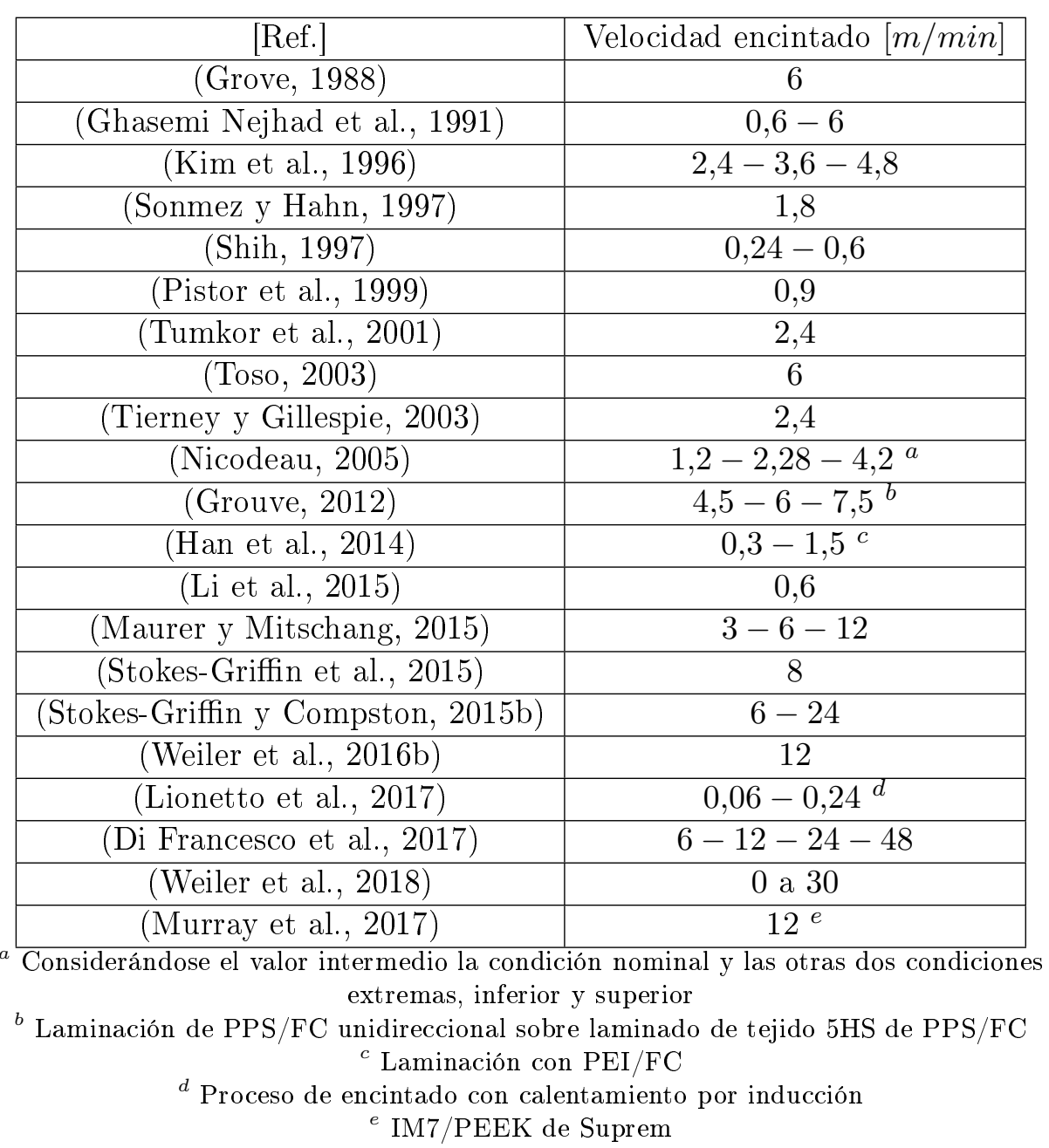

Tabla 2.5: Velocidades de encintado para PEEK-FC y otros termoplásticos en procesos de laminación y consolidación in-situ 


\begin{tabular}{|c|c|c|c|c|c|}
\hline [Ref.] & Reflectancia & Absorbancia & Emisividad & $\begin{array}{c}\text { Índice } \\
\text { refracción }(\mathrm{n}) \\
\text { Material }\end{array}$ & $\begin{array}{c}\text { Índice } \\
\text { refracción (n) } \\
\text { Rodillo }\end{array}$ \\
\hline (Grove, 1988) & 0,28 & - & - & - & - \\
\hline (Grouve, 2012) & - & - & 0,9 & 1,8 & - \\
\hline (Stokes-Griffin y Compston, 2015a) & - & - & - & 1,95 о $2,30^{a}$ & 1,42 \\
\hline$(\overline{D i}$ Francesco et al., 2017$)$ & - & $0,6^{b}$ & $0,8^{c}$ & - & - \\
\hline (Weiler et al., 2018) & - & 1 & 0,9 & - & - \\
\hline (Reichardt et al., 2018) & - & - & - & - & 1,4 \\
\hline
\end{tabular}

Reichardt et al., 2018

ción ejecutada, como superficie especular o medio cilindro de micras de diámetro

${ }_{b}$ Medida con ángulo de incidencia del láser de $80^{\circ}$

${ }^{c}$ En la referencia se indica que dicho valor ha sido calculado en un proceso experimental sin tener en cuenta las posibles reflexiones del material de aporte, utilizar un valor superior de emisividad podría compensarlo.

Tabla 2.6: Propiedades ópticas del material compuesto PEEK-FC 
Algunos de los trabajos que tienen en cuenta el comportamiento óptico del material en sus simulaciones son: (Grouve, 2012) con una aproximación tipo "ray tracing" bidimensional o (Stokes-Griffin y Compston, 2015a) con una aproximación tridimensional. En estos trabajos se expone que el empleo de una aproximación tipo "ray tracing" para describir el comportamiento del material está justificada por tener las fibras de carbono un orden de magnitud superior a la longitud de onda de trabajo del láser.

(Stokes-Griffin y Compston, 2015a) ejecuta la modelización termo-óptica partiendo del resultado del modelo óptico bajo la hipótesis de "micro half cylinder" (MHC), fuente emisora divergente y una función de emitancia espacial. En el trabajo ejecuta intercomparaciones con diferentes metodologías de representación tanto de la superficie del material (especular, no especular o MHC) como del sistema de irradiación. También incorpora un análisis de las variaciones en los perfiles térmicos causados por las diferencias en la orientación de la fibra del material sustrato, observando que dicho efecto puede considerarse despreciable.

(Schaefer et al. 2017a) emplea un modelo termo-óptico en el encintado con poliamida reforzada con fibra de carbono (PA-6/FC), para ello establece un término fuente del láser dependiente de la absorbancia del material la cual es a su vez dependiente del ángulo de incidencia del láser. (Reichardt et al. 2018) desarrolla un modelo tridimensional considerando reflexión no especular.

En las referencias se coincide en la identificación del polímero PEEK como un material donde el principal comportamiento ante la radiación láser es la transmisión (tanto en un estado amorfo como semicristalino). Por su parte, la fibra de carbono actúa como un elemento altamente absorbente y en el cual la radiación reflejada depende de la orientación de las fibras frente al foco radiante. Para el caso particular de la laminación y consolidación in-situ, (Stokes-Griffin y Compston, 2015a) analizan las contribuciones de la primera reflexión del haz sobre el sustrato y sobre el material de aporte. En su trabajo, se observa como las reflexiones partiendo del sustrato y que llegan al material de aporte inciden más en la proximidad del NIP, por contra, las procedentes del aporte contra el sustrato, a causa de la curvatura del material en esa zona, retornan al sustrato en áreas más alejadas del NIP.

Cuando un láser irradia un material, parte de la energía suministrada es absorbida por el material, parte es transmitida y parte es reflejada, el porcentaje en que afectan cada una de estas contribuciones está directamente relacionado con las propiedades del material sobre el que se actúa, afectando también su estado cristalino o amorfo. Debido a esa participación de las 
propiedades del material, algunos estudios se dedican a su determinación y a la estimación de sus dependencias con respecto a diferentes factores, por ejemplo la temperatura ((Grouve, 2012) para el FC/PPS o (Stokes-Griffin y Compston, 2015c) para el FC/PEEK o (Schaefer et al. 2017a) para FC/PA6). Entre los resultados obtenidos para el FC/PEEK (material objetivo en este trabajo) destacan las siguientes conclusiones.

Relativas a la resina:

- Las fases cristalinas dispersan la luz por variaciones locales del índice de refracción. El hecho de detectar mayor absorbancia en un material semicristalino frente a un amorfo se asocia a la recepción posterior de los rayos reflejados. En el caso del material compuesto, el limitado espesor de la capa de resina superficial y el bajo tamaño de las esferulitas formadas, hace que esos puntos de reflexión sean limitados y que puedan considerarse despreciables.

- El comportamiento a reflexión del PEEK en el NIR (Infrarrojo cercano) puede estimarse representativo del que presenta este material bajo la radiación láser.

- El índice de refracción de la resina se estima que es dependiente con la temperatura de modo inverso a la dependencia del coeficiente de expansión térmica.

Relativas a la fibra:

- Las propiedades ópticas de la fibra de carbono pueden considerarse constantes en el rango de temperaturas experimentadas en un proceso de laminación y consolidación in-situ (Le Louët et al., 2017).

Relativas al material compuesto:

- Se considera que la radiancia es proporcional a la irradiancia en este material.

- La transmitancia puede considerarse despreciable para el FC/PEEK. El polímero, que en estado amorfo tendría una alta trasmitancia de la energía láser, al estar reforzado por la fibra, tendría un efecto despreciable sobre el conjunto. Es posible despreciar la trasmitancia en los cálculos.

- En el material compuesto, la reflexión depende de la orientación de la fibra respecto del foco emisor, mostrando patrones de reflexión especulares. 
- Conocido el ángulo de incidencia del láser, es posible estimar el ángulo de reflexión mediante la aplicación de la ley de Snell.

- Una vez estimado el ángulo de reflexión es posible determinar la reflectancia en función de si la luz está polarizada en -s o -p con las ecuaciones de Fresnel ((Soares, 2014) $)$. Cuando la luz no se encuentra polarizada, se efectúa una estimación de una contribución en un $50 \%$ de cada una de ellas, -s y -p.

- Puede estimarse que la mayor parte de la luz incidente es tanto absorbida como reflejada por la primera capa de fibras de carbono de la superficie y esto permite simplificar el análisis a una superficie para ejecutar modelos de comportamiento macroscópicos.

- Es posible considerar el índice de refracción en el material compuesto sólo por su parte real pues no hay prácticamente absorción.

Relativas al haz láser y a la simulación:

- En la simulación de la radiación, elegir un haz colimado con la geometría de un perfil tipo sombrero no es lo apropiado cuando se trabaja con láseres NIR con las inclinaciones requeridas por el proceso de ISC, es imprescindible considerar la divergencia del haz.

- Transcurridas dos reflexiones del haz, la intensidad de irradiación se hace despreciable. Para modelizar de forma realista la transmisión de calor, el perfil de incidencia del láser debería contabilizar también esas dos primeras reflexiones.

Una vez desarrollado el modelo óptico, el paso siguiente es ejecutar su acoplamiento con el modelo térmico. En los trabajos bibliográficos, se resalta la importancia de elaborar estas simulaciones termo-ópticas por la subestimación que los modelos térmicos convencionales hacen de la energía real requerida por el material para su calentamiento, pues no tienen en cuenta la reflectancia del material. En (Weiler et al., 2016b) se recopila información de diferentes trabajos donde se apoya la anterior afirmación y otros donde se indica que la radiación del láser impacta sobre sustrato y material de aporte siendo reflejada desde cada uno de ellos sobre el otro y por tanto quedando un balance final en el que no existe pérdida ni ganancia energética, el autor presenta una variación de la absorbacia y la reflectancia en función del ángulo de incidencia de la fuente de calentamiento donde puede observarse que superados ángulos de incidencia de $60^{\circ}$ la reflectancia comienza a ser importante, estimando que su impacto sobre la exposición radiante (integración en el tiempo de la exposición a la radiación) de aproximadamente un $16 \%$. 
Referido al acoplamiento termo-óptico, en (Grouve, 2012) se modeliza bajo la suposición de que la velocidad de conducción del calor en sentido de avance del encintado es muy inferior a la de desplazamiento de la máquina. En dichas condiciones, queda el proceso gobernado por la conducción a través del espesor, proponiéndose una metodología de resolución del balance energético basada en un método pseudoespectral o de colocación. También (Reichardt et al. 2018) acopla sus modelos óptico y térmico, con la especial característica de describir la reacción del material a la radiación con un micro-modelo, las reflexiones obtenidas de su aplicación se extrapolan al macro-modelo. En (Stokes-Griffin y Compston, 2015a) también se ejecuta una simulación conjunta con el acoplamiento del modelo termo-óptico y base en las hipótesis listadas anteriormente.

Para tener en cuenta las orientaciones de los rayos reflejados, (Reichardt et al. 2018) utiliza una función de distribución de reflectancia bidireccional, resolviendo el problema termo-óptico de modo numérico. También es el primer trabajo localizado donde se resuelve el problema (contabilizando el efecto óptico) de modo analítico, comparando los resultados de la aplicación de ambas metodologías. Los resultados numéricos y analíticos son muy semejantes cuando en la solución numérica se tiene en consideración una reflexión especular de la luz.

En la anterior recopilación de trabajos donde se acoplan los modelos ópticos, la fuente de calentamiento convencionalmente empleada consiste en un láser de óptica fija, con un haz estacionario. Limitadas alusiones han sido encontradas al empleo de ópticas variables, se reporta aquí el trabajo de (Pistor et al., 1999) donde las lentes de forma de los láseres convencionales son sustituidas por un sistema de escaneo que consiste en un galvo magnético móvil. El propósito perseguido por esta referencia en el empleo de estos sistemas es generar una línea de calentamiento del material cuya dimensión sea cambiante en función del ancho del material que requiera calentarse.

(Weiler et al., 2016b) propone un modelo óptico para una fuente de calentamiento tipo VCSEL. El trabajo ejecuta un primer recorrido sobre las generalidades del calentamiento láser y los requisitos para simularlo, considerando la distribución de la intensidad angular, la irradiancia y la intensidad absorbida, pero dejando fuera del estudio la profundidad de penetración del láser. En la simulación se ejecuta un cálculo para considerar la superposición del efecto de las lámparas independientes constituyentes del VCSEL demostrándose que, la irradiación decae hacia el NIP en el sustrato y crece hacia el NIP en el material de aporte.

Un modelo con consideraciones ópticas más sencillo es el que propone 
(Maurer y Mitschang, 2015), primer documento en que se observa el empleo del software COMSOL Multiphysics. Este trabajo utiliza a su vez dos subrutinas programadas en MATLAB para la fuente de calentamiento y para el rodillo. El modelo del láser, estima la potencia que se aplica sobre el material sustrato y el de aporte, dado que el sistema está focalizado, se modeliza considerando la altura del punto focal y la distancia focal al NIP. Además, el haz láser tiene adherido su propio sistema coordenado que permite variar su posición en el modelo cambiando las distribuciones de temperatura sustratoaporte. El flujo de calor incidente en el material procede de un cálculo en el cual se tiene en cuenta la absorción y la reflexión (considerando mismo ángulo para incidencia y reflexión).

Por su parte, el modelo de rodillo se emplea para aproximar la longitud de contacto efectuando una simplificación de su geometría mediante un componente rectangular (área de contacto con el sustrato) y otro trapezoidal (área de bajada del material de aporte). El rodillo simulado tiene en cuenta el sistema de refrigeración del que consta.

(Lionetto et al. 2016) también utiliza COMSOL Multiphysics para ejecutar un modelo térmico sobre un proceso con calentamiento con una fuente de ultrasonidos. Se emplea malla móvil para la simulación, un elemento posibilitado por las características del software. La ecuación del calor a resolver incorpora un término que contabiliza la endoterma correspondiente al calor absorbido durante el proceso de fusión del material. Se emplea la Ecuación 2.3 para tener en cuenta la fusión como un proceso dependiente de la distribución estadística de lamelas. Siendo $X_{m}=H(T) / H_{T}$ la relación entre el área parcial del calor de fusión a una temperatura $\mathrm{T}$ y el área total del pico de fusión, $T_{C}$ la temperatura del pico de fusión de DSC, $k_{m b}$ un factor de intensidad relacionado con lo abrupta que sea la distribución y $d$ un parámetro de forma. Los autores de este trabajo se sirven de la ley de mezclas para el cálculo de las propiedades térmicas en un polipropileno (PP) con fibra de vidrio tipo E. El mismo grupo de investigación desarrolla también un trabajo donde el calentamiento se efectúa mediante una fuente de inducción sobre FC/PEEK (Lionetto et al. 2017), contabilizando nuevamente el flujo de calor de la fusión, Ecuación 2.3 e incorporando un término correspondiente a la cristalización, Ecuación 2.4. Este último término, se obtiene mediante la ecuación de Ozawa, siendo $C_{r}$ la cristalinidad relativa, cuya relación con la temperatura y el tiempo se describe como indica la Ecuación 2.5. La ecuación de Ozawa, como se verá más adelante, no es la más adecuada representación para describir la cristalización en el PEEK en condiciones dinámicas.

$$
X_{m}(T)=\left[1+(d-1) \exp \left(k_{m b}\left(T-T_{C}\right)\right)\right]^{\frac{1}{1-d}}
$$




$$
\begin{gathered}
X_{c}=C_{r}\left[0,42-0,03 \ln \left(\frac{d T}{d t}\right)\right] \\
\log \left[-\ln \left(1-C_{r}\right)\right]=\log (\exp [-0,037 \cdot T+11,3])+n \log \left(\frac{d T}{d t}\right)
\end{gathered}
$$

A parte de los trabajos donde se analiza puramente el modelo de transferencia de calor en el conjunto, existen trabajos donde se efectúan acoplamientos multi-modelo donde se analizan de modo conjunto todas las posibles físicas implicadas en este proceso (térmico-unión-cristalización-degradación) (Nicodeau, 2005, Grouve, 2012).

\subsubsection{Determinación experimental de la temperatura}

Por como se desarrolla este proceso de fabricación, es preciso conocer en tiempo real las temperaturas del encintado para actuar operativamente variando la intensidad suministrada de la fuente de calentamiento en base a esas lecturas. Los equipos utilizados a este efecto, suelen reportar valores de temperatura por medidas sin contacto sobre el área de actuación de la fuente de calentamiento. El área de aplicación de presión del rodillo, queda oculta a la lectura sin contacto, perdiéndose de este modo toda esa información del perfil de enfriamiento. (Grove, 1988) reporta una velocidad para los perfiles de enfriamiento y las sucesivas etapas de recalentamiento, en el entorno de $200 \mathrm{~K} / \mathrm{s}$. Entre otras, esta es una de las motivaciones de llevar a cabo las simulaciones, asimismo, ejecutar medidas experimentales con diversos sistemas contribuye a extraer dicha información y a valorar si las simulaciones desarrolladas se aproximan a los resultados reales.

Las metodologías empleadas para monitorizar la temperatura y analizar la validez de los resultados de las simulaciones son diferentes según el documento consultado. Suelen basarse en lecturas de sondas de temperatura tipo termopar tal y como aparece en (Kim et al. 1996. Saliba et al., 1989 Schlottermuller et al., 2003; Hassan et al., 2005, Nicodeau, 2005; Barasinski et al. 2011a; Stokes-Griffin et al. 2015, Lionetto et al., 2016, 2017, Schaefer et al. 2017a Shih, 1997), pirómetros (Pitchumani et al., 1996) o cámaras termográficas (Grouve, 2012), estas últimas utilizadas también como alternativa para la localización de defectos en el encintado por (Denkena et al. 2016).

En la verificación con las lecturas de los termopares de los perfiles térmicos, son varias las referencias que descartan los resultados de los encintados de las primeras capas sobre el termopar. La causa de descartar esas medidas se basa en los efectos desfavorables de una irradiación directa del láser 
sobre el termopar (Schaefer et al. 2017a), que puede quedar rodeado por aire tras los primeros encintados sobre el mismo. A medida que evoluciona el encintado se mejora el embebido del termopar, siendo los datos más rigurosos. Las simulaciones podrán servir posteriormente para complementar la información sobre aquellas medidas que no se consideraron rigurosas.

Buscando corregir ese efecto negativo de la medida, (Stokes-Griffin y Compston, 2015a) analizan la temperatura registrada por el termopar en una localización. Tomando un punto situado a la misma distancia respecto al NIP que el termopar, estima las diferencias entre la lectura de la termografía y del termopar. Esas diferencias se utilizarán para proponer una corrección del valor en temperatura del termopar, la cual se aplicará para conocer lo que ocurre en zonas donde la termografía no puede emplearse como sistema de medida.

En relación con el control a través de una cámara termográfica, (StokesGriffin y Compston, 2015b) establecen el efecto contaminante de las reflexiones del material que está siendo encintado sobre la lectura térmica en el material sustrato. Esto ocasiona que las lecturas en la cámara termográfica puedan ser superiores a los valores reales que presenta el laminado.

Teniendo en cuenta las posiciones de material de aporte y de sustrato, en la biliografía se indica la imposibilidad de monitorizar la temperatura en ambos del mismo modo. El sustrato, admite la monitorización con termopares, sin embargo, el material de aporte queda relegado a las medidas con termografía.

En (Oromiehie et al. 2016, Takeda et al. 2017) se incluye otro sistema que posibilita la monitorización de temperaturas en sistemas de fabricación con materiales compuestos termoplásticos, el empleo de sensores de fibra de Bragg (FBG). El principio básico de las FBG's radica en grabar una pequeña sección de una fibra óptica de tal modo que el índice de refracción del núcleo se modula periódicamente utilizando un patrón de interferencia óptica, permitiendo recibir una respuesta en reflexión. Bajo unas determinadas condiciones, la respuesta obtenida presenta un pico centrado en una longitud de onda diferente respecto a la inicial grabada sobre el sensor, estando este hecho relacionado con un efecto externo como la aplicación de una carga mecánica o una carga térmica. Es posible encontrar información al respecto de cómo independizar las contribuciones en carga y en temperatura sobre el sensor en (Oromiehie et al., 2017, Saenz del Castillo et al., 2016).

En los diferentes trabajos que han sido analizados para llevar a cabo esta tesis doctoral, se han encontrado resultados muy dispares tanto en el mode- 
lizado como en el aspecto experimental. Algunas propuestas de modelizado se apoyan en simplificaciones completamente diferentes a otras, asimismo, en el caso experimental también han sido localizados resultados dispares en relación a qué número de capas siguen desarrollando la fusión o la transición vítrea del material por debajo de la que recibe la irradiación directa. No obstante, existen tantas variables interactuando y las diferencias en los equipos impactan tanto en los resultados que cada trabajo puede ser exactamente igual de riguroso a pesar de las variaciones. Las desviaciones encontradas entre medida y realidad están asociadas a diferentes posibles causas, entre ellas, el error cometido en la estimación de las propiedades de los materiales, donde suelen tomarse valores medios de los mismos. (Shih, 1997) incluye en su trabajo información sobre la variación en la densidad de un polímero como el PEEK considerando un estado amorfo o semicristalino en el mismo $\left(1262,6 \mathrm{~kg} / \mathrm{m}^{3}\right.$ o $\left.1400,6 \mathrm{~kg} / \mathrm{m}^{3}\right)$, con el consiguiente error cometido presuponiendo un estado $\mathrm{u}$ otro.

\subsubsection{Sistemas de control}

Los modelos térmicos permiten conocer, las temperaturas experimentadas por puntos cualesquiera de los laminados durante el proceso de encintado. Otro objetivo del desarrollo del modelo es ejercer un control sobre el equipo de encintado, buscando que de modo autónomo pueda ejecutar las modificaciones en la señal de potencia enviada por el láser y que en simultáneo sea capaz de extraer los estados de consolidación, cristalinidad, tensión residual o efectos de degradación.

Obtener información sobre qué ocurre en capas inferiores a la posicionada permite establecer un posible estado de la calidad en la pieza, sin embargo, para un control activo parece lógico que el sistema utilice como criterio fundamental para el control los requisitos de adhesión de la capa objeto de encintado en ese instante concreto. (Khan, 2011) recalca la problemática de aplicar un control mediante un PID (sistema proporcional-integral-derivativo) por la lenta respuesta de este sistema a cambios en el perfil, con desviaciones de hasta $15 \mathrm{~K}$ respecto a la temperatura de consigna. Para compensar este problema, propone dos soluciones basadas en dos metodologías diferentes dentro de la teoría de control: estrategia de control cuadrático óptimo o modelo de control predictivo (MPC).

En el sistema de control cuadrático óptimo se persigue la determinación de una ley para un vector de control, se utiliza un regulador cuadrático lineal (LQR) que recibe las medidas de fuentes externas tipo pirómetros, acompañado por un estimador cuadrático lineal (LQE), filtro de Kalman, para predecir las incertidumbres en zonas donde no es posible extraer valores de las mediciones. La combinación de ambos se efectúa mediante un 
control lineal cuadrático gaussiano (LQG). El punto fuerte del modelo de control predictivo (MPC) consiste en la combinación entre algoritmos de control junto al modelizado del proceso para la predicción de la respuesta. Las respuestas mediante ambos sistemas de control (LQG y MPC) son similares salvo cuando se tienen en cuenta ciertas restricciones en el MPC. Estas restricciones pueden ser limitaciones del tipo: valor máximo de potencia que puede suministrar el sistema de calentamiento o valor máximo de temperatura que puede alcanzarse durante el proceso.

(Heider et al. 2002), por su parte, basa su sistema de control en el empleo de una red neuronal. El sistema se utiliza para controlar los valores de los parámetros de máquina, buscando aquéllos que conducen a la solución más óptima de fabricación. En el estudio se manifiestan las mejores capacidades de respuesta de este sistema de control en comparación con el obtenido por un sistema proporcional-integral-derivativo (PID) tradicional. 


\subsection{Degradación térmica}

Por definición, la degradación térmica de un polímero consiste en un proceso tal que, por la acción de calor o temperatura elevada se produce una pérdida de propiedades físicas, mecánicas o eléctricas (Beyler y Hirschler. 2002).

En el proceso de degradación de un material polimérico, las largas moléculas normalmente se fraccionan en segmentos más pequeños capaces de volatilizarse. A mayor ligereza de los fragmentos, mayor es su capacidad para evaporarse nada más generarse; por su parte, el resto de moléculas permanecerán en la fase condensada (líquida o sólida) y continuarán experimentando descomposición hasta que los fragmentos presenten el tamaño apropiado. Algunos de los residuos generados pueden permanecer en forma de residuo carbonáceo, no volatilizándose. La atmósfera en que se desarrolla el proceso tiene un papel importante sobre el mismo, cuando el oxígeno interviene (atmósfera oxidativa) puede producir cambios tanto en la velocidad de reacción como en el orden de la reacción. También puede ocasionar que la mínima temperatura requerida para que tenga lugar la degradación se reduzca.

Los mecanismos que aplican en la descomposición térmica de un polímero son:

- Escisión aleatoria de cadenas. La rotura se produce en posiciones aparentemente aleatorias de la cadena.

- Escisión en fin de cadena. Unidades monoméricas individuales son sucesivamente eliminadas del final de la cadena.

- Pelado de la cadena. Se rompen átomos o grupos de los mismos que no forman parte del esqueleto o cadena principal del polímero.

- Entrecruzamiento. Se forman enlaces entre cadenas del polímero.

El empleo de procesos de fabricación donde se requiere elevar la temperatura de los polímeros aproximándose a su degradación, hace que sea importante analizar su resistencia térmica. (Hancox, 1998) ejecuta una revisión sobre los principales mecanismos de descomposición de los materiales poliméricos. En el caso particular del PEEK, la referencia indica que, siendo éste un material con una estructura aromática, su comportamiento a degradación térmica es más estable que el de otros polímeros, presentando una energía de activación en el proceso que puede sucesivamente crecer o decrecer en las distintas etapas que lo conforman. En el trabajo se indica que la degradación del primer 1-2\% en el material tiene lugar por medio de un 
mecanismo autocatalítico.

La descomposición del PEEK ha sido estudiada también por (Hay y Kemmish, 1987), que plantean el proceso como un mecanismo de escisión de cadenas principalmente en los enlaces éter y carbonilo, consideración también ejecutada por (Nandan et al. 2003). De hecho, la forma general de las curvas de termogravimetría obtenidas de este material son las típicas de una reacción radicalaria o por rotura de cadenas en las que los volátiles sólo se producen en las últimas etapas de la descomposición. En el trabajo, el análisis de los productos de la descomposición mediante la aplicación de espectroscopía de masas, manifiesta que los enlaces éter son los menos estables, siendo por tanto los puntos más débiles para el comienzo de la reacción. Los radicales generados podrán asociarse con los hidrógenos de los fenilenos adyacentes o producir entrecruzamientos. Las cadenas escisionadas, también pueden ciclarse para generar derivados del benzofurano.

En los trabajos de (Prime y Seferis, 1986, Nam y Seferis, 1992), se indica que los principales gases detectados en la degradación del PEEK por espectroscopía de masas acoplada a termogravimetría son: fenol, difenil-éter, benzofenona y la benzoquinona. (Perng et al. 1999) utiliza la misma técnica de análisis y reporta el mecanismo de escisión de cadenas como el proceso fundamental en la degradación de este material. En su trabajo indica que la escisión del enlace éter alcanza su máximo antes de que lo haga la del enlace cetona y que la formación de los compuestos detectados procede de la interacción entre sí de las cadenas que resultan escindidas. El proceso de degradación en atmósfera inerte para el PEEK lo explican en dos etapas, en una primera etapa donde se produce rotura de la cadena principal y formación de compuestos como fenol, dióxido de carbono y fluorenona y una segunda etapa donde se rompe la fluorenona resultando en la producción de dióxido de carbono.

Por su parte, (Cole y Casella, 1993) utilizan la espectroscopía infrarroja por transformada de Fourier para analizar la degradación del material PEEK reforzado con fibra de carbono. Sus conclusiones indican que el resultado de la degradación es fundamentalmente una nueva formación carbonilo, tipo fluorenona. Los resultados varían dependiendo de en qué atmósfera tiene lugar la degradación del polímero, en el caso de atmósfera oxidativa, en la cual se desarrolla el proceso de fabricación bajo estudio de esta tesis, se genera un compuesto tipo carbonilo a mayor velocidad en comparación con la que lo generaría en el caso inerte (observado por el desplazamiento de la banda de 1653 a $1739 \mathrm{~cm}^{-1}$ y la aparición de una banda débil en $1065 \mathrm{~cm}^{-1}$ ).

Los trabajos de (Nicodeau, 2005, Patel et al., 2010) también analizan los 
posibles productos obtenidos en el proceso de degradación en el PEEK. El primero de los trabajos efectúa hipótesis sobre las dos posibles vías en las que se espera que ocurra la degradación el material en atmósfera oxidativa. En su primera hipótesis se considera que la degradación tiene lugar por la rotura de los propios enlaces constituyentes de la cadena del polímero (rotura en enlaces éter o cetona) y una segunda hipótesis es que los radicales que inician la reacción procedan de los peróxidos que pueden existir en la estructura del polímero (posiblemente generados durante el proceso de impregnación del material). Partiendo del polímero, el oxígeno puede actuar arrancando los hidrógenos de los enlaces aromáticos $\mathrm{C}-\mathrm{H}$, quedando una estructura con una posición libre para reaccionar, generando reticulación y atracción entre las distintas posiciones que han quedado libres en la cadena.

El segundo de los trabajos ((Patel et al. 2010) $)$, estudia la respuesta a fuego del PEEK. En su trabajo, destaca el análisis ejecutado sobre cómo tiene lugar la rotura y recombinación de enlaces de la cadena. En el proceso, tanto en atmósfera oxidativa como en inerte hay dos mecanismos fundamentales, donde la presencia de refuerzos como la fibra de carbono otorgan estabilidad retardando el proceso de degradación. Al contrario de lo reportado por otros trabajos, los autores indican que el proceso se inicia con la rotura del enlace carbonilo-cetona y continúa con la rotura del enlace carbonilo-éter.

El grupo de trabajo anteriormente referenciado presenta también un análisis de descomposición del PEEK mediante el uso de la termogravimetría (Patel, 2011). En el documento se alude a la existencia de dos etapas de degradación en el proceso de descomposición del polímero en atmósfera oxidativa. La primera etapa se basa en la escisión de los enlaces éter y cetona y el segundo estadio se asocia con la oxidación del residuo carbonáceo. En el trabajo, son desarrollados ensayos de calorimetría a diferentes velocidades; con dichos ensayos es posible observar que el primero de los procesos no se encuentra afectado por la velocidad, no ocurriendo lo mismo con el segundo, que presenta una marcada dependencia con la velocidad. Además, en la intercomparación entre atmósferas oxidativa e inerte que efectúan, el comportamiento del polímero refleja un inicio de degradación adelantado para el caso oxidativo con unos $100 K$ de diferencia respecto al caso inerte, sin embargo, en la primera etapa de degradación en inerte se presenta una caída un $10 \%$ superior a la del caso oxidativo.

En línea con esas observaciones efectuadas sobre las curvas de termogravimetría en PEEK, (Nandan et al. 2003) manifiestan el corto intervalo de temperaturas entre la degradación de un $5 \%$ en masa y el pico máximo de degradación del material (siendo éste intervalo el equivalente a unos $10 \mathrm{~K}$ ). Dicho resultado manifiesta que, a pesar de tener este material una tempera- 
tura de degradación elevada, la velocidad a la que ésta se produce es muy alta y una vez generada la aparición de volátiles, la evolución de la degradación del polímero es rápida.

Los efectos de degradación sobre muestras sometidas a ciclos cortos de calentamiento, son analizados en los trabajos de (Bayerl et al., 2015, Tsotra et al. 2018). (Bayerl et al. 2015) recoge un estudio sobre la posible degradación térmica experimentada por PEEK reforzado con fibra de carbono bajo la acción de una fuente de calentamiento tipo láser (Longitud de onda 980 $\mathrm{nm}$ ) y tiempos de mantenimiento de temperatura del orden de milisegundos. Las técnicas experimentales empleadas para el análisis son la calorimetría diferencial de barrido, la microscopía electrónica y la espectroscopía de infrarrojos por transformada de Fourier. La espectroscopía de infrarrojos lleva a concluir que la descomposición comienza con la rotura del enlace fenilo, del enlace éter y del hidrógeno aromático, apareciendo nuevos picos que son el resultado de nuevas asociaciones de las cadenas escindidas.

La detección de efectos de degradación mediante la calorimetría, suele asociarse a reducciones en el onset del pico de fusión, a causa de un tamaño inferior de cadenas por haber experimentado éstas procesos de escisión, siendo este hecho significativo en situaciones en las que por termogravimetría es posible detectar pérdidas de masa de un $4 \%$ en el polímero. De hecho, en el trabajo se indica que la caída en masa por degradación suele ser menor a la caída en la cristalización, suponiendo una muestra de que el primer efecto se asocia con variaciones de la estructura del polímero. También se reportan efectos de degradación a través de variaciones en la temperatura de transición vítrea del material, con valores de temperatura crecientes con la temperatura de degradación y el tiempo de mantenimiento, al contrario de lo que ocurría con la temperatura de fusión. Otro efecto es la creación de una capa superior degradada que impide la difusión de oxígeno hacia el interior cuando se genera una degradación extrema por un exceso de temperatura en el calentamiento.

(Dolo et al. 2017) indica que con la calorimetría diferencial de barrido es posible localizar una caída de la velocidad de cristalización asociada con la reducción de posibles puntos de nucleación y con la dificultad para el desarrollo de esferulitas cuando se produce entrecruzamiento de cadenas. En la anterior referencia se alude a los tiempos mínimos a cada temperatura que es capaz de soportar el material compuesto APC2 para que tenga lugar el comienzo de la degradación, indicando un comportamiento de tipo cinético. La evolución que proponen ha sido recogida en el gráfico de la Figura 2.3 . donde es sencillo constatar que cuando la temperatura crece, el tiempo de mantenimiento para que tenga lugar la degradación experimenta una caída 


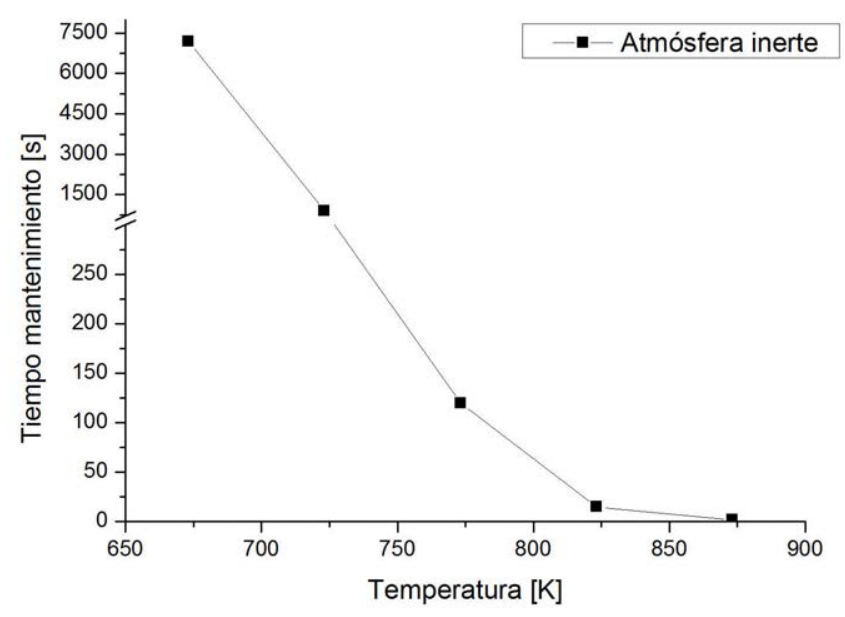

Figura 2.3: Tiempo de mantenimiento para el comienzo de la degradación en APC2 bajo atmósfera inerte (Dolo et al. 2017)

de tipo exponencial (típico comportamiento Arrhenius con la temperatura), llegando a hacerse tan pequeño como $2 s$ en atmósfera inerte. En la referencia se indica un indicio más para la detección de la degradación térmica del polímero, mediante el pico de cristalización fría que se hace mas ancho cuando hay presentes efectos de degradación, se reduce también su amplitud y se desplaza a mayores temperaturas.

\subsubsection{Determinación experimental de la degradación térmi- ca}

En el apartado previo, se ha hecho alusión a diferentes tecnologías empleadas por grupos de trabajo con el fin de determinar los productos de descomposición en el PEEK (termogravimetría, espectroscopía de masas, infrarrojos, etc). A continuación se recuperan los trabajos donde se hace uso de las técnicas de termogravimetría y reología para la predicción de la degradación térmica, por ser éstas las dos técnicas más empleadas en los análisis cinéticos del proceso de degradación.

La termogravimetría (TGA) es la metodología más referenciada para el estudio de la degradación térmica en los polímeros. Estos ensayos se basan en el análisis de la evolución de la degradación mediante la pérdida de peso de la muestra ensayada a causa de la generación de volátiles. Dado su extendido uso, el siguiente apartado (2.4.2) destinado a la cinética de degradación 
térmica se focalizará en trabajos previos utilizando este sistema de análisis.

El criterio para estimar la existencia de degradación en un material por termogravimetría varía según la referencia consultada, (Dolo et al. 2017) documenta en sus trabajos un $1 \%$ de degradación por pérdida en masa como un valor aceptable previo a considerar la muestra afectada. Por su parte, en los trabajos de (Nandan et al. 2003; Batista et al. 2015) los resultados se proporcionan utilizando como criterio la pérdida de masa de un $5 \%$.

Por su parte, la reología es también una técnica de utilidad, por ser muy sensible a los cambios en la estructura molecular del polímero. Esta técnica ha sido empleada en numerosas referencias tratando de constatar el comportamiento de diferentes materiales termoplásticos y materiales reforzados. (Nicodeau, 2005) plantea un análisis de degradación en PEEK utilizando la reología, indicando que es posible obtener una cinética de degradación térmica utilizando los resultados generados por ella. Su estudio se fundamenta en ejecutar ensayos a una deformación y frecuencia mantenida y aplicando barridos temporales, que manifestarán una evolución de las variables reológicas con el tiempo. El seguimiento de la evolución de la degradación del polímero procede de analizar las variaciones en el peso molecular en un determinado instante en comparación con el peso molecular inicial (considerando que inicialmente la muestra no se encuentra degradada). A partir del anterior desarrollo se obtiene la evolución de un parámetro llamado número de actos de reticulación, que monitoriza la evolución de la degradación en el material, tal y como plantea la Ecuación 2.6. Su estudio, a pesar de permitir extraer unas tendencias de evolución en la degradación con la temperatura, se fundamenta en una serie de hipótesis imprecisas como considerar una evolución de los actos de reticulación con el peso molecular como la que tendría un polímero de cadena lineal (hecho que durante el proceso de rotura de cadenas y entrecruzamiento podría no ser realista) o estimar que no hay variación en el índice de polidispersidad del polímero entre el inicio y el desarrollo de la degradación.

Considerando la reología como técnica para el análisis cinético, en (Nicodeau, 2005) se indica que el criterio límite para detectar degradación en la muestra son $10^{-7}$ actos de reticulación.

$$
\text { Reticulación }=\frac{I_{p 0}}{M_{w 0}}\left[1-\left(\frac{\eta_{0}}{\eta}\right)^{1 / 3,4}\right]
$$

En el trabajo de (Modi et al. 2010), también se plantea la evolución de los pesos moleculares en función del tiempo de mantenimiento de una temperatura que a su vez puede observarse a partir de los cambios en la magnitud 
de la viscosidad compleja medida por reología. (Filippone et al. 2015b a) utilizan la reología para analizar la degradación térmica de la poliamida PA-11. En estos trabajos se emplea la técnica TRMS (Time-Resolved Mechanical Spectroscopy), apropiada cuando se pretende analizar la degradación rápida de un polímero, fundamentándose en la realización sucesiva de barridos en frecuencia sobre una misma muestra y la obtención de la variación de las propiedades reológicas con el tiempo utilizando cortes con líneas isócronas sobre los ensayos. La anterior metodología también ha sido empleada en (Salehiyan et al. 2017) para mezclas de PA6 con polietileno lineal de baja densidad (LLDPE). La técnica TRMS se apoya en el hecho de que es a baja frecuencia donde es más posible detectar las relajaciones de los segmentos más largos de cadena en los polímeros (las transiciones en cadenas largas se verán mejor estudiando las curvas con ensayos a baja frecuencia), pero a su vez, supone tiempos de mantenimiento superiores que pueden provocar que la muestra se vea afectada por efectos de degradación durante la toma de datos.

La utilidad de la reología radica fundamentalmente en el hecho de que la degradación termo-oxidativa del polímero puede ocurrir de modo anticipado a la que predice la termogravimetría, tal y como indican (Phillips et al. 1997). Los autores de este trabajo analizan el impacto del incremento de viscosidad causado por la degradación del material, que hace que sea más difícil el movimiento de las cadenas poliméricas y condiciona los resultados obtenidos en el grado de consolidación en los laminados fabricados. En Fink et al. 2000) también se analiza el impacto de la degradación térmica sobre la consolidación del material en su aplicación al proceso de encintado automático y consolidación in-situ. El análisis de degradación en el anterior trabajo se efectúa mediante los resultados de resistencia a cortadura interlaminar en probetas fabricadas bajo diferentes condiciones de calentamiento, concluyendo que a alta temperatura se induce un efecto de degradación en el polímero que no puede compensarse en las pasadas sucesivas y que hace que decaiga el valor de resistencia en el ensayo.

\subsubsection{Cinética de degradación térmica}

Una cinética, entendida como una representación matemática de la correlación entre el perfil temperatura-tiempo sobre la degradación térmica del material, resulta de utilidad para un proceso como el encintado automático y consolidación in-situ, donde se requiere laminar a alta velocidad y llevar al material a un límite donde su viscosidad sea lo más baja posible sin que intervengan efectos de degradación térmica. La cinética de degradación permite, por tanto, obtener la mejor combinación de valores temperatura-velocidad de encintado para que no aparezcan efectos de descomposición en el polímero. 
De modo habitual, las cinéticas de degradación en los polímeros aparecen asociadas a ensayos de termogravimetría, mediante el análisis de la evolución de la pérdida de masa de las muestras con la aplicación de perfiles de calentamiento isotermos o dinámicos, tal y como se recoge en (Flynn y Wall, 1966). La ecuación cinética general, Ecuación 2.7. se emplea para efectuar la representación matemática del comportamiento a degradación de cualquier material. Siendo $t$ el tiempo, $k(T)$ la constante de velocidad, $\alpha$ la conversión (dependiente de la correlación entre el peso inicial de la muestra, su peso en un tiempo "t" y la relación de pesos inicial y final, como se recoge en la Ecuación 2.8 y $f(\alpha)$ la función de dependencia de la conversión o modelo de reacción del proceso.

$$
\begin{gathered}
\frac{d \alpha}{d t}=k(T) f(\alpha) \\
\alpha=\frac{W_{0}-W_{t}}{W_{0}-W_{f}}
\end{gathered}
$$

Presentando la constante de velocidad una dependencia de tipo Arrhenius, $k(T)=A \exp \left(\frac{-E}{R T}\right)$, con la temperatura. Siendo $A$ el factor pre-exponencial, $E$ la energía de activación, $T$ la temperatura y $R$ la constante de los gases ideales.

La re-organización de la anterior ecuación mediante la toma de logaritmos a ambos lados, permite obtener la forma indicada por la Ecuación 2.9 .

$$
\ln \left(\frac{d \alpha}{d t}\right)=\ln (A f(\alpha))-\frac{E}{R T}
$$

La función $f(\alpha)$ suele representarse de forma general como $f(\alpha)=\alpha^{m}(1-$ $\alpha)^{n}[-\ln (1-\alpha)]^{p}$, modelo empírico de Sestak-Berggren. Tomando $n, m$ y $p$ distintos valores según el mecanismo de reacción que aplica. Normalmente se emplea en su forma truncada, con $p=0$ (Prout-Tompkins). La determinación del modelo de reacción es un punto crítico del estudio cinético y es la causa raíz de la publicación de diversos trabajos de investigación donde se cuestionan los desarrollos basados en presuponer ciertos mecanismos de reacción sin partir de una ecuación genérica como la anterior y permitir que sean los resultados experimentales los que conduzcan a los valores de los índices del proceso (Vyazovkin et al. 2011; Arshad y Maaroufi, 2014).

La definición completa de la cinética de degradación en un polímero, requiere el conocimiento de lo que se conoce como "triplete cinético", formado por: la energía de activación, el factor pre-exponencial y el mecanismo de reacción. La metodología comúnmente empleada para la obtención de 
la energía de activación, es la basada en la aplicación de los métodos isoconversionales. Por su parte, la obtención del mecanismo de reacción suele fundamentarse en el empleo de modelos de ajuste tal y como se recoge en (Chrissafis, 2009).

Los métodos isoconversionales o métodos libres de modelo, son una alternativa matemática para el cálculo de la energía de activación del proceso sin necesidad de hacer suposiciones sobre el modelo de reacción que interviene. Se fundamentan, tal y como se reporta en (Vyazovkin, 2008, Vyazovkin et al. 2011) en el principio isoconversional, por el cual, a una conversión fija, la velocidad de la reacción es únicamente función de la temperatura. Para su aplicación, requieren la elaboración de 3 a 5 ensayos con diferentes programas térmicos.

Algunos de los diferentes métodos isoconversionales existentes, se recogen en la Tabla 2.7, suelen dividirse en dos grupos, derivativos e integrales. Los derivativos utilizan relaciones procedentes de la ecuación cinética en su forma diferencial mientras que los integrales se basan en esas aproximaciones matemáticas derivadas de la integración de la Ecuación 2.7. La integración de esta ecuación, no tiene una solución explícita. Debido al hecho anterior, se hacen necesarias aproximaciones numéricas en la resolución. De estas aproximaciones derivan modelos cinéticos como los de Flynn-Wall, Schlomilch o Doyle (Lyon, 1997).

Utilizar una técnica como la termogravimetría, que reporta datos no derivativos, requiere de su derivación para usarlos en dicho modo, supone introducir ruido en las curvas que se emplearán para las estimaciones de la energía de activación, restando precisión a su determinación. La aplicación de los distintos métodos conduce a la obtención de valores diferentes para la energía de activación, dado que se basan en aproximaciones, por tanto es habitual que en su aplicación se obtengan resultados distintos tal y como ilustra (P. Arrieta et al., 2014).

El método de Kissinger también se incluye en la bibliografía como una metodología para los estudios cinéticos de degradación (Blaine y Kissinger. 2012). Erróneamente, aparece en ocasiones clasificado como método isoconversional, pero no pertenece en realidad a este conjunto, de ahí que no se recopile junto con todos los demás. Este método se basa en la Ecuación 2.10 . donde $T_{p}$ es la temperatura donde se alcanza el valor pico/máximo de conversión para las distintas velocidades ensayadas. No se puede considerar dentro del conjunto de los métodos isoconversionales porque ese valor de pico sí presenta una dependencia con la velocidad de calentamiento. La aplicación de este método esta condicionada por múltiples limitaciones, entre ellas se 
encuentra que la determinación de $f^{\prime}\left(\alpha_{p}\right)$ debería ser independiente de la velocidad del ensayo, hecho que es únicamente cierto para modelos de reacción de primer orden. Asimismo, este método sólo es válido cuando no existen variaciones de la energía de activación con la conversión, pues no permite detectarlas.

$$
\ln \left[\frac{\beta_{i}}{T_{p, i}^{2}}\right]=\ln \left(-\frac{A R}{E} f^{\prime}\left(\alpha_{p}\right)\right)-\frac{E}{R T_{p, i}}
$$




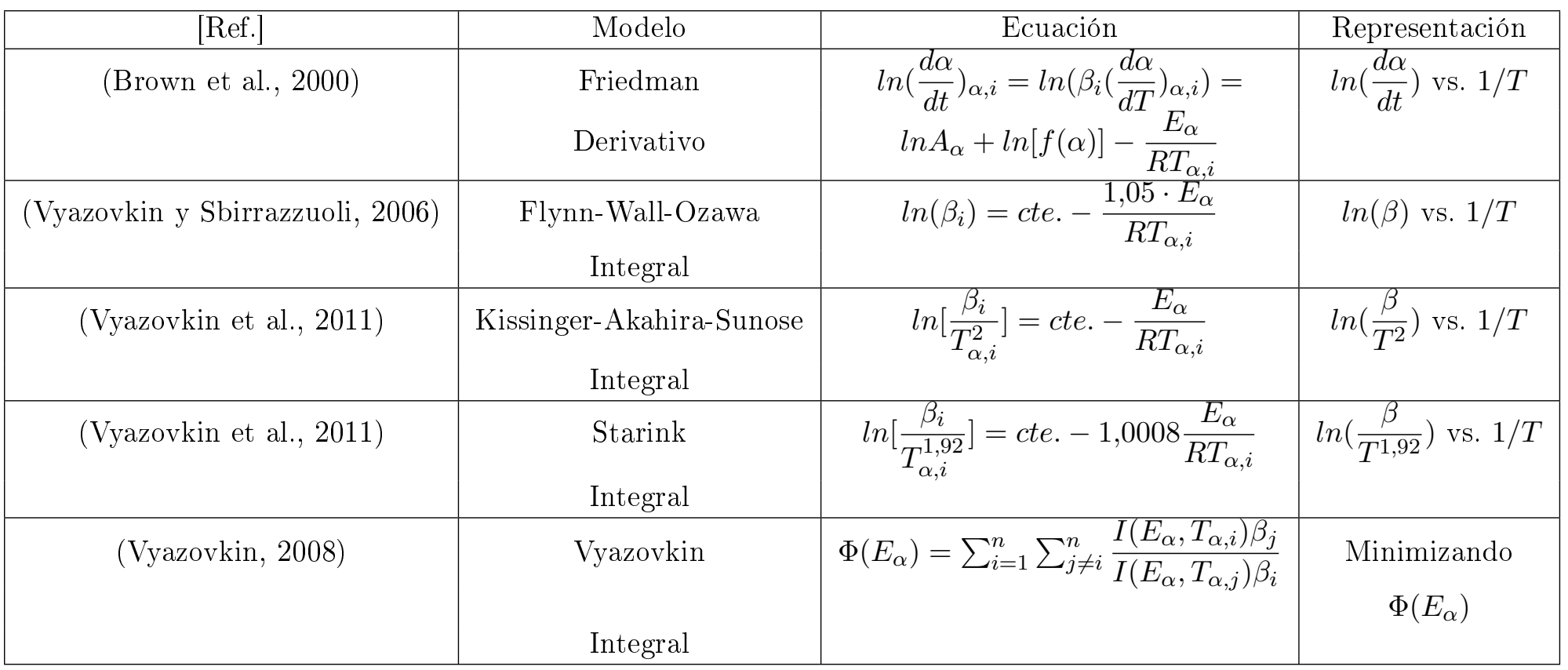

Tabla 2.7: Modelos isoconversionales 
Estos modelos, son también una herramienta útil para la detección de reacciones de degradación en las que intervienen múltiples mecanismos de descomposición. En los polímeros, las reacciones de degradación termo-oxidativas suelen comenzar por los enlaces más débiles de la cadena del polímero. Posteriormente, cuando los macro radicales se han formado, la reacción continúa a través de ellos siendo la energía de activación requerida inferior. La anterior explicación, recogida por (Vyazovkin y Sbirrazzuoli, 2006, Khawam y Flanagan 2005) es la causa de la existencia de energías de activación variables, detectables con la aplicación de los métodos isoconversionales.

Respecto al mecanismo de reacción; pueden agruparse en tres tipos fundamentales por como se desarrolla la evolución de la conversión con el tiempo, siendo: acelerado, decelerado o sigmoidal (o autocatalítico) tal y como recogen (Vyazovkin et al. 2011, Goswami et al. 2012). En un mecanismo acelerado, la velocidad del proceso crece de forma continua con la conversión y alcanza el máximo al final del proceso, en el decelerado, la velocidad es máxima al inicio del proceso y decae con el crecimiento de la conversión, en el caso del mecanismo sigmoidal, el máximo se alcanza en un punto intermedio entre el inicio y final de la conversión. La representación de la evolución de la conversión con el tiempo reporta información valiosa sobre el tipo de mecanismo que aplica para el material objeto del estudio.

Para la extracción del modelo de reacción, entre las diferentes metodologías que lo posibilitan, se encuentra el procedimiento de Malek empleado por (Janković et al. 2008), que obtiene el tipo de mecanismo de reacción a partir de representaciones gráficas de los datos obtenidos de los ensayos de termogravimetría y utilizando el valor de energía de activación resultado de la aplicación previa de los métodos isoconversionales.

Otras metodologías se basan en el empleo de modelos de ajuste, ejemplo de ellos es el análisis cinético combinado propuesto por (Sánchez-Jiménez et al. 2010b a, 2011, Perejón et al. 2013), en ellos se emplean los resultados de los análisis bajo diferentes programas de calentamiento sobre las muestras. El método se basa en una recombinación de la Ecuación 2.11. Representando el lado izquierdo de la ecuación frente a $1 / T$ y obligando a que dicha representación siga una tendencia lineal por medio de la optimización/máximización del índice de correlación de Pearson, se obtiene el valor de los índices del mecanismo de reacción (considerándose la aproximación genérica del mecanismo de reacción por medio de la forma modificada de Sestak-Berggren).

$$
\ln \left(\frac{d \alpha / d t}{f(\alpha)}\right)=\ln (A)-\frac{E}{R T}
$$


En el estudio mediante la aplicación del análisis cinético combinado, las referencias hacen alusión al empleo de un tipo particular de ensayos, del tipo SCTA (Sample Controlled Thermal Analysis). Este tipo de ensayos se describen en (Criado y Pérez-Maqueda, 2005) y han sido aplicados por (Carrasco et al. 2014) en el análisis cinético propuesto para el ácido poli-láctico (PLA) reforzado. Un ensayo tipo SCTA puede tener dos variaciones: CRTA (Constant Rate Thermal Analysis) y SIA (Stepwise Isothermal Analysis). En el primero de los casos, se controla la temperatura del equipo de modo que se mantenga constante la velocidad de reacción del proceso de degradación en todo momento, en el segundo, se impone un calentamiento hasta que la velocidad excede un determinado límite, en ese instante se para el calentamiento y se deja que la reacción evolucione de modo isotermo hasta que la velocidad de reacción cae por debajo de otro límite inferior. La representación de la evolución de la conversión con la temperatura siguiendo este sistema de ensayo, permite discernir el modelo de reacción que está interviniendo solo mediante la morfología adoptada por la curva obtenida, siendo una nueva vía para aproximar el modelo de reacción.

Tal y como se ha mencionado con anterioridad, la aplicación de los métodos isoconversionales permite la detección de la posible presencia de múltiples mecanismos de reacción interactuando. Para solventar la problemática del modelizado cuando hay varios procesos participando en el proceso, la referencia (Perejón et al., 2011) plantea el empleo de la deconvolución de las curvas de modo que se generen curvas independientes representativas de cada uno de los procesos de reacción. Este sistema se ha empleado en el presente trabajo para el análisis de degradación del PEEK y por tanto se aportarán más detalles del mismo la sección 4.2 del documento, donde se ejecuta la presentación y discusión de los resultados. Su desarrollo se basa en la Ecuación 2.12 representando "i" cada una de las etapas implicadas.

$$
\frac{d \alpha / d t}{f(\alpha)}=w_{i} k_{i}(T) f_{i}\left(\alpha_{i}\right)
$$

Cuando se ejecutan análisis cinéticos utilizando los resultados de termogravimetría, es importante tener en consideración la forma de las muestras ensayadas y las diferentes velocidades de los ensayos. El primero de los factores, condiciona la interacción entre la superficie y el oxígeno para la degradación mientras que el segundo puede ocasionar que no exista tiempo suficiente para que tenga lugar la difusión de los productos de degradación, evidencias reportadas por (Yao et al., 1991). Esta referencia, reporta los resultados de la aplicación del método de Flynn-Wall a la degradación del PEEK y del APC2, obteniendo respectivamente valores de energías de activación de $198,2 \mathrm{~kJ} / \mathrm{mol}$ y $210,3 \mathrm{~kJ} / \mathrm{mol}$ en atmósfera inerte y valores de $145,2 \mathrm{~kJ} / \mathrm{mol}$ 
y $151,0 \mathrm{~kJ} / \mathrm{mol}$ en atmósfera oxidativa. En el trabajo se incluye únicamente una energía de activación en cada atmósfera, resultado que parece aludir a la simplificación que los autores ejecutan sobre la interacción de un único mecanismo de degradación en el material.

(Nam y Seferis, 1992) proponen un modelo para la degradación en atmósfera inerte compuesto por dos procesos o mecanismos de reacción, basando sus resultados en la ecuación 2.13. Esta representación, se apoya en las evidencias sobre los mecanismos de degradación en el material mediante la observación de los productos de descomposición obtenidos y supone que ambos procesos implicados evolucionan bajo la misma constante de velocidad, hipótesis poco estricta.

$$
\begin{aligned}
\frac{d \alpha}{d t} & =k\left[y_{1}(1-\alpha)+y_{2} \alpha(1-\alpha)\right] \\
& =4,959 \cdot 10^{14} \exp \left(-\frac{240,2 \cdot 10^{3}}{R T}\right)[0,0215(1-\alpha)+0,9785 \alpha(1-\alpha)]
\end{aligned}
$$

En (Perng et al. 1999) se aplica el método isoconversional de Ozawa en la determinación de la energía de activación en el proceso de degradación por termogravimetría del PEEK, obteniendo un valor para conversiones de 0,2 a $0,6(230,12 \mathrm{~kJ} / \mathrm{mol})$ y un valor superior para conversiones mayores $0,9 \mathrm{a}$ $0,98(384,93 \mathrm{~kJ} / \mathrm{mol})$, indicativo nuevamente, de la existencia de una reacción multi-proceso. No obstante, todo el trabajo se desarrolla bajo la suposición de un modelo de reacción conocido y tipo $(1-\alpha)^{n}$ para el cual se estiman los valores del índice de reacción, quedando por tanto limitado el resultado a la veracidad del mecanismo de reacción supuesto.

En (Nandan et al. 2003), se emplea el método de Freeman y Carrol en la determinación de la energía de activación y del índice de reacción del PEEK y las mezclas de este polímero con poli-aril-éter-sulfona (PES). El trabajo nuevamente falla por presuponer los mecanismos de degradación del polímero como conocidos y por establecer que el PEEK se degrada siguiendo un único proceso de descomposición.

(Patel, 2011) analiza la cinética de degradación del PEEK aplicando en este caso la ecuación de Kissinger y diferentes métodos isoconversionales para obtener su energía de activación y el valor del factor pre-exponencial. Los valores de energía de activación obtenidos en el cálculo, son constantes para conversiones de hasta un $70 \%$, creciendo la energía en conversiones superiores, asociándose este efecto con la oxidación del residuo carbonáceo. 


\subsection{Adhesión}

En el análisis del mecanismo de adhesión entre las capas del material preimpregnado, el proceso debe describirse atendiendo a dos factores, por un lado, la eliminación de la rugosidad superficial en el material para permitir el desplazamiento de las cadenas poliméricas y por otro lado, el mecanismo que controla ese desplazamiento de cadenas.

\subsubsection{Teoría del contacto íntimo}

Entre dos superficies de materiales compuestos preimpregnados termoplásticos puestos en contacto, sin la aplicación de presión ni temperatura, existen huecos a causa de la irregularidad inherente de las superficies del material tras su proceso de fabricación. Los elevados valores de viscosidad de las resinas termoplásticas hace que tengan una limitada capacidad para fluir y cubrir esas áreas únicamente mediante el flujo del polímero, haciendo necesario forzar la puesta en contacto de ambas superficies mediante medios físicos (aplicación de presión). Para poder contabilizar el efecto de esa puesta en contacto y la evolución de la destrucción de la irregularidad surgen los modelos de "contacto íntimo" cuyo punto de partida pasa por caracterizar el estado superficial del material.

Conviene precisar aquí que, el tiempo necesario para conseguir el contacto entre las superficies se incrementará cuanto mayor sea la irregularidad portada por el material, de ahí la importancia de caracterizar y controlar este efecto, cuyo impacto sobre la productividad del proceso es decisivo.

\subsubsection{Representación superficial del material}

El punto de partida para modelizar la eliminación de rugosidad en el material pasa por conocer el estado inicial del mismo. En la bibliografía es posible localizar diferentes referencias donde se incluyen modelos de representación del material atendiendo a diferentes aproximaciones geométricas de su superficie. (Woo Il Lee y Springer, 1987) proponen modelizar la superficie de estos materiales como una sucesión de rectángulos idénticos. Por su parte, (Loos y Dara, 1987) utilizan un histograma de alturas medidas sobre la superficie del material para representar su irregularidad mediante una función de distribución tipo Weibull. En (Marchello y Messier, 1996), se propone aproximar la superficie por irregularidades rectangulares tales que los parámetros altura, ancho y separación, adoptan todos el mismo valor. 
(Pitchumani et al. 1996) utiliza un modelo superficial de rectángulos. En su trabajo se emplean los perfiles de temperatura y presión desarrollados en el proceso de encintado automático para evaluar la evolución del estado de rugosidad del material, a diferencia de valores empleados por otros trabajos donde se emplean valores promedio estimados en temperatura.

(Yang y Pitchumani, 2001, 2002b, 2003) proponen una representación mediante superficies fractales, modelo también empleado en sus estudios por (Khan y Schledjewski, 2009 Stokes-Griffin y Compston, 2016b) y que conducirá a la Ecuación 2.20. Dicha aproximación se basa en proponer que la irregularidad superficial existe en diferentes escalas. En (Khan y Schledjewski 2009) se analiza la necesidad de efectuar pasadas de re-consolidación sobre el material para alcanzar altos valores de contacto íntimo. En el trabajo se concluye que son necesarias al menos tres pasadas de reconsolidación sin aporte de material bajo las condiciones particulares de su proceso de encintado para lograr un $100 \%$ de grado de contacto.

En (Schaefer et al. 2017b) se presenta un resumen de las mencionadas metodologías de representación de la superficie. Los autores ejecutan la aplicación de los modelos de rectángulos idénticos y de superficies fractales para el análisis del grado de contacto íntimo en poliamida (PA6) reforzada con fibra de carbono. Respecto a la aplicación de los modelos fractales se indica que con ellos es posible obtener los parámetros requeridos por el modelo mediante simples medidas profilométricas, hecho importante en comparación con los modelos que utilizan rectángulos pues se apoyan en aproximaciones por ajustes matemáticos. Como contrapartida, estos modelos no son siempre aplicables a cualquier material y tras su empleo muestran una subestimación del grado de contacto íntimo real entre las partes.

En (Di Francesco et al. 2016) la determinación experimental del grado de contacto se obtiene de los análisis de las áreas con y sin desconsolidar en las entre-caras de las distintas capas del material, tal y como proponía (Levy et al. 2014), que utilizaba un algoritmo de optimización para extraer los parámetros de rugosidad partiendo de los resultados bajo condiciones específicas de procesado.

En (Perez et al. 2018) la superficie del material se representa por medio de elementos multi-nivel. Los autores ejecutan una comparación de cómo es la evolución del grado de contacto íntimo con el tiempo en el encintado automático y consolidación in-situ partiendo de diferentes acabados superficiales del material y bajo la actuación de diferentes potencias láser. En todos los resultados se presenta el material con el perfil de rugosidad más estable como aquél que requiere el menor tiempo para llegar al $100 \%$ del grado de contacto. 
Similares desarrollos se han localizado también aplicados sobre material termoestable (Yu et al. 2017); acoplando al modelo efectos como el curado parcial de la resina durante los encintados. En el caso de estos materiales, tal y como ocurría con los termoplásticos, la temperatura, la viscosidad, la fuerza de compactación y la velocidad de encintado son los parámetros que impactan en el resultado.

\subsubsection{Evolución de la irregularidad superficial}

Considerando una distribución inicial de rectángulos idénticos en la superficie del material, con altura $a_{0}$, ancho $b_{0}$ y separación entre ellos $w_{0}$ (Woo Il Lee y Springer, 1987) utiliza la ecuación de conservación del volumen, Ecuación 2.14 como herramienta para analizar la evolución del contacto íntimo en las superficies del material una vez que tiene lugar el aplastamiento.

$$
V_{0}=a_{0} b_{0}=a b
$$

Como definición para el grado de contacto íntimo entre dos superficies, se establece la relación existente entre: el ancho final de la irregularidad o rectángulo $(b)$ sobre la suma de ancho inicial $\left(b_{0}\right)$ más la separación de rectángulo iniciales $\left(w_{0}\right)$. Además, teniéndose en cuenta la conservación del volumen se llega a la Ecuación 2.15

$$
D_{i c}=\frac{b}{w_{0}+b_{0}}=\frac{\frac{a_{0}}{a}}{1+\frac{w_{0}}{b_{0}}}
$$

Mediante la aplicación de las ecuaciones de conservación de la masa a un volumen de control, asumiendo flujo laminar, ejecutando simplificaciones algebraicas y estimando la fuerza a ejercer en la unidad de área, en la referencia se llega a la ecuación que predice la evolución del grado de contacto íntimo como función del tiempo, temperatura, presión y acabado superficial del material, Ecuación 2.16 .

$$
D_{i c}=\frac{1}{1+\frac{w_{0}}{b_{0}}}\left[1+\frac{5 P_{a p p}}{\mu_{m f}}\left(1+\frac{w_{0}}{b_{0}}\right)\left(\frac{a_{0}}{b_{0}}\right)^{2} t\right]^{1 / 5}
$$

Considerando que el grado total de contacto se alcanza cuando $D_{i c}=1$, es posible calcular el tiempo necesario para obtenerlo tal y como recoge la 
Ecuación 2.17

$$
t_{i c}=\frac{\mu_{m f}}{5 P_{a p p}} \frac{1}{1+\frac{w_{0}}{b_{0}}}\left(\frac{b_{0}}{a_{0}}\right)^{2}\left[\left(1+\frac{w_{0}}{b_{0}}\right)^{5}-1\right]
$$

Cuando las condiciones de proceso son no isotermas, (Sonmez y Hahn, 1997, Toso 2003) reportan la expresión integral para analizar la evolución del grado de contacto íntimo, Ecuación 2.18 .

$$
D_{i c}=\frac{1}{1+\frac{w_{0}}{b_{0}}}\left[1+5\left(1+\frac{w_{0}}{b_{0}}\right)\left(\frac{a_{0}}{b_{0}}\right)^{2} \int_{0}^{t} \frac{P_{a p p}}{\mu_{m f}} d t\right]
$$

Expresión que en (Pitchumani et al. 1996) aparece simplificada como la Ecuación 2.19.

$$
D_{i c}=a^{*}\left[\int_{0}^{t_{b}} \frac{P_{a p p}}{\mu_{m f}} d t\right]^{1 / 5}
$$

Adoptando $a^{*}$ un valor de 0,29 para el caso de APC2/AS4.

Por su parte, cuando se ejecuta la representación de la irregularidad con superficies fractales, la Ecuación 2.20 es la empleada para la evolución del grado de contacto íntimo. Siendo, $D$ la dimensión fractal, $f$ el factor de escalado, $n$ el número de irregularidades, $L_{r}$ la longitud total para establecer el conjunto de Cantor, $P_{a p p}$ la presión aplicada, $t$ la duración de presionado del rodillo, $\eta_{m f}$ la viscosidad del compuesto y $h_{r}$ el receso de la profundidad de la primera generación encontrada de irregularidades.

$$
D_{i c}^{n}(t)=\frac{1}{f^{n}}\left[\frac{5}{4}\left(\frac{h_{r}}{L_{r}}\right)^{2}\left(\frac{(f)^{\left(\frac{2 n D}{2-D}+n+4\right)}}{(f+1)^{2}} \int_{t_{n+1}}^{t} \frac{P_{a p p}}{\eta_{f m}} d t+1\right]^{1 / 5}\right.
$$

Como puede desprenderse de la ecuaciones anteriores, el cálculo requiere del conocimiento de la viscosidad del material compuesto fibra-resina, este valor puede obtenerse de forma teórica empleando ecuaciones como las propuestas por (Roberts y Jones, 1995), partiendo de los valores calculados sobre el polímero neto.

(Schaefer et al. 2017b) considera también la posibilidad de representar la viscosidad del material objeto de su estudio, PA6/FC, directamente con la viscosidad de la resina, apoyado sobre la hipótesis de que la capa más 
superficial de este material es fundamentalmente polímero. La viscosidad se determina como el valor obtenido de las viscosidades "zero shear rate" a diferentes temperaturas, asumiendo que en el proceso de encintado en automático no interviene la velocidad de cortadura.

Para el caso del material APC2/AS4, la Tabla 2.8 recoge las ecuaciones plateadas por diferentes referencias bibliográficas. 


\begin{tabular}{|c|c|c|c|c|}
\hline [Ref.] & $w_{0} / b_{0}$ & $a_{0} / b_{0}$ & $\mu_{\text {matriz }}[P a \cdot s]$ & $\mu_{\text {mat.compuesto }}[\mathrm{Pa} \cdot \mathrm{s}]$ \\
\hline \begin{tabular}{|c|c|} 
Woo Il Lee y Springer & 1987 \\
(Marchello y Messier, & 1996
\end{tabular} & 1 & 0,3 & $\begin{array}{c}1,13 \cdot 10^{-10}\left[\exp \left(\frac{19100}{T}\right)\right] \\
\text { PEEK } 150 \mathrm{P}\end{array}$ & $1,14 \cdot 10^{-12}\left[\exp \left(\frac{26300}{T}\right)\right]$ \\
\hline (Mantell y Springer, & & & $1,13 \cdot 10^{-10}\left[\exp \left(\frac{19100}{T}\right)\right]$ & $132,95\left[\exp \left(\frac{2969}{T}\right)\right]$ \\
\hline$($ Sonmez y Hahn, 1997) & & & & $132,95\left[\exp \left(\frac{2969}{T}\right)\right]$ \\
\hline (Khan y Schledjewski, 2009$)$ & & & & $643\left[\exp \left(\frac{4367}{T}\right)\right]$ \\
\hline
\end{tabular}

Tabla 2.8: Definición de parámetros bibliográficos para las ecuaciones del grado de contacto íntimo 


\subsubsection{Teorías del movimiento de cadenas poliméricas - au- tohesión}

Cuando dos superficies poliméricas se ponen en contacto entre sí, habiéndose incrementado su temperatura sobre su transición vítrea, se produce una difusión de las cadenas del polímero en la entrecara, comúnmente conocida como healing, difusión o autohesión. En el desarrollo de una unión resistente debe desarrollarse una correcta difusión de la cadena de tal modo que la intercara pueda llegar a volverse indistinguible.

La teoría básica para explicar el mecanismo de difusión de las cadenas en la intercara es la teoría de reptación de De Gennes (de Gennes, 1971 . De Gennes y Leger 1982). La explicación de la reptación se apoya en la teoría del tubo de Rouse (Doi y Edwards, 1988; McLeish, 2002). El modelo del tubo se basa en la teoría uni-paramétrica simple de que las cadenas poliméricas entrelazadas tienen de modo individual incapacidad para cruzar el área ocupada por otras cadenas. A causa del hecho anterior, cada cadena se encuentra confinada en su movimiento curvilíneo lateral pero no en el movimiento paralelo (en longitudinal a la cadena). Los finales de cadena, no presentan restricciones y se encuentran libres en el fundido sin restricción topológica. En el sentido estricto, la restricción al movimiento curvilíneo lateral tampoco es total pues la cadena puede desplazarse dentro de la limitación impuesta por un tubo de un radio aproximado como "a" (por ejemplo, con movimientos tipo acordeón). Esta restricción aplicada por el tubo presenta un carácter temporal y a medida que la cadena va abandonando ese tubo, nuevas limitaciones comienzan a aplicar.

La propuesta de De Gennes se basa en modelizar la liberación de restricciones de la cadena mediante el movimiento de Rouse en el tubo, pero asumiendo que la velocidad es proporcional a la fracción de finales de cadena existentes.

En escalas temporales cortas, el tiempo de Rouse será el que defina el movimiento de la cadena, siendo el coeficiente de difusión curvilíneo inversamente proporcional al número de monómeros de la red. Por su parte, el tiempo de relajación o reptación, recogido por la Ecuación 2.21. correspondiente con el tiempo para la salida completa del tubo de la cadena, será superior y su orden de magnitud será el cubo del número de monómeros. La aproximación para dicho tiempo es la típica para una difusión Fickiana. El coeficiente de difusión para el caso del modelo de De Gennes será proporcional a la inversa del cuadrado del número de monómeros, Ecuación 2.22 . 


$$
\tau_{\text {rep }} \sim \frac{L^{2}}{D_{c}} \sim N^{3}
$$

Siendo, $\tau_{\text {rep }}$ el tiempo de reptación, $L$ la longitud de la cadena y $D_{c}$ el coeficiente de difusión curvilíneo, que a su vez se aproxima por $D_{c} \sim N^{-1}$. Con $N$ el número de monómeros constituyentes.

$$
D_{3 d} \sim \frac{R^{2}}{\tau_{\text {rep }}} \sim N^{-2}
$$

En el modelo de reptación se considerarán por tanto tres escalas fundamentales de tiempo (Jarrousse, 2004):

- El tiempo de relajación de Rouse, entre los enlaces de peso molecular $M_{e}$, principalmente gobernado por un movimiento de serpenteo, desplazamientos del orden del diámetro del tubo.

- El segundo tiempo se relaciona con la propagación de los movimientos a lo largo del contorno de la cadena, se corresponde con el tiempo de relajación de Rouse de la cadena completa.

- El tiempo más relevante para la soldadura de materiales termoplásticos, el tiempo de reptación, tiempo que le lleva a la cadena del polímero abandonar por completo el tubo inicial que la contiene. Normalmente, se considera como el tiempo en el cual aproximadamente un $70 \%$ de la cadena ha salido del tubo. Este tiempo de reptación es muy superior al tiempo de relajación de Rouse.

No será extraño encontrar modos de relajación de las cadenas cuyos tiempos asociados sean inferiores a los del tiempo de reptación (el mayor de ellos), a causa de la rapidez con la que los segmentos del tubo que originariamente se encuentran próximos a los bordes abandonan dicha limitación topológica en comparación con la que requieren los que se encuentran en el centro de la cadena.

Experimentalmente, es posible establecer una relación de proporcionalidad entre la viscosidad, el peso molecular y el tiempo de relajación, según la Ecuación 2.23 La relación planteada establece una dependencia entre el tiempo de reptación y el peso molecular que difiere del valor teórico, presentado por la Ecuación 2.21, hecho que se justifica por el efecto de las fluctuaciones en la longitud del tubo y también por la circunstancia presentada en el párrafo previo sobre los finales de cadena y las posiciones centrales.

$$
\tau \sim \eta \sim M^{3,4}
$$


Por su parte, en (McLeish, 2002) se presentan las relaciones de dependencia para la viscosidad con el peso molecular, recogidas por el conjunto de las Ecuaciones 2.24. Un polímero termoplástico se compone de un conjunto de cadenas que se entrelazan entre sí, a cada entrelazado se le asigna un peso molecular de valor $M_{e}$ (peso molecular del segmento de cadena entre puntos de unión intermoleculares). Cuando se alcanza el enmarañamiento completo, el valor obtenido de la masa molar es de $M_{c}$ (masa molar crítica), considerándose que es posible aproximar $2 M_{e} \sim M_{c}$ tal y como figura en (Fetters, 1965). Para cada material, el peso molecular crítico establece un límite tal que, incrementos de peso molecular por encima de dicho valor suponen un lento crecimiento del valor de la viscosidad.

$$
\begin{gathered}
\eta \sim M^{1} \text { si } M<M_{c} \\
\eta \sim M^{3,4} \text { si } M>M_{c}
\end{gathered}
$$

A pesar de que la predicción de De Gennes sobre la dependencia del coeficiente de difusión con la inversa del cuadrado del peso molecular, Ecuación 2.22 fue demostrada de modo experimental, ensayos más recientes manifiestan que la dependencia se aproxima más a la inversa de la potencia 2,3 , es decir, $D_{3 d} \sim N^{-2,3}$.

\subsubsection{Extrapolación a difusión de cadenas en ISC}

Avanzando ahora hacia el mecanismo de adhesión entre dos superficies de material durante del encintado automático y considerando la reptación de cadenas, es preciso tener en cuenta el movimiento de las conocidas como: "cadenas menores" (Wool, 2002). Inicialmente, una cadena se encuentra rodeada en su totalidad por un tubo (restricciones topológicas), durante un tiempo $t_{1}$, la cadena comienza a abandonar el tubo, principalmente por los extremos, a esas porciones iniciales que han evacuado el tubo se las denomina cadenas menores, como se representa en la Figura 2.4. La longitud de cadena que abandona el tubo $l(t)$, es una función creciente con el tiempo, dicha magnitud será el principal mecanismo de control en el desarrollo de la resistencia de unión.

En función de la capacidad de interpenetración de la cadena polimérica en la entrecara del material, es posible desarrollar una unión más o menos resistente, siendo causa directa del comportamiento mecánico de las piezas. En (Wool y O'Connor, 1981) se consideran cinco etapas en el healing de los polímeros: 


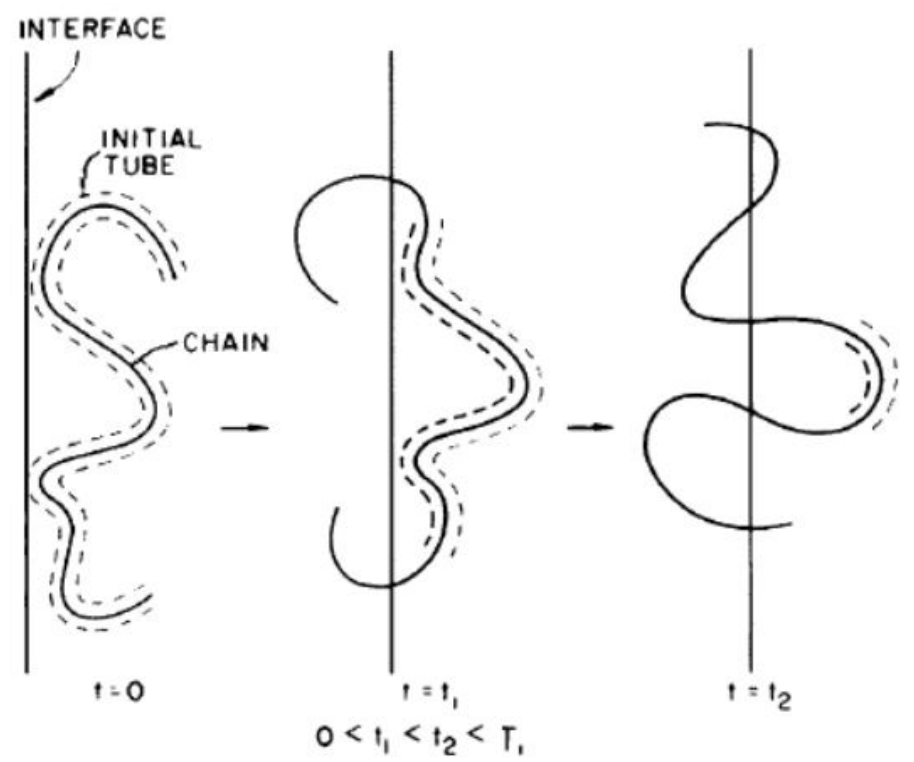

Figura 2.4: Teoría de reptación de De Gennes, movimiento de cadenas menores (Wool, 2002)

- Reorganización de la superficie.

- Aproximación de superficies.

- Mojado.

- Difusión

- Distribución aleatoria.

Las etapas de mojado y de difusión son las que condicionan el desarrollo de propiedades mecánicas a través del análisis de una función de difusión. Las propiedades mecánicas proporcionan información orientativa sobre el estado de reptación de las cadenas, llegándose a las siguientes conclusiones en relación con las dependencias de las propiedades mecánicas y los tiempos (considerando las propiedades con subíndice " $\infty$ " las que se obtendrían como valor máximo/condiciones de equilibrio), Ecuaciones 2.25

$$
\begin{array}{rll}
\sigma, \epsilon \sim t^{1 / 4} ; E \sim t^{1 / 2} & \text { si } & t<t_{\infty} \\
\sigma, \epsilon \sim M^{1 / 2} ; E \sim M & \text { si } & t=t_{\infty}
\end{array}
$$


El estudio también analiza el impacto de parámetros como la masa molar $(\mathrm{M})$, la presión $(\mathrm{P})$ o la temperatura $(\mathrm{T})$ sobre el tiempo de equilibrio $t_{\infty}$, obteniéndose las relaciones de las Ecuaciones 2.26

$$
\begin{array}{r}
t_{\infty} \sim M^{3} \\
t_{\infty} \sim \exp (P) \\
t_{\infty} \sim \exp (1 / T)
\end{array}
$$

Respecto a la distancia penetrada por la cadena en la entrecara y la longitud evacuada de la cadena respecto al tubo, se reporta la siguiente dependencia, dada por la Ecuación 2.27. Asimismo, existe una relación de proporcionalidad entre la distancia interpenetrada y el tiempo de reptación, representada por la Ecuación 2.28

$$
\begin{gathered}
\left\langle\chi^{2}\right\rangle \sim\left\langle l^{2}\right\rangle^{1 / 2} \\
\chi \sim t_{r}^{1 / 4}
\end{gathered}
$$

Siendo $t_{r}$ el tiempo de reptación, que cumple $t_{r}<t_{\infty}$, donde $t_{\infty}$ es el tiempo para la consecución de la difusión completa. Ese tiempo de reptación se relaciona con la temperatura mediante una relación de tipo Arrhenius, Ecuación 2.29 tal y como figura en (Ageorges et al. 2001). Con $A_{r}$ y $B_{r}$ parámetros obtenidos experimentalmente.

$$
t_{r}=B_{r} \exp \left(\frac{A_{r}}{T}\right)
$$

Para los casos concretos de largos tiempos $\left(t_{\infty}\right)$ y largas distancias, se propone una modificación de la Ecuación 2.28 a 2.30 tal como proponen (Wool y O'Connor, 1981).

$$
\chi \sim t^{1 / 2}
$$

En (Bastien y Gillespie, 1991; Yang y Pitchumani, 2002a) se alude directamente a la relación de la difusión/healing con las propiedades mecánicas desarrolladas por la entrecara del material, presentándose las siguientes dependencias para la resistencia y la energía de fractura con el tiempo, Ecuaciones 2.31 y la estimación del valor del grado de difusión, Ecuación 2.32 Esta última relación busca determinar el grado de difusión o healing $D_{h}$ bajo la suposición de mismos coeficientes de proporcionalidad para la resistencia 
respecto a la raíz cuadrada de la longitud de cadena menor y para la relación en el caso de la máxima resistencia desarrollable.

$$
\begin{gathered}
\frac{\sigma}{\sigma_{\infty}}=\left(\frac{t}{t_{r}}\right)^{1 / 4} \\
\frac{G_{c}}{G_{c \infty}}=\left(\frac{t}{t_{r}}\right)^{1 / 2} \\
D_{h}=\frac{\sigma}{\sigma_{\infty}}=\frac{\chi}{\chi_{\infty}}=\left(\frac{l}{L}\right)^{\frac{1}{2}}
\end{gathered}
$$

Asimismo, la referencia establece una relación entre las longitudes (de cadena menor y de cadena totalmente evacuada) con los tiempos de mantenimiento de la temperatura, únicamente en condiciones isotermas, pues en esa situación puede suponerse la existencia de un coeficiente de difusión constante, esa relación es la representada por la Ecuación 2.33 .

$$
\frac{l}{L}=\left(\frac{t}{t_{r}}\right)^{\frac{1}{2}}
$$

Combinando las anteriores ecuaciones y para el caso de condiciones isotermas, el grado de healing puede expresarse como se indica en la Ecuación 2.34. como función del tiempo de mantenimiento de las condiciones del proceso y del tiempo de reptación del polímero.

$$
D_{h}=\left(\frac{t}{t_{r}}\right)^{\frac{1}{4}}
$$

(Sonmez y Hahn, 1997) reformulan la ecuación dividiendo la historia térmica en intervalos infinitesimales para tener en cuenta las posibles condiciones no isotermas del proceso. De este modo se obtiene la Ecuación 2.35. La integración de la anterior expresión conduce a la Ecuación 2.36 para el cálculo del grado de autohesión.

$$
\begin{gathered}
\frac{d l}{L}=\frac{d t}{2 \sqrt{\eta t_{r}(\eta)}} \\
D_{h}=D_{a u}=\frac{S}{S_{\infty}}=\left(\int_{0}^{t} \frac{d \eta}{2 \sqrt{\eta t_{r}(\eta)}}\right)^{1 / 2}
\end{gathered}
$$

En los trabajos de (Woo Il Lee y Springer, 1987) se ejecuta una comprobación experimental del valor de healing alcanzado en APC2/AS4 mediante un ensayo mecánico de tracción entre dos partes unidas bajo distintos ciclos 
térmicos en prensa. Terminada la estabilización de temperatura, las probetas son (quencheadas) enfriadas bruscamente en agua fría. En base al grado de healing obtenido, los autores son capaces de proporcionar una relación de dependencia con el tiempo y la temperatura, como recoge la Ecuación 2.37. Observándose que a mayor temperatura, menos tiempo se requiere para alcanzar el $100 \%$ del grado de autohesión. Es importante anotar aquí, que los modelos utilizados por la referencia son válidos en el caso de materiales amorfos, de ahí el hecho de efectuar el quenching sobre las muestras.

$$
D_{h}=44,1 \exp \left(\frac{3810}{T}\right) t_{a}^{\frac{1}{4}}
$$

(Pitchumani et al. 1996) por su parte, hace uso de los modelos de Bastien y Gillespie, 1991) para los materiales compuestos con base PEEK, estimando el grado de healing alcanzado mediante la Ecuación 2.38 cuando el proceso transcurre en condiciones no isotermas.

$$
D_{h}\left(\tau_{h}\right)=\left(\frac{1}{t_{r}^{*}}\right)^{\frac{1}{4}} \sum_{j=1}^{\frac{\tau_{h}}{\Delta \tau}} \frac{\left(\tau_{j}\right)^{\frac{1}{4}}-\left(\tau_{j-1}\right)^{\frac{1}{4}}}{a_{T} T_{j}^{\frac{1}{4}}}
$$

Con $a_{T}$ :

$$
a_{T}=\exp \left(\left(\frac{E_{a}}{R}\right)\left(\frac{1}{T}-\frac{1}{T_{r e f}}\right)\right)
$$

Los parámetros de la ecuación adoptan en la referencia citada los siguientes valores numéricos, $E_{a}=57,3 \mathrm{kJmol}^{-1} \mathrm{y}\left(t_{r}\right)^{*}=0,11 \mathrm{~s}$ para la temperatura de referencia $673 \mathrm{~K}$.

Trabajos más recientes, como los de (Khan y Schledjewski, 2009, Khan et al. 2010), emplean la relación integral matemática de la Ecuación 2.41 para la extracción del grado de healing a través de su dependencia con el tiempo de soldadura. Esta ecuación ya había sido empleada por Yang y Pitchumani. 2002a, 2003) en su análisis estadístico bajo la aplicación de la ecuación de difusión, sobre la probabilidad de encontrar un segmento de cadena en un tiempo determinado, en una posición específica del espacio.. Dicho tiempo de soldadura se extrae para la mayor relajación molecular del polímero fundido y a una temperatura específica de ensayo. La mayor relajación la localizan en el cambio del régimen lineal al no lineal en las curvas obtenidas de un ensayo dinámico de reología. Asimismo, plantean una solución para la evolución de ese tiempo con la temperatura basada en una relación de dependencia de tipo Arrhenius con PEEK 150 PF, Ecuación 2.40. Conviene puntualizar aquí que, la relación de tipo Arrhenius no es la única propuesta 
bibliográfica para la evolución del tiempo de reptación con la temperatura, en los análisis donde la temperatura es próxima a la transición vítrea, aplica la relación de WLF (William-Landel-Ferry).

$$
\begin{gathered}
t_{w}(T)=2 \cdot 10^{-5} \exp \left(\frac{43000}{R T}\right) \\
D_{h}=\left[\int_{0}^{t} \frac{1}{t_{w}} d t\right]^{1 / 4}
\end{gathered}
$$

Algunas teorías más completas incorporan más mecanismos interactuando que únicamente la reptación en el proceso de autohesión, tal y como se describe en (Vega et al., 2004), donde se habla de fluctuaciones en la longitud de contorno de cadena, efectos cooperativos (reptación doble) y dilatación dinámica del tubo.

\subsubsection{Teoría de unión}

Una vez obtenidos los grados de contacto íntimo y difusión, es posible combinar sus resultados para obtener información sobre el grado general de unión.

En algunos trabajos particulares como en (Mantell et al. 1992), se ejecuta una aproximación, asumiendo el grado de autohesión igual a 1 y por tanto analizando la unión desde el punto de vista del contacto íntimo.

En el trabajo de (Pitchumani et al. 1996$)$ se indica que durante el encintado automático con material reforzado termoplástico, los tiempos de desarrollo del contacto íntimo son muy inferiores a los de reptación o difusión de cadenas (pues este mecanismo no necesita una presión asociada para tener lugar), pudiendo por tanto evolucionar siempre que la temperatura no congele el movimiento de las cadenas y permitiendo hacer la siguiente simplificación para el grado de unión, Ecuación 2.42. Experimentalmente, parece existir una buena correlación entre los valores de grado de unión obtenidos y los de resistencia de las probetas ensayadas a "short beam shear" (SBS).

$$
D_{b}\left(\tau_{b}\right) \approx D_{h}\left(\tau_{h}\right) \cdot D_{i c}\left(\tau_{i c}\right)
$$

(Sonmez y Akbulut, 2007) presenta un algoritmo completo para localizar los mejores parámetros en el encintado con material termoplástico y para ello analiza el grado de unión por medio de la Ecuación 2.43 que es una 
convolución de los grados de contacto y de difusión.

$$
D_{b}\left(t_{b}\right)=\int_{0}^{t_{b}}\left[\int_{0}^{t_{b}-\tau} \frac{d \eta}{\sqrt{\left.\eta t_{r}(\eta)\right)}}\right]^{\frac{1}{2}} \frac{d D_{i c}}{d \tau} d \tau
$$

Sin aplicar simplificaciones, (Schell et al. 2009 Stokes-Griffin y Compston 2016b), proponen la Ecuación 2.44 para modelizar el comportamiento a unión. El primero de los trabajos, propone un parámetro $\Omega$ que contabiliza la relación entre la escala temporal para la difusión y para el contacto íntimo, reportando por tanto información sobre qué mecanismo es predominante, Ecuación 2.45.

Si $\Omega<1$ el control es del contacto íntimo, si es $\Omega>1$ el control es de la difusión.

La innovación del segundo trabajo citado es plantear la posibilidad de que exista desarrollo de unión en rangos de temperatura bajo la fusión del material (posibilidad también considerada por (Awaja et al. 2013), que indica mejoras de autohesión en el material con tratamiento plasma e implantación de iones). La anterior hipótesis se fundamenta en que los valores obtenidos por los modelos, considerando como límite de validez la fusión del polímero, siempre subestiman el valor real obtenido de la unión. En el trabajo se detecta que considerar como límite para la unión la temperatura de fusión subestima el resultado, pero considerar la transición vítrea lo sobreestima, especialmente a bajas velocidades de encintado por el desarrollo de la cristalización que bloquea los movimientos de las cadenas. En (Sonmez y Hahn, 1997) también se tenía en cuenta esta consideración y las iteraciones del cálculo para estimar la unión sólo paraban al alcanzarse $543 \mathrm{~K}$, temperatura bastante por debajo de la fusión.

$$
D_{b}\left(t_{b}\right)=D_{i c}(0) D_{a u}\left(t_{b}\right)+\int_{0}^{t_{b}} D_{a u}\left[t, t_{b}\right] \frac{d D_{i c}}{d t} d t
$$

El grado de autohesión se calcula entre $t$ y $t_{b}$ siendo $t$ el tiempo de formación de un nuevo incremento en el grado de contacto íntimo.

$$
\Omega=\left(\frac{P t_{R}}{\mu(T)}\right)^{1 / 5} R_{c}
$$

(Nicodeau, 2005) recopila modelos de diversos autores y clarifica que la aplicación de algunos de ellos se encuentra restringida a polímeros termoplásticos amorfos. En el caso de polímeros semicristalinos, no sólo se presenta un 
comportamiento diferente sino que se aclara también que, no alcanzándose una fusión perfecta en el material se genera un remanente de cristal en el conjunto que impide los movimientos libres de las cadenas. También incorpora un elemento más al estudio que da una idea de la complejidad del proceso con materiales semicristalinos, la adhesión y formación de una interfaz cristalina, el efecto de la co-cristalización, que hace complejo el mecanismo de fractura en las entrecaras. La obtención experimental de los tiempos de relajación se efectúa mediante el empleo de ensayos de reología y atendiendo a diferentes criterios: con el tiempo proporcionado por el modelo de Carreau en el cambio de tenencia entre régimen newtoniano y shear thinning, con el tiempo del cruce de de las pendientes de $G^{\prime}$ y $G^{\prime \prime}$ cuando la frecuencia del ensayo dinámico tiende a cero y con el tiempo más largo del espectro de relajación.

El empleo de reología para la obtención de los valores aparece también reportado en (Lamèthe et al. 2005, Regnier et al. 2007), donde se establece una relación con la temperatura del tiempo de relajación siguiendo una evolución de tipo Arrhenius, estableciendo el tiempo como el valor donde se produce el cambio del régimen newtoniano al de shear thinning.

También (Tierney y Gillespie, 2006) analizan el fenómeno del contacto íntimo y de reptación de las cadenas mediante el empleo de los parámetros obtenidos por (Pitchumani et al., 1996). En el trabajo se presenta el desarrollo del contacto íntimo en función de las pasadas de encintado y de la velocidad de laminación. Sus resultados reflejan que con velocidades de encintado muy elevadas, incrementar las pasadas de consolidación no impacta sobre el grado de contacto pero, en cambio sí aumenta con las pasadas cuando baja la velocidad. También detectan que aproximar la distancia entre de la antorcha de gas caliente y el laminado, incrementa el valor obtenido del grado de contacto íntimo.

En estudios recientes como el de (Chu et al., 2018), que efectúa el encintando con polipropileno reforzado con fibra de vidrio, se emplean también las ecuaciones anteriormente expuestas para el análisis del grado de autohesión y de contacto íntimo. Su finalidad es determinar los tiempos mínimos necesarios para alcanzar el grado total de unión, resaltándose la importancia de la viscosidad del material en la estimación de este tiempo.

Entre las limitaciones localizadas en la aplicación de estos modelos se encuentra por un lado el hecho de analizarse la consolidación en la primera etapa de unión entre dos capas de material, siendo el proceso evolutivo e implicando la unión de múltiples capas impactando una vez tras otra sobre las inferiores. (Zhao et al. 2018) presenta un trabajo que trata de cubrir esta 
problemática, presentando una ecuación para el análisis de la presión recibida en la capa n-ésima y la relación del grado de contacto con la evolución del encintado de cada capa. El trabajo se ejecuta bajo la suposición de que la viscosidad del material compuesto puede aproximarse por la de la resina por ser éste el componente más superficial de la lámina.

Los tiempos descritos con anterioridad tanto para grado de contacto íntimo como para la difusión o healing, pueden resultar elevados si se extrapolan a la aplicación industrial del proceso de encintado automático y consolidación in-situ, pues resultan en valores de velocidad muy conservativos. 


\subsection{Cristalización}

La cristalización consiste en un proceso de cambio de fase desde líquido a una estructura sólida ordenada de cristal.

Convencionalmente se han considerado explicaciones al proceso de la cristalización desde un punto de vista meramente termodinámico basándose en teorías de equilibrio, pero diferentes trabajos de investigación han llevado a concluir que este mecanismo se explica con mayor precisión con teorías cinéticas (Zhang et al. 2016). En esta sección se presentan las principales teorías y consideraciones que aplican a cada una de ellas.

La teoría más aceptada para la explicación general de la cristalización es la del doblado o plegado de cadenas y empaquetado de las mismas en el proceso de ordenación. Según esta teoría, las regiones cristalinas se componen de placas delgadas en las que las cadenas se pliegan repetidamente y están alineadas de forma perpendicular a las caras planas de las láminas. Según el modo de plegado de las cadenas, es posible diferenciar tres configuraciones (Alvarez et al. 2011):

- Cadenas plegadas adyacentes regulares: Presentan un cambio de fase brusco entre la fase cristalina y la amorfa. La cadena re-entra en el espacio adyacente vecino.

- Modelo switchboard (propuesto por Flory): las cadenas se pliegan aleatoriamente sobre la propia lamela o la lamela adyacente. Se genera una fase intermedia entre la zona cristal y el área del puramente amorfo.

- Modelo de nucleación intramolecular

Un modo visual de comprender como tiene lugar el ordenamiento, que será explicado con más detalle en lo sucesivo, es el representado por la Figura 2.5 .

\subsubsection{Termodinámica en la cristalización de polímeros}

La termodinámica ofrece una explicación a la variación del crecimiento lamelar con el grado de enfriamiento. La teoría clásica de la termodinámica (Zhang et al., 2016) recoge que, la energía libre total para la formación de cristales desde la fase amorfa es igual al sumatorio de los términos de la derecha en la Ecuación 2.46. Siendo respectivamente los términos de la derecha de la ecuación (de izquierda a derecha): energía superficial lateral total, energía superficial de doblado y energía libre del conjunto. Con $A_{\text {lat }}$ el área superficial lateral, $A$ el área superficial doblada, $l$ el espesor de la lamela, $\sigma$ 


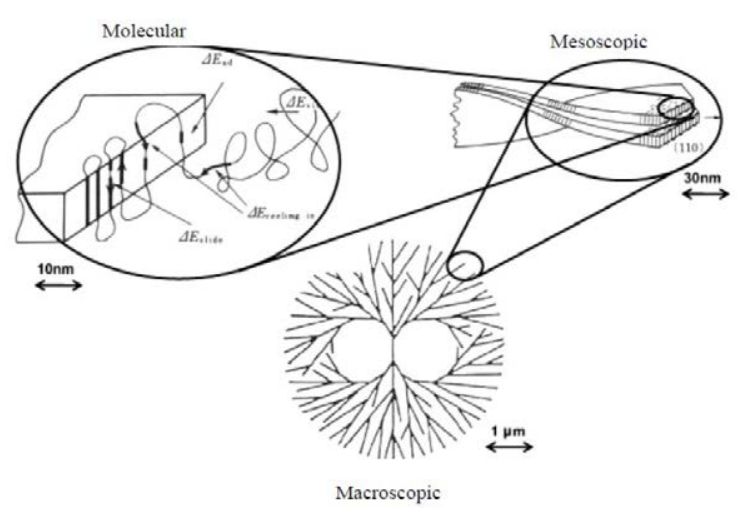

Figura 2.5: Estructura de formación del cristal (Hynstová, 2010)

la energía libre de superficie lateral y $\sigma_{e}$ la energía libre de superficie final doblada.

$$
\Delta G=\Sigma A_{l a t} \sigma+2 A \sigma_{e}-\Delta F A l
$$

Como el área doblada es muy superior al área lateral para cristales suficientemente grandes, se podría ejecutar la simplificación de $A>>A_{\text {lat }}$, reduciéndose al caso de la Ecuación 2.47

$$
\Delta G=2 A \sigma_{e}-\Delta F A l
$$

Según la termodinámica, el caso en que $\Delta G=0$, sería el que proporcionaría el menor espesor lamelar para el cristal y el que limitaría la superación de la barrera energética para la formación del núcleo estable. Bajo esta consideración, puramente termodinámica, la mínima energía se obtendría para cristales de cadena extendida. Los estados con lamelas de mayor espesor también son termodinámicamente estables, teniendo habitualmente los cristales un tamaño mayor a ese valor mínimo; tal y como indica la Ecuación 2.48 .

$$
l=l_{\min }+\delta l
$$

La energía libre se define por tanto como muestra la Ecuación 2.50.

$$
\Delta G(T)=\Delta H(T)-T \Delta S(T)
$$


Ejecutando una aproximación de primer orden de las relaciones entre las variaciones de entalpía y entropía, que se pueden estimar constantes en las proximidades de la temperatura de fusión, se obtiene una relación lineal que indica que la fuerza para producir la cristalización se incrementará con el sobre-enfriamiento. Esta relación solo tiene validez para enfriamientos $\Delta T$ pequeños, cuando estos son grandes, la contribución de la capacidad calorífica es importante, haciendo preciso tenerla en cuenta en los cálculos tal y como se presenta en las Ecuaciones 2.50 y 2.51.

$$
\begin{aligned}
& \Delta H(T)=\Delta H-\int_{T}^{T_{m}} \Delta C_{p} d T^{\prime} \\
& \Delta S(T)=\Delta S-\int_{T}^{T_{m}} \frac{\Delta C_{p}}{T^{\prime}} d T^{\prime}
\end{aligned}
$$

Las anteriores ecuaciones se simplificaron a otras por las dificultades existentes para estimar la dependencia de la capacidad calorífica con el tiempo. Las simplificaciones han dado lugar a relaciones tan conocidas como la de Gibbs-Thomson, Ecuación 2.52 que establece una dependencia entre el tamaño del cristal y el punto de fusión, cuya validez ha sido demostrada en su aplicación al polipropileno isotáctico y el polietileno (Yamada et al., 2003), siendo un método útil para la obtención del valor de la temperatura de fusión de equilibrio.

En la referencia (Nicodeau, 2005) se explica como, en los polímeros se deben distinguir dos temperaturas de fusión: la temperatura de fusión y la de fusión termodinámica. La temperatura de fusión es la obtenida en el cruce de las energías libres de Gibbs respectivamente de parte amorfa y parte semicristalina. Por otro lado, la temperatura de fusión termodinámica es algo superior a la anterior siendo una garantía de encontrase la menor energía libre en la parte líquida y por tanto garantizando la completa fusión del polímero. Para el PEEK, se ha estimado su valor en $663 \pm 5 K\left(390 \pm 5^{\circ} \mathrm{C}\right)$ y su superación es la única garantía de haber destruido todo el remanente cristalino.

$$
T_{m}=T_{m}^{0}\left[\frac{2 \sigma_{e}}{l \Delta H_{f}^{\infty} T_{m}^{0}}\right]
$$

La Ecuación 2.52 permite obtener el valor de la temperatura de fusión termodinámica $T_{m}^{0}$ y la energía superficial del área doblada $\sigma_{e}$, con la representación de la temperatura de fusión $T_{m}$ frente al espesor de la formación cristalina 1/l. Su obtención se basa en ensayos previos de obtención de la temperatura de fusión y del espesor de la lamela. 
Otra de estas relaciones es la de Hoffman-Weeks (Xu, 1999) y (Muthukumar, 2004) que ha dado lugar al conocido como "gráfico de Hoffman-Weeks", empleado para la obtención de la temperatura de fusión termodinámica con base en la relación lineal entre la temperatura de fusión y de cristalización, Ecuación 2.53 para un factor de engrosamiento $(\beta)$ constante e igual al indicado por la Ecuación 2.54 (Jenkins, 2001).

$$
\begin{gathered}
T_{m}=\frac{1}{\beta} T_{c}+\left(1-\frac{1}{\beta}\right) T_{m}^{0} \\
\beta=\frac{\sigma_{e} l}{2 \sigma l_{e}}
\end{gathered}
$$

\subsubsection{Teoría cinética}

La cristalización, desde un punto de vista cinético puede analizarse desde una perspectiva microscópica y también macroscópica. La perspectiva microscópica analiza aspectos moleculares mientras que la macroscópica solo considera el paso global de líquido a sólido.

En las teorías cinéticas sobre cristalización se consideran dos elementos, por un lado la fuerza generadora y por otro lado la barrera de energía (Zhang et al. 2016). En el caso de la fuerza generadora el efecto se relaciona con la variación de energía libre entre la fase amorfa y la cristalina (fundamentalmente idéntica para todas las teorías cinéticas), por su parte, el término de barrera de energía ha dado lugar a diferentes teorías cinéticas.

\subsubsection{Teoría cinética microscópica}

Una teoría ampliamente aceptada desde el punto de vista microscópico es la de Hoffman y Lauritzen (Cheng y Lotz, 2005). En esta teoría, se asume que la generación del núcleo crítico procede de la creación de una única agrupación obtenida por fluctuación aleatoria, de tamaño superior tamaño al crítico de lamela (ya mencionado con anterioridad en la sección de Cristalización y Termodinámica). Nuevas agrupaciones se van generando sobre la superficie, completándose el proceso de crecimiento. Por tanto, este modelo se basa en la generación del núcleo y su crecimiento lateral. El modelo de cristalización de Hoffman y Lauritzen distingue entre tres regímenes, para su comprensión se hace preciso definir $i$ como la velocidad de deposición neta por unidad de superficie de sustrato y $g$ como la tasa de propagación.

- Regimen I: a alta temperatura, la nucleación es mucho menor que la velocidad de crecimiento lateral, estando gobernada la cristalización por 
la nucleación. La velocidad de crecimiento de cristal se expresa como $G_{I}=b i L$, existe una relación de proporcionalidad entre la velocidad de cristalización $(G)$ y el ancho del cristal $(L)$, siendo $i$ la velocidad de nucleación por unidad de longitud de sustrato. Según esta formulación, los cristales de mayor ancho producirán una velocidad de crecimiento de cristal superior. La ecuación ha sido re-formulada en base a las observaciones experimentales como $G_{I}=b i L_{p}$, siendo $L_{p}$ la longitud de persistencia, pues la experimentación muestra que la velocidad de crecimiento de cristal es independiente de su tamaño, anulando el resultado que proporcionaría la ecuación inicialmente propuesta.

- Regimen II: tiene lugar cuando las velocidades de nucleación y de crecimiento lateral son próximas. Ocurre en un rango moderado de temperaturas. La ecuación representativa de este regimen es $G_{I I}=b \sqrt{i g}$.

- Regimen III: la velocidad de nucleación es mucho mayor que la de crecimiento lateral, correspondiendo con bajas temperaturas de cristalización. En este caso, se generan tantos núcleos que el espacio entre los mismos se vuelve constante y la velocidad de crecimiento lateral pasa a ser irrelevante. En este caso $G_{I I I}=b i L_{p}$.

La teoría de Hoffman y Lauritzen procede de precisar los análisis de Turnbull y Fisher, cuyas ecuaciones expresan las dependencias con la temperatura de la velocidad de nucleación esporádica homogénea, Ecuación 2.55 y de la velocidad de crecimiento, Ecuación 2.56 .

$$
\begin{gathered}
g=g_{0} \exp \left(\frac{-\Delta E_{a c t}}{R T}\right) \exp \left(\frac{-\Delta f G^{*}}{R T}\right) \\
N=N_{0} \exp \left(-\frac{E_{D}}{k T}-\frac{\Delta G^{*}}{k T}\right)
\end{gathered}
$$

La ecuación propuesta por Hoffman y Lauritzen reportada por Chen y Chen 1998) presenta la forma de la Ecuación 2.57

$$
G=G_{0} \exp \left(-\frac{\frac{U^{*}}{R}}{T-T_{\infty}}\right) \exp \left(-\frac{k_{g}}{T \Delta T_{f}}\right)
$$

A pesar de que no sea aplicable para la cristalización de polímeros con cadenas largas como la del PEEK (Varun, 1999), su conocimiento aporta información sobre cómo se desarrolla esta física en los termoplásticos semicristalinos. Estimando unos valores iniciales de $T_{m}^{0}$ y $U^{*}$, se puede efectuar una representación de $\ln G+\frac{U^{*}}{R\left(T_{c}-T_{\infty}\right)}$ frente a $\frac{1}{T_{c} \Delta T f}$, obteniéndose una 
tendencia lineal, los cambios en la linealidad son un reflejo de los cambios en los regímenes de cristalización, asimismo, el cruce con el eje y la pendiente de la curva reportan los valores para $G_{0}$ y $k_{g}$. La aplicación de esta teoría en el documento de (Chen y Chen 1998) ha permitido a los autores determinar dos regímenes en la cristalización del PEEK, regimen II y III. En condiciones isotermas, indican que para las bajas temperaturas, la cristalización se aproxima al regimen III y en altas al regimen II.

Este desarollo, si bien es útil en el análisis, se basa en numerosos parámetros que presentan un sentido físico, de ahí que su aplicación presente una gran complejidad y diversidad de resultados en los diferentes documentos donde se plantea su empleo.

\subsubsection{Teoría cinética macroscópica}

Analizando el proceso de cristalización en el polímero desde un punto de vista macroscópico, es posible diferenciar tres etapas: un periodo de inducción, una cristalización primaria y una cristalización secundaria.

En el periodo de inducción, tienen lugar procesos de pre-cristalización, que conllevan la generación de una organización en paralelo de los segmentos de cadena.

La cristalización primaria se asocia a la formación del núcleo inicial, por su parte, la cristalización secundaria consiste en el crecimiento desde las superficies por la inducción de más y más moléculas del polímero.

La cristalización podrá dividirse en espontánea y heterogénea. Si en la formación del núcleo no participa ningún otro elemento externo sino que la formación sólo se genera por el enfriamiento, hablaríamos de una nucleación espontánea. La nucleación es heterogénea cuando requiere o se inicia desde otro agente precursor. Además existe el efecto de "self-nucleation" que se produce cuando en una etapa de fusión previa no se consigue una buena eliminación del residuo cristalino, quedando el remanente como agente iniciador para la formación de nuevos cristales.

Las metodologías para el análisis de la cristalización del "bulk" de un polímero semicristalino son las basadas en el empleo del método de Kolmogoroff, Evans o Avrami (Wan et al. 2012, Hynstová, 2010). El método de Avrami, uno de los más empleados en la literatura consultada, se asienta sobre la siguiente formulación matemática, Ecuación 2.58 (Jenkins et al. 2003), que estima la evolución del grado de cristalinidad $(\theta)$ del polímero con el tiempo. Donde $k$ y $n$ son los parámetros de Avrami, siendo respectivamente, la cons- 
tante de velocidad y el exponente de Avrami. Esa $k$ no sólo depende de la temperatura sino también del índice $n$, de ahí que normalmente se sustituya por $K^{n}=k$, dando lugar a la formulación de la Ecuación 2.59 tal como aparece en (Supaphol, 2001). La constante de Avrami $k$ es una función de la forma de crecimiento cristalino, de la cantidad y del tipo de nucleación, por su parte, el exponente depende del tipo de nucleación y la geometría de crecimiento, no estando afectado por la cantidad de nucleación.

$$
\begin{gathered}
\theta=1-\exp \left(-k t^{n}\right) \\
\theta=1-\exp \left(-(K t)^{n}\right)
\end{gathered}
$$

La ecuación procede de estudios probabilísticos donde se expresa como aparece en la Ecuación 2.60 , tomando $\bar{F}$ diferentes expresiones en función de cómo se desarrolla el proceso de cristalización.

$$
\theta=1-\exp (-\bar{F})
$$

Con:

- Crecimiento bidimensional, formación de discos con velocidad de nucleación $\dot{N}$. Ecuación 2.61.

$$
\bar{F}=\frac{\pi}{3} G^{2} \dot{N} t^{3}
$$

- Crecimiento tridimensional, formación de esferas con formación en el mismo instante. Ecuación 2.62

$$
\bar{F}=\frac{4 \pi}{3} G^{3} N t^{3}
$$

- Crecimiento tridimensional, formación de esferas con velocidad de nucleación $\dot{N}$. Ecuación 2.63 .

$$
\bar{F}=\frac{\pi}{3} G^{3} \dot{N} t^{4}
$$

Tomando logaritmos a ambos lados de la Ecuación 2.58 es posible representarla como indica la Ecuación 2.64. De esta ecuación es sencillo extraer el índice de Avrami con la representación del término a la izquierda de la ecuación frente a $\log (t)$, siendo la pendiente de la recta obtenida el valor buscado.

$$
\log [-\ln (1-\theta)]=\log (K)+n \log (t)
$$


Por su parte, el valor de $k$ suele extraerse de la Ecuación 2.65 donde $t_{1 / 2}$ se corresponde el tiempo para alcanzar el $50 \%$ de conversión durante el proceso de cristalización en condiciones isotermas.

$$
k=\ln (2) /\left(t_{1 / 2}\right)^{n}
$$

La ecuación de Avrami, a pesar de representar bien el proceso de la cristalización primaria, está afectada por numerosas limitaciones, que hacen que su empleo en los análisis de cristalización de polímeros no sea riguroso.

- Considera que no hay cambios de volumen.

- Asume que la geometría que se construye es constante: disco, barra o esfera.

- Se asume un crecimiento radial constante.

- No tiene en cuenta tiempo de inducción.

- Considera un único tipo de nucleación.

- Modeliza una cristalización completa de la muestra.

- Considera una distribución aleatoria de los núcleos.

- No tiene en cuenta la ausencia de superposición entre frentes de cristalización.

Aunque la ecuación de Avrami sea la más conocida y empleada para el modelizado de la cristalización en isotermo del polímero, otros modelos como el de Tobin con Ecuación 2.66, Malkin con Ecuación 2.67y Urbanovici-Segal con Ecuación 2.68 han sido empleados con diferentes materiales termoplásticos (Supaphol, 2001; Al-Mulla, 2007). Estos métodos han suscitado una cierta controversia por parte de aquellos que consideran que la cristalización no debe fundamentarse en una descripción matemática sino tener en cuenta la física existente tras este proceso (Piorkowska et al. 2006).

$$
\begin{gathered}
\theta(t)=\frac{K_{t} t}{1+\left(K_{t} t\right)^{n_{t}}} \\
\theta(t)=1-\frac{C_{0}+1}{C_{0}+\exp \left(C_{1} t\right)}
\end{gathered}
$$


Con $C_{0}$ el exponente de Malkin, que relaciona la velocidad de crecimiento de cristal $G$ con la velocidad de nucleación primaria $I$. Y $C_{1}$ la constante de velocidad de cristalización.

$$
\theta(t)=1-\left[1+(r-1)\left(K_{u s} t\right)^{n_{u s}}\right]^{\frac{1}{1-r}}
$$

Con $K_{u s}$ y $n_{u s}$ la constante de velocidad de cristalización y el exponente de Urbanovici-Segal respectivamente. Y siendo $r$ un parámetro de valor superior a 0 , que cuando tiende a 1 convierte a esta ecuación en la ecuación de Avrami 2.59).

También (Pérez-Cárdenas et al. 1991) propone una alternativa para compensar la falta de precisión en la aplicación de Avrami a causa de su incapacidad para la representación de la existencia de mecanismos secundarios en la cristalización. Su propuesta, validada en el estudio de la cristalización en polietieno, es capaz de contabilizar la presencia de cristalización secundaria sin que se haya completado el total desarrollo de la primaria. La base del trabajo se fundamenta en el empleo de la Ecuación 2.69 para la cristalización primaria y de la Ecuación 2.70 para la secundaria. La cristalización final se obtiene por medio de una combinación de ambas 2.71 .

$$
\begin{gathered}
\frac{d \chi_{p}(t)}{d t}=k n[1-\chi(t)-(1-\xi)] t^{n-1} H[\xi-\chi(t)] \\
\frac{d \chi_{s}(t)}{d t}=k^{\prime} n^{\prime}[1-\chi(t)] t^{n^{\prime}-1} \\
X(t)=X_{p}(t)+X_{s}(t)
\end{gathered}
$$

Siendo $\chi_{p}$ la contribución de la cristalización primaria, $\chi_{s}$ la contribución de la secundaria, $(1-\xi)$ la parte de cristalización que se desarrolla sólo en la etapa secundaria y $H$ la función de Heaviside que toma los valores indicados por las Ecuaciones 2.72 .

$$
\begin{array}{r}
H[\xi-\chi(t)]=1 \text { si } \chi(t) \leq \xi \\
H[-\chi(t)]=0 \text { si } \chi(t)>\xi
\end{array}
$$

De forma general, la ecuación de Avrami se emplea para los estudios de cristalización en condiciones isotermas por su simplicidad matemática. No obstante, las condiciones de enfriamiento isotermo no son únicas en los procesos industriales, sino que en muchos de ellos aplican condiciones dinámicas 
(Pascon et al. 2013 ), haciendo preciso conocer cómo proceder en la modelización bajo dichas condiciones.

Para modelizar los procesos de cristalización en condiciones dinámicas suele emplearse el método de Ozawa, representado por la Ecuación 2.73 cuya aplicación en el caso del polietilentereftalato ha sido demostrada por (Sajkiewicz et al. 2001) para velocidades bajas y utilizando curvas obtenidas de ensayos de calorimetría diferencial de barrido (DSC).

$$
1-x_{r e l}=\exp \left(\frac{-k(T)}{\left|\frac{d T}{d t}\right|^{n}}\right)
$$

Tomando logaritmos en la ecuación anterior, se puede llegar a una expresión del tipo del de la Ecuación 2.74

$$
\ln \left[-\ln \left(1-x_{r e l}\right)\right]=\ln [-k(T)]+n \ln \left(\frac{1}{\left|\frac{d T}{d t}\right|}\right)
$$

En (Long et al. 1995), se puede encontrar una revisión de modelos aplicados a la cristalización dinámica bajo una condición de velocidad constante de enfriamiento, incluyéndose información sobre los modelos de Ziabicki, Harnisch y Muschik, Ozawa y Nakamura y Tobin (estos dos últimos también utilizados por (Martins y Cruz Pinto, 2000)).

Aplicado a condiciones no-isotermas (Joraid, 2005) contiene unos desarrollos sobre la aplicación del método de Johnson-Mehl-Avrami (JMA) para un proceso de cristalización de un material no polimérico. Este método se sirve de derivar la ecuación de Avrami para obtener la formulación de la Ecuación 2.75 donde $\phi$ es el flujo de calor en cada tiempo $t$ de la exoterma del ensayo entre flujo exotérmico total. En el trabajo también se indica que cuando JMA falla, es posible utilizar la ecuación de Sestak-Berggren, Ecuación 2.76. siendo $m$ un parámetro dependiente de la dimensión del cristal. El método de JMA funciona bien cuando aplica a enfriamientos muy elevados pues se asienta en la hipótesis de una nucleación total en la primera etapa de cristalización y despreciable en las subsiguientes.

$$
\begin{gathered}
\frac{\frac{d \chi(t)}{d t}}{\Delta H}=\phi \\
=n K(1-\chi)[-\ln (1-\chi)]^{1-\frac{1}{n}} \\
\phi=\Delta H K(1-\chi)^{n}(\chi)^{m}
\end{gathered}
$$

(Joraid 2005) incorpora también indicaciones al empleo del método de Matusita, formulado como indica la Ecuación 2.77 con $\alpha$ la velocidad del 
programa dinámico, cuando se requiera estimar el índice de Avrami $n$ en ensayos a velocidad constante.

$$
\ln [-\ln (1-\chi)]=-n \ln \alpha-1,052 \frac{m E_{c}}{R T}+c t e
$$

El trabajo anteriormente incluido contempla también la ejecución de análisis basados en el método de Malkin, utilizado por (Trende et al., 1999), donde se propone la nueva formulación de la Ecuación 2.78 para modelizar el proceso de cristalización en una poliamida.

$$
\frac{d \alpha}{d t}=\frac{d \alpha}{d t}(T, \alpha)=\left(f_{1}(T)+f_{2}(T) \alpha\right)(1-\alpha)
$$

En el anterior modelo, las componentes $f_{1}$ y $f_{2}$ se corresponden respectivamente con un proceso de incremento de cristalización por formación de núcleo y por crecimiento de cristal, adoptando la forma que recoge la Ecuación 2.79 y siendo: $k_{i}$ una constante, $E$ la energía de activación para el trasporte de cristales en la interfaz amorfo-cristal, $R$ la constante de los gases ideales, $\psi_{i}$ una constante asociada con la energía de formación un núcleo de dimensiones críticas y $T_{m}^{0}$ la temperatura de fusión de equilibrio.

$$
f_{i}=k_{i} \exp \left(-\frac{E}{R T}-\frac{\psi_{i} T_{m}^{0}}{T\left(T_{m}^{0}-T\right)}\right)
$$

Recientemente, en los trabajos de (Perejón et al. 2017) aparece una nueva metodología prometedora para los análisis cinéticos de cristalización, fundamentada en el empleo de ensayos tipo "Sample Controlled Thermal Analysis" (SCTA) y corroborada en el trabajo para el gel de circonia. Esta metodología, empleada en los análisis de degradación del material, requiere procesos independientes para ser aplicada y permite conocer de forma rápida el mecanismo de reacción que aplica al proceso bajo análisis. Su fundamento puede enlazarse con el trabajo de (Vyazovkin y Wight, 1998), donde se aporta una visión general del análisis cinético de las reacciones en estado sólido apoyándose en los métodos isoconversionales, descritos con detalle en la sección de este documento destinada al estudio de degradación térmica, el documento proporciona información para el análisis de reacciones como descomposiciones y curados pero no incorpora detalles en lo relativo a la cristalización.

\subsubsection{Transcristalización}

La transcristalización, tal y como se define en (Sajkiewicz et al., 2001) consiste en un proceso de crecimiento cristalino afectado por restricciones 
espaciales. La cristalización interfacial o transcristalización, ofrece una nueva posibilidad para mejorar la interacción entre el polímero y el refuerzo en un material compuesto. El refuerzo actúa como un núcleo que induce el crecimiento del cristal, como ocurre con el PEEK sobre los refuerzos de fibra de carbono (Ning et al. 2012). La presencia del refuerzo obliga a que el crecimiento se produzca en una dirección perpendicular a la superficie de las fibras, generando una formación cristalina en columna (Quan et al. 2005).

En el caso de los materiales compuestos de resina PEEK y refuerzo de fibra de carbono, el crecimiento cristalino del material se produce en dirección perpendicular a la fibra, hasta que los cristales formados chocan con aquéllos generados en el "bulk", tal y como describe (Quan et al. 2005), donde se hace alusión a diversas causas en la creación de capa transcristalina: topografía de la fibra (rugosidad superficial, tratamientos), diferencia de coeficientes térmicos fibra-resina, conductividad térmica de la fibra, composición química de la superficie de la fibra o energía superficial de la fibra. En el estudio referenciado se analiza la transcristalinidad en el PEEK, indicándose su formación así como su disminución con el incremento en la temperatura de cristalización.

Esta formación cristalina tiene un impacto fundamental sobre el comportamiento mecánico del material. En el caso de las propiedades longitudinales se reporta una mejora de las mismas con la interacción de la capa transcristalina, pues la matriz en dirección de la fibra posee mayor resistencia y rigidez y se reduce su expansión térmica, que impacta directamente sobre los esfuerzos residuales. En sentido transversal se reporta un ejemplo para la poliamida reforzada con fibra de vidrio, donde existe un máximo en la resistencia a tracción y en el módulo para casos donde el enfriamiento lento conduce a mejores capas transcristalinas. Más información al respecto del efecto de esta capa sobre las propiedades mecánicas, se incluye en la sección destinada a la relación propiedades mecánicas frente a cristalización.

\subsubsection{Estudios de cristalización en el PEEK}

Son numerosos los estudios bibliográficos donde se analiza el fenómeno de cristalización en el polímero PEEK y en los materiales compuestos de matriz termoplástica PEEK, de forma general aplicados a diferentes procesos de fabricación como en (Pascon et al., 2013) y al proceso particular del encintado automático y la consolidación in-situ (Tierney y Gillespie Jr. 2004: Guan y Pitchumani, 2004).

En (Guan y Pitchumani, 2004), se hace alusión a la posibilidad de obtener valores de cristalinidad idénticos variando parámetros del proceso de encintado, siendo la morfología de cristal el elemento afectado por las di- 


\begin{tabular}{|c|c|c|c|}
\hline Ref. & $\mathrm{a}(\AA)$ & $\mathrm{b}(\AA)$ & $c(\AA)$ \\
\hline (Kumar et al. 1986$)$ & $7,75-7,78$ & $5,89-5,92$ & $9,88-10,06$ \\
\hline (King et al. 1989$)$ & 7,83 & 5,94 & 9,86 \\
\hline (Blundell y Newton 1991) & $7,76 \pm 0,15$ & $5,89 \pm 0,1$ & $9,95 \pm 0,1$ \\
\hline (Nicodeau, 2005) & $7,73-7,88$ & $5,84-5,94$ & $9,86-10,06$ \\
\hline
\end{tabular}

Tabla 2.9: Parámetros de la celdilla unidad

ferentes modificaciones. Dándose esta circunstancia, la cristalización en un polímero como el PEEK debería analizarse atendiendo a: su fundamento físico e interrelación con la morfología del cristal, el mecanismo cinético y su modelización y la correlación entre la cristalización y las propiedades mecánicas finales.

La cinética de cristalización, entendida como una representación matemática con sentido físico, debería poder aportar información sobre cómo evoluciona la cristalización desde un punto de vista porcentual y también orientativo de la morfología desarrollada.

\subsubsection{Análisis físico de la cristalización}

El polímero PEEK presenta una estructura cristalina tipo ortorrómbica, con dimensiones fundamentales que varían ligeramente según la referencia consultada tal y como aparecen recogidas en la Tabla 2.9.

En esa estructura ortorrómbica, las cadenas se alinean en la dirección del eje "c" de la celdilla unidad (King et al., 1989, Lamèthe, 2004; Jin et al. 2014). En una escala dimensional superior, la dirección longitudinal de crecimiento del cristal se corresponde con el eje cristalográfico "b", siendo "c" la dirección perpendicular al crecimiento de la lamela (Karacan, 2005, Nicodeau, 2005).

Además, Kumar et al., 1986, Tan et al., 1999 Jin et al. 2014). constatan la formación esferulitas en la cristalización del PEEK. Su mejor desarrollo se ha observado en condiciones de enfriamiento tales que, la fusión posterior (analizada por calorimetría diferencial), manifiesta un doble pico. Dicha formación se asocia a una nucleación más lenta que permite el crecimiento de esferulitas de mayor tamaño, asociadas con enfriamientos lentos y cristalizaciones a alta temperatura.

En línea con la existencia de dobles picos de fusión en los gráficos de 


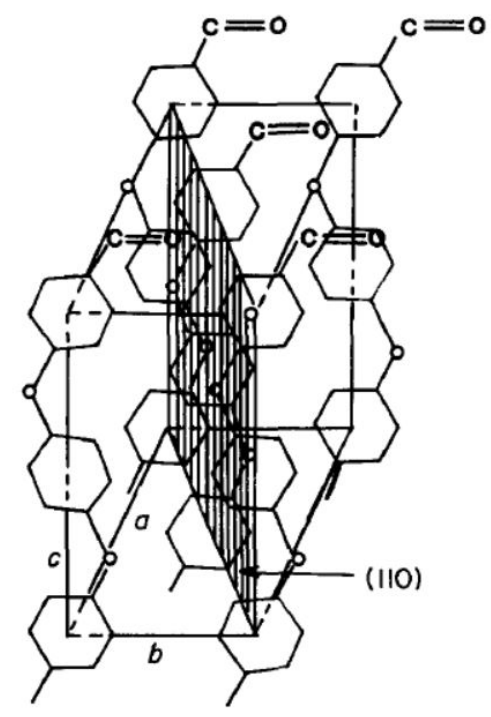

Figura 2.6: Celdilla unidad del PEEK (Kumar et al. 1986)

calorimetría diferencial, es posible encontrar en la literatura una serie extensa de trabajos donde diferentes grupos de investigación han tratado de aportar una justificación a los mismos. Estos estudios siguen dos principales corrientes de pensamiento, por un lado los que explican el mecanismo como la existencia de diferentes morfologías de cristal formado en el tratamiento previo o aquellos que lo justifican como efectos de fusión-recristalización activados por la técnica de ensayo empleada (Blundell, 1987, Bassett et al. 1988, Marand y Prasad, 1992, Vaughan y Stevens, 1995, Jenkins et al., 2003. Wei et al. 2003; Chen et al., 2013; Furushima et al., 2017, 2016; Jin et al. 2014 , Tardif et al., 2014).

Atendiendo a la explicación basada en las diferentes morfologías de cristal, la primera de las formaciones proporcionaría el mayor punto de fusión en el material y se correspondería con la generación de esferulitas, mientras que la segunda se derivaría de la generación de estructuras lamelares en las regiones intersticiales constituyentes de la esferulita principal.

La cristalización en este polímero ha sido analizada con diferentes técnicas experimentales, en (Jenkins et al. 2003) analizan su desarrollo desde el estado fundido con el empleo de las técnicas Wide Angle X-Ray Scattering (WAXS) y Small Angle X-Ray Scattering (SAXS). Concluyen que, a bajas temperaturas, el proceso de cristalización se encuentra fundamentalmente gobernado por la nucleación y a mayores temperaturas es la difusión de cadenas al frente de crecimiento del cristal el mecanismo prioritario. 
En (Hsiao et al. 1993), se reporta nuevamente la formación de esferulitas en el PEEK, que aparecerían en las formaciones cristalinas tanto en procesos de enfriamiento como en calentamiento. El estudio anteriormente citado, establece además una temperatura límite, $573 \mathrm{~K}$, que determina dos posibles vías de desarrollo de cristalinidad en el polímero. Cuando el polímero cristaliza por debajo de $573 K$, las esferulitas están formadas por lamelas estrechas, por su parte, cuando la cristalización tiene lugar por encima de $573 K$, la esferulita se forma por lamelas ramificadas grandes que se apilan formando paquetes en adición a las lamelas estrechas anteriormente mencionadas. Dicho comportamiento, observado con técnicas como rayos-X o microscopía electrónica de transmisión (TEM). El efecto de una posible generación de estructuras cristalinas en las regiones internas de las esferulitas, impactaría directamente en la distancia interlamelar ("L"), reduciéndola, sirviendo como sistema para su detección.

En (Di Lorenzo y Silvestre, 1999) se propone un nuevo límite térmico, indicándose que es a $569 \mathrm{~K}$ cuando el PEEK manifiesta un cambio en las curvas de la teoría de Hoffman y Lauritzen, asociado con una transición de regimen II a III en el desarrollo cristalino. En línea con la anterior aseveración, (Toft, 2012 indica como, al aproximarse a la transición vítrea, el sistema tiene mucha menos energía y el movimiento molecular de las cadenas se ve reducido. En ese estado viscoso, la barrera energética oponiéndose a la formación de un núcleo estable es pequeña, pero debido a la baja movilidad molecular para el transporte de las cadenas, el crecimiento del frente cristalino esta impedido, generándose una microestructura con un gran número de cristales pero de pequeño tamaño.

En el estudio de (Di Lorenzo et al. 2018) se indica también, la posible existencia de una porción de material conocida como Fracción Amorfa Rígida (RAF), que corresponde a la parte amorfa que queda entre las esferulitas tras el choque entre ellas y donde se insertarán nuevas lamelas, también referenciada por Toft en (Toft, 2012). Esa parte amorfa, tal como indica el trabajo de la referencia, presenta una temperatura de transición vítrea superior a la del resto del "bulk" amorfo.

El comportamiento a cristalización de un polímero como el PEEK, requiere modelizarse desde una perspectiva de doble cristalización como resultado de las evidencias mostradas con anterioridad de los dos procesos existentes. Entre las referencias que tienen en cuenta estos efectos se encuentran (Tardif et al. 2014) que efectúa una modelización apoyándose en el trabajo previo de (Hillier, 1965). 
En la modelización debería tenerse en cuenta también que, durante el proceso de calentamiento del material, podría no superarse la temperatura de fusión de equilibrio termodinámico. (Nicodeau, 2005) indica que, manteniendo una temperatura por debajo $658 K$ (considerada la temperatura de fusión de equilibrio para el PEEK), si aumenta la temperatura de fusión (siempre bajo dicho límite de equilibrio), decrece la cristalización. La explicación del efecto anterior radica en que existe una dependencia basada en el \% de núcleos eliminados durante el proceso de fusión, desarrollándose la nucleación sobre núcleo pre-existente o self-seeding y por tanto variándose el mecanismo de cristalización bajo estas condiciones.

El análisis global de la cristalización en el PEEK, requiere conocer también cómo se desarrolla su cristalización en frío, es decir, qué capacidad de cristalización existe cuando el material se calienta por encima de su temperatura de transición vítrea pero por debajo de la temperatura de fusión, partiendo de un material en un estado casi amorfo o parcialmente cristalizado. Nicodeau, 2005) manifiesta un $n=1,5$ como índice de Avrami en la aplicación de modelos cinéticos a las curvas de cristalización del APC2 durante el calentamiento, valor que contrasta con el índice $n=3,5$ obtenido en la aplicación a las curvas de enfriamiento, pero siendo un valor próximo al reportado por (Tan et al. 1999), que concluye la existencia de un mecanismo de cristalización diferente del polímero en su desarrollo en frío o desde fundido.

Los estudios de (Martineau et al. 2019), analizan la autohesión/difusión de cadenas del PEEK cuando se parte de material amorfo y se calienta sobre la transición vítrea, sus análisis llevan a conclusiones tales como: a bajas temperaturas sobre la $T_{g}$ la difusión de cadenas es muy lenta y se ve obstaculizada por la formación de cristales en las entrecaras; por otro lado, cuando la temperatura es bastante superior a la transición vítrea, la difusión predomina a la cristalización y se mejora la resistencia de adhesión. Los autores hacen la hipótesis de que los incrementos en porcentajes de cristalización en las zonas de unión se deben a que la entrecara actúa como un elemento nucleante, no obstante, si se produce más nucleación, esos cristales también podrían ser un freno a los movimientos de cadenas en las entrecaras. En contraposición al anterior efecto que perjudicaría la unión, otra hipótesis que lanza el estudio es que las cadenas más cortas tienen una cinética mucho más rápida, moviéndose a la entrecara y generando ese incremento en la cristalización.

En (Ivanov et al., 1999, 2000) se incluye también la posible detección de diferentes mecanismos de cristalización mediante los análisis del comportamiento del material en las curvas dinamo-mecánicas (DMA). Indica la 
posibilidad de detectar diferencias en las relajaciones de las zonas amorfas con ensayos a diferentes temperaturas de calentamiento en muestras cristalizadas en frío bajo la misma isoterma de calentamiento.

Hasta ahora, toda la revisión bibliográfica ejecutada se asentaba en el comportamiento del polímero PEEK, sin embargo, reforzar el material juega un papel importante en el desarrollo de la cristalización, desde un punto de vista cinético (acelerándola o retardándola) y desde un punto de vista morfológico. (Blundell et al. 1989) analiza el desarrollo de la cristalización en un material compuesto fibra de carbono/PEEK mediante microscopía electrónica de barrido (SEM) tras la aplicación de un "etching" permangánico para la eliminación de la parte amorfa, que permite constatar que, en presencia de fibra de carbono la nucleación puede desarrollarse sobre el bulk o sobre la superficie del refuerzo. Cuando la velocidad de enfriamiento es lenta o la temperatura de cristalización isoterma es alta, se favorece el desarrollo de cristales sobre la fibra; por otro lado, las cristalizaciones en frío partiendo de una muestra amorfa, generan una elevada nucleación que conduce a numerosas esferulitas de pequeño tamaño, tal y como se observa en la Figura 2.7 . Asimismo, este estudio contiene también observaciones sobre muestras donde no se efectuó una fusión completa del cristal existente, haciendo posible detectar una morfología completamente diferente asociada a los efectos de "self-seeding" o nucleación sobre núcleos pre-existentes.

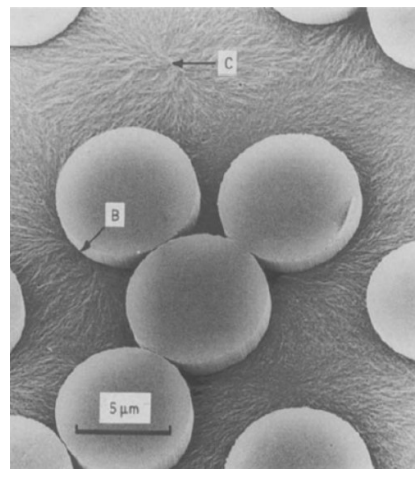

(a)

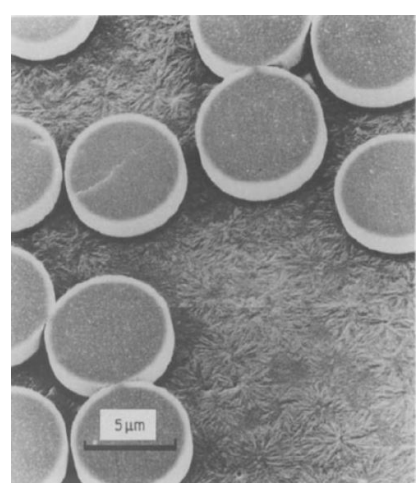

(b)

Figura 2.7: SEM sobre muestras de etching de PEEK/FC a) Enfriada lentamente desde fundido y b) Recocida desde un estado amorfo por debajo de la fusión y sobre la transición vítrea (Blundell et al., 1989) 


\subsubsection{Análisis cinético de la cristalización y aplicación a la con- solidación in-situ}

Los estudios cinéticos sobre el PEEK suelen aparecer asociados al tratamiento matemático sobre curvas obtenidas de ensayos de calorimetría diferencial de barrido ejecutados con diferentes perfiles de enfriamiento (isotermos y dinámicos, desde el fundido y desde el estado amorfo).

En los estudios ejecutados en condiciones isotermas sobre PEEK Cebe y Hong, 1986, Bas, 1995: Tan et al. 1999), se recurre a la aplicación de la ecuación de Avrami para modelizar la cristalización, en ellos es posible observar la obtención de valores para los parámetros de Avrami que, si bien se encuentran próximos entre sí, no son idénticos. (Cebe y Hong, 1986) reportan un índice de $n=3$ en la descripción de la primera fase de cristalización del material, atribuyéndose un proceso de cristalización simultánea y heterogénea en forma de esferulitas. Por su parte, en (Bas, 1995) los valores de " $n$ " oscilan entre 2,3 y 2,7 en fusión y desde 2,7 y 3,1 en cristalización desde amorfo.

La aplicación del método matemático de Avrami (utilizando la representación lineal tomando logaritmos en la ecuación) arroja también la evidencia de una segunda tendencia lineal en la curva con una pendiente distinta, relacionada con el segundo estadio de la cristalización. En las cristalizaciones isotermas desarrolladas a más temperatura, los cambios de tendencia de la curva de un tipo a otro de cristalización son más marcados y ocurren a conversiones cristalinas inferiores, tal y como reportan (Cebe y Hong, 1986). En (Tan et al., 1999) se presenta un índice de Avrami de 1 a 1,4 para el crecimiento en forma de lamelas entre las que ya constituyen la formación principal. Esos cristales formados, conocidos como metaestables (generados a una temperatura que les deja en un estado termodinámico no estable), han sido obtenidos ejecutando recocidos sobre muestras inicialmente amorfas que posteriormente habían sido cristalizadas en frío con isotermas de $493 K$ y $24 h$.

La inclusión de refuerzos en el polímero, cambia sustancialmente su cinética de cristalización en condiciones isotermas, tal y como se ilustra en (Wang et al. 2013; Kuo et al. 2010). Los dopantes o refuerzos insertados pueden tener un comportamiento acelerador de la cristalización al actuar como puntos de nucleación o pueden actuar como barreras a la cristalización, limitando el movimiento de las cadenas en el proceso de ordenamiento. En (Wang et al. 2013) se emplea nuevamente Avrami para la descripción de la primera etapa de cristalización en el polímero y se incluyen además unas ecuaciones para el análisis de la cristalización isoterma que permiten extraer los tiempos para la obtención del $50 \%$ de la cristalinidad total (la ya reportada Ecuación 2.65 y el tiempo $t_{i}$ para obtener la máxima velocidad de flujo de calor como función de los parámetros de Avrami, Ecuacion 2.80. 


$$
t_{i}=\left((n-1) n^{-1} k^{-1}\right)^{1 / n}
$$

A causa de la imposibilidad para obtener buenos resultados en la aplicación de Ozawa para el PEEK en su cristalización dinámica, tal y como queda de manifiesto en los trabajos de (Cebe, 1988b), (Cebe y Hong, 1986), (Sattari et al. 2014), (Di Lorenzo y Silvestre, 1999) y (Bas, 1995), otros modelos han sido propuestos para el estudio de la cristalización en condiciones dinámicas. En todos ellos, se asocia la causa fundamental del fallo del método de Ozawa a que no tiene en cuenta el efecto de la cristalización secundaria, que puede llegar a suponer entre un $45-70 \%$ al proceso global de cristalización en el polímero.

Entre los modelos alternativos para simular la cristalización dinámica en el PEEK se encuentra el propuesto por (Nakamura et al. 1972, Sajkiewicz et al. 2001), que se caracteriza por ajustarse a la descripción del proceso tanto en condiciones dinámicas como isotermas de cristalización bajo el supuesto de una misma ecuación matemática, Ecuación 2.81. De hecho, es posible extraer relaciones entre los parámetros de las ecuaciones de Avrami y Ozawa, empleando la ecuación de Nakamura. La relación entre la "k" que aparece en el modelo de Avrami y la "K" del modelo de Nakamura se recoge en la Ecuación 2.82,

$$
\begin{gathered}
X(t)=1-\exp \left[-\left(\int_{0}^{t} K(T(\tau)) d \tau\right)^{n}\right] \\
K(T)=k(T)^{\frac{1}{n}}
\end{gathered}
$$

(Wang et al. 2013) analiza la cristalización en condiciones no isotermas de un compuesto de PEEK y oxido de gadolinio mediante el empleo del método de Avrami modificado por Jeziorny y con una propuesta de combinación Avrami-Ozawa.

En la modificación de Jeziorny, representada por la Ecuación 2.83, se establece una nueva definición de la constante de velocidad de Avrami, representada ahora por $Z_{t}$, donde su obtención requiere una combinación entre esa variable definida por Avrami $\left(k=Z_{c}\right)$ y la velocidad o programa dinámico utilizado para el ensayo $\Phi$, quedando finalmente la Ecuación 2.84.

$$
\begin{gathered}
\log Z_{c}=\log Z_{t} \Phi^{-1} \\
\log \left(-\ln \left(1-X_{c}(t)\right)\right)=n \log (t)+\Phi \log \left(Z_{c}\right)
\end{gathered}
$$


La ecuación combinada de Avrami-Ozawa (Ecuación 2.85 considera $K(T)$ como el parámetro de velocidad de cristalización y $\alpha$ la relación $\left(n_{\text {Avrami }} / n_{O z a w a}\right)$ entre los exponentes de Avrami y Ozawa, siendo $\Phi$ y $F(T)$ representados por las Ecuaciones 2.86 y 2.87. Utilizando la Ecuación 2.86 y representando $\log \Phi$ frente al logt para valores de conversión constante, es posible extraer $F(T)$ y $\alpha$ de la intersección con el eje y la pendiente de las curvas obtenidas. Esos valores, con el conocimiento de los datos tras la aplicación de Avrami, permiten obtener $m$ y $K(T)$, componentes del modelo de Ozawa.

Este modelo también es empleado por (Kuo et al. 2006, Sattari et al. 2014), reportando buenos resultados en su aplicación a PEEK y PEEK dopado.

$$
\begin{gathered}
\log \left(Z_{t}\right)+n \log (t)=\log (K(T))-m \log (\Phi) \\
\log \Phi=\log F(T)-\alpha \log t \\
F(T)=\left[\frac{K(T)}{Z_{t}}\right]^{1 / m}
\end{gathered}
$$

La falta de linearidad mostrada tras la aplicación de Ozawa, llevó a (Cebe y Hong, 1986) a presentar una alternativa de estudio. Su propuesta se basaba en aplicar Avrami a las curvas de los ensayos dinámicos considerando sólo los porcentajes más bajos de conversión, obteniéndose de este modo una tendencia lineal para la evaluación de $k$ y de $n$. A pesar de alcanzarse la linealidad, los valores obtenidos para $n$ resultan extremadamente elevados contrastando con los previamente obtenidos en condiciones isotermas.

Dado que el mecanismo de cristalización del PEEK parece estar gobernado por dos mecanismos fundamentales, una metodología para representarlo, tanto en el caso isotermo como dinámico, es la mostrada en Velisaris y Seferis, 1986), mediante el empleo del acoplamiento de dos ecuaciones de Avrami con sus respectivos factores de peso. Este sistema fue posteriormente reformulado por (Cebe, 1988a) y aparecen alusiones a él en los trabajos de (Baran et al. 2017).

Este modelo se basa en el resultado experimental de obtención de dos claras tendencias lineales en la aplicación de Avrami a los casos de cristalización isoterma del PEEK; tal y como se efectúa en los sistemas compuestos por dos fases, se considera la posibilidad de describir la cristalización empleando una combinación de dos modelos de Avrami ya sea en serie o en paralelo, Ecuación 2.88 . 


$$
\begin{array}{r}
\frac{X_{v c \infty}}{X_{v c}}=\frac{w_{1}}{F_{v c 1}}+\frac{w_{2}}{F_{v c 2}} \\
\frac{X_{v c}}{X_{v c \infty}}=w_{1} F_{v c 1}+w_{2} F_{v c 2}
\end{array}
$$

Siendo $w_{1}$ y $w_{2}$ los factores de peso asociados a cada mecanismo de cristalización y $F_{v c 1}$ y $F_{v c 2}$ las fracciones en volumen cristalino normalizadas. Los valores de $w_{1}$ y $w_{2}$ son variables con la temperatura, la velocidad de enfriamiento y en caso de los materiales compuestos también presentan una dependencia con el \% de fibra (Velisaris, 1988). Expresando la ecuación en forma extendida con una combinación de Avrami en paralelo se obtiene la expresión de la Ecuación 2.89

$$
\frac{X_{v c}}{X_{v c \infty}}=w_{1}\left[1-\exp \left[-k_{1}(T)\right] t^{n_{1}}\right]+w_{2}\left[1-\exp \left[-k_{2}(T)\right] t^{n_{2}}\right]
$$

En el caso de condiciones dinámicas, debe utilizarse la representación de la Ecuación 2.90 para $F_{v c i}$ (Velisaris, 1988).

$F_{v c(i)}=1-\exp \left[-C_{1(i)} \int_{0}^{t} T \exp \left[-\left(\frac{C_{2(i)}}{T-T_{g}+51,6}+\frac{C_{3(i)}}{T\left(T_{m(i)}-T\right)^{2}}\right)\right] n_{i} t^{\left(n_{i}-1\right)} d t\right]$

Con, $k_{1}$ y $k_{2}$ y $n_{1}$ y $n_{2}$, los parámetros de velocidad e índice de Avrami respectivamente para cada uno de los dos procesos. Por su parte, el significado de las variables: $C_{1}, C_{2}$ y $C_{3}$, es:

- $C_{1}=$ Coeficiente constante del factor pre-exponencial dependiente de la temperatura $\left[s^{-n}\right]$

- $C_{2}=$ Parámetro empírico asociado con la dependencia con la temperatura de la viscosidad $[K]$

- $C_{3}=$ Parámetro asociado con la entalpía libre de nucleación $\left[K^{3}\right]$

(Cebe, 1988a) demuestra como los picos de fusión de mayor temperatura se asocian con la cristalización de mayor índice de Avrami y a diferencia de (Velisaris, 1988), plantea su modelo considerando la temperatura de fusión del supuesto cristal infinito $T_{m}^{0}$, con la consiguiente variación de la ecuación 
representativa de este modelo, Ecuación 2.91

$F_{v c(i)}=1-\exp \left[-C_{1(i)} \int_{0}^{t} \exp \left[-\left(\frac{C_{2(i)}}{T-T_{g}+51,6}+\frac{2 T C_{3(i)}}{T\left(T_{m}^{0}-T\right)\left(T_{m}^{0}+T\right)}\right)\right] n_{i} t^{\left(n_{i}-1\right)} d t\right]$

Tal y como se muestra en el estudio, el PEEK comienza cristalizando en formaciones esferulíticas aisladas entre sí. Cuando las esferulitas comienzan a chocar entre sí, su velocidad de crecimiento con el tiempo se frena y se inicia el desarrollo de cristales según un proceso secundario. A los primeros cristales formados se les conoce como formación lamelar dominante y los segundos, formación subsidiaria.

En los trabajos de (Tierney y Gillespie Jr. 2004) se propone un modelo con fundamento nuevamente en el doble Avrami, Ecuación 2.92, con la misma formulación matemática que la propuesta por (Velisaris, 1988) pero con una variación en los valores numéricos, considerando la misma temperatura de fusión en los dos procesos e igual a $611 K$, temperatura de pico de fusión.

En la ecuación, $w_{1}$ y $w_{2}$, son los factores de peso correspondientes a los dos mecanismos y cumplen la relación de la Ecuación 2.93. $F_{v} c(i)$ representa las fracciones en volumen cristalino normalizadas, formuladas como indica la Ecuación 2.94 .

$$
\begin{gathered}
X_{v c}=X_{v c \infty}\left(w_{1} F_{v c 1}+w_{2} F_{v c 2}\right) \\
1=w_{1}+w_{2} \\
F_{v c(i)}=1-\exp \left[-C_{1(i)} \int_{0}^{t} T \exp \left[-\left(\frac{C_{2(i)}}{T-T_{g}+51,6}\right)+\frac{C_{3(i)}}{T\left(T_{m}-T\right)^{2}}\right] n_{i} t^{\left(n_{i}-1\right)} d t\right]
\end{gathered}
$$

Este estudio, considera un valor de $w_{1}=0,61$ pues es el obtenido para análisis en APC2/AS4 en condiciones no isotermas con perfiles de enfriamiento superiores a $110 \mathrm{~K} / \mathrm{s}$.

En el mismo año de publicación del trabajo de Tierney y Gillespie Jr., (Guan y Pitchumani, 2004) publicaron sus trabajos de análisis de la cristalización esferulítica en el proceso de laminación automática, cuyo fundamento matemático era nuevamente la ecuación propuesta por (Velisaris, 1988). La 
particularidad de este trabajo es el análisis ejecutado sobre las diferentes variables del proceso relacionadas con la fuente de calentamiento (antorcha de gas caliente), como son el ángulo de inclinación o el flujo y el análisis de su impacto sobre la transferencia térmica y a su vez sobre la cristalización. Asimismo, en el trabajo reconocen que la cristalinidad final de una capa es el resultado de la historia térmica completa de múltiples pasadas en el laminado.

En el trabajo de (Quinlan, 2011) se ejecuta una revisión de los modelos de Velisaris y Seferis, Cebe y Hong, Tierney y Gillespie y Nakamura para su aplicación a la laminación automática y consolidación in-situ. La autora concluye que, con los parámetros establecidos por estos autores no es posible ejecutar un buen ajuste para la cinética de cristalización del material con los bruscos perfiles de enfriamiento de este proceso de fabricación. Propone valores nuevos para los parámetros de ajuste de las ecuaciones, sin embargo, no son parámetros fijos sino que varían según el perfil de enfriamiento por lo que no serían aplicables en la obtención de un modelo general del proceso de cristalización.

Nuevos desarrollos basados en el doble mecanismo de Avrami han sido propuestos más recientemente por (Bessard et al., 2011), cuyo modelo se basa en la nueva Ecuación 2.95. En su trabajo presentan un modelo donde, $k_{i}$ y $w_{i}$ son dependientes de la temperatura, obteniéndose valores constantes para $n_{i}$. No obstante, su estudio no aparece validado en temperaturas más extremas, donde las tendencias de cristalización pueden cambiar.

$$
\frac{d \alpha}{d t}=\dot{\alpha}=\left(\exp \left((-K t)^{n}\right)\right) n K^{n} t^{n-1}
$$

Para el caso del material compuesto (APC2/Fibra de carbono), los autores reconocen la importancia de la nucleación heterogénea, actuando la fibra como un nucleante; en estas circunstancias la constante de velocidad de Avrami, durante el programa de enfriamiento dinámico está determinada principalmente por la contribución del término de crecimiento lineal y no por la velocidad de nucleación. Además, la presencia de la fibra de carbono provoca que el crecimiento del cristal ocurra simultáneamente en tridimensional y en transcristalización sobre la fibra.

\subsubsection{Cristalización y propiedades mecánicas}

A pesar de que existen numerosos efectos condicionando el comportamiento mecánico final de las piezas fabricadas con materiales compuestos de 
matriz termoplástica (porosidad, tensiones residuales, etc.), la cristalización es uno de los factores más resaltados en las referencias consultadas como elemento clave en el desarrollo de unas propiedades mecánicas u otras (Lee y Weitsman, 1991, Yu et al., 2012, Regis et al., 2017, Yang et al., 2017; Tregub et al. 1993). Su obtención está ligada a los perfiles térmicos a los que se ve sometida la pieza. Las referencias analizan el impacto de la cristalización atendiendo fundamentalmente al impacto del porcentaje de cristalinidad, al impacto de la morfología del cristal y a la propiedad mecánica bajo análisis.

El impacto de la cristalinidad del polímero sobre las propiedades mecánicas requiere ser presentado de modo independiente para el polímero neto y con refuerzo. En el material compuesto, se debe considerar, la contribución de la fibra como agente nucleante y la repercusión de la capa transcristalina en el resultado bajo diferentes solicitaciones mecánicas.

\subsubsection{Cristalización y propiedades mecánicas en PEEK}

En (Cebe et al. 1987) analizan el comportamiento mecánico afectado por la cristalinidad para el polímero PEEK neto, sirviéndose de ensayos de tracción sobre muestras que han sido respectivamente: enfriadas bruscamente para obtención de estado amorfo, cristalizadas desde el estado amorfo y cristalizadas a rápida y lenta velocidad desde el fundido. Además, los ensayos se ejecutan a tres temperaturas diferentes bajo la transición vítrea. Las muestras cristalizadas en las condiciones de enfriamiento lento desde el fundido, presentan en todos los casos de ensayo una zona de comportamiento plástico con los menores valores de deformación a rotura y de resistencia a rotura final. Resulta interesante extraer del estudio las notables diferencias existentes entre el enfriamiento rápido y la cristalización en frío, a pesar de que no exista en el estudio un valor específico medido sobre la velocidad a la que fue ejecutado este enfriamiento rápido.

\subsubsection{Cristalización y propiedades mecánicas en material com- puesto}

En el trabajo de (Talbott et al. 1987), se concluye que el porcentaje de cristalinidad afecta a las propiedades mecánicas del material, pero no se hace alusión su morfología.

(Lee et al. 2017) analiza materiales compuestos de fibra de vidrio y polipropileno bajo diferentes perfiles de enfriamiento, extrayendo conclusiones 
frente a diferentes estados de solicitación mecánica. En tracción unidireccional, el mayor valor se obtiene para el caso de menor velocidad de enfriamiento por la buena adhesión conseguida entre resina y fibra, en cambio, en fractura (modo I, modo II y mixto), en cortadura interlaminar (ILSS) e impacto, el comportamiento mejora a mayor velocidad de enfriamiento. No obstante, conviene recalcar aquí que los ensayos han sido ejecutados con programas de enfriamiento a 1,10 y $20 \mathrm{~K} / \mathrm{min}$, rangos entre sí muy próximos y poco representativos de los grandes valores observados en la laminación automática y consolidación in-situ.

Una de las causas que se aluden como más probables a las variaciones en las propiedades mecánicas es el correcto o incorrecto desarrollo de la capa transcristalina durante el enfriamiento del material, tal y como aparece en (Yan et al. 2014). El trabajo extrae diferentes conclusiones sobre los efectos de aplicar diferentes condiciones de "recocido" sobre muestras con poliamida 6 y poliamida 6 con refuerzos continuos de fibra de carbono. Entre sus conclusiones, aluden a la variación causada en la conductividad térmica (incrementada) con la cristalización pues es una propiedad que depende de la vibración de la estructura del enrejado cristalino, asimismo uno de los métodos más innovadores que emplean para detectar las diferencias en cristalinidad tras los diferentes recocidos es un análisis térmico local mediante imágenes tomadas con un microscopio de fuerzas atómicas.

(Gao y Kim, 1999) y (Gao y Kim, 2000) muestran una correlación entre cristalinidad y propiedades como resistencia a cortadura interfacial (IFSS) o cortadura en probeta corta (SBS). Según sus análisis, existe una diferencia marcada entre probetas que han experimentado enfriamientos a $1 \mathrm{~K} / \mathrm{min}$ y sobre las que lo han hecho a $600 \mathrm{~K} / \mathrm{min}$, reflejando un decremento tanto en propiedades mecánicas como en el valor de cristalinidad medido por calorimetría. Su estudio de las entrecaras de fractura, manifiesta además un comportamiento tipo cohesivo cuando el enfriamiento ha sido lento y un comportamiento combinado cohesivo-adhesivo (matriz-fibra) cuando el enfriamiento ha sido brusco. Estos mismos autores ampliaron sus investigaciones al análisis del efecto de la cristalinidad sobre la tenacidad a fractura interlaminar en laminados con PEEK y fibra de carbono (Gao y Kim, 2001a). En modo I sus conclusiones son que la propagación de grieta es más estable a medida que crece la velocidad de enfriamiento, como causa del comportamiento plástico de la resina en la entrecara de despegado. Asimismo, para mayor velocidad de enfriamiento también es menor la longitud de grieta para un desplazamiento de apertura dado. En ambos modos de fallo, I y II, la energía decae con el incremento de la cristalinidad, lo cual equivale a incrementos en la energía con la subida de la velocidad de enfriamiento, no obstante, esos incrementos no son tan elevados como los que experimenta 
la resina neta sometida a esos perfiles de enfriamiento. Las posibles causas a las diferencias en tenacidad con la resina se asocian al comportamiento no plástico de la fibra y también a la débil interfaz fibra-resina generada en los enfriamientos rápidos. Una tercera extensión del trabajo de (Gao y Kim. 2001b), analiza la relación entre cristalinidad y comportamiento a daño por impacto en muestras cristalizadas en el rango de 1 a $80 \mathrm{~K} / \mathrm{min}$. Según los ensayos elaborados, los laminados con menor porcentaje cristalino (mayor velocidad de enfriamiento y menor tamaño de esferulita) se caracterizan por ser más dúctiles y tener mayor capacidad para resistir el comienzo de la delaminación y absorber la energía del impacto.

Respecto al comportamiento a tracción y flexión y el efecto de la cristalinidad sobre estas propiedades, (Gao y Kim 2002) publicaron un estudio donde se manifiestan los resultados de análisis a tracción y flexión, transversal y longitudinal a la fibra. Salvando la tracción longitudinal, influenciada por la fibra, el resto de los ensayos muestran una tendencia decreciente con la disminución de la cristalinidad, estando mucho más afectada la propiedad a flexión. Las muestras procedentes de enfriamientos rápidos, contienen una matriz rica en fase amorfa, incapaz de soportar la carga de flexión, particularmente la componente a compresión. Además, los autores reportan un valor límite en la velocidad de enfriamiento de $600 \mathrm{~K} / \mathrm{min}$, por encima de la cual no existen variaciones en los resultados.

(El Kadi y Denault, 2001) propone analizar la variación de propiedades mecánicas, tanto estáticas como a fatiga, en laminados donde se ha constatado la presencia y ausencia de formaciones esferulíticas. En su trabajo hace alusión a otras referencias bibliográficas donde se indica que la variación en propiedades mecánicas con el enfriamiento rápido está más asociada al incremento en tensiones residuales que a las modificaciones de estructura cristalina, así como a la posibilidad de obtener porcentajes de cristalinidad similares con morfologías de cristal totalmente diferentes. En fatiga no parece haber un efecto importante de las características de la matriz, pero por su parte en condiciones estáticas no ocurre de esta manera y nuevamente se alude al importante efecto de la entrecara fibra-matriz.

En línea con el efecto sobre las propiedades mecánicas de la cristalización, existe también un efecto de la cristalinidad sobre la transición vítrea y sobre la relación entálpica tal y como propone Toft en (Toft, 2012). Se indica que la interfaz cristal-amorfo tiene un papel remarcable en la respuesta al envejecimiento térmico en las proximidades de la transición vítrea, detectable a través de la relajación entálpica. Mayores grados de cristalinidad implican mayor número de cadenas con restricción y por tanto necesidad de mayores temperaturas para conseguir que esas cadenas se muevan, en calorimetría se 
puede observar ese efecto por un ancheamiento de la transición vítrea. Cuando las muestras tienen un mismo grado de cristalinidad, puede ocurrir que se presenten formaciones donde las lamelas sean menos abundantes y más gruesas, luego en estos casos hay menores áreas de interfaz amorfo-cristal y las cadenas de parte amorfa tendrán por tanto más facilidad de movimientos, disminuyendo el valor numérico de la $T_{g}$. 


\title{
Capítulo 3
}

\section{Procedimiento Experimental}

\author{
La ciencia será siempre una búsqueda, \\ jamás un descubrimiento real. Es un \\ viaje, nunca una llegada.
}

Karl Raimund Popper

\begin{abstract}
Resumen: Este capítulo se divide en cuatro subsecciones cuyo contenido consta de: descripción de los materiales objeto de estudio en esta tesis doctoral, fabricación de paneles mediante la tecnología de laminación automática y consolidación in-situ y su intercomparación con paneles fabricados por métodos convencionales fuera de autoclave (prensa), análisis de los medios empleados para la monitorización de temperaturas en los ciclos térmicos y detalle de las técnicas experimentales de las que se ha hecho uso junto al objetivo perseguido con su empleo, aportando información pormenorizada sobre los equipos.
\end{abstract}

\subsection{Materiales}

El material empleado para la ejecución de esta tesis doctoral ha sido el compuesto termoplástico APC2/AS4. Se trata de un material comercial adquirido a la empresa Solvay/Cytec, en dos formatos de ancho: 1/4in para los trabajos de encintado en automático y $300 \mathrm{~mm}$ para los trabajos de encintado en manual. El material de menor ancho procede de un proceso de corte tras la fabricación del de $300 \mathrm{~mm}$, todas las propiedades aplican a ambos de modo indistinto.

Este compuesto está constituido por dos elementos básicos: fibra de carbono continua tipo AS4 y resina polimérica tipo PEEK (cuya unidad monomérica se recoge en la Figura 3.1), sus propiedades más relevantes se recogen 
en la Tabla 3.1. Hexcel es el productor de la fibra refuerzo, perteneciendo al grupo de fibras de alta resistencia, sin embargo se desconocen los compatibilizantes empleados para mejorar su adhesión en el proceso de impregnación con la resina.

\begin{tabular}{|c|c|}
\hline$T_{g}[K]$ & $\sim 416$ \\
\hline$T_{\text {servicio }}[K]$ & $\sim 533$ \\
\hline$T_{\text {procesado }}[K]$ & $\sim 655 K$ \\
\hline Densidad $[\mathrm{g} / \mathrm{cc}]$ & 1.32 \\
\hline
\end{tabular}

Tabla 3.1: Propiedades APC2/AS4

En la Tabla 3.2 se incluyen algunos de los valores de propiedades mecánicas incluidos en la DataSheet del material y que se emplearán como referencia/intercomparación respecto a los ensayos ejecutados en este estudio.

\begin{tabular}{|c|c|c|}
\hline Propiedad & PEEK & APC2/AS4 \\
\hline $0^{\circ}$ Flexión (Resistencia [MPa]) & 170 & 2070 \\
\hline $0^{\circ}$ Flexión (Módulo [GPa]) & 4,1 & 138 \\
\hline IPSS (Resistencia [MPa]) & & 186 \\
\hline IPSS (Módulo [GPa]) & & 5,7 \\
\hline
\end{tabular}

Tabla 3.2: Propiedades mecánicas PEEK y APC2/AS4

Asimismo, con objeto de simplificar algunas de las tareas del estudio, se trabajó con material polimérico tipo PEEK suministrado por Victrex tratando de desacoplar la contribución de la fibra de carbono. En particular, este suministrador permite adquirir PEEK con tres pesos moleculares diferentes codificados como 90, 150 y 450 y con dos formatos posibles (pellet o polvo). La codificación en relación al peso molecular hace alusión a la viscosidad del polímero medida en un ensayo a $673 \mathrm{~K}$ y para un valor de shear rate de $10001 / s$; siendo 100Pa.s el valor aproximado para PEEK 90G y 350Pa.s para PEEK 450G. Dos materiales en formato "pellet" fueron adquiridos, correspondientes con PEEK 150G y 450G, la motivación para dicha selección se fundamentó en la información aportada en la referencia (Nicodeau, 2005) donde se alude al posible empleo de PEEK 450G como resina de impregnación del APC2/AS4. Además, tal como queda patente en diversas secciones de este documento de tesis, son numerosas las referencias donde se indica un efecto importante del peso molecular sobre la mayoría de las variables que afectan al proceso de fabricación bajo análisis, por ello se ha querido valorar su efecto mediante ciertas intercomparaciones con el PEEK 150G, 


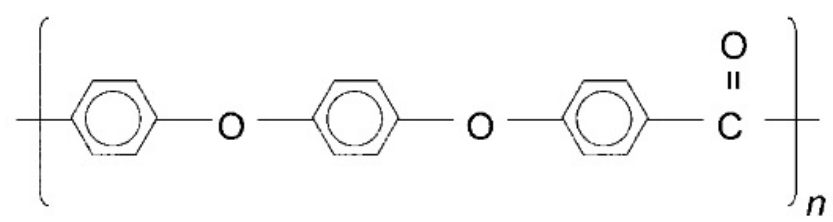

Figura 3.1: Unidad monomérica del PEEK

sin olvidar la suposición sobre el probable uso de PEEK 450G en nuestro composite laminado.

El PEEK (poli-éter-éter-cetona) es un termoplástico semicristalino. Es uno de los polímeros considerados de altas prestaciones debido a sus propiedades. Este material se clasifica dentro de la familia de las poli-éter-cetonas, materiales a los que se puede acceder por dos vías de sintetización distintas:

- Ruta electrofílica

- Ruta nucleofílica aromática

En los dos casos resulta (PEEKK). Dependiendo de la estructura del monómero y de la síntesis, se puede variar la proporción de grupos éter y cetona, generando diferentes poliétercetonas.

Entre las propiedades destacables se encuentra la resistencia a solventes, siendo el ácido sulfúrico concentrado el único solvente a temperatura ambiente.

\subsection{Fabricación de paneles}

Con objeto de analizar ciertas peculiaridades del proceso de fabricación bajo estudio, fue requerida la extracción de probetas para ensayos mecánicos. Para ello, fueron ejecutados paneles en la máquina de encintado automático de MTorres en las instalaciones de FIDAMC, que posiciona una única "tow" de material en formato de $1 / 4$ in y paneles en prensa de platos calientes para utilizarse como valor de referencia.

\subsubsection{Paneles fabricados en máquina de encintado automá- tico (ISC)}

La máquina de encintado automático empleada para las tareas descritas en este documento se caracteriza por estar basada en un sistema tipo 


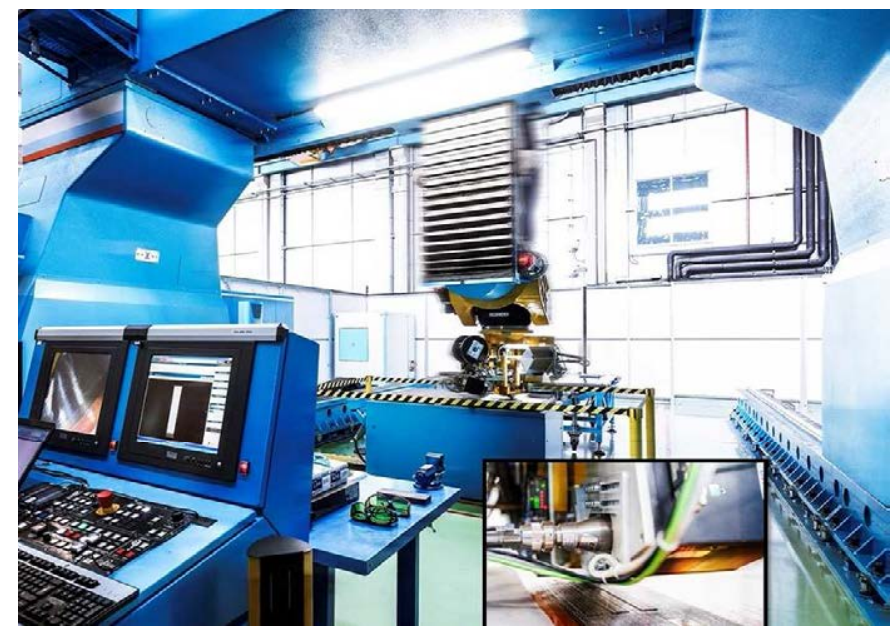

Figura 3.2: Máquina Unitow

"gantry", Figura 3.2 desarrollado por el Grupo Industrial español MTorres en estrecha colaboración con FIDAMC .

Entre las características más remarcables del equipo se encuentran: movimiento en 6 ejes y capacidad de encintado en ancho y longitud de unos 2,5m.

La operativa básica de la máquina consiste en la deposición de una cinta de material compuesto termoplástico de 1/4in. Dada la inexistencia de "pegajosidad" como propiedad inherente a los preimpregnados termoplásticos, la adhesión entre capas se consigue mediante el calentamiento directo por encima de la temperatura de fusión de sustrato y de material de aporte. El calentamiento del material está posibilitado por la incorporación en el conjunto de una fuente térmica tipo láser.

Esta fuente térmica consiste en un láser de diodos con óptica variable de la empresa Rofin, sus parámetros fundamentales aparecen incluidos en la Tabla 3.3 .

\begin{tabular}{|c|c|}
\hline Potencia [W] & 500 \\
\hline Longitud de onda [nm] & 980 \\
\hline Punto de focalización [mm x mm] & $1 \times 1$ \\
\hline Distancia focal del galvo [nm] & $200-300$ \\
\hline Diámetro de la lente [mm] & 120 \\
\hline
\end{tabular}

Tabla 3.3: Propiedades de la fuente térmica 
Una vez alcanzada la fusión, ambas partes del material se ponen en contacto mediante la aplicación de presión ejercida por un rodillo de compactación. Dicho rodillo de compactación juega un papel importante en las transferencias de calor en el conjunto, motivo por el cual porta un recubrimiento externo con un material tipo elastomérico.

El documento aludirá en su mayoría al tipo de configuración de máquina descrita con anterioridad; no obstante, durante la ejecución de esta tesis doctoral, tuvieron lugar diversas modificaciones del cabezal base de la laminación. El sistema de encintado se modificó para posibilitar la deposición simultánea de 8 tows de material, favoreciendo la reducción de tiempos e incremento de productividad del proceso. Tales evoluciones, a pesar de no alterar los principios físicos que gobiernan el proceso, presentan notables diferencias que alteran los resultados básicos de los modelos incluidos en el apartado de resultados (modificaciones del área de calentamiento, presión, velocidad de encintado, etc) y por ello requieren de un estudio independiente.

Dos paneles con diferentes orientaciones fueron encintados, un panel con secuencia $(0)_{16}$ y otro con secuencia $(+/-)_{4 s}$. En ambos paneles se aplicaron las condiciones habituales de fabricación con la máquina de encintado automático, se detallan en la siguiente tabla:

\begin{tabular}{|c|c|}
\hline Velocidad de encintado $[\mathrm{m} / \mathrm{min}]$ & 1 \\
\hline Fuerza de compactación $[N]$ & 50 \\
\hline Temperatura media $[\mathrm{K}]$ & $623-673$ \\
\hline Tensión tow $[N]$ & 6 \\
\hline Temperatura utillaje $[K]$ & 473 \\
\hline
\end{tabular}

Tabla 3.4: Parámetros de encintado

\subsubsection{Paneles fabricados en prensa de platos calientes}

Por su parte, dos paneles con las mismas orientaciones anteriormente descritas $(0)_{16}$ y $(+/-)_{4 s}$ se fabricaron en el equipo prensa de platos calientes IDEC-PRE 01 SN:001 de FIDAMC. Los parámetros empleados para la fabricación se extrajeron de la Data Sheet del material que es posible encontrar de forma abierta en la web de Cytec/Solvay en Internet, no obstante, se adjunta el esquema de trabajo en la Figura 3.3 .

Mediante el empleo de un termopar embebido en el panel durante el ciclo se ha obtenido el siguiente registro temperatura-tiempo, Figura 3.4. Se 


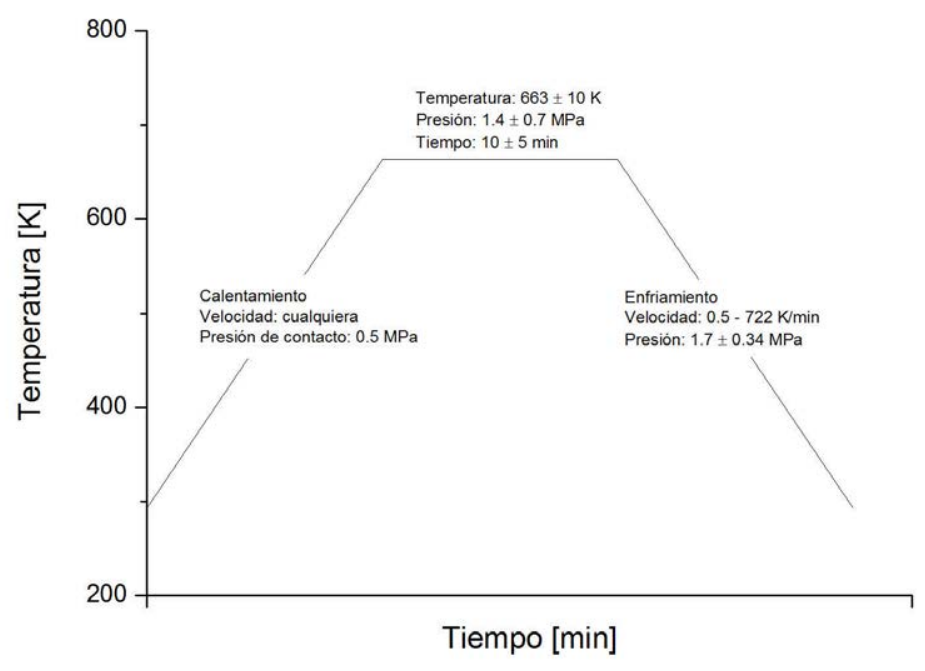

Figura 3.3: Ciclo Cytec/Solvay prensa

observa como el gráfico mantiene bien los valores sugeridos por el suministrador del material; respecto al tramo correspondiente al enfriamiento del material, se podría estimar una bajada de $1 \mathrm{~K} / \mathrm{min}$ hasta $523 \mathrm{~K}$, que se corresponde con el valor donde se espera que haya concluido la cristalización del material, en el capítulo destinado a cristalización se analizará con más detalle este gráfico y la información que proporciona.

\subsubsection{Inspección no destructiva de los paneles}

La inspección mediante análisis no destructivo (NDT) fue ejecutada siguiendo los criterios aplicables para el estudio de materiales compuestos de fibra de carbono (AITM-4005), donde figuran los requisitos que aplican para la aceptación o rechazo de pieza.

El equipo utilizado para el estudio fue un Triton $8000 \mathrm{TT}+$ de Tecnitest y palpador de Tecnisonic.

El sistema de inspección por ultrasonidos, tiene su principio físico en la transmisión y reflexión de ondas sonoras (Campbell, 2004). La onda sonora viaja por el material compuesto, de modo que en su camino puede encontrar defectos, por ejemplo, porosidad; cuando esto ocurre, parte de la energía será reflejada en dicha entre-cara mientras que la energía restante pasará a través del poro. Cuanto mayor es el efecto de la porosidad, mayor es la can- 

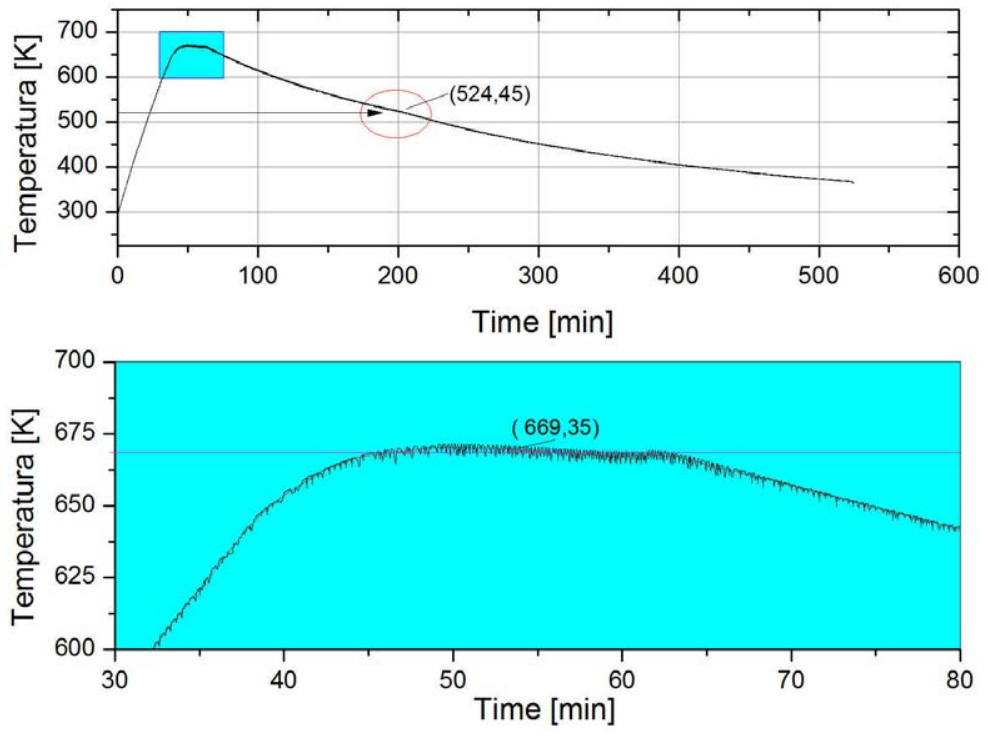

Figura 3.4: Ciclo real prensa FIDAMC

tidad de energía reflejada y menor energía es transmitida a través del defecto.

Una onda ultrasónica se produce cuando un generador de señal envía una ráfaga de energía eléctrica a un cristal piezoeléctrico en el transductor, ello causa una vibración del cristal y produce una conversión de pulsos eléctricos en vibraciones mecánicas (ondas sonoras). Ese mismo cristal piezoeléctrico convertirá las ondas sonoras que retornan en energía eléctrica. Los defectos son detectables porque alteran la cantidad de sonido que retorna al receptor.

La inspección por ultrasonidos se ejecuta en el rango de frecuencias entre $1-30 M H z$, siendo $1-5 M H z$ el rango más habitual de trabajo con estructuras de materiales compuestos. Altas frecuencias son más sensibles a pequeños defectos, mientras que bajas frecuencias pueden penetrar a mayores profundidades. Una vez que el haz ultrasónico atraviesa el material, se atenúa o se pierde como causa de ser: dispersado, absorbido o esparcido. La pérdida de atenuación se expresa normalmente en decibelios $(d B)$.

En particular, los trabajos de análisis por NDT han sido ejecutados según la técnica pulso-eco, donde el sonido es transmitido y recibido por el mismo transductor. La amplitud del eco recibido, se ve alterada por la presencia de defectos; la atenuación del ultrasonido está afectada por los defectos y su retardo temporal por la profundidad del defecto. La comparativa del análisis 


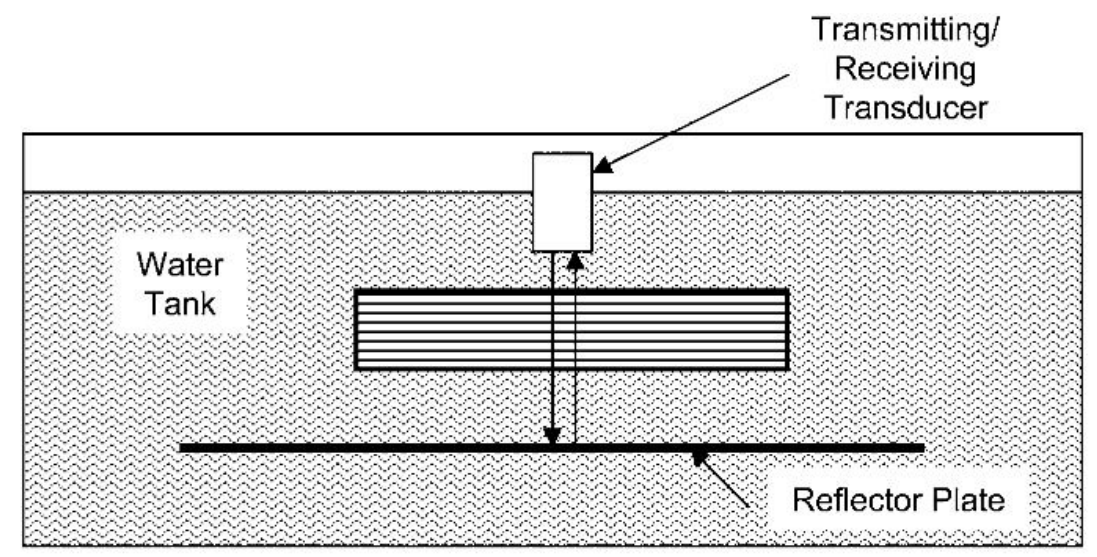

Figura 3.5: Unidad de escaneo por NDT automático - placa reflectante

resultante con el obtenido empleando una probeta patrón permite establecer

Cuando las inspecciones se ejecutan en automático, se emplea un sistema de placa reflectante sumergida como el de la Figura 3.5 .

La representación de los resultados se efectúa mediante C-scan, un mapa plano de la pieza donde, según la escala de colores que ha sido seleccionada en el trabajo, las zonas más blancas refieren menor atenuación del sonido y por tanto mayor calidad que aquellas áreas más "oscuras" (grises - negras).

\subsection{Monitorización de temperatura}

\subsection{Técnicas de ensayo}

\subsubsection{Propiedades térmicas y termomecánicas}

\subsubsection{Calorimetría diferencial de barrido (DSC)}

La técnica de Calorimetría Diferencial de Barrido o en adelante (DSC) ha sido empleada una con finalidad múltiple a lo largo de este estudio.

- Ensayos sobre material procesado para determinar su estado:

1. Análisis de temperatura de transición vítrea

2. Análisis de dobles picos de fusión

3. Análisis de efectos de cristalización fría 
4. Análisis de efectos de degradación

- Ensayos dinámicos e isotermos para análisis de cinética de cristalización.

- Cálculo de capacidad calorífica del material para su uso en el modelo térmico.

Los ensayos han sido elaborados sobre resina pura y sobre material compuesto FC/PEEK. Los ensayos se han elaborado bajo indicaciones de la norma AITM 3-0027, ajustando las masas de las muestras a unos $10 \mathrm{mg}$ para el caso de resina pura y por encima de $20 \mathrm{mg}$ en los casos en los que el material de trabajo fuera material compuesto FC/PEEK.

El equipo empleado para estos trabajos fue el modelo Q2000 de la marca TA Instruments, apropiadamente calibrado con ciclohexano, zafiro e indio. Con un flujo de nitrógeno de $50 \mathrm{ml} / \mathrm{min}$. Las muestras fueron herméticamente selladas con cestillos de aluminio tipo "Tzero".

Para conocer el comportamiento cinético a cristalización del material, se han desacoplado los efectos en la laminación y se ha trabajado en las condiciones permisibles por el equipo DSC, sometiendo el material a enfriamientos dinámicos entre $2 K / \min$ y $30 K / \min$, así como a isotermas de enfriamiento de $593 \mathrm{~K}$ a $599 \mathrm{~K}$. Con los datos resultantes, han sido aplicadas diferentes ecuaciones de ajuste para obtener información sobre los mecanismos que describen la cristalización del material, serán explicados con detalle en el apartado destinado a resultados

Por otro lado, han sido elaborados ensayos de calorimetría diferencial sobre los paneles resultantes de los procesos de fabricación en prensa y en laminación automática y consolidación in-situ. Dichos ensayos se han elaborado sobre al menos 3 muestras de material procedentes de diferentes áreas del panel. Las condiciones de ensayo constaron de 3 ciclos de calentamientoenfriamiento-calentamiento bajo las siguientes condiciones:

1. Calentamiento a $10 \mathrm{~K} / \mathrm{min}$ hasta $670 \mathrm{~K}$, isoterma 5 minutos.

2. Enfriamientos variabales hasta ambiente.

3. Calentamiento a $10 \mathrm{~K} / \mathrm{min}$ hasta $670 \mathrm{~K}$.

Con la información extraída del primer ciclo de calentamiento es posible determinar, en los casos en los que el material lo permita (en ocasiones un valor elevado de cristalinidad ocultará el valor de la transición vítrea), la temperatura de transición vítrea y el porcentaje de cristalinidad del material tras el proceso de fabricación. El valor de la temperatura de transición vítrea se extrae empleando la herramienta del software TA Universal Analysis 
con el criterio del valor en la mitad del ancho. Por su parte, el valor de la cristalinidad se obtendrá aplicando la siguiente ecuación:

$$
\alpha=\frac{\Delta H_{100 \% \text { resina }}}{\Delta H_{100 \%}} \cdot 100=\frac{\Delta H_{\text {fusión }}}{\Delta H_{100 \%} \cdot R_{c}} \cdot 100
$$

Donde $\alpha$ es la representación de la evolución de la conversión, entendida aquí como "cristalinidad", que se iguala al producto de: $\Delta H_{100 \% \text { resina valor }}$ de la entalpía de fusión para una supuesta muestra $100 \%$ resina. El valor de la entalpía de fusión se obtiene de la integración de la endoterma en la señal de flujo de calor del DSC. Además, dicho valor deberá ser corregido en los casos en los que se trabaje con el material reforzado, de modo que el valor se multiplicará por el porcentaje en masa que supone la resina sobre el total del composite $\left(R_{c}\right)$ y que en este caso particular se documenta en un $34 \%$ del total. El valor previamente calculado debe dividirse por el valor que supone la entalpía de fusión del polímero en cuestión, considerando que tiene una estructura idealmente $100 \%$ cristalina; en el caso del PEEK, se documenta que dicho valor son $130 \mathrm{~J} / \mathrm{g}$.

En aquellos casos en los que se detecte la presencia de cristalización fría, está deberá extraerse del área total de la endoterma de fusión pues contabilizará la fusión de los cristales obtenidos del proceso de fabricación más los obtenidos durante la cristalización fría en el calorímetro.

$$
\alpha=\frac{\left(\Delta H_{\text {fusión }}-\Delta H_{C C}\right)}{\Delta H_{100 \%} \cdot R_{c}} \cdot 100
$$

Siendo $\Delta H_{C C}$ el valor de la integración de la exoterma de cristalización fría en la señal de flujo de calor del DSC.

Fueron ejecutados diversos ensayos enfocados en demostrar la procedencia de los dobles picos de fusión observables en las muestras procedentes de procesos de fabricación en prensa. Para ello, se sometieron varias muestras del material procedente de prensa a diferentes ciclos de calentamiento, de modo que permitieran analizar el impacto de la velocidad de calentamiento en la curva de flujo de calor.

Se trataron de comprobar ciertas condiciones aplicables al proceso de laminación automática y consolidación in-situ. Entre ellas: análisis del estado del material APC2/AS4 "as received" mediante ensayo básico de calentamiento- 
enfriamiento-calentamiento descrito con anterioridad, pruebas de calentamiento a $1 \mathrm{~K} / \mathrm{min}$ hasta $473 \mathrm{~K}$ y mantenimiento para chequear el comportamiento del material de primera capa posicionado sobre la mesa de laminación autocalefactada, pruebas de encintado de probeta en escalón para monitorizar la evolución de la cristalinidad con el incremento del número de capas del conjunto.

Con objeto de alimentar los parámetros requeridos por el software de simulación del problema térmico, Comsol Multiphysics, fueron ejecutados ensayos para la determinación del valor de capacidad calorífica del material. El cálculo de este parámetro se efectuó en condiciones de ensayo isotermo y en modo modulado. Los ensayos se ejecutaron de modo que el valor de capacidad calorífica de la muestra a un determinado valor de temperatura isoterma se obtenía a través del resultado obtenido de la inter-relación con el valor del mismo ensayo ejecutado sobre una muestra de zafiro por medio de los siguientes cálculos.

$$
\begin{gathered}
k_{c_{p}}=\frac{c_{p_{\text {teórico }}}}{c_{p_{\text {medido }}}} \\
c_{p_{\text {real }}}=c_{p_{\text {medido }}} \cdot k_{c_{p}}
\end{gathered}
$$

Con la calorimetría también se trato de localizar efectos de degradación en el material mediante el análisis de posibles modificaciones inducidas en la posterior cristalización del material.

\subsubsection{Termogravimetría (TGA)}

La aplicación de la técnica Termogravimetría se ha ejecutado con un doble objetivo:

- Determinación de efectos de degradación en muestras tras procesar.

- Análisis y extracción de la cinética de degradación para PEEK puro.

Los ensayos fueron ejecutados con un equipo Q500 de la marca TA Instruments, con un horno tipo EGA.

Los ensayos elaborados sobre el material con la finalidad de estimar si presentaba efectos de degradación consistieron en ejecutar intercomparaciones entre dos muestras semejantes ensayadas bajo las mismas condiciones. 


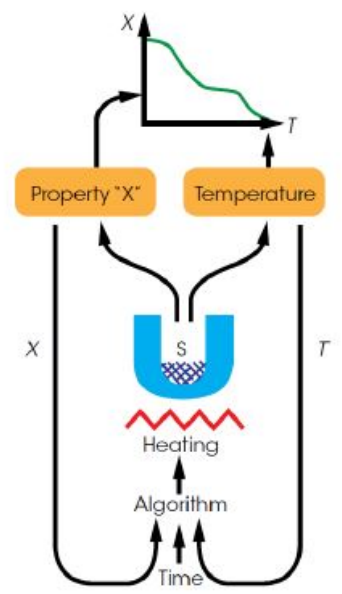

Figura 3.6: Fundamento de la metodología de ensayo tipo CRTA

Para el análisis cinético del material, fueron efectuados ensayos dinámicos a cuatro programas de calentamiento diferentes: $2,5 \mathrm{~K} / \mathrm{min}, 4 \mathrm{~K} / \mathrm{min}$, $10 \mathrm{~K} / \mathrm{min}$ y $15 \mathrm{~K} / \mathrm{min}$, con muestras de masas lo más similares posibles y en el entorno de $5 \mathrm{mg}$. Asimismo, con el objetivo de reproducir en la medida de lo posible las condiciones de funcionamiento de la máquina de encintado automático, los ensayos para el cálculo cinético fueron elaborados bajo atmósfera oxidativa con flujos de $10 \mathrm{ml} / \mathrm{min}$ de nitrógeno y $90 \mathrm{ml} / \mathrm{min}$ de oxígeno.

Para refutar los resultados obtenidos del análisis cinético, fueron también ejecutados ensayos tipo CRTA(Constant Reaction Thermal Analysis); estos ensayos fueron ejecutados con el mismo equipo con la premisa de velocidad de reacción constante de tal modo que el equipo, en base a la evolución de la reacción de degradación, determinará en qué momentos calentar o frenar el calentamiento de la muestra evitando que se acelere o frene el proceso y permitiendo mantener constante su velocidad durante todo el experimento. La Figura 3.6 contiene un esquema del modo de trabajo del equipo bajo estas condiciones de análisis.

\subsubsection{Reología}

La finalidad del empleo de esta técnica reside en:

- Determinación de la relación viscosidad-temperatura para el material.

- Análisis de tiempos de relajación de cadena - correlación con healing. 
- Análisis de efectos de degradación en el material motivados por crosslink.

Los ensayos han sido ejecutados con un reómetro de platos paralelos ARG2 de TA Instruments trabajando en todo momento bajo condiciones de atmósfera oxidativa.

Los ensayos para la determinación de la viscosidad del material han sido fundamentalmente elaborados sobre resina pura sin refuerzo, evitando la complejidad en la medida sobre el preimpregnado con un equipo como el empleado. Los ensayos han sido ejecutados en su mayoría en modo oscilatorio para evitar la posible destrucción de la estructura del polímero bajo estudio en condiciones de ensayo en flujo; no obstante, para la obtención de valores reales de viscosidad en el material fue aplicada la transformación de "Cox-Merz"; se trata de una ley empírica de validez demostrada en polímeros. Dicha ley establece una correlación entre la viscosidad en un ensayo de cortadura en estado estacionario (flujo) ( $\eta$ vs. $\dot{\gamma}$ ) y viscosidad compleja frente a frecuencia angular $\left(\left|\eta^{*}\right|\right.$ vs. $\left.\omega\right)$ (oscilatorio), donde se define la viscosidad compleja del siguiente modo:

$$
\begin{aligned}
\eta^{*} & =\frac{G^{*}}{i \omega} \\
\left|\eta^{*}\right| & =\frac{\left|G^{*}\right|}{\omega}
\end{aligned}
$$

$\mathrm{Su}$ utilidad es primordial por la incapacidad para emplear ensayos de flujo cuando la velocidad de cortadura es muy elevada, siendo los ensayos oscilatorios más confiables. Se incorporará un acoplamiento flujo/oscilatorio transformado por Cox-Merz para constatar la aplicabilidad del método.

\subsubsection{Análisis dinamo-mecánico (DMA)}

Para la elaboración de ensayos dinamomecánicos se empleó un equipo Q800 de la marca TA Instruments. Se llevaron a cabo ensayos de viga en voladizo ("single cantilever") sobre probetas de dimensión aproximada 35x10x2 $\mathrm{mm}^{3}$ procedentes de los paneles fabricados en máquina de encintado automático y prensa. El ensayo se ejecutó en modo dinámico, siguiendo una rampa de calentamiento a $5 K / \min$ desde ambiente hasta $523 K$, con una frecuencia de $1 \mathrm{~Hz}$ y una amplitud de $15 \mu \mathrm{m}$.

El objetivo de la elaboración de estos ensayos era extraer diferencias significativas en las curvas que pudieran relacionarse con variaciones en la estructura cristalina del material, fundamentalmente cambios en su $T_{g}$. 
La normativa consultada para la elaboración de estos ensayos fue la ISO 6721-11:2012, que determina el procedimiento para extraer la temperatura de transición vítrea en materiales no metálicos.

Las primeras probetas se cortaron de los paneles con orientación $0^{\circ} \mathrm{y}$ fueron ensayadas sin ningún acondicionamiento previo, no obstante, en vista de los resultados se optó por cortar probetas con orientación $90^{\circ}$ con la finalidad de obtener curvas donde el resultado fuera más dependiente de la resina. Asimismo, la aparición de variaciones en las curvas en el entorno de los $323-353 K$ sugirió la necesidad de llevar a cabo secados en las probetas; se aplicaron secados a $323 K$ y $378 K$ durante una semana, monitorizando la evolución de la masa de la probeta, la selección de ambas condiciones de secado se fundamenta en la idea de no sobrepasar la temperatura donde aparece esa transición en el material.

\subsubsection{Propiedades mecánicas}

Dadas las grandes diferencias existentes entre los dos procesos de fabricación descritos con anterioridad, el material quedará en un estado final donde diversas propiedades se verán afectadas, entre ellas sus propiedades mecánicas, por ello se han seleccionado 3 ensayos mecánicos distintos que analizan las propiedades del material en el plano de la lámina, entre capas y a flexión, con el fin de observar cuál de ellos se encuentra más afectado y de qué modo.

\subsubsection{Resistencia a cortadura en el plano (IPSS)}

Los ensayos se ejecutaron conforme a normativa AITM 1-0002, no obstante las probetas procedían de laminados con 16 capas en lugar de las 8 recomendadas por la norma, la causa de esta diferencia era permitir su intercomparación con trabajos previos ejecutados en FIDAMC así como con los valores de referencia contenidos en la IPS del material perteneciente a Airbus.

La máquina empleada para la ejecución de estos ensayos fue una máquina universal de ensayos MTS modelo 370.10 con célula de carga de $100 k N$. En el cálculo de cortadura fueron empleados dos extensómetros, uno de espesores y otro de pinzar, ambos Epsilon. La velocidad de ejecución del ensayo fue de $1 \mathrm{~mm} / \mathrm{min}$ hasta un $2 \%$ de deformación, momento desde el cual se incrementó la velocidad de ensayo a $10 \mathrm{~mm} / \mathrm{min}$.

Las probetas ensayadas presentaban dimensiones aproximadas de $230 x 25 x 2 \mathrm{~mm}^{3}$. 


\subsubsection{Resistencia a flexión}

Dadas las dificultades para emplear ensayos de cortadura interlaminar para referenciar valores cuantitativos por los modos de fallo no aceptables derivados de estos ensayos sobre material termoplástico, se optó por emplear ensayos de flexión acorde con EN 2562 tipo A.

Las probetas a ensayar contaban con unas dimensiones aproximadas de $100 \times 10 x 2 \mathrm{~mm}^{3}$, siendo $80 \mathrm{~mm}$ la distancia fija entre apoyos. Todas las probetas fueron cortadas y ensayadas a $0^{\circ}$.

El valor de la resistencia a flexión se estimó, tal como indica la norma, con la siguiente expresión:

$$
\sigma_{b}=\frac{3}{2} \frac{P_{R}}{b} \frac{l_{v}}{h^{2}}
$$

Donde, $P_{R}$ representa el valor de la carga a rotura $[\mathrm{N}], b$ es el ancho de la probeta $[\mathrm{mm}], l_{v}$ es la distancia entre apoyos [mm] y $h$ es el espesor de la probeta $[\mathrm{mm}]$.

Por su parte, el módulo a flexión se estima a través de:

$$
E_{b}=\frac{P_{R}\left(l_{v}\right)^{3}}{10 b h^{3}\left(f_{2}-f_{1}\right)}
$$

Siendo $f_{1}$ la deflexión correspondiente con $\frac{P_{R}}{10}$ y $f_{2}$ la correspondiente a $\frac{P_{R}}{2}$.

\subsubsection{Resistencia a cortadura interlaminar (ILSS)}

Los ensayos para analizar la resistencia a cortadura interlaminar se desarrollaron en una máquina universal de ensayos Zwick/Roell Z010 con una célula de carga de $10 k N$ y conforme a la normativa EN2563:1997. La dimensión aproximada de las probetas empleadas para el ensayo era de $20 x 10 x 2 \mathrm{~mm}^{3}$. La velocidad de desplazamiento del indentador sobre la probeta se establece en $1 \mathrm{~mm} / \mathrm{min}$.

Siguiendo las indicaciones de la norma se estimó la distancia entre apoyos (modificada en función del espesor promedio medido de la probeta) y el valor de la resistencia a cortadura interlaminar. Asimismo, en el apartado destinado a resultados se incluirá información relativa al modo de fallo experimentado por las distintas probetas, siendo en la mayoría de los casos un tipo de fallo por deformación plástica o flexión; considerados no validos según los criterios del estándar empleado. 


\subsubsection{Ensayos de pelado}

Los ensayos de pelado no fueron ejecutados en base a ninguna normativa. La principal finalidad de su elaboración era establecer diferencias en valor de carga de separación entre dos capas de material APC2/AS4 unidas por el proceso de ISC o en prensa. Fueron fabricadas probetas donde se generó una pregrieta inducida por un kapton posicionado en uno de los extremos. En el ensayo, las zonas de la probeta separadas por el kapton se mantenían sujetas por la mordaza del equipo Zwick/Roell Z010 con célula de carga de $10 k N$, y su separación se hacía posible por la interacción de un rodillo de bajo diámetro.

El valor cuantitativo de la carga de pelado, se encuentra pendiente de efectuar variaciones en el utillaje de ensayo, no obstante, los trozos separados de las probetas fueron empleados para elaborar un análisis óptico por medio de microscopia electrónica de barrido (SEM).

\subsubsection{Análisis superficial}

Para analizar el estado superficial del material se empleó un rugosímetro tipo Profiltest SM-7. El equipo permitió seleccionar tanto el "Cut-Off" como la longitud de recorrido de la medida.

La finalidad de este análisis es conocer información sobre la superficie del material de partida APC2/AS4. Dicha información se empleará para los cálculos de grado de contacto íntimo basados en modelos teóricos que serán explicados en detalle en el capítulo destinado a este tema.

\subsubsection{Espectroscopía}

\subsubsection{Espectroscopía de fotoelectrones emitidos por rayos $\mathrm{X}$ (XPS)}

La técnica de espectroscopía de fotoelectrones emitidos por rayos $\mathrm{X}$, en adelante XPS, ha sido empleada con la finalidad de ejecutar análisis superficial del material preimpregnado APC2/AS4 tras la irradiación por medio de la fuente láser de diodos empleada como sistema de calentamiento en el proceso de laminación automática y consolidación in-situ. Esta técnica se apoya en el efecto fotoeléctrico, permitiendo extraer información al respecto de: identificación de elementos y estado químico, composición relativa de constituyentes en la región superficial y estructura de la banda de valencia. 
En el presente documento, el objetivo de empleo de esta técnica, es la determinación de posibles efectos de degradación superficial en el material tras la irradiación láser no detectables mediante otras técnicas de ensayo. El procesado de los datos obtenidos de esta técnica se efectuará mediante el software CasaXPS.

Los ejecución de los ensayos fue elaborada con un equipo SPECS GmbH con sistema de UHV, como sistema analizador de energía, Phoibos 150 9MCD y se empleó una fuente de magnesio no monocromática de $200 \mathrm{~W}$ y $12 \mathrm{kV}$.

\subsubsection{Espectroscopía de infrarrojos por transformada de Fou- rier (FTIR)}

De nuevo, con el objetivo de extraer información acerca de la composición superficial del material para ejecutar comparativas entre los estados pre- y post- irradiación del láser, se empleó la técnica de espectroscopía de infrarrojos aplicada sobre muestras de material APC2/AS4 "as received" y tras la irradiación del láser. Asimismo, fue analizada una muestra de PEEK 450G tras inducir sobre el material un $2 \%$ de degradación con termogravimetría.

El equipo empleado es un Nicolet iN10/Nicolet iZ10 de Thermo Scientific. En particular, ha sido empleado el accesorio Smart iTX para la ejecución de medidas de reflexión total atenuada (ATR).

\subsubsection{Difracción de rayos $\mathrm{X}$ (XRD)}

El equipo empleado fue un Empyrean PANanlytical, perteneciente a IMDEA Materiales. El barrido se ejecutó en un rango aproximado de $2 \theta$ desde $4^{\circ}$ a $40^{\circ}$. El paso de escaneo fue seleccionado como $0,039^{\circ}$, dando como resultado un barrido de 1041 puntos y tiempos de escaneo de unos 30 minutos por muestra. Los ensayos se ejecutaron con ánodo de "Cu", voltaje de $45 k \mathrm{~V}$, intensidad de corriente de $40 \mathrm{~mA}$ y longitud de onda de la línea $\mathrm{K}-\alpha$ de $1,5405980 \AA$.

El empleo de la difracción de rayos X buscaba la obtención de información relativa a la cristalinidad en el material. Dado que el material de trabajo (APC2/AS4) es un compuesto reforzado con fibras de carbono y una resina semicristalina, fue necesario tomar medidas sobre fibra AS4, así como sobre material polimérico (PEEK) 100\% amorfo. Tales mediciones, permitieron desacoplar en los espectros las contribuciones de ambos, de modo que el espectro resultante sólo contabilizara el efecto de cristal en el material.

Con la información suministrada por esta técnica es posible obtener valores del grado de cristalinidad en el material y también información a nivel 
de microestructura, en particular valores relacionados con distancias entre planos cristalinos.

El tamaño de cristal se estima como una relación con el ancho medio de los picos (FWHM) a través de la ecuación de Scherrer, Ecuación 3.9

$$
L_{h k l}=\frac{K \lambda}{\beta \cdot \cos \theta}
$$

Donde, $L_{h k l}$ son las dimensiones del cristal en dirección perpendicular al plano cristalográfico hkl (en $\AA$ ), $\beta$ es el ancho del pico a la altura media relacionado con el plano cristalográfico $h k l$ (en radianes), $K$ es una constante (generalmente se toma como valor 0.89), $\theta$ el ángulo de difracción de la reflexión $h k l$ y $\lambda$ la longitud de onda empleada.

\subsubsection{Análisis óptico}

\subsubsection{Microscopía}

La técnica de microscopía ha sido empleada con varias finalidades a lo largo del presente trabajo de tesis doctoral. Ha sido de utilidad en el análisis de los laminados fabricados. Ha sido empleada para los análisis de grado de contacto íntimo para las determinaciones de áreas de material con y sin contacto entre capas.

Las probetas empleadas para este análisis se caracterizaron por fabricarse con 3 láminas de material APC2/AS4 con orientación (0/90/0), variando los tiempos de permanencia a la temperatura de fusión, más detalles a este respecto se incluirán en la sección de resultados. Tras el procesado, fueron cortadas, pulidas y tratadas mediante microscopía.

Para el pulido se empleó una pulidora Phoenix 4000 de Buehler GmbH; por su parte, las imágenes de microscopia se obtuvieron con un equipo Eclipse LV150 de Nikon.

Asimismo, para la observación y determinación de modo de fallo en los ensayos de cortadura interlaminar se empleó el modelo SMZ800 de Nikon.

\subsubsection{Microscopía electrónica de barrido (SEM)}

Esta técnica permite obtener una mayor resolución de la permitida con la microscopía óptica convencional. Para ello, un haz de electrones incide sobre la superficie de la muestra. 
Las imágenes SEM incluidas en este documento de tesis han sido obtenidas mediante el empleo de un equipo FIB-FEGSEM perteneciente a IMDEA Materiales. El equipo es un modelo Helios NanoLab 600i trabajando con $2 k \mathrm{~V}$ y $0,17 n A$.

Todas las muestras fueron recubiertas con película de oro empleando el equipo Quorum Q150T ES. El ciclo empleado para la deposición ha consistido en la aplicación del recubrimiento durante 90 segundos con una corriente de $15 m A$ (espesor aproximado de deposición igual a $15 \mathrm{~nm}$ ) 



\title{
Capítulo 4
}

\section{Discusión de resultados}

\author{
La ciencia nunca resuelve un problema \\ sin crear otros diez más. \\ George Bernard Shaw
}

RESUMEN: A continuación se presenta una compilación de todos los ensayos y resultados extraídos de los mismos durante la ejecución de este trabajo doctoral. El capítulo se organiza, como ya se hizo con el estado del arte, en cuatro apartados básicos: transferencia de calor, degradación térmica, adhesión y cristalización. Dado el carácter teórico/experimental de esta tesis, el capítulo incluye un primer análisis de la física bajo estudio y posteriormente incorpora los resultados de los modelos matemáticos que han podido obtenerse.

Para los desarrollos relacionados con la transferencia térmica, se plantea una resolución numérica del problema mediante el empleo del software Comsol Multiphysics. Asimismo se incluirán los resultados de las mediciones sin contacto (termografía) y por contacto (sondas de temperatura tipo termopar) sobre una ejecución de encintado con el equipo.

El estudio de degradación en el material se ha elaborado siguiendo dos rutas, el análisis directo sobre muestras calentadas por la fuente del calentamiento, en busca de posibles efectos de degradación y los desarrollos enfocados a la obtención de un modelo capaz de predecir el comportamiento del polímero bajo un programa de calentamiento cualquiera, empleando para ello los resultados de ensayos de termogravimetría y de reología.

En los análisis de adhesión, se incluirán desarrollos para el análisis del contacto íntimo entre las partes del material con una combinación teórico-experimental en la aproximación de los parámetros que describen la superficie rugosa del material. La reptación de las cadenas poliméricas se analizará mediante ensayos de reología sobre resina pura. 
La cristalización ha sido estudiada desde el punto de vista físico, tratando de comprender cómo tiene lugar la evolución de la misma en un proceso de encintado automático y consolidación in-situ, mostrando un crecimiento secuencial con la evolución del encintado para casos particulares de encintado según la temperatura del utillaje. Asimismo, se ha tratado de obtener la cinética que describe el comportamiento a cristalización del material empleando las formulaciones de la cinética clásica y mediante la aplicación de las nuevas propuestas previamente reportadas por otros autores.

En gran parte del trabajo, se encontrarán alusiones a los resultados obtenidos de ejecuciones mediante otros procesos de fabricación con el mismo material, procesos tipo fuera de autoclave como prensa, la finalidad es determinar comportamientos diferenciales que permitan dar explicación a efectos particulares en el sistema de laminación automática y consolidación in-situ. Siguiendo dicha metodología, han sido elaboradas comparaciones entre los resultados de ensayos mecánicos diferentes tratando de localizar qué propiedades son las más afectadas y su posible vínculo con las particularidades de estos procesos de fabricación. 


\subsection{Transferencia de calor}

Considerando que el punto de partida para que el proceso de laminación automática y consolidación in-situ tenga lugar es el calentamiento del material, valorar como se distribuye la temperatura en el conjunto pudiendo estimar que parámetros afectan más al calentamiento del material resulta de utilidad para poder actuar sobre el mismo de una manera óptima sin necesidad de recurrir a la prueba/error experimental.

\subsubsection{Determinación experimental de la transferencia de ca- lor}

Para la determinación experimental de la temperatura observada por el laminado durante el proceso de encintado se han empleado dos lecturas diferentes; por un lado, las medidas que reporta la cámara termográfica instalada en el conjunto del cabezal de la máquina y que se emplea también como sistema de alimentación para el control de la potencia del láser y por otro lado, sondas de contacto tipo termopar.

La termografía permite extraer los valores de temperatura en la superficie directamente irradiada por el láser, como se recoge en la Figura 4.1. Para la monitorización con termografía se ha empleado el equipo FLIR A325sc con una resolución de 320x240 pixeles y una frecuencia de refresco de imagen de $60 \mathrm{~Hz}$. Con esta técnica se pierde información relativa a lo que les continúa ocurriendo a las capas inferiores que siguen re-calentándose por conducción en las sucesivas etapas de posicionado del material. La termografía, con la aplicación de correcciones sobre la temperatura de ambiente circundante y considerando un valor para la emisividad del material, permite obtener valores fiables sobre la temperatura a la que se somete el material previo a su consolidación. Unida a la pérdida de información sobre las capas previas, existe también una pérdida de información sobre el perfil de enfriamiento experimentado por el material, siendo un condicionante del estado de cristalización en que quedará la pieza y por tanto, de su respuesta mecánica.

El tratamiento de los datos de termografía se ha ejecutado mediante el software ResearchIR de FLIR. En la representación incluida de la Figura 4.1 se han incluido tres líneas representativas de los laterales de la tow encintada y de su línea media. Como puede observarse en la imagen, el área calentada supera ligeramente el ancho del material posicionado, asegurando el calentamiento de toda la tira. La Figura 4.2 contiene la representación temperatura-distancia al NIP de la linea central (Line 2 en 4.1), en ella se puede observar, tal y como también quedará patente en las lecturas con los termopares, que la zona que se mantiene por encima de la temperatura del 


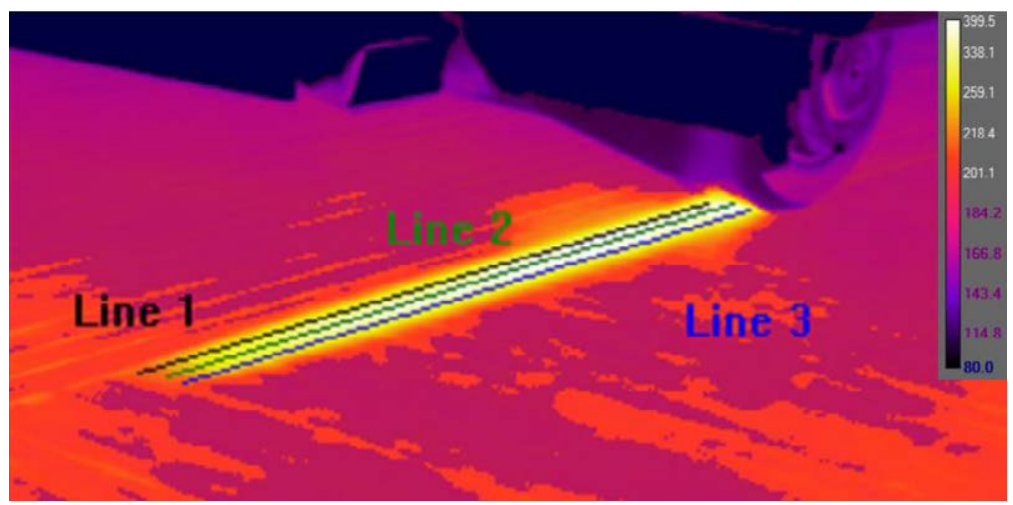

Figura 4.1: Termografía durante el encintado con APC2/AS4

pico de fusión del APC2/AS4 se corresponde con unos 5,4s respecto a los $7,8 s$ de área total calentada.

Por su parte, en la monitorización por medio de termopares, éstos quedarán embebidos en los laminados, permitiendo obtener la evolución del proceso a medida que crece el número de capas del conjunto y la curva seguida por el material en la etapa de enfriamiento. En el transcurso del presente trabajo fueron adquiridos diferentes tipos de termopares de varios suministradores hasta localizar el más óptimo para esta aplicación.

Los primeros análisis elaborados, se recogen en el Apéndice A por no obtenerse medidas lo suficientemente precisas. Se desarrollaron empleado cable de termopar trenzado de TC Direct, modelo 818-021, cable trenzado de tipo JX y diámetro individual de $0,2 \mathrm{~mm}$. Dado el recubrimiento portante, teflón tipo PFA con temperatura máxima recomendada de uso de $523 \mathrm{~K}\left(250^{\circ} \mathrm{C}\right)$, los cables se desnudaron para evitar la descomposición del recubrimiento durante la laminación. También fue empleada una sonda de temperatura tipo $\mathrm{K}$, con vaina de INCONEL y diámetro $0,75 \mathrm{~mm}$, modelo 406-622. En las ejecuciones con doble láser que se reportan también en el Apéndice A fue empleado cable de termopar tipo K, modelo K1KP-25SA adquirido a Termya y cuyos hilos presentan un diámetro individual de $0,25 \mathrm{~mm}$ y recubrimiento de kapton, capaz de soportar las temperaturas del encintado. El cable de Termya posibilitó el trabajo sin necesidad de desnudar los componentes individuales, no obstante, también fueron separados entre sí retirando el recubrimiento general para reducir al máximo el sobre-espesor generado por el cable.

Entre las problemáticas que se derivaron del uso de estos termopares se encuentran: la necesidad de fijarlos con elementos adhesivos o con la propia 


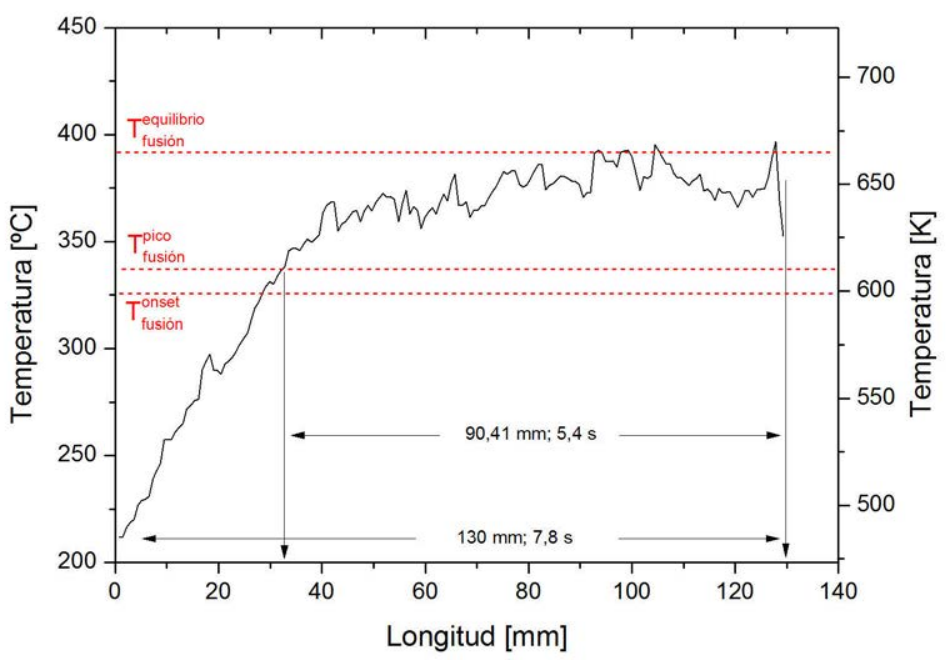

Figura 4.2: Perfil Temperatura-Longitud en el encintado de APC2/AS4 Lectura de cámara termográfica

resina termoplástica para poder garantizar que quedan en una posición definida y no son arrastrados por el rodillo durante el encintado. Los materiales empleados para la fijación, deben ser capaces de resistir las temperaturas consignadas durante el encintado, sin descomponerse antes de la colocación de la siguiente capa. Emplear materiales ajenos para la fijación, también supone una alteración de las características del encintado normal pudiendo introducir efectos de distorsión en las medidas. Además, los termopares que han sido mencionados en el párrafo anterior, tienen un espesor que supera el espesor nominal de capa del material encintado $(0,135 \mathrm{~mm})$. Esto provoca sobre-espesores durante el encintado que pueden causar excesivos calentamientos y alteran el resultado de la medida requerida.

Con el fin de solventar la problemática del espesor, se efectuaron mediciones en el último periodo de desarrollo de esta tesis doctoral con un nuevo modelo de termopar de tipo K, su empleo ya había sido reportado en los trabajos de (Stokes-Griffin y Compston, 2016a). Estos termopares fueron adquiridos a OMEGA con las codificaciones CHAL-0005 y diámetro $0,013 \mathrm{~mm}$ y CHAL-002 de diámetro $0,05 \mathrm{~mm}$, la longitud limitada de los mismos obligó a trabajar con conectores de tipo HMPW-K para prolongarlos hacia el equipo registrador. Estos termopares fueron conectados a un equipo OM-DAQXL-1-EU que permite una frecuencia de muestreo de 125 muestras por segundo con un único canal conectado ( $8 \mathrm{~ms}$ de refresco), 50 muestras por segundo con 2 canales trabajando en simultáneo $(20 \mathrm{~ms})$ y 25 respectiva- 
mente con 3 canales $(40 \mathrm{~ms})$. Los termopares de $0,013 \mathrm{~mm}$ ofrecieron muchas dificultades en su empleo, rompiéndose los cables en las pasadas del cabezal y durante la propia etapa de posicionado, siendo finalmente descartados.

Para resolver el problema de sujeción del termopar sobre la capa, éste se colocó sobre la misma y a continuación, se le superpuso manualmente la capa inmediatamente superior fijándola mediante la aplicación de puntos de soldadura. Una vez pre-colocada, asegurando la sujeción del termopar, se hizo pasar el láser sobre ella sin aporte de material y con la aplicación de presión del rodillo para conseguir así embeberlo.

Los registros de temperatura leídos por el termopar en una ejecución como la mencionada y con el utillaje a temperatura ambiente se incluyen a continuación. La ejecución se basó en la laminación de 16 capas con orientación $0^{\circ}$. Se seleccionó un número igual a 16 capas con el fin de monitorizar la evolución típica en el laminado más habitual empleado para caracterizar este proceso de fabricación (IPSS con $[+/-]_{4 s}$ ). En los resultados, se descartará la medición registrada en la primera pasada del láser sin aporte de material por la problemática asociada a no encontrarse el termopar correctamente embebido en el laminado, de ahí que el primero de los registros se corresponda con el encintado de la capa 3, Figura 4.4. Para facilitar la comparación de los resultados, todos los perfiles de temperatura se han intentado representar de modo que su origen temporal estuviera lo más aproximado posible al inicio del calentamiento láser. Se recogerá una medida correspondiente a un intervalo temporal de $25 \mathrm{~s}$, tiempo suficiente como para que el punto recupere su temperatura inicial (salvo los perfiles obtenidos desde el encintado de la capa 10).

En la primera de las mediciones reportadas, recogida en la Figura 4.4 se observan los siguientes efectos:

- Zona de estabilización de la temperatura a unos $640 \mathrm{~K}\left(370^{\circ} \mathrm{C}\right)$ durante unos $4 \mathrm{~s}$, con una zona total de calentamiento correspondiente a $7,8 \mathrm{~s}$, valor que ajusta con la correlación velocidad de máquina $(1 \mathrm{~m} / \mathrm{min})$ y longitud calentada por el láser $(\sim 130 \mathrm{~mm})$. Los puntos a) y b) en el gráfico, marcan la extensión temporal de la zona considerada de calentamiento.

- En el punto b) se observa una subida de la temperatura a unos $660 \mathrm{~K}$ $\left(390^{\circ} \mathrm{C}\right)$. La hipótesis más probable de ese comportamiento es el incremento de espesor generado por el termopar embebido que puede generar un efecto de sobrecalentamiento. Otra causa posible es el incremento del dibujo impuesto al perfil de calentamiento en el área del NIP. 
- Entre los puntos b) y c) se presenta una caída de temperatura equivalente a unos $45 \mathrm{~K}$, que podría asociarse, tal y como ya presentaban (Stokes-Griffin y Compston, 2016a), con una zona en sombra al calentamiento láser. La caída puede estar causada por una sombra del propio termopar, que incrementa levemente el espesor del material en la zona donde está embebido generando un área en sombra tras el mismo. Otra causa posible para el efecto de sombra es que esté generada por el rodillo y la bajada de material de aporte previa a la entrada en contacto entre ambas partes, impidiendo al láser llegar de forma directa sobre dicho punto. Teniendo en cuenta los $0,3 s$ de duración de dicha caída y la velocidad de desplazamiento de máquina, esa caída se corresponde con $5 \mathrm{~mm}$ de extensión en longitud, la Figura 4.3 contiene dos imágenes de marcados con el láser en la parte delantera del rodillo con el fin de visualizar posibles efectos de sombra generada, la imagen de la izquierda es un croquis para mostrar el efecto al que se alude y la de la derecha presenta una extensión de unos $4 \mathrm{~mm}$ de sombra respecto al perfil del láser dibujado. La caída de temperatura también podría estar asociada al propio efecto de fusión del polímero, una reacción de tipo endotérmico que se desarrolla con absorción de calor.

- Dado que el material de aporte también se encontraba caliente (por acción de la apertura del calentamiento láser) y que ambas partes se presionan entre sí por medio del rodillo de compactación, se vuelve a generar una subida de temperatura hasta d) alcanzándose el valor máximo ya observado en b).

Esa nueva subida de temperatura también podría asociarse al perfil de presión generado por el rodillo, que se asemeja a una campana donde el pico máximo de presión se localiza en el plano central del rodillo.

- En el punto e), se espera que se produzca la salida del rodillo de compactación, por la relación existente entre la velocidad de encintado $(1 \mathrm{~m} / \mathrm{min})$ y la huella de aplicación de presión del rodillo en el sentido de encintado (aproximada a $12 \mathrm{~mm}$ ). En ese instante, el polímero debería haber completado su solidificación para evitar efectos de desconsolidación.

- En el punto f), la temperatura cae de modo que el material atraviesa su transición vítrea en $441 K\left(158^{\circ} \mathrm{C}\right)$. Podría asociarse a ese valor el cambio en la tendencia de la pendiente de la curva de enfriamiento, que tenía una tendencia inicial de decaimiento próxima a $300 \mathrm{~K} / \mathrm{s}$ $(18000 \mathrm{~K} / \mathrm{min})$ y cambia a $45 \mathrm{~K} / \mathrm{s}(2700 \mathrm{~K} / \mathrm{min})$. Ambas, velocidades elevadas considerando los valores de enfriamiento que se incluyen en la ficha técnica del material, donde el límite superior de enfriamiento para el ciclo del material (autoclave) es de $720 \mathrm{~K} / \mathrm{min}$. Otra hipótesis en la justificación de la aparición de la transición en el punto f) es un 
posible cambio en la transmisión térmica por un cambio de medio de enfriamiento, es decir, que antes de ese punto la transmisión del calor fuera hacia el rodillo y pasado dicho punto esa transmisión fuera a ambiente. Considerando que el rodillo tiene un periodo aproximado de aplicación de $0,72 s$, tomando el punto f) y desplazando ese intervalo hacia atrás, el punto coincidiría aproximadamente con el punto d). Luego otra posibilidad es que el rodillo actúe de d) a f) o que se haya subestimado su huella de actuación sobre el laminado.

- Transcurrido un periodo de unos $15 \mathrm{~s}$, el ciclo completo ya se ha desarrollado. Calentamiento, estabilización y enfriamiento y el material se estabiliza a la temperatura del utillaje de laminación (en este caso, temperatura ambiente).

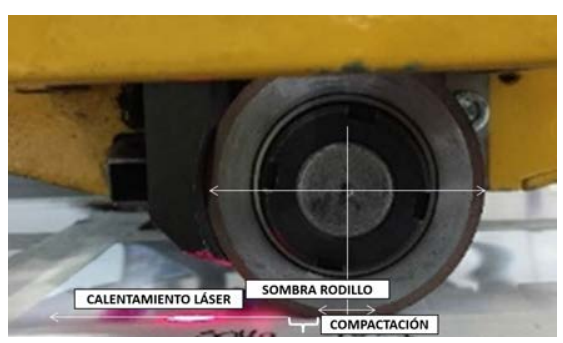

(a)

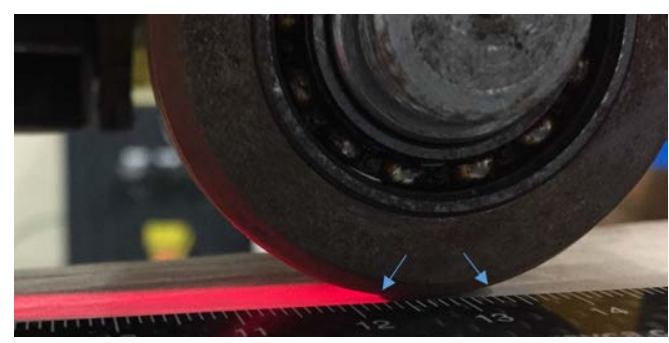

(b)

Figura 4.3: Marcados láser en la búsqueda de determinar posibles efectos de sombra generada por el rodillo de compactación

Algunas de las hipótesis de comportamiento planteadas con anterioridad para el encintado de la capa 3, van a ser cuestionadas en base a la observación de los siguientes perfiles tiempo-temperatura en el termopar durante los encintados de capas superiores. La observación de los resultados permitirá valorar cuál de las hipótesis se aproxima más al efecto del encintado real.

Al continuarse el encintado, ese punto entre las capas 1 y 2 vuelve a experimentar el calentamiento mientras se encinta la capa 4 (Figura 4.5) La tendencia observada en el gráfico es similar a la del encintado de la capa previa, las particularidades presentes radican en: el máximo de temperatura es en este caso $630 \mathrm{~K}\left(360^{\circ} \mathrm{C}\right)$, el incremento de una capa ha impactado en una pérdida de $30 \mathrm{~K}$ respecto al estadio de calentamiento inicial, tal evidencia hace pensar que en el encintado de la capa 2 el valor de temperatura que debió experimentar la entre-cara 1 a 2 fue un valor próximo a $690 \mathrm{~K}\left(420^{\circ} \mathrm{C}\right)$ en su pico máximo y unos $660 \mathrm{~K}\left(390^{\circ} \mathrm{C}\right)$ en la zona de estabilización, tal y como había sido obtenido en la lectura de la termografía. 


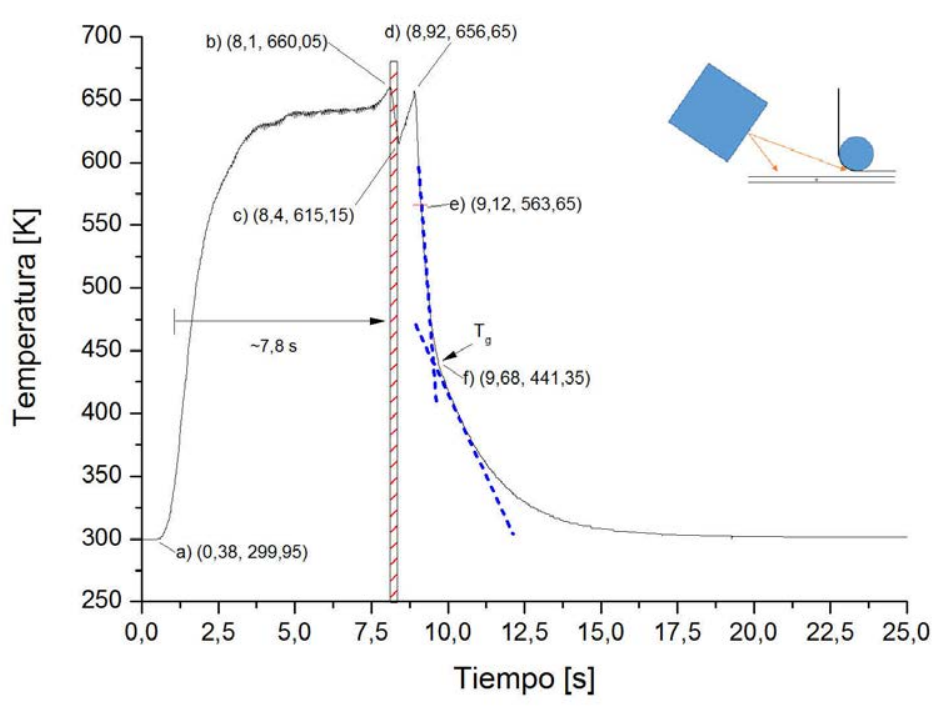

Figura 4.4: Perfil temperatura vs tiempo punto entre capas 1 y 2 encintando capa 3 con útil frío - Lectura con OMEGA CHAL-002

El perfil tiene una zona menos estable que la observada durante el encintado previo, por la transmisión del calor en este caso con dos capas interpuestas. Considerando la información que reporta la termografía, a medida que se incrementa el espesor del laminado, se pierde esa zona de meseta estable en los perfiles longitud calentada-temperatura. La causa probable del anterior efecto es la gran capacidad del carbono para conducir el calor, conducción más limitada en las capas inferiores por la menor masa de material y por los aislantes interpuestos entre primera capa y útil. Con base a la problemática descrita con anterioridad, durante los encintados se efectúan cambios en el perfil/dibujo del láser al ir incrementándose el espesor de los laminados, el perfil se modifica por otros que imponen un calentamiento superior en la zona más alejada del NIP para compensar así el menor valor de temperatura inicial (este cambio se aprecia en el encintado de la capa 5, recogiendo el efecto en el punto b* de la Figura 4.6.

Respecto al enfriamiento, los gradientes de caída son similares a los ya observados con anterioridad, unos $300 \mathrm{~K} / \mathrm{s}$ en el tramo inicial y $45 \mathrm{~K} / \mathrm{s}$ pasada la transición observable a $453 K\left(180^{\circ} \mathrm{C}\right)$, en este caso, este valor es muy elevado como para poder relacionarlo con la transición vítrea en el polímero PEEK, cuyo valor teórico reportado bibliográficamente por (Campo, 2006) corresponde con unos $415 K\left(142^{\circ} \mathrm{C}\right)$. 


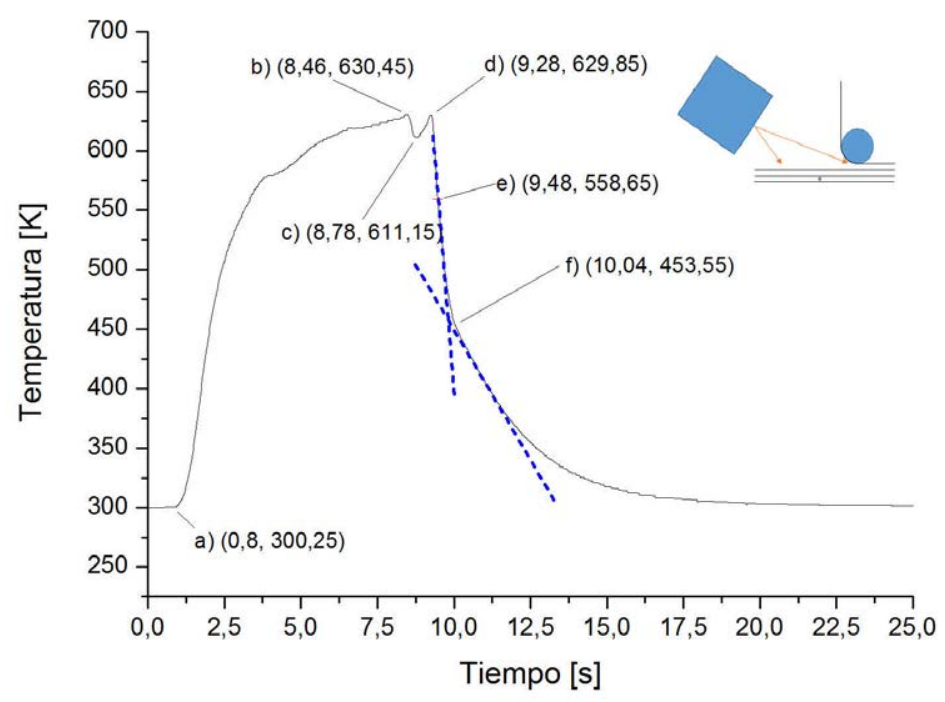

Figura 4.5: Perfil temperatura vs tiempo punto entre capas 1 y 2 encintando capa 4 con útil frío - Lectura con OMEGA CHAL-002

En el encintado de la capa 5, recogido en la Figura 4.6, se observa que con la modificación del perfil de calentamiento, el máximo aparece con anterioridad a como tenía lugar en las ejecuciones de las capas 3 y 4 . Como ya se indicó, la óptica variable del láser permite que la zona de calentamiento se adapte para generar un calentamiento mayor en el área más separada del NIP. El máximo de temperatura registrado en esta etapa de la laminación son unos $615 K\left(\sim 340^{\circ} \mathrm{C}\right)$. Este valor de temperatura, coincide aproximadamente con el pico de fusión del polímero (observado por calorimetría), lo que indica que la fusión no será completa, quedando remanente de cristal previo que pudiera existir sobre el que generar las subsiguientes formaciones cristalinas.

Encintando una capa más sobre el conjunto, la capa 6, cuyo perfil se ilustra en la Figura 4.7 la máxima temperatura alcanzada por el punto se aproxima a $600 \mathrm{~K}\left(\sim 325^{\circ} \mathrm{C}\right)$. Este valor es aproximadamente el valor del onset extrapolado de fusión (corte de las rectas tangentes en el inicio del pico de fusión; este valor debe tomarse con cautela pues como se reportará en el capítulo destinado al análisis de la cristalización del polímero, su valor puede modificarse según el estado previo de cristalinidad en que se encuentre el material). La anterior afirmación implicaría que durante el encintado de la capa 6, un punto entre las capas 1 y 2 se encuentra en su límite para experimentar fusión. Si el polímero no funde, podría generarse cristalización 


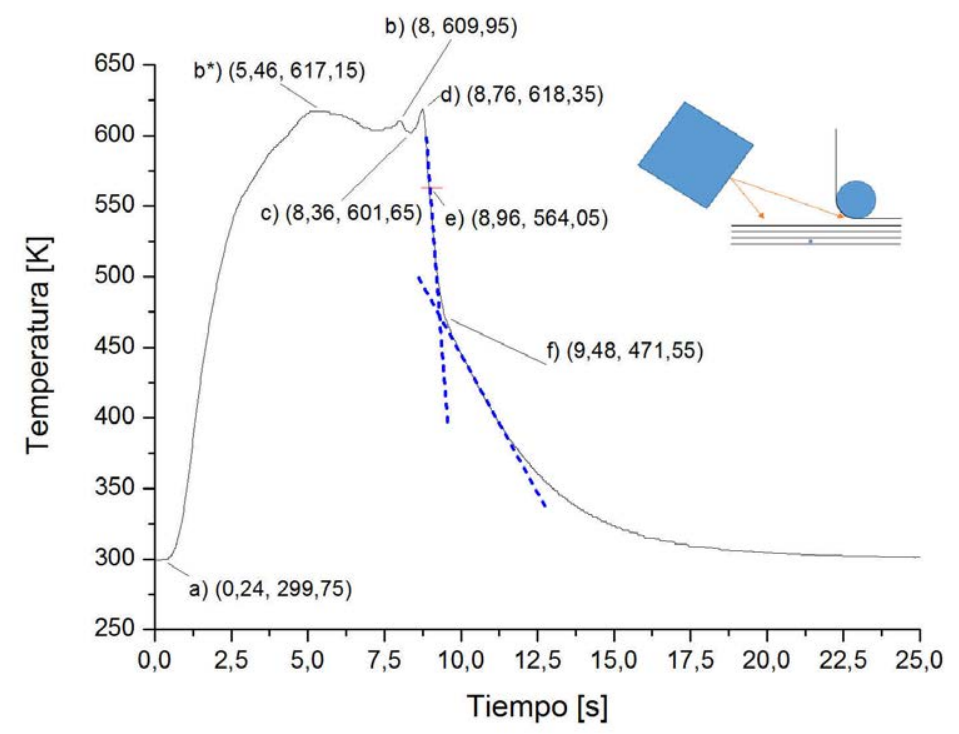

Figura 4.6: Perfil temperatura vs tiempo punto entre capas 1 y 2 encintando capa 5 con útil frío - Lectura con OMEGA CHAL-002

fría al someterse a una temperatura sobre la transición vítrea pero bajo la fusión. La transición o cambio de tendencia en el enfriamiento aparece a una temperatura similar a la observada durante el encintado de capa 5, $472 \mathrm{~K}$ $\left(\sim 200^{\circ} \mathrm{C}\right)$. El hecho de encontrarse en el límite del desarrollo de la fusión supone un gran condicionante para el desarrollo de la posterior cristalización y también para los fenómenos de consolidación en el material, la viscosidad del polímero a esa temperatura es más elevada pero las cadenas pueden continuar desplazándose en la entrecara (siempre y cuando los cristales no bloqueen los movimientos) para incrementar el grado de difusión y por tanto incrementar la resistencia de esa unión, esto tiene una implicación directa en las mejores resistencias en las entre-caras de las capas inferiores respecto a las superiores, luego como se deriva de la anterior explicación, se produce un acoplamiento de los distintos fenómenos del encintado. 


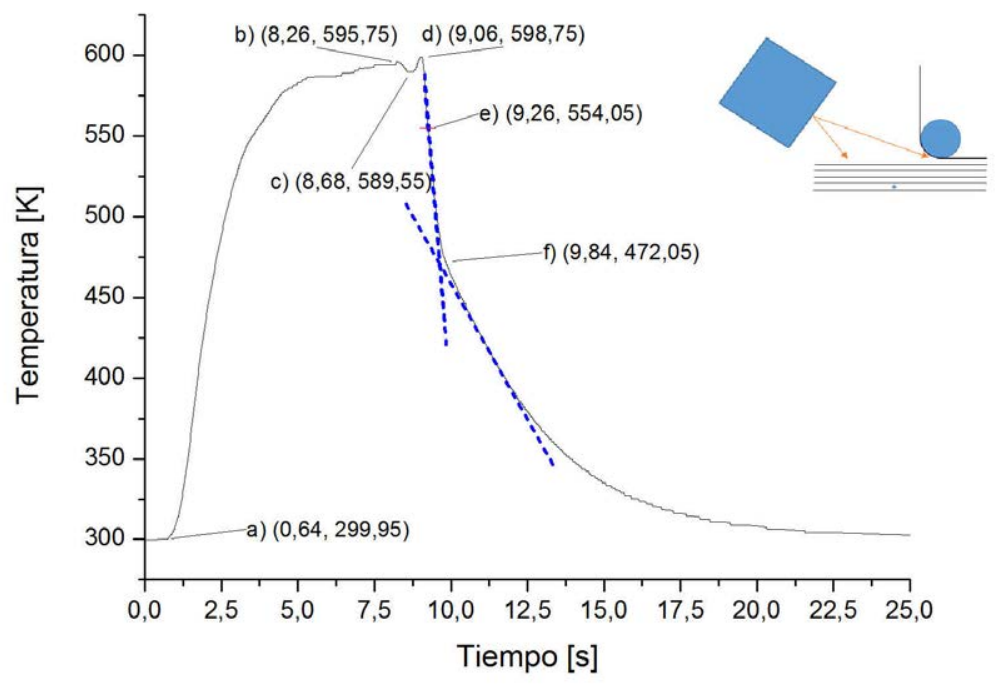

Figura 4.7: Perfil temperatura vs tiempo punto entre capas 1 y 2 encintando capa 6 con útil frío - Lectura con OMEGA CHAL-002

En el encintado de la capa 7 (Figura 4.8), la máxima temperatura registrada por el termopar fue de unos $590 K\left(\sim 315^{\circ} \mathrm{C}\right)$, temperatura a la cual no se espera que el material funda pero sí que supere su transición vítrea. El cambio en la tendencia del perfil de enfriamiento se mantiene en el entorno de los $470 K\left(\sim 200^{\circ} C\right)$ ya obtenidos desde el encintado de la quinta capa.

En el encintado de la capa 8, representado en la Figura 4.9, la máxima temperatura registrada fue de $580 \mathrm{~K}\left(\sim 300^{\circ} \mathrm{C}\right)$. Ese valor fue también el obtenido durante el encintado de capa 9, reportado en la Figura 4.10. En el periodo de enfriamiento tras el encintado de la capa 9, las tendencias de enfriamiento en el punto de medida han cambiado, pasando a experimentarse rampas de $130 \mathrm{~K} / \mathrm{s}(7800 \mathrm{~K} / \mathrm{min})$ y $20 \mathrm{~K} / \mathrm{s}(1200 \mathrm{~K} / \mathrm{min})$. 


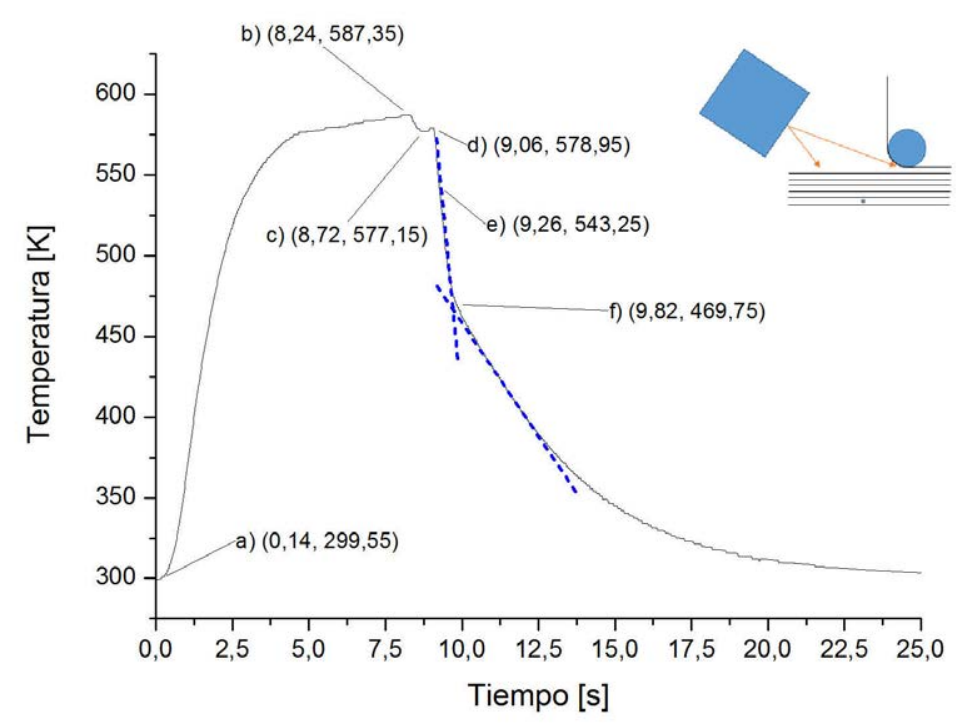

Figura 4.8: Perfil temperatura vs tiempo punto entre capas 1 y 2 encintando capa 7 con útil frío - Lectura con OMEGA CHAL-002

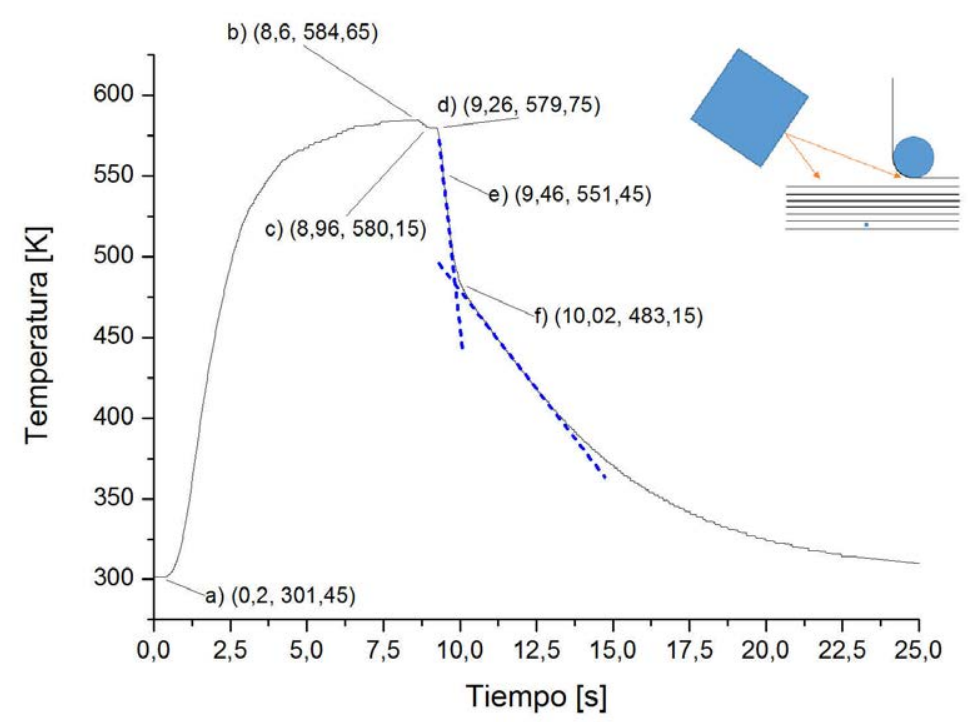

Figura 4.9: Perfil temperatura vs tiempo punto entre capas 1 y 2 encintando capa 8 con útil frío - Lectura con OMEGA CHAL-002 


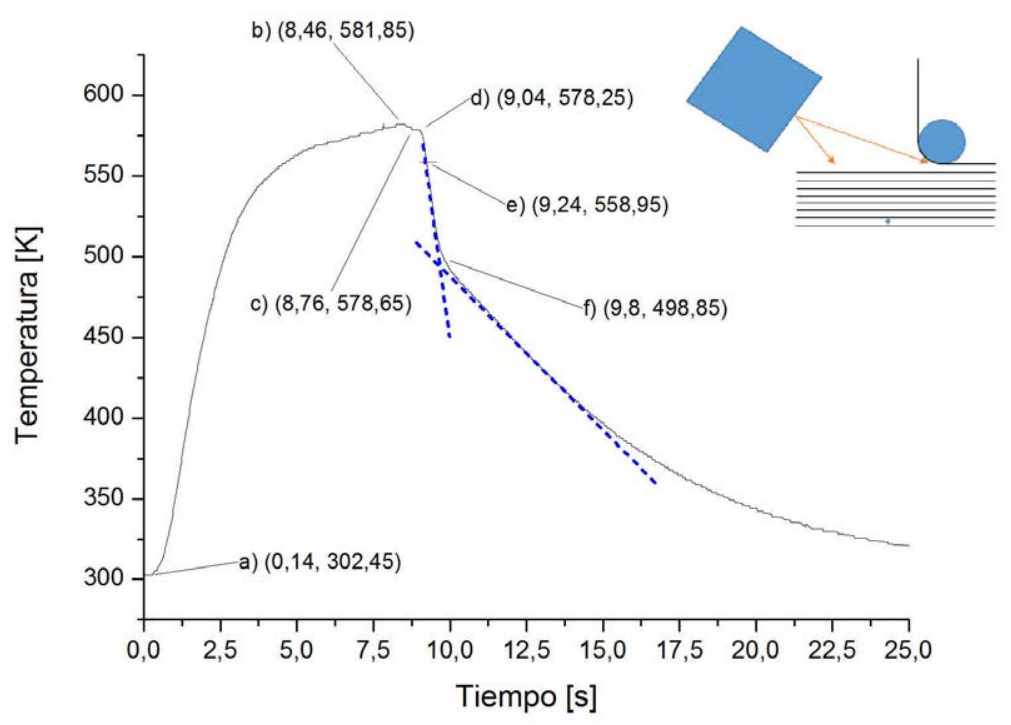

Figura 4.10: Perfil temperatura vs tiempo punto entre capas 1 y 2 encintando capa 9 con útil frío - Lectura con OMEGA CHAL-002

Cuando se ejecuta el encintado de la capa 10 (Figura 4.11), el hecho más significativo detectable es la no recuperación de la temperatura inicial en el enfriamiento transcurridos los $25 \mathrm{~s}$ considerados para la representación del perfil $\mathrm{T}$ - $\mathrm{t}$ en todos los casos anteriores. Al concluir los $25 \mathrm{~s}$, el punto queda unos $50 K$ sobre el valor de temperatura $300 K$. En esta situación, el salto en las rampas de enfriamiento se localiza en $500 \mathrm{~K}\left(\sim 220^{\circ} \mathrm{C}\right)$.

Los siguientes estadios del encintado, desde capa 11 y hasta la capa 16 (recogidos en las Figuras 4.12, 4.13, 4.14, 4.15, 4.16 y 4.17), muestran perfiles similares. La diferencia a destacar, consiste en una leve recuperación de temperatura detectable justo tras la primera rampa de enfriamiento desarrollada por el material.

Tal y como se ejecutan los laminados en la producción de paneles para la caracterización mecánica del material bajo esta tecnología, suele elaborarse una última pasada de re-consolidación sin aporte de material, únicamente con calentamiento láser y compactación con el rodillo. La Figura 4.18 contiene la información del perfil tiempo-temperatura recogido por el termopar durante esa pasada de re-consolidación. Comparando su resultado con el del encintado de la capa 16 (Figura 4.17), no se observan diferencias destacables, la gran distancia que separa al punto de la fuente de calor, impide al sensor captar la variación que puede suponer el posicionado de material. En 


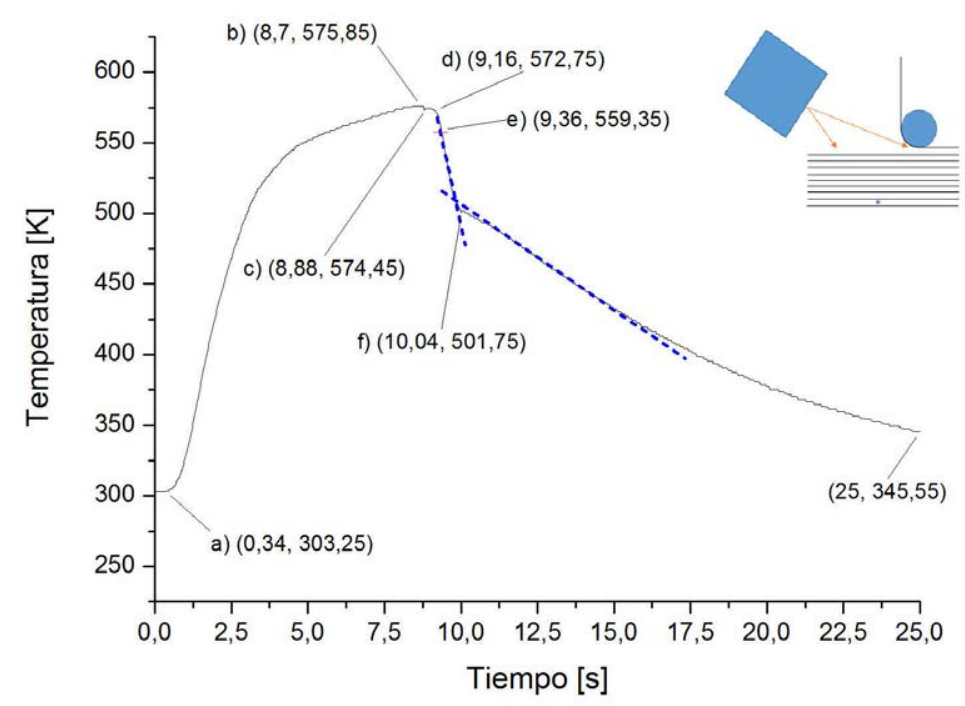

Figura 4.11: Perfil temperatura vs tiempo punto entre capas 1 y 2 encintando capa 10 con útil frío - Lectura con OMEGA CHAL-002

ejecuciones más próximas al termopar donde se han registrado medidas con y sin aporte de material, la única diferencia que pudo ser detectada entre los perfiles se relacionaba con la segunda pendiente del enfriamiento, siendo un poco más lento el enfriamiento sin aporte de material que con él, sin embargo, toda el área de calentamiento y hasta el contacto del rodillo presentaba la misma forma en los gráficos, indicando por tanto que el material aportado no afecta directamente a ese perfil.

Tras en análisis individual de cada uno de los picos, éstos han sido representados de modo conjunto en la Figura 4.19 y también se ha recogido la evolución de los máximos de temperatura alcanzados en cada etapa del encintado como función de la distancia a la fuente de irradiación láser en la Figura 4.20, Ambos gráficos permiten observar que, en un encintado con 16 capas, un punto posicionado entre las capas 1 y 2 experimentará una temperatura superior a la de fusión de equilibrio cuando el láser pase justo encima del punto, es decir, cuando se ejecute el primer posicionado de material. Cuatro capas por encima, el material seguirá experimentando fusión aunque el grado en que está se produce será cada vez menor. Cinco capas sobre el punto, la temperatura ya no sobrepasará la del onset de fusión (salvo en dos situaciones puntuales, pues la tendencia de comportamiento no es completamente homogénea por como transcurre el proceso de encintado y por posibles irregularidades en el material), pero se mantendrá en todo el 


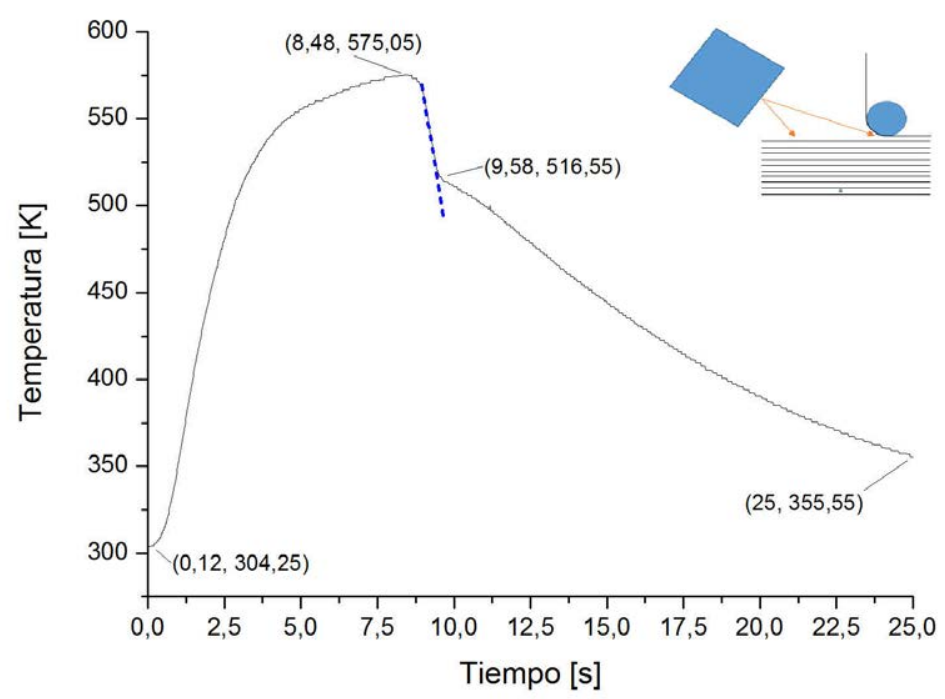

Figura 4.12: Perfil temperatura vs tiempo punto entre capas 1 y 2 encintando capa 11 con útil frío - Lectura con OMEGA CHAL-002

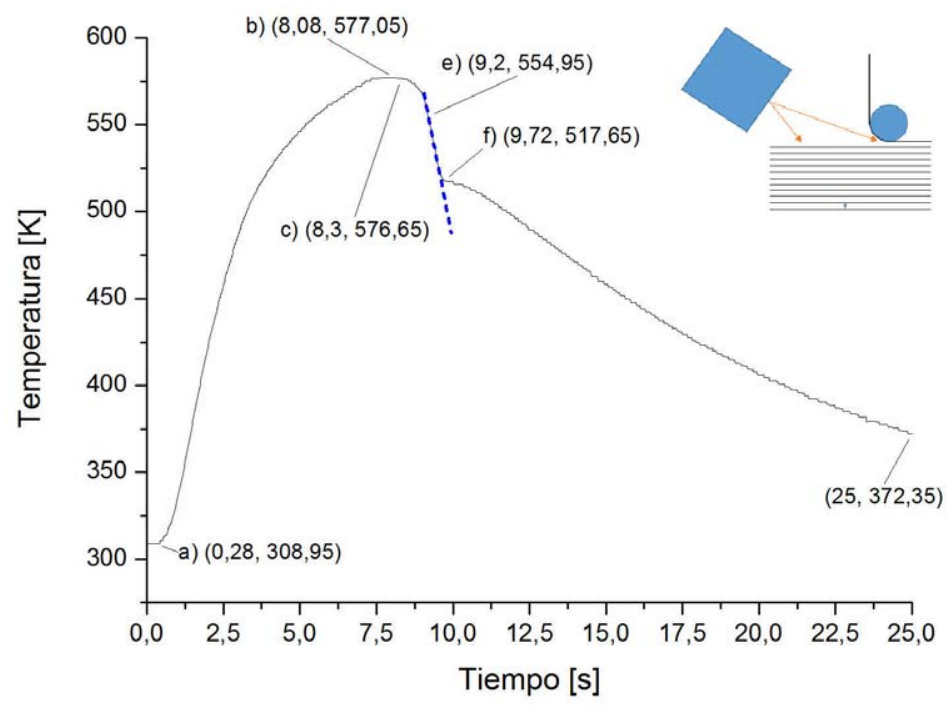

Figura 4.13: Perfil temperatura vs tiempo punto entre capas 1 y 2 encintando capa 12 con útil frío - Lectura con OMEGA CHAL-002 


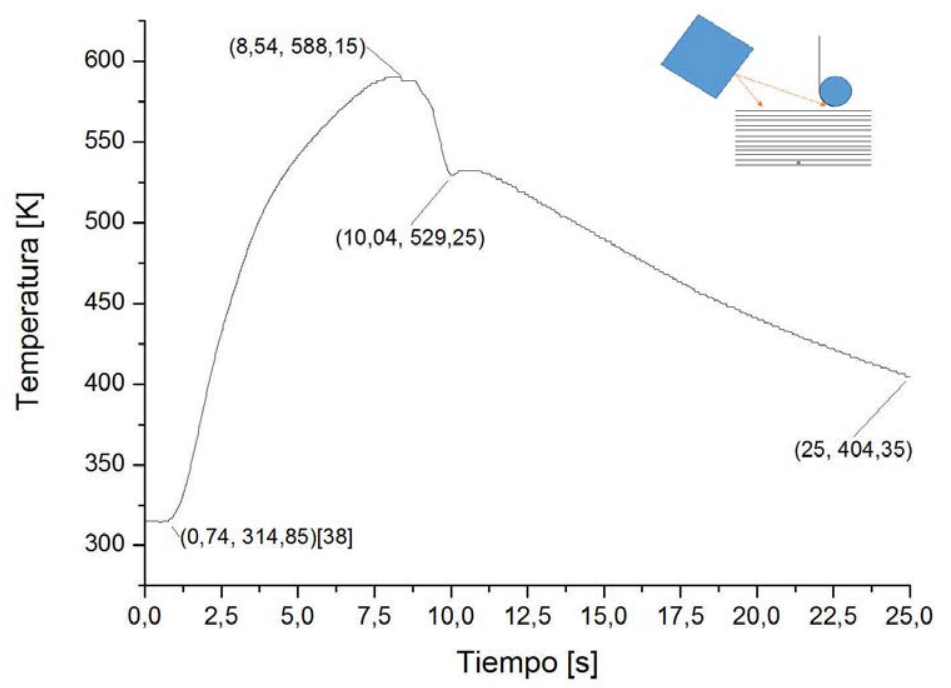

Figura 4.14: Perfil temperatura vs tiempo punto entre capas 1 y 2 encintando capa 13 con útil frío - Lectura con OMEGA CHAL-002

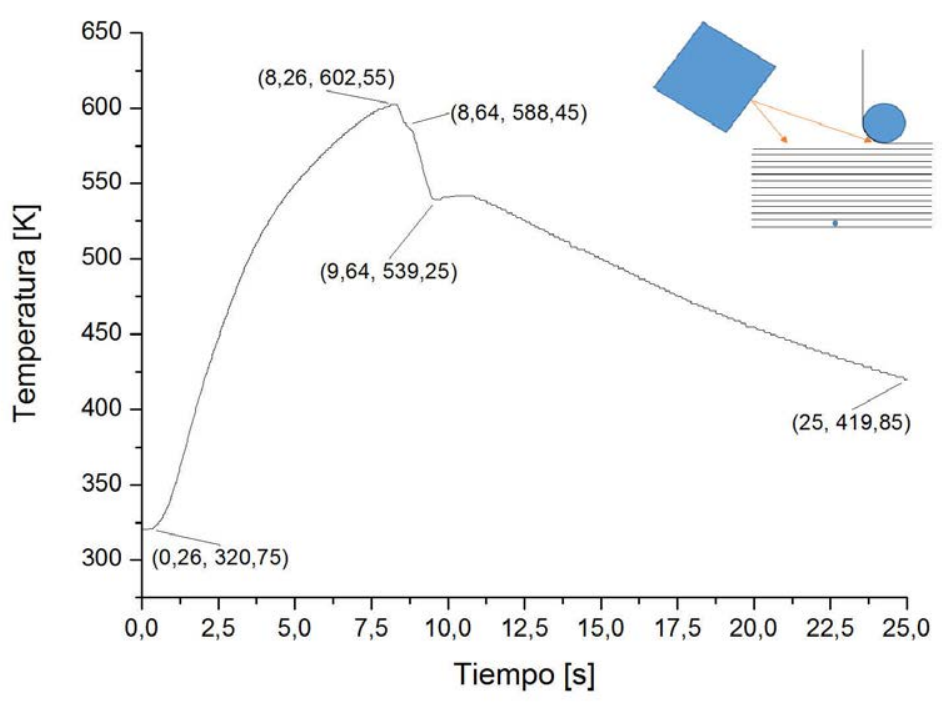

Figura 4.15: Perfil temperatura vs tiempo punto entre capas 1 y 2 encintando capa 14 con útil frío - Lectura con OMEGA CHAL-002 


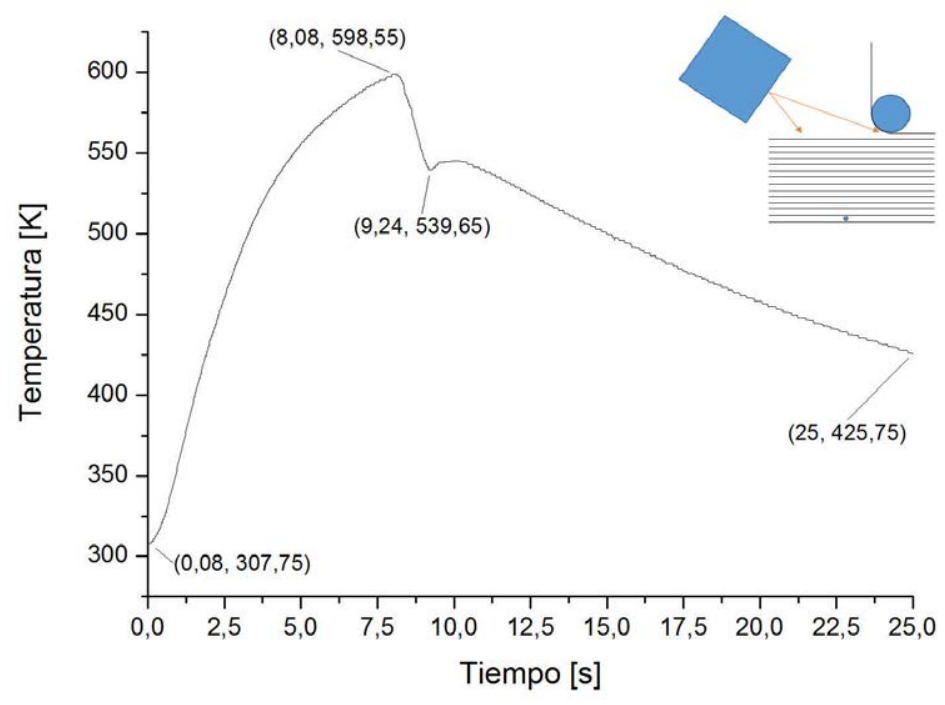

Figura 4.16: Perfil temperatura vs tiempo punto entre capas 1 y 2 encintando capa 15 con útil frío - Lectura con OMEGA CHAL-002

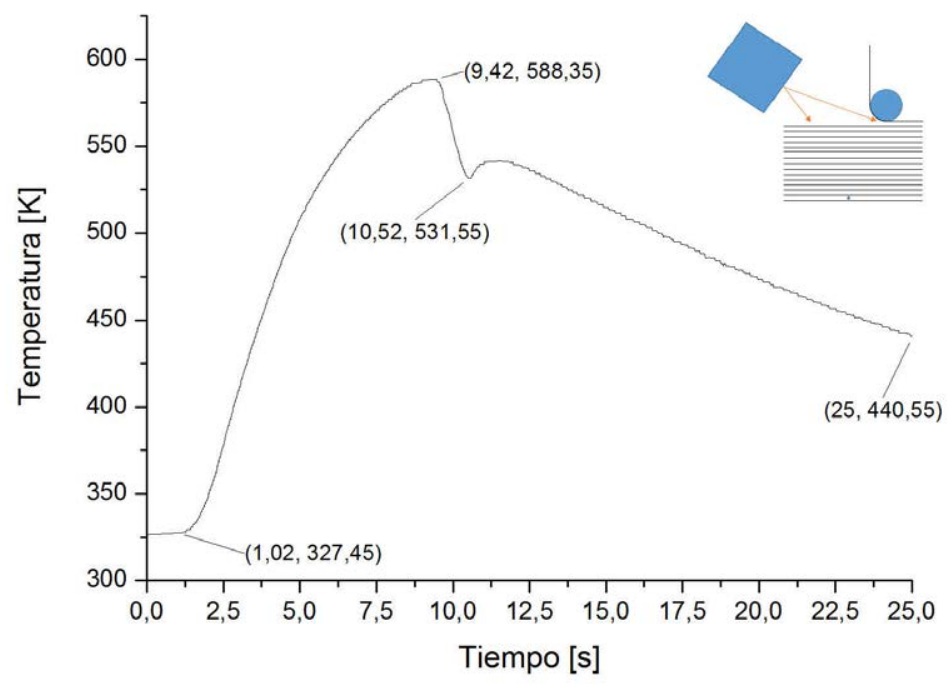

Figura 4.17: Perfil temperatura vs tiempo punto entre capas 1 y 2 encintando capa 16 con útil frío - Lectura con OMEGA CHAL-002 


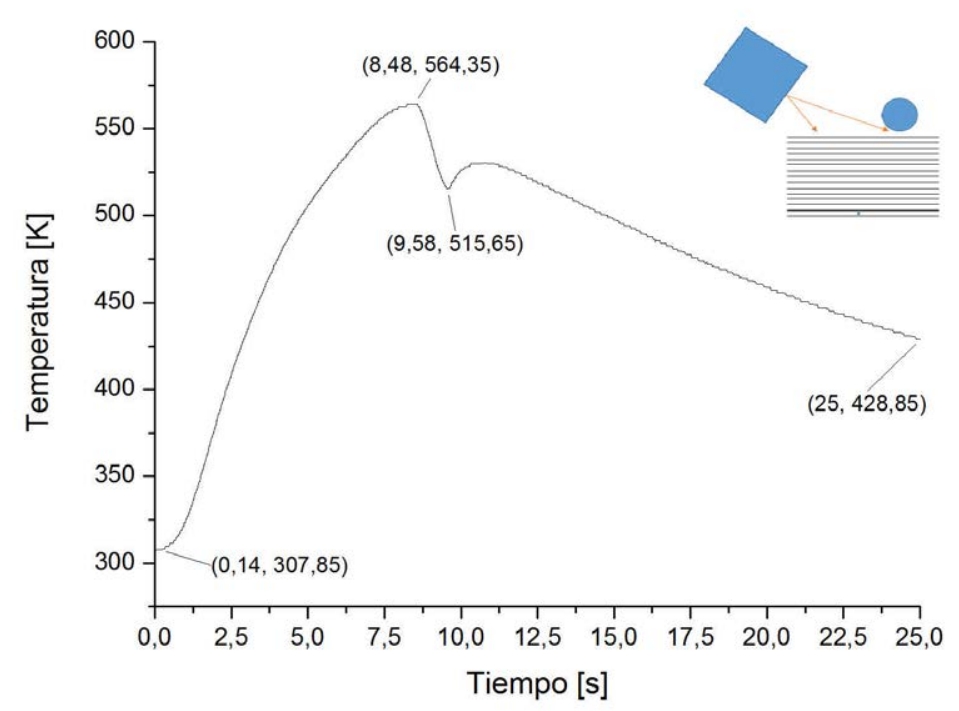

Figura 4.18: Perfil temperatura vs tiempo punto entre capas 1 y 2 reprocesando sobre la capa 16 sin aporte de material con útil frío - Lectura con OMEGA CHAL-002

encintado sobre su transición vítrea.

Según las anteriores observaciones, el único momento en que el material conseguirá eliminar todo el estado previo de posible cristalización existente será justo en el instante de recibir la irradiación directa del láser sobre él. Trascurrida esa etapa, en las siguientes 3 pasadas de calentamiento, el material podrá fundir parcialmente y alcanzada la cuarta, no se producirá más la fusión de esa capa. Esta situación debe analizarse desde el punto de vista de la cristalización del material, desde que no es capaz de superar la temperatura de fusión de equilibrio, quedarán remanentes de cristal en el polímero pudiendo acelerar el proceso de cristalización y actuando como nucleantes en el proceso de cristalización posterior. Además, desde que el material no sea capaz de llegar al onset de fusión, se producirá una posible interacción de la cristalización fría que se acoplará al efecto de la falta de fusión anteriormente mencionada, efectos que deberían comenzar a apreciarse desde el encintado de la tercera capa del laminado y que serán más acusados desde la sexta.

Por otro lado, las consideraciones anteriores también deben tenerse en cuenta desde el punto de vista del desplazamiento de las cadenas poliméricas en las entre-caras. Según el resultado observado, un punto volverá a fundir hasta que se completa la colocación de hasta 4 capas sobre él. No siendo una 


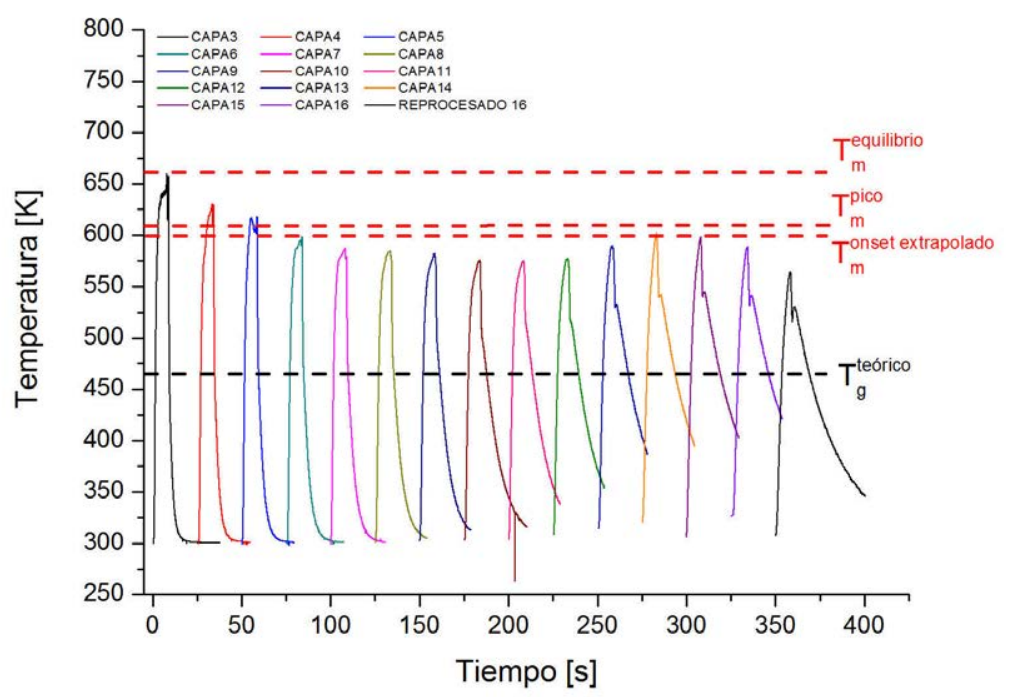

Figura 4.19: Perfil temperatura vs tiempo punto entre capas 1 y 2 tras el encintado de 16 capas con útil frío - Lectura con OMEGA CHAL-002

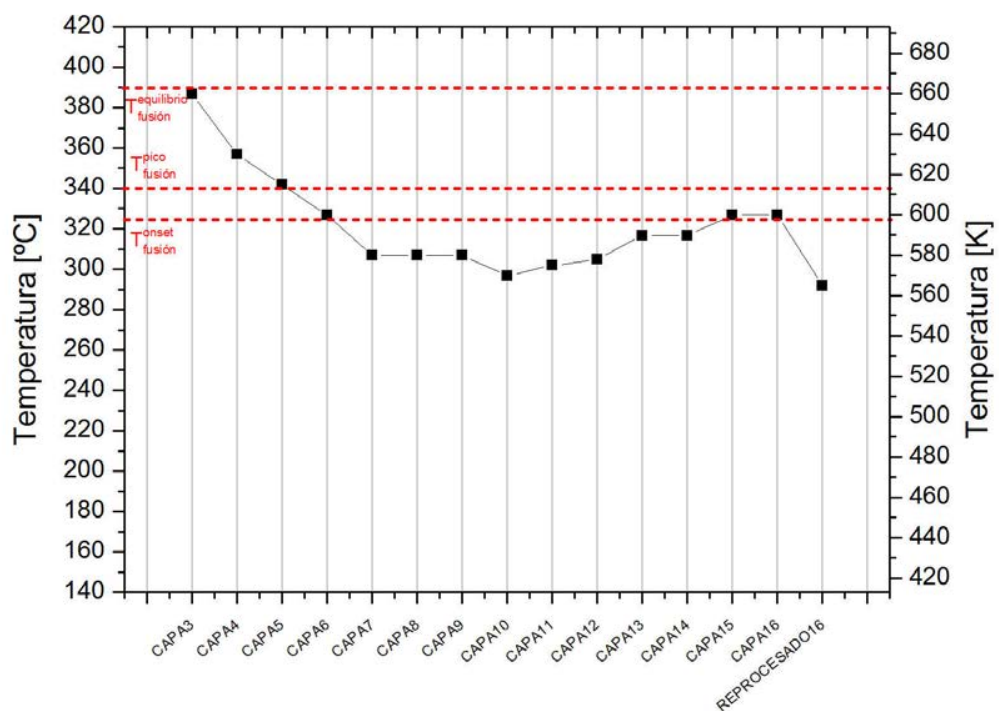

Figura 4.20: Evolución de los máximos registrados por el termopar durante el encintado - Lectura con OMEGA CHAL-002 
fusión completa pero otorgando al material movilidad para la eliminación de la rugosidad superficial y permitiendo que las cadenas repten con facilidad en las entrecaras. Superado ese límite de 4 capas, la temperatura no alcanzará la fusión y la reptación de las cadenas en la entre-cara se verá más limitada no solo por viscosidad sino también por las formaciones cristalinas. A causa de los efectos anteriores, se estima que el mayor grado de consolidación podrá alcanzarse durante las primeras 4 pasadas sobre el punto en consideración. Por ello, en un encintado con 16 capas y considerando un único reprocesado sin aporte de material sobre la capa 16, serán las capas 14,15 y 16 y las entre caras entre ellas, las zonas más afectadas por efectos de desconsolidación y una cristalización diferente a la del resto del laminado.

Con el fin de comprobar algunas de las hipótesis elaboradas sobre el comportamiento térmico, se ha tratado de profundizar en el efecto del rodillo sobre el perfil de enfriamiento.

Vista la dificultad para establecer una causa fija a los efectos observados en los perfiles, se optó por efectuar una modificación en el "set-up" de máquina, persiguiendo variaciones que fueran capaces de demostrar las diferencias. Para ello se ejecutó la misma prueba descrita anteriormente pero con un rodillo de compactación tipo cerámico, este rodillo no presenta capacidad de deformación por lo que el área de actuación del mismo se ve reducida. Si el punto de cambio en la tendencia del perfil de enfriamiento está asociado al rodillo, los nuevos gráficos incorporarán evidencias de su impacto.

En el rodillo cerámico, la huella de presión en el sentido del encintado son unos $3 \mathrm{~mm}$, lo cual supone un tiempo de permanencia de aproximadamente $0,18 \mathrm{~s}$ bajo la acción del mismo, frente a los $0,72 \mathrm{~s}$ del rodillo deformable (considerando $1 \mathrm{~m} / \mathrm{min}$ la velocidad del encintado). En este caso, la monitorización se ha hecho con la máxima frecuencia de muestreo, de modo que se obtuviera una medida cada $8 m s$ con el fin de obtener más resolución en la medición. Tal y como puede observarse en la Figura 4.21 en el rodillo cerámico se pierde el efecto de caída y recuperación, posiblemente porque la sombra generada por el mismo es menor o porque ese efecto esté generado por el perfil de presión no constante del rodillo deformable. El cambio en la transición del enfriamiento aparece adelantada en el tiempo para el rodillo cerámico pues su área de aplicación es inferior.

Las observaciones anteriores parecen indicar que las áreas de aplicación de la presión son superiores a las que se habían presupuesto en el análisis y que habían sido obtenidas con sensores de presión. Las longitudes que se estiman según estos gráficos son de $21 \mathrm{~mm}$ para el caso del rodillo deformable y $11 \mathrm{~mm}$ para el cerámico. 
La evolución con el encintado de las monitorizaciones mediante el empleo de rodillo cerámico quedan recogidas en la Figura 4.22 donde aparecen como ejemplo, los perfiles tiempo temperatura para un punto entre las capas 1 y 2 durante el encintado de las capas (a) 5, (b) 8, (c) 11 y (d) 16.

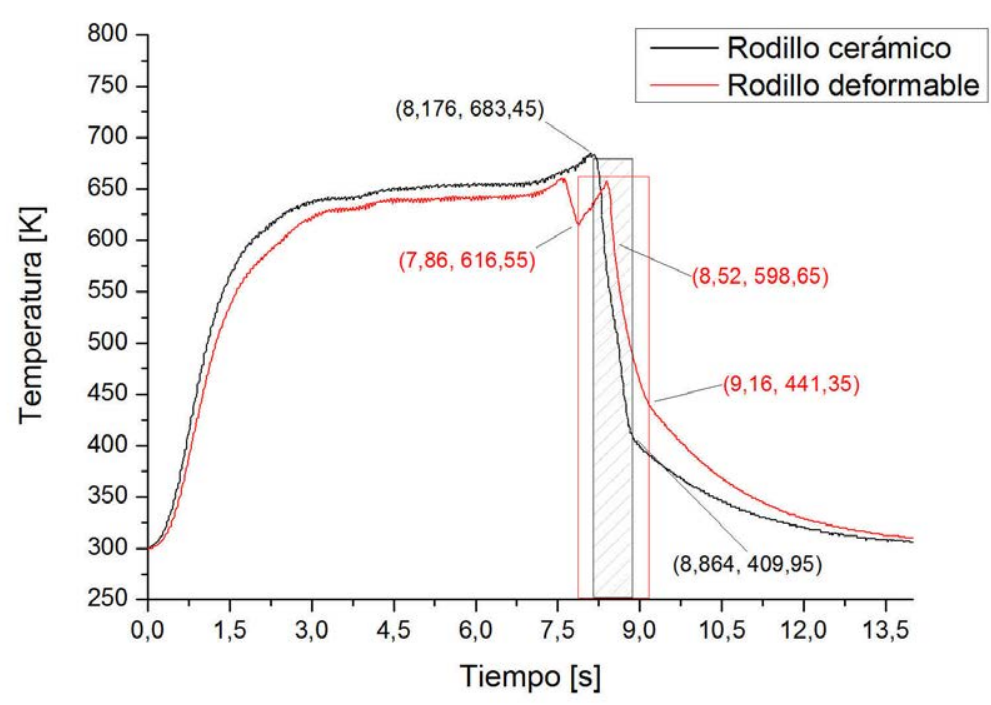

Figura 4.21: Perfil temperatura vs tiempo punto entre capas 1 y 2 encintando capa 3 con útil frío con rodillos diferentes - Lectura con OMEGA CHAL-002, los rectángulos incluidos tratan de aproximar las áreas de compactación de cada uno de los rodillos considerados 


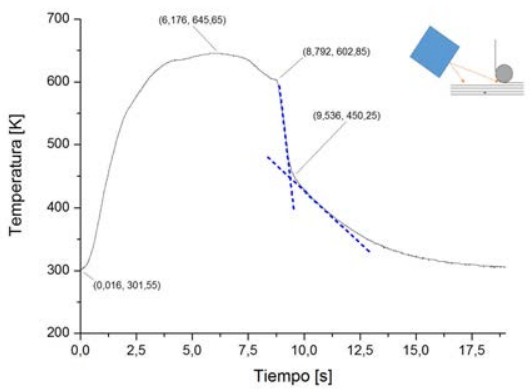

(a)

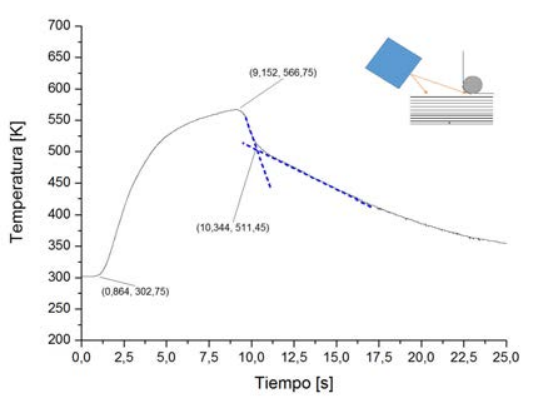

(c)

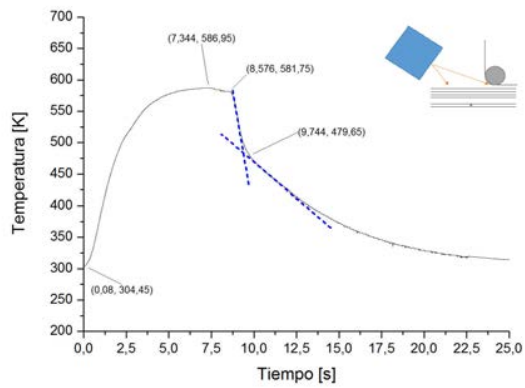

(b)

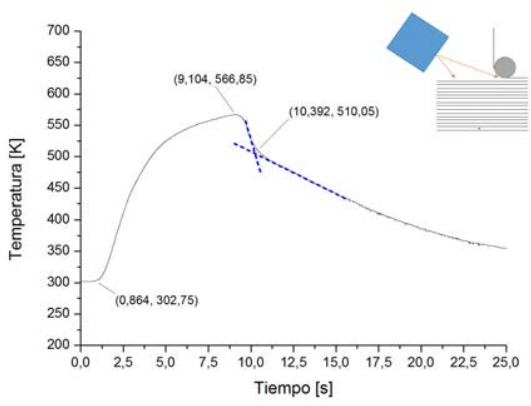

(d)

Figura 4.22: Perfil temperatura vs tiempo, punto entre capas 1 y 2 encintando capa (a) 5, (b) 8, (c) 11 y (d) 16, con útil frío y rodillo cerámico - Lectura con OMEGA CHAL-002 


\subsubsection{Simulación térmica}

Considerando la complejidad de la resolución matemática de la ecuación del calor por medios analíticos, se decidió simplificar el estudio a un problema bi-dimensional y aplicar su resolución numérica con el método de elementos finitos y el software de análisis Comsol Multiphysics y el módulo de transferencia de calor en sólidos. La resolución se basa en las hipótesis que se incluyen a continuación.

- Se considera un caso bi-dimensional, tratando de analizar qué ocurre con la transferencia de calor en la dirección "z" del laminado.

- Fuente de calentamiento (flujo de calor hacia el laminado). Se considera que el calentamiento es uniforme en la longitud calentada (en el caso real del proceso de encintado, la distribución del calor es normalmente no homogénea a causa del empleo de un láser con óptica variable). Además se ha estimado inicialmente una zona de calentamiento y una zona de contacto con el rodillo, sin valorar los efectos de sombra generados por el rodillo en el NIP. Dado que el desarrollo experimental ha empleado un láser de óptica variable, el área de calentamiento puede presentar también una alta heterogeneidad detectable en variaciones de la lectura en función de la posición de colocación del termopar. En el trabajo tampoco se ha tenido en cuenta el efecto de la capacidad real del material para absorber la radiación láser y el efecto de las reflexiones y rebotes de los rayos del láser por la necesidad de elaborar una caracterización óptica previa del material de encintado y un acoplamiento del modelo térmico con modelos ópticos. Sí se ejecuta un análisis donde se busca determinar si existe un mejor ajuste de los perfiles cuando se aplica un factor de corrección sobre el máximo de la potencia irradiada, corrección que pretende simular el efecto de la no absorbancia del total de la radiación.

- Conducción de calor en dirección longitudinal y transversal a la fibra como funciones dependientes de la temperatura.

- Transferencia de calor por convección con el aire circundante (en reposo, se estima que no hay convección forzada por la velocidad a la que se efectúa la laminación).

- Análisis de resistividad térmica en las entrecaras a causa de la posible presencia de aire, que irá variando a medida que incrementa el contacto íntimo entre las partes (en este estudio, este parámetro no se irá variando con el número de capas encintadas sino que se estima un valor constante para todas las entrecaras de material en todo instante a través de una condición de "Resistive layer"). En un caso de encintado 
real, las sucesivas pasadas de deposición de material, ejercen un efecto de re-consolidación sobre las capas inferiores y por tanto, el efecto de resistividad térmica entre capas irá disminuyendo a medida que crece el espesor; tener en cuenta este efecto requiere conocer con más precisión la evolución del grado de contacto íntimo con el crecimiento en espesor y por tanto un acoplamiento de modelos del proceso.

- El análisis no ha tenido en cuenta los procesos exotérmico/endotérmico causado por los fenómenos de fusión/cristalización en el material. Estas fuentes de calor son, en general, mucho menos influyentes que otras por lo que se cree que despreciarlas no tiene un efecto relevante sobre los resultados. En el estado del arte de este documento fueron referenciados diversos trabajos que apoyan esta hipótesis.

- Considerando las dimensiones ancho/largo de las tows, se podría despreciar la transferencia de calor desde los extremos, no obstante, en la simulación se han aplicado condiciones de flujo de calor al ambiente en dichos contornos.

- La capacidad calorífica del material se ha considerado dependiente de la temperatura.

- Transferencia de calor por conducción con el rodillo de compactación.

- Conducción térmica con el útil de encintado. Estimando las posibles situaciones de útil calefactado y sin calefactar y tomando como material un metal (aluminio).

- Se estima que las superficies del útil en contacto con el entorno tienen un comportamiento adiabático (sin intercambio de calor hacia dicho entorno).

- El efecto de la velocidad de desplazamiento de la máquina se ha tenido en cuenta mediante la incorporación de una ecuación en "fuente de calentamiento" y en "rodillo" que modifique sus posiciones con el tiempo.

Teniendo en cuenta las anteriores físicas interactuando, las ecuaciones que describirán el problema a resolver se adjuntan a continuación.

- Ecuación 4.1 Transferencia de calor en sólidos .

$$
\rho C_{p} \frac{\partial T}{\partial t}+\rho C_{p} \mathbf{u} \cdot \nabla T=\nabla \cdot(k \nabla T)+Q
$$


- Útil adiabático (condición aplicada a los laterales derecho e izquierdo del útil), Ecuación 4.2 .

$$
-\mathbf{n} \cdot(-k \nabla T)=0
$$

- Temperatura útil (en caso de tener mesa calefactada, Ecuación 4.3 o mesa fría, Ecuación 4.4.

$$
\begin{gathered}
T_{u \text { útil caliente }}=473 \mathrm{~K} \\
T_{u \text { út frio }}=300 \mathrm{~K}
\end{gathered}
$$

- Fuente de calentamiento, Ecuación 4.5 y Ecuación 4.6

$$
\begin{gathered}
-\mathbf{n} \cdot(-k \nabla T)=Q_{b} \\
Q_{b}=\frac{P_{b, t o t}}{A}
\end{gathered}
$$

- Condición resistiva entre capas

Se va a estimar que la dimensión de una porosidad entre capas puede tener un orden de unos $20 \mu m$ y que en ella el valor del coeficiente de transferencia térmica se aproxima en orden de magnitud al del aire; $10 \mathrm{~W} / \mathrm{Kmm}^{2}$. Esta condición quedará representada por las ecuaciones $4.7,4.8,4.9$ у 4.10.

$$
\begin{gathered}
-\mathbf{n}_{d} \cdot\left(-k_{d} \nabla T_{d}\right)=-k_{s} \frac{T_{u}-T_{d}}{d_{s}} \\
-\mathbf{n}_{u} \cdot\left(-k_{u} \nabla T_{u}\right)=-k_{s} \frac{T_{d}-T_{u}}{d_{s}} \\
k_{s}=\frac{d_{s}}{\sum_{j} \frac{d_{s j}}{k_{s j}}} \\
d_{s}=\sum_{j} d_{s j}
\end{gathered}
$$

- Transferencia de calor con el rodillo, Ecuación 4.11

$$
-\mathbf{n}_{u} \cdot\left(-k_{u} \nabla T_{u}\right)=h_{\text {roller }} \cdot\left(T_{\text {ext }}-T\right)
$$


- Transferencia de calor con el aire circundante 4.12

$$
-\mathbf{n}_{u} \cdot\left(-k_{u} \nabla T_{u}\right)=h_{a i r} \cdot\left(T_{e x t}-T\right)
$$

Para que el software tuviera en cuenta el desplazamiento de la máquina durante el encintado, las condiciones de Fuente de calentamiento y Transferencia con el rodillo se impusieron a través de la consideración de una función rectángulo con una posición variable tempo-dependiente sobre el laminado.

Se incluyen a continuación las tablas con los parámetros utilizados en la simulación. Por un lado se incluyen los que aplican al proceso, Tabla 4.1 y por otro lado los relativos al material, Tabla 4.2. En relación con los parámetros del material, la mayoría han sido exportados de valores reportados bibliográficamente, mientras que otros como la capacidad calorífica $\left(c_{p}\right)$ han sido calculados experimentalmente, este análisis se incluye en la sección 4.1.2.1.

En la Tabla 4.3 se reportan los valores empleados de convección térmica con el aire y con el rodillo. Bajo la hipótesis de una capa resistiva delgada (aire) entre las capas de material, se ha impuesto un valor para el coeficiente de resistividad térmica entre tows (aplicado en su espesor), de orden $10^{5} \mathrm{~W} / \mathrm{m}^{2} \mathrm{~K}$.

\begin{tabular}{|c|cc|}
\hline Parámetro & Valor & Unidades \\
\hline Velocidad de encintado & 1 & {$[\mathrm{~m} / \mathrm{min}]$} \\
\hline Longitud de calentamiento láser & 130 & {$[\mathrm{~mm}]$} \\
\hline Ancho de calentamiento láser & 7,5 & {$[\mathrm{~mm}]$} \\
\hline Potencia media empleada & $150-300$ & {$[\mathrm{~W}]$} \\
\hline Huella del rodillo & $16 \times 12$ (sentido encintado) & {$\left[\mathrm{mm}^{2}\right]$} \\
\hline
\end{tabular}

Tabla 4.1: Valores simulación - proceso

En el equipo de encintado, el láser se encuentra posicionado con una cierta inclinación respecto a la horizontal tal que permita los $130 \mathrm{~mm}$ de calentamiento sobre el material sustrato. A causa de la divergencia del haz del láser y también como causa de las reflexiones de los rayos del láser desde el material sustrato, se produce también un calentamiento del material de aporte en un área menor. La simulación contabilizará dicho calentamiento previo al posicionado en contacto de las tows de material, permitiendo analizar qué ocurre cuando las proporciones de superficie calentada de material 


\begin{tabular}{|c|c|c|}
\hline Parámetro & Valor & Unidades \\
\hline Espesor lámina APC2/AS4 & 0,135 & {$[\mathrm{~mm}]$} \\
\hline $\begin{array}{l}\text { Densidad }(\rho) \text { APC2/AS4 } \\
(\text { Phillips et al. }, 1994)\end{array}$ & 1600 & {$\left[\frac{\mathrm{kg}}{\mathrm{m}^{3}}\right]$} \\
\hline $\begin{array}{c}\text { Conductividad }\left(k_{L}-k_{T}\right) \text { APC2 } / \mathrm{AS} 4 \\
\text { (Stokes-Griffin et al. } 2015)\end{array}$ & $f_{1}^{a}(T)-f_{2}^{b}(T)$ & {$\left[\frac{W}{m K}\right]$} \\
\hline $\begin{array}{c}\text { Capacidad calorífica }\left(c_{p}\right) \overline{\mathrm{APC} 2} / \mathrm{AS} 4 \\
(\text { Lionetto et al. } 2017)\end{array}$ & $f_{3}^{c}(T)$ & {$\left[\frac{J}{k g K}\right]$} \\
\hline Espesor kapton & 0,06 & {$[\mathrm{~mm}]$} \\
\hline $\begin{array}{l}\text { Conductividad kapton } \\
\text { (MatWeb, 2018) }\end{array}$ & 0,12 & {$\left[\frac{W}{m K}\right]$} \\
\hline Espesor fibra vidrio & 0,18 & [mm] \\
\hline Conductividad fibra vidrio & 0,04 & {$\left[\frac{W}{m K}\right]$} \\
\hline
\end{tabular}

Tabla 4.2: Parámetros de los materiales utilizados

${ }^{a} \mathrm{y}^{b}$ Función de dependencia con la temperatura según (Stokes-Griffin et al. 2015 ${ }^{c}$ estimado por DSC

\begin{tabular}{|c|cc|}
\hline Parámetro & Valor & Unidades \\
\hline $\begin{array}{c}\text { Coeficiente de transferencia de calor (aire) } \\
(\text { Shih }, 1997)\end{array}$ & 10 & {$\left[\frac{W}{m^{2} K}\right]$} \\
\hline $\begin{array}{c}\text { Coeficiente de transferencia de calor (rodillo) } \\
(\text { Stokes-Griffin et al. }\end{array}$ & 1000 & {$\left[\frac{W}{m^{2} K}\right]$} \\
\hline $\begin{array}{c}\text { Coeficiente de } \\
\text { Hransferencia de calor entre tows (aire) } \\
\text { Hipótesis }\end{array}$ & 100000 & {$\left[\frac{W}{m^{2} K}\right]$} \\
\hline
\end{tabular}

Tabla 4.3: Coeficientes convección térmica - proceso

sustrato a alimentado se modifican. Como base, se estima que en el material de aporte, hay unos $15 \mathrm{~mm}$ de material calentados por el láser, presentando la máquina un limitado espacio de área libre en la bajada del material de aporte para el calentamiento láser a causa del peine que constituye el sistema de guiado.

Para la resolución se ha empleado un mallado tipo "mapped", cuyos elementos rectangulares tenían unas dimensiones tales que: 3 elementos constituyendo el espesor de la lámina $(0,14 / 3=0,046 \mathrm{~mm})$ y en sentido longitudinal con una dimensión de $5 \mathrm{~mm}$ por elemento. Un mallado bastante más grueso que el ya reportado en (Nicodeau, 2005), con elementos de dimensión: $0,4 \mathrm{~mm}$ en sentido del encintado y $0,012 \mathrm{~mm}$ en el espesor. La selección de este mallado más gruesa, se vio motivada por el tiempo de cálculo requerido 
para ejecutar las iteraciones en la resolución de un laminado multi-capa para ver la evolución del perfil de un punto con la laminación secuencial con el tiempo de capas sobre el mismo.

El utillaje ha sido modelizado como un rectángulo de espesor aproximado unas 100 veces el espesor individual de capa, dada su gran masa en comparación con la del laminado, su contribución a la transferencia total de calor será mínima.

El análisis temporal del problema se ha hecho considerando unos valores para el tiempo de retroceso del cabezal hacia el punto inicial del encintado, considerando $40 s$ en cada retorno. Esta variable se ha introducido en el modelo de forma paramétrica, siendo posible modificar su valor para acercarlo a las condiciones más próximas a un encintado real. La división temporal en la resolución se ha seleccionado igual a $200 \mathrm{~ms}$ por estimarse un rango suficiente para detectar todas las transiciones interactuando (considerando un encintado a $1 \mathrm{~m} / \mathrm{min}$ ).

Toda la geometría del conjunto se crea inicialmente y los diferentes elementos quedarán inactivos hasta que el láser alcance esa posición de laminación.

Con el fin de facilitar la comparación con los datos experimentales, en la sección 4.1.3 se ha seleccionado en el modelo un punto situado entre las capas 1-2 y se ha representado su perfil térmico (temperatura-tiempo), incluido en la Figura 4.23. Dado que se ha simulado el láser actuando justo desde el borde de inicio del laminado, se ha tomado un punto cuya coordenada en el sentido de encintado estuviera a mayor distancia desde el inicio de encintado que la longitud total de calentamiento de la fuente láser. Para simular el valor de potencia del láser se ha utilizado un valor de $40000 \mathrm{~W}$ para que el software en su cálculo de la densidad de potencia en el tramo de aplicación considere en realidad un valor aproximado de unos $300 \mathrm{~W}$, una condición usual en el encintado con útil frío. 


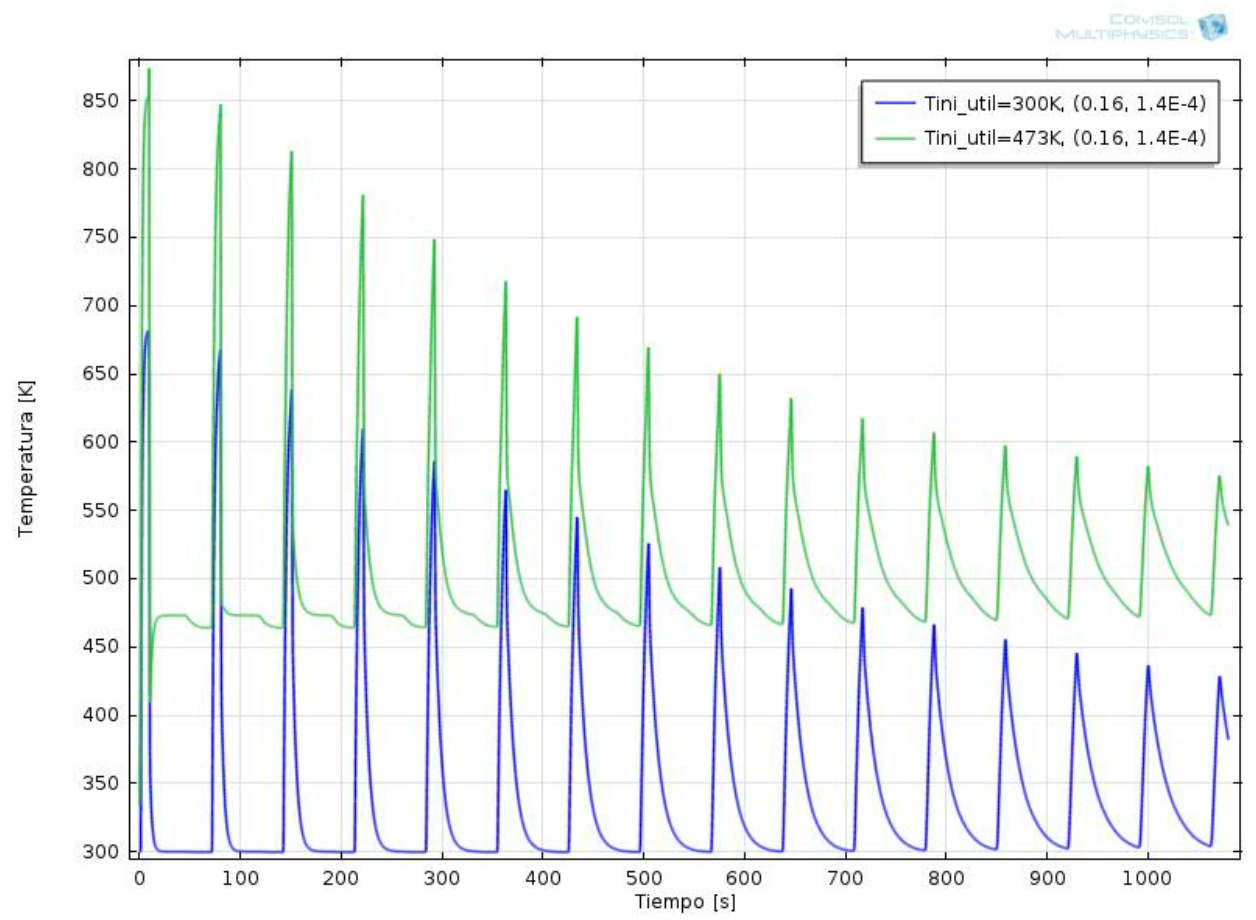

Figura 4.23: Perfil simulado T-t en un punto situado entre capas 1 y 2 encintando 16 capas, con útil frío y útil calefactado

El análisis detallado de los resultados de la simulación y las modificaciones ejecutadas en los diferentes parámetros con el fin de determinar su participación en el resultado, se recogerán en el apartado de comparación simulación-experimental.

\subsubsection{Determinación experimental de la capacidad calorífica}

La capacidad calorífica del material es un parámetro muy relevante en los cálculos pues, en combinación con la densidad $\left(\rho c_{p}\right)$, representan la capacidad calorífica volumétrica en el material, que establece la capacidad del material para almacenar la energía térmica.

Además, la difusividad térmica $\alpha=\frac{k}{\rho c_{p}}$ relaciona este parámetro con la conductividad térmica del material, estableciendo la relación existente en el material para conducir la energía térmica en base a su capacidad para almacenarla. 
Dada la importancia del parámetro y la diversidad de valores encontrados en la búsqueda bibliográfica, se optó por extraer su valor mediante el empleo de la técnica calorimetría diferencial de barrido (DSC), ejecutando ensayos en diferentes programas isotermos que permitían extraer un valor aproximado de dicho parámetro a la temperatura seleccionada.

La elaboración de los ensayos se llevó a cabo siguiendo una instrucción interna desarrollada por FIDAMC. En los ensayos, la extracción del valor de $\left(c_{p}\right)$ se obtuvo mediante la intercomparación con el mismo ensayo ejecutado sobre una muestra de zafiro. Las muestras se calentaban a la temperatura requerida por el programa isotermo especificando modo "Zero Heat Flow" en el procedimiento, de modo que el valor del parámetro se localizaba cuando se alcanzaba ese valor nulo de flujo de calor.

Los valores de capacidad calorífica del zafiro para diferentes temperaturas son conocidos y están tabulados, se recogen en el Apéndice B.

Una vez ensayado el material a la isoterma requerida, el valor real de su $c_{p}$ se extrae utilizando la Ecuación 4.13 que lo relaciona con la constante del zafiro a esa temperatura. Donde el valor de $K_{c_{p}}$ procede de la relación entre los valores teórico y ensayado para el zafiro, como reporta la Ecuación 4.14 .

$$
\begin{gathered}
c_{\text {preal }}=c_{\text {pmedido }} \cdot K_{c_{p}} \\
K_{c_{p}}=\frac{c_{p T}}{c_{p M}}
\end{gathered}
$$

Las primeras ejecuciones experimentales se llevaron a cabo sobre el material puro PEEK 150G, para posteriormente evaluar el resultado sobre APC2/AS4 y extraer una comparativa del efecto causado por la incorporación de la fibra. La elaboración sobre polímero de grado 150G en lugar de 450G se debió a causas de disponibilidad inicial del material, no obstante, se considera que existe una variación menor en órdenes de magnitud entre los dos grados de polímero para este parámetro particular.

A pesar de que en algunas referencias bibliográficas se especifica una distinción entre los valores del parámetro en función de si el material se encuentra en estado cristalino o amorfo, se ha optado por despreciar dicha variación por lo siguientes motivos:

- Es complejo determinar en cada instante particular del proceso de fabricación en qué estado cristalino se encuentra el material. 
- La variación numérica no parece relevante de cara al cálculo de temperaturas.

- Los procesos de calentamiento/enfriamiento son tan rápidos que la variación numérica del parámetro de su valor "ambiente" a "fusión" es casi instantánea quedando por tanto muy limitada la interacción en el proceso del estado cristalino del material.

Los programas isotermos a los que se elaboraron los ensayos fueron: $298 K$, $323 K, 373 K, 448 K, 473 K, 523 K, 613 K, 618 K, 623 K, 628 K, 633 K, 638 K$ y $643 K$. Como puede observarse, hay una gran cantidad de ensayos concentrados en el rango de temperaturas de 610 a $650 \mathrm{~K}$ como causa de tener lugar el proceso de fusión. Para cada una de dichas isotermas, se ejecutaron 3 ensayos con diferentes muestras e idénticas condiciones para analizar su variabilidad, estimándose el valor del coeficiente como el promedio de los tres, se adjunta un ejemplo ilustrativo en la Figura 4.24 para el caso de $373 K$.

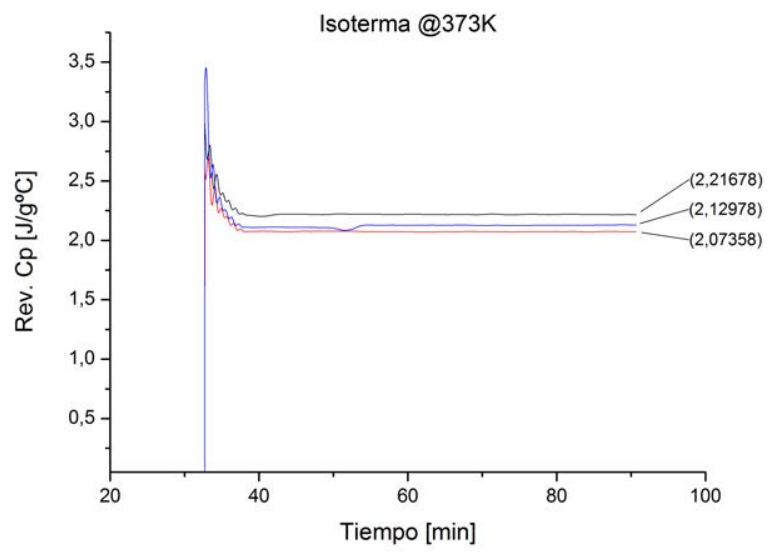

Figura 4.24: Ensayo DSC a $373 K$ para determinación de Cp en APC2/AS4

Tras los diferentes ensayos, fue posible representar la siguiente evolución de la capacidad calorífica del material con la temperatura, Figura 4.25. En la curva es notorio como el material sin carbono presenta una mayor capacidad para almacenar el calor que el reforzado. Los datos del parámetro en función de la temperatura fueron incluidos en la simulación como una función de interpolación. 


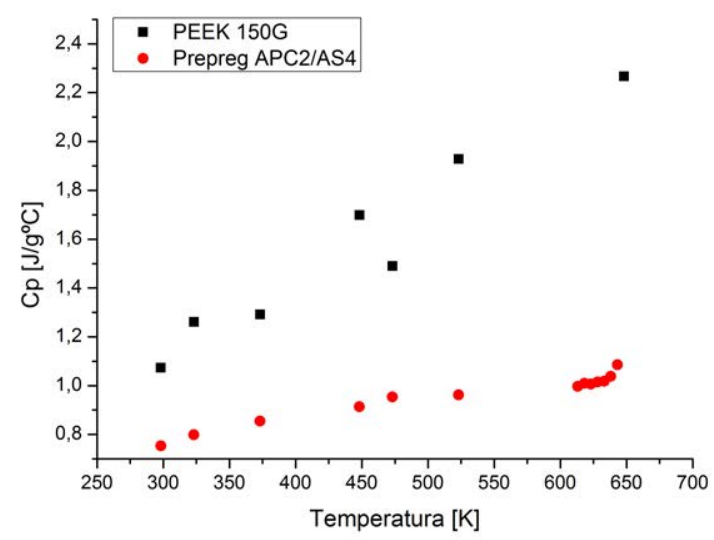

Figura 4.25: Cp vs. temperatura para PEEK 150G y APC2/AS4

\subsubsection{Simulación térmica vs. experimental}

Para analizar la validez del resultado obtenido de la simulación, se van a comparar los resultados en temperatura del segundo pico de la Figura 4.23 (correspondiente a termopar embebido entre capas 1 y 2 encintando 3 ) con el primero de los picos obtenidos en la medida del termopar, Figura 4.19 (correspondiéndose nuevamente con un termopar embebido entre capas $1 \mathrm{y}$ 2, encintando 3). La comparación, recogida por la Figura 4.26 manifiesta la existencia de una desviación entre los máximos en el entorno de $50 \mathrm{~K}$, reflejando la simulación un valor de $700 K$ frente a los $650 K$ del análisis experimental. El valor de potencia especificado en el modelo se corresponde con $300 W$ y durante el encintado real se ha comprobado la necesidad de aplicar valores en el entorno a $300-320 W$. El modelo sobre-estima el valor de la temperatura experimentada por un punto del laminado.

Las causas posibles a esa desviación entre simulación y realidad, radican en el hecho de que en la simulación se está considerando una densidad de potencia homogéneamente distribuida en todo el área de calentamiento mientras que en la realidad, al trabajarse con óptica variable, tal y como se observaba en la Figura 4.1. la distribución de densidad de potencia no es homogénea.

Además, en algunos de los estudios referenciados en el estado el arte de este trabajo indicaban la necesidad de efectuar un acoplamiento termoóptico para tener en consideración la capacidad del material para absorber la radiación del láser en la longitud de onda de trabajo. Al no presentar el material solo absorbancia sino reflejar parte de la radiación recibida, se 


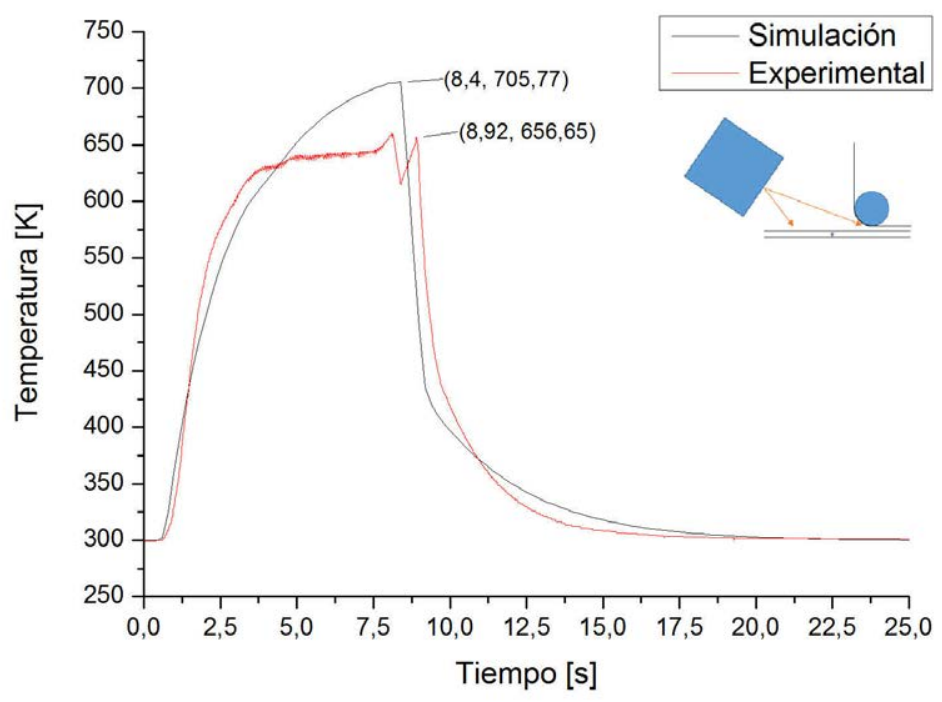

Figura 4.26: Perfil temperatura vs tiempo, punto entre capas 1 y 2 encintando capa 3 con útil frío - Simulación vs. experimental

decidió ejecutar una simulación donde el valor de potencia se multiplicó por un factor de reducción, de modo que su valor se estima como el real impuesto de salida del sistema de control de potencia multiplicado por 0,95, 0,9 o 0,8 . El resultado obtenido se incluye en la Figura 4.27 la aplicación del factor igual a 0,9 reporta el perfil más aproximado al medido por el termopar.

Durante el encintado, la potencia varía en función de los requisitos propios del calentamiento de la capa encintada a través de las lecturas tomadas por una cámara termográfica, experimentalmente se ha comprobado que los incrementos en espesor suponen un requisito de incremento de potencia a medida que se asciende en el espesor del laminado pues la fibra de carbono actúa como un buen sistema conductor del calor, fluyendo hacia las capas inferiores con gran rapidez. En la simulación no se ha tenido en cuenta este efecto y se ha mantenido un valor constante de la potencia durante toda la laminación, cuyo análisis queda pendiente como trabajo futuro derivado de esta tesis doctoral.

En los perfiles simulados también aparecen dos etapas en las que tiene lugar el enfriamiento del material, una primera etapa con un enfriamiento muy brusco y un etapa secundaria donde la caída es más progresiva. Para analizar esa variación, se han ejecutado barridos paramétricos utilizando la herramienta "parametric sweep" del programa. 


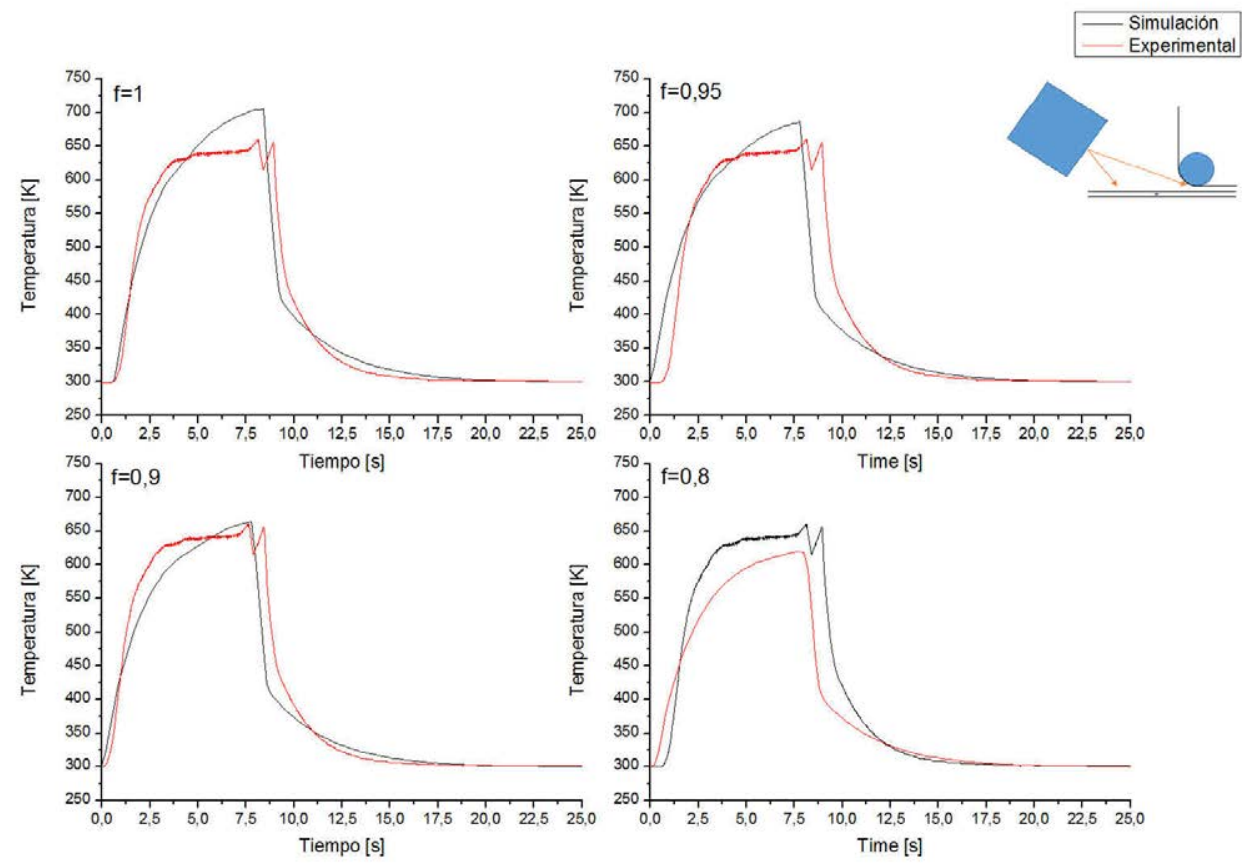

Figura 4.27: Perfil temperatura vs tiempo punto entre capas 1 y 2 encintando capa 3 con útil frío - Simulación vs. experimental con factores multiplicativos en la potencia

A continuación se incluyen una serie de simulaciones con objeto de analizar la influencia de la variación de diferentes parámetros sobre el perfil global de calentamiento del material. Estas simulaciones únicamente pretenden representar tendencias en el comportamiento de los perfiles en función del valor numérico adoptado por los parámetros. 


\subsubsection{Efecto del rodillo}

El rodillo afecta de forma radical a los perfiles de enfriamiento medibles en el laminado; por un lado por la extensión longitudinal de aplicación de su efecto y por otro por la conducción térmica hacia el mismo. Para valorar ambos efectos, han sido elaborados dos barridos paramétricos para observar lo que ocurre durante el encintado de la capa 2 sobre un punto situado sobre capa 1, modificando el valor de la longitud de aplicación de la condición "rodillo" (Figura 4.29) y modificando el valor del coeficiente de transferencia de calor $h_{\text {rodillo }}$ (Figura 4.28.

El resultado de la Figura 4.28 manifiesta que cuanto menor es el coeficiente $h_{\text {rodillo }}$, peor es la transferencia de calor hacia el mismo y por tanto más suave tiene lugar la rampa de enfriamiento en el material. Por contra, cuanto mayor es el valor, más fácil es la transferencia de calor hacia él y más brusco es el enfriamiento.

Teniendo en cuenta los valores observados en el apartado de medida experimental con termopares, donde el termopar registraba un salto en las pendientes de enfriamiento en un valor de temperatura aproximado a $440 \mathrm{~K}$ y considerándose que la huella estimada de aplicación de rodillo se ajusta bien a su valor real, el parámetro $h_{\text {rodillo }}$ debe ser un valor más próximo a $800 \mathrm{~W} / \mathrm{m}^{2} \mathrm{~K}$.

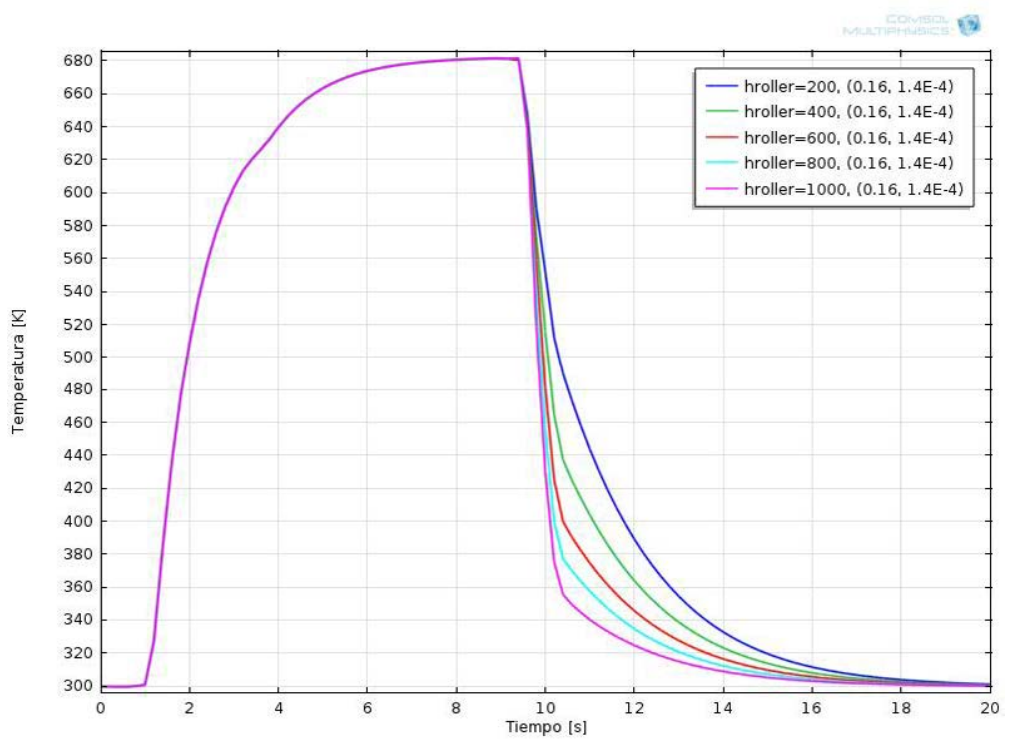

Figura 4.28: Barrido paramétrico en $h_{\text {rodillo }}$ laminando capa 2 con punto de muestreo sobre capa 1 


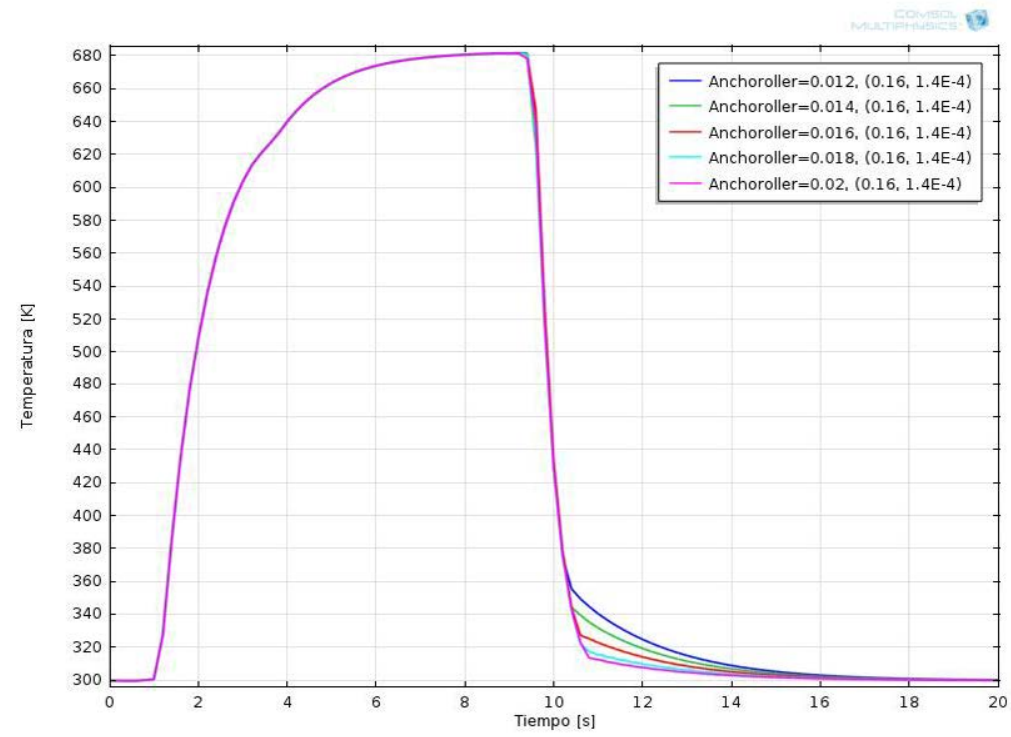

Figura 4.29: Barrido paramétrico en la longitud de compactación de rodillo laminando capa 2 con punto de muestreo sobre capa 1

\subsubsection{Efecto sombra del rodillo}

La posible existencia de un efecto de sombra justo antes de la entrada del rodillo también ha sido simulada. La Figura 4.30 contiene una representación de los perfiles térmicos obtenidos en un punto entre las capas 1 y 2 durante el encintado de capa 2, considerando una distancia de $5 \mathrm{~mm}, 3 \mathrm{~mm}$ y $1 \mathrm{~mm}$ en la separación entre la condición de contorno de transferencia térmica al rodillo y fuente láser. El impacto consiste en una caída de temperatura, en el entorno de los $30 K$ previa a la entrada del rodillo.

\subsubsection{Efecto de la temperatura del útil}

Los incrementos en la temperatura del utillaje favorecen alcanzar la temperatura requerida de consigna en el material con valores inferiores de potencia del láser. En la Figura 4.31 se ejecuta una representación de la temperatura observada por un punto entre las capas 1 y 2 durante el encintado de capa 2. En la simulación se ha mantenido constante la potencia del láser en todos los casos y ha sido el resuelto el problema suponiendo 6 valores fijos diferentes de temperatura de utillaje. Como puede verse, en un caso de encintado con útil a $480 K$ (condiciones habituales de trabajo en ISC), podría dismunirse la potencia, pues el resultado manifiesta un sobrecalentamiento equivalente a $200 K$. 


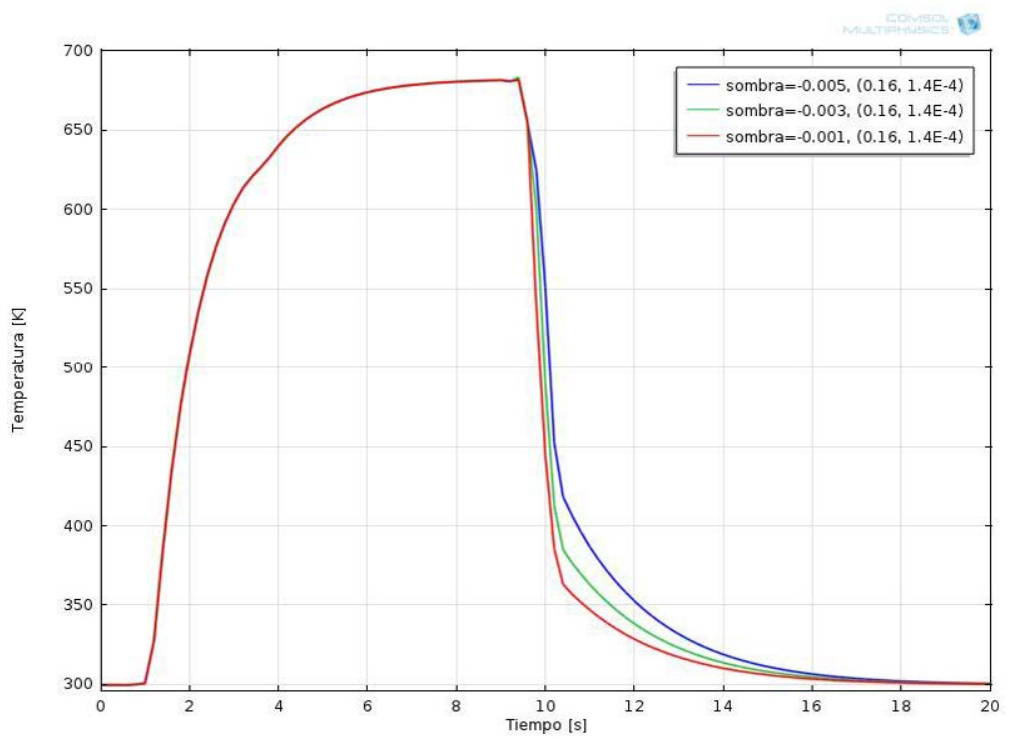

Figura 4.30: Simulación de calentamiento con barrido paramétrico en variación de distancia entre láser y entrada de rodillo

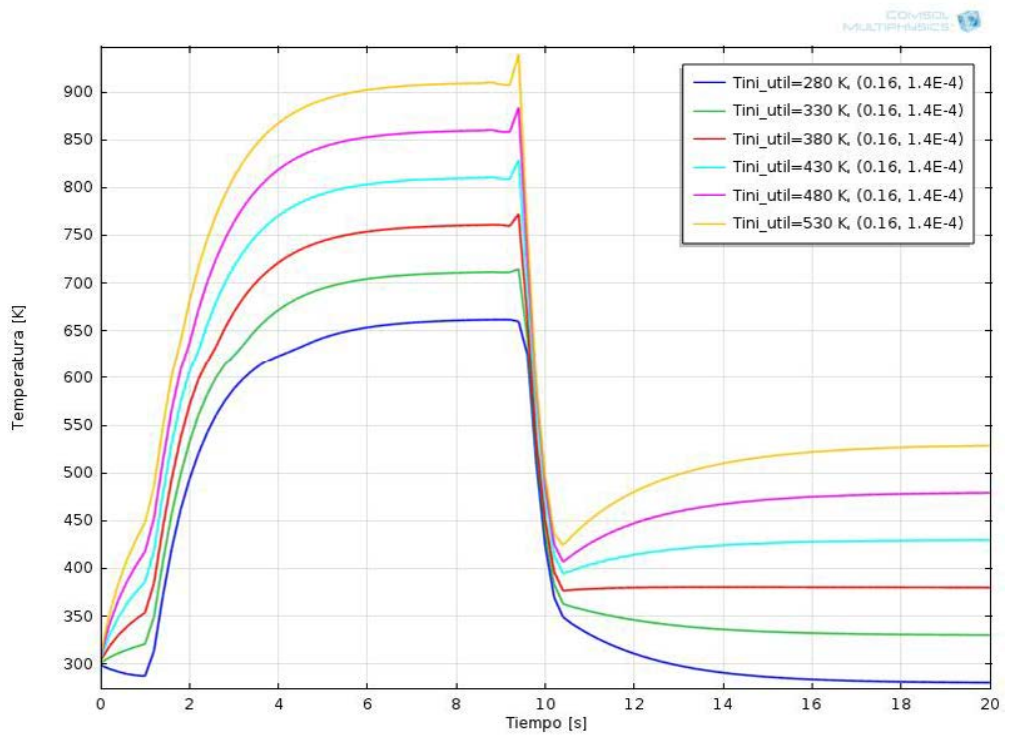

Figura 4.31: Simulación de calentamiento con barrido paramétrico en temperatura del útil de $280 K$ a $530 K$

\subsubsection{Efecto de la velocidad de encintado}

En el modelo desarrollado, ha sido evaluada la variación del perfil térmico de un punto situado entre las capas 1 y 2 , durante el encintado de 
capa 2, dejando a la velocidad oscilar entre $1 \mathrm{~m} / \mathrm{min}$ y $19 \mathrm{~m} / \mathrm{min}$ con incrementos de $1 \mathrm{~m} / \mathrm{min}$. Las Figuras 4.32 y 4.33 contienen el resultado de la simulación (nota, los valores de velocidad aparecen en unidad). Como puede observarse, mantenido el mismo valor de potencia en el láser, los incrementos de velocidad de encintado de la máquina repercuten en menores tiempos de calentamiento y en la imposibilidad según el caso para alcanzar el valor consignado de temperatura de $673 \mathrm{~K}$.

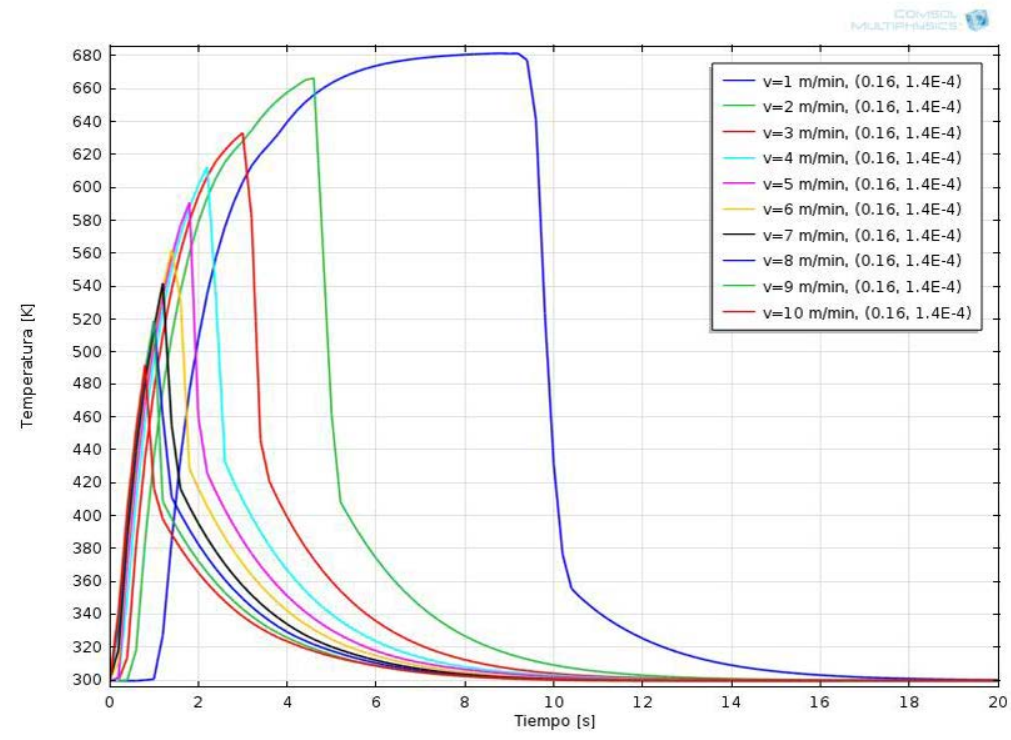

Figura 4.32: Simulación de calentamiento con barrido paramétrico en velocidad de encintado 1 a $10 \mathrm{~m} / \mathrm{min}$

\subsubsection{Efecto de la resistividad térmica entre capas}

La resistividad entre capas se refiere al efecto del aire atrapado entre las mismas impidiendo una correcta transferencia térmica de unas a otras. Como puede observarse en el resultado obtenido, representado en la Figura 4.34, el primero de los picos representa el efecto de calentamiento cuando se deposita la capa 2 sobre la 1 pre-posicionada sobre el útil, en este pico no hay una importante interacción de la resistividad entre capas pues el punto recibe la irradiación directa del láser. El segundo pico, se corresponde con el calentamiento sobre la capa 2 visto por un punto posicionado entre las capas 1 y 2 , en este caso sí se detecta una importante influencia de la resistividad entre capas en el resultado. A medida que la resistividad es mayor (menor valor del $\left.h_{\text {towtow }}\right)$ más difícil se hace la conducción de calor hacia la capa inferior, detectándose una temperatura cada vez más baja en el punto utilizado en el control. 


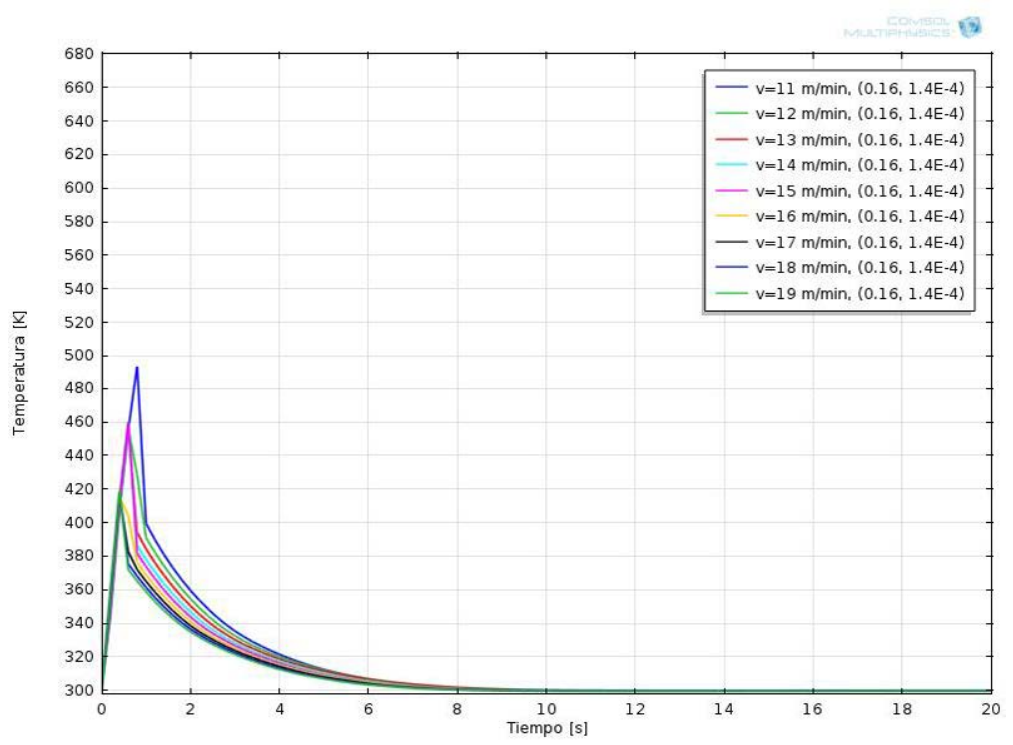

Figura 4.33: Simulación de calentamiento con barrido paramétrico en velocidad de encintado 11 a $19 \mathrm{~m} / \mathrm{min}$

En relación al proceso real, cuando no se consigue una óptima eliminación del aire atrapado entre capas, peor es el proceso de calentamiento en las etapas sucesivas, al no permitirse una buena evacuación del flujo de calor pueden tener lugar sobre calentamientos y efectos de degradación sobre la capa que está siendo encintada.

\subsubsection{Efecto de la radiación recibida por el material de aporte}

El material que está siendo encintado, no recibe una irradiación directa del láser. El láser se encuentra orientado de tal modo que su perfil apunta hacia el material sustrato, sin ser posible con la configuración actual, variar su inclinación durante los encintados. A pesar de no recibir la irradiación directa del láser, este material aportado se calienta por la propia apertura del haz y por las reflexiones que se generan desde el sustrato. Con las mediciones con los termopares, considerando que en la entrada del material de aporte se acoplan también los efectos del rodillo, resulta complejo conocer qué ocurre con el material de aporte; las lecturas de la termografía tampoco permiten visualizar su estado a causa de su orientación hacia la medida del sustrato.

Con objeto de entender qué ocurre con el material de aporte, se han simulado dos situaciones, una en la que se modifica la potencia recibida por el material de aporte mediante un factor multiplicativo en la potencia que se 


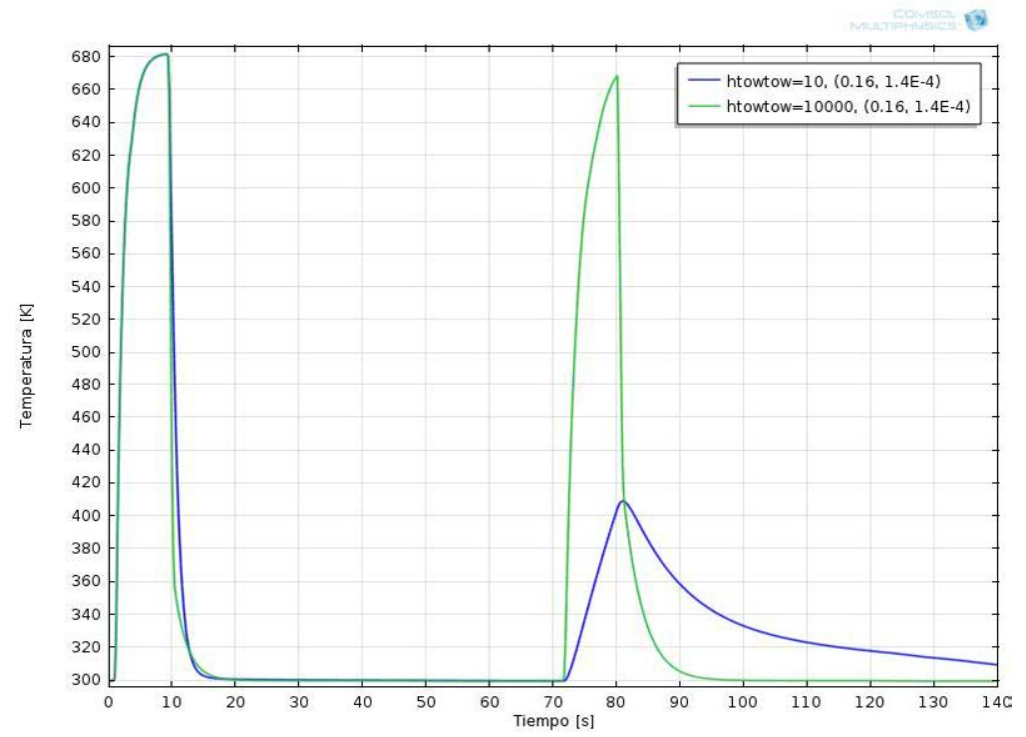

Figura 4.34: Efecto de la resistividad térmica entre capas

ha hecho variar de 0,6 a 1,2 (se recuerda aquí, que en el sustrato 0,9 ha sido el factor más ajustado al resultado real). El resultado se recoge en la Figura 4.35. En la figura, se ha efectuado una ampliación de la zona que se ve más afectada, apareciendo un pico justo al final de la estabilización que ya fue detectado en las medidas con los termopares.

También ha sido simulada una situación en la que además de existir ese barrido en la potencia recibida por el material de aporte, se ha añadido al modelo el efecto de separación entre la actuación de la condición de contorno rodillo y láser, tratando de simular de este modo posibles efectos de sombra causados por el rodillo. Este perfil, reproduce ahora el efecto de bajada de temperatura y recuperación al final de la estabilización ya observado con los termopares, Figura 4.36 . 


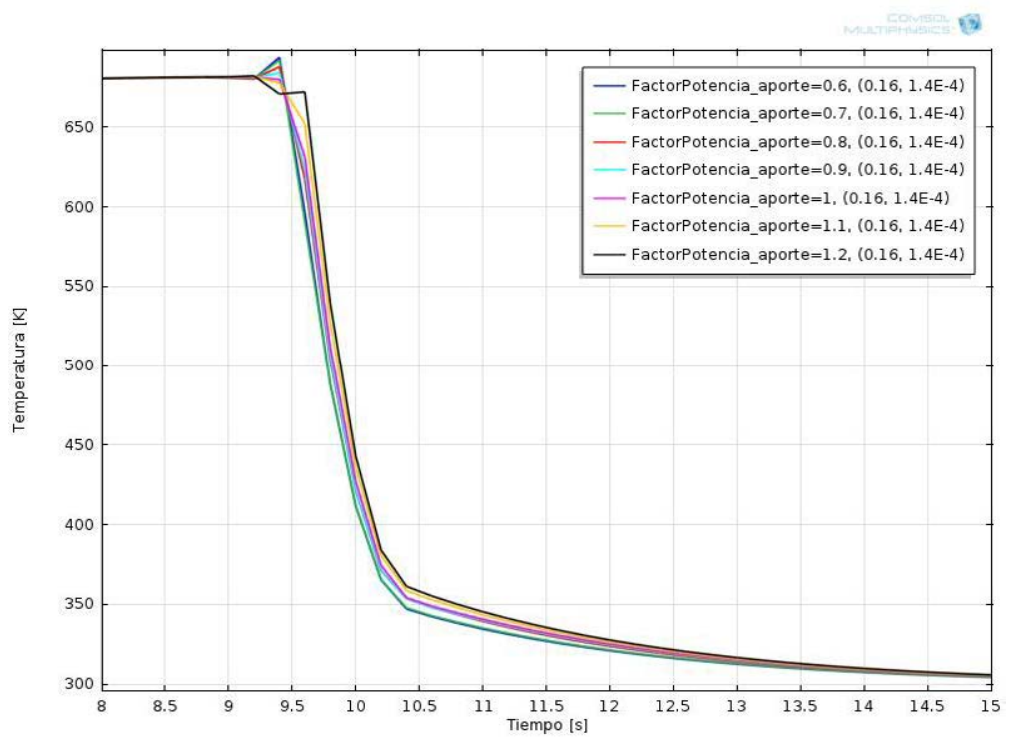

Figura 4.35: Efecto de la potencia recibida por el material de aporte

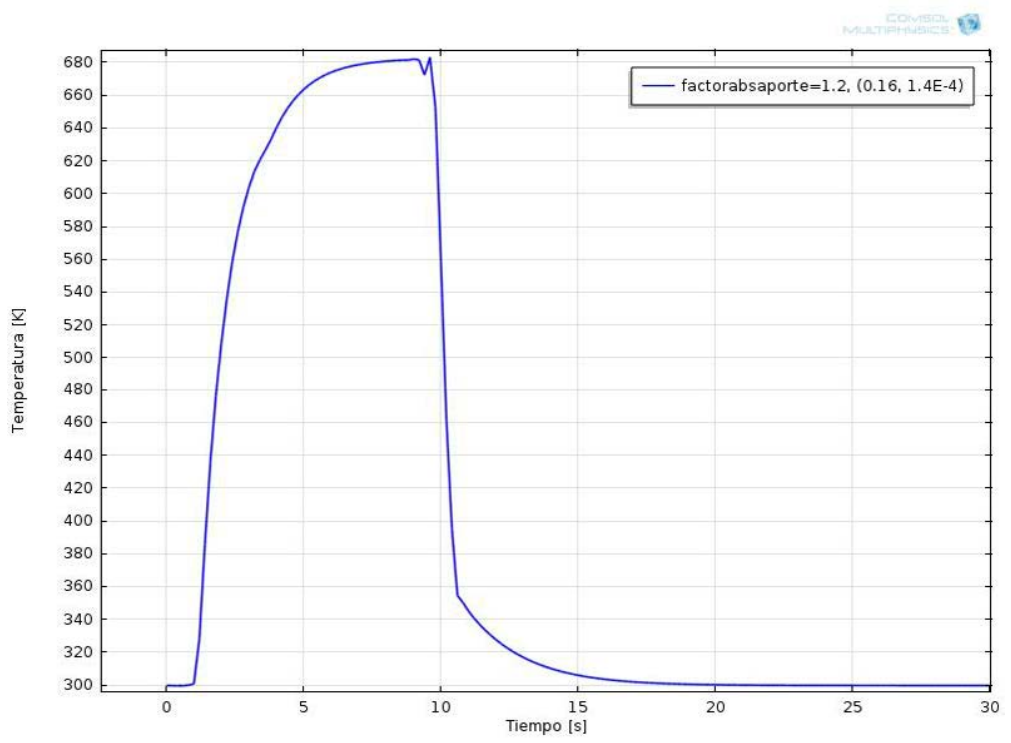

Figura 4.36: Efecto de la potencia recibida por el material de aporte con condición de sombra generada por el rodillo de compactación 


\subsection{Degradación térmica}

Tal como ya aparece indicado en diversas secciones de este documento, el control de temperatura durante el encintado se ejecuta con base a los registros de la lectura sin contacto de una cámara termográfica. Hasta el momento en que fue desarrollado e instalado un sistema de control en bucle cerrado de actuación automática, la actuación sobre la potencia del láser se ejecutaba manualmente como respuesta a la percepción que el sujeto que laminaba tenía de las imágenes recogidas por la cámara. La velocidad en la respuesta podía ocasionar sobrecalentamientos impactando en la degradación térmica del material.

Asimismo, analizando el proceso de fabricación, queda patente que, la consecución de un buen grado de consolidación en el material se encuentra relacionada con las variables temperatura, tiempo y presión. Una reducción en tiempo (incremento en velocidad de encintado) debería ir acompañada de un incremento en temperatura, de ahí que se haga necesario establecer las relaciones de tiempo-temperatura en el material para evitar efectos de degradación.

Para analizar los efectos de degradación térmica en el proceso de fabricación, se han seguido dos rutas de trabajo. Por un lado, se han tratado de extraer modelos matemáticos capaces de predecir el comportamiento en degradación del polímero y por otro lado se han testado muestras de material tras su procesado en condiciones normales de operación en encintado automático y consolidación in-situ y han sido comparadas con muestras en su estado de recepción, con el fin de establecer diferencias entre ambas.

\subsubsection{Determinación experimental de degradación térmica}

En esta sección se incluyen los análisis ejecutados sobre diferentes muestras con el fin de chequear el estado del material una vez ha sido procesado/calentado por el láser. No es un modo de trabajo predictivo como el que se describirá en la sección 4.2 .2 con los modelos, pero sí permite obtener una información que podrá contrastarse con los resultados de los cálculos posteriormente desarrollados.

Para ejecutar este análisis, se emplearon diversas técnicas de caracterización efectuando inter-comparaciones entre muestras de partida y muestras con posibles efectos de degradación. 


\subsubsection{Determinación experimental de degradación térmica - termogravimetría}

La termogravimetría se ha empleado para comparar el comportamiento a degradación de muestras fabricadas tanto por ISC como en prensa, con la finalidad de observar entre ellas efectos diferenciales. Para ejecutar la intercomparación, el ensayo ha sido ejecutado sobre trozos de paneles de secuencia $[0]_{16}$ fabricados según ambas metodologías. Los trozos de ambos paneles se han tratado de cortar con una geometría lo más similar posible para evitar así posibles variaciones causadas por el área superficial en contacto con el aire durante el ensayo, teniendo las muestras masas similares (próximas a 20mg).

Para valorar la repetitividad del resultado, han sido elaborados dos ensayos idénticos (S1 y S2) sobre dos trozos diferentes de cada uno de los paneles fabricados según cada tecnología. Los ensayos, ejecutados en rampa dinámica a $10 \mathrm{~K} / \min$ y atmósfera oxidativa, se presentan en la Figura 4.37. La representación de la evolución de la derivada del peso respecto al tiempo ha permitido detectar que en el comienzo de la degradación y hasta alcanzado un valor de un $20 \%$ de caída de masa, ambas muestras manifiestan exactamente el mismo comportamiento; sin embargo, en la siguiente etapa de degradación, ambas muestras presentan comportamientos diferentes adelantándose unos $20 K$ la degradación en la muestra obtenida por ISC. Además, en prensa, la ocurrencia de los diferentes posibles mecanismos en esa segunda gran etapa de degradación parece secuencial pues desde $875 \mathrm{~K}$ en adelante, es posible apreciar con claridad al menos 2 hombros sobre el pico principal, por su parte, en las muestras de ISC, esos sub-picos no están definidos con claridad y se confunden con el pico principal. Considerando que esas segundas etapas suelen ir asociadas con la oxidación del residuo carbonáceo, se cree que una posible causa de lo que ocurre es un estado diferente de oxidación previo en las muestras.

La fibra de carbono AS4 también fue analizada sometiéndola al mismo perfil de calentamiento $(10 \mathrm{~K} / \mathrm{min})$ bajo atmósfera oxidativa. En el ensayo, manifestó una importante componente de ruido al inicio posiblemente afectado por las características de la muestra, cuya masa conseguida fue de $2,5 \mathrm{mg}$. El onset de degradación obtenido para el AS4 fue de $889 K\left(\sim 615^{\circ} \mathrm{C}\right)$ y el máximo de degradación de $944 K\left(\sim 670^{\circ} \mathrm{C}\right)$.

En un ensayo a $10 \mathrm{~K} / \mathrm{min}$ en atmósfera oxidativa se ha observado que la pérdida del $100 \%$ de masa de PEEK 450G tiene lugar una vez han sido alcanzados $1030 K$, tal y como ilustra la Figura 4.47. Ese valor se asemeja al obtenido en el preimpregnado. En el caso de AS4, el ensayo de TGA manifiesta que la caída del primer $1 \%$ de masa tiene lugar en el entorno de los $827 K$ y su pico máximo de degradación en $942 K$, finalizando en $980 K$. 


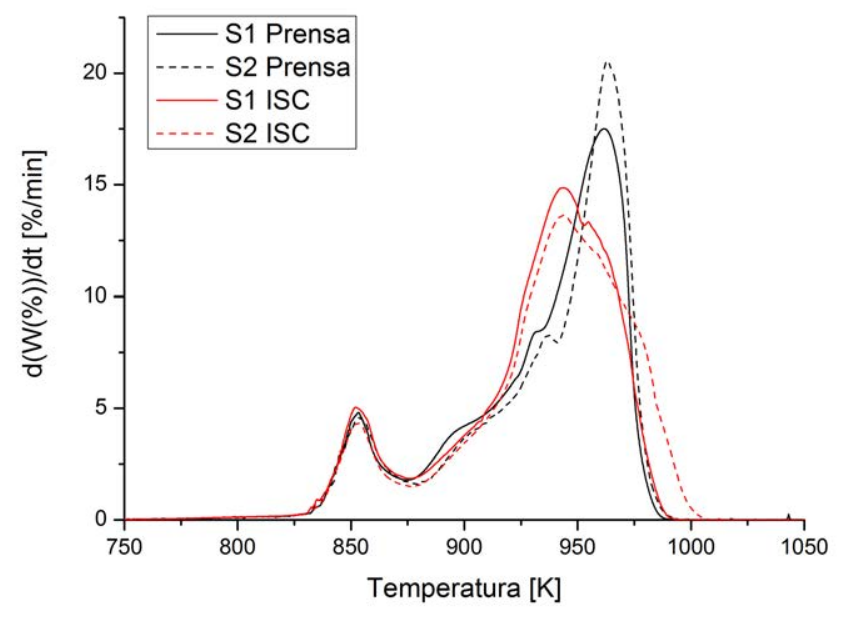

Figura 4.37: Comparativa ensayo TGA para panel en prensa y panel en ISC, rampa de calentamiento $10 \mathrm{~K} / \mathrm{min}$ y atmósfera oxidativa

\subsubsection{Determinación experimental de degradación térmica - CRTA TGA}

Los ensayos CRTA (Constant Reaction Thermal Analysis) fueron referenciados en el capítulo de estado del arte de este trabajo, entre las ventajas que plantea su aplicación se encuentra la gran herramienta que suponen para la detección de procesos de degradación compuestos por múltiples mecanismos. El gráfico de la Figura 4.38 contiene los perfiles obtenidos de la aplicación de esta metodología a una muestra de PEEK 450G (C1) en atmósfera oxidativa y con una velocidad de reacción constante e igual a $0,004 \mathrm{~min}^{-1}$. En la representación del gráfico de la izquierda se puede observar como en el ensayo se ha conseguido mantener esa velocidad de reacción constante y la forma en que horno ha ido modificando el perfil de calentamiento para lograrlo. Por su parte, el gráfico de la derecha de la figura contiene la representación de la evolución de la conversión con la temperatura detectándose la presencia de al menos tres mecanismos de degradación en cada uno de los sub-intervalos de conversión $(\alpha=0-0,02),(\alpha=0,02-0,08)$ y $(\alpha=0,08-0,3)$. 


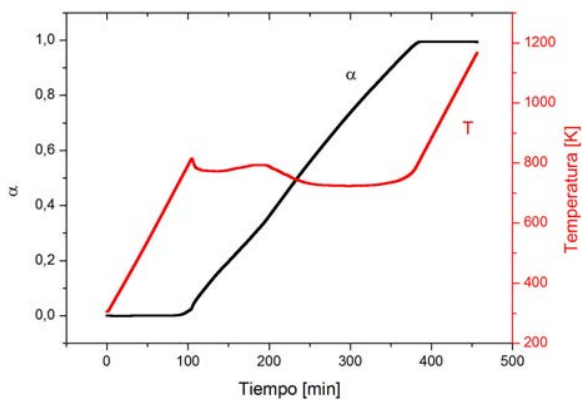

(a)

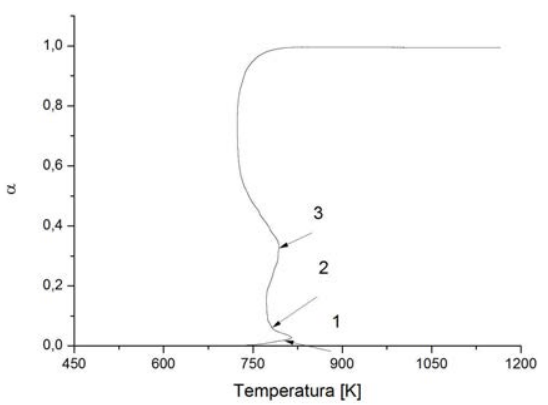

(b)

Figura 4.38: Ensayo CRTA con velocidad de reacción igual a 0,004min ${ }^{-1}$ para PEEK 450G (C1) en atmósfera oxidativa

\subsubsection{Determinación experimental de degradación térmica - DSC}

En el capítulo de estado del arte de esta tesis doctoral, se incluyeron trabajos donde se indicaba que los efectos de degradación térmica del material podrían ser más notables en fenómenos como la cristalización por el efecto de rotura de cadenas, que puede modificar la forma en que éstas se ordenan.

Tras la fabricación de los paneles en prensa e ISC que serán utilizados en esta tesis doctoral con diferentes propósitos, fueron ejecutados ensayos de calorimetría (DSC) sobre tres muestras procedentes de cada uno de los paneles, la finalidad era ejecutar comparaciones en los valores de fusión y de cristalización. Las muestras fueron sometidas a tres barridos sucesivos de calentamiento $(10 \mathrm{~K} / \mathrm{min}$ hasta $663 \mathrm{~K}$ y estabilización $5 \mathrm{~min})$ - enfriamiento $(5 \mathrm{~K} / \mathrm{min}$ hasta $293 \mathrm{~K})$ - calentamiento $(10 \mathrm{~K} / \mathrm{min}$ hasta $663 \mathrm{~K})$. Los termogramas utilizados, empleados también en las explicaciones del capítulo de cristalización, se incluyen en el Apéndice C, siendo las Figuras C.1 C.2 y C.3 para las muestras del panel de prensa y C.4 C.5 y C.6 para el panel de ISC.

El primero de los ciclos de calentamiento, revela información sobre el estado previo de enfriamiento al que fue sometido el panel. La Figura 4.39 manifiesta una clara diferencia de unos $6 K$ entre los valores del onset extrapolado de fusión para las muestras procedentes de prensa en comparación con las de consolidación in-situ. La diferencia es inexistente en lo relativo al pico de fusión entre ellas.

Este comportamiento, no es una garantía de un estado de degradación en 


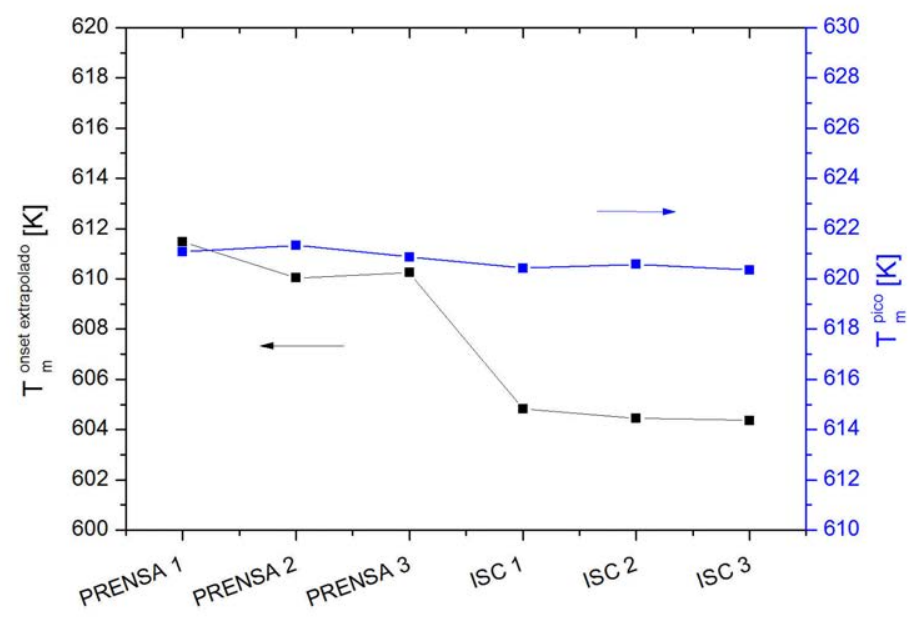

Figura 4.39: Comparativa del valor onset extrapolado y pico de fusión en ciclo 1 sobre tres muestras procedentes de un panel de prensa y otras tres de un panel de ISC

la muestra pues, los bruscos perfiles de enfriamiento en los paneles obtenidos por consolidación in-situ pueden provocar diferencias en la morfología de los cristales formados durante el proceso de enfriamiento alterando el valor del onset extrapolado. A causa de ello, han sido analizados los valores en el pico exotérmico de cristalización (Figura 4.40) obtenido durante el enfriamiento de todas las muestras y también se ha analizado el pico de fusión en un tercer ciclo, segundo calentamientode la muestra (Figura 4.41), tras ser enfriadas de modo idéntico, en caso de existir efectos de degradación, permanecerán tras la primera fusión.

Las anteriores comparaciones manifiestan que las diferencias por degradación, en caso de existir, no son suficientes como para ser detectables con la técnica de calorimetría diferencial de barrido. Se puede concluir que entre las muestras ensayadas, las variaciones entre los valores medidos con el fin de localizar efectos de degradación son despreciables, una posible causa es que en ambos procesos, el material se encuentra sometido a atmósferas oxidativas y por tanto ese efecto de degradación podría ser similar entre ellos. Un futuro trabajo de análisis más detallado de estos efectos debería buscar forzar la degradación de la muestra para contrastarque realmente se esta técnica puede ser sensible a detectar tales diferencias. 


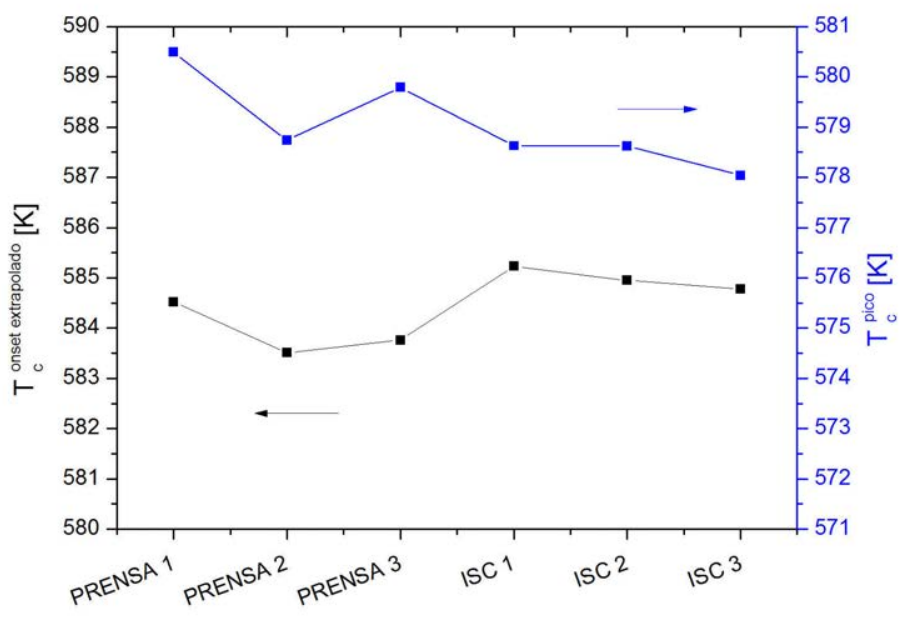

Figura 4.40: Comparativa del valor onset extrapolado y pico de cristalización en ciclo 2 sobre tres muestras procedentes de un panel de prensa y otras tres de un panel de ISC

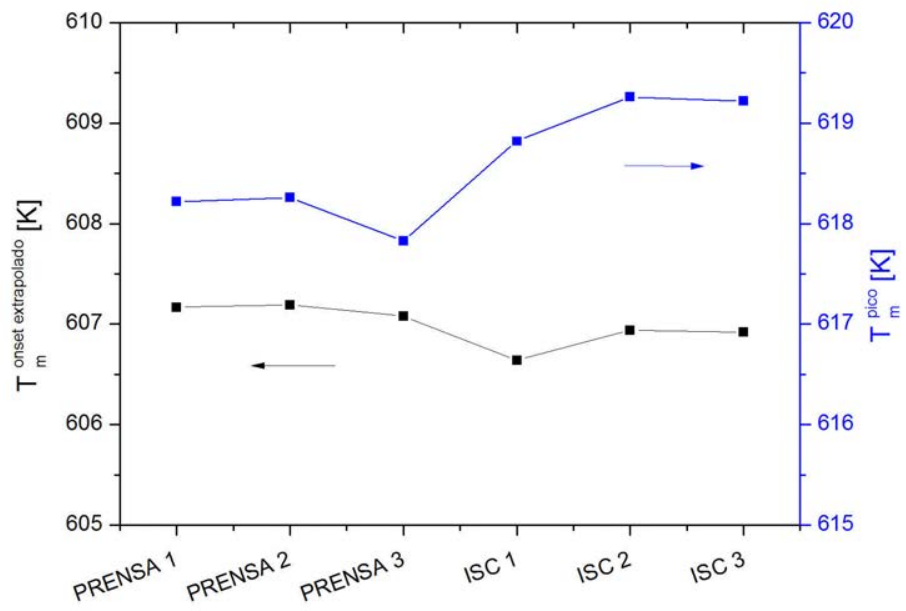

Figura 4.41: Comparativa del valor onset extrapolado y pico de fusión en ciclo 3 sobre tres muestras procedentes de un panel de prensa y otras tres de un panel de ISC 
Dada la imposibilidad para detectar efectos de degradación mediante el empleo del equipo de calorimetría, se ha considerando que otra posible causa es que ésta pueda tener un efecto localizado en la superficie del material. Siendo así, habría un pequeño componente degradado frente a la masa total de muestra ensayada en DSC, por ello, se optó por emplear técnicas de análisis donde la medida fuera superficial, tipo FTIR (modo ATR) y XPS.

\subsubsection{Determinación experimental de degradación térmica - FTIR (ATR)}

La técnica de infrarrojo por transformada de Fourier, arroja un espectro tras el ensayo donde los picos son una representación de los componentes que el equipo es capaz de detectar como constituyentes de la muestra bajo análisis.

Con el propósito de conocer qué cambios aparecen en el espectro del material cuando éste experimenta efectos de degradación, se han ejecutado análisis sobre muestras en las cuales dicha degradación ha sido auto-inducida con un ensayo previo de termogravimetría y sustrayendo del horno el residuo resultante analizados diferentes porcentajes de degradación.

Una vez obtenida esa información previa, han sido ejecutados análisis sobre muestras de material pregimpregnado APC2/AS4 en su estado natural tras su envío por el suministrador y tras experimentar diferentes calentamientos por la fuente láser. Con la información previa del espectro del PEEK 450G degradado, se persigue localizar similares alteraciones del espectro tras el calentamiento con la fuente láser.

Para su representación, los datos han sido tratados mediante el software OriginPro 8.6, ejecutando sustracciones de línea base mediante el empleo del método de suavizado de Savitzky-Golay seleccionando varios puntos por donde se hará pasar la línea base. Una vez sustraída la línea base, se normalizarán los espectros en absorbancia utilizando como referencia el pico correspondiente al enlace $[\mathrm{C}=\mathrm{C}]$ en la banda de $1592 \mathrm{~cm}^{-1}$, considerado el más estable y el más improbable para experimentar cambios durante los procesos de degradación en el polímero.

La Tabla 4.4 contiene un resumen de las codificaciones otorgadas a cada una de las muestras analizadas.

Los ensayos sobre muestras de PEEK 450G (C1) y PEEK 450G tras alcanzar un $2 \%$ de degradación en el ensayo de termogravimetría (C2), apare- 


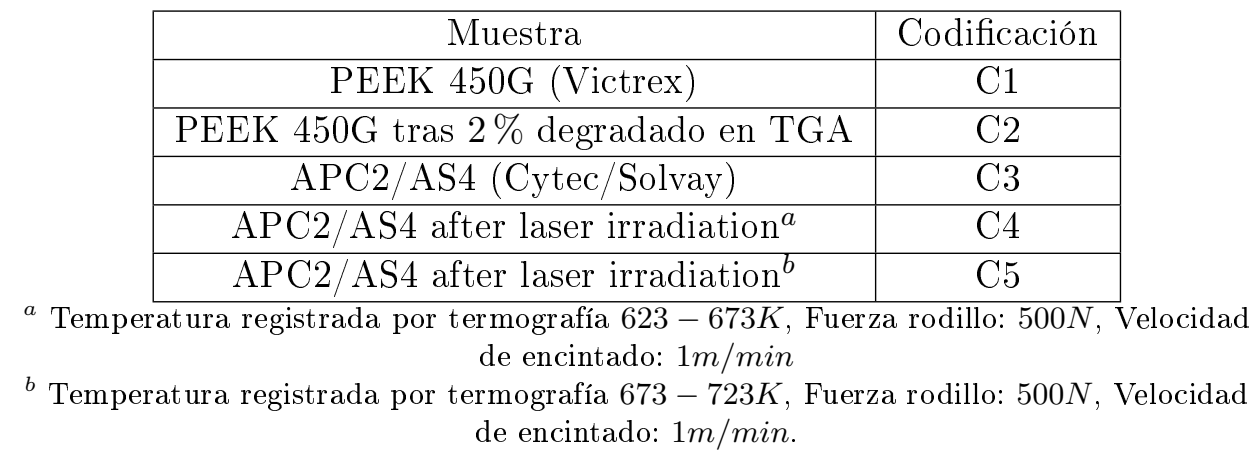

Tabla 4.4: Codificación muestras FTIR-ATR

cen recogidos en la Figura 4.42 donde las principales conclusiones obtenidas, en línea con las reportadas por (Bayerl et al. 2015), son las siguientes:

- En la muestra degradada se observa la aparición de un pico en la banda $1714 \mathrm{~cm}^{-1}$, vinculado con la rotura de enlaces adyacentes al enlace cetona y a la reducción del doble enlace conjugado fenilo.

- Decaen las intensidades de los picos de las bandas $1486 \mathrm{~cm}^{-1}, 1304 \mathrm{~cm}^{-1}$ y $1010 \mathrm{~cm}^{-1}$ asociados con efectos en el grupo fenilo, hipótesis que adquiere más importancia con el incremento observado de hidrógeno no aromático (rango de $2800-3000 \mathrm{~cm}^{-1}$ no incluido en la representación).

- Desaparición del pico en la banda $1276 \mathrm{~cm}^{-1}$, asociado con la rotura de los enlaces tipo éter. Este mismo efecto se asocia también a los incrementos observados de las bandas $1215 \mathrm{~cm}^{-1}, 1184 \mathrm{~cm}^{-1}$ y $1156 \mathrm{~cm}^{-1}$.

- Los picos en $926 \mathrm{~cm}^{-1}, 836 \mathrm{~cm}^{-1}$ y $680 \mathrm{~cm}^{-1}$ decaen también, dicha variación se asocia también con la pérdida de hidrógenos aromáticos.

Por su parte, las muestras de material APC2/AS4 tras la recepción por parte del suministrador y tras su calentamiento con la fuente láser en un rango de trabajo habitual y en un rango ligeramente superior al normal, han permitido la representación de los espectros recogidos en la Figura 4.43. Las diferencias entre los espectros son muy leves, solo es posible detectar ligeras variaciones en el hombro a $1253 \mathrm{~cm}^{-1}$, que se asocia con posibles roturas de los enlaces éter y cambios en los hidrógenos no aromáticos.

En base a los resultados obtenidos, es posible concluir que las diferencias no son lo suficientemente pronunciadas como para considerar la existencia de un efecto de degradación superficial en el material analizado tras su calentamiento láser. 

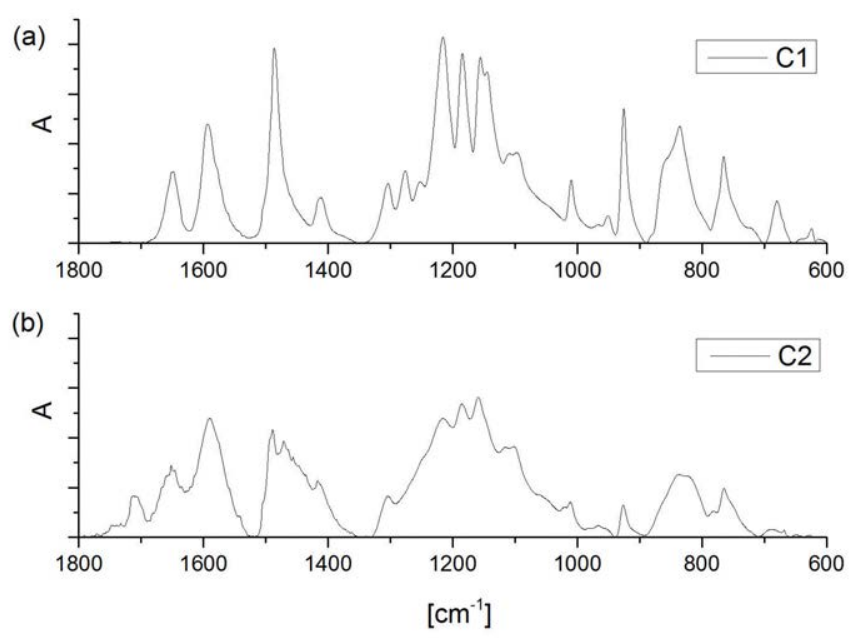

Figura 4.42: Espectro FTIR-ATR para (a) PEEK 450G (C1) y (b) PEEK $450 \mathrm{G}(\mathrm{C} 2)$ tras una degradación de un $2 \%$ en ensayo de TGA
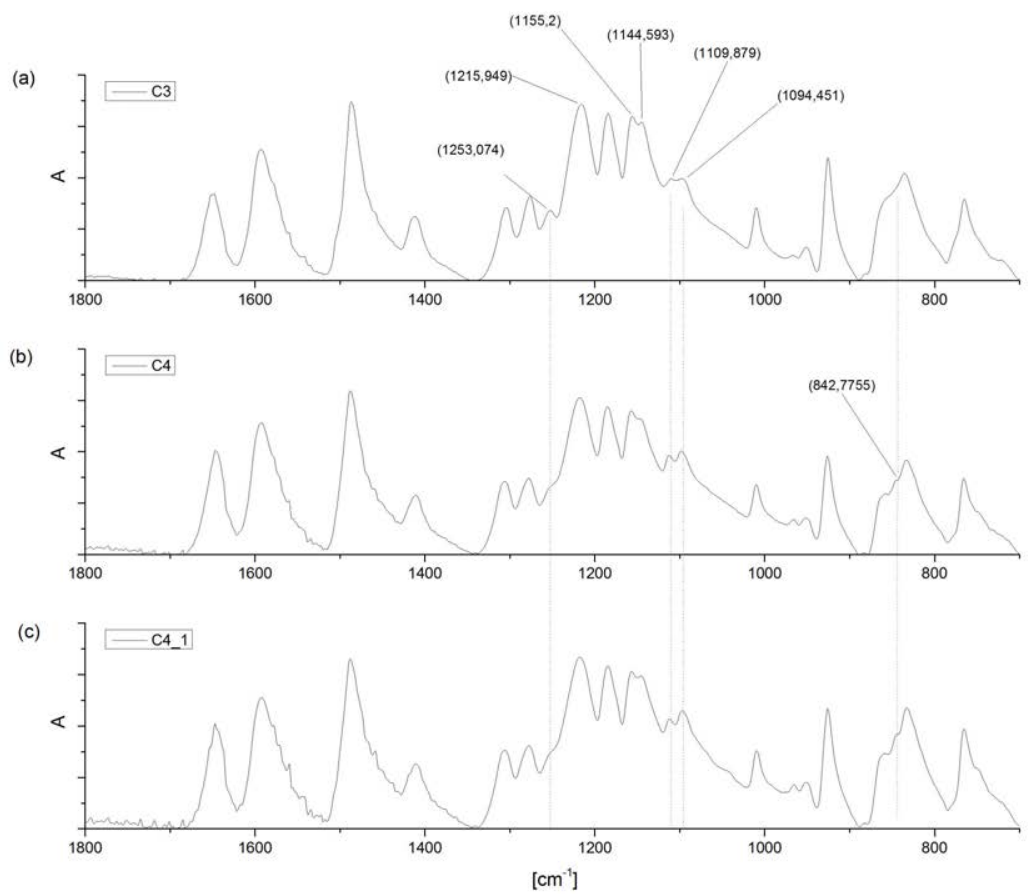

Figura 4.43: Espectro FTIR-ATR para (a) APC2/AS4 (C3) (suministrador), (b) APC2/AS4 tras calentamiento con la fuente láser (C4), (c) APC2/AS4 tras calentamiento con la fuente láser (C5) 


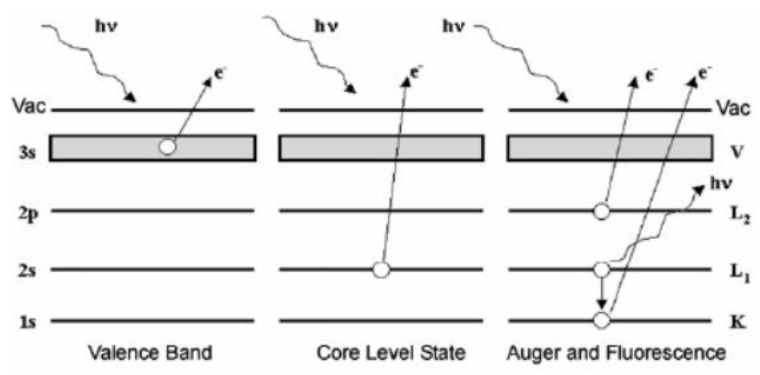

Figura 4.44: Principio general del XPS

\subsubsection{Determinación experimental de degradación térmica - XPS}

Las medidas efectuadas para analizar efectos de degradación superficiales con el equipo FTIR-ATR se ven también influenciadas por el hecho de que la rugosidad del material condiciona el correcto apoyo del sensor del equipo contra la muestra. Por el anterior motivo, se seleccionó también la técnica de espectroscopía por rayos-X para este análisis. Esta técnica se basa en el efecto fotoeléctrico, el material es irradiado por una fuente rayos-X generando fotones que producen una excitación en los electrones de los niveles centrales de los átomos de un componente sólido en un ambiente de vacío.

La energía cinética de los electrones que se emiten se corresponde con la representada por la ecuación 4.15 donde $h w$ es la energía del fotón incidente, $E_{b}$ es la energía de ligadura de los electrones (diferencia de energía entre el nivel interno y el nivel de Fermi) y $\phi_{w}$ es la función de trabajo (energía para extraer un electrón desde el nivel de Fermi al nivel de vacío). La superficie explorada con la técnica tiene poca profundidad (entorno de nanómetros), luego óptima para analizar la superficie más externa de PEEK que se espera que exista en el material irradiado por la fuente de calentamiento durante el proceso de encintado.

$$
E_{c}=h w-E_{b}-\phi_{w}
$$

En los espectros XPS obtenidos, los picos pueden presentar diferentes orígenes como describe la Figura 4.44 pueden asociarse a emisiones de los niveles internos, a emisiones de la banda de valencia (electrones con baja energía de ligadura) y picos Auger (cuando se ioniza un átomo en una capa determinada, los electrones de las capas más altas de energía tienden a llenar su hueco a menor energía, generando un fotón). 


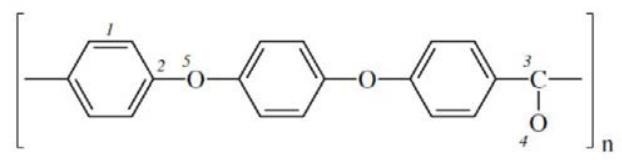

Figura 4.45: Consideraciones espectrales en el monómero del PEEK

Este trabajo, no persigue ejecutar un análisis exhaustivo de la composición química del material, sino que busca establecer una intercomparación entre muestras con y sin irradiación láser, para localizar diferencias remarcables entre ambos espectros. En el caso del PEEK, (Louette et al., 2005) reporta la siguiente información sobre las características espectrales de este material, recogidas en la Figura 4.45 y ligadas a la información de la tabla 4.5 .

El ensayo sólo fue ejecutado sobre muestras de material preimgpregnado APC2/AS4, en dos estados: estado de recepción por el suministrador (C3) y tras irradiación con el láser de la máquina de encintado en FIDAMC en condiciones normales de trabajo (C4). Se descartó la ejecución sobre elementos con sobre-irradiación como el (C5) pues ya se observó una limitada diferencia entre su espectro y el de (C4) en FTIR-ATR. En un trabajo futuro sería de interés ejecutar su aplicación sobre muestras donde la degradación haya sido auto-inducida, como ya se hizo con el PEEK en el ensayo FTIR-ATR, determinándose de este modo la sensibilidad de la técnica a percibir estos efectos de degradación, asimismo sería recomendable establecer correlaciones velocidad-temperatura y aplicar estos ensayos sobre muestras con alta potencia de irradiación pero alta velocidad de deposición.

\begin{tabular}{|c|c|c|c|}
\hline Posición en Figura 4.45 & Elemento & Energía de pico $[\mathrm{eV}]$ & Concentración \% \\
\hline 1 & $\mathrm{C} 1 \mathrm{~s}$ & 284,70 & 64,5 \\
\hline 2 & C 1s & 286,31 & 16,0 \\
\hline \multirow[t]{2}{*}{3} & C 1s & 287,10 & 1,8 \\
\hline & C 1s & 291,59 & \\
\hline 4 & O $1 \mathrm{~s}$ & 531,31 & 4,9 \\
\hline \multirow[t]{2}{*}{5} & O 1s & 533,40 & 11,9 \\
\hline & O 1s & 540,91 & \\
\hline
\end{tabular}

Tabla 4.5: Tabla espectral para el PEEK

Los espectros de XPS obtenidos, fueron tratados con el software SPECS CasaXPS buscando localizar las áreas de interés. Con la finalidad de determinar los efectos de la posible degradación sobre los componentes mayoritarios, 


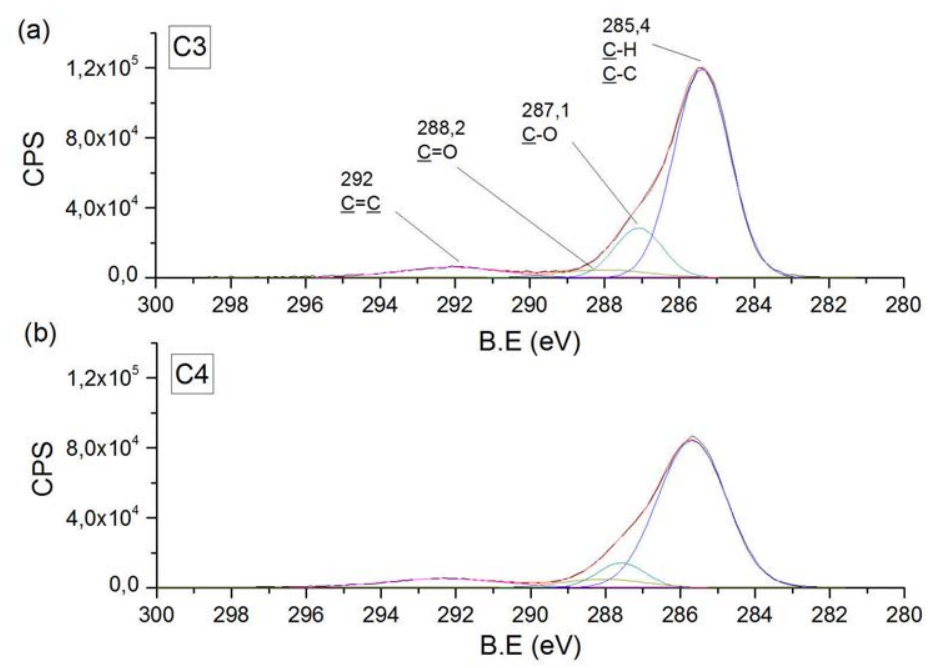

Figura 4.46: Espectro de XPS obtenido sobre (a) Muestra de APC2/AS4 (C3) y muestra de APC2/AS4 tras irradiación láser en condiciones normales de laminación en ISC (C4)

carbono y oxígeno, estos picos fueron analizados de modo independiente. Sobre ellos se aplicó una sustracción del background mediante una selección de línea base empleando OriginPro 8.6 y el método de Savitzky-Golay en ambos casos (se trató de ejecutar mediante la aplicación del método de Shirley pero no se conseguía un buen ajuste al gráfico de la línea base), tras ello se ejecutó un ajuste de los picos mediante funciones Gaussianas (en la referencia (Jain et al. 2018) se describen las posibilidades de aplicación de funciones tipo Gaussianas, Lorentzianas o combinaciones de las mismas para los análisis de los espectros de esta técnica). El ajuste para la zona de la energía de ligadura típica del C-1s ha proporcionado la información que se incluye en la Figura 4.46, por contra, en el área de la energía de ligadura para el O-1s no se pudo ejecutar un ajuste sin ambigüedad para los distintos picos y se descartó su uso para la determinación de posibles efectos de degradación en la muestra, basando las conclusiones en las observaciones ejecutadas sobre el carbono. 
En el caso del carbono, comparando las áreas de los picos, se puede observar un incremento para los carbonos aromáticos del entorno de un 2,1\% y una caída tanto de los éter (del orden $1,6 \%$ ) y de los cetona (del orden de $0,53 \%$ ). Todos ellos valores muy bajos como para estimar una degradación importante del polímero, tal y como ya reportaron el resto técnicas empleadas con este objetivo. El XPS, concluye nuevamente que la degradación en las condiciones habituales de encintado puede considerarse despreciable.

\subsubsection{Modelos de degradación térmica}

Los modelos de degradación han sido extraídos para el polímero sin refuerzo. Esta simplificación está motivada por la necesidad de obviar la presencia de la fibra de carbono en los ensayos que a continuación se expondrán; suponiendo su incorporación una fuente de error en los cálculos elaborados. Esta simplificación es, no obstante, conservativa, pues el efecto de la fibra de carbono será a retardar el comienzo de la degradación.

\subsubsection{Modelo de degradación por TGA - Análisis termo-gravimétrico}

La termogravimetría, como ya se describió con anterioridad en este documento, permite analizar los efectos de degradación tomando como variable de referencia la evolución de la masa de la muestra. Considerando que la muestra parte con un $100 \%$ de la masa, se representa su evolución a medida que el programa térmico se ejecuta, la caída en masa de la muestra vendrá ocasionada por efectos de degradación y formación de cadenas menores capaces de volatilizarse. Por tanto, para que el equipo sea capaz de percibir algún efecto, es requisito imprescindible la pérdida de masa.

Para extraer un modelo cinético representativo del proceso de degradación por pérdida de masa, se partió de la ecuación general para reacciones de estado sólido 4.16. Se recupera nuevamente aquí su representación pues será el punto de partida para el análisis elaborado.

$$
\frac{d \alpha}{d t}=k(T) f(\alpha)
$$

La fracción reaccionada o conversión, en el estudio por termogravimetría, se obtiene mediante 4.17, con $W_{0}$ el porcentaje en peso al comienzo del ensayo (un $100 \%$ ), $W_{t}$ el porcentaje en un instante temporal $t$ y $W_{f}$ el porcentaje en peso al final del ensayo. En todos los ensayos empleados para este estudio se alcanza un residuo nulo, por lo que $W_{f}=0$. 


$$
\alpha=\frac{W_{0}-W_{t}}{W_{0}-W_{f}}
$$

La variación de la fracción reaccionada con el tiempo puede expresarse también en función de su dependencia con la temperatura según la Ecuación 4.18. considerando un programa de calentamiento lineal y siendo $\beta=\frac{d T}{d t}$ la velocidad del ensayo.

$$
\frac{d \alpha}{d T}=\frac{A}{\beta} \exp \left(\frac{-E_{a}}{R T}\right) f(\alpha)
$$

Por tanto, para definir la ecuación representativa de la degradación del material, se hace requisito conocer los valores de $A, E_{a}$ y $f(\alpha)$ (triplete cinético).

Para ejecutar el estudio, se optó por simplificar el problema al análisis sobre resina pura PEEK 450G sin fibra de carbono. La fibra de carbono juega un papel importante en el comportamiento a degradación del material, actuando como un retardante, entre otros motivos por su alta capacidad para conducir el calor. No obstante, la incorporación de la fibra de carbono impedía distinguir con claridad los mecanismos de degradación, imposibilitando un control sobre la fracción reaccionada en cada caso. Además, la ejecución del estudio sólo sobre resina genera un modelo más conservativo de cara a evitar efectos de degradación en el material, pues los límites obtenidos de inicio de degradación serán en todo caso superiores con la incorporación de la fibra de carbono.

Para desarrollar los ensayos empleados se han utilizado muestras similares en geometría partiendo de pellets de PEEK 450G adquiridos a Victrex. Las masas de todas las muestras se han seleccionado lo más próximas entre sí y cercanas a $5 \mathrm{mg}$. Los programas de calentamiento seleccionados para el desarrollo de este estudio cinético han sido $2,5 \mathrm{~K} / \mathrm{min}, 4 \mathrm{~K} / \mathrm{min}, 10 \mathrm{~K} / \mathrm{min}$ y $15 \mathrm{~K} / \mathrm{min}$, todos ellos ejecutados bajo atmósfera oxidativa pues es la condición más aproximada al desarrollo real del proceso de encintado. Las curvas experimentales obtenidas se incluyen en la Figura 4.47.

Como se referenció en el capítulo de estado del arte, en la bibliografía se proponen una serie de métodos de cálculo conocidos como "isoconversionales" que facilitan la obtención de algunos de los parámetros cinéticos (principalmente el valor de $E_{a}$ ) sin efectuar ninguna suposición previa sobre el modelo de reacción que está teniendo lugar en el material. 


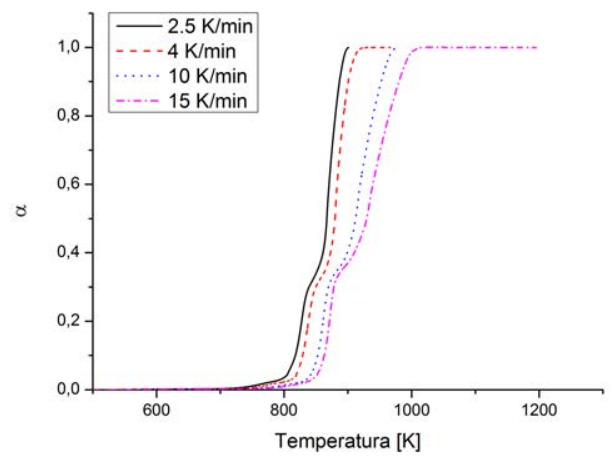

(a)

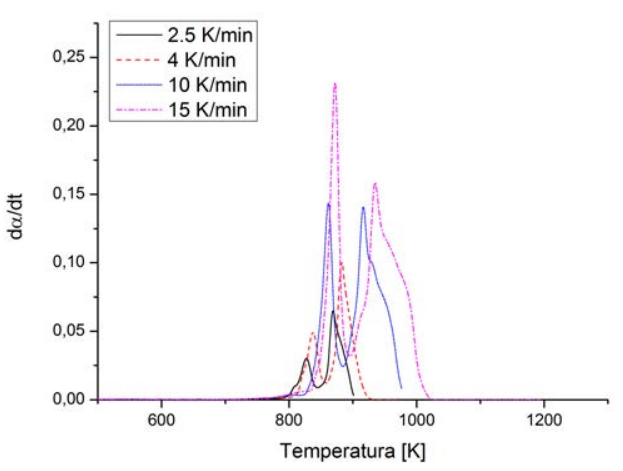

(b)

Figura 4.47: Ensayos experimentales sobre PEEK 450G a diferentes programas de calentamiento a) Conversión frente a temperatura y b) Derivada de la conversión con el tiempo frente a la temperatura

Entre estos métodos de cálculo, se encuentra el método isoconversional de Friedman, cuya ecuación 4.19 se incluye en este apartado pues se efectuará su aplicación sobre los resultados de las curvas de ensayo del PEEK 450G. La representación del término izquierdo de la ecuación frente a la inversa de la temperatura, permite extraer el valor de energía de activación a través del valor de la pendiente de la curva. En la ecuación, el índice $i$ representa cada uno de los programas de velocidad de calentamiento empleados para el análisis y $\alpha$ hace alusión a un valor particular de la conversión.

La aplicación de este método al estudio de la degradación en el PEEK $450 \mathrm{G}$, reveló una alta dependencia del valor de energía de activación con la evolución de la conversión. Dicho efecto, es un reflejo de la presencia de múltiples mecanismos de degradación interactuando en el proceso y complica la metodología para la obtención de la ecuación cinética general.

$$
\ln \left(\beta_{i} \frac{d \alpha}{d T}_{\alpha, i}\right)=\ln \left(f(\alpha) A_{\alpha}\right)-\frac{E_{a}}{R T_{\alpha, i}}
$$

Tras la observación de la presencia de múltiples mecanismos de degradación, la metodología de análisis se modificó. La etapa previa a la ejecución de cualquier análisis para la obtención de los tripletes cinéticos requería la localización de los diferentes mecanismos de reacción e independizarlos, para ello se empleó un proceso de deconvolución. Las curvas $\frac{d \alpha}{d t}$ de cada programa de calentamiento, se deconvolucionaron empleando el software Fityk y funciones de tipo Fraser-Suzuki, dado el comportamiento no simétrico de los procesos de degradación en los polímeros ya ilustrado por (Perejón et al. 


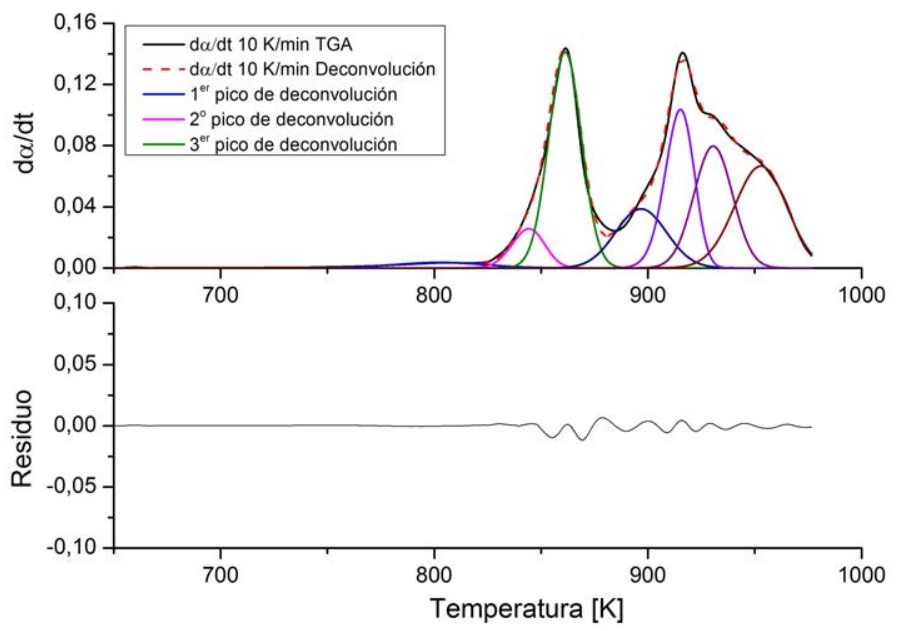

Figura 4.48: Deconvolución aplicada al ensayo sobre PEEK 450G en atmósfera oxidativa a $10 \mathrm{~K} / \mathrm{min}$

2011).

La Figura 4.48 contiene la información de la deconvolución aplicada sobre la curva del ensayo a $10 \mathrm{~K} / \mathrm{min}$. Deconvolucionar por completo la curva hasta residuo nulo hace necesario el empleo de siete funciones tipo FraserSuzuki de ajuste, no obstante, la ecuación se calculará empleando sólo los tres primeros picos, pues corresponden con aproximadamente un $30 \%$ de degradación en el PEEK 450G, valor muy por encima de los límites aceptables de degradación según criterios ya referenciados por (Nandan et al., 2003 . Batista et al. 2015, Dolo et al. 2017), donde se proponían valores máximos de $1 \%$ o $5 \%$.

Son, por tanto, los tres primeros mecanismos los estudiados, cada uno con su propia energía de activación, factor pre-exponencial y modelo cinético. Tras cada uno de dichos mecanismos de degradación, el material queda degradado hasta un $2 \%$, un $6 \%$ y finalmente hasta un $24 \%$. Dichos valores se emplearán posteriormente como factores de "peso" para definir las contribuciones individuales de los mecanismos al global de la ecuación de degradación del material.

Las curvas pertenecientes al primer, segundo y tercer pico de deconvolución para cada programa de calentamiento son representadas de forma conjunta en las figuras $4.49,4.50$ y 4.51 , se requieren agrupar de este modo 


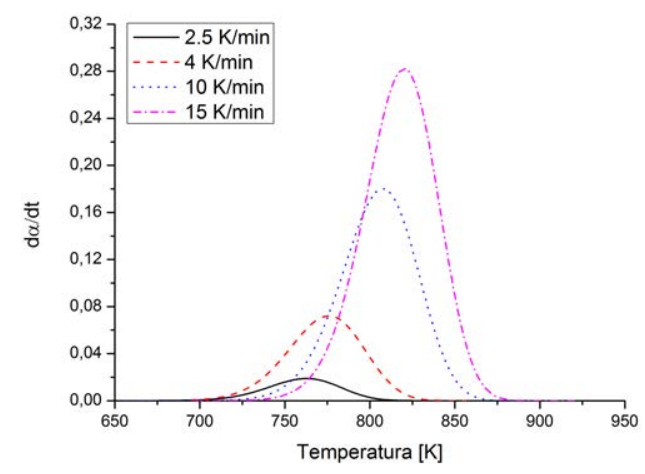

Figura 4.49: Curvas de deconvolución aplicadas al primer pico

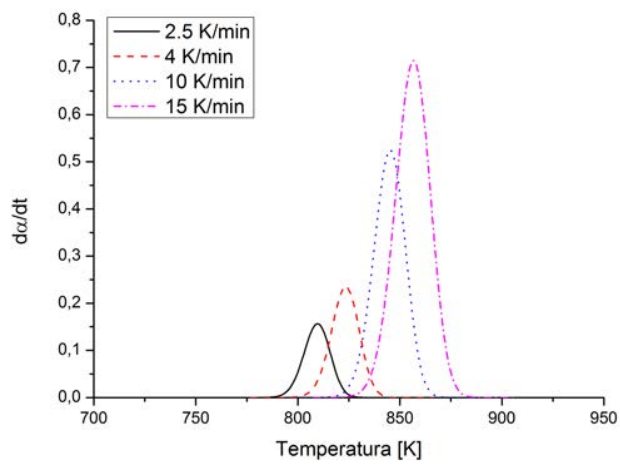

Figura 4.50: Curvas de deconvolución aplicadas al segundo pico

pues el análisis cinético se va a ejecutar sobre cada uno de los grupos de modo independiente.

La deconvolución de las curvas permitió la extracción de tres picos asociados a tres mecanismos diferentes de degradación, a todos ellos les fue aplicado el método isoconversional de Friedman reflejando un comportamiento estable en la evolución de la energía de activación frente a la conversión, tal y como ilustra la Figura 4.52 Los valores obtenidos de energías se adjuntan en la Tabla 4.6 . 


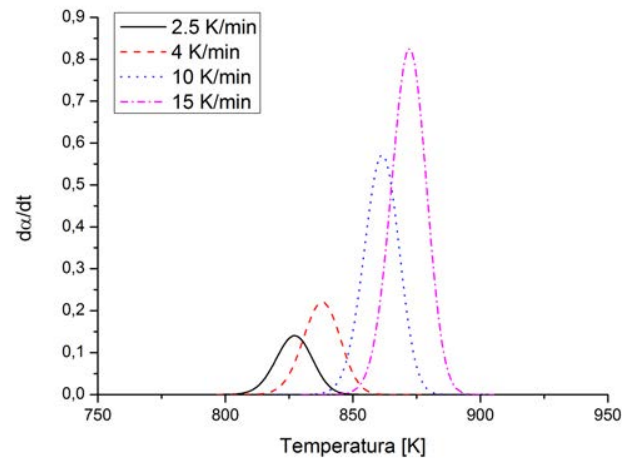

Figura 4.51: Curvas de deconvolución aplicadas al tercer pico

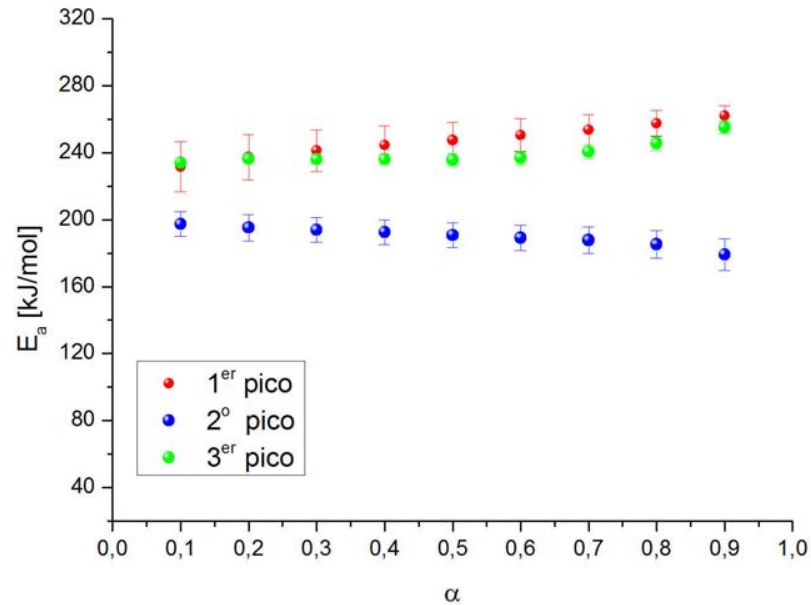

Figura 4.52: Energía de activación frente a conversión para los 3 mecanismos iniciales del proceso en PEEK 450G 


\begin{tabular}{c|c|c|c} 
& Pico 1 & Pico 2 & Pico 3 \\
\hline Energía de activación promedio (kJ/mol ) & 247,36 & 190,17 & 239,65 \\
\hline Desviación estándar en energía de activación & 9,20 & 5,26 & 6,43 \\
\hline
\end{tabular}

Tabla 4.6: Energías de activación por Friedman tras deconvolucionar

Los métodos isoconversionales no son capaces de proporcionar toda la información requerida para definir por completo el triplete utilizado en la ecuación cinética. De ahí que se recurriera a una reformulación del problema, basada en los trabajos ya propuestos para EPM (etileno-propileno) y EPDM (etileno-propileno-dieno) por (Perejón et al., 2013), cuya aplicación previa sobre PEEK no se ha encontrado reportada en la bibliografía. Esta nueva metodología consideraba la ecuación 4.20 , ecuación cinética general donde el valor de $f(\alpha)$ ha sido sustituido por $\alpha^{m}(1-\alpha)^{n}$, ecuación de SestakBerggren. De esta ecuación se ha demostrado su aplicabilidad para ajustar procesos gobernados por cualquier mecanismo cinético (Vyazovkin et al. 2011).

$$
\ln \left(\frac{d \alpha}{d t} \frac{1}{\alpha^{m}(1-\alpha)^{n}}\right)=\ln (c A)-\frac{E_{a}}{R T}
$$

Utilizando los cuatro ensayos para cada pico obtenido de la deconvolución, se aplicó un programa de optimización que forzaba a que la representación de $\ln \left(\frac{d \alpha}{d t} \frac{1}{\alpha^{m}(1-\alpha)^{n}}\right)$ frente a $1 / T$ fuera una línea recta, utilizando como elemento de optimización el valor de coeficiente de correlación de Pearson $\left(R^{2}\right)$ y considerando una evolución de la conversión entre 0,01 y 0,99 para prevenir los errores experimentales a las muy altas y muy bajas conversiones. Esta optimización se efectuó con el programa matemático Mathcad, permitiendo obtener directamente los valores de $E_{a}, c A, n$ y $m$, la Figura 4.53 muestra los gráficos de dichos ajustes numéricos.

En la Tabla 4.7 se incluyen los valores obtenidos de la optimización. 


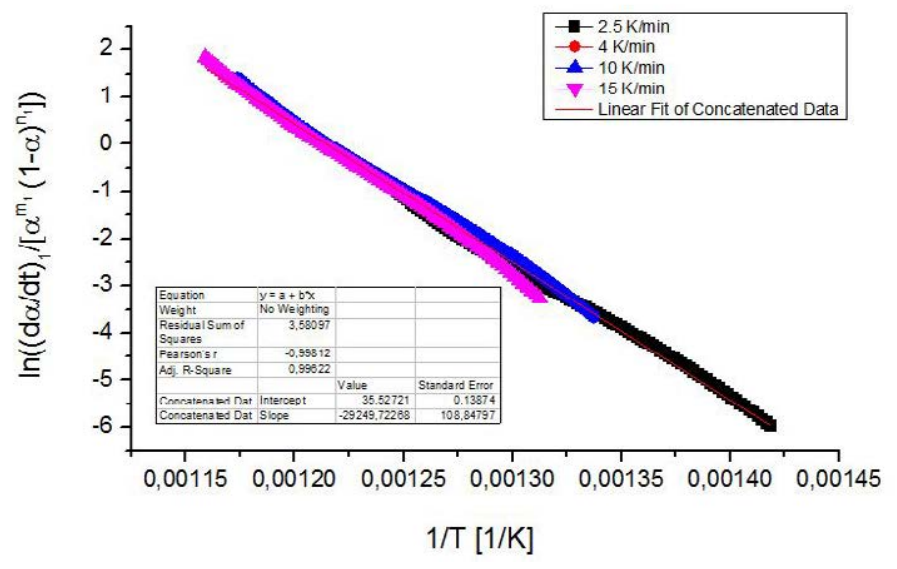

(a)

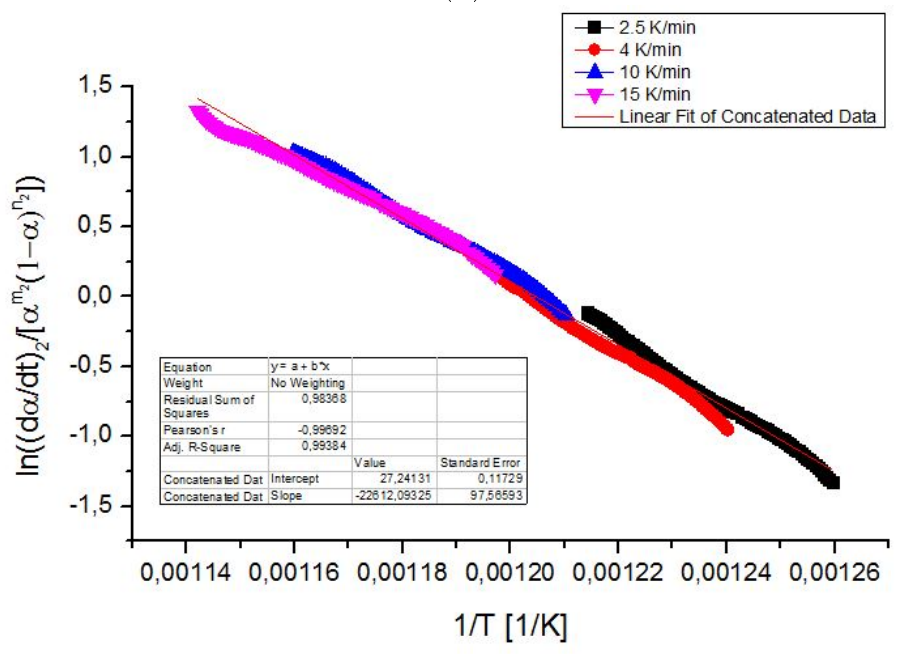

(b)

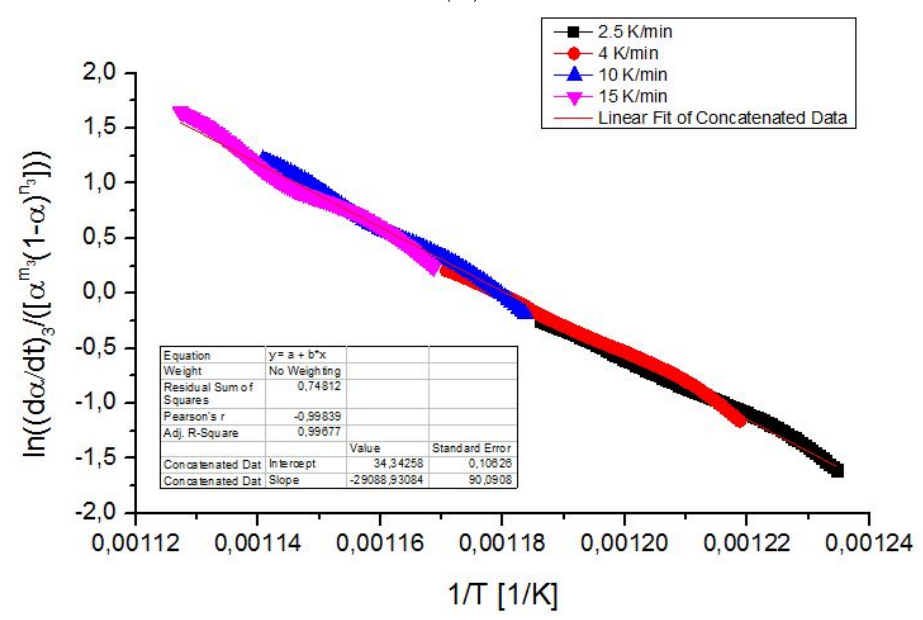

(c)

Figura 4.53: Ajuste lineal tras la aplicación de la optimización mediante el empleo de Sestak-Berggren (a) Pico 1, (b) Pico 2, (c) Pico 3 


\begin{tabular}{|c|c|c|c|c|c|c|}
\hline $\begin{array}{c}\text { Proceso } \\
(\text { pico })\end{array}$ & $\begin{array}{c}\text { Contribución } \\
\text { del proceso } \\
(\%)\end{array}$ & $\begin{array}{c}\text { Factor } \\
\text { Pre-exponencial } \\
(\mathrm{cA})[1 / \mathrm{min}]\end{array}$ & $\begin{array}{c}\text { Energía de } \\
\text { Activación } \\
{[\mathrm{kJ} / \mathrm{mol}]}\end{array}$ & $\begin{array}{c}\text { Rango de } \\
\text { conversión } \\
\alpha\end{array}$ & $\mathrm{n}$ & $\mathrm{m}$ \\
\hline 1 & 2 & $2,6 \cdot 10^{15} \pm 3,6 \cdot 10^{14}$ & $242,9 \pm 0,9$ & $0,01-0,99$ & 1,215 & 0,201 \\
\hline 2 & 6 & $6,9 \cdot 10^{11} \pm 8,1 \cdot 10^{10}$ & $188,1 \pm 0,8$ & $0,01-0,99$ & 0,940 & 0,720 \\
\hline 3 & 24 & $8,0 \cdot 10^{14} \pm 8,6 \cdot 10^{13}$ & $241,7 \pm 0,8$ & $0,01-0,99$ & 0,939 & 0,677 \\
\hline
\end{tabular}

Tabla 4.7: Triplete cinético tras optimización lineal 


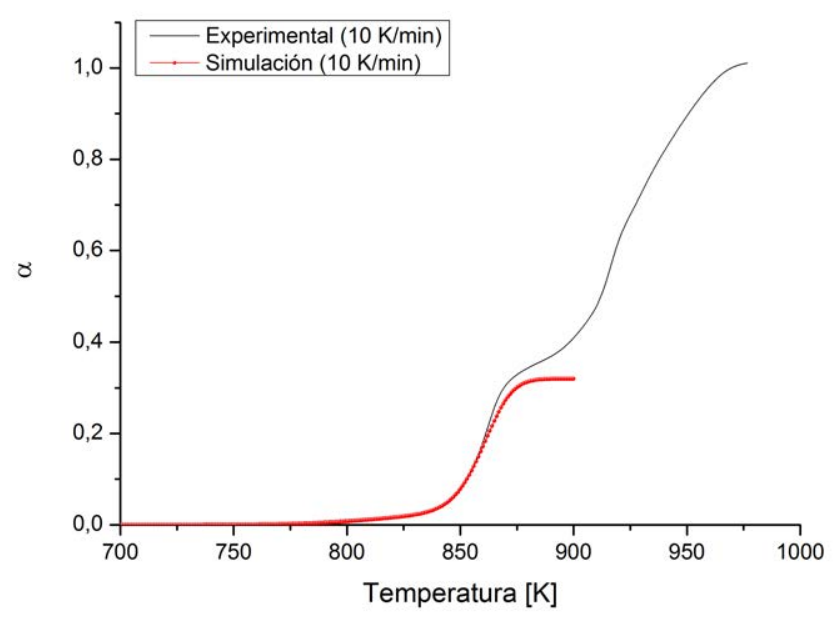

Figura 4.54: Comprobación ensayo vs. simulación en la degradación oxidativa del PEEK $450 \mathrm{G}$ a $10 \mathrm{~K} / \mathrm{min}$

Obtenidos todos los parámetros que definen la ecuación, es posible representar la ecuación completa del proceso de degradación en el material, Ecuación 4.21 .

$$
\begin{gathered}
\frac{d \alpha}{d t}=0,02\left(2,6 \cdot 10^{15} \exp \left(\frac{-242,9 \cdot 10^{3}}{R T}\right)\left(\alpha^{0,201}(1-\alpha)^{1,215}\right)\right)+ \\
0,06\left(6,9 \cdot 10^{11} \exp \left(\frac{-191 \cdot 10^{3}}{R T}\right)\left(\alpha^{0,720}(1-\alpha)^{0,940}\right)\right)+ \\
0,24\left(8,0 \cdot 10^{14} \exp \left(\frac{-241,7 \cdot 10^{3}}{R T}\right)\left(\alpha^{0,677}(1-\alpha)^{0,939}\right)\right)
\end{gathered}
$$

Una vez extraído dicho modelo, su capacidad para reproducir un experimento real fue comprobada, la ecuación se integró empleando Runge-Kutta de orden 4 como método de resolución y $10 \mathrm{~K} / \mathrm{min}$ como velocidad de programa de calentamiento, siendo comparada con un ensayo a dicha velocidad de calentamiento. El solape entre la curva obtenida de modo teórico y la experimental manifestó una buena correlación para el rango de degradación del primer $30 \%$.

Con los valores de $\mathrm{n}$ y $\mathrm{m}$ definidos se ha ejecutado una comparativa gráfica con algunos de los modelos de reacción ya conocidos y documentados en bibliografía: F1 (Mampel, primer orden), A2 (Avrami-Erofeev) y L2 (Escisión aleatoria). La representación, incluida en la Figura 4.55 muestra como 


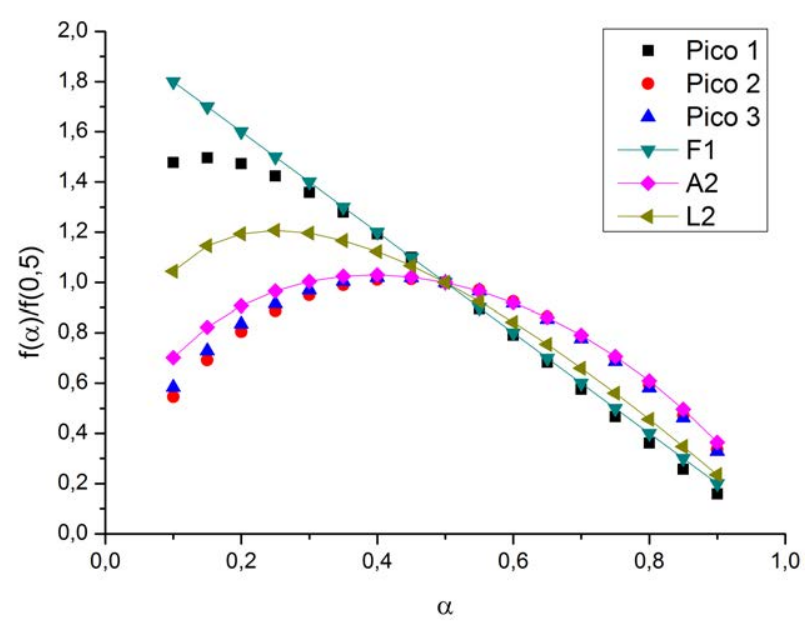

Figura 4.55: Comparativa entre los modelos de reacción obtenidos para PEEK 450G y los modelos teóricos de la bibliografía

los picos 2 y 3 tienen un comportamiento casi idéntico al mecanismo A2 mientras que el pico 1 se solapa, a excepción de para conversiones muy bajas, con el mecanismo de primer orden F1.

Tras chequear la bondad del modelo, éste fue empleado para predecir posibles estados de degradación en el material sometido a diferentes programas de calentamiento, los cuales fueron seleccionados en relación con los típicos existentes en ISC (isotermas de $5 s$ con temperaturas en el entorno de $673 K$ ). En la Figura 4.56 se puede observar la integración de la curva para valores incrementales de $50 K$ desde 673 a $1073 K$. Debe tenerse en cuenta que el valor de conversión $\alpha=1$ representado en el gráfico, equivale a una degradación de un $30 \%$ en el material por la consideración efectuada de analizar exclusivamente ese tramo de la degradación. La parte inferior de la imagen representa un zoom para el primer $6 \%$ (1,8\% real), como puede verse, los valores de temperatura desde 673 a $873 K$ no manifiestan degradación en el material, para $923 K$ el material alcanza una degradación de un $2 \%(0,6 \%$ real) transcurridos $2 s$ de isoterma. La condición habitual de trabajo en la máquina $673 \mathrm{~K}$, parece localizarse muy lejos del área de una posible degradación, no obstante, durante el proceso, se producen picos extremadamente bruscos en áreas localizadas a causa de presencia de defectos, baja planitud del material, etc, permitiendo este modelo conocer su valor numérico, como puede verse, para $1023 \mathrm{~K}$ supone ya completa degradación tras $3 \mathrm{~s}$. 

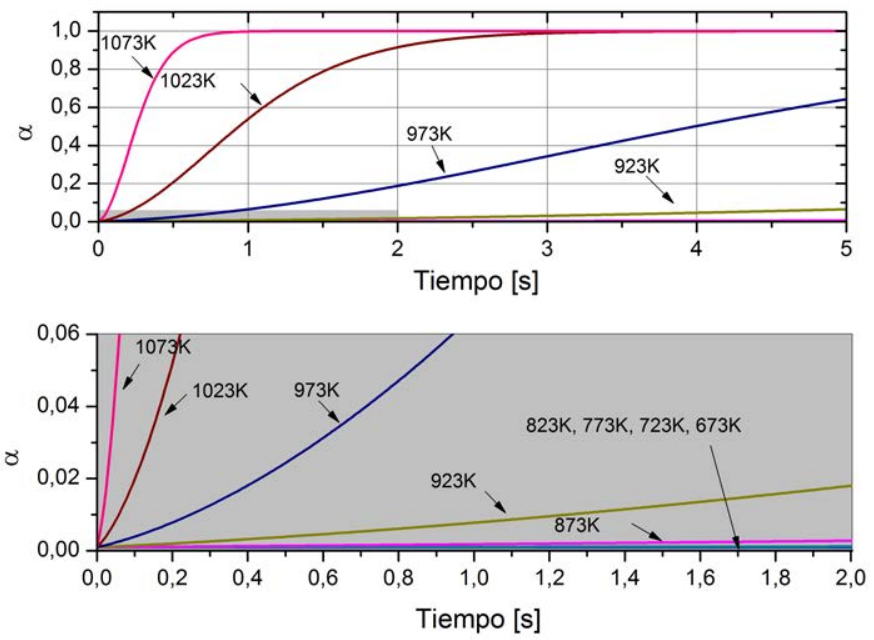

Figura 4.56: Comprobación ensayo vs. simulación en la degradación oxidativa del PEEK 450G a diferentes isotermas de calentamiento

\subsubsection{Modelo de degradación por reología}

Diferentes referencias bibliográficas incluidas en la revisión del estado del arte de este trabajo aluden a la existencia de efectos de degradación previos a la detección de pérdida de masa, la degradación tiene lugar por rotura de las cadenas poliméricas, cuando dichas cadenas son suficientemente pequeñas tienen la capacidad para volatilizarse causando una pérdida de masa en la muestra. Podría también darse la situación en la que las cadenas sufran escisiones de un tamaño mayor al requerido para poder volatilizar, en ese caso, el material se encontraría "degradado" pero ese estado no sería detectable con una técnica como la termogravimetría. De ahí el empleo de la reología como técnica de análisis, muy sensible a pequeñas variaciones de viscosidad.

Nuevamente, el análisis se ha ejecutado sobre PEEK 450G sin fibra de carbono pues en un reómetro de platos paralelos como el empleado, la presencia de la fibra hace difícil detectar las posibles variaciones experimentadas en la estructura del polímero. Las muestras utilizadas se han ajustado de modo que el "gap" entre platos del reómetro fuera lo más próximo posible a $1000 \mu \mathrm{m}$, buscando en todos los ensayos que la muestra generara menisco.

Los ensayos empleados para este análisis fueron desarrollados en condiciones isotermas a $653,673,693,713,733$ y $753 \mathrm{~K}$, empleado como parámetros de ensayo, un valor de $0,2 \mathrm{~Hz}$ de frecuencia y una deformación de $0,2 \%$ para asegurar el desarrollo de los mismos dentro del régimen de viscoelasticidad 


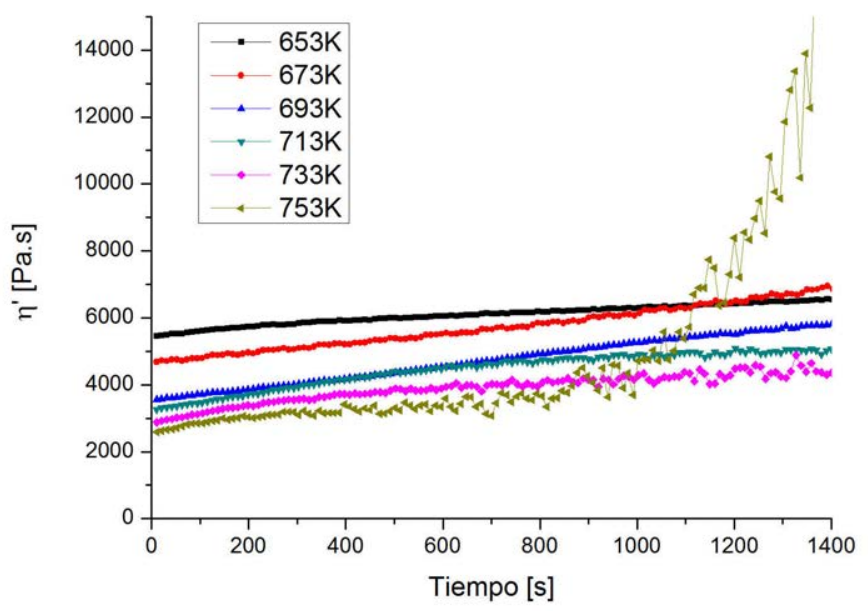

Figura 4.57: Variación de $\eta^{\prime}$ con el tiempo para diferentes programas isotermos en PEEK 450G

lineal del material, más información sobre el comportamiento del material en esta región puede localizarse en (Irgens, 2014). Se puede considerar que la atmósfera de los ensayos era oxidativa y aunque la superficie de muestra en contacto con el ambiente oxidativo es pequeña, impactará en la evolución del ensayo tal y como lo describen (Filippone et al. 2015b).

Al igual que en el caso de análisis de degradación por pérdida de masa, para establecer un modelo cinético de degradación debe definirse una variable de seguimiento, en este caso será la evolución del número de actos de reticulación o entrecruzamiento mediante la determinación de modificaciones en la "viscosidad". Para aplicar este desarrollo se han seguido las indicaciones propuestas en el trabajo de (Nicodeau, 2005), que ejecuta el estudio mediante ensayos sobre PEEK pero bajo atmósfera inerte.

El número de cadenas en un polímero tiene un vínculo directo con la masa molecular del mismo, de hecho, se obtiene mediante la suma de las masas atómicas de todos los átomos de una molécula. El efecto de variación en la estructura por efecto de reticulación se simplifica como la diferencia entre el número de cadenas iniciales y el número de las mismas en un instante temporal concreto, considerando el número de cadenas como la inversa de la masa molar en número $\left(\frac{1}{M_{n}}\right)$, esta variación se puede representar tal y como describe la ecuación 4.22. Asimismo, la masa molecular en número $\left(M_{n}\right)$ puede relacionarse con la masa molecular en peso $\left(M_{W}\right)$ a través del 
índice de polidispersidad $\left(I_{p}\right)$, tal como recoge la ecuación 4.23 (amplitud de la gausiana que representa la distribución de pesos moleculares).

$$
\begin{gathered}
n=\frac{1}{M_{n_{0}}}-\frac{1}{M_{n}}=\frac{I_{p_{0}}}{M_{W_{0}}}-\frac{I_{p}}{M_{W}} \\
I_{p}=\frac{M_{W}}{M_{n}}
\end{gathered}
$$

Siendo $M_{n_{0}}$ el peso molecular medio en número al comienzo del proceso, $M_{n}$ el peso molecular medio en número en un instante temporal concreto del proceso de reticulación, $I_{p_{0}}$ el ínice de polidispersidad inicial, $I_{p}$ el índice de polidispersidad en un instante concreto del proceso.

Como hipótesis, tal y como figura en (Nicodeau, 2005), se considera que el índice de polidispersidad inicial del polímero se mantiene invariable durante todo el proceso de reticulación, quedando por tanto la ecuación simplificada a 4.24

$$
n=\frac{I_{p_{0}}}{M_{W_{0}}}\left[1-\frac{M_{W_{0}}}{M_{W}}\right]
$$

Además, efectuando la hipótesis de suponer el polímero como lineal, puede emplearse la relación bibliográfica de dependencia de la viscosidad con el peso molecular con una relación de proporcionalidad de la potencia 3,4 del peso molecular, Ecuación 4.25 .

$$
\eta_{0}^{\prime}=K M_{W_{0}}^{3,4}
$$

Y sustituyendo 4.25en 4.24 se obtiene la Ecuación 4.26 que relaciona los actos de reticulación con las viscosidades complejas inicial y en un instante cualquiera.

$$
n=\frac{I_{p_{0}}}{M_{W_{0}}}\left[1-\left(\frac{\eta_{0}^{\prime}}{\eta^{\prime}}\right)^{\frac{1}{3,4}}\right]
$$

La Ecuación 4.26 representa la relación buscada entre los actos de reticulación y la viscosidad medida por reología. Como valores para los parámetros se han empleado, $I_{p_{0}}=2,9$ y $M_{W_{0}}=106900 \frac{\mathrm{g}}{\mathrm{mol}}$ de la referencia utilizada como guía para ejecutar este cálculo.

Existe por tanto, una dependencia temporal de la reticulación, a través de la dependencia que presenta con el tiempo la viscosidad. Además, tal y como se ve en las curvas experimentales, la viscosidad varía con el tiempo 
presentando un comportamiento inicial con tendencia lineal, es decir, en el límite de tiempo nulo se podría decir que se puede representar según la relación de la Ecuación 4.27

$$
\left.\frac{d n}{d t}\right|_{0}=f^{\prime}(0)
$$

Este valor de $\left.\frac{d n}{d t}\right|_{0}$ se conoce como velocidad aparente de reticulación $k_{a p p}$, que además se relaciona con la temperatura mediante una expresión de tipo Arrhenius 4.28 .

$$
k_{a p p}=A \exp \left(-\frac{E_{a}}{R T}\right)
$$

Con las anteriores consideraciones, se establece que el comportamiento de la reticulación puede aproximarse por una relación dependiente del tiempo y de la temperatura como la descrita por la Ecuación 4.29 .

$$
n=n(t, T)=\left(\left.\frac{d n}{d t}\right|_{0}\right) t=A \exp \left(-\frac{E_{a}}{R T}\right) t
$$

En el proceso de laminación automática y consolidación in-situ, se puede estimar que el material presentará un comportamiento similar al que se observa en esa zona inicial de las curvas, pues las isotermas de calentamiento son del orden de $5 \mathrm{~s}$ (con velocidades de calentamiento en el entorno de $6000 \mathrm{~K} / \mathrm{min})$.

La Ecuación 4.29 permitirá conocer cómo evolucionan los actos de reticulación en el material en función del tiempo y la temperatura del programa de calentamiento aplicado sobre el material.

Utilizando las curvas de ensayo representadas en la Figura 4.57 se ha seguido el procedimiento de cálculo presentado con anterioridad, obteniéndose los siguientes valores para los parámetros: $A=84,64 \mathrm{~kJ} / \mathrm{mol}$ y $E_{a}=$ $7,91 \cdot 10^{-3} \mathrm{~mol} / \mathrm{gs}$. Pudiendo representarse, por consiguiente, la evolución de los actos de reticulación en función del tiempo para el PEEK 450G en atmósfera oxidativa (Figura 4.58). 


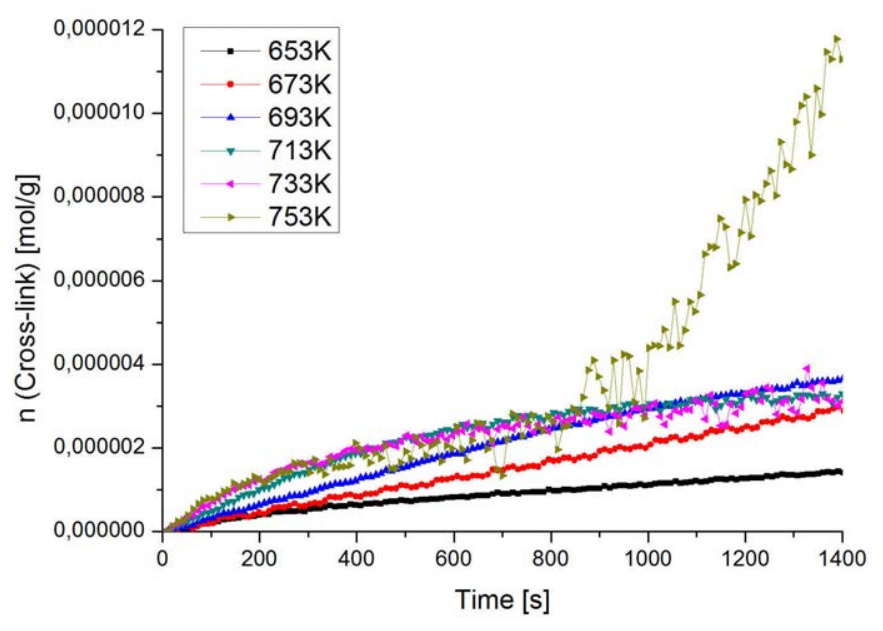

Figura 4.58: Variación de $n$ (actos de reticulación) con el tiempo para diferentes programas isotermos en PEEK 450G

\subsection{Adhesión}

En el proceso de laminación automática y consolidación in-situ, el material de aporte y sustrato comienzan a entrar en contacto en el instante que el rodillo ejerce presión contra ambos. Debido a la velocidad de desplazamiento de la máquina este contacto dura un corto espacio temporal, condicionado por la geometría y la capacidad de deformación del rodillo. Durante ese breve periodo de tiempo, el material debe aplanarse y las cadenas del polímero deben reptar de una entrecara a otra para generar la unión.

En un proceso de consolidación convencional como es el caso del procesado en prensa, el material se encuentra bajo la acción de la presión desde el instante inicial del proceso. Una vez alcanzada la temperatura de procesado recibirá la máxima presión y se mantendrá bajo dicha condición hasta que se enfríe (quedando solidificado), por tanto, la etapa de aplicación de presión es un proceso de duración equivalente a horas. En el proceso de laminación automática y consolidación in-situ, el rodillo contacta con el material justo después de cesar el calentamiento del láser, teniendo lugar en ese instante el comienzo de la caída de la temperatura, luego la presión se ejerce durante un periodo del enfriamiento en un intervalo gobernado por la huella del rodillo y la velocidad de desplazamiento del cabezal. Para este estudio, considerando las características de la máquina de encintado de una sola "tow", se emplean valores medidos de huella del rodillo que se aproximan a 12 (sentido encintado) x $16 \mathrm{~mm}^{2}$. Como valor de fuerza vertical aplicada durante el encintado, 
se seleccionan $490 \mathrm{~N}$.

Para la modelización del proceso de adhesión entre las capas del material, deben contemplarse dos partes (tal y como se ilustraba en el apartado de estado del arte), el contacto íntimo y la difusión de las cadenas.

\subsubsection{Contacto íntimo}

El contacto íntimo, se relaciona con la capacidad para destruir la irregularidad superficial del material para conseguir un contacto perfecto entre las partes.

Aunque, tal y como fue ilustrado en la sección de estado del arte, existen diferentes aproximaciones para establecer la estructura superficial del material, en este trabajo se ha recurrido a la simplificación de considerar la superficie del material como una secuencia de rectángulos definidos por su altura, anchura y por la separación entre los mismos. La representación matemática del grado de contacto íntimo que tiene en cuenta esos parámetros de la geometría, se corresponde con la Ecuación 4.30 donde $D_{i c, 0}$ es el grado de contacto íntimo inicial (Ecuación 4.31).

$$
\begin{gathered}
D_{i c}\left(t_{c}\right)=D_{i c, 0}\left[1+5\left(1+\frac{w_{0}}{b_{0}}\right)\left(\frac{a_{0}}{b_{0}}\right)^{2} \int_{0}^{t_{c}} \frac{P_{a p p}}{\eta(T)} d t\right]^{1 / 5} \\
D_{i c, 0}=\frac{1}{1+\frac{w_{0}}{b_{0}}}
\end{gathered}
$$

La ecuación 4.30 tiene en cuenta los valores de la morfología inicial del material (descritos en la sección 2.5.1.2), la presión aplicada y la viscosidad del material como función dependiente del perfil tiempo-temperatura. Para la obtención de los parámetros de la ecuación, fueron ejecutadas medidas de profilometría acompañadas de un análisis óptico con micrografías sobre probetas que habían sido sometidas a ciclos específicos de calentamiento. Los valores de viscosidad se tomaron inicialmente de referencias bibliográficas y posteriormente se extrajeron también de modo experimental mediante medidas reológicas. Los perfiles tiempo-temperatura que aplican al proceso, se extrajeron de las mediciones ejecutadas con termopares embebidos en los laminados y que fueron incluidas en el apartado de transferencia de calor 4.1.1.

El material objeto de estudio en esta tesis doctoral, APC2/AS4, adquirido a Solvay/Cytec presenta una superficie irregular y una distribución heterogénea de fibra y resina. Diferentes muestras de material fueron embutidas y pulidas, para su caracterización por microscopia óptica (Figuras 4.59 4.60 
y 4.61 .

Analizando las imágenes de la muestra 1, incluidas en la Figura 4.59. pueden destacarse los efectos que se listan a continuación. Respecto al contenido superficial de resina: comparando la imagen 4.59 e con cualquiera de las otras cinco, es posible observar como en esa zona particular del material, las superficies se encuentran prácticamente desprovistas de resina superficial que favorecería la adhesión en un proceso de fabricación como el estudiado. Por el contrario, en la porción de material representada en la Figura 4.59f, se detecta un exceso de resina en la esquina superior izquierda. Asimismo, todas ellas presentan una irregularidad superficial muy marcada, especialmente destacable en los casos de 4.59 y 4.59 . La distribución de fibra y resina tampoco es homogénea, como demuestra el caso $4.59 \mathrm{~d}$ donde hay una amplia zona cubierta por resina y sin fibra de carbono. Similares efectos pueden observarse en la muestra 2 (Figura 4.60) y en la 3 (Figura 4.61).

Las figuras mencionadas con anterioridad también manifiestan la presencia de porosidad intralaminar, que debe ser eliminada durante el procesado del material.

Todas las heterogeneidades observadas en el material suponen una limitación a la consecución de buenas calidades en el proceso de encintado automático y consolidación in-situ, de ahí que numerosos grupos de investigación trabajando en la misma temática aludan a estudios conjuntos de optimización de los parámetros del encintado junto a mejoras en la producción del material como únicas alternativas para conseguir llevar el proceso a una escala aceptable de productividad industrial. 


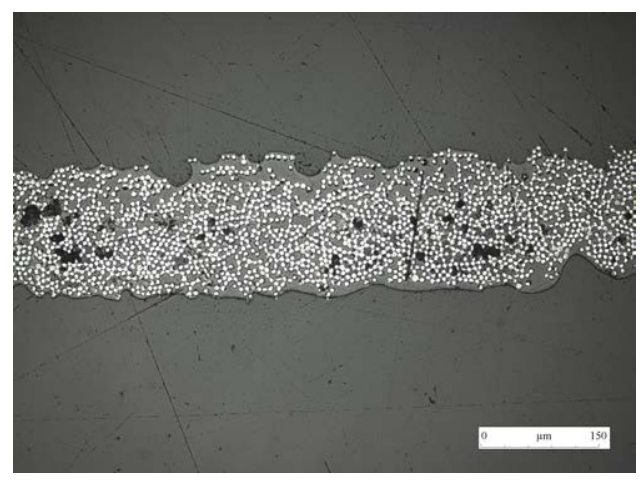

(a)

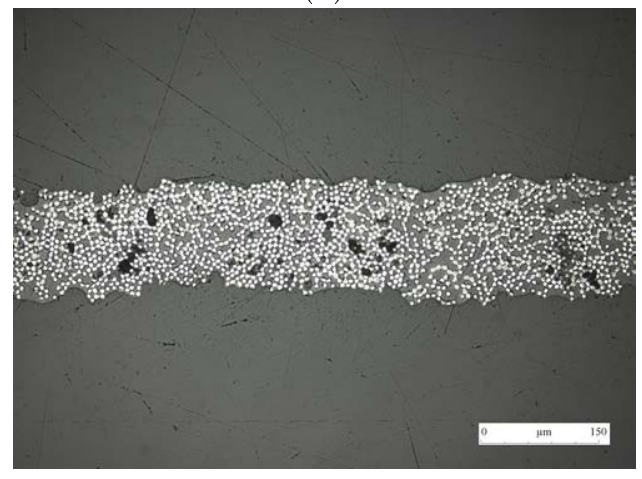

(c)

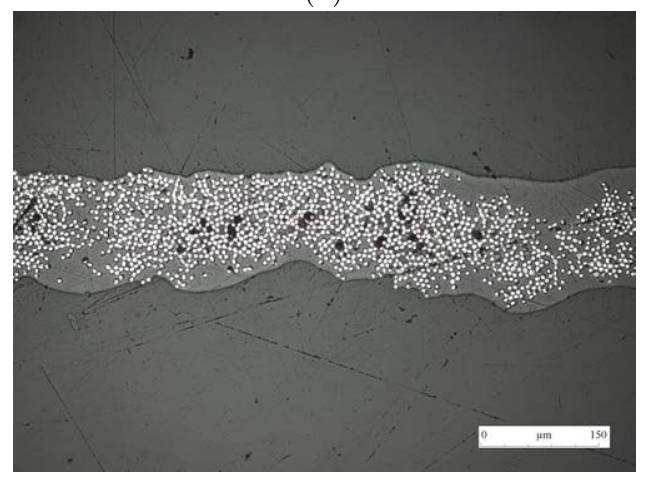

(e)

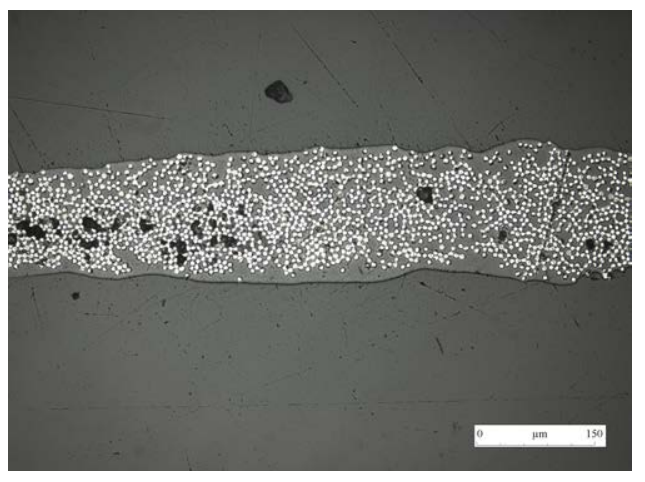

(b)

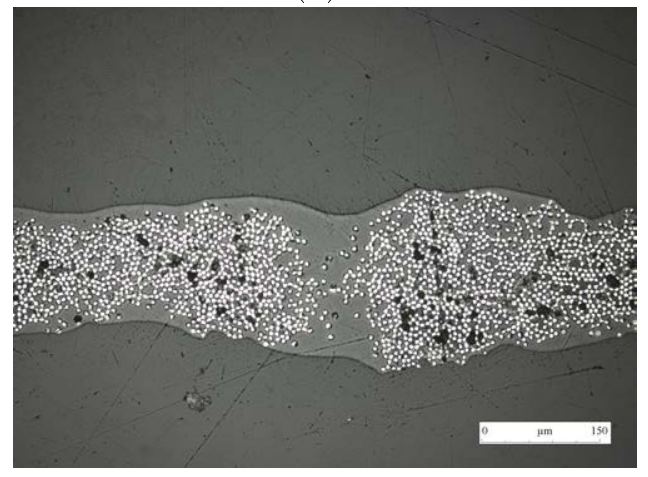

(d)

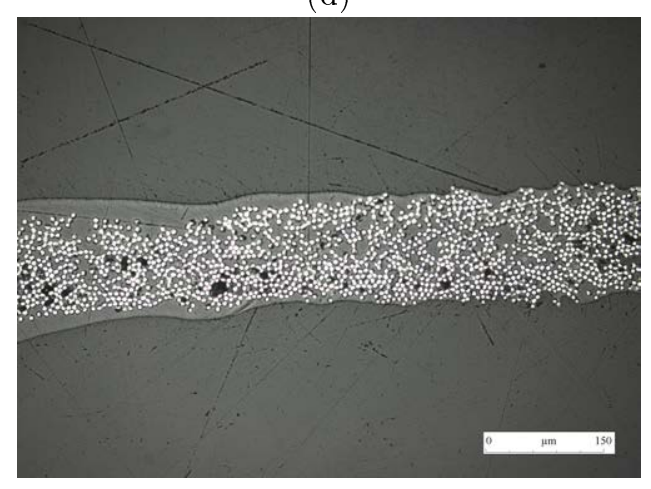

(f)

Figura 4.59: Micrografías (20x) en muestra 1 del material APC2/AS4 tras ser recibido por el suministrador

\subsubsection{Análisis de profilometría en APC2/AS4}

Para extraer los valores de morfología superficial inicial del material, se ejecutaron medidas de rugosidad utilizando un profilómetro como el descrito en la sección 3.4.3 las medidas se evaluaron tanto en longitudinal como en transversal a la dirección de la fibra. Para la modelización, se tomaron las medidas en transversal, por considerarse el caso más desfavorable a la hora de 


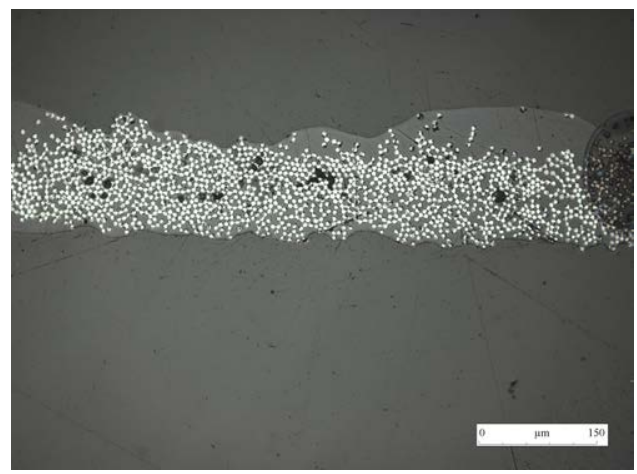

(a)

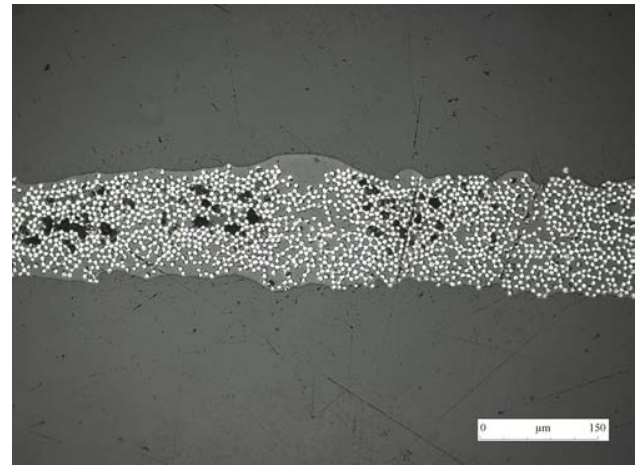

(c)

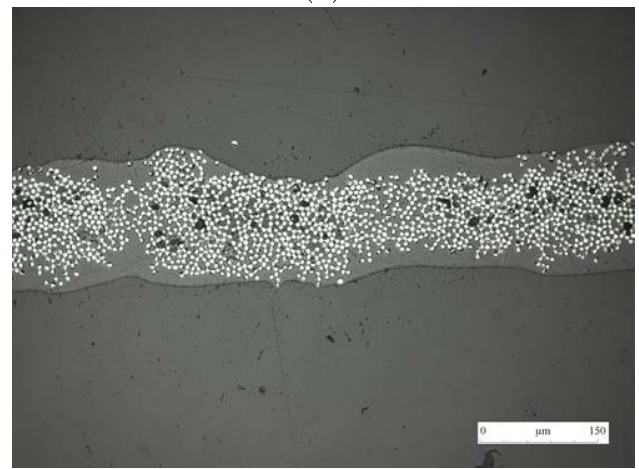

(e)

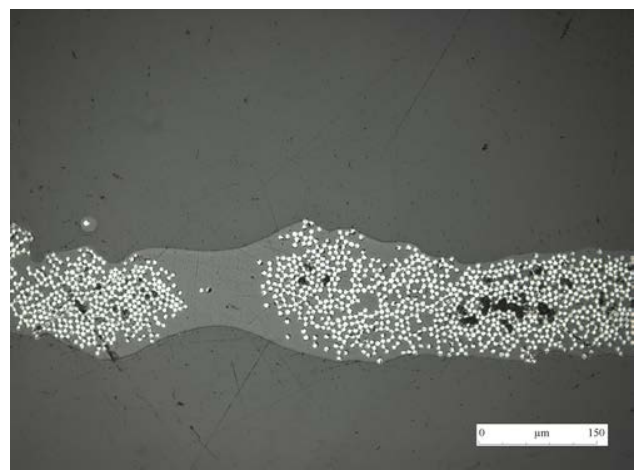

(b)

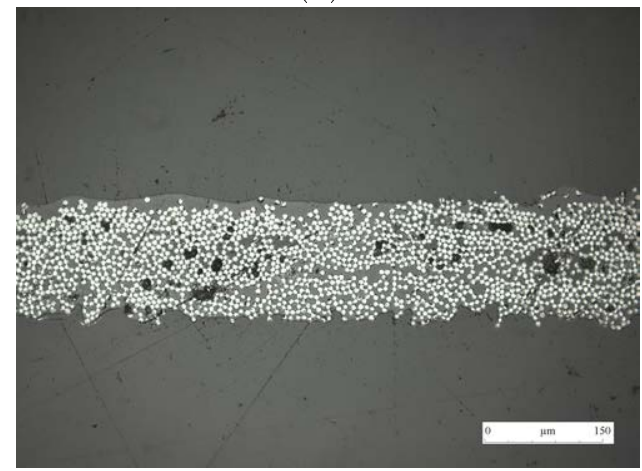

(d)

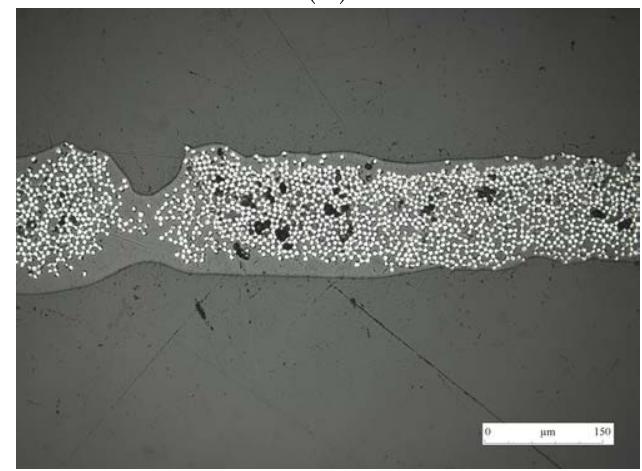

(f)

Figura 4.60: Micrografías (20x) en muestra 2 del material APC2/AS4 tras ser recibido por el suministrador

estimar el grado de contacto íntimo entre las partes, la Figura 4.62 contiene la representación de los cinco perfiles empleados para promediar el valor de la altura de la rugosidad. Con dichas mediciones y siguiendo el procedimiento experimental propuesto en el trabajo de (Levy et al. 2014), se obtuvo una estimación para el valor de $a_{0}$ o valor de altura de la rugosidad, calculado como dos veces el valor de desviación estándar del perfil de rugosidad inicial. 


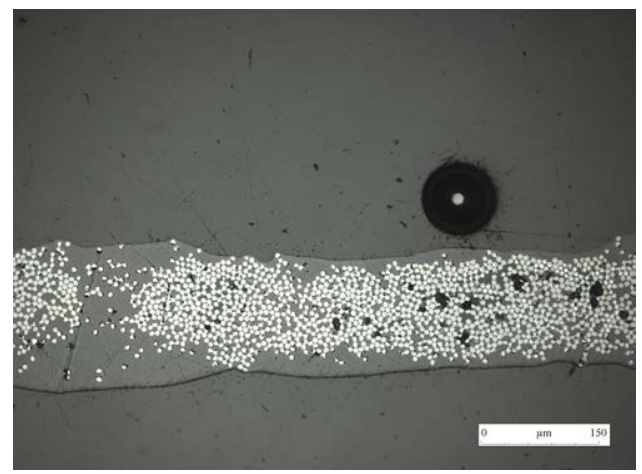

(a)

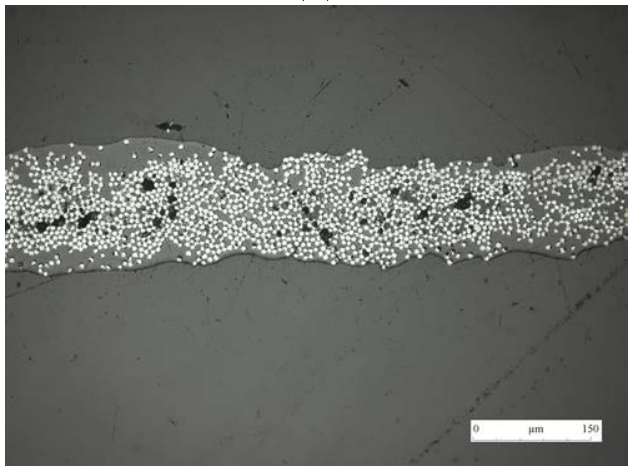

(c)

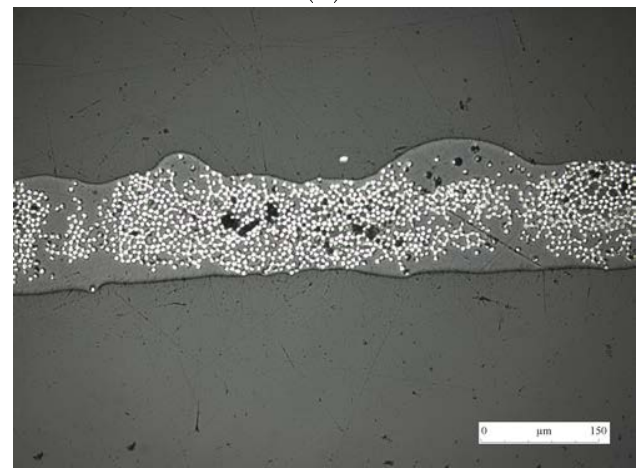

(e)

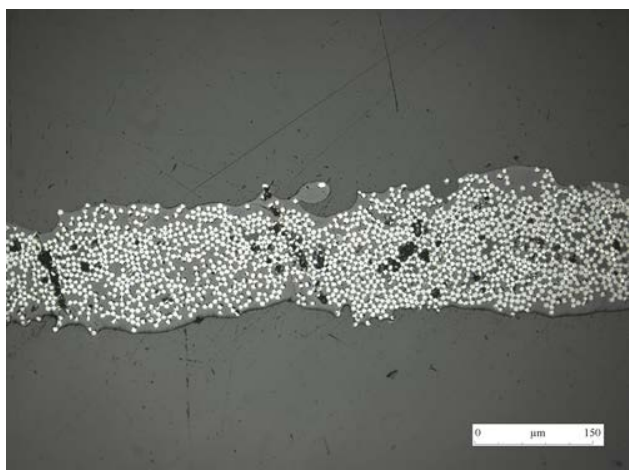

(b)

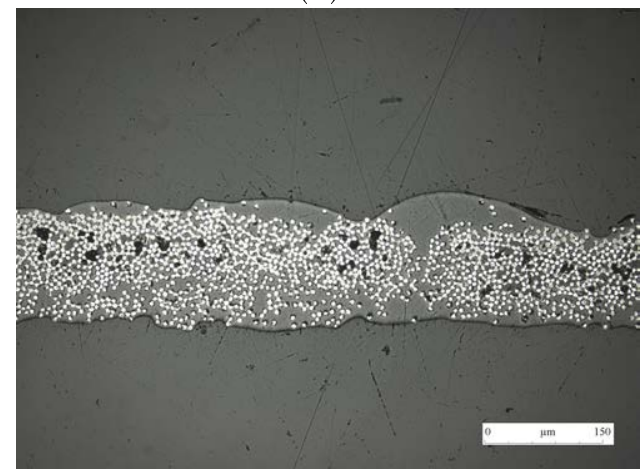

(d)

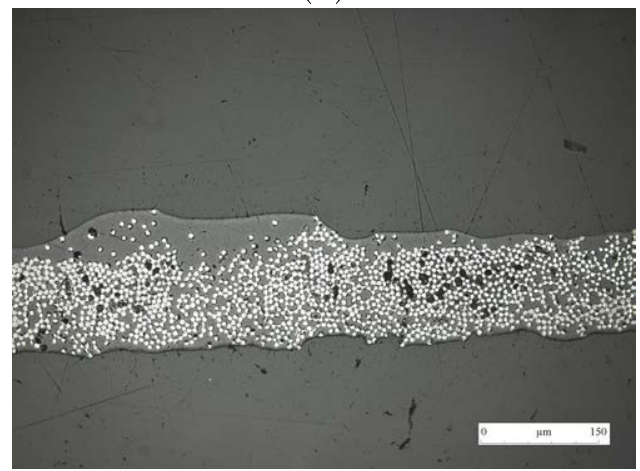

(f)

Figura 4.61: Micrografías (20x) en muestra 3 del material APC2/AS4 tras ser recibido por el suministrador

En base a los perfiles de rugosidad obtenidos, se ha estimado un valor de altura de la rugosidad para el material APC2/AS4 equivalente a $a_{0}=21,95 \mu m$ con una desviación estándar de $2,47 \mu m$.

Siguiendo los desarrollos experimentales del estudio referenciado de (Levy 


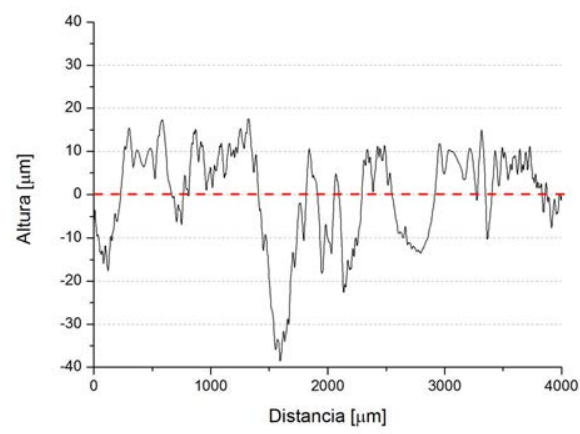

(a)

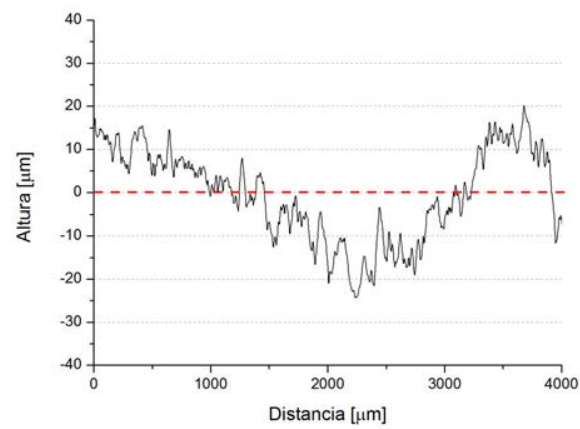

(c)

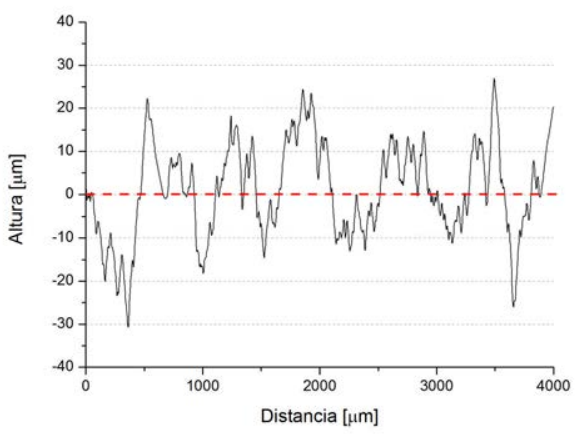

(b)

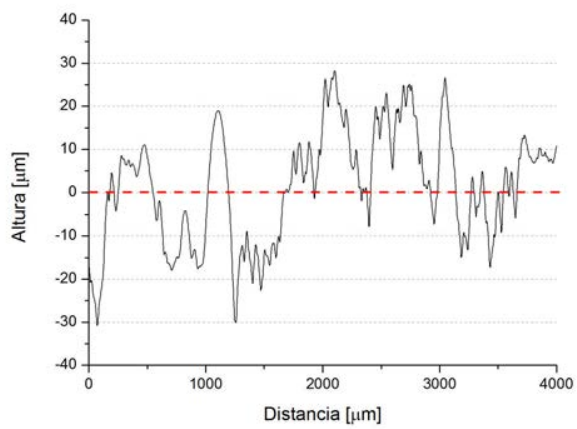

(d)

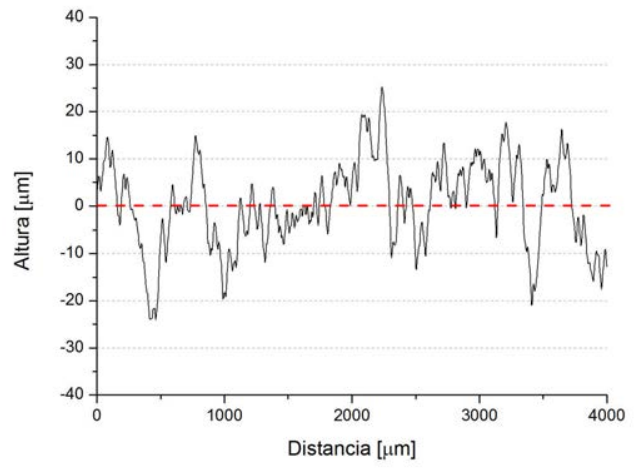

(e)

Figura 4.62: Perfiles de rugosidad medidos en muestras de APC2/AS4 sin tratamiento, estado de recepción por el suministrador

et al. 2014), se efectuaron laminados de dimensiones $100 x 100 \mathrm{~mm}^{2}$, apilando tres capas de material con orientaciones $[0,90,0]$ para facilitar la posterior distinción de las entre-caras por microscopia. Dichas probetas fueron calentadas dentro de una prensa de platos calientes y compactadas con un valor de pre- 
sión controlada. La presión fue controlada mediante la selección de un peso metálico cuya base tenía la misma geometría y unas dimensiones ligeramente inferiores a las de la probeta (solo el área de probeta que quedó bajo el peso se utilizó para los análisis posteriores). Para asegurar que la compactación se ejecutaba bajo las condiciones de la isoterma propuesta, el útil empleado como sistema de presión fue aislado por todas sus caras salvo por la inferior, que se mantuvo en contacto con el plato de la prensa a la temperatura de consigna hasta estabilizarse a ese valor. Una vez alcanzada la temperatura de consigna, la probeta se colocó bajo el peso y sobre el plato de la prensa.

Entre las probetas se variaron los tiempos de mantenimiento bajo la acción del peso a una determinada isoterma, alcanzando así diferentes grados de contacto (ejecutando la simplificación de suponer que todo el desarrollo de contacto procede del mantenimiento a la isoterma pues sólo en ese intervalo interviene una presión no nula). Una vez finalizada la estabilización definida, las probetas se extrajeron de la prensa, enfriándose de modo brusco al ambiente. Esta condición no es favorable de cara al desarrollo de la porosidad, pues al no encontrarse la probeta presionada en el enfriamiento puede incrementarse el nivel de porosidad previo a completar la cristalización, sin embargo, los valores que se obtendrán serán en todo caso más conservativos de cara a las predicciones de grado de contacto desarrollado.

Una vez tratadas, las probetas fueron cortadas a dimensión de 20x20 $m m^{2}$, pulidas y observadas por microscopia óptica (como esquematiza la Figura 4.63). En todas las probetas se analizó el grado de contacto como el cociente entre las áreas longitudinales con conexión entre capas frente a la longitud total analizada, observándose una pérdida de contacto más marcada a medida que se disminuía el tiempo de mantenimiento (tendencia no mantenida en este caso particular de representación para las probetas de $1 \mathrm{y}$ $2 \mathrm{~min}$ ). Conocido el grado de contacto íntimo en unas condiciones de trabajo específicas (temperatura, tiempo y presión), se empleó un análisis inverso para estimar los otros dos parámetros que definían la morfología del modelo de rectángulos del material (ancho y separación) mediante el empleo de la Ecuación 4.32 expresión simplificada de la Ecuación 4.30 por utilizarse en este caso particular en condiciones isotermas. La obtención de los mismos se elaboró mediante programación en Matlab, estableciendo una función de minimización que permitiese variar los valores de los parámetros $w_{0}$ y $b_{0}$ de modo que la diferencia entre la función teórica de $D_{i c}$ y el valor experimental extraído de la observación de las micrografías fuera lo menor posible.

$$
D_{i c}\left(t_{c}\right)=D_{i c, 0}\left[1+5 \frac{P_{a p p}}{\eta(T)}\left(1+\frac{w_{0}}{b_{0}}\right)\left(\frac{a_{0}}{b_{0}}\right)^{2} t\right]^{1 / 5}
$$


Para la viscosidad del material, se empleó el valor reportado para el material APC2/AS4 por (Levy et al., 2014), Ecuación 4.33 por la imposibilidad en el periodo de desarrollo de estos ensayos para ejecutar medidas de viscosidad a alta temperatura por las limitaciones del equipo de reología. Durante el transcurso de la tesis doctoral, la adquisición de un nuevo horno para el reómetro permitió elaborar ensayos sobre el material, utilizándose posteriormente para validar la veracidad del valor de viscosidad previamente empleado.

$$
\mu(T)=1,14 \cdot 10^{-12} \exp \left(\frac{26300}{T}\right)
$$

El código de optimización arrojó unos valores para los parámetros tales que: $\frac{a_{0}}{b_{0}}=0,85$ y $\frac{w_{0}}{b_{0}}=0,45$, diferentes a los que se reportaban en (Levy et al. 2014) $\left(\frac{a_{0}}{b_{0}}=1,237 \mathrm{y} \frac{w_{0}}{b_{0}}=0,743\right)$, a pesar de emplearse el mismo material. Las diferencias pueden estar motivadas por el propio procedimiento experimental empleado, donde se hace complejo asegurar los mantenimientos durante tiempos del orden de segundos y donde el análisis de las zonas en contacto de las probetas se hace a través de una observación por medio de la microscopia. Asimismo, la optimización se encuentra afectada por el valor de arranque que se les asigna a estos parámetros, por lo que se tendrá también en cuenta el impacto de variaciones de los mismos sobre el resultado del grado de contacto íntimo.

\subsubsection{Cálculo del grado de contacto íntimo}

Fijados los parámetros anteriormente indicados, la evolución del grado de contacto íntimo en condiciones isotermas podría representarse como se indica en la Ecuación 4.34. Quedando la ecuación definida para un estudio dependiente de una pareja temperatura-tiempo y de un valor de presión aplicada. Se han elaborado barridos en el tiempo para un valor fijo de una de las otras dos variables (presión o temperatura) y dejándose variar la otra, de este modo se obtendrán curvas donde podrían analizarse los requisitos temporales mínimos bajo ciertas condiciones para alcanzar el grado de contacto íntimo del $100 \%$. En este punto, conviene puntualizar que, en un proceso de consolidación general en prensa, el material también puede desarrollar contacto íntimo durante la etapa de calentamiento, que se estima aquí despreciable por asociarse a un valor de presión prácticamente nula, así como también durante la rampa de enfriamiento hasta que se completa la solidificación, para ejecutar un análisis más estricto en las condiciones particulares de ese proceso de fabricación, ese tramo del enfriamiento debería sumarse a la contribución de la destrucción de la irregularidad superficial durante el 


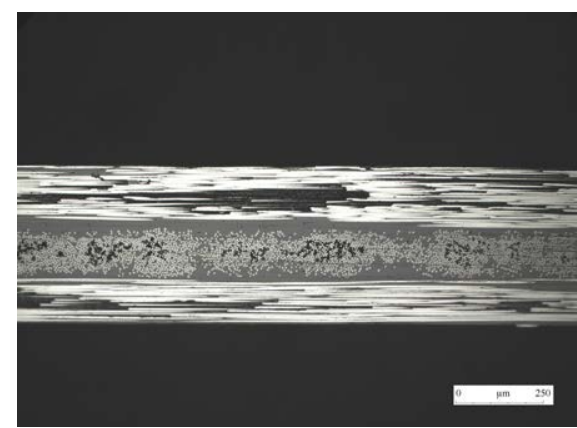

(a)

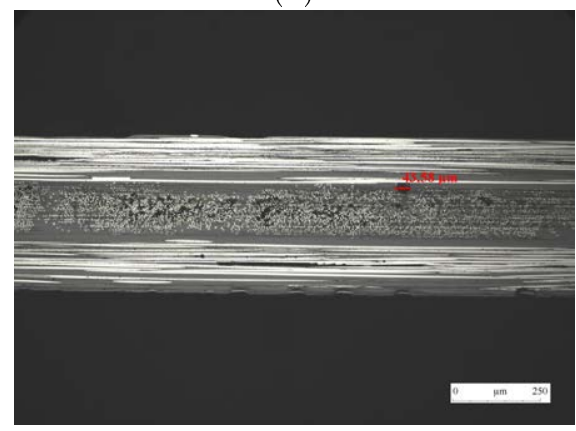

(c)

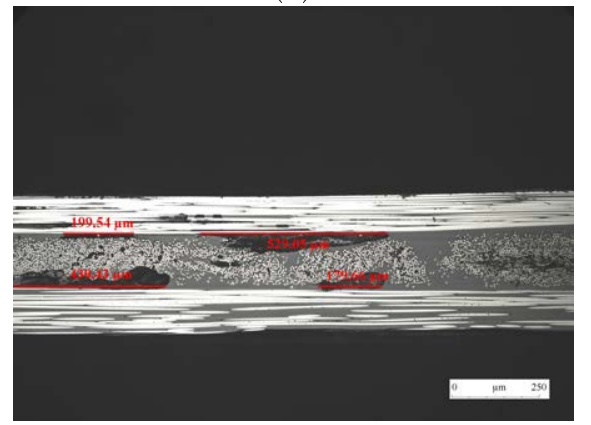

(e)

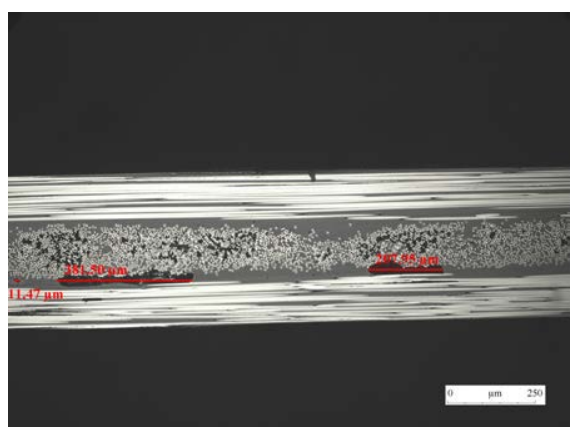

(b)

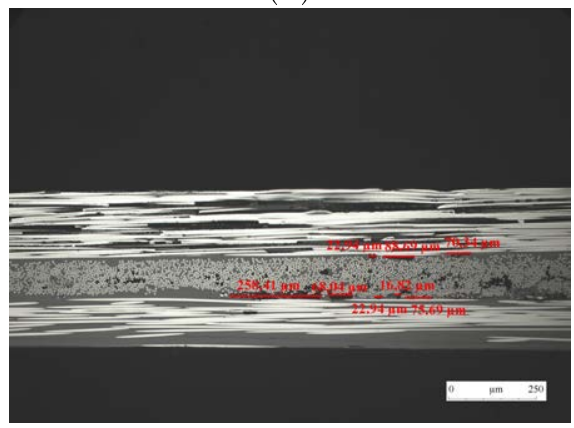

(d)

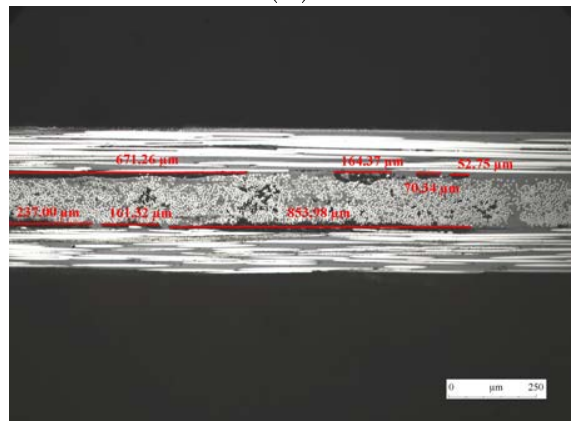

(f)

Figura 4.63: Análisis por imagen del grado de contacto entre superficies con tiempos de mantenimiento (a) $3 \mathrm{~min}$, (b) $2 \mathrm{~min}$, (c) $1 \mathrm{~min}$, (d) $20 \mathrm{~s}$, (e) 10 $\mathrm{s},(\mathrm{f}) 5 \mathrm{~s}$

tramo de la isoterma. En esta última situación, no se podría trabajar con la Ecuación 4.34 sino con su representación integral (condiciones no isotermas) y el grado de contacto íntimo inicial, será el que se obtuviera al finalizar a primera etapa. 


$$
D_{i c}\left(t_{c}\right)=0,69\left[1+4,59 \cdot 10^{12} \frac{P_{a p p} t}{\exp \left(\frac{26300}{T}\right)}\right]^{1 / 5}
$$

La Figura 4.64 contiene una representación de la evolución del grado de contacto íntimo para un intervalo de $60 \mathrm{~s}$ y valores de presión evolucionando desde $0,1 \mathrm{MPa}$ a $2,1 \mathrm{MPa}$ (fijando como temperaturas $623 \mathrm{~K}, 648 \mathrm{~K}, 673 \mathrm{~K}$ y $698 \mathrm{~K}$ ). Los gráficos se han filtrado para que el eje de las ordenadas evolucione en valores entre $D_{i c, 0}$ y 1 (máximo valor con sentido físico alcanzable). Como puede verse comparando los ejes de las abscisas para las 4 condiciones de temperatura consideradas, el tiempo requerido para conseguir el máximo grado de contacto es cada vez menor con el incremento de temperatura, causa directa de la reducción de viscosidad del polímero.

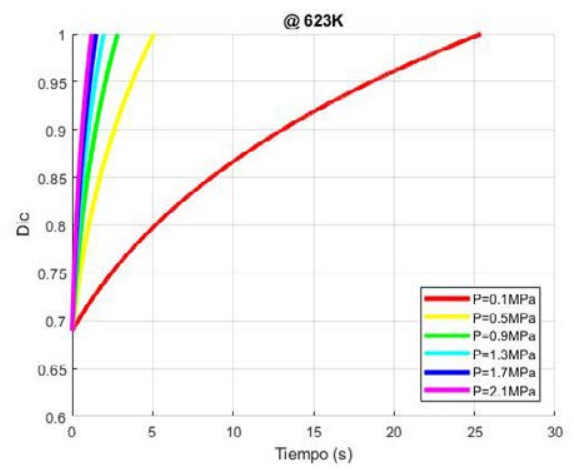

(a)

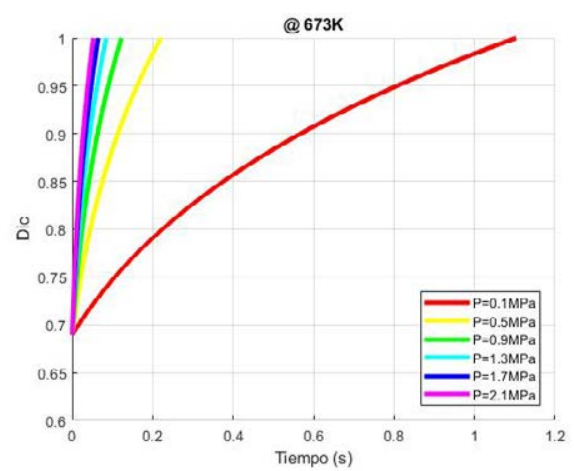

(c)

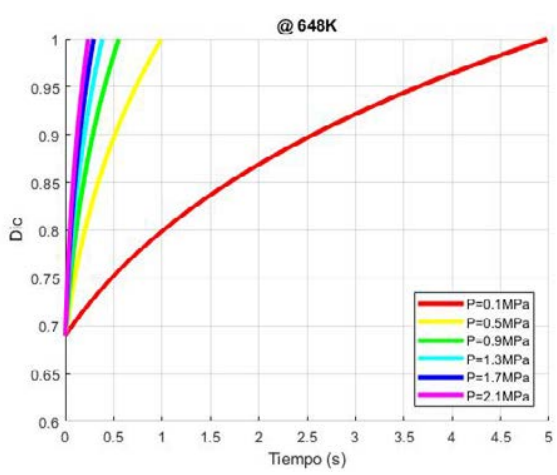

(b)

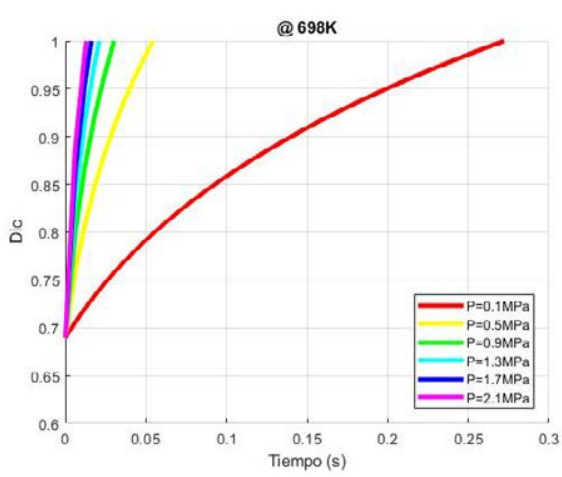

(d)

Figura 4.64: Análisis de la evolución del grado de contacto íntimo con el tiempo en condiciones isotermas (a) $623 K$, (b) $648 K$, (c) $673 K$ y (d) $698 K$ para diferentes valores de presión aplicada

El mismo gráfico ha sido representado manteniendo fijo el valor de presión y dejando a la temperatura variar entre los cuatro valores indicados con 
anterioridad, el resultado se muestra en la Figura 4.65

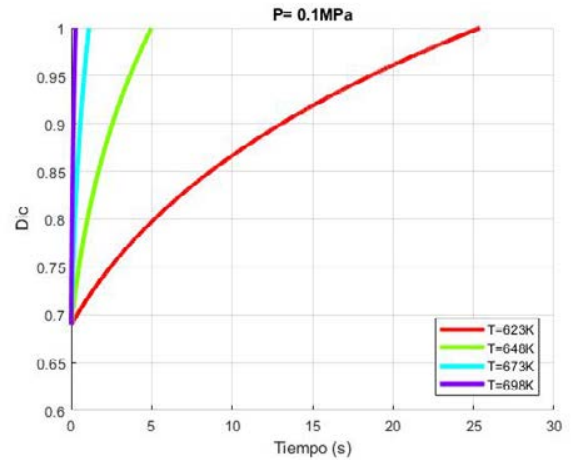

(a)

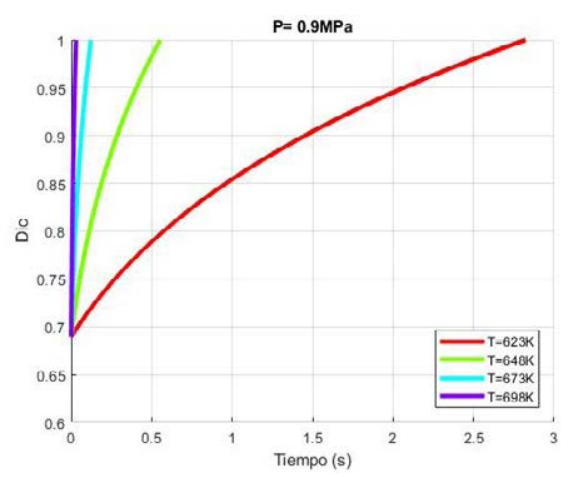

(c)

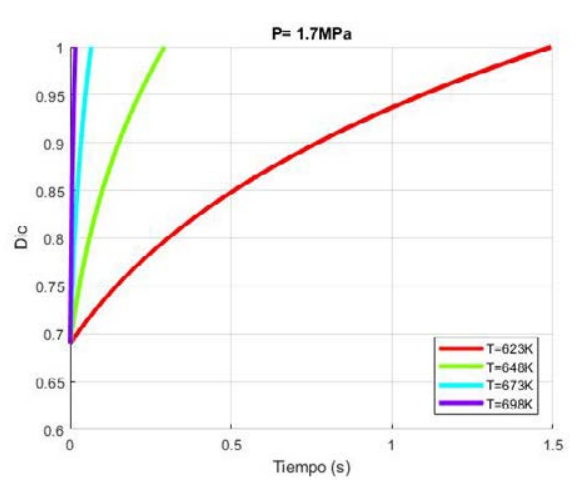

(e)

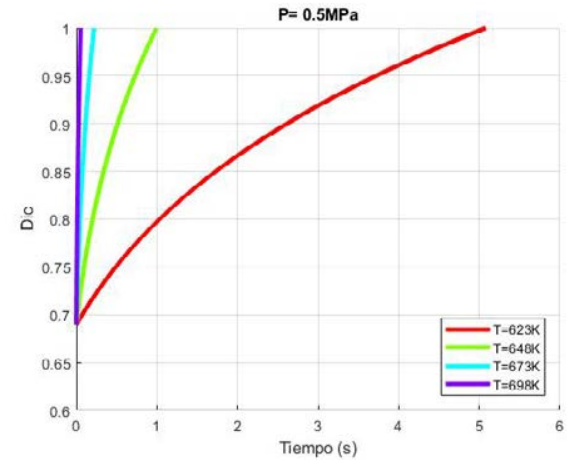

(b)

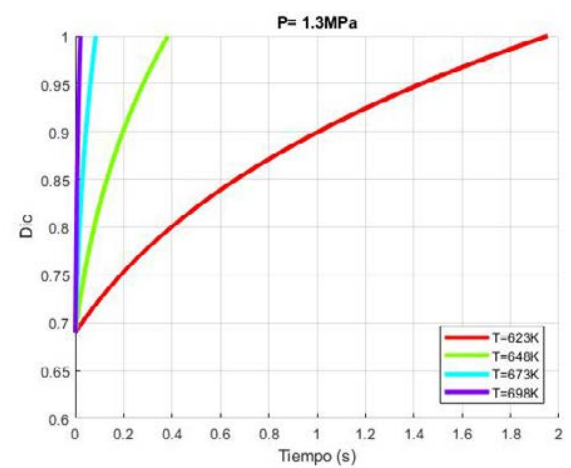

(d)

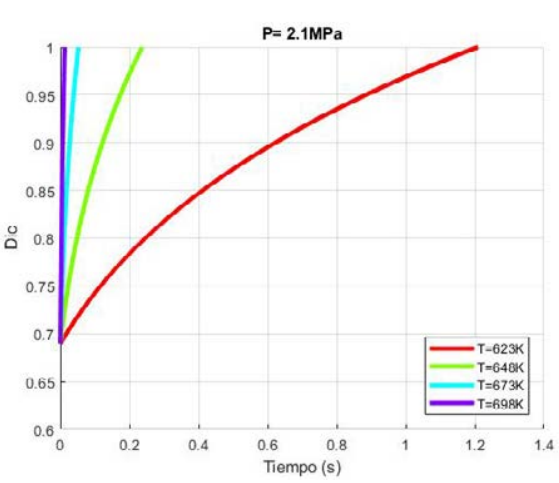

(f)

Figura 4.65: Análisis de la evolución del grado de contacto íntimo con el tiempo en condiciones de presión constante e igual a (a) 0,1MPa, (b) 0,5MPa, (c) $0,9 M P a$, (d) $1,3 M P a$, (e) 1,7MPa y (f) 2,1MPa para diferentes valores de temperatura isoterma 
Los anteriores gráficos se han obtenido mediante el empleo de los parámetros de rugosidad extraídos de la optimización elaborada en esta tesis doctoral. Se ha comparado que su desviación respecto a los resultados obtenidos con la aplicación de los valores obtenidos por (Levy et al. 2014$)$ para el caso concreto de presión $2,1 M P a$ y temperatura $673 \mathrm{~K}$ es de un tiempo igual a $2 m s$ en la obtención del $100 \%$ del grado de contacto íntimo.

Una vez analizado lo que ocurre para un caso de condiciones isotermas, se busca extrapolar la solución al caso del proceso de laminación automática y consolidación in-situ, empleando la Ecuación 4.35. En este proceso, como ya se explicó con anterioridad, la presión se ejerce sólo cuando el material se encuentra bajo la acción del rodillo y el intervalo temporal de duración de esta compactación depende no sólo de las características del rodillo (dimensiones y capacidad de deformación) sino también de la velocidad de desplazamiento del cabezal. Como caso de estudio se trabajará con las características de un encintado a $1 \mathrm{~m} / \mathrm{min}$ y mesa fría, estimando que el perfil tiempo-temperatura en el intervalo de actuación de la presión del rodillo es el que reflejaba la primera rampa de enfriamiento de los termopares aproximando su forma a la de una curva exponencial (caso de enfriamiento de la Figura 4.4 con un incremento de $30 \mathrm{~K}$ por tratarse de la capa directamente irradiada). Para el cálculo, ejecutado mediante la función "quad" del software Matlab, la integración se inicia tomando como punto de partida el comienzo de aplicación de presión y como límite final un tiempo equivalente a $0,72 \mathrm{~s}$. Al acabar la compactación del rodillo, se espera que el material se encuentre a una temperatura próxima a los $473 \mathrm{~K}\left(200^{\circ} \mathrm{C}\right)$, en la cual el material presenta una viscosidad muy baja y se descartan efectos posteriores de variación del grado de contacto desde dicho punto.

$$
D_{i c}\left(t_{c}\right)=0,69\left[1+5,24 \int_{0}^{t_{c}} \frac{P_{a p p}}{1,14 \cdot 10^{-12} \exp \left(\frac{26300}{T}\right)} d t\right]^{1 / 5}
$$

El resultado de la integración ha permitido obtener las curvas incluidas en la Figura 4.66 a donde se observa como durante los $0,72 s$ de compactación del rodillo, el máximo grado de contacto íntimo alcanzado es de 0,81 frente al 0,69 de partida, siendo dicho resultado un indicativo de la imposibilidad de alcanzar la completa consolidación del material en la primera pasada del láser. Asimismo, se ha incluido un gráfico donde se permite la variación de la velocidad de encintado para comprobar cuál sería el grado de contacto íntimo bajo dichas circunstancias, hacia $2,5 \mathrm{~m} / \mathrm{min}$ la curva de evolución (Figura 4.66 b) comienza a decaer y en $20 \mathrm{~m} / \mathrm{min}$ el valor de contacto íntimo obtenido es de 0,76. Estos gráficos son de alta importancia a la hora de explicar las posibles causas de las bajas productividades de este proceso de fabricación. 
Los valores obtenidos, son consistentes con las observaciones que posteriormente se extraen de la microscopia óptica en los paneles encintados a $1 \mathrm{~m} / \mathrm{min}$. En ellos, se observa un limitado contenido en huecos en las entrecaras de las primeras capas y un incremento de los mismos en las tres últimas entre-caras. Las entrecaras de las primeras capas, recibirán múltiples calentamientos, dependientes del número de capas laminadas encima. Para poder analizar la evolución correcta de este parámetro se requiere un estudio más detallado, ejecutando análisis sobre probetas con 2 capas, 3 capas y así sucesivamente para determinar un grado de contacto íntimo inicial que se asocie con el grado de contacto final obtenido de la ejecución de laminación anterior. Asimismo, ese estudio deberá tener en consideración una tendencia de enfriamiento diferente en cada iteración y para cada entre-cara, este desarrollo se propone como trabajo futuro derivado a las ejecuciones de esta tesis. Para la elaboración de ese estudio, nuevas medidas de profilometría serán requeridas pues tras ser encintado el material, su topografía superficial deja de ser la de base que portaba tras su fabricación, adquiriendo los detalles derivados del encintado con uno u otro tipo de rodillo. La aplicación de tomografía, sugerida como trabajo futuro, podría permitir obtener los grados de rugosidad inicial en laminados con diferente número de capas.

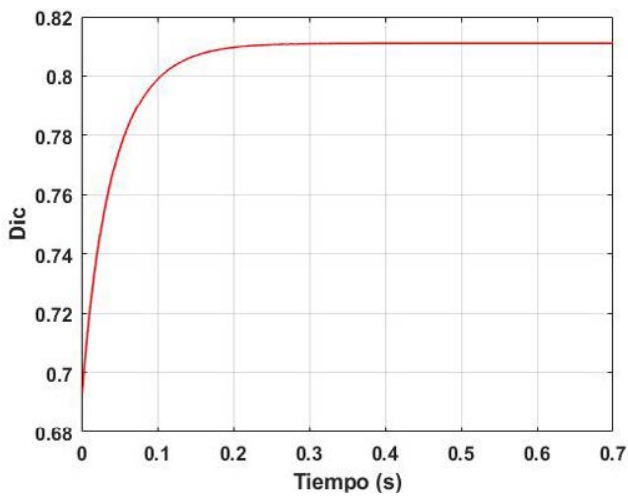

(a)

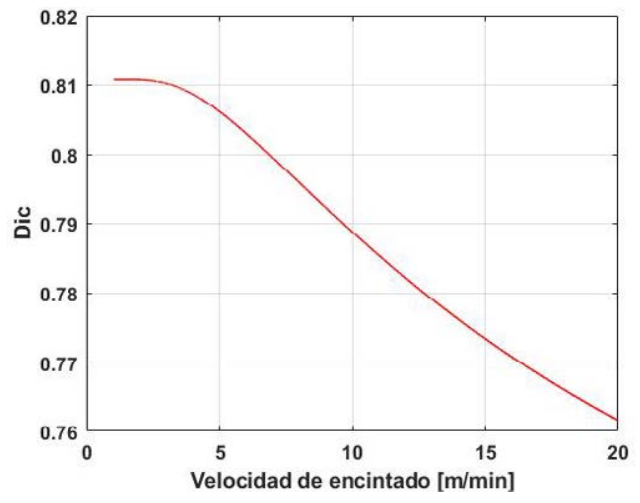

(b)

Figura 4.66: Análisis de la evolución del grado de contacto íntimo con el tiempo en (a) Integrando con el perfil de enfriamiento bajo el efecto del rodillo en el proceso de laminación a $1 \mathrm{~m} / \mathrm{min}$ y (b) Variando la velocidad de encintado bajo la suposición de misma tendencia de enfriamiento

Para estimar qué ocurriría en un segundo calentamiento sobre el material, se ha ejecutado un nuevo cálculo que considera que el grado de contacto íntimo inicial es $D_{i c, 0}=0,81$ pero bajo la hipótesis de que se mantienen los valores de $\frac{a_{0}}{b_{0}}=0,85$ y $\frac{w_{0}}{b_{0}}=0,45$. Este análisis deberá generar un resultado más conservativo al real esperado, pues los parámetros de la rugosidad ini- 
cial deben ser inferiores para esa entrecara considerando que láser y rodillo ya pasaron sobre ella. El cálculo, se ha elaborado suponiendo una tendencia similar en el perfil tiempo-temperatura pero valores escalados a $30 K$ bajo los considerados en el primer calentamiento, su resultado queda representado por los gráficos de la Figura 4.67 donde se observa una leve subida del grado de contacto a 0,835. Asimismo, analizando el impacto de la velocidad de encintado Figura 4.67b, se observa que en este caso, las diferencias entre $1 \mathrm{~m} / \mathrm{min}$ y $20 \mathrm{~m} / \mathrm{min}$ se han recortado respecto a las obtenidas en la Figura $4.66 \mathrm{~b}$.

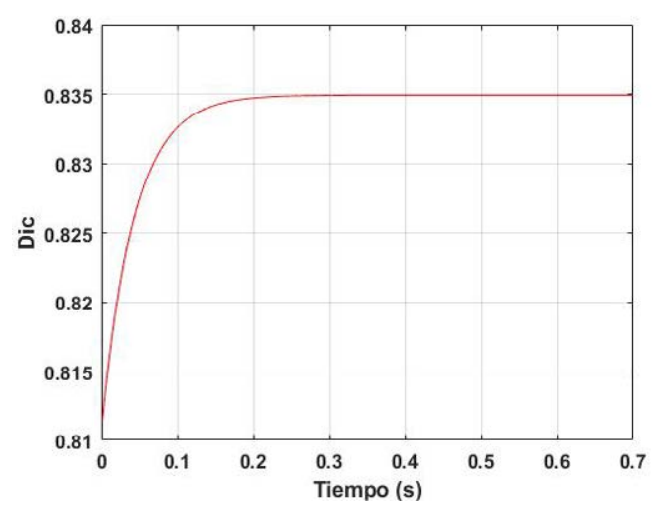

(a)

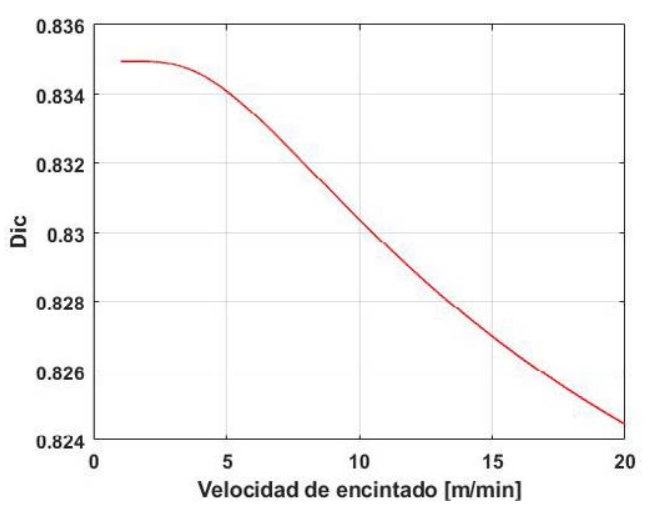

(b)

Figura 4.67: Análisis de la evolución del grado de contacto íntimo con el tiempo en la segunda pasada de calentamiento (a) Integrando con el perfil de enfriamiento bajo el efecto del rodillo en el proceso de laminación a $1 \mathrm{~m} / \mathrm{min}$ y (b) Variando la velocidad de encintado estimando la misma tendencia de enfriamiento

\subsubsection{Determinación experimental de la viscosidad del material}

Con la disponibilidad del horno para ensayos de reología a alta temperatura, se ejecutaron ensayos sobre PEEK neto en un rango de temperaturas en el área del pico de fusión y sus proximidades.

Como queda patente en el cálculo del grado de contacto íntimo, el valor de viscosidad seleccionado para el material es totalmente crítico para el resultado del estudio. Se desconoce con exactitud cuál es la resina empleada por Solvay para ejecutar la impregnación de la fibra de carbono, de ahí que durante los desarrollos de este trabajo fueran adquiridas resinas de dos pesos moleculares diferentes con el fin de aproximar el caso real. En la Figura 4.68 se recoge una comparativa de los resultados de viscosidad tras ensayar 
a $653 \mathrm{~K}\left(380^{\circ} \mathrm{C}\right)$ PEEK con dos pesos moleculares diferentes (PEEK 150G y PEEK 450G). El resultado de ese ensayo manifiesta una variación de valores entre 400 y $10000 P a . s$ en la zona del primer plateau newtoniano, quedando patente la diferencia que causaría emplear uno u otro material para el análisis.

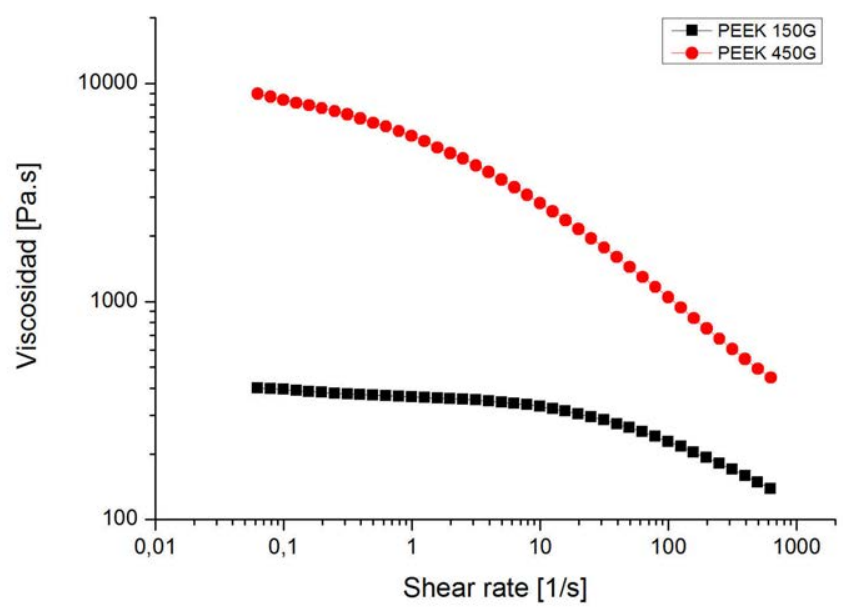

Figura 4.68: Comparativa viscosidades entre PEEK150G y PEEK450G

Considerando el caso más restrictivo a la hora de predecir los resultados de las diferentes físicas del proceso de laminación automática y consolidación in-situ y las alusiones en diversos trabajos sobre la similitud del APC2 con el polímero PEEK 450G, se ha optado por ejecutar los análisis sobre dicho material.

Sobre PEEK 450G, se han ejecutado ensayos isotermos con barridos oscilatorios de frecuencia comprendida entre 100 y $0,01 \mathrm{~Hz}$ y deformación del $1 \%$ (extraída del estudio del rango de viscoelasticidad lineal del material). Los ensayos se ejecutaron de mayor a menor frecuencia tratando de prevenir la degradación del polímero durante el ensayo, los valores correspondientes a las bajas frecuencias, debido al tiempo necesario para la adquisición de datos, muestran posibles efectos de degradación en el material. Una vez obtenidas las curvas, fue aplicada la transformación de Cox-Merz para la obtención de los valores de viscosidad real del material. Los ensayos recogidos por las Figuras 4.69 a 4.74 contienen la información del ensayo oscilatorio sobre el material (izquierda) y su transformación de Cox-Merz (derecha) para ensayos ejecutados en condiciones isotermas: $613 K, 623 K, 633 K, 643 K, 653 K$ y 
$673 K$.

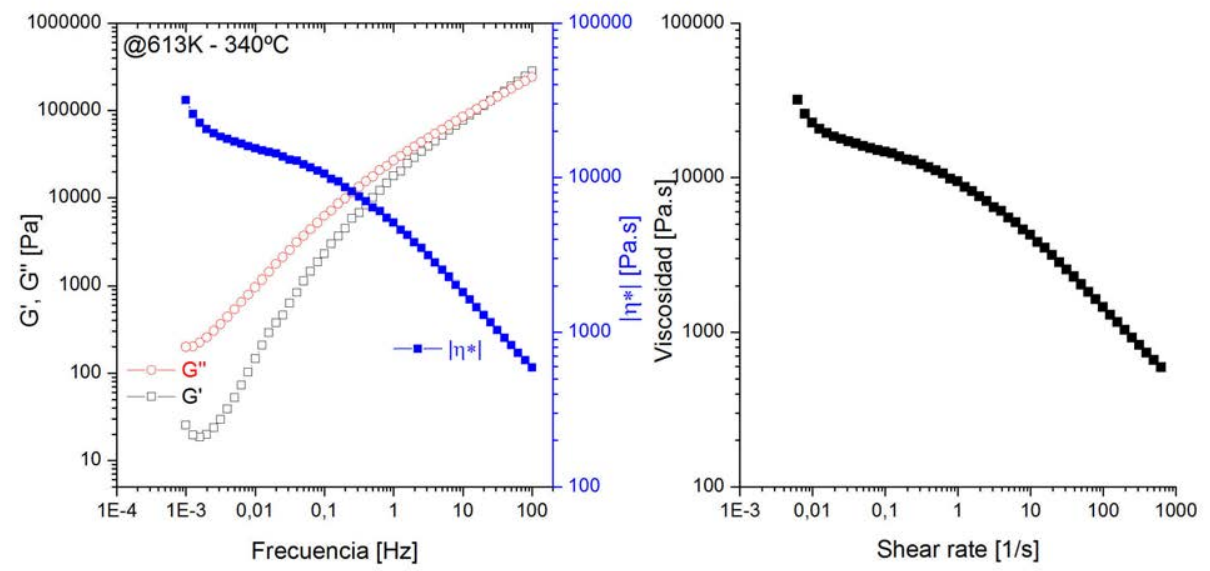

Figura 4.69: Ensayo oscilatorio y transformación de Cox-Merz. Isoterma a $613 \mathrm{~K}$.

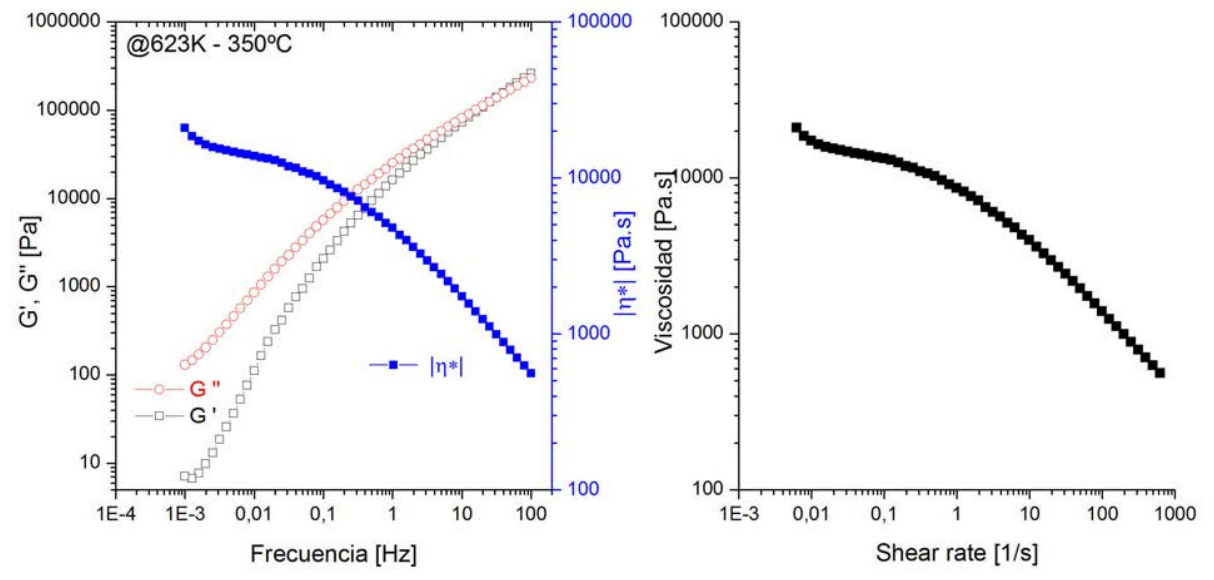

Figura 4.70: Ensayo oscilatorio y transformación de Cox-Merz. Isoterma a $623 \mathrm{~K}$.

En la Figura 4.75 se recoge una compilación de las curvas obtenidas tras la aplicación de Cox-Merz para los diferentes ensayos isotermos. Como puede verse, existe una tendencia decreciente de la viscosidad a medida que aumenta la temperatura del ensayo. 


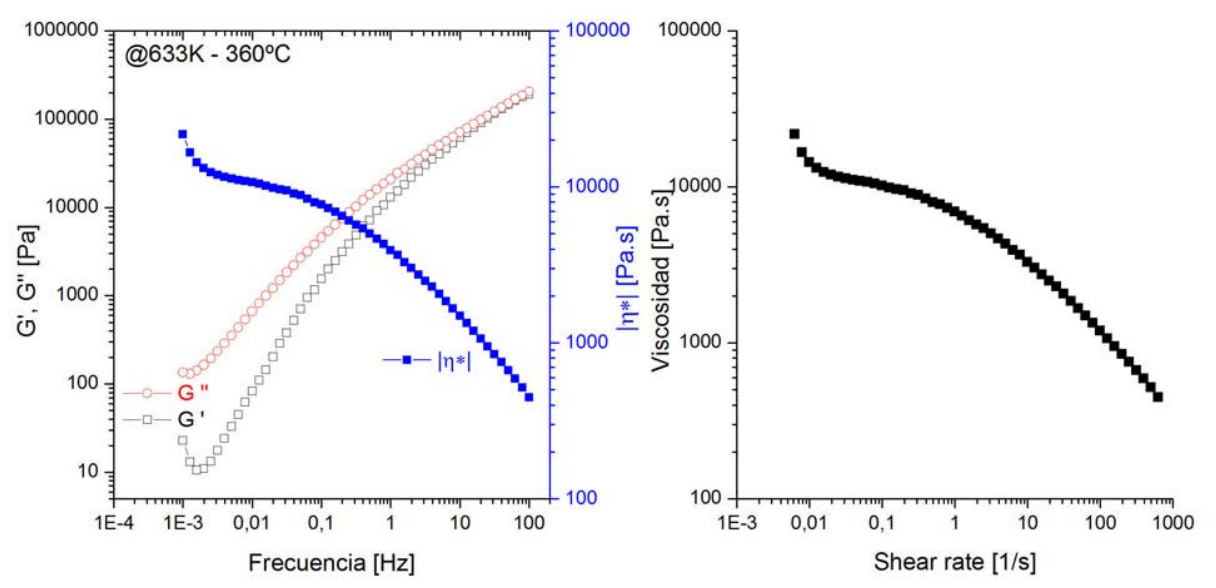

Figura 4.71: Ensayo oscilatorio y transformación de Cox-Merz. Isoterma a $633 \mathrm{~K}$.

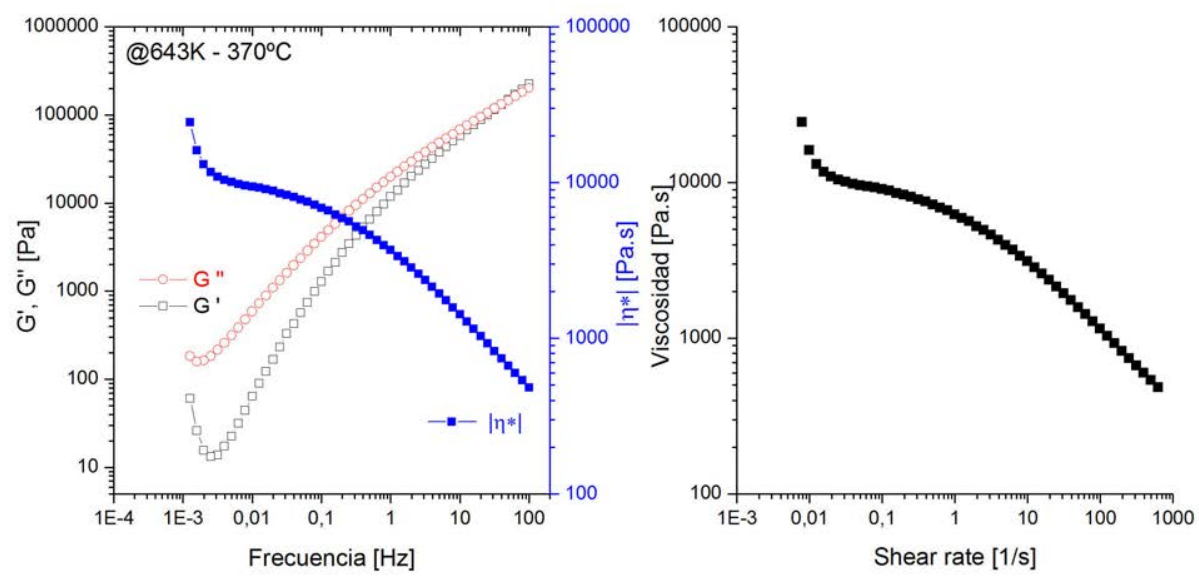

Figura 4.72: Ensayo oscilatorio y transformación de Cox-Merz. Isoterma a $643 \mathrm{~K}$.

Con el desarrollo de los ensayos de reología se obtienen unas curvas de variación de la viscosidad con la velocidad de cortadura ("shear rate") y por tanto, para definir el valor de viscosidad a utilizar, se hace preciso determinar cuál es la velocidad de cortadura en el proceso de fabricación a estudio. La gran mayoría de los trabajos reportados en el estado del arte se basan en la hipótesis de que, en el transcurso del encintado, el material se encuentra en la región del primer plateau newtoniano. Tomando en consideración 


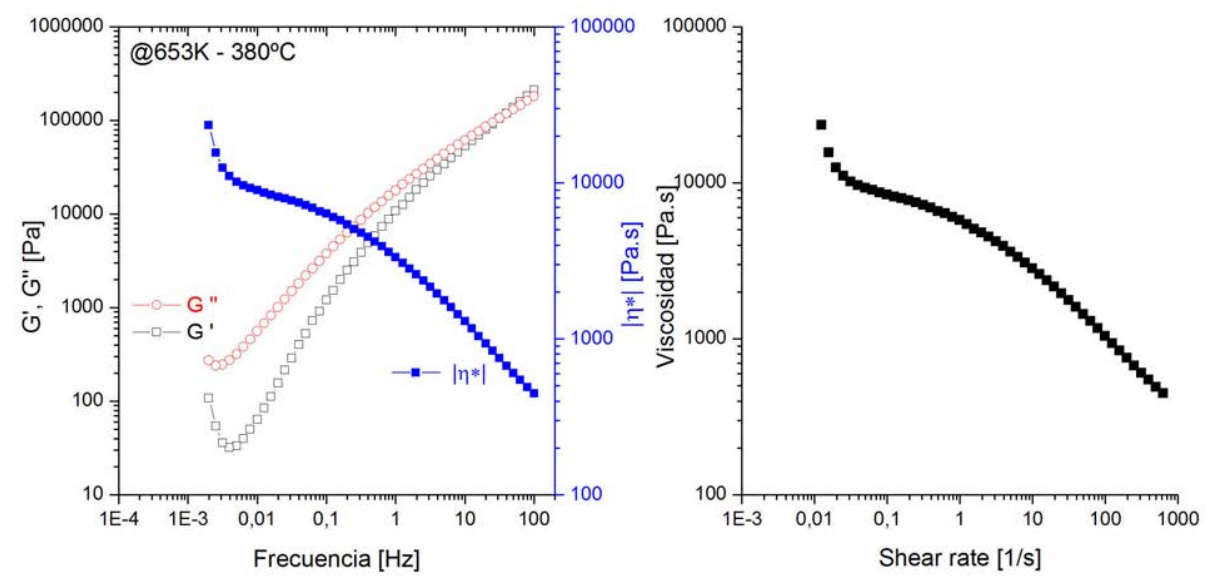

Figura 4.73: Ensayo oscilatorio y transformación de Cox-Merz. Isoterma a $653 \mathrm{~K}$.

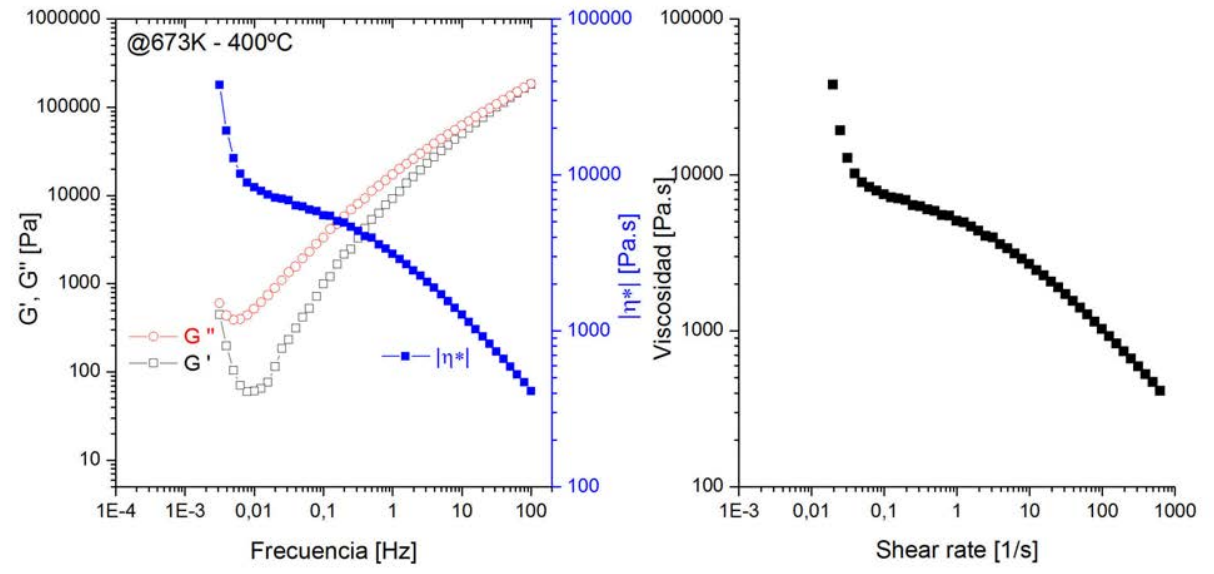

Figura 4.74: Ensayo oscilatorio y transformación de Cox-Merz. Isoterma a $673 \mathrm{~K}$.

dicha afirmación, los ensayos realizados no permitirían extraer un valor con precisión a causa de la posible degradación experimentada por el material durante el ensayo.

Otros grupos de investigación centrados en el análisis del mismo proceso, como es el caso de la empresa "Automated Dynamics", afirman la posibilidad de encintar a más velocidad justificando que los valores más bajos se derivan 


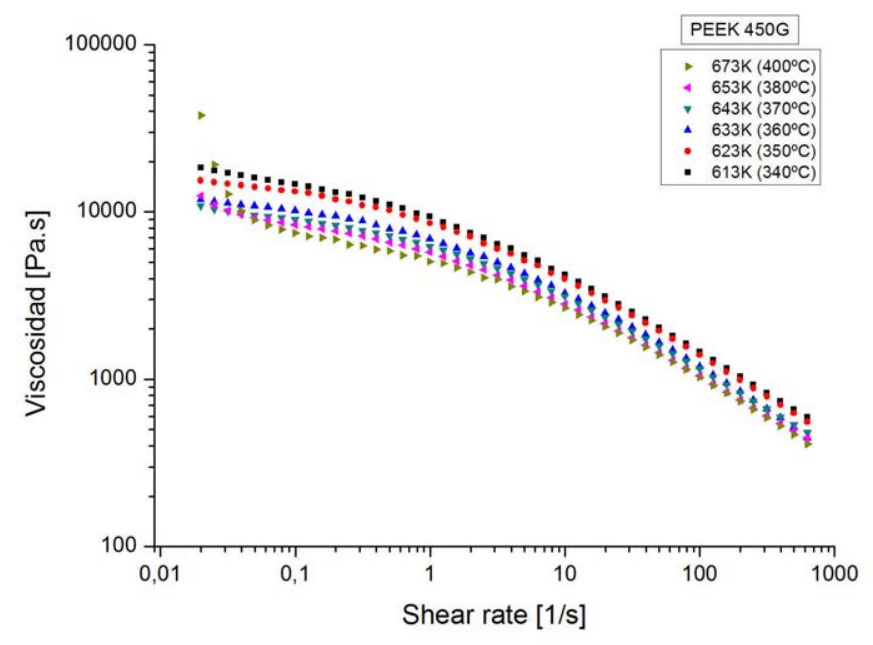

Figura 4.75: Comparativa viscosidades a diferentes isotermas, PEEK 450G

de una mala interpretación de la teoría clásica de la reptación. Según sus trabajos, durante los encintados a mayor velocidad, el material se encuentra en la región del "shear thinning" y por tanto, su viscosidad cae notablemente en comparación con la que tendría en el régimen del primer "plateau newtoniano". En (Narnhofer et al., 2013), se presenta un análisis sobre los valores que condicionan la velocidad de cortadura a la que se somete al material en el encintado automático. Aplicando un análisis basado en la conservación del volumen sobre un elemento diferencial en el proceso de encintado, el trabajo anteriormente referenciado, reporta las velocidades de cortadura para cada uno de los planos $x z$ y $x y$ (considerando " $y$ " en el sentido del espesor del material y "z" la dirección de encintado). En el plano $x y$ existe una dependencia de la velocidad respecto a la adhesión del material contra el sustrato y contra el rodillo, cuando se considera que no hay adhesión, la cortadura puede estimarse nula. Existiendo adhesión, el valor de cortadura no puede despreciarse. El estudio reporta un valor de cortadura para el proceso de fabricación en el entorno de $100 \mathrm{~s}^{-1}$ con un rodillo de dimensiones similares a las del empleado en este trabajo; dicho valor se encuentra dentro de la zona de "shear thinning" en las curvas de reología obtenidas en este trabajo para PEEK 450G, resultando en una caída considerable de los valores de viscosidad.

En el trabajo también se indica que, no tener en cuenta la cortadura, puede suponer sobre-estimaciones de los valores de viscosidad y con ello selecciones de velocidades de encintado inferiores a las que podrían ser viables, 
junto con presiones requeridas superiores a las reales. Sin embargo, el trabajo efectúa el análisis de la viscosidad sobre las curvas de resina neta y no sobre las curvas del material preimpregnado para aludir a la caída radical que puede observarse entre el régimen newtoniano y el shear thinning.

A continuación se presentan los ajustes para obtener la evolución de la viscosidad con la temperatura. Con el fin de chequear la capacidad de los ensayos en flujo para reportar los valores de viscosidad del material en los bajos "shear rate", se ejecutaron también ensayos en flujo a las mismas temperaturas, realizando una superposición con la misma isoterma en condiciones oscilatorias. Los ensayos en flujo no se emplean de modo habitual con termoplásticos puesto que el movimiento que inducen sobre la muestra puede ocasionar pérdida de la estructura del material, no obstante, pueden proporcionar información para velocidades de cortadura bajas. La Figura 4.76 contiene a modo de ejemplo su aplicación en la isoterma a $673 \mathrm{~K}$. Como puede observarse, los ensayos en flujo y en oscilatorio transformado por CoxMerz pueden acoplarse para obtener la tendencia de comportamiento en la región del primer plateau newtoniano.

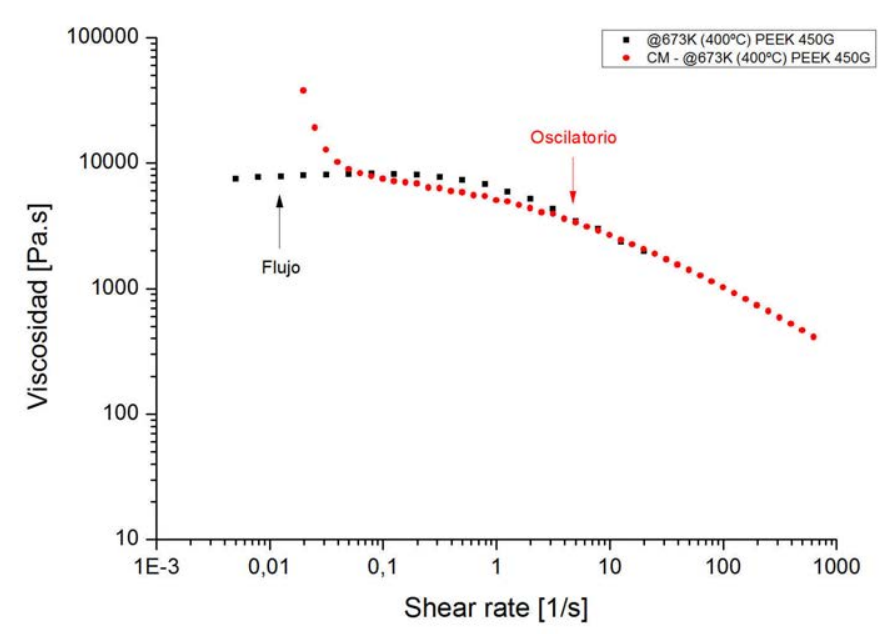

Figura 4.76: Comparativa viscosidades flujo vs. oscilatorio a $673 \mathrm{~K}$, PEEK $450 \mathrm{G}$

Tomando en consideración los valores de viscosidad para cada isoterma de ensayo, en el régimen del primer plateau newtoniano se han extraído los valores de viscosidad "zero shear rate" con la aplicación de la ecuación de Carreau (Ecuación 4.36), para los ensayos en flujo y también sobre los os- 


\begin{tabular}{|c|c|c|}
\hline Isoterma $[\mathrm{K}]$ & $\begin{array}{c}\text { Viscosidad } \eta_{0} \\
\text { (Ley de Carreau) [Pa.s] }\end{array}$ & $\begin{array}{c}\text { Viscosidad } \eta_{0} \\
\text { (Flujo) [Pa.s] }\end{array}$ \\
\hline 613 & 13835 & 17950 \\
\hline 623 & 12515 & 15680 \\
\hline 633 & 9675 & 12870 \\
\hline 643 & 8495 & 11000 \\
\hline 653 & 7889 & 9991 \\
\hline 673 & 6945 & 7985 \\
\hline
\end{tabular}

Tabla 4.8: Relación viscosidad vs. temperatura PEEK 450G

cilatorios obviando la zona donde se perdía la tendencia del "plateau". Los valores se recogen en la Tabla 4.8 y se representan en la Figura 4.77.

$$
\eta_{a}=\eta_{\infty}+\frac{\eta_{0}-\eta_{\infty}}{\left[1+\left(\lambda_{c} \dot{\gamma}\right)^{2}\right]^{N}}
$$

En la Tabla 4.8 existe una variación entre los resultados de flujo y oscilatorios, causada posiblemente por el limitado número de puntos de la zona del primer "plateau newtoniano" que pueden contabilizarse para el ajuste de los ensayos oscilatorios.

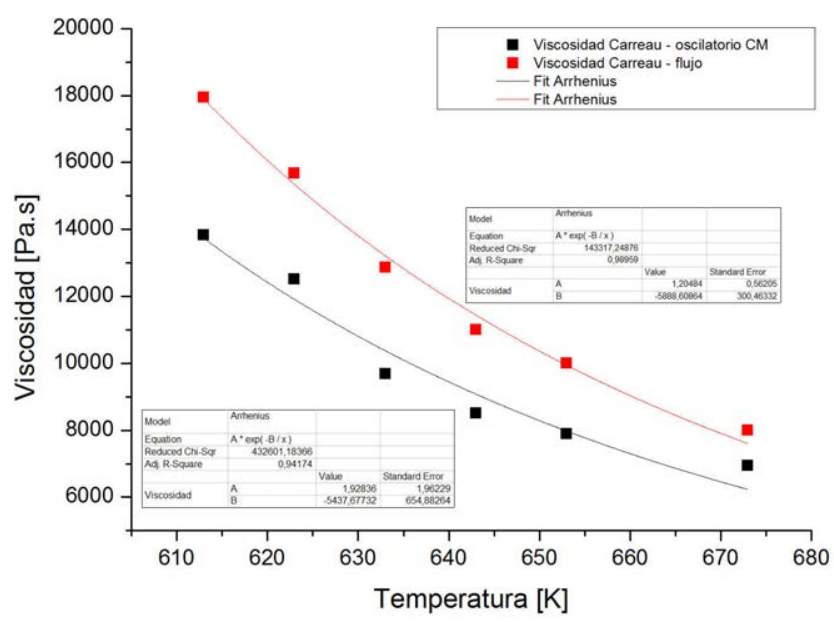

Figura 4.77: Ajuste Arrhenius viscosidad vs. temperatura valores primer plateau newtoniano de ensayos en flujo y oscilatorio transformado por Cox-Merz 
El ajuste ejecutado según la ecuación de Arrhenius, reporta los valores de factor pre-exponencial y energía de activación recogidos en la Tabla 4.9 .

\begin{tabular}{|c|c|c|c|}
\hline Ensayo & Flujo & Oscilatorio & Osc. Shear Thinning $\sim 100[1 / \mathrm{s}]$ \\
\hline Parámetro $[\mathrm{Pa} . \mathrm{s}]$ & 1.205 & 1.928 & 15.19 \\
\hline$\left|E_{a}\right|[\mathrm{kJ} / \mathrm{mol}]$ & 48.96 & 45.21 & 23.21 \\
\hline
\end{tabular}

Tabla 4.9: Parámetros de ajuste por Arrhenius de las curvas viscosidad vs. temperatura PEEK 450G

Efectuando el ajuste nuevamente bajo la consideración de un "shear rate" de 100[1/s] sobre los ensayos en oscilatorio con PEEK 450G, se obtuvo el resultado recogido por la Figura 4.78, asociado a los valores de los parámetros de la tercera columna de la Tabla 4.9 .

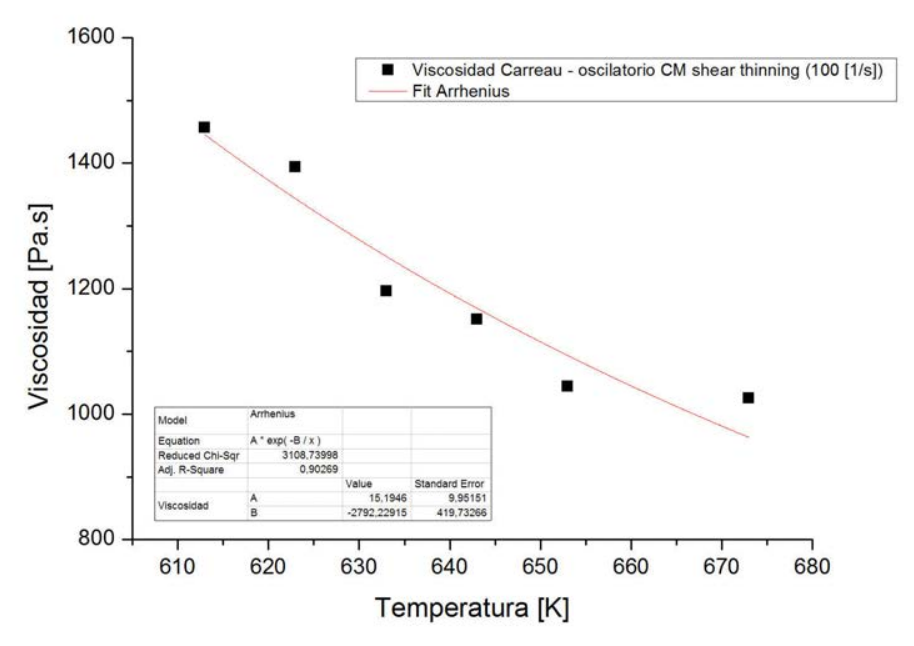

Figura 4.78: Ajuste Arrhenius viscosidad vs. temperatura valores en shear thinning $100[1 / s]$ de los ensayos oscilatorios

A la vista de los resultados de viscosidad obtenidos, es posible remarcar la notoria diferencia entre las viscosidades habituales de un material termoestable en relación con la del termoplástico, siendo valores normales de un termoestable, el rango de $1-10 P a \cdot s$. Estas diferencias se relacionan de modo directo con la dificultad para conseguir la movilidad en el polímero durante su procesado. 
Durante el proceso de encintado en automático y consolidación in-situ, es el material preimpregnado el que interviene, por lo que es esperable un incremento notorio del valor de viscosidad por la presencia de la fibra de carbono, de ahí que el modelo de grado de contacto íntimo se fundamente realmente en el parámetro $\mu_{f m}$, viscosidad del conjunto fibra-matriz. Con la reología de platos paralelos, extraer de forma cuantitativa el valor de la viscosidad de este material es complejo, pudiendo interferir la fibra sobre las mediciones. Los ensayos ejecutados sobre el material preimpregnado APC2/AS4 presentaron un comportamiento tal que las curvas no reflejaban sensibilidad a las variaciones de temperatura entre los ensayos, hecho indicativo de la clara influencia de la fibra de carbono sobre el resultado. No fue posible observar la región del primer "plateau newtoniano" y el valor aproximado de viscosidad obtenido en el entorno de los $100[1 / s]$ fue de unos $6000[$ Pa.s $]$, unas seis veces superior al valor reportado para el PEEK 450G neto.

Algunos trabajos relacionados con la laminación automática y consolidación in-situ, efectúan la hipótesis de considerar que la viscosidad representativa del preimpregnado es igual a la del polímero; esa simplificación procede de considerar que la capa superior del material pregimpregnado es fundamentalmente una lámina de un cierto espesor de PEEK.

En este trabajo, se va a intentar generar un valor de viscosidad para el material compuesto, optándose por emplear modelos matemáticos predictivos del valor de viscosidad en el material compuesto basándose en las curvas de los ensayos sobre la resina, tal y como se propone en el trabajo de (Roberts y Jones, 1995), con los modelos de Binding (Ecuación 4.37), Christensen (Ecuación 4.38 y 4.39) y Pipes (Ecuación 4.40).

Modelo de Binding

$$
\frac{\eta_{L}}{\eta_{M}}=\frac{1-f}{(1-\sqrt{\widehat{f}})^{2}}
$$

Modelo de Christensen

$$
\begin{aligned}
\frac{\eta_{L m f}}{\eta_{M}} & =\frac{1+0,873 \widehat{f}}{(1-0,8815 \widehat{f})^{1 / 2}(1-\widehat{f})^{1 / 2}} \\
\frac{\eta_{T m f}}{\eta_{M}} & =\frac{(1-0,193 \widehat{f})^{3}}{(1-0,5952 \widehat{f})^{3 / 2}(1-\widehat{f})^{3 / 2}}
\end{aligned}
$$

Modelo de Pipes

$$
\frac{\eta_{L m f}}{\eta_{M}}=\frac{2-\sqrt{\widehat{f}}}{2(1-\sqrt{\widehat{f}})} \frac{\eta_{T m f}}{\eta_{M}}=\frac{1}{1-\sqrt{\widehat{f}}}
$$


Donde, $\eta_{L}$ es la viscosidad del material compuesto en dirección longitudinal, $\eta_{T}$ es la viscosidad del material compuesto en dirección transversal, $\eta_{M}$ es la viscosidad de la matriz. Con $f$ la concentración en volumen de fibra y $\widehat{f}=\frac{2 \sqrt{3}}{\pi} f$.

Estos modelos se apoyan en las siguientes hipótesis: los datos de la matriz proceden del régimen lineal, la distribución de fibras se puede considerar hexagonal y las dependencias para las viscosidades dinámicas son las mismas que para la viscosidad estacionaria.

En este estudio, se estimarán los valores de las viscosidades tanto longitudinal como transversal por los tres métodos, efectuando su ajuste a una ecuación tipo Arrhenius y obteniendo como resultado las curvas de la Figura 4.79, derivadas de las ecuaciones para los casos longitudinal de Binding 4.41. Christensen 4.42 y Pipes 4.44. Considerando la viscosidad transversal, las ecuaciones obtenidas fueron para el modelo de Christensen la Ecuación 4.43 y para el de Pipes la Ecuación 4.45. Se incluye también una representación de la evolución viscosidad-temperatura del APC2/AS4 según el modelo de (Levy et al., 2014) y de las evoluciones estimadas de la viscosidad del PEEK 450 G en "zero shear rate" y en $100[1 / s]$ obtenidas de los ensayos de reología elaborados en este trabajo (Figura 4.80).

Viscosidad longitudinal de Binding

$$
\mu_{L m f}=15,91 \cdot \exp (5888,76 / T)
$$

Viscosidad longitudinal de Christensen

$$
\mu_{L m f}=5,59 \cdot \exp (588,68 / T)
$$

Viscosidad transversal de Christensen

$$
\mu_{T m f}=10,20 \cdot \exp (5888,56 / T)
$$

Viscosidad longitudinal de Pipes

$$
\mu_{L m f}=7,18 \cdot \exp (5888,51 / T)
$$

Viscosidad transversal de Pipes

$$
\mu_{T m f}=2,06 \cdot \exp (5888,56 / T)
$$

En la simulación ejecutada en la sección anterior para predecir el grado de contacto íntimo entre las capas, se había empleado el modelo teórico reportado por (Levy et al. 2014). Comparando la viscosidad del citado artículo científico con las obtenidas de la aplicación de los anteriores modelos 


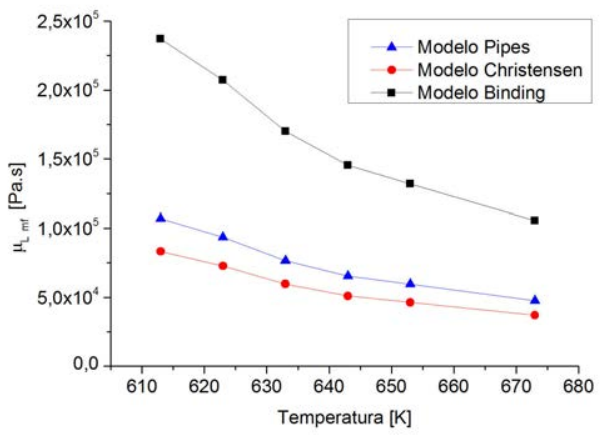

(a)

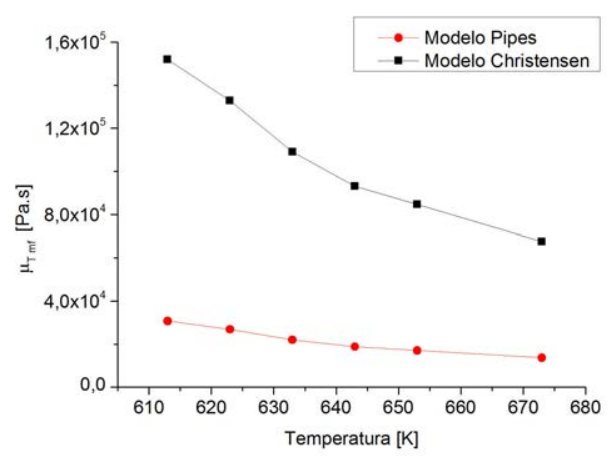

(b)

Figura 4.79: Viscosidad del material compuesto APC2/AS4 según diferentes modelos (a) Longitudinal a la fibra y (b) Transversal a la fibra

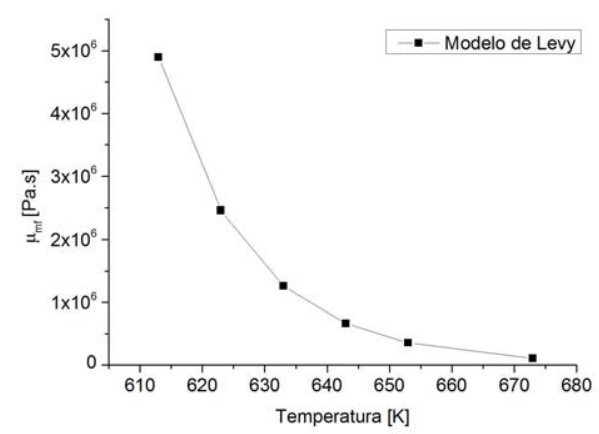

(a)

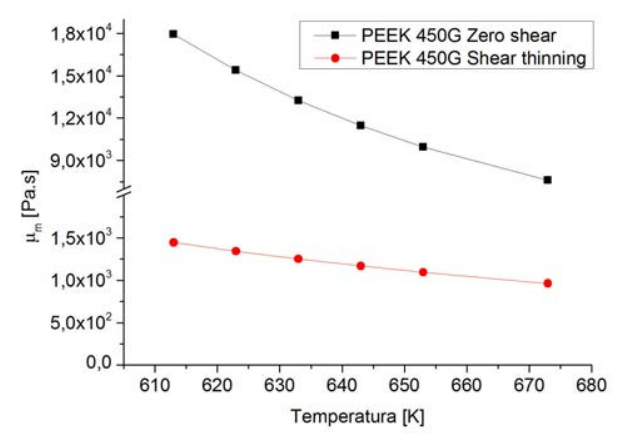

(b)

Figura 4.80: (Viscosidad de (a) APC2/AS4 según (Levy et al. 2014) y (b) PEEK450G en "zero shear rate" y "shear thinning"

teóricos sobre los ensayos experimentales elaborados sobre el PEEK450G (Figuras 4.79 y 4.80), se detecta que los valores obtenidos de la aplicación del modelo del trabajo bibliográfico utilizado son un orden de magnitud superiores a los obtenidos en el caso más desfavorable de los modelos teóricos considerados.

A la vista de la desviación de resultados presente, se ha optado por ejecutar una nueva simulación sobre la variación existente en el grado de contacto íntimo considerando el modelo de viscosidad longitudinal de Binding. Se recalca aquí el hecho de que dicha viscosidad corresponde al régimen newtoniano del material y no a la zona del "shear thinning".

En la simulación han vuelto a ser analizados los casos de estudio con 
condiciones isotermas y el caso del perfil de enfriamiento del termopar durante el encintado automático. Los gráficos de la Figura 4.81 representan barridos de presión para las cuatro temperaturas establecidas, el único caso crítico parece presentarse para un valor de presión de $0,1 M P a$ donde para conseguir el contacto total se requieren tiempos entre 0,7 y $2,1 s$. En la Figura 4.82 se incluyen los barridos en temperatura para presiones predeterminadas. Por su parte, los gráficos de las Figuras 4.83a y 4.83b, son el resultado de la aplicación del modelo con el perfil de enfriamiento del termopar en ISC. Para la expresión de la viscosidad considerada según el modelo de Binding longitudinal, el proceso necesitaría únicamente $0,065 \mathrm{~s}$ para alcanzar el $100 \%$ del grado de contacto, tiempo muy inferior a los $0,72 \mathrm{~s}$ de mantenimiento de la compactación en la máquina de encintado. Considerando incrementar la velocidad de encintado, hasta encintados en el entorno de $11 \mathrm{~m} / \mathrm{min}$ el grado de contacto conseguido sería el máximo, disminuyendo progresivamente hasta un valor por debajo de 0,95 en el encintado a $20 \mathrm{~m} / \mathrm{min}$.

La experiencia con los encintados reales elaborados en este trabajo doctoral, indica que no es posible alcanzar el total del grado de contacto en la primera pasada de aporte de material a $1 \mathrm{~m} / \mathrm{min}$, con lo que la aplicación del modelo de Binding estaría sobre-estimando el resultado. Siendo el caso de análisis con el modelo del estudio de (Levy et al., 2014) más representativo de los resultados. 


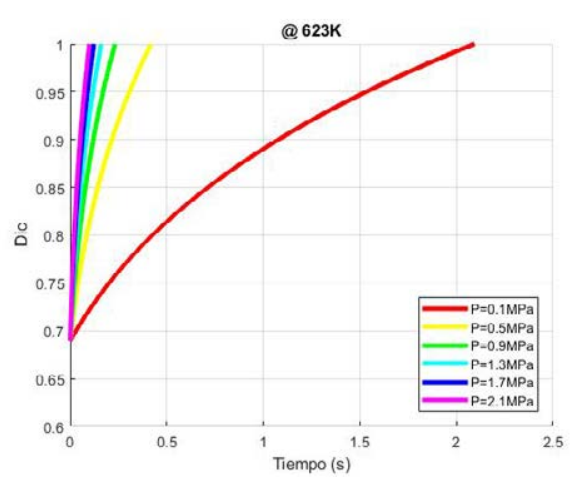

(a)

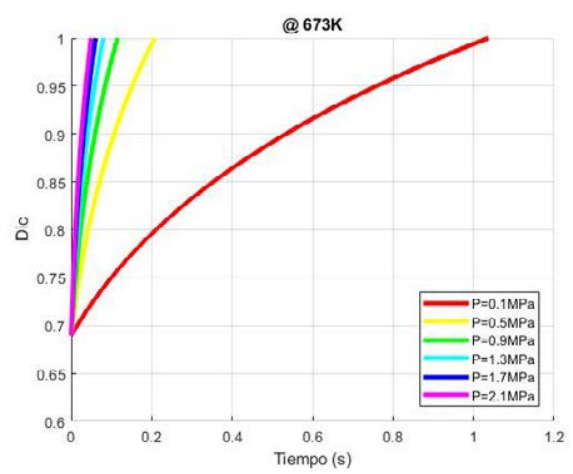

(c)

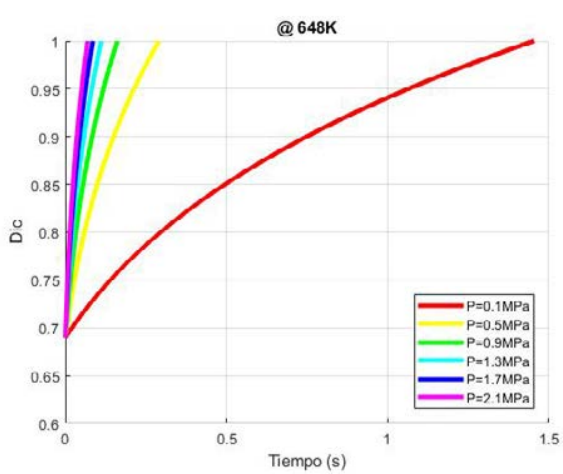

(b)

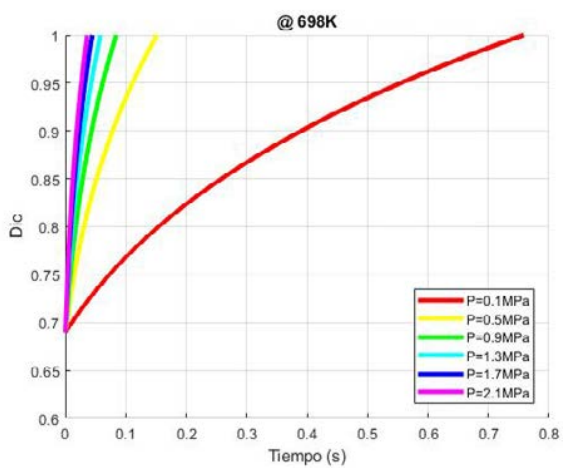

(d)

Figura 4.81: Análisis de la evolución del grado de contacto íntimo con el tiempo en condiciones isotermas con viscosidad longitudinal de Binding (a) $623 K$, (b) $648 K$, (c) $673 K$ y (d) $698 K$ para diferentes valores de presión aplicada

\subsubsection{Difusión - Autohesion - Healing}

Las teorías de la difusión, se fundamentan en el análisis de los movimientos de las cadenas del polímero desde la superficie de una capa hacia la otra para formar una unión sólida entre ellas.

En la referencia (Yang y Pitchumani, 2002a) se especifica que el proceso consiste en la difusión intermolecular entre las capas del material en contacto íntimo, este mecanismo se relaciona directamente con la resistencia interlaminar y se ve afectado por la historia térmica a la que se ha sometido al material. A diferencia del contacto íntimo, la difusión no está gobernada por la presión sino que se produce por los mantenimientos de tiempo y temperatura una vez alcanzado el contacto entre las partes. 


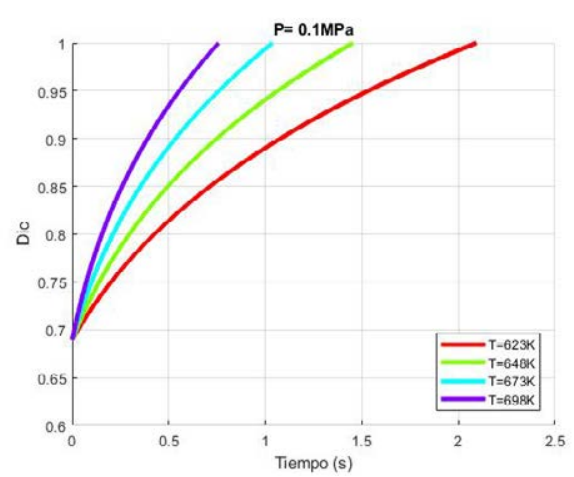

(a)

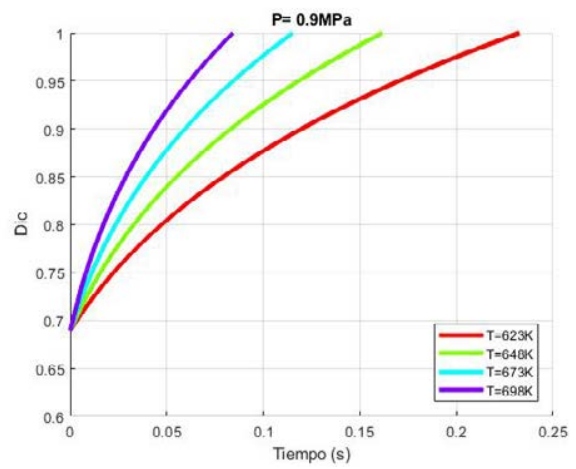

(c)

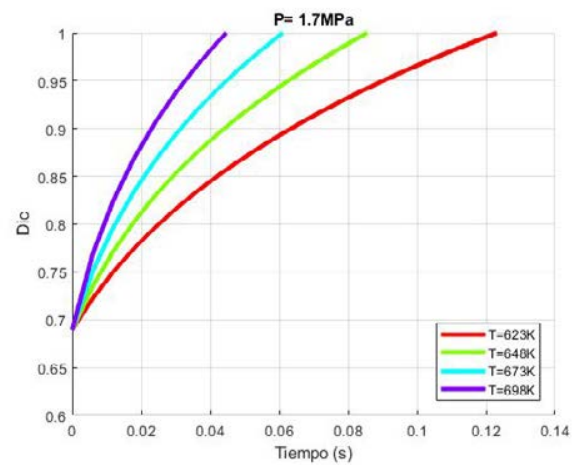

(e)

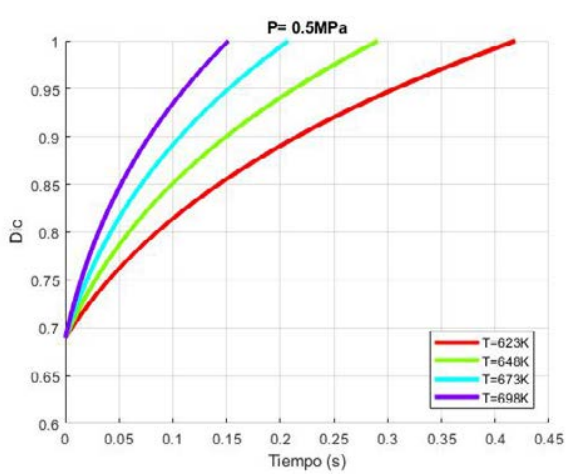

(b)

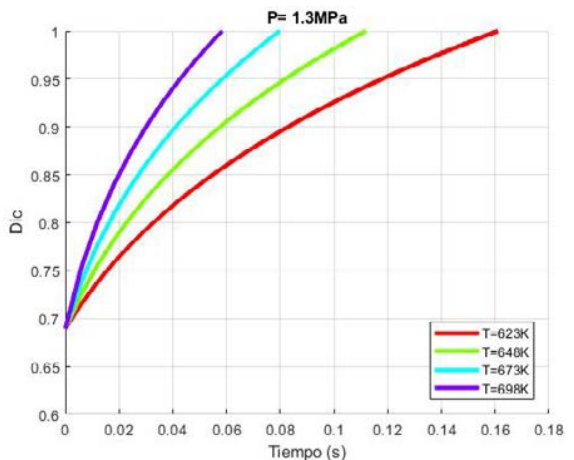

(d)

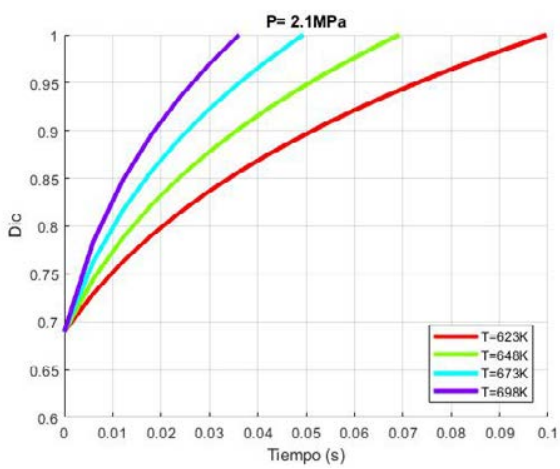

(f)

Figura 4.82: Análisis de la evolución del grado de contacto íntimo con el tiempo en condiciones de presión constante e igual a (a) 0,1MPa, (b) 0,5MPa, (c) 0,9MPa, (d) 1,3MPa, (e) 1,7MPa y (f) 2,1MPa para diferentes valores de temperatura isoterma y viscosidad según modelo longitudinal de Binding

El healing, al igual que otras físicas interactuando en el proceso, experimenta variaciones sucesivas a medida que se incrementa el espesor del 


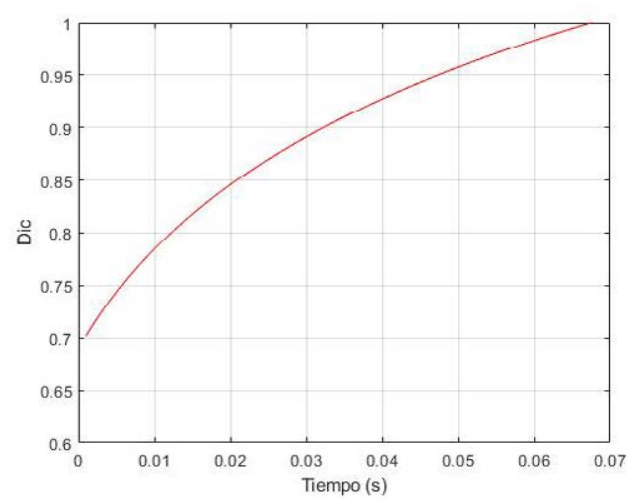

(a)

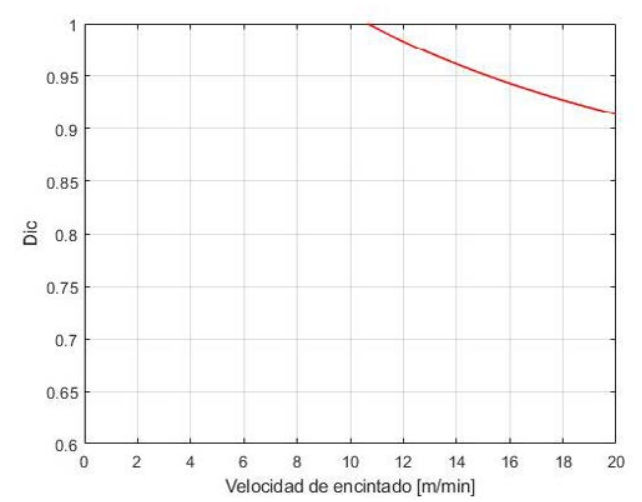

(b)

Figura 4.83: Análisis de la evolución del grado de contacto íntimo con el tiempo y modelo de viscosidad longitudinal de Binding en (a) Integrando con el perfil de enfriamiento bajo el efecto del rodillo en el proceso de laminación a $1 \mathrm{~m} / \mathrm{min}$ y (b) Variando la velocidad de encintado bajo la suposición de la misma tendencia de enfriamiento

laminado, es decir, inicialmente en la unión de las capas 1 y 2 se desarrolla un cierto grado pero su valor se incrementará por re-calentamiento y por compactar nuevamente el material (que supone incrementos del valor de contacto íntimo previo al desplazamiento de las cadenas). Por esta causa, se estima que las cadenas que se desplazarán menos serán las correspondientes a las capas superiores y las de mayor healing/difusión las de las inferiores.

Una metodología para determinar el grado de healing consiste en el empleo de ensayos mecánicos (ejecutando una correlación entre el valor de la propiedad mecánica y el posible desplazamiento de la cadena polimérica), este sistema presenta diferentes problemáticas que se contemplan a continuación. Si se considera como ensayo de referencia uno de tipo tenacidad a fractura $\left(G_{I c}\right)$, se ejecutará un análisis de la intercara localizada en el plano medio del laminado. El resultado de ese ensayo no será representativo del comportamiento general del laminado, pues la probeta, por las propias características del encintado no es homogénea. La tenacidad a fractura obtenida con este ensayo estaría sobre-estimando los valores de healing en comparación con los que presentarían las capas más altas del laminado, a diferencia de lo que ocurriría con otros ensayos como la cortadura en el plano o cortadura interlaminar, que sí tienen en cuenta todo el conjunto laminado. El ensayo más representativo del proceso, debería permitir la separación entre capas cualesquiera del laminado para la evaluación de las entrecaras existentes entre todas ellas. Los ensayos de pelado se han empleado en la bibliografía como medio de análisis, extrayendo relaciones mediante el valor obtenido del 
ensayo de probetas de referencia en autoclave o estufa. No obstante, la dificultad para obtener el fallo por la zona deseada de la probeta, unido al hecho de que el APC2/AS4 es un material semi-cristalino y desarrolla efectos de co-cristalización entre las capas, genera una rotura compleja que hace que no sea tan sencilla la correlación de los resultados con valores de healing/difusión.

Los modelos bibliográficos de análisis del grado de healing se basan en dos posibles metodologías; por un lado, las comparaciones de valores de propiedades mecánicas (sistema del que ya han sido indicadas las problemáticas) y por otro en ecuaciones de dependencia de los tiempos requeridos de reptación de las cadenas en función de la temperatura a la que se somete el material. Los modelos basados en la reptación de cadenas, requieren incluir la evolución de ese tiempo en función de la temperatura. La bibliografía no es muy clara respecto a la definición de estos tiempos, planteando la existencia de valores diferentes según el tipo de movimiento de relajación considerado en la cadena polimérica (salida total del tubo imaginario propuesto en la teoría de reptación o salida parcial).

En este trabajo, se presentan los valores de los tiempos de relajación de las cadenas poliméricas medidos por reología sobre la resina neta y cómo se ven afectados por la temperatura.

Utilizando los ensayos de reología ejecutados sobre PEEK 450G, se platean aquí las metodologías para establecer órdenes de magnitud de los tiempos de difusión (siendo las indicaciones de (Regnier y Le Corre, 2016) $)$. Estos valores pueden estimarse en base a los siguientes criterios y su representación gráfica se recoge en la Figura 4.84

- Punto de corte entre las pendientes de $G^{\prime}$ y $G^{\prime \prime}$ con frecuencias bajas (pendientes de valor 1 y 2 ).

- Punto de cruce entre las curvas de $G^{\prime}$ y $G^{\prime \prime}$.

- Punto de cruce entre la tangente para bajas frecuencias a $G^{\prime \prime}$ y la tangente a $G^{\prime}$ en la zona de la meseta plástica

- El cambio entre la zona del primer plateau newtoniano y la zona del "shear thinning" en $\eta^{*}$.

De todos ellos, se debe definir cuál es el tiempo de relajación para conseguir una interfaz donde se produzca el healing completo. En polímeros con altos índices de polidispersidad, es complejo definir un tiempo porque los 


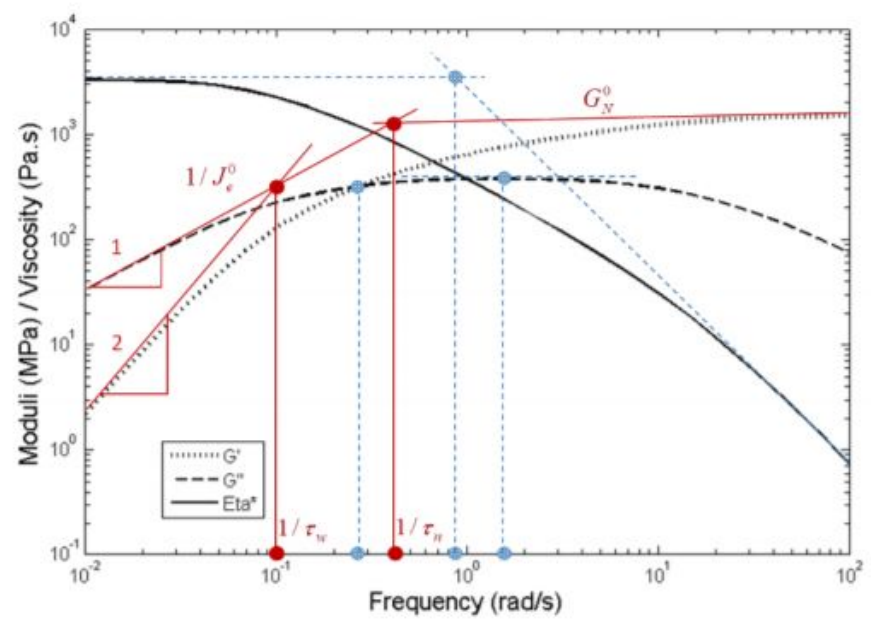

Figura 4.84: Vías para la determinación de los tiempos de relajación en el polímero (Regnier y Le Corre, 2016)

movimientos moleculares son complejos; no obstante, tal y como ilustran diferentes trabajos, no parece este el caso del PEEK. Para conseguir el healing o autodifusión en la entrecara se necesita una completa reorganización de cadenas del polímero, luego se requieren tiempos de relajación largos, como los asociados al comportamiento terminal, siendo una buena aproximación considerar el primero de los tiempos enumerados en la lista previa (cruce de las tangentes a $G^{\prime}$ y $G^{\prime \prime}$ con pendientes 2 y 1 ).

\subsubsection{Tiempo de healing según tangentes a $G^{\prime}$ y $G^{\prime \prime} \omega \longrightarrow 0$}

Los ensayos elaborados para analizar la intersección de las tangentes a $G^{\prime}$ y $G^{\prime \prime}$ en la zona de las curvas con la frecuencia tendiendo a cero, no han permitido obtener los valores teóricos de 2 y 1 para las pendientes (como ilustra la Figura 4.85 para ensayo (a) $613 \mathrm{~K}$ y (b) $673 \mathrm{~K}$, condiciones extremas ensayadas), probablemente a causa de los efectos de degradación que puede experimentar el polímero ensayado bajo atmósfera oxidativa, para obtener información del comportamiento a bajas frecuencias, se debe utilizar la información generada por los ensayos en flujo.

En base a los resultados se concluye que no es posible aplicar esta metodología para obtener un valor realista del tiempo de relajación de cadena. 


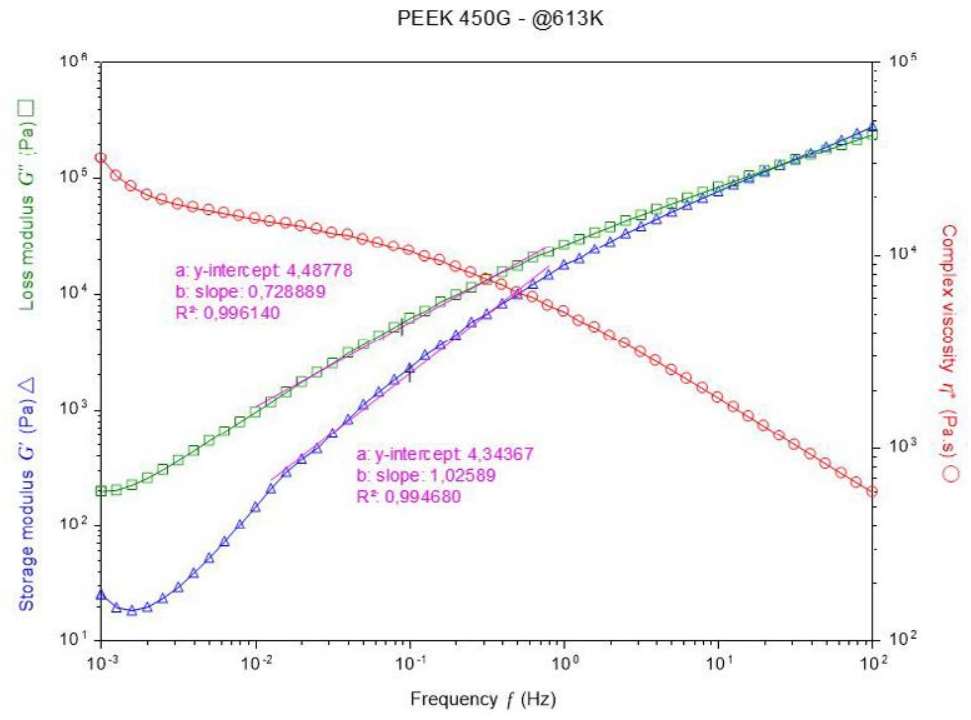

(a)

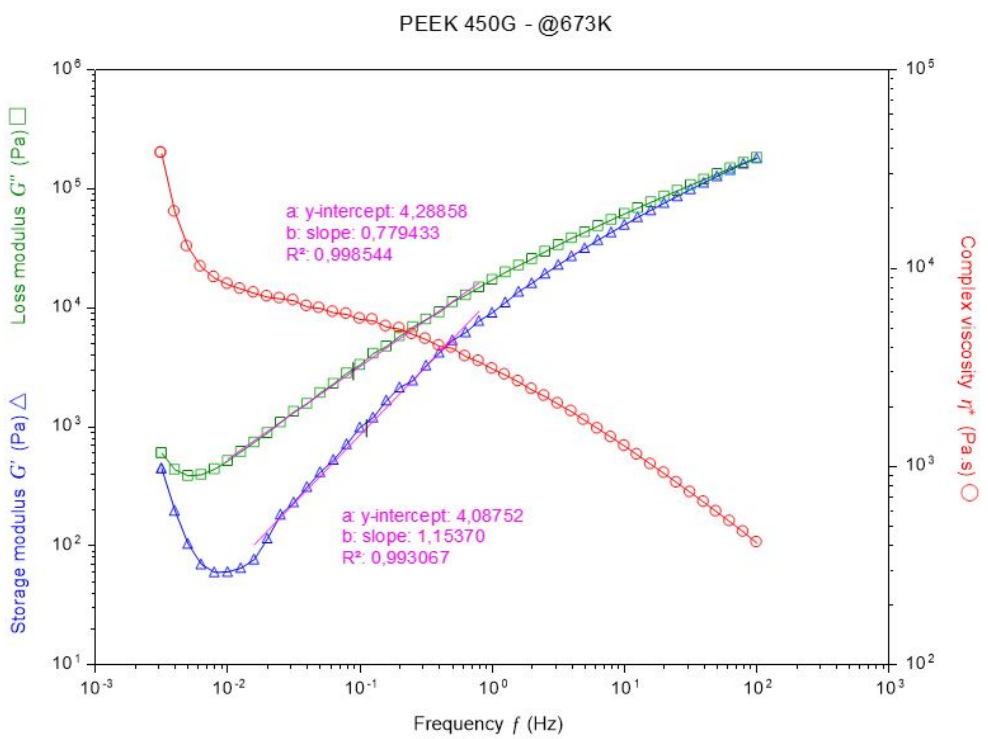

(b)

Figura 4.85: Tiempo de healing obtenido según el cruce de las rectas tangentes a $G^{\prime}$ y $G^{\prime \prime}$ cuando $\omega \longrightarrow 0$

\subsubsection{Tiempo de healing según cruce de $G^{\prime}$ y $G^{\prime \prime}$}

Considerando las intersecciones de las curvas de $G^{\prime}$ y $G^{\prime \prime}$; de los ensayos elaborados sólo fue posible observar el cruce entre ellas para las isotermas a $613,623,633,643$ y $653 K$. Los valores del módulo y de la frecuencia en el 
cruce se incluyen en la Tabla 4.10

Como puede observarse, los tiempos requeridos para la difusión de las cadenas poliméricas son muy bajos; inferiores a los que se habrían obtenido por el procedimiento anterior del cruce de las tangentes. La tendencia esperable es una caída del valor en tiempo de difusión de la cadena con el incremento en temperatura, tendencia que se pierde en el caso de $653 K$; asimismo, el ensayo a $633 \mathrm{~K}$ manifiesta un valor elevado del módulo de almacenamiento en comparación con los demás programas de temperatura ensayados, los resultados podrían estarse viendo afectados por efectos de degradación por oxidación en las muestras. No obstante, ejecutar estos ensayos en atmósfera inerte también aleja el desarrollo experimental de las condiciones reales de trabajo.

\begin{tabular}{|c|c|c|c|}
\hline Temperatura de ensayo [K] & Módulo [Pa] & Frencuencia [Hz] & $\tau_{\text {Gcross }}[\mathrm{s}]$ \\
\hline 613 & 130113 & 25,38 & 0,039 \\
\hline 623 & 128810 & 27,12 & 0,037 \\
\hline 633 & 154700 & 33,98 & 0,029 \\
\hline 643 & 134235 & 41,58 & 0,024 \\
\hline 653 & 109608 & 34,01 & 0,029 \\
\hline 673 & ${ }^{*}$ & ${ }^{*}$ & $*$ \\
\hline \multicolumn{2}{|c|}{} \\
\hline
\end{tabular}

Tabla 4.10: Tiempos de relajación en el cruce G'y G"

Con los valores obtenidos se ha ejecutado un ajuste tipo Arrhenius obteniéndose la Figura 4.86 que permite ejecutar la aproximación matemática de la ecuación 4.46 .

$$
\tau_{\text {Cross Modulus Healing }}=3,27 \cdot 10^{-5} \cdot \exp \left(\frac{4345,22}{T}\right)
$$

\subsubsection{Cambio de tendencia en la curva de viscosidad}

Teniendo en cuenta la forma de las curvas de reología presentadas para el PEEK 450G en las Figuras 4.69 a 4.74 es posible observar como el cruce de los módulos de almacenamiento y de pérdidas se produce a frecuencias más altas que el cambio en el régimen de newtoniano a "shear thinning". Considerar ese tiempo, dará un resultado más restrictivo en la estimación del tiempo requerido para alcanzar la difusión. 


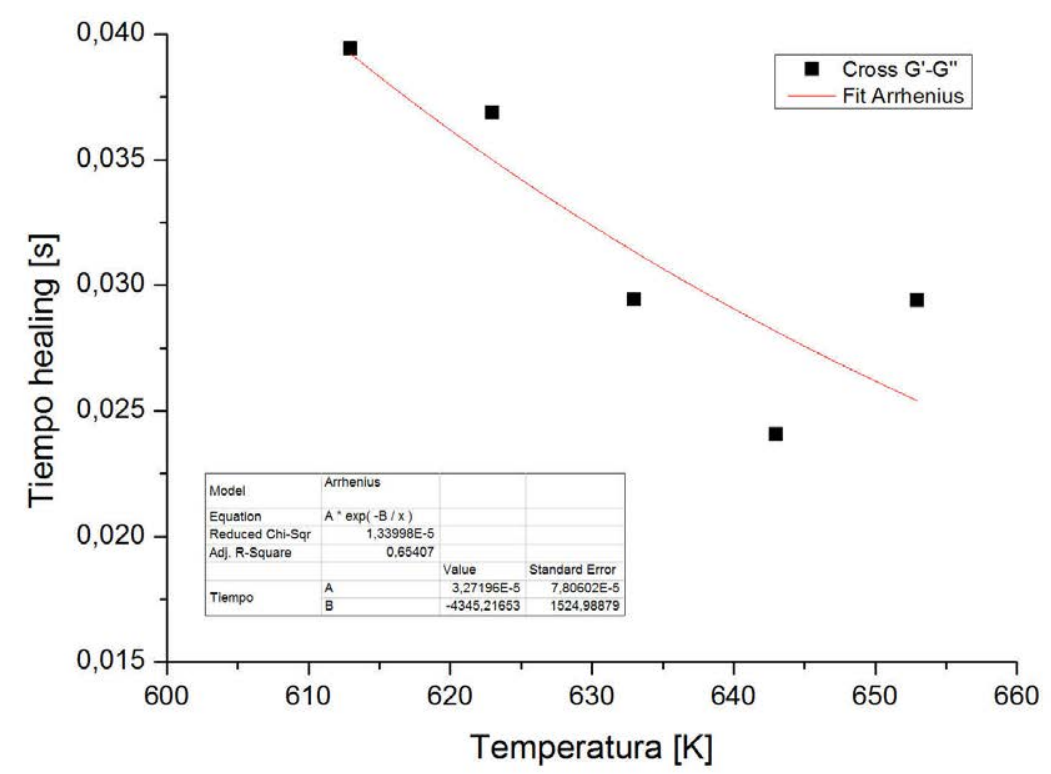

Figura 4.86: Tiempo healing vs. temperatura G'-G" cross-point

Sobre los ensayos en elaborados flujo y en oscilatorio y bajo la aplicación del modelo de Carreau, se recopilan en la Tabla 4.11 los valores del parámetro de consistencia del modelos, que se relaciona con el tiempo donde se produce el cambio en la tendencia de la curva de viscosidad.

\begin{tabular}{|c|c|c|}
\hline Temperatura $[\mathrm{K}]$ & $\tau_{\text {Carreau flujo }}[\mathrm{s}]$ & $\tau_{\text {Carreau osc }}[\mathrm{s}]$ \\
\hline 613 & 2,40 & 3,00 \\
\hline 623 & 1,50 & 2,39 \\
\hline 633 & 1,28 & 2,24 \\
\hline 643 & 0,88 & 1,99 \\
\hline 653 & 1,06 & 2,08 \\
\hline 673 & 0,65 & 0,72 \\
\hline
\end{tabular}

Tabla 4.11: Tiempos de relajación en la transición de newtoniano a shear thinning

Descartándose los valores del ensayo a $653 \mathrm{~K}$ en los ajustes tipo Arrhenius, por no reflejar la tendencia mantenida por el resto de ensayos, los resultados obtenidos han sido los recogidos por las Ecuaciones 4.47 y $4.48 \mathrm{y}$ representados en la Figura 4.87. 


$$
\begin{gathered}
\tau_{\text {Carreau flujo Healing }}=2,08 \cdot 10^{-8} \cdot \exp \left(\frac{11348,37}{T}\right) \\
\tau_{\text {Carreau osc Healing }}=1,13 \cdot 10^{-4} \cdot \exp \left(\frac{6191,33}{T}\right)
\end{gathered}
$$

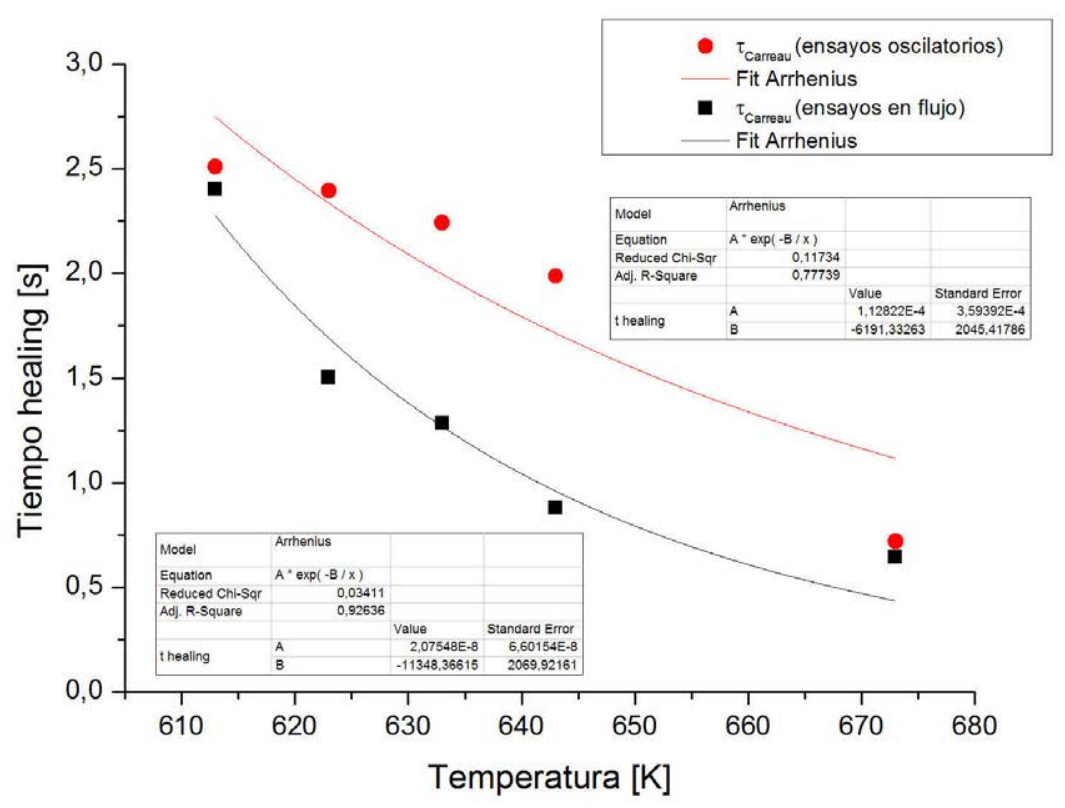

Figura 4.87: Tiempo healing vs. temperatura a través del parámetro de consistencia de Carreau en ensayos en flujo y oscilatorio trasformado por CoxMerz

La bibliografía indica que, para un caso como el del PEEK, tratándose de un polímero de cadena larga, es posible que se desarrolle casi el $100 \%$ de la resistencia máxima sin que las cadenas poliméricas abandonen por completo el tubo inicial de la teoría de reptación. En estas situaciones concretas, el grado de difusión puede estimarse según se representa en la Ecuación 4.49 . donde las variables implicadas ya fueron definidas en el apartado 2.5.2.1 de este documento.

$$
D_{h}(t)=\frac{\sigma}{\sigma_{\infty}}=\frac{\chi}{\chi_{\infty}}=\left(\frac{l}{L_{w}}\right)^{0,5}=\left(\frac{t}{t_{w}}\right)^{0,25}
$$


Para el análisis en condiciones no isotermas del proceso de difusión, el trabajo de la referencia (Yang y Pitchumani, 2002a, 2003), parte de la consideración de una función de probabilidad que analiza la posibilidad de encontrar una porción de cadena en una posición "s" en un tiempo "t". La representación matemática se ejecuta por medio de la ecuación de difusión, en ella, el parámetro de difusión no será constante sino dependiente de la temperatura. Esas estimaciones permiten representar el grado de difusión como se muestra en la Ecuación 4.50.

$$
D_{h}(t)=\left(\frac{1}{L_{w}}\right)^{0,5}=\left[\int_{0}^{\infty} \frac{1}{t_{w(T)}} d t\right]^{\frac{1}{4}}
$$

Presentando $t_{w}(T)$ una dependencia tipo Arrhenius con la temperatura, tal y como muestra la Ecuación 4.51 .

$$
D_{h}(t)=\left[\int_{0}^{\infty} \frac{1}{A \cdot \exp \left(\frac{-E}{R T}\right)} d t\right]^{\frac{1}{4}}
$$

Para definir el grado de healing, la anterior ecuación, establece una integración desde cero hasta infinito. En la referencia (Regnier y Le Corre, 2016) se propone, por otro lado, emplear la Ecuación 4.52. En esta última ecuación, el tiempo se obtiene de las transiciones del regimen newtoniano al "shear thinning" y el grado final de healing se estima integrando con unos límites que van desde el inicio del contacto del rodillo hasta el tiempo de inicio de la cristalización.

$$
D_{h}(t)=\left[\int_{t_{\text {contacto }}}^{t_{\text {cristal }}} \frac{d t}{\lambda(T(t))} d t\right]^{\frac{1}{4}}
$$

En el proceso de laminación automática y consolidación in-situ se deben considerar dos situaciones para el healing, el que se desarrolla en las capas ya posicionadas y el que tiene lugar para la que está siendo laminada en ese instante. Considerando una capa que está siendo depositada en el momento de observación del proceso, el contacto se inicia bajo el rodillo, desde ese instante podría comenzar a contabilizarse la contribución en healing.

En el análisis previo elaborado sobre el grado de contacto íntimo, se indicó que éste se iniciaba en el punto de inicio de aplicación de presión del rodillo y se consideraba finalizado una vez que esa presión dejaba de actuar. En el caso particular del healing, cesar la presión no implica directamente que las cadenas no puedan seguir desplazándose, sino que el límite más realista de parada de su movimiento es el instante en el que el polímero solidifica, 
la cristalización complica el posible movimiento de las cadenas poliméricas, aun existiendo una parte amorfa en el material.

La complejidad de establecer ese punto de fin o desarrollo de la cristalización radica en que, las bruscas velocidades de enfriamiento impiden conocer ese valor con precisión. Además, ese punto variará en función de si se considera un trabajo sobre útil a temperatura ambiente o calefactado. En un enfriamiento con mesa fría, observando la capa 2 encintada sobre el sustrato, el perfil de enfriamiento es tan brusco que la muestra queda parcialmente amorfa, luego podría desarrollarse healing hasta alcanzada la $T_{g}$, sin embargo, con mesa calefactada a $473 \mathrm{~K}$, la cristalización posible se desarrollará y bajo dicho valor no podrá seguir difundiéndose la cadena.

En un ensayo de calorimetría diferencial de barrido sobre APC2/AS4 a $30 \mathrm{~K} / \mathrm{min}$, se obtiene que el comienzo de cristalización en el material se produce aproximadamente en $570 \mathrm{~K}$ (unos $300^{\circ} \mathrm{C}$ ). Analizando los perfiles térmicos, se puede observar que durante la etapa de presionado del rodillo, el material cae por debajo de ese valor de temperatura, luego el healing estaría desarrollándose en un intervalo temporal inferior al que supone el del grado de contacto íntimo.

Si se tiene en cuenta el material que ya fue depositado con anterioridad, podrían darse situaciones diferentes basadas en cómo se encuentra de cristalizado el material sustrato. Si el material ha quedado en un estado prácticamente amorfo, por el proceso brusco de enfriamiento previo, al subir su temperatura sobre la transición vítrea, las cadenas tienen la capacidad para desplazarse en las intercaras de las diferentes capas del material, consideraremos la fase de calentamiento como una subida instantánea hasta $673 \mathrm{~K}$ $\left(400^{\circ} \mathrm{C}\right)$ y mantenimiento durante un tiempo aproximado de $5 \mathrm{~s}$. Tiempo durante el cual el material puede experimentar healing en todas las zonas donde existe contacto entre las partes. Ese healing se incrementa con el desarrollado nuevamente en el enfriamiento.

En este trabajo, va a analizarse únicamente cómo se desarrolla el healing en la primera etapa de contacto entre las superficies del material, para ello se integrará la ecuación 4.52 entre el tiempo de inicio de contacto del rodillo y el fin de dicho contacto (tomando la suposición de que se produce una cristalización en el material que bloquea el sucesivo desarrollo de healing posteriormente, futuros trabajos deberían destinarse a precisar el momento exacto en el que se produce la congelación de la difusión de las cadenas). Para el tiempo de healing en la ecuación, ha sido utilizada la relación de la Ecuación 4.47. La evolución de la temperatura con el tiempo se representará mediante un ajuste obtenido de los perfiles de enfriamiento de los termopa- 
res, tal como se hiciera con el contacto íntimo.

El resultado de la integración, representado en la Figura 4.88, muestra como para las condiciones definidas, el valor de healing alcanzado durante el periodo de $0,7 \mathrm{~s}$ es de un $60 \%$, valor que, al igual que ocurría con el grado de contacto íntimo cae sustancialmente al incrementarse la velocidad de encintado. No obstante, se recalca aquí, que el healing continuará desarrollándose durante todo el encintado posterior, incluso en las etapas de calentamiento pues no requiere presión para evolucionar.

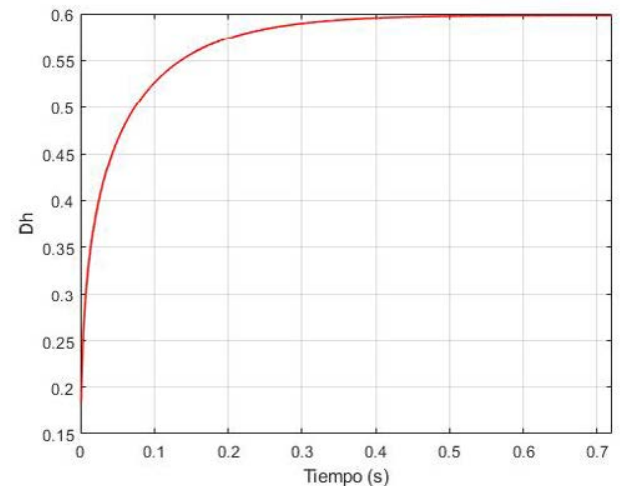

(a)

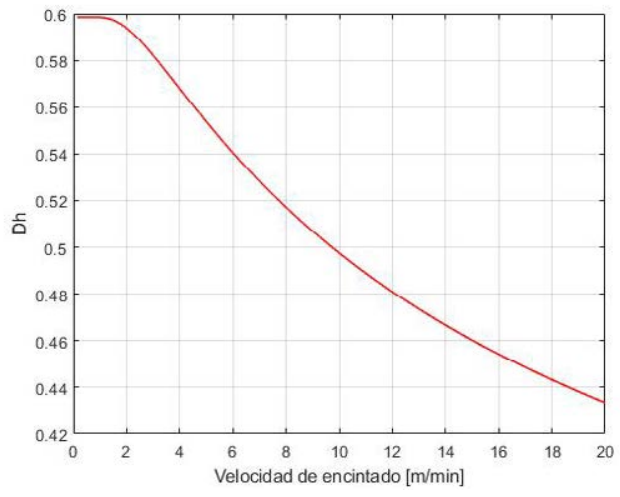

(b)

Figura 4.88: Análisis de la evolución del grado de healing con el tiempo en (a) Integrando con el perfil de enfriamiento bajo el efecto del rodillo en el proceso de laminación a $1 \mathrm{~m} / \mathrm{min}$ y (b) Variando la velocidad de encintado estimando la misma tendencia de enfriamiento

\subsubsection{Unión}

Teniendo en cuenta los desarrollos de (Pitchumani et al. 1996), la ecuación que describe el grado final de unión y que toma en consideración los valores del grado de contacto íntimo y de healing, se corresponde con la expresión 4.53 .

En la expresión, se tiene en cuenta que, en un intervalo de tiempo definido por $\Delta \tau$, el grado de contacto íntimo se incrementa como $\frac{d D_{i c}}{d \tau} d \tau$. Asimismo, en el proceso de encintado automático, suele ocurrir que el tiempo de healing es muy superior al de contacto íntimo (por el limitado tiempo que el rodillo se encuentra ejerciendo presión durante el desplazamiento del cabezal), reportándose tiempos del orden de $0,05 \mathrm{~s}$ para el contacto íntimo y de $1 \mathrm{~s}$ para el healing del polímero. Considerándose que existe esa desviación entre los 
órdenes de magnitud de los tiempos, se abre la posibilidad de ejecutar la simplificación que se incluye en la Ecuación 4.54.

$$
\begin{gathered}
D_{b}\left(\tau_{h}\right)=\left[\int_{0}^{\tau_{i c}} D_{h}\left(\tau_{h}-\tau\right) \frac{d D_{i c}}{d \tau}(\tau) d \tau\right] \\
D_{b}\left(\tau_{h}\right) \sim D_{h}\left(\tau_{h}\right) \cdot D_{i c}\left(\tau_{i c}\right)
\end{gathered}
$$

Considerando los resultados obtenidos para el análisis del grado de contacto íntimo y para el healing, el resultado de la adhesión de las dos primeras capas de material para un encintado a $1 \mathrm{~m} / \mathrm{min}$ podría aproximarse a un $48,6 \%$, valor que se estima muy inferior al realmente desarrollado por dos capas de material en una ejecución real.

En vista de dicho resultado, se ejecutó una nueva evaluación del grado de healing utilizando el criterio de corte entre las curvas $G^{\prime}-G^{\prime \prime}$, reportado en la ecuación 4.46, esa evaluación mostró que el grado de healing igual a un $100 \%$ se alcazaba tras $30 \mathrm{~ms}$, valor inferior a los $72 \mathrm{~ms}$ de aplicación de carga del rodillo. En esas condiciones, el grado de unión obtenido sería de un $81 \%$. 


\subsection{Cristalización}

La cristalización de un polímero, entendida como el ordenamiento de las cadenas poliméricas, empaquetándose y formando una estructura más densa, tiene un impacto fundamental en el comportamiento mecánico de la pieza final fabricada.

Dado que la cristalización generada en el material está ligada al proceso de enfriamiento al que se somete (perfil temperatura-tiempo) y que en el proceso de laminación automática y consolidación in-situ el enfriamiento es radicalmente diferente en comparación a los generados en los procesos convencionales, la cristalización del material ha sido analizada desde dos perspectivas, morfológica y cinética. Por un lado, se han estudiado los modelos cinéticos que predicen el valor porcentual de cristalinidad en función del perfil de enfriamiento al que se somete el material. Estos modelos se verán condicionados por las desviaciones respecto a los procesos de cristalización convencionales; entre ellas: fusiones incompletas, perfiles de enfriamiento lejos del alcance de los equipos experimentales, sucesivos estadios de cristalización por calentamientos-enfriamientos secuenciales.

En vista de las problemáticas asociadas al empleo de los modelos típicos de cristalización de polímeros, se ha tratado de conocer desde una perspectiva física cómo se desarrolla dicho proceso tratando de utilizar dicha información para la generación de modelos más realistas y comparando la cristalización en el proceso de laminación automática y consolidación in-situ con la de un ciclo convencional en prensa. Se han empleado diferentes técnicas experimentales buscando determinar cuál es el valor real de cristalinidad tras los procesos de fabricación en prensa y laminación automática y consolidación in-situ, comparando entre sí sus porcentajes y las posibles diferencias morfológicas.

Para tratar de aproximar qué ocurre con la cristalinidad en un proceso de fabricación como el del objeto de este trabajo doctoral, se ha analizado qué ocurre con ella al incrementar el espesor de los laminados. Fueron fabricadas dos probetas incrementando progresivamente el número de capas de tal modo que pudieran extraerse muestras para ensayar por calorimetría diferencial de barrido cada uno de los escalones constituyentes hasta dieciséis capas, teniéndose en cuenta dos posibles situaciones de encintado: utillaje calefactado y utillaje frío. 


\subsubsection{Determinación experimental de cristalinidad}

Durante este apartado, serán referenciados diferentes termogramas de los ensayos ejecutados sobre el material que han sido incluidos en el Apéndice C] del documento para facilitar visualizar los efectos referidos.

Para comprender la evolución de la cristalinidad se han tomado como referencias los termogramas de PEEK 450G amorfo (Figura C.7), PEEK 450G cristalizado hasta el máximo alcanzable en un enfriamiento lento en prensa (Figura C.8) y APC2/AS4 "as received" (Figura C.9).

El material amorfo, se obtuvo tras un "quenching". Material PEEK 450G en forma de pellets, fue sometido a un calentamiento en prensa hasta $670 \mathrm{~K}$ y una vez terminada la estabilización de $15 \mathrm{~min}$ a esa temperatura, se efectuó una inmersión del material en agua con hielo, provocando un enfriamiento brusco que dejó el material en un estado prácticamente amorfo. Tras esta ejecución ya fue detectable visualmente una variación en el estado cristalino del material, pues partiendo de pellets opacos y con una coloración ocre, se obtuvo una lámina de material prácticamente translúcida, característica típica de las estructuras amorfas. Posteriormente, diversos análisis confirmarían la consecución de un estado amorfo real.

El PEEK 450G con la máxima cristalinidad, se obtuvo ejecutando sobre un nuevo conjunto de pellets, un ciclo de prensa, con una estabilización a $670 K$ durante 15 minutos y aplicando una rampa de enfriamiento posterior en el entorno de $2 K /$ min.

En el análisis de los termogramas obtenidos por calorimetría diferencial de barrido de las diferentes muestras, se prestará especial atención a lo definida que se encuentra la temperatura de transición vítrea, a su posición, a la morfología del pico de fusión, al área del pico de fusión, a las posiciones de inicio, pico y fin de fusión, a la presencia del pico de cristalización fría (en caso de tenerlo) y a las posiciones de inicio, pico y fin del pico de cristalización fría (en caso de tenerlo).

El material compuesto presentará variaciones respecto al polímero neto en lo relativo a la cristalización. La fibra de carbono actuará como agente nucleante acelerando el proceso de cristalización y generando una estructura típica de capa transcristalina (cristales que crecen sobre la fibra de carbono y se orientan perpendicularmente a ella).

Considerando el termograma del material amorfo, recogido en la Figura C.7. se destaca la marcada transición observable en el rango de $T_{g}$. Tal 
comportamiento es una muestra clara de la limitada presencia de cristales interrumpiendo los movimientos de la parte amorfa. Superado el valor de la transición vítrea, localizado en $416 K\left(\sim 143^{\circ} \mathrm{C}\right)$ aparece un pico exotérmico cuyo onset extrapolado se localiza en $443,51 K\left(\sim 170^{\circ} \mathrm{C}\right)$ y pico máximo en $447,47 \mathrm{~K}\left(\sim 175^{\circ} \mathrm{C}\right)$. Tras la exoterma, aparece una endoterma correspondiente a la fusión del material cuya área es algo superior a la obtenida del pico de cristalización fría, la causa de esa desviación de valores puede ser la existencia de una cristalización de bajo porcentaje existente en el material, o al posible desarrollo de efectos de cristalización/fusión durante el proceso de calentamiento en el rango de la fusión.

En el caso del material sobre el que se ha aplicado un ciclo lento de enfriamiento en la prensa, Figura C.8 se observa que la transición asociada con la $T_{g}$ no está claramente definida. La transición, que se asemeja más una exoterma, se asocia a la relajación de una fase amorfa atrapada entre formaciones cristalinas, una fase amorfa "rígida". A causa de esto, el valor de esta transición aparece ahora desplazado a $435,57 K\left(\sim 162^{\circ} \mathrm{C}\right)$. Tras esa transición, no se detectan efectos de cristalización fría, hecho lógico considerando que el polímero desarrolló toda la posible durante su fase de enfriamiento lento. La siguiente transición es el proceso endotérmico de fusión, cuya morfología es muy diferente a la que presentaba el pico de fusión del material amorfo, en este caso compuesta por un pico principal y un hombro adjunto. Ese cambio en la forma del pico de fusión se relaciona con la fusión de dos tipos de cristales diferentes.

En el gráfico C.9 se incluye el termograma sobre el material compuesto APC2/AS4 según es recibido tras su envío por el fabricante. El termograma refleja un comportamiento prácticamente idéntico al que presentaba el material PEEK 450G amorfo. La transición vítrea está perfectamente marcada y se presenta a un valor de temperatura de $418,00 K\left(\sim 145^{\circ} C\right)$. El pico y el onset extrapolado de la cristalización fría también tienen una desviación de unos $2 K$ respecto al valor obtenido en el PEEK amorfo, tal y como ocurre con el valor de $T_{g}$. El pico de fusión también presenta un único pico y su área es algo superior a la que se obtenía integrando el pico de cristalización fría. En vista de este termograma, podríamos decir que el material preimpregnado se encuentra en un estado prácticamente amorfo inicial.

La Tabla 4.12 recoge la información de los distintos valores de temperatura y el valor de cristalinidad de las muestras. 


\begin{tabular}{|c|c|c|c|c|c|c|c|c|}
\hline Material & $\begin{array}{c}T_{g} \\
{[\mathrm{~K}]}\end{array}$ & $\begin{array}{c}T_{c c} \\
\text { onset [K] }\end{array}$ & $\begin{array}{c}T_{c c} \\
\text { pico [K] }\end{array}$ & $\begin{array}{c}T_{m}^{*} \\
\text { onset [K] }\end{array}$ & $\begin{array}{c}T_{m} \\
\text { pico [K] }\end{array}$ & $\begin{array}{c}\Delta H_{c c} \\
{[\mathrm{~J} / \mathrm{g}]}\end{array}$ & $\begin{array}{c}\Delta H_{f} \\
{[\mathrm{~J} / \mathrm{g}]}\end{array}$ & $\begin{array}{c}\text { Cristalinidad } \\
\%\end{array}$ \\
\hline $\begin{array}{c}\text { PEEK amorfo } \\
\text { C.7 }\end{array}$ & 416,00 & 443,51 & 447,47 & 593,78 & 615,66 & 31,94 & 40,06 & 8 \\
\hline $\begin{array}{c}\text { PEEK cristalizado } \\
\text { C.8 }\end{array}$ & 435,57 & - & - & 600,63 & 619,32 & - & 49.87 & 38.05 \\
\hline $\begin{array}{c}\text { APC2/AS4 } \\
\text { C.9 }\end{array}$ & 418,09 & 445,06 & 449,30 & 600,37 & 619,43 & 10,81 & 15,53 & 10,9 \\
\hline $\begin{array}{c}\text { APC2/AS4 prensa } \\
\text { C.1 }\end{array}$ & - & - & - & 610,59 & 621,10 & - & 21,27 & 37,05 \\
\hline $\begin{array}{c}\text { APC2 AS4 ISC } \\
\text { Mesa @ } 473 K \text { C.4 }\end{array}$ & - & - & - & 604,55 & 620,46 & - & 15,64 & 35,39 \\
\hline
\end{tabular}

${ }^{*}$ Valor obtenido con la herramienta de integración de pico con línea base recta de TA Universal Analysis $T_{c c}$ Temperatura "cold crystallization" de cristalización en frío

Tabla 4.12: DSC sobre PEEK 450G amorfo, cristalizado, APC2/AS4 as received, laminado de APC2/AS4 procesado en prensa y procesado por ISC con mesa calefactada a $473 K$ 
Considerando los procesos de fabricación en prensa, estufa o autoclave, las velocidades de enfriamiento se encuentran en el orden de 2 a $5 \mathrm{~K} / \mathrm{min}$. Además, en todos ellos, el enfriamiento se inicia partiendo de un estado de fusión completa del material pues los ciclos implican minutos de estabilización sobre la temperatura equilibrio de fusión. Por su parte, en laminación automática y consolidación in-situ, los ciclos implican calentamientos bruscos y mantenimientos de la estabilización durante segundos, seguidos de un enfriamiento extremo. La calorimetría diferencial de barrido posibilita analizar el estado en que quedó el material tras el ciclo de enfriamiento al que fue sometido mediante el análisis de cómo se desarrolla la fusión posterior; en la Figura 4.89 se ha incluido la representación del comportamiento del APC2/AS4 tras haber sido sometido a un calentamiento láser típico de ISC con temperatura de consigna $673 K$.

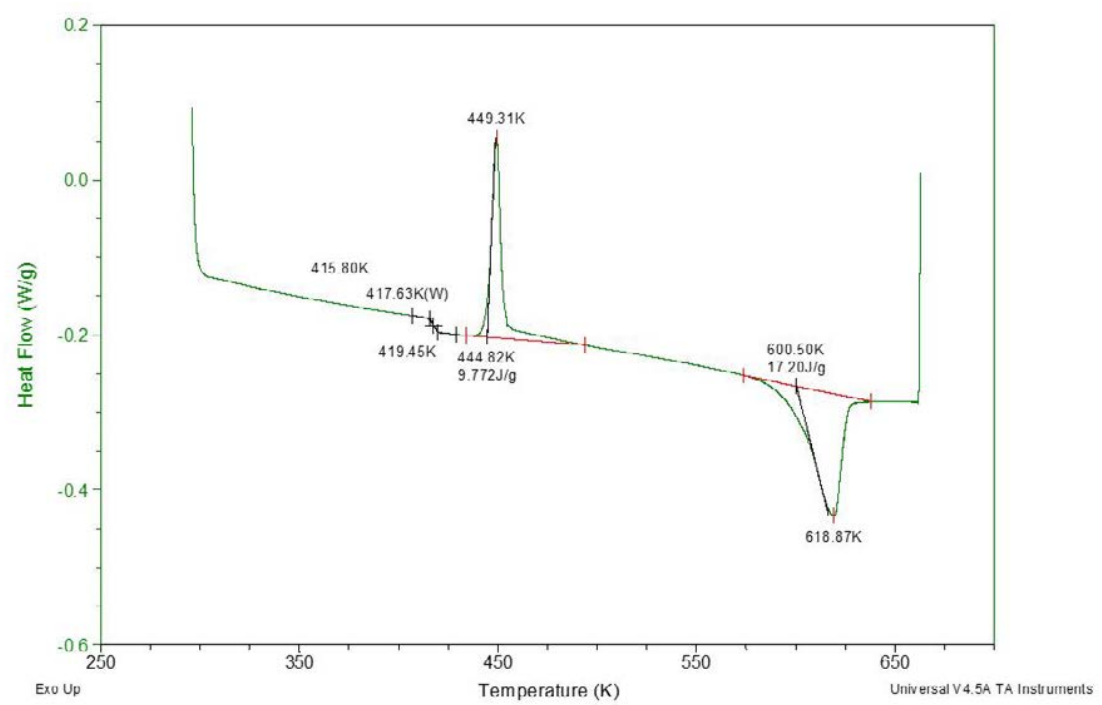

Figura 4.89: Termograma APC2/AS4 tras ser calentado por el láser a $473 K$ d consigna, rampa de calentamiento en DSC $10 \mathrm{~K} / \mathrm{min}$

La Figura C.14 representa el ciclo de calentamiento a $10 \mathrm{~K} / \mathrm{min}$ sobre muestras diferentes procedentes de un panel procesado en prensa y otro por laminación automática y consolidación in-situ con utillaje calefactado a $473 \mathrm{~K}\left(\sim 200^{\circ} \mathrm{C}\right)$. En ninguno de los termogramas ha sido incluido el valor de la $T_{g}$ por la dificultad para distinguirla, la cristalinidad desarrollada por el material y la presencia de la fibra de carbono imposibilita que la fase amorfa adquiera la movilidad necesaria sin restricciones físicas para ser detectable en el termograma. El pico de fusión en cada muestra presenta un comportamiento diferente, en el caso del laminado de prensa, el pico tiene 
un hombro adjunto reflejo de la fusión de más de una morfología de cristal, por su parte, el procedente de la laminación en automático es un pico simple.

Se cree que en el proceso de laminación en automático, el brusco enfriamiento al que se somete el material, genera una formación grande de núcleos que chocan entre sí, impidiendo que crezcan como lo harían en el proceso en prensa, donde el enfriamiento es lento y la nucleación está menos favorecida.

A cada una de las muestras anteriores se les ha sometido tras ese ciclo de calentamiento a un enfriamiento controlado a $10 \mathrm{~K} / \mathrm{min}$ y a un nuevo calentamiento a $10 \mathrm{~K} / \mathrm{min}$. El propósito de analizar el pico de fusión en ese segundo ciclo de calentamiento es descartar posibles efectos de degradación en las muestras provocados por la fabricación. El resultado, adjunto en la Figura C.15 refleja un comportamiento prácticamente idéntico entre ellas, descartándose por tanto posibles efectos de degradación en el material tras su proceso de fabricación.

Teniéndose en cuenta las diferencias observadas entre los picos de fusión de las muestras y bajo la hipótesis de proceder de diferentes morfologías generadas por el proceso de fabricación, los modelos matemáticos deberían contabilizar esas variaciones. La principal problemática en este punto radica en cómo generar modelos basados en esos mecanismos cuando las técnicas experimentales del laboratorio solo pueden reproducir enfriamientos de hasta $70 \mathrm{~K} / \mathrm{min}$, valor muy alejado de la pendiente real de enfriamiento en laminación automática y consolidación in-situ.

Otro factor condicionante es conocer de dónde procede la cristalización generada en el panel con laminación en automático y consolidación in-situ; los cristales se generan en los enfriamientos, en las fases de calentamiento y el uso de utillajes calefactados está siendo una razón más de su desarrollo.

Se ha ejecutado un ensayo de calorimetría diferencial de barrido tratando de reproducir el ciclo inicial experimentado por la primera capa posicionada de forma manual sobre la mesa. El material se coloca sobre la mesa en frío, la consigna de mesa se sube a $473 K$ y progresivamente se calienta desde temperatura ambiente (una rampa de aproximadamente $1 K / \mathrm{min}$ ). Se ha ejecutado una isoterma posterior de 120 minutos a $473 K$ para comprobar qué ocurre en la estabilización posterior, analizando si el material continúa desarrollando cristalización (en el proceso habitual de encintado, la primera capa se mantiene un cierto tiempo sobre la mesa esperando a que ésta estabilice su temperatura). Tras la estabilización previa, se ha llevado el material hasta fusión con una subida a la máxima velocidad posible por el equipo, para comprobar el estado de cristalización en el que con esas condiciones se 
ha dejado el material.

- Rampa $1 K / \min$ hasta $473 K$

- Isoterma $120 \mathrm{~min}$

- Salto a $668 K$

El primer ciclo sobre el material, se incluye en la Figura C.17. En el calentamiento a $1 \mathrm{~K} / \mathrm{min}$, el material atraviesa la transición vítrea definida con claridad en 414,50K, reflejando el previo estado amorfo del APC2/AS4 "as received" como ya había sido indicado con anterioridad. Tras la transición vítrea, el material cristaliza en frío, estando el pico de la cristalización en frío localizado en $438,22 K$, una cristalización adelantada respecto a la que se obtuvo con el calentamiento de la muestra a $10 \mathrm{~K} / \mathrm{min}$ en C.9 cuyo pico se localizaba en 449,30K. Asimismo, el área del pico es levemente inferior pero los valores son semejantes. Ese estado será el primero en que el láser encontrará al material en la primera ejecución de encintado (con útil calefactado).

Sobre esa muestra, se mantuvo una isoterma posterior de $120 \mathrm{~min}$ a los $473 \mathrm{~K}$ donde no se apreció ningún efecto posterior de cristalización (Figura C.18), considerándose que la máxima desarrollable se consiguió durante la subida lenta a dicha temperatura de consigna; posteriormente se incrementó la temperatura hasta la fusión para analizar la morfología y características del pico, tal como refleja la Figura C.19. En el termograma, se observa una exoterma, con un área muy baja que se considera prácticamente despreciable. El pico de fusión obtenido tiene un único pico y está centrado en $620,81 K$.

Un trozo de material sometido a ese ciclo real en la mesa de calentamiento, ha sido ensayado por DSC, su termograma se recoge en la Figura C.16. En el gráfico, puede observarse nuevamente la dificultad en la definición de la transición vítrea, que se estima que puede ocupar una posición próxima a $435,83 \mathrm{~K}$. No hay efectos de cristalización fría porque el material fue capaz de desarrollar prácticamente toda la cristalización anteriormente sobre la mesa a $473 \mathrm{~K}$. La fusión presenta un pico fundamental a $619,47 \mathrm{~K}$ con un pequeño hombro separado del pico principal. Ese efecto de un pico separado pero junto a la fusión, ya se reportaba en el trabajo de (Tardif et al. 2014) ligado a cristalizaciones previas completas en isotermas próximas a la temperatura consignada para la mesa. El área representada por el pico es muy pequeña en comparación con la del pico principal de fusión, suponiendo toda la fusión una cristalización previa de un 36,5\%. Este pico de fusión es prácticamente idéntico al obtenido en la simulación de condiciones ejecutada en el calorímetro y representada por la Figura C.19 
Continuando en el proceso para conocer qué ocurre con la cristalización en la consolidación in-situ, se hace preciso establecer qué le ocurre al PEEK cuando se varía la velocidad de enfriamiento/calentamiento. La cristalización es un proceso cinético, altamente afectado por el perfil tiempo-temperatura impuesto en el material. Para conocer el efecto sobre la cristalización se han ejecutado ensayos de calorimetría variando las condiciones de rampa de calentamiento y de enfriamiento. En el caso del calentamiento se han impuesto condiciones de subida de temperatura de 2, 5, 10, 15, 20 y $30 \mathrm{~K} / \mathrm{min}$ sobre el material "as received" por el suministrador, Figura C.11. Para el enfriamiento, todas las muestras fueron calentadas a $10 \mathrm{~K} / \mathrm{min}$ hasta $663 \mathrm{~K}$, mantenidas en dicho valor de consigna durante $5 \min$ y enfriadas a $2,5,10$, 15,20 y $30 \mathrm{~K} / \mathrm{min}$ (asegurando que en todas ellas se partía de un estado inicial amorfo fundido), Figura C.12 El efecto de incrementar la velocidad (tanto para el calentamiento como para el enfriamiento) provoca un retraso en la aparición del pico exotérmico de cristalización, en el caso de los enfriamientos esto impacta en un desplazamiento del pico hacia la izquierda (menores valores de temperatura de inicio de cristalización), mientras que en el caso del calentamiento el pico se retrasa desplazándose hacia la derecha (mayor temperatura de inicio de cristalización en frío).

Teniéndose en cuenta los acusados perfiles tanto de calentamiento como de enfriamiento a los que se somete el material en el proceso de laminación automática y consolidación in-situ, es esperable que el material no llegue a cristalizar en frío durante los calentamientos o que el área total de dicho pico de cristalización sea muy baja. Del mismo modo, con los bruscos enfriamientos se espera que el material desarrolle muy poca cristalización en el proceso, con un onset de inicio inferior a $570 \mathrm{~K}\left(\sim 300^{\circ} \mathrm{C}\right)$ siendo $10 \mathrm{~K}$, el intervalo de temperatura requerido para alcanzar el pico máximo desde el onset (que supone un porcentaje aproximado del total de cristalinidad del pico de un $\sim 30 \%$ por la forma no simétrica del pico de cristalización). Volviendo a los gráficos de enfriamiento reportados en el apartado 4.1.1 se observa que el material está bajo la interacción del rodillo en ese pequeño intervalo de tiempo que dura el proceso de cristalización del material.

Considerando las hipótesis elaboradas con anterioridad sobre la posibilidad de desarrollarse o no la cristalización a esas velocidades, éstas se soportan con los trabajos de (Jin et al. 2014) y (Tardif et al. 2014), donde los análisis se han ejecutado mediante el uso de la técnica Flash DSC que permite trabajar con programas dinámicos de hasta $2000 \mathrm{~K} / \mathrm{s}$. Los ensayos elaborados en esas condiciones sobre PEEK muestran que este material no es capaz de desarrollar cristalización fría a esa velocidad de calentamiento. Este comportamiento se espera que sea también el que se presente en las condiciones de calentamiento impuestas por la laminación y consolidación in-situ. 
En la ficha técnica del fabricante del material, se propone un ciclo de procesado con un amplio rango de velocidades de enfriamiento: $0,5-720 \mathrm{~K} / \mathrm{min}$, siendo ese el rango permitido para que el material cristalice adecuadamente. En el proceso de laminación automática y consolidación in-situ el orden de magnitud del enfriamiento es de $10000 \mathrm{~K} / \mathrm{min}$, muy alejado del rango de valores de la ficha del suministrador. La normativa de certificación que aplica a este material, también es permisiva con el rango de cristalinidad (en \%) aceptable tras la fabricación, posiblemente por ese rango amplio de enfriamiento que permite el propio fabricante. No obstante, las normativas no consideran los posibles efectos derivados de procesados como los de la consolidación insitu, donde el porcentaje de cristalinidad desarrollado puede ser semejante en número pero no en morfología.

Para comprender mejor el desarrollo de la cristalización en el proceso de laminación automática y consolidación in-situ, se plantean dos situaciones de encintado, encintado de 16 capas con útil frío y misma situación con útil calefactado.

\subsubsection{Cristalización en ISC con útil frío}

La probeta que se va a estudiar en este apartado está compuesta por un escalón de 16 capas encintadas a $0^{\circ}$ con material APC2/AS4, partiendo de un patrón de primera capa pre-posicionado manualmente sobre la mesa de encintado. La configuración de probeta se incluye en la Figura 4.90 Se han ejecutado dos ensayos de calorimetría sobre trozos de cada capa; para las capas más bajas, varios trozos de material se utilizaron con el fin de dotar de mayor sensibilidad a la medida.

La primera capa de material se coloca sobre una mesa a temperatura ambiente. Esta capa, porta una cristalinidad aproximada a la recogida por la Tabla 4.12 para APC2/AS4 "as received", estando el material prácticamente amorfo.

En el encintado de la siguiente capa, ese material sustrato se calienta a una elevada velocidad hasta la temperatura de consigna, próxima a los $673 \mathrm{~K}$ $\left(\sim 400^{\circ} \mathrm{C}\right)$. Al calentarse el material, se pueden desarrollar dos situaciones, que el material sea capaz de desarrollar cristalización en frío y que en la fusión posterior se elimine o que directamente la alta velocidad de calentamiento no permita cristalizarlo en frío, llevándolo directamente a fusión del limitado componente cristalino pre-existente. El análisis de dos capas mostrado en el termograma de la Figura C.21 manifiesta la existencia de una marcada cristalización fría. 


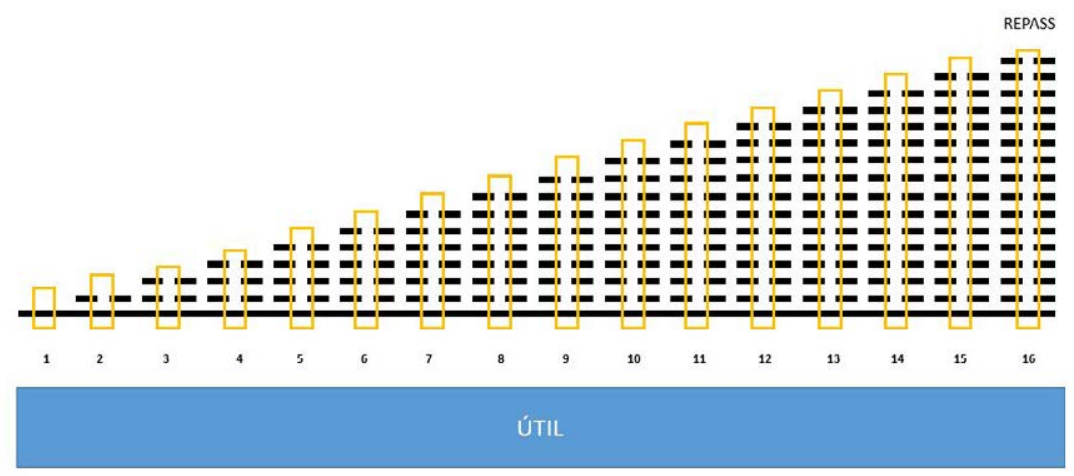

Figura 4.90: Esquema de probeta escalón encintada con útil frío

Si el material desarrolla algo de cristalinidad desde el estado de partida, es posible que no sea posible eliminar todo el germen cristalino previo durante la fusión a la temperatura de estabilización, por el limitado tiempo de duración (en el entorno de $5 s$ ), quedando un remanente de cristal actuando como núcleo y acelerando la posterior cristalización en el enfriamiento. Cada vez, ese remanente cristalino va siendo superior.

Durante el encintado de la capa 3, las capas 1 y 2, tal y como indicaban las lecturas de los termopares experimentaron nuevamente la fusión con una temperatura aún por encima del pico de fusión. El material vuelve a calentarse rápidamente y a enfriarse bruscamente. El termograma de la Figura C.22 muestra una evidente transición vítrea y un pico de cristalización fría casi del mismo valor que la fusión posterior.

En las lecturas de los termopares pudo observarse también que en el encintado de la capa 4, el punto posicionado entre las capas 1 y 2 , ya no era capaz de sobrepasar la temperatura de fusión de equilibrio, luego desde este punto, la contribución de los desarrollos de cristalización en frío y posterior fusión incompleta generada por el proceso de fabricación debería comenzar a ser detectable. En el termograma de la Figura C.23 correspondiente a una muestra conteniendo las capas 1 a 4 , se detecta que el pico exotérmico correspondiente a la cristalización fría tiene un área inferior a la que presentaba en los casos anteriores.

Ese área se verá reducida con cada etapa sucesiva de encintado, presentando un área pequeña en los encintados de las capas 5 (Figura C.24), capa 6 (Figura C.25) y capa 7 (Figura C.26). Y desapareciendo por completo al- 
canzada la capa 8 (Figura C.27), haciéndose también poco definido el valor de la transición vítrea.

En el encintado de la capa 8, probablemente sigan existiendo capas (las más altas) que desarrollarían cristalización fría en el calorímetro, sin embargo, la muestra total colocada para ensayar contiene una porción mayor que habrá ido cristalizando en frío en el proceso de fabricación, implicando que la contribución al total del laminado de las que sí mostrarían efectos de cristalización fría sea menor. Asimismo, a medida que se asciende en la altura en el laminado, los puntos cada vez se encuentran más alejados del sumidero de calor que supone el utillaje, presentando perfiles de enfriamiento algo más suaves. Al subir en altura del laminado, las repetidas etapas de consolidación, incrementan el grado de contacto íntimo favoreciendo el desarrollo de la co-cristalización en las entre-caras inferiores, actuando positivamente sobre el porcentaje de cristalización.

Analizando los termogramas de los encintados de las siguientes capas, Figuras C.28, C.30, C.31, C.32, C.33, C.34 y C.35 se repite el comportamiento de pérdida de definición en la transición vítrea y de inexistencia de cristalización fría. La fusión presenta un único pico típico de la fusión de una sola formación cristalina. Ese pico, con máximo en unos $619 \mathrm{~K}$ se comparará con el obtenido en la próxima sección en el encintado con útil calefactado.

En la Figura 4.91 se recoge la información tras la integración de los picos para obtener la cristalinidad de las muestras, con ella se ha ejecutado la representación gráfica donde se aprecia que la cristalinidad sube progresivamente durante el encintado de las primeras capas hasta alcanzarse un valor estable mantenido de un 30 a un $40 \%$. El comportamiento con el incremento en el número de capa, sigue una evolución tipo exponencial asintótica, como se ilustra en la Figura 4.92

Aún pudiendo aproximar su resultado en \% de cristalinidad a los valores habituales de otros procesos de fabricación, estos cristales proceden de procesos de nucleación masiva que genera un número muy elevado de gérmenes cristalinos y de pequeño tamaño.

\subsubsection{Cristalización en ISC con útil calefactado}

Actualmente, como alternativa de trabajo y con el objetivo fundamental de reducir las tensiones residuales en los paneles fabricados por laminación automática y consolidación in-situ, se emplean útiles calefactados. La temperatura del utillaje debe seleccionarse entre el fin de la cristalización y la temperatura de transición vítrea del material, para ser lo más efectiva posible 


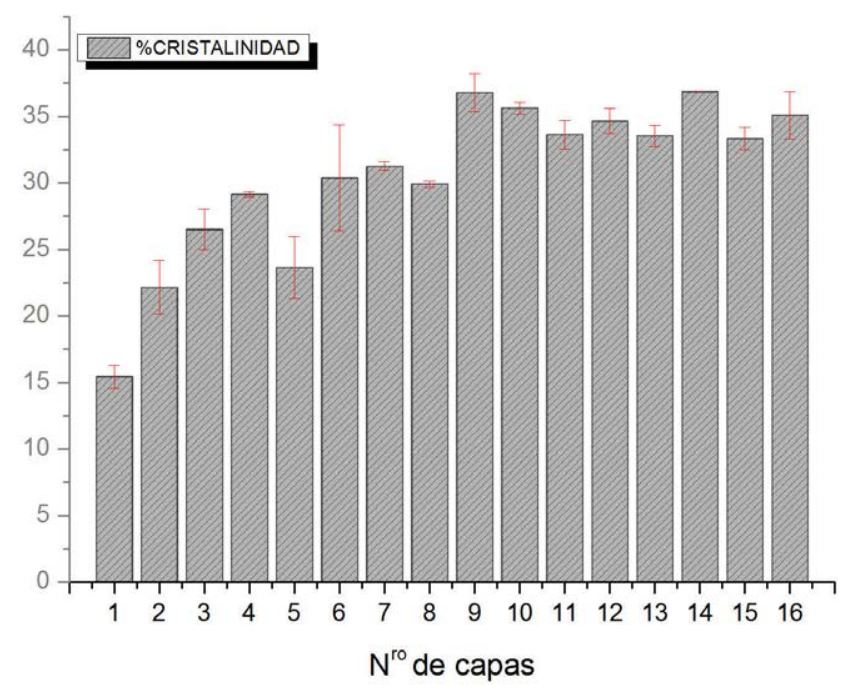

Figura 4.91: Evolución de la cristalinidad en probeta escalón encintada en útil frío

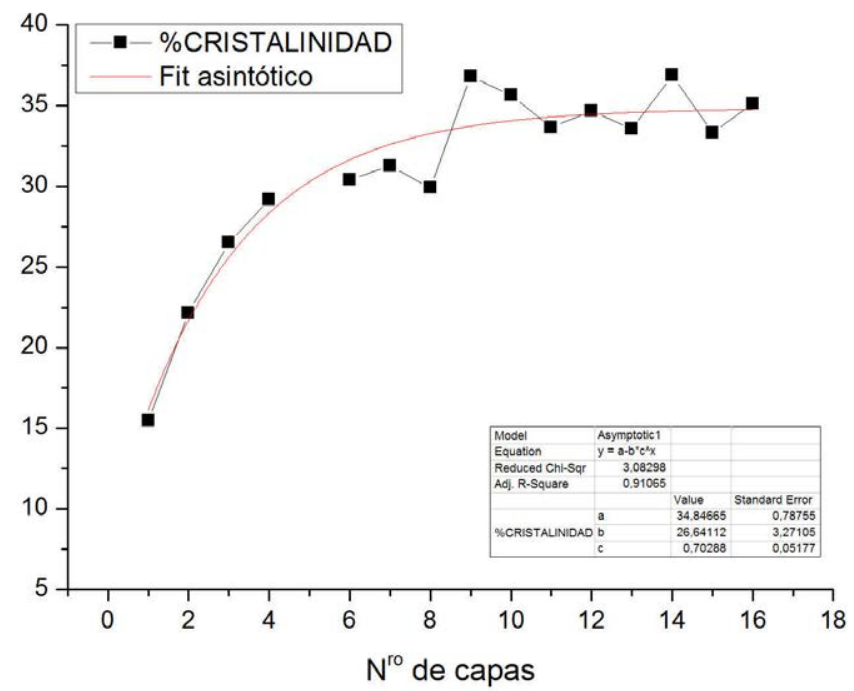

Figura 4.92: Evolución de la cristalinidad en probeta escalón encintada en útil frío, ajuste asintótico 
al propósito de reducir tensión residual. De este modo se evitan los efectos de desconsolidación en el laminado por mantenerlo a alta temperatura sin presión antes de solidificar y se limita el gradiente térmico al que se somete el material. Definir la temperatura a la que tiene lugar la cristalización del material en un proceso como el estudiado es complejo, complicando la selección de temperatura del utillaje. Como se vio anteriormente, a medida que aumenta la velocidad de enfriamiento, el pico de cristalización se desplaza hacia la izquierda (temperaturas menores), simultáneamente, la incompleta fusión causada por los bajos tiempos de estabilización y el progresivo desarrollo de cristalización en frío, provoca la presencia de núcleos cristalinos que aceleran el proceso de cristalización, modificando la tendencia descrita anteriormente, desplazando el pico hacia la derecha (mayores temperaturas).

Con el fin de analizar como evoluciona la cristalización en un laminado elaborado sobre mesa a $473 K$, se ha repetido la probeta ya estudiada en el apartado anterior con la nueva condición de útil calefactado. Sobre ella se han ejecutado nuevamente ensayos de calorimetría conteniendo diferente número de capas del total de las 16 componentes del laminado general (Figura 4.93 .

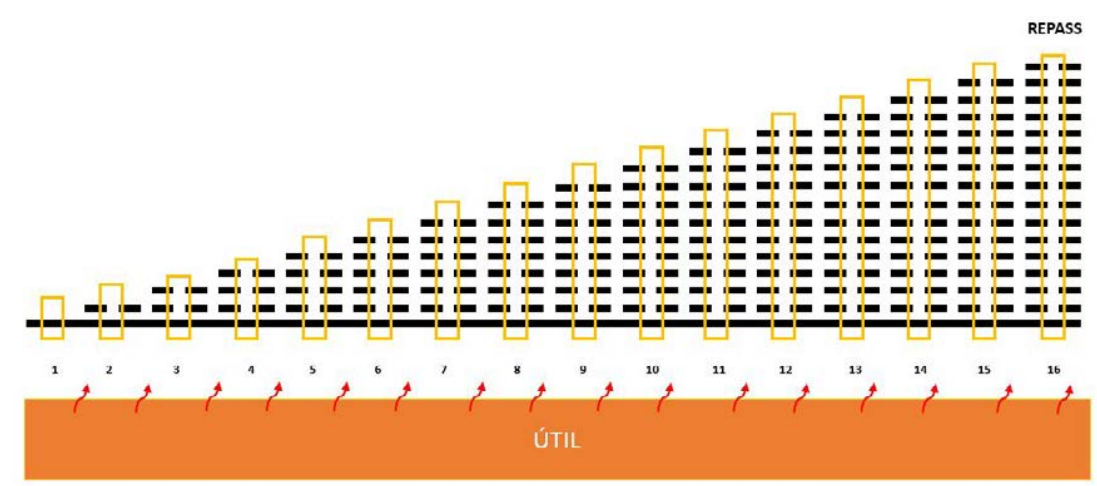

Figura 4.93: Esquema de probeta escalón encintada con útil caliente

La primera capa se posiciona manualmente en frío y se eleva la temperatura del utillaje lentamente hasta el entorno de $473 K(\sim 443 K$ por los elementos aislantes colocados en la interfaz con la mesa) y se mantiene en una isoterma hasta que comienza el trabajo de encintado. Esto supone que, a diferencia del caso anteriormente descrito con útil frío, el material de primera capa comienza el proceso con un cierto valor de cristalinidad, este valor debe aproximarse al que se presentaba en el termograma de la Figura C.16. En el anterior caso, existía una cristalización fría muy leve y se extrajo un 
valor de cristalización en la muestra de 36,5\%. Del termograma de la Figura C.36 extraído de la primera capa de probeta escalón encintada en caliente, se ha obtenido un valor de $32,14 \%$, inferior pero similar al obtenido en el caso antes referido.

Una vez alcanzada la estabilización a la temperatura consignada de mesa, comienza el encintado. A diferencia de lo que ocurría con la mesa fría, donde tanto sustrato como material de aporte se encontraban en estado amorfo previo al calentamiento, en el proceso actual, el material sustrato se encuentra cristalizado por el periodo de tiempo mantenido en la mesa calefactada y el material de aporte baja por el guiado del equipo en estado prácticamente amorfo. En el rápido calentamiento experimentado pueden quedar remanentes de cristal sin fundir actuando como nucleantes en la cristalización posterior. Asimismo, el enfriamiento actual recupera el perfil en la bajada a la temperatura del utillaje, favoreciendo el desarrollo de una cristalización en isotermo a $473 \mathrm{~K}$.

La hipótesis ejecutada en este caso es que la cristalización observada en el material se genera a la isoterma de estabilización sobre mesa, a diferencia de la hipótesis del caso de mesa fría donde se estimó que el material cristalizaba por las subidas sobre $T_{g}$ sin alcanzar la fusión. En las subsiguientes etapas de posicionado de material, el material de sustrato se encuentra siempre en estado cristalizado por la isoterma correspondiente a la mesa.

El diagrama de la Figura 4.94 resume las anteriores hipótesis sobre cómo se espera que proceda la cristalización en este caso.

Los termogramas incuidos en las Figuras C.38 a C.50 son una muestra de cómo va evolucionando el material al crecer el espesor del laminado. En ninguno de ellos es detectable la presencia de cristalización fría y la fusión se compone por un único pico.

Representando conjuntamente los valores medios de cristalinidad obtenidos por cada capa, se obtiene el gráfico de la Figura 4.95. En este caso, no es posible presentar una tendencia asintótica porque el valor máximo ya parece haberse alcanzado desde el comienzo.

Otro efecto de cristalización posible en esta ejecución es que el desmoldeo se ejecuta en frío, una vez finaliza la probeta, la mesa se apagará reduciéndose su temperatura progresivamente. Esta etapa, supone una rampa de enfriamiento lenta de 2 a $5 \mathrm{~K} / \mathrm{min}$ desde $473 \mathrm{~K}$, estadio durante el cual, el material podría continuar con el proceso de cristalización aunque muy limitado por la baja movilidad de las cadenas poliméricas en estas condiciones. 


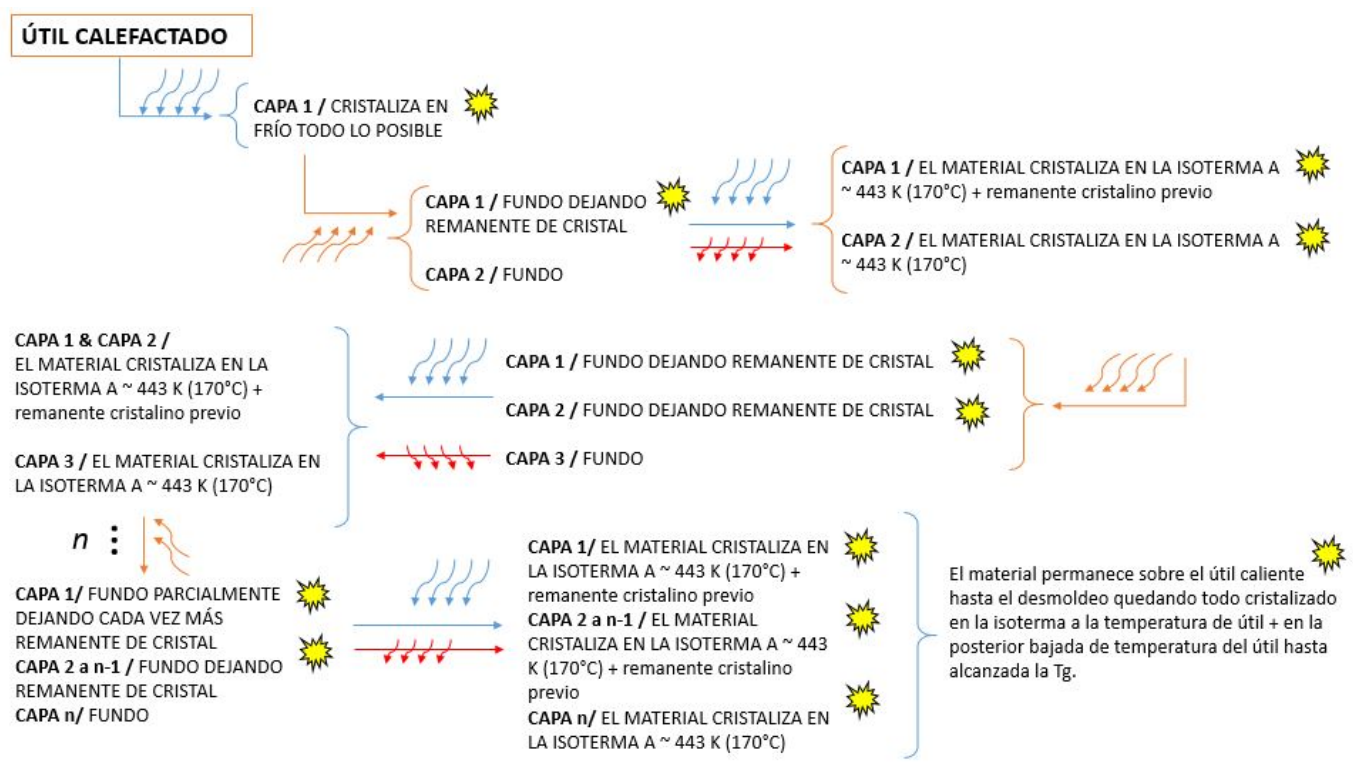

Figura 4.94: Diagrama progreso de cristalización en ISC con útil calefactado

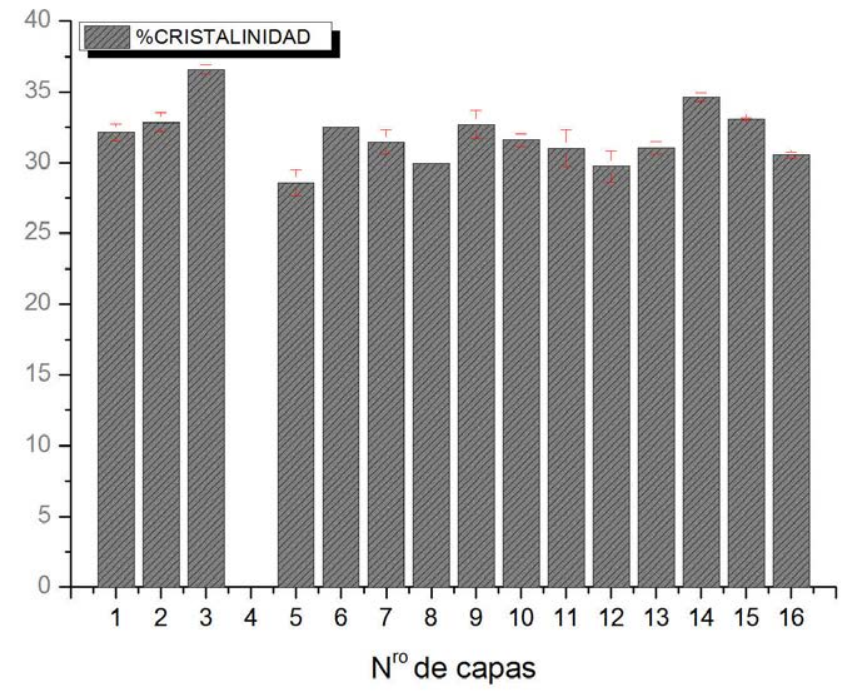

Figura 4.95: Evolución de la cristalinidad en probeta escalón encintada en útil caliente 


\subsubsection{Determinación de cristalinidad por XRD (X-Ray Diffrac- tion)}

Dos observaciones extraídas de los resultados de calorimetría llevaron a recurrir a una nueva técnica para el análisis de la cristalización. Por un lado, observar valores de cristalinidad del orden de un $8 \%$ en muestras que se estimaban amorfas y por otro, dar explicación a las diferencias morfológicas derivadas de la observación de los picos de fusión.

Al ejecutar las comparaciones entre los valores de cristalinidad obtenidos por calorimetría en los laminados fabricados en prensa y por laminación automática y consolidación in-situ con útil calefactado, se reportaron valores de cristalinidad de $37,05 \%$ en prensa y de $35,39 \%$ en laminación automática. Aun presentando valores similares, la comparación entre los picos de fusión del primer barrido de calentamiento en los termogramas de las Figuras C.1 y C.4. existe una diferencia muy notable en la morfología del pico.

De este efecto ya se incorporó información en el estudio del estado del arte de este documento, quedado abierta la posibilidad a deberse a dos efectos, por un lado un efecto fusión-recristalización durante el calentamiento a temperaturas de fusión y por otro a una diferente morfología de cristal. No se descarta el efecto de fusión-recristalización, pero se estima más probable la causa de una diferente morfología de cristal, teniéndose en cuenta las teorías de cristalización, en la laminación automática se generará una alta densidad de núcleos seguidos por un leve crecimiento, en contraste con una nucleación seguida de mayor crecimiento en un proceso convencional como estufa o prensa.

Para ratificar la existencia de variaciones morfológicas entre las muestras, se ejecutó un estudio de las mismas mediante X-Ray Diffraction (XRD). Los datos proporcionados por el XRD fueron tratados gráficamente para obtener únicamente las contribuciones de parte cristalina en el espectro.

Tal y como se indicó en el apartado de 3.4.5, para hacer posible este estudio sobre el material preimpregnado, se ejecutaron análisis previos sobre PEEK 450G amorfo (tras quenching) y cristalizado en un proceso de enfriamiento muy lento $(2 \mathrm{~K} / \mathrm{min})$ y sobre la fibra AS4 seca. La Figura 4.96 incluye los espectros en bruto sin tratar sobre el polímero y en la Figura 4.97 se incorpora el de la fibra de carbono.

Los valores de la red ortorrómbica calculados en este trabajo para el PEEK 450G semicristalino fueron los listados a continuación, teniendo en 


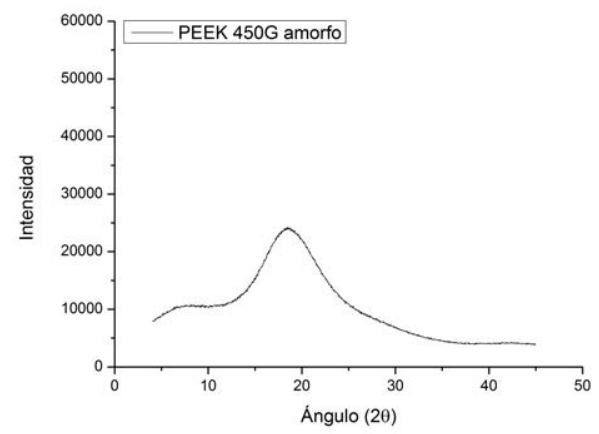

(a)

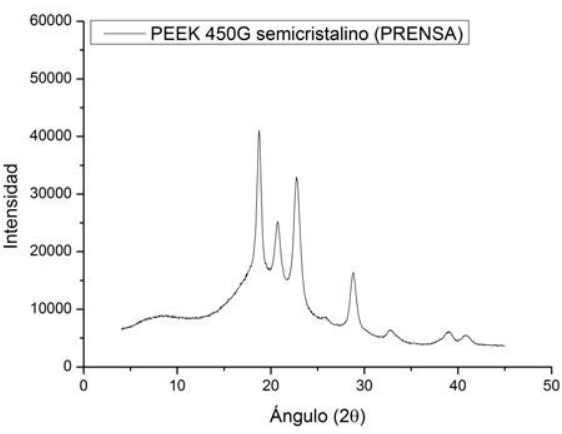

(b)

Figura 4.96: Espectros WAXS de a) PEEK 450G amorfo y b) PEEK 450G cristalizado lentamente en prensa

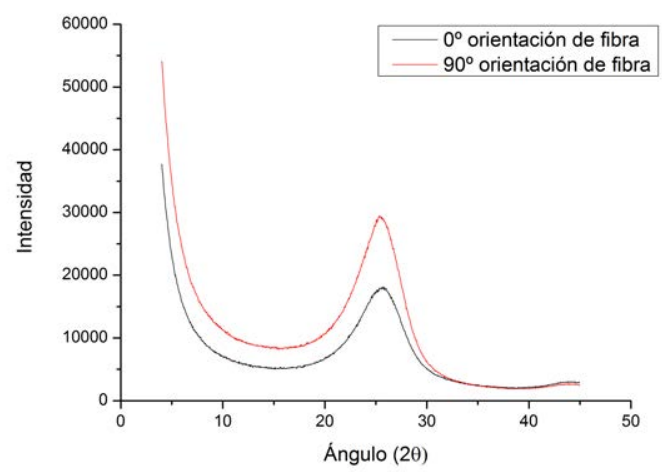

Figura 4.97: Espectros WAXS de AS4

cuenta las Ecuaciones 4.55 y la Ley de Bragg 4.56 para su estimación:

$$
\begin{gathered}
\frac{1}{d_{h k l}^{2}}=\frac{h^{2}}{a^{2}}+\frac{k^{2}}{b^{2}}+\frac{l^{2}}{c^{2}} \\
n \lambda=2 d \operatorname{sen}(\theta)
\end{gathered}
$$

En los cálculos se ha trabajado suponiendo $n=1$.

- $a=7,74 \AA$

- $b=5,98 \AA$

- $c=9,95 \AA$ 
El parámetro $d$ de la ley de Bragg, representa la distancia entre planos de sucesivos de átomos idénticos en el cristal, siendo $\lambda$ la longitud de onda de los Rayos-X empleados.

Sobre el pregimpregnado APC2/AS4 también se efectuaron ensayos. Se empleo material tras ser enviado por el suministrador y tras permanecer en útil calefactado a $473 \mathrm{~K}$ durante un tiempo (rampa calentamiento lento hasta $473 K$ y estabilización de 2 horas o superior), resultando en los gráficos de la Figura 4.98, Los ensayos sobre paneles procedentes de prensa e ISC se reportan en la Figura 4.99 Las muestras de los paneles fueron analizadas por ambas caras; para los paneles de prensa se observó el mismo comportamiento desde ambas caras mientras que, por su parte, las muestras de ISC presentaban diferencias apreciables entre la cara en contacto con el útil y la cara superior (última capa encintada).

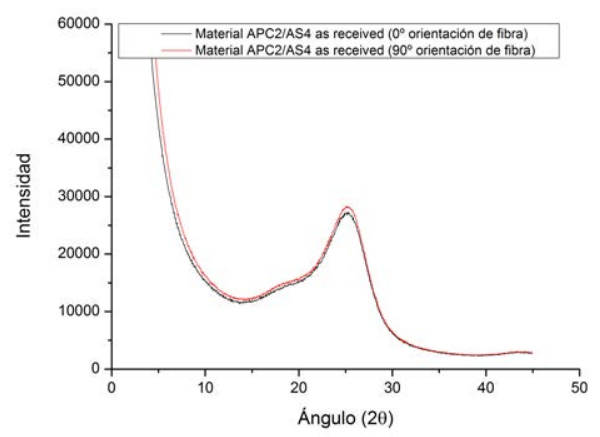

(a)

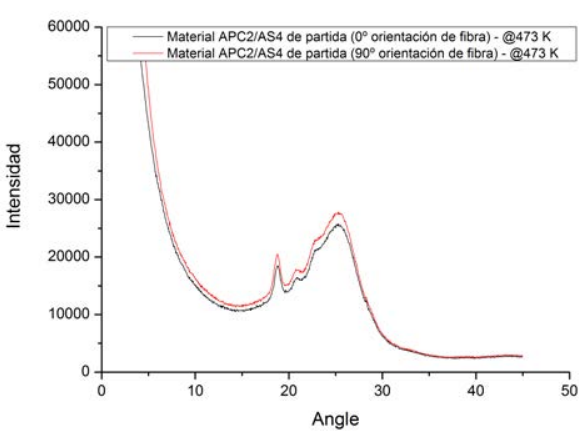

(b)

Figura 4.98: Espectros brutos WAXS de a) APC2/AS4 as received y b) APC2/AS4 as received tras permanecer en mesa a $473 \mathrm{~K}$

El tratamiento matemático de los espectros se efectuó con Origin 8.6. Una vez ejecutada la sustracción del área correspondiente al halo amorfo y ajustada la línea base, se prestará atención a los 4 picos fundamentales correspondientes a los planos cristalinos [110] $(2 \theta=18,79)$, [111] $(2 \theta=20,76)$, [200] $(2 \theta=22,69)$ y [211] $(2 \theta=28,72)$, tal y como se presenta en el trabajo de (Hsiao et al. 1993). En el caso del material compuesto, (Gao y Kim, 2000), explica que con relación a la fibra de carbono, el cristal orienta su crecimiento de forma ortogonal, siendo la dirección de crecimiento del cristal en ese caso, "b".

El PEEK 450G tras su tratamiento matemático, sustrayendo al espectro el halo amorfo que envolvía con precisión la parte inferior de la curva, se presenta en la Figura 4.100, centrando el resultado en el rango de $15^{\circ}$ a $45^{\circ}$, 


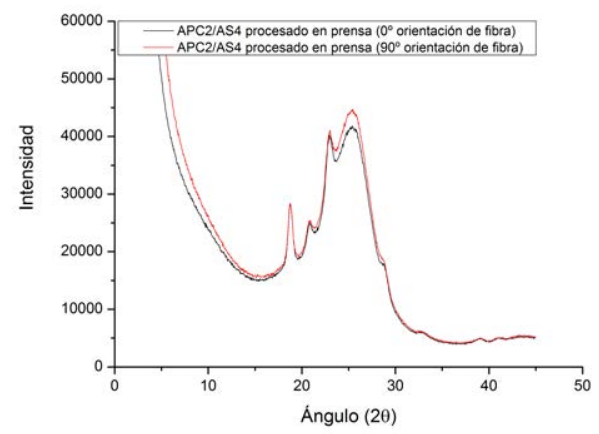

(a)

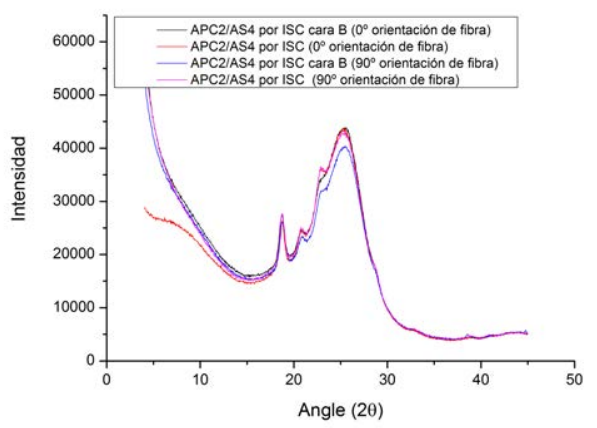

(b)

Figura 4.99: Espectros brutos WAXS de a) APC2/AS4 as received y b) $\mathrm{APC} 2 / \mathrm{AS} 4$ as received tras permanecer en mesa a $473 \mathrm{~K}$

donde se localizan los picos de interés.

Una vez extraídos los espectros de la contribución de la parte cristalina, se efectuaron ajustes mediante curvas gaussianas para cada uno de los picos, de estos ajustes se van a tomar los valores de FWHM para el cálculo del tamaño cristalino por la ecuación de Scherrer, correspondiendo el FWHM al valor $\beta$ que aparece en la citada ecuación (la definición de los parámetros de esta ecuación se puede encontrar en la sección 3.4.5.

$$
L_{h k l}=\frac{K \lambda}{\beta \cdot \cos \theta}
$$

Adoptando en este caso el cristal unas dimensiones en Amstrong de:

- $[110]=145,69 \AA$

- $[111]=125,48 \AA$

- $[200]=102,18 \AA$

- $[211]=100,51 \AA$

Los laminados fueron los que ofrecieron más complejidad para efectuar este tratamiento de los datos. Para la simplificación del espectro previa al ajuste gaussiano, se resolvió un sistema de 3 ecuaciones que se basaba en considerar que el espectro de la muestra debía ser el resultado del sumatorio del de PEEK cristalizado, PEEK amorfo y fibra de carbono (en tres posiciones representativas del espectro, los picos de [110], [111] y [200]). Una vez ejecutado dicho procesado de las curvas, se volvieron a aplicar ajustes 


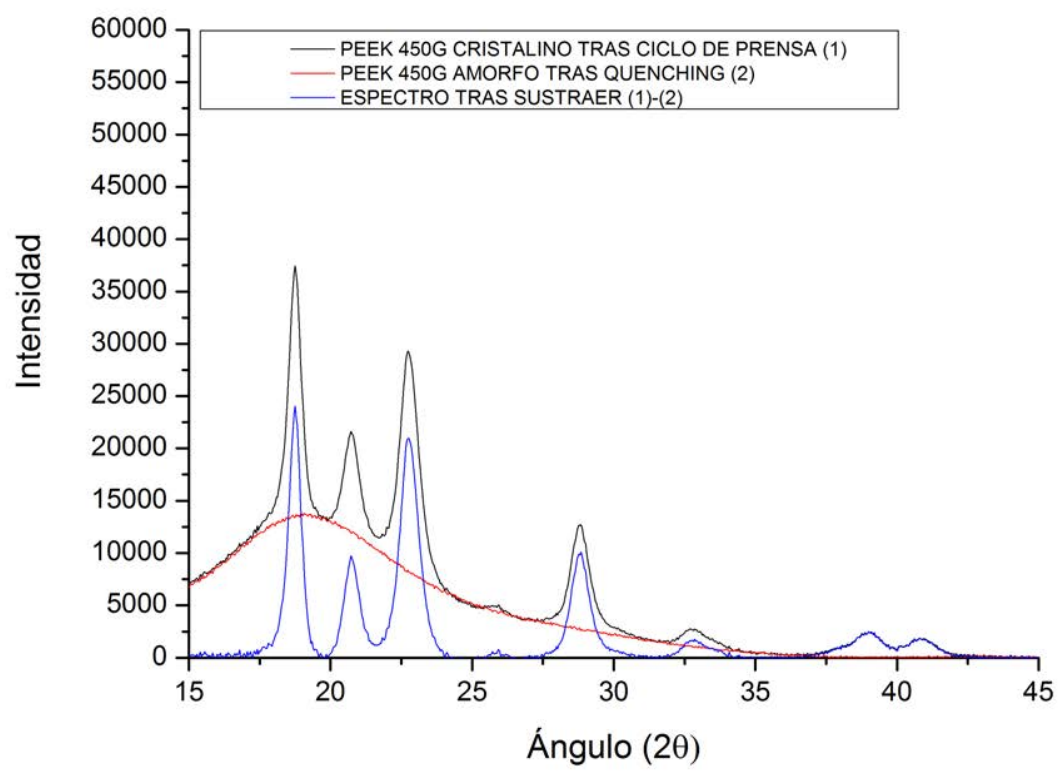

Figura 4.100: Espectros WAXS PEEK 450G sustracción de halo amorfo

mediante curvas gaussianas. A continuación se adjunta un gráfico intercomparativo de los resultados obtenidos. En las probetas de ISC se ha codificado como "cara B" a la coincidente con el útil.

La Figura 4.102 muestra el resultado tras la aplicación de la ecuación de Scherrer sobre todos los espectros tratados matemáticamente. Se considera que los resultados más estrictos son aquéllos que derivan de los picos [110] y [111] pues fueron los más robustos en todo el proceso de análisis. Como puede observarse, el mayor valor de "L" en ambos casos se reporta en el caso del PEEK 450G neto. Prensa e ISC presentan valores muy similares para [110], sin embargo, para el [111] es ISC cara útil el que presenta el mayor valor, con una diferencia significativa respecto a la cara superior del laminado, siendo un $75 \%$ su tamaño respecto al observado en la cara inferior, previo a su comparación con un resultado de otro proceso de fabricación, ya es posible remarcar la presencia de heterogeneidad de resultados a lo largo del espesor en paneles de ISC, no presentes en el caso de la prensa (los espectros en ambas caras solapan).

Con base en los estudios de la literatura, los paneles de prensa, a causa del lento enfriamiento que experimentan, desarrollan cristales tipo esferulitas de gran tamaño que dejan espacios para el crecimiento de morfologías 


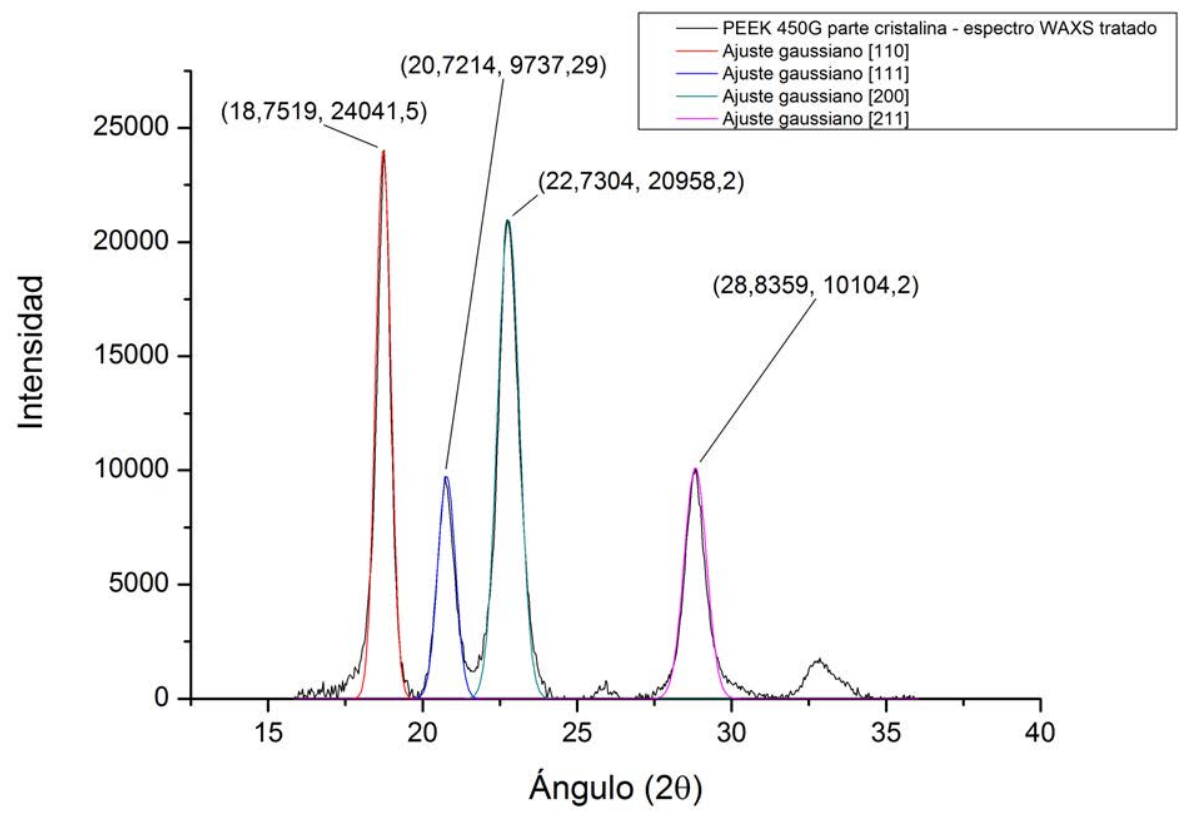

Figura 4.101: Ajuste gaussianas en PEEK 450G semicristalino

de menor dimensión entre las ramificaciones de las lamelas, esto ocasiona que los espaciados (L, parámetro del que se está obteniendo la estimación) sean inferiores y por tanto esa dimensión entre planos se observe algo inferior.

Analizando el material que se colocó sobre la mesa a $473 K$ es posible detectar un comportamiento muy diferente respecto a los demás en cualquiera de los planos, esto sugiere el siguiente efecto: ese material presenta una cristalización en frío, teniendo el material baja movilidad para ordenarse. El material en ISC experimenta un proceso diferente, la primera capa borra su historia térmica durante la primera pasada del láser y se enfría desde fusión hasta la temperatura de mesa (superior a la transición vítrea) donde se mantiene hasta que se ejecute el encintado de la capa subsiguiente (orden de magnitud de minutos), es decir, experimenta un "jump" hasta aproximadamente $473 \mathrm{~K}$ y se cristaliza de modo isotermo a esa temperatura (partiendo de un estado que no es totalmente amorfo dada la alta capacidad para cristalizar del PEEK y los cortos tiempos de fusión).

Con la técnica XRD, ha sido posible detectar diferencias entre los laminados de ISC y prensa, así como dentro de una misma probeta de ISC variaciones entre su cara superior e inferior. No obstante, no ha sido posible asociar la variación detectada en $\left[\begin{array}{lll}1 & 1 & 1\end{array}\right]$ con una determinada posición u 


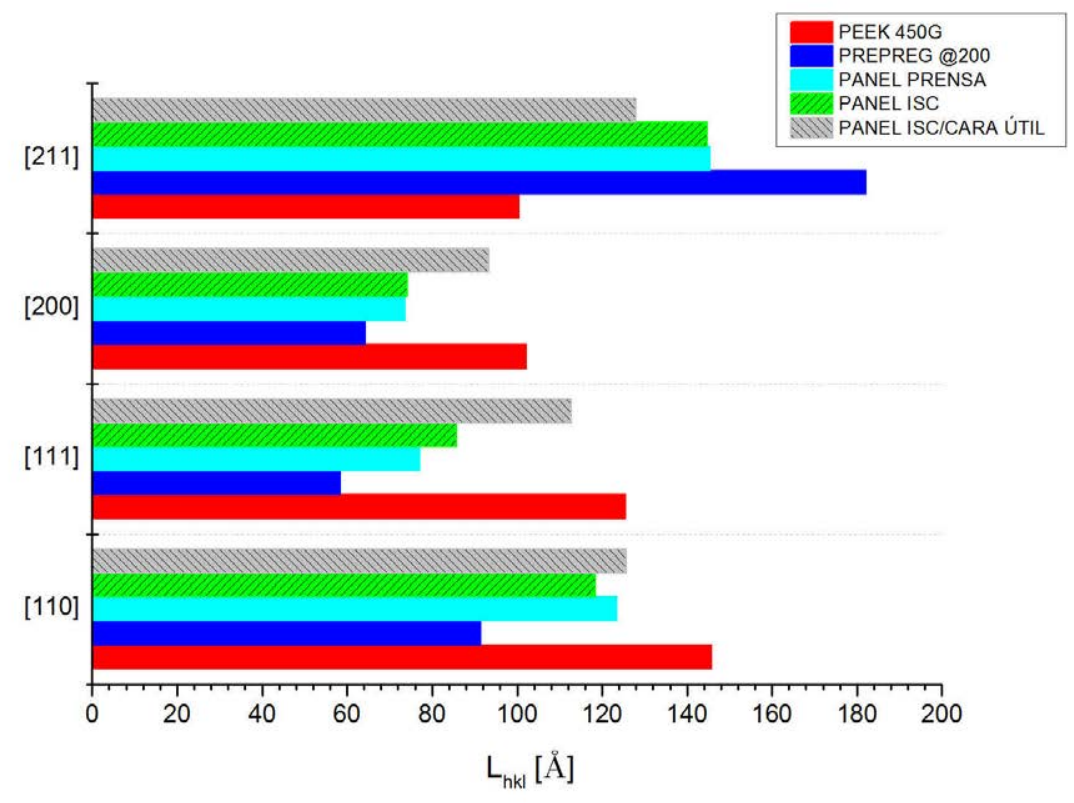

Figura 4.102: Comparativa dimensiones de cristales

orientación sobre la fibra en cada uno de los materiales.

Como trabajo futuro, sería de interés ejecutar nuevas mediciones sorbe paneles de ISC encintados en mesa fría o incluso sobre los diferentes escalones de las probetas mostradas en los apartados previos. 


\subsubsection{Modelos de cristalización}

Considerando la información del estado del arte y los análisis elaborados en la determinación experimental de cristalización, se pretende ejecutar ahora una modelización matemática de este proceso. Factores influyentes en el mismo serán los efectos de cambio de morfología por la velocidad de enfriamiento y también la presencia de la fibra de carbono, actuando como nucleante.

Con el fin de simplificar el análisis y entender con mayor precisión qué ocurre con el PEEK durante la cristalización, se ha ensayado de modo independiente el polímero neto (considerando diferentes pesos moleculares PEEK 150G y PEEK 450G) y material preimpregnado (APC2/AS4). Tal como ocurría con la reología, el desconocimiento del peso molecular del APC2 ha hecho que se estimara necesario el análisis en cristalización de los dos pesos moleculares disponibles, $150 \mathrm{G}$ y $450 \mathrm{G}$.

En una comparación sobre los ensayos ejecutados en PEEK 450G y PEEK 150G (Figura C.10), se puede observar como el material de más bajo peso molecular (PEEK 150G) cristaliza antes que el de mayor peso molecular (PEEK 450G), con unos $10 K$ de diferencia en los valores del onset extrapolado de cristalización y para un ensayo a la misma velocidad de enfriamiento: $20 \mathrm{~K} / \mathrm{min}$ (partiendo ambos de un mismo estado de fusión completa de muestra). La causa de este efecto es la mayor facilidad de la cadena polimérica más corta para desplazarse en la formación de la estructura ordenada de cristal.

Teniéndose en cuenta el gráfico de la Figura C.12, donde se presenta la tendencia decreciente del inicio de la cristalización motivada por la mayor velocidad de enfriamiento en APC2/AS4, es posible observar que el ensayo a $20 \mathrm{~K} / \mathrm{min}$ presenta un "onset extrapolado" de cristalización de $574,50 \mathrm{~K}$. Teniendo en consideración que la fibra de carbono tiene un efecto acelerante sobre la cristalización, parece que el polímero en el APC2/AS4, debiera asemejarse más al de alto peso molecular, los valores se adjuntan en la Tabla 4.13 .

En todos los casos de enfriamiento (diferentes velocidades), comparando APC2/AS4 contra el PEEK 450G, la cristalización en el material preimpregnado ocurre de modo anticipado a la del polímero neto. 


\begin{tabular}{|c|c|c|c|}
\hline $\begin{array}{c}\text { Onset extrapolado } \\
\text { de cristalización }\end{array}$ & PEEK 150G & PEEK 450G & APC2/AS4 \\
\hline$[K]$ & 579,47 & 569,42 & 574,50 \\
\hline
\end{tabular}

Tabla 4.13: Onset extrapolado de cristalización en el enfriamiento a 20K/min tras fusión completa para PEEK 150G, PEEK 450G y APC2/AS4

\subsubsection{Modelo de Avrami en PEEK}

Existen diversos modelos focalizados en la descripción matemática de la evolución de la cristalinidad en estos materiales. El punto de partida habitual suele ser el empleo del modelo de Avrami, Ecuación 4.58 que se basa en la información obtenida de ensayos bajo condiciones isotermas.

$$
\alpha=1-\exp \left(-\left(K^{n} t^{n}\right)\right.
$$

El análisis a aplicar bajo las consideraciones de este modelo, se presenta aquí sobre los ensayos con PEEK 150G, incluyéndose posteriormente la información del resultado de su aplicación a ambos pesos moleculares $150 \mathrm{G}$ y 450G. Las isotermas empleadas para el estudio con PEEK 150G fueron 593, $594,595,597$ y $599 K\left(320,321,322,324\right.$ y $\left.326^{\circ} C\right)$. Sobre PEEK $450 \mathrm{G}$ fueron empleados otros valores de temperatura de ensayo: 595, 596, 597 y $598 K$.

En la ecuación de Avrami (4.58), " $\alpha$ ", es la cristalinidad relativa o conversión, una función tempo-dependiente cuya extracción se ha ejecutado con la herramienta "running integral" del software TA Universal Analysis, como se ilustra la Figura 4.103 La Figura 4.104, contiene la representación de la evolución de la conversión (en porcentual) con el tiempo para todos los programas isotermos considerados.

En la representación de 4.104 se ha trabajado bajo la suposición de que en todos los casos se alcanza una conversión final del $100 \%$, esa suposición no es estrictamente realista sabiendo que cada programa de enfriamiento genera un \% de cristalización propio. En el gráfico se destaca también la gran diferencia entre los tiempos para completar la cristalización en PEEK 150G (30 min) y PEEK 450G (130 min).

Como puede detectarse en la Figura 4.104 a mayor temperatura isoterma de cristalización más se retrasa el inicio de la cristalización. 


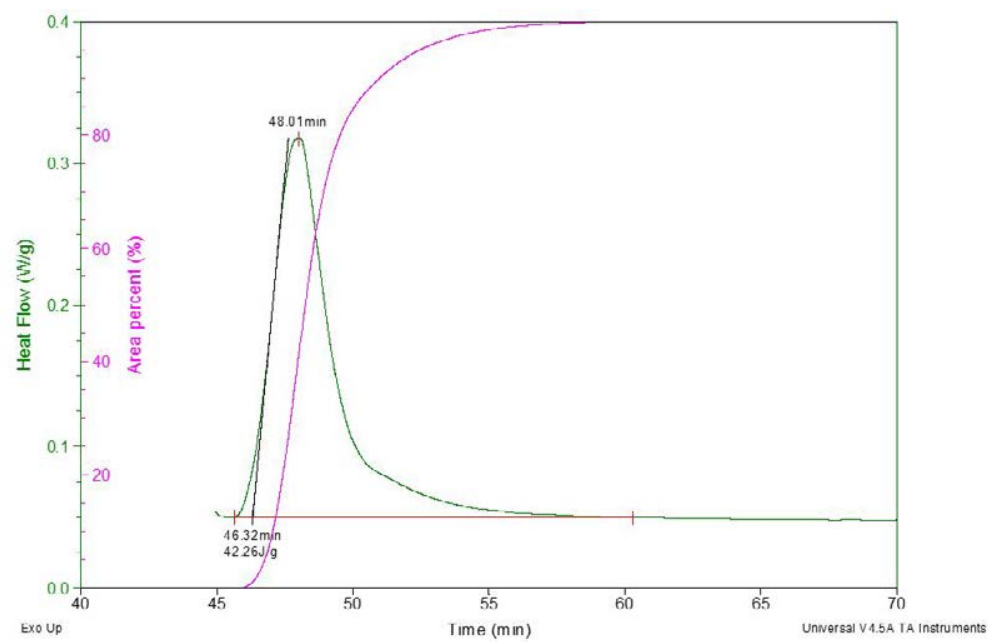

Figura 4.103: Evolución de la cristalinidad relativa en PEEK 150G en su enfriamiento isotermo a $@ 593 K\left(320^{\circ} \mathrm{C}\right)$

Si sobre la ecuación de Avrami (4.58) se toman logaritmos (estimando ahora una evolución de la conversión desde 0 a 1), se obtiene una expresión como la representada por la Ecuación 2.64. Representando en un gráfico $\ln [-\ln (1-\alpha)]$ frente a $\log (t)$ se obtendría una línea recta cuya pendiente daría como valor del índice de Avrami. La aplicación a PEEK 150G se recoge en el gráfico de la Figura 4.105 ; como es detectable, en la representación existe un tramo amplio inicial de inducción al proceso de cristalización que debe obviarse en los análisis, tras dicho tramo, todas las curvas presentan una pendiente similar y en el entorno de 3 . El anterior valor es característico de formaciones tridimensionales, por su parte, el segundo tramo de la curva presenta una pendiente inferior, próxima a 1, asociada a las formaciones cristalinas que se generan entre las ramificaciones de las esferulitas de la formación principal. 


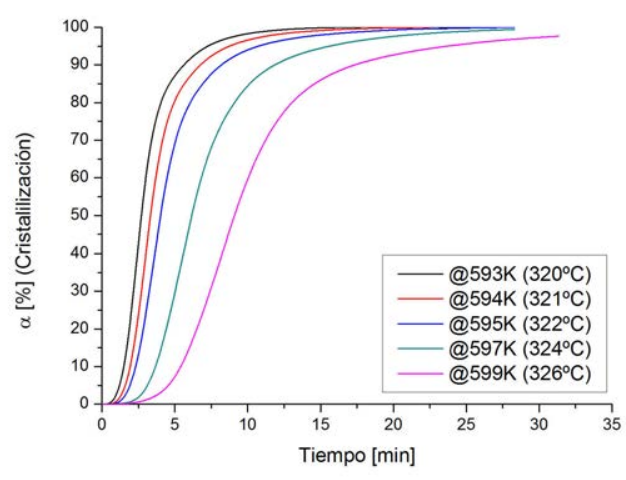

(a)

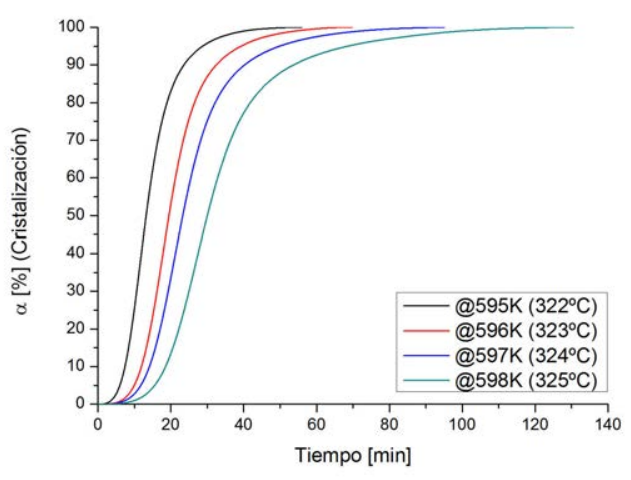

(b)

Figura 4.104: Evolución de la cristalinidad relativa con el tiempo enfriando bajo diferentes programas isotermos (a) PEEK 150G y (b) PEEK 450G

En las Tablas 4.14 y 4.15 se reportan los valores del índice de Avrami para el primer proceso, estimados considerando un rango de conversión evolucionando entre $1 \%$ y $50 \%$ para PEEK $150 \mathrm{G}$ (el cambio en la tendencia entre procesos se aproxima al $70 \%$ de la conversión) y para PEEK 450G. Los valores son elevados respecto a los reportados bibliográficamente, probablemente por el amplio rango de conversión considerado. En la tabla se ha considerado de interés incluir el tiempo transcurrido desde el inicio de la cristalización hasta alcanzarse el $50 \%$ de la misma para cada isoterma de ensayo.

\begin{tabular}{|c|c|c|c|c|}
\hline Temperatura $[\mathrm{K}]$ & $\begin{array}{c}\text { PEEK 150G } \\
t_{1 / 2}[\mathrm{~min}]\end{array}$ & $\begin{array}{c}\text { PEEK 150G } \\
n_{\text {Avrami } 1}\end{array}$ & $\begin{array}{c}\text { PEEK 150G } \\
k_{\text {Avrami }}\left[s^{-n}\right]\end{array}$ & $R^{2}$ \\
\hline 593 & 2,71 & 3,29 & $5,58 \cdot 10^{-3}$ & 0,999 \\
\hline 594 & 3,34 & 3,86 & $4,79 \cdot 10^{-3}$ & 0,999 \\
\hline 595 & 4,03 & 3,76 & $3,94 \cdot 10^{-3}$ & 0,999 \\
\hline 596 & - & - & - & - \\
\hline 597 & 6,17 & 4,09 & $2,56 \cdot 10^{-3}$ & 0,999 \\
\hline 598 & - & - & - & - \\
\hline 599 & 9,10 & 3,86 & $1,70 \cdot 10^{-3}$ & 0,999 \\
\hline
\end{tabular}

Tabla 4.14: Índice-k de Avrami y $t_{1 / 2}$ en PEEK 150G

La aplicación de Avrami, no ha permitido extraer un modelo para determinar la evolución de la cristalización en el APC2/AS4 durante el proceso de laminación automática y consolidación in-situ, pero sí ha permitido conocer el hecho de que ésta transcurre a través doble proceso basado en formaciones tridimensionales iniciales seguidas por una formación de menor dimensión 


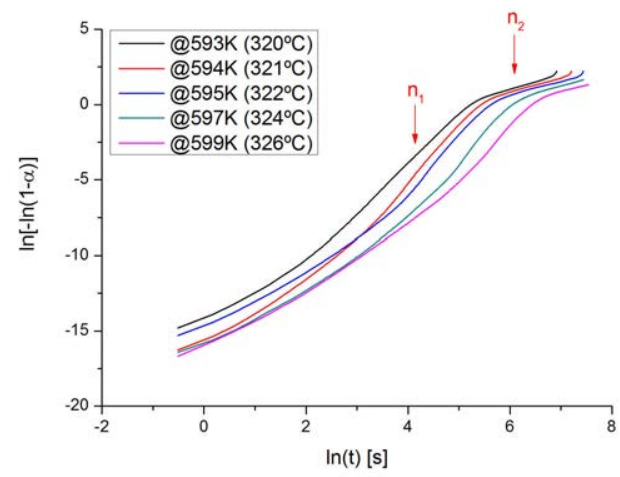

(a)

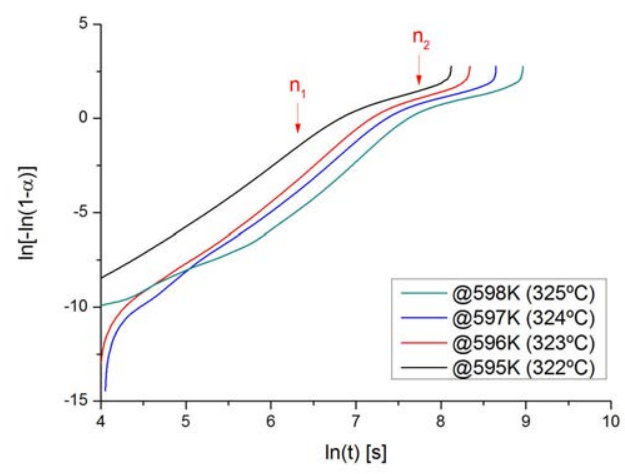

(b)

Figura 4.105: Obtención del índice de Avrami en ensayos isotermos sobre (a) PEEK 150G y (b) PEEK 450G

\begin{tabular}{|c|c|c|c|c|}
\hline Temperatura [K] & $\begin{array}{c}\text { PEEK 450G } \\
t_{1 / 2}[\mathrm{~min}]\end{array}$ & $\begin{array}{c}\text { PEEK 450G } \\
n_{\text {Avrami } 1}\end{array}$ & $\begin{array}{c}\text { PEEK 450G } \\
k_{\text {Avrami }}\left[s^{-n}\right]\end{array}$ & $R^{2}$ \\
\hline 593 & - & - & - & - \\
\hline 594 & - & - & - & - \\
\hline 595 & 13,23 & 3,34 & $1,16 \cdot 10^{-3}$ & 0,999 \\
\hline 596 & 19,49 & 3,91 & $7,79 \cdot 10^{-4}$ & 0,999 \\
\hline 597 & 23,29 & 3,82 & $6,52 \cdot 10^{-4}$ & 0,999 \\
\hline 598 & 30,03 & 3,99 & $5,14 \cdot 10^{-4}$ & 0,999 \\
\hline 599 & - & - & - & - \\
\hline
\end{tabular}

Tabla 4.15: Índice-k de Avrami y $t_{1 / 2}$ en PEEK 450G

entre los espacios de la primera.

\subsubsection{Modelo de Avrami modificado por Jeziorny en PEEK}

En la laminación automática, los perfiles de enfriamiento impuestos son fundamentalmente dinámicos, rampas de enfriamiento muy bruscas cuando el rodillo contacta con el material (también hay efectos de cristalización en isotermo por la temperatura del útil y de cristalización en frío durante los recalentamientos de capas. Considerando enfriamientos en dinámico, también se ha analizado qué ocurre sometiendo al material a diferentes rampas de enfriamiento; en estas situaciones, no se hace posible emplear la ecuación de Avrami, sino que la estimación del índice se debe ejecutar bajo la utilización de métodos como el de Ozawa. En la revisión del estado del arte se incluye- 
ron diversas referencias que afirman la imposibilidad de aplicar este método al caso particular del PEEK, descartándose su empleo en este trabajo. Se ha empleado el análisis por medio de la ecuación modificada de Avrami por Jeziorny, Ecuación 4.59 extraída del trabajo de (Wang et al., 2013).

$$
\alpha=1-\exp \left(-\left(Z_{t} t^{n}\right)\right.
$$

En la ecuación anterior, $\alpha$ representa el porcentaje de cristalización relativa, $n$ es el índice/exponente de Avrami y $Z_{t}$ es la constante de velocidad de reacción de Avrami, que debe modificarse por $Z_{c}$, presentando la relación indicada por la Ecuación 4.60 con la velocidad del programa de enfriamiento dinámico $(\beta)$.

$$
\log \left(Z_{t}\right)=\log \left(Z_{c}\right) \cdot \beta
$$

El procedimiento de trabajo para este análisis fue igual al empleado en el caso isotermo, aunque en este caso los gráficos representativos proceden de ensayos en modo dinámico y son dependientes de la temperatura, como indica la Figura 4.106

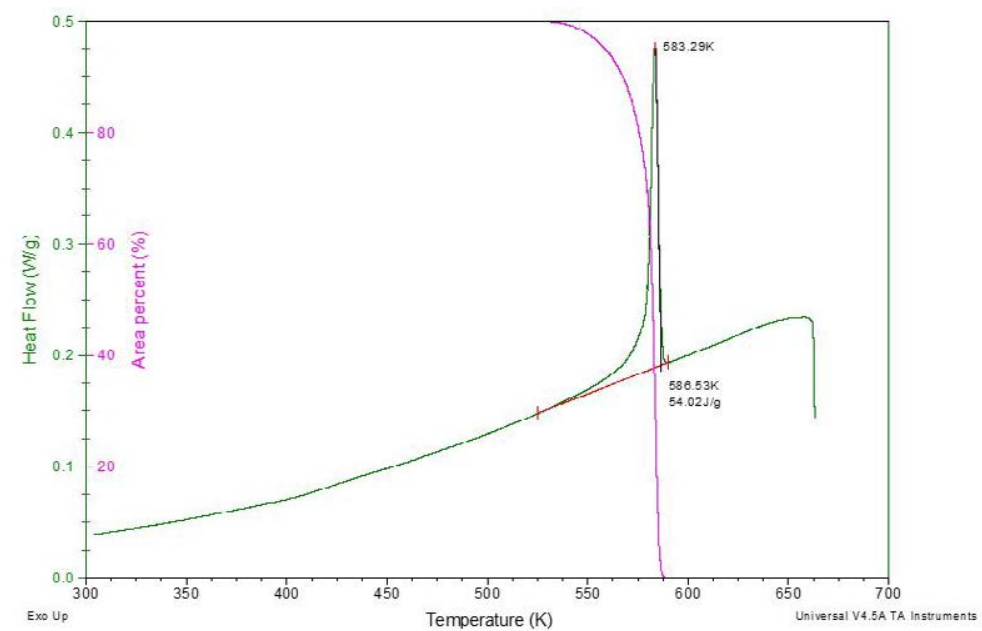

Figura 4.106: Evolución de la cristalinidad relativa en PEEK 450G en su enfriamiento dinámico a $2 K /$ min

Comparando los resultados sobre PEEK 150G y PEEK 450G (Figura 4.107), es posible observar como para las mismas velocidades, la cristalización del PEEK 150G adelanta a la del PEEK 450G, apareciendo a tempera- 
turas superiores a las registradas por el de mayor peso molecular.

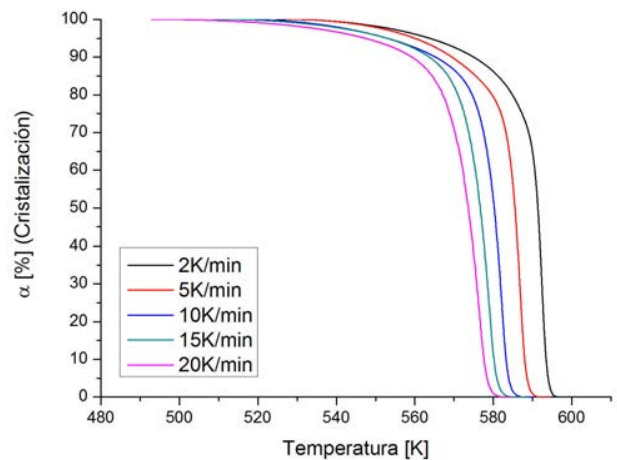

(a)

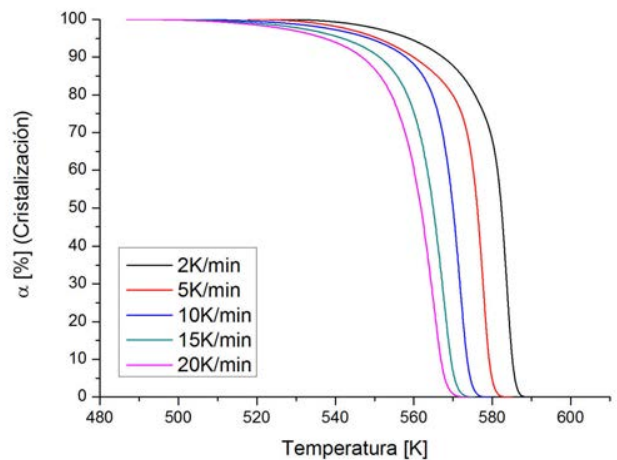

(b)

Figura 4.107: Evolución de la cristalinidad relativa con la temperatura enfriando con diferentes programas dinámicos (a) PEEK 150G y (b) PEEK $450 \mathrm{G}$

La representación ejecutada en la aplicación de Avrami modificado se incluye en los gráficos de la Figura 4.108 para el PEEK 150G y Figura 4.108p para el PEEK 450G. Tras ejecutar los ajustes lineales en los dos tramos de las curvas, se obtuvieron valores para el primer tramo que carecían de sentido físico respecto al proceso analizado. Se incluirán en la Tabla 4.16 los valores de los $t_{1 / 2}$ para ambos materiales, PEEK $150 \mathrm{G}$ y $450 \mathrm{G}$.

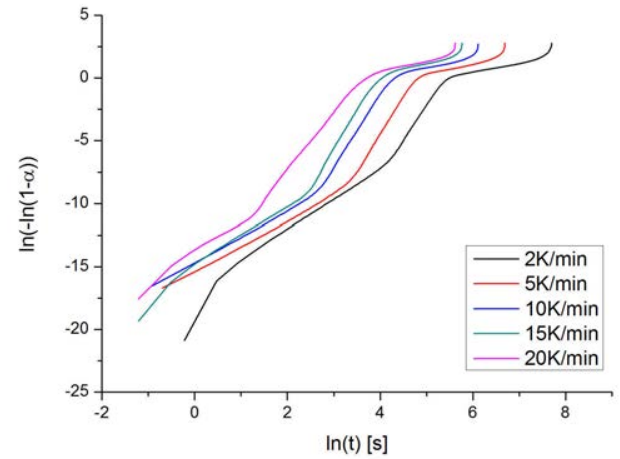

(a)

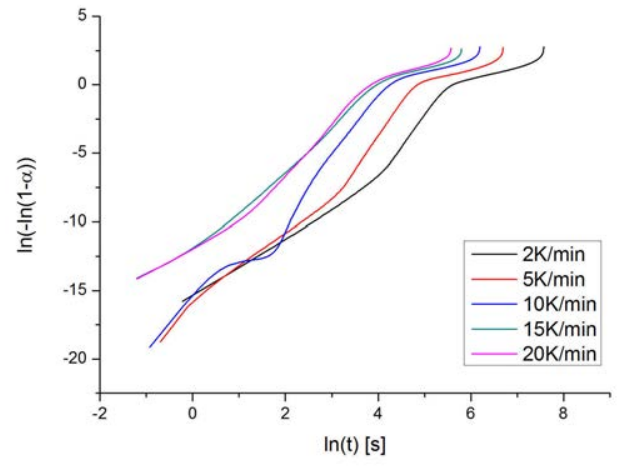

(b)

Figura 4.108: Obtención del índice de Avrami modificado en ensayos dinámicos sobre PEEK 150G y PEEK 450G 


\begin{tabular}{|c|c|c|}
\hline Velocidad [K/min] & $\begin{array}{c}\text { PEEK 150G } \\
t_{1 / 2}[\mathrm{~min}]\end{array}$ & $\begin{array}{c}\text { PEEK 450G } \\
t_{1 / 2}[\mathrm{~min}]\end{array}$ \\
\hline 2 & 3,55 & 3,89 \\
\hline 5 & 1,87 & 1,87 \\
\hline 10 & 1,12 & 1,04 \\
\hline 15 & 0,84 & 0,76 \\
\hline 20 & 0,60 & 0,68 \\
\hline
\end{tabular}

Tabla 4.16: $t_{1 / 2}$ en PEEK 150G y PEEK 450G

\subsubsection{Modelo de Avrami en APC2/AS4}

Considerando ahora el material reforzado con fibra de carbono, también fueron ejecutados ensayos en modo isotermo $(591,593,595$ y $591 K)$ y dinámico $(2,5,10,15,20$ y $30 \mathrm{~K} / \mathrm{min})$ para comprobar el impacto de la fibra de carbono sobre el proceso de cristalización. Los tiempos requeridos para alcanzar el $50 \%$ de cristalización $\left(t_{1 / 2}\right)$ se recogen en la Tabla 4.17 para condiciones de ensayo isotermas y en la Tabla 4.18 para condiciones dinámicas. El ensayo a $10 \mathrm{~K} / \mathrm{min}$ se descartó de la representación por presentar en dos repeticiones del mismo un comportamiento fuera de la tendencia esperada.

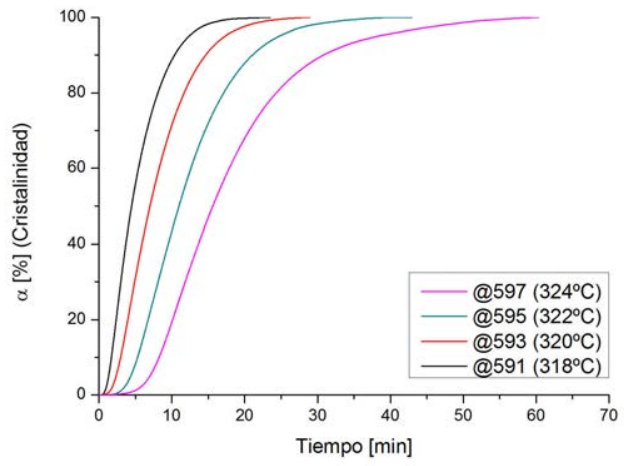

(a)

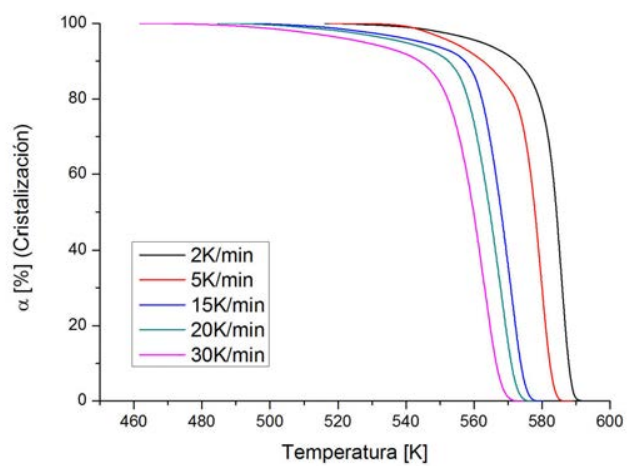

(b)

Figura 4.109: Evolución de la cristalización relativa en enfriamientos (a) isotermos y (b) dinámicos en APC2/AS4

Como resumen, se han recogido en los gráficos de la Figura 4.110 los tiempos obtenidos de los ensayos en los que se alcanza el $50 \%$ de la cristalización bajo condiciones dinámicas e isotermas sobre los dos pesos moleculares del PEEK y sobre APC2/AS4. 


\begin{tabular}{|c|c|c|c|}
\hline Temperatura $[\mathrm{K}]$ & $\begin{array}{c}\text { APC2/AS4 } \\
t_{1 / 2}[\mathrm{~min}]\end{array}$ & $\begin{array}{c}\text { APC2/AS4 } \\
n_{\text {Avrami } 1}\end{array}$ & $R^{2}$ \\
\hline 591 & 4,48 & 3,36 & 0,999 \\
\hline 593 & 7,01 & 3,05 & 0,996 \\
\hline 595 & 10,99 & 4,07 & 0,999 \\
\hline 597 & 15,63 & 4,22 & 0,999 \\
\hline
\end{tabular}

Tabla 4.17: $t_{1 / 2}$ en ensayos isotermos sobre APC2/AS4

\begin{tabular}{|c|c|}
\hline Velocidad [K/min] & $\begin{array}{c}\text { APC2/AS4 } \\
t_{1 / 2}[\mathrm{~min}]\end{array}$ \\
\hline 2 & 4,76 \\
\hline 5 & 2,23 \\
\hline 10 & - \\
\hline 15 & 0,85 \\
\hline 20 & 0,68 \\
\hline 30 & 0,52 \\
\hline
\end{tabular}

Tabla 4.18: $t_{1 / 2}$ en ensayos dinámicos sobre APC2/AS4

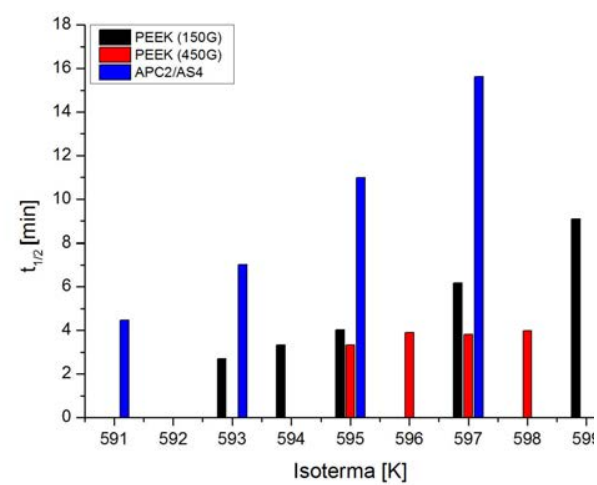

(a)

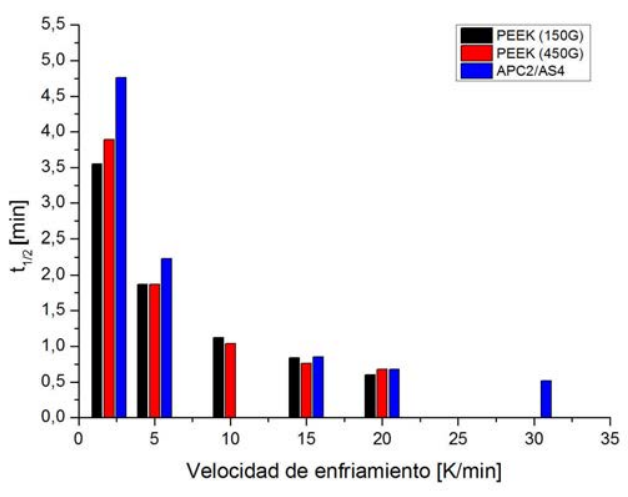

(b)

Figura 4.110: Tiempos para alcanzar el $50 \%$ de la cristalización en PEEK 150G, PEEK 450G y APC2/AS4 con (a) condiciones isotermas y (b) condiciones dinámicas

Además de los ensayos anteriormente incluidos, se considera de interés conocer cómo se produce la cristalización en frío, durante los calentamientos del material APC2/AS4 tomando como partida su estado "as received", prácticamente amorfo. En el comienzo del capítulo ya se indicó que los in- 
crementos de velocidad en calentamiento del material desde su estado "as received" provocaban que el pico exotérmico de cristalización en frío se desplazara hacia mayores temperaturas (Figura C.11), se reporta en la Figura 4.111 la evolución de la conversión con la temperatura para los programas de calentamiento $2,5,10,15,20$ y $30 \mathrm{~K} / \mathrm{min}$.

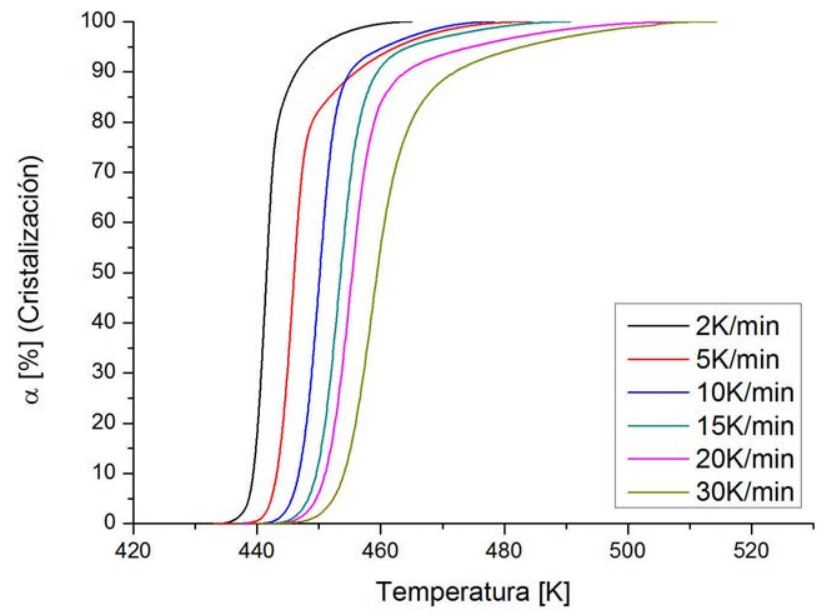

Figura 4.111: Evolución de la cristalinidad relativa en APC2/AS4 en su calentamiento dinámico

\subsubsection{Modelos predictivos del porcentaje de cristalización}

En el proceso de laminación en automático y consolidación in-situ, el calentamiento/enfriamiento experimentado por el material, consiste en un proceso complejo que, como trató de explicarse con anterioridad, también se ve afectado por el hecho de trabajar o no con un utillaje auto-calefactado. Las características del proceso hacen que sea muy complejo desarrollar un modelo de evolución de cristalización que describa con precisión todos los efectos que interactúan.

Considerando un laminado ejecutado con utillaje frío y recurriendo a los perfiles tiempo-temperatura del gráfico de la Figura 4.19 la cristalización en la primera capa debería estudiarse bajo las siguientes consideraciones: calentamiento hasta fusión donde se elimina todo el germen cristalino del material (se ejecuta como hipótesis que todo funde), seguido por un proceso de enfriamiento a unos $10000 \mathrm{~K} / \mathrm{min}$ (imposible de reproducir con los equipos del laboratorio existentes), quedando el $\mathrm{APC} 2 / \mathrm{AS} 4$ con una cristalización de 
un X\%. Según el perfil tiempo-temperatura, la primera capa fundirá nuevamente por completo al encintar la 3, luego el proceso anterior se repetirá. Desde el encintado de la capa 4 ya no se supera la temperatura de fusión de equilibrio y el material no se funde al $100 \%$. El residuo que queda de esa fusión incompleta, altera la cinética de cristalización posterior, efecto que no va a poder ser modelizado tomando en consideración los resultados de los ensayos elaborados y previamente incluidos al comienzo de esta sección. Desde la capa 6 y en adelante, si el material desarrolla cristalinidad será por el calentamiento sobre la $T_{g}$ pero no por su enfriamiento; en este caso además ocurrirá como en el caso reportado para el enfriamiento, la cristalización ya se inició anteriormente por lo que no es una cristalización en frío partiendo de un estado amorfo previo sino que dependerá de la estimación del porcentaje de cristal generado con anterioridad.

Se pretende encontrar en este apartado una ecuación matemática capaz de aproximar el valor de cristalización obtenido bajo ciertas condiciones de proceso (tiempo-temperatura), para ello se presentarán dos desarrollos. El primero de los desarrollos se basará en ejecutar deconvoluciones y ajustes lineales basados en la ecuación cinética general, tal como se hiciera con la cinética de degradación en la sección 4.2.2 el segundo de los análisis tendrá en cuenta los modelos bibliográficos de cristalización basados en la consideración de un mecanismo tipo "doble Avrami".

Tratando de aplicar un análisis semejante al elaborado para la cinética de degradación por termogravimetría, se recurrió nuevamente a la ecuación cinética general, tratando de definir un triplete cinético para cada uno de los mecanismos que intervienen en el proceso de cristalización, previa definición de los mismos por medio de la deconvolución de las curvas exotérmicas de cristalización. La aplicación de dicha metodología se encuentra aquí con más problemáticas que en la aplicación que se hizo al proceso de degradación. En la degradación, se establecía una evolución de conversión de modo tal que todos los ensayos tenían asociado un $100 \%$ de conversión cuando toda la masa de la muestra desaparecía. En la cristalización, la conversión se ha representado como la evolución de la integral del pico exotérmico para cada instante o temperatura (en caso isotermo o dinámico) en relación con el valor del área total del pico.

Ya se indicó en el estudio cinético de degradación, que se recurría al análisis sobre el polímero neto por las problemáticas para aplicar un estudio de este tipo sobre un material reforzado (cada muestra puede portar porcentajes diferentes alterando los resultados). Ejecutar una simplificación a resina neta para el caso de cristalización no impacta en un resultado conservativo sino que altera el análisis por no permitir tener en consideración los efectos 
de cristalización motivados por la presencia de la fibra de carbono en el conjunto.

El proceso de deconvolución de los picos fue aplicado sobre los ensayos ejecutados sobre PEEK 450G y APC2/AS4. Dicho procedimiento, elaborado mediante el software Fityk y funciones asimétricas tipo Frase-Suzuki, mostró la necesidad de emplear 2 picos en la deconvolución de los ensayos sobre el PEEK neto, Figura 4.112. Los dos picos obtenidos están posiblemente asociados con los dos mecanismos de cristalización que ya se pudieron intuir tras la aplicación del método de Avrami (formaciones tridimensionales que chocan entre sí y conducen al desarrollo de formaciones de menor orden). En el caso del material compuesto, APC2/AS4, fueron necesarios 3 picos para conseguir una buena deconvolución de la exoterma general de cristalización, Figura 4.116 efecto probablemente motivado por el desarrollo de morfologías transcristalinas.

Para el caso del PEEK 450G, se emplearon los resultados de los ensayos de enfriamiento dinámico a 2, 5, 10 y $15 \mathrm{~K} / \mathrm{min}$, la Figura 4.112 recoge la representación de uno de los resultados tras la aplicación de la deconvolución de la curva para el caso particular de $15 \mathrm{~K} / \mathrm{min}$.

Una vez ejecutada la deconvolución para los 4 ensayos considerados, se ejecutó la representación conjunta de los picos asociados al primer y al segundo proceso para todos los programas de enfriamiento, Figura 4.113 . Se estableció para cada caso el área ocupada respecto a la total de la exoterma del ensayo, Figura 4.114. Del último gráfico se puede estimar una contribución variable de cada pico al proceso general, con unos valores promedio de $71,02 \%$ para el primero y $28,97 \%$ para el segundo. La anterior manifestación, revela un importancia predominante del proceso de nucleación y crecimiento de esferulita sobre el proceso de crecimiento tras su choque, efecto que no se espera que ocurra a altas velocidades de enfriamiento, provocando variaciones en estos \% de contribución que complican los procesos de análisis cinético.

Con los picos deconvolucionados, se utilizaron los métodos isoconversionales en la búsqueda de la energía de activación representativa de cada uno de ellos. La aplicación del método isoconversional de Friedman a ambos conjuntos de curvas no permitió obtener un valor constante de energía de activación en función de la conversión, con variaciones de hasta el $60 \%$ de su valor analizado de 0,1 a 0,9 de conversión.

La optimización con Mathcad para la obtención de los valores de los índices del modelo de reacción " $n$ " y " $m$ " considerando un rango de conversiones 


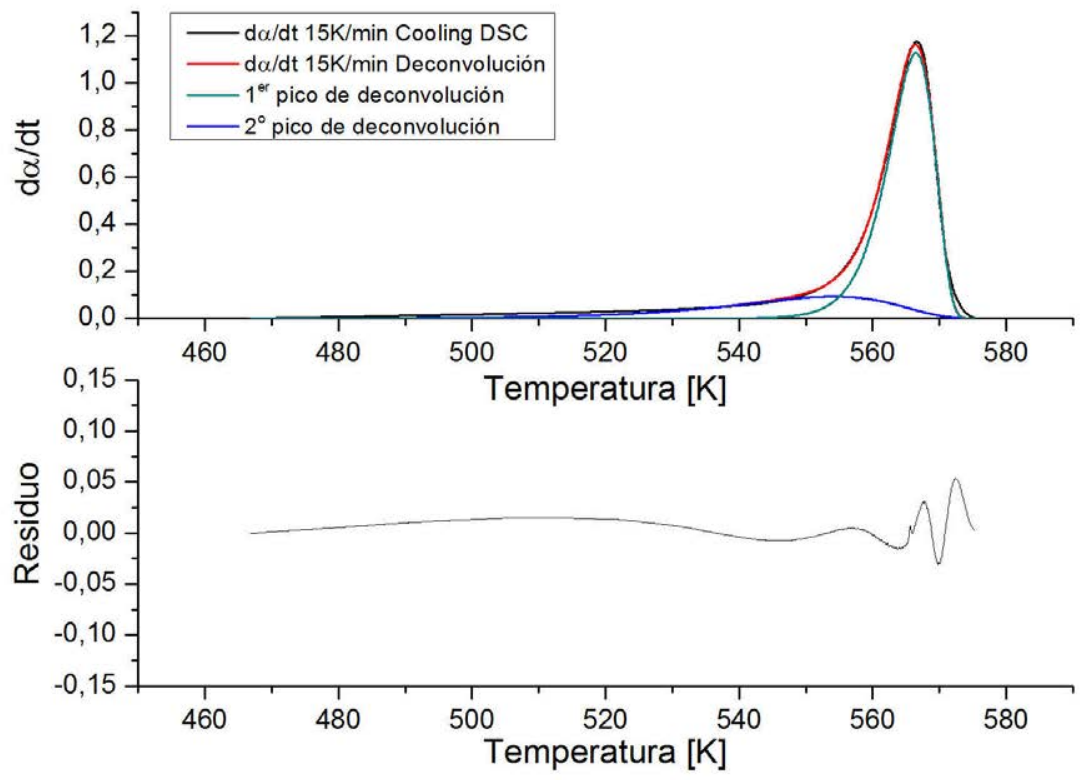

Figura 4.112: Deconvolución del pico exotermo de cristalización en PEEK $450 \mathrm{G}$ enfriando a $15 \mathrm{~K} / \mathrm{min}$

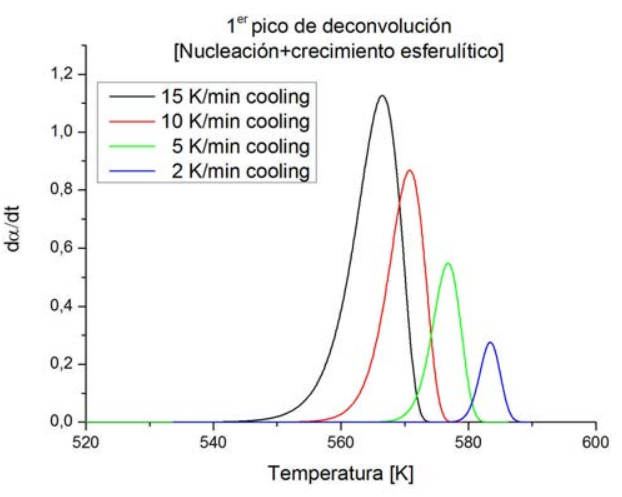

(a)

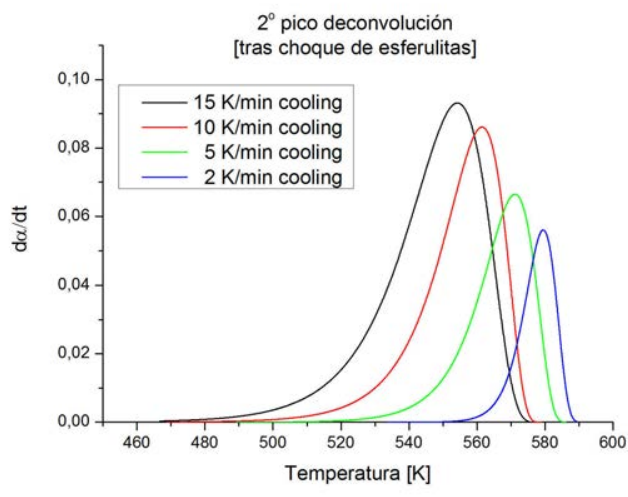

(b)

Figura 4.113: Deconvolución aplicada a PEEK 450G, (a) Primer pico - nucleación y crecimiento esferulítico y (b) Segundo pico - cristalización tras el choque de esferulitas

de 0,1 a 0,75 ha reportado unos valores iguales a: $n_{1}=1,225$ y $m_{1}=0,7$, con una energía de activación de valor: $E_{a 1}=-174,636 \mathrm{~kJ} / \mathrm{mol}$ (para el primer proceso) y $n_{2}=1,644$ y $m_{2}=0,553$, con una energía de activación de valor: 


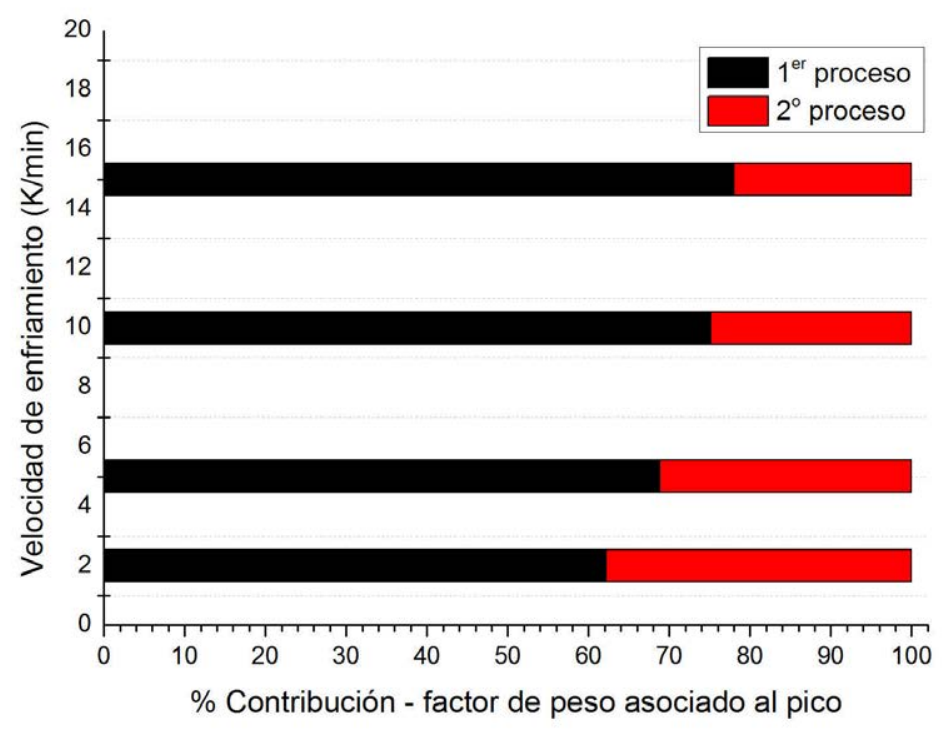

Figura 4.114: Factores de peso asociados a la deconvolución del PEEK 450G

$E_{a 2}=-84,13 k J / m o l$ (para el segundo proceso). En ambos casos, el ajuste ha generado un $R^{2}$ muy bajo como para poder asumirlo como solución del proceso de cristalización.

Entre las posibles causas de la falta de un buen ajuste, se considera la variación existente reportada en la Figura 4.114 relativa a las contribuciones de cada uno de los picos al proceso global. Asimismo, la estimación de una evolución de 0 al $100 \%$ en la conversión de todos los ensayos elaborados tiene un porcentaje de error al variar la cristalinidad final de la muestra en relación con el perfil de enfriamiento aplicado. La corrección para tal efecto debería pasar por, volver a calentar la muestra de la que es extraído el perfil exotérmico y establecer el porcentaje de cristalización real que se obtuvo durante el enfriamiento, ese valor supondrá un porcentaje respecto al máximo desarrollable por el material (que debería extraerse de un ensayo muy lento (la bibliografía reporta $37 \%$, que es el valor aproximado obtenido en el ensayo a $2 \mathrm{~K} / \mathrm{min}$ ). Teniendo en consideración dicho efecto e integrando el pico de fusión en un segundo ciclo de calentamiento, las conversiones oscilarían entre $(0-1)$ para $2 K / \min$, de $(0-0,965)$ para $5 K / \min$, de $(0-0,9411)$ para $10 K /$ min y de $(0-0,8751)$ para $15 K /$ min.

Desarrollando nuevamente los cálculos con la corrección del máximo de conversión alcanzable, el resultado obtenido tampoco mostró un buen ajuste, reportando valores de: $n_{1}=1,353$ y $m_{1}=0,726$, con una energía de activa- 
ción de valor: $E_{a 1}=-163,605 \mathrm{~kJ} / \mathrm{mol}$ y $n_{2}=1,88$ y $m_{2}=0,602$, con una energía de activación de valor: $E_{a 2}=-81,793 \mathrm{~kJ} / \mathrm{mol}$.

Viendo que esa modificación seguía sin permitir alcanzar un buen ajuste, se trataron de evaluar modificaciones que compensaran las desviaciones en los \% de contribución de los picos. Para ello, se elaboraron ensayos a mayor velocidad de enfriamiento, buscando alcanzar un comportamiento estable en los factores de peso que aplicaban a cada uno de los dos procesos. Los ensayos fueron ejecutados a 20,25, 30 y $50 \mathrm{~K} / \mathrm{min}$. Las exotermas fueron nuevamente deconvolucionadas (se incluye un ejemplo de la deconvolución para el caso a 30K/min en la Figura D.1 del apéndice D). La representación conjunta de los picos deconvolucionados se presenta en la Figura D.2 del mismo apéndice.

El resultado para estos programas de enfriamiento, muestra un comportamiento de las contribuciones en peso de cada uno de los picos más estable $\left(w_{1}=84,36 \%\right.$ y $\left.w_{2}=15,64 \%\right)$, siendo el primer proceso el más predominante aún a estas velocidades más elevadas.

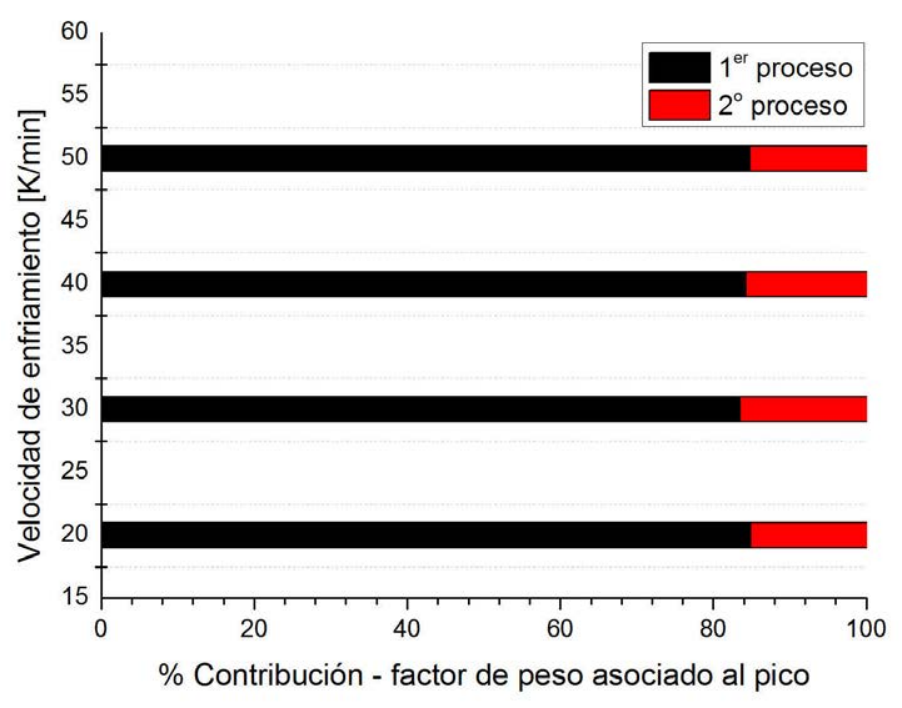

Figura 4.115: Factores de peso asociados a la deconvolución del PEEK 450G, programas de enfriamiento a mayor velocidad

Los índices de las reacciones de primer y segundo proceso, obtenidos por medio de Mathcad en el rango de análisis de conversión de 0 a 0,7 resultaron en: $n_{1}=1,796$ y $m_{1}=0,693$, con una energía de activación de valor: $E_{a 1}=-79,451 \mathrm{~kJ} / \mathrm{mol}$ y $n_{2}=2,616$ y $m_{2}=0,487$, con una energía de acti- 
vación de valor: $E_{a 2}=-120,049 \mathrm{~kJ} / \mathrm{mol}$. Las energías obtenidas por el método isoconversional de Friedman dieron valores semejantes $E_{a 1 \text { Friedman }}=$ $-87,63 \mathrm{~kJ} / \mathrm{mol}$ (desviación de $19,7 \%$ ) y $E_{a 1 \text { Friedman }}=-111,42 \mathrm{~kJ} / \mathrm{mol}$ (desviación de $4,16 \%)$.

A pesar de que los ensayos a mayores velocidades resultaron en mejores ajustes del proceso, siguen presentando desviaciones y resultan totalmente inestables para conversiones de 0,7 a 1 . Asimismo, la comparativa con los modelos típicos de reacción los asemeja por su forma a modelos tipo A-Avrami Erofeev, pero sin ofrecer un buen solape con las curvas que se obtendrían con la aplicación directa de las ecuaciones que definen estos modelos.

En la aplicación del anterior procedimiento a los ensayos ejecutados sobre APC2/AS4, se hizo necesario emplear 3 picos para el ajuste de la deconvolución, tal como se muestra en la Figura 4.116 y por tanto elaborar el procedimiento de optimización sobre los 3 picos de modo independiente.
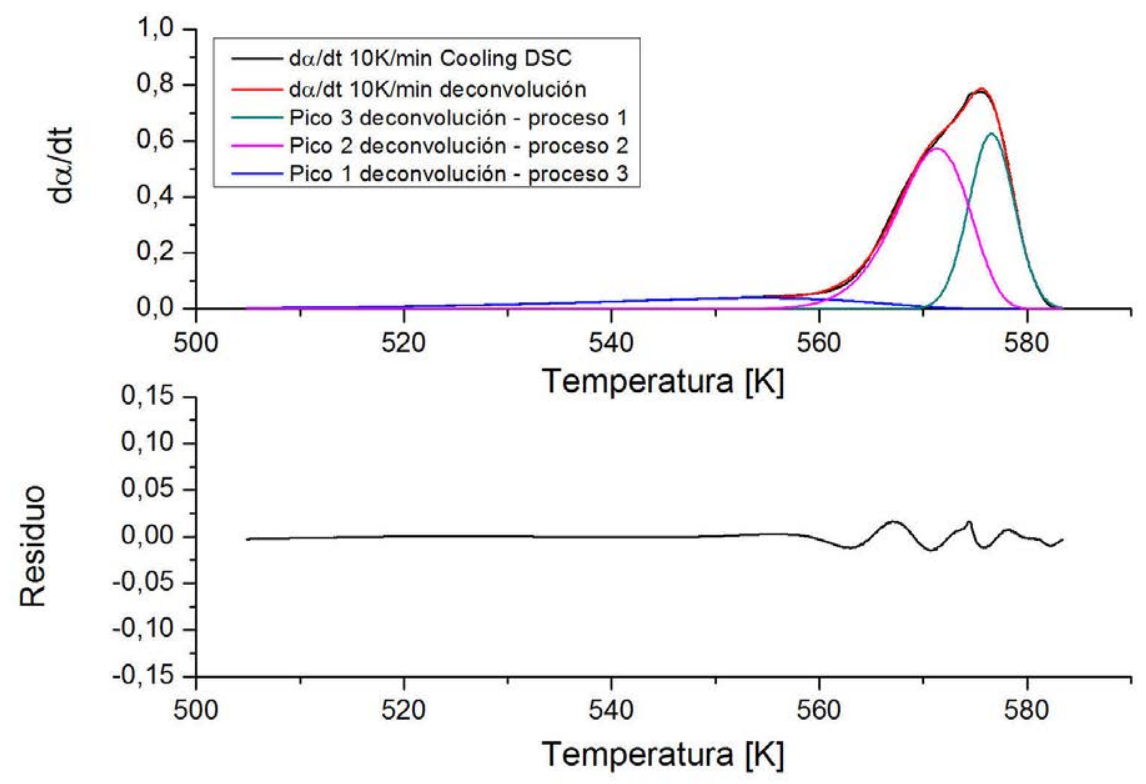

Figura 4.116: Deconvolución del pico exotermo de cristalización en APC2/AS4 enfriando a $10 \mathrm{~K} / \mathrm{min}$

Dada la dificultad para obtener buenos resultados en el primer y tercer proceso de cristalización empleando los cuatro programas de enfriamiento, se ejecutó la optimización excluyendo el programa de enfriamiento a $15 \mathrm{~K} / \mathrm{min}$ 
para esos dos casos.

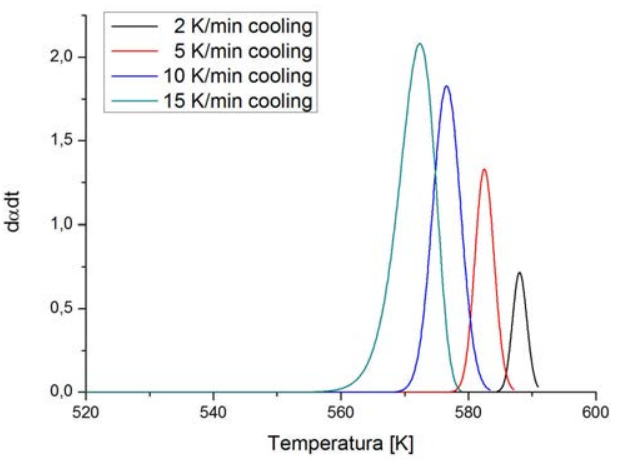

(a)

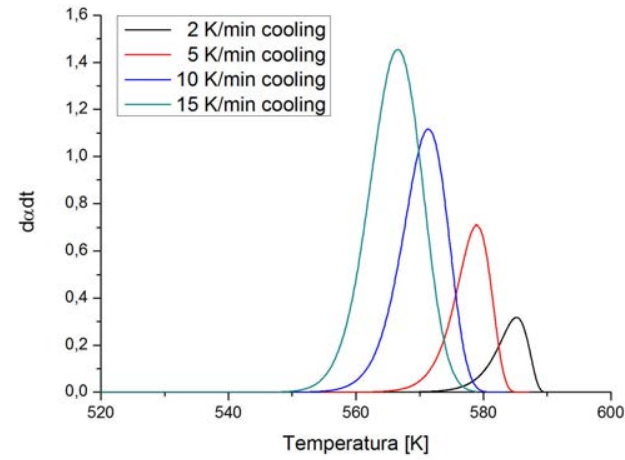

(b)

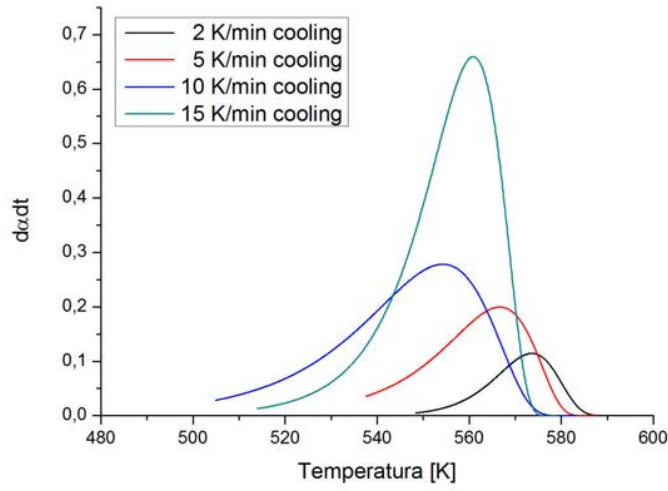

(c)

Figura 4.117: Deconvolución aplicada a APC2/AS4, (a) Primer pico - efectos de cristalización sobre AS4, (b) Cristalización esferulítica en el bulk, (c) Cristalización tras el choque de esferulitas 
Tal y como fue ejecutado con el material neto, se analizaron las contribuciones en peso generadas por cada uno de los picos de las deconvoluciones en cada programa de enfriamiento considerado, Figura 4.118 mostrando una clara variabilidad en función del programa de enfriamiento que está siendo aplicado.

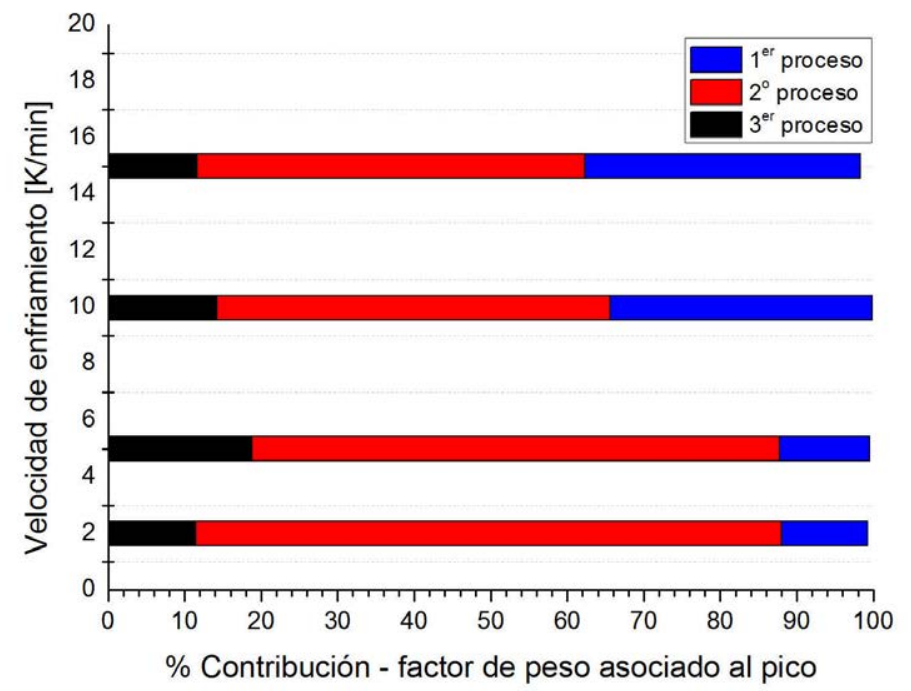

Figura 4.118: Factores de peso asociados a la deconvolución del APC2/AS4

Nuevamente fueron elaborados ajustes mediante Mathcad, cuya representación se ilustra en las Figuras 4.119 4.120 y 4.121 (para el rango de conversión de 0,1 a 0,9$)$.

Los valores numéricos asociados a los ajustes se recopilan en la Tabla 4.19. En la tabla puede observarse que existe un ajuste lineal pobre, con un valor de $R^{2}$ bajo. Estos valores, tampoco permitieron el acoplamiento con los resultados de los modelos de reacción teóricos recogidos por la bibliografía, donde se esperaban resultados asociados con crecimiento controlado por difusión (esferulítico y en forma de barra). 


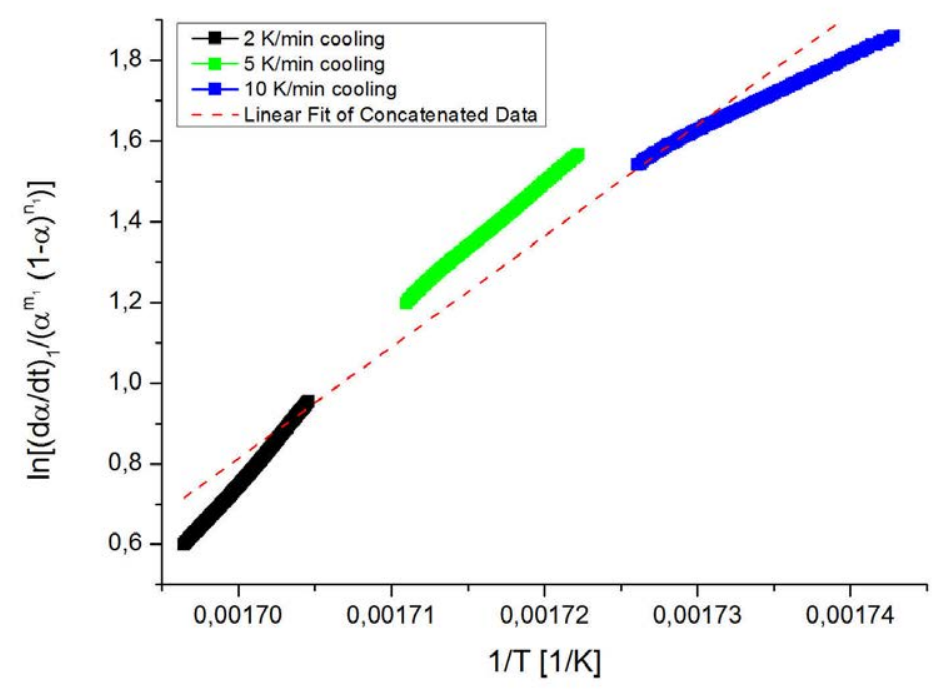

Figura 4.119: Ajuste lineal tras la aplicación de la optimización mediante el empleo de Sestak-Berggren Pico 1 en cristalización de APC2/AS4

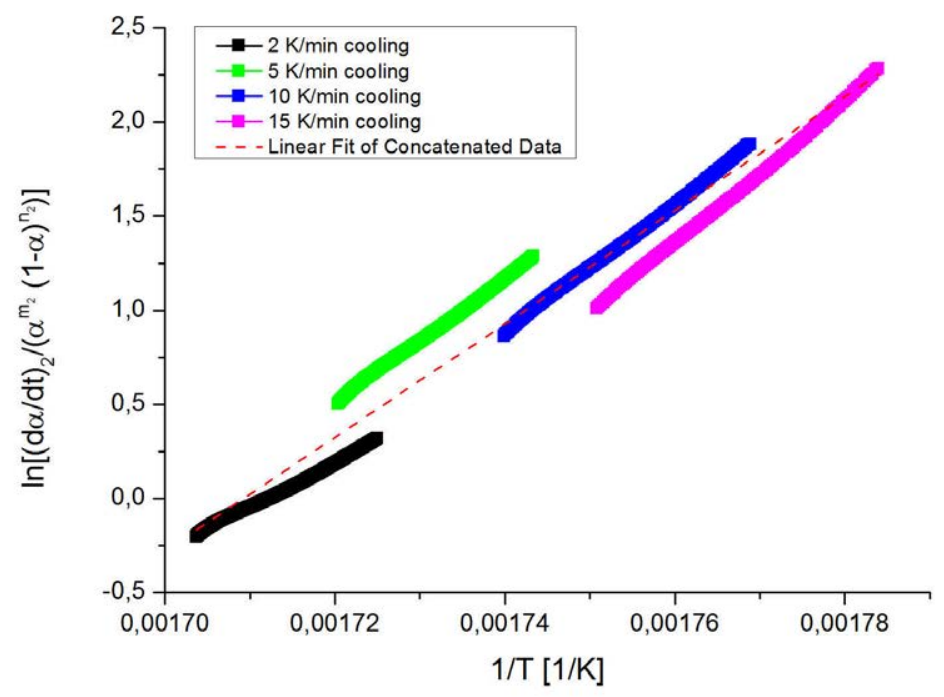

Figura 4.120: Ajuste lineal tras la aplicación de la optimización mediante el empleo de Sestak-Berggren Pico 2 en cristalización de APC2/AS4 


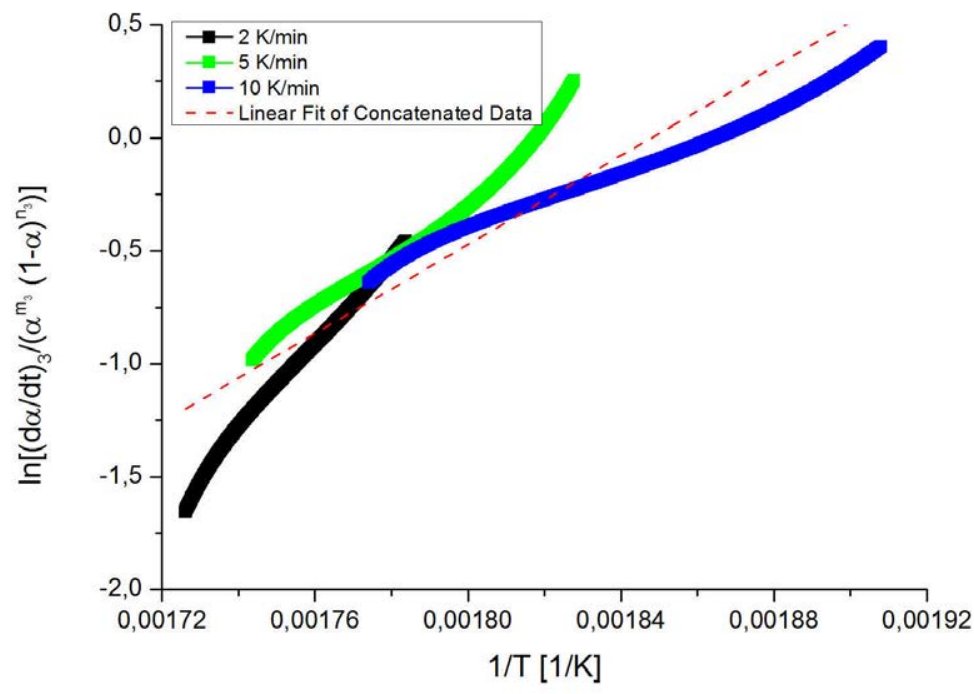

Figura 4.121: Ajuste lineal tras la aplicación de la optimización mediante el empleo de Sestak-Berggren Pico 3 en cristalización de APC2/AS4

\begin{tabular}{|c|c|c|c|c|}
\hline Proceso & $\mathrm{n}$ & $\mathrm{m}$ & $E_{a}[\mathrm{~kJ} / \mathrm{mol}]$ & $R^{2}$ \\
\hline 1 (Pico3) & 0,719 & 0,870 & $-228,842$ & 0,952 \\
\hline 2 (Pico2) & 0,525 & 1,221 & $-250,925$ & 0,953 \\
\hline 3 (Pico1) & 0,374 & 1,225 & $-81,762$ & 0,931 \\
\hline
\end{tabular}

Tabla 4.19: Parámetros del ajuste lineal para APC2/AS4

Recuperando los resultados de los trabajos de (Tierney y Gillespie Jr. 2004), se ha efectuado una comparativa de los valores de los factores de peso de los dos mecanismos de cristalización implicados en el proceso. Según la referencia bibliográfica y para el caso del PEEK, el primero de los procesos de cristalización (formación de esferulitas) tiene una contribución de un $10 \%$ para una velocidad próxima a $2 \mathrm{~K} / \mathrm{min}$ y se incrementa bruscamente hasta valores que evolucionan desde un 70 a un $75 \%$ entre 10 y $2700 \mathrm{~K} / \mathrm{min}$. Por su parte, para el material compuesto APC2/AS4 los autores indican que el valor de la contribución en peso del primer proceso de cristalización, considerado la formación de esferulitas, es de un $61 \%$, valor estable para velocidades iguales a $10 \mathrm{~K} / \mathrm{min}$ o superiores. En base a los resultados de este trabajo, se ha comprobado que en el caso del PEEK 450G, la contribución del primer proceso para $2 \mathrm{~K} / \mathrm{min}$ es de un porcentaje aproximado de $60 \%$ y se incrementa a un valor cercano al $85 \%$ para velocidades de hasta $50 \mathrm{~K} / \mathrm{min}$, 
sin embargo, no puede asegurarse que dicho valor permanezca estable con perfiles de enfriamiento tan acusados como los de la laminación automática y consolidación in-situ. Por su parte, en el APC2/AS4, las curvas parecen indicar la necesidad de evaluar el proceso en base a 3 sub-procesos constituyentes, siendo el tercero de ellos el menos importante. Respecto a los dos procesos predominantes y que suponen casi todo el área del pico de cristalización, se ha observado como existe un cambio en la tendencia haciéndose el primer proceso más predominante a medida que se incrementa la velocidad de enfriamiento, pero suponiendo una contribución observable de hasta un $40 \%$. Se ha podido comprobar que dicho valor sube hasta un $54 \%$ sobre un ensayo donde se impuso una rampa de enfriamiento de $30 \mathrm{~K} / \mathrm{min}$. Los valores obtenidos, están en consonancia con los mostrados en la referencia bibliográfica citada y son un reflejo de la importancia del primer proceso de cristalización frente al secundario al incrementarse las velocidades de enfriamiento.

Teniendo en cuenta los picos de fusión de los laminados fabricados en prensa y consolidación in-situ, de los dos picos observados en el laminado de la prensa se puede asociar el pico principal de fusión (que aparece en segundo lugar) con la fusión de la primera formación cristalina, es decir con el primer pico obtenido de la deconvolución, de mayor contribución porcentual al total. Por su parte, el hombro asociado al pico de fusión se relacionará con la fusión de las formaciones cristalinas obtenidas por el desarrollo de los picos 2 y 3 de la deconvolución (cuyo porcentaje de contribución será alto por tratarse de un proceso de enfriamiento cercano a $2 \mathrm{~K} / \mathrm{min}$ ).

En base a esa hipótesis, pudiendo monitorizar un enfriamiento como el del proceso de fabricación de la laminación automática y consolidación insitu, la deconvolución de su exoterma debería resultar en un pico con un área equivalente a prácticamente el total de la exoterma y una leve contribución de picos secundarios.

Toda la información obtenida de la aplicación del anterior proceso de análisis, se cree que no es suficiente para definir por completo el proceso cinético experimentado por el material durante la cristalización. La variabilidad de los resultados se considera un factor limitante para poder presentar un modelo basado en una ecuación matemática representativa, la cual, según el estudio realizado debería tener una formulación como en la Ecuación 4.61 para el APC2/AS4 a velocidades de enfriamiento en el entorno de los $20 K / \min$. Como puede deducirse de la ecuación, los factores de peso considerados son los obtenidos en la deconvolución del ensayo a $20 \mathrm{~K} / \mathrm{min}$, siendo por tanto no extrapolables para programas de enfriamiento a velocidades superiores, donde ya se ha observado que la contribución del primer pico se 
incrementaba hasta un $54 \%$ en un ensayo a $30 \mathrm{~K} / \mathrm{min}$.

La imposibilidad para ejecutar enfriamientos controlados a velocidades superiores a $60 \mathrm{~K} / \mathrm{min}$ (limitación del equipo de calorimetría) impide obtener datos precisos para la elaboración de este estudio. Futuros desarrollos derivados de esta tesis doctoral tratarán de localizar técnicas que permitan elaborar programas de enfriamiento más acusados.

$$
\begin{gathered}
\frac{d \alpha}{d t}=0,361\left(1,06 \cdot 10^{-20} \exp \left(\frac{228,84 \cdot 10^{3}}{R T}\right)\left(\alpha^{0,870}(1-\alpha)^{0,719}\right)\right)+ \\
0,507\left(4,05 \cdot 10^{-23} \exp \left(\frac{250,93 \cdot 10^{3}}{R T}\right)\left(\alpha^{1,221}(1-\alpha)^{0,525}\right)\right)+ \\
0,116\left(1,272 \cdot 10^{-8} \exp \left(\frac{81,76 \cdot 10^{3}}{R T}\right)\left(\alpha^{1,225}(1-\alpha)^{0,374}\right)\right)
\end{gathered}
$$

Considerando los trabajos propuestos por diversas referencias bibliográficas, donde se indica que la cristalización podría ser descrita mediante un acoplamiento de dos ecuaciones de tipo Avrami en paralelo o serie, se ha tratado de analizar la veracidad de los modelos sugeridos. Para ello han sido representados los resultados de la aplicación de modelos como los de Velisaris, Tierney o Cebe ((Quinlan 2011), Ecuaciones 4.63 y 4.62) y comparados con ensayos reales. Tal y como figura en (Velisaris y Seferis, 1986), el ajuste basado en la combinación en paralelo de Avrami, ha reportado los mejores resultados, de ahí que sólo se considere tal aproximación en los cálculos ejecutados. La ecuación con la que se trabajará se define de modo general como representa la Ecuación 4.62 para los casos de estudio de (Velisaris y Seferis, 1986) y (Tierney y Gillespie Jr., 2004) y como la Ecuación 4.63 para el caso de estudio de (Cebe 1988a).

$$
\begin{aligned}
\frac{\chi_{v c}}{\chi_{v c \infty}}= & \\
& w_{1}\left[1-\exp \left[-C_{11} \int_{0}^{t}\left(T \exp \left[-\frac{C_{21}}{T-T_{g}+51,6}-\frac{C_{31}}{T\left(T_{m 1}-T\right)^{2}}\right] n_{1} t^{n_{1}-1}\right) d t\right]\right] \\
& +w_{2}\left[1-\exp \left[-C_{12} \int_{0}^{t}\left(T \exp \left[-\frac{C_{22}}{T-T_{g}+51,6}-\frac{C_{32}}{T\left(T_{m 2}-T\right)^{2}}\right] n_{2} t^{n_{2}-1}\right) d t\right]\right]
\end{aligned}
$$




$$
\begin{aligned}
\frac{\chi_{v c}}{\chi_{v c \infty}}= & \\
& w_{1}\left[1-\exp \left[-C_{11} \int_{0}^{t}\left(\exp \left[-\frac{C_{21}}{T-T_{g}+51,6}-\frac{2 C_{31} T}{T\left(T_{m}^{0}-T\right)\left(T_{m}^{0}+T\right)}\right] n_{1} t^{n_{1}-1}\right) d t\right]\right] \\
& +w_{2}\left[1-\exp \left[-C_{12} \int_{0}^{t}\left(\exp \left[-\frac{C_{22}}{T-T_{g}+51,6}-\frac{2 C_{32} T}{T\left(T_{m}^{0}-T\right)\left(T_{m}^{0}+T\right)}\right] n_{2} t^{n_{2}-1}\right) d t\right]\right]
\end{aligned}
$$

Cuyos parámetros varían según la referencia como se indica en las Tablas

\begin{tabular}{|c|c|c|}
\hline Parámetro & $(\text { Velisaris y Seferis }, 1986)^{*}$ & $(\text { Tierney y Gillespie Jr. } \mid 2004)^{*}$ \\
\hline$w_{1}$ & 0,61 & 0,61 \\
\hline$C_{11}\left[s^{-n}\right]$ & $2,08 \cdot 10^{10}$ & $2,08 \cdot 10^{10}$ \\
\hline$C_{21}[K]$ & 4050 & 4050 \\
\hline$C_{31}\left[K^{3}\right]$ & $1,8 \cdot 10^{7}$ & $1,8 \cdot 10^{7}$ \\
\hline$T_{m 1}[K]$ & 593 & 611 \\
\hline$n_{1}$ & 2,5 & 2,5 \\
\hline$w_{2}$ & 0,39 & 0,39 \\
\hline$C_{12}\left[s^{-n}\right]$ & $2,08 \cdot 10^{10}$ & $2,08 \cdot 10^{10}$ \\
\hline$C_{22}[K]$ & 7600 & 7600 \\
\hline$C_{32}\left[K^{3}\right]$ & $3,2 \cdot 10^{6}$ & $3,2 \cdot 10^{6}$ \\
\hline$T_{m 2}[K]$ & 615 & 611 \\
\hline$n_{2}$ & 1,5 & 1,5 \\
\hline
\end{tabular}
4.20 y 4.21 .

* Estimados para enfriamientos a velocidades iguales o superiores a $10 \mathrm{~K} / \mathrm{min}$

Tabla 4.20: Parámetros de la ecuación de doble Avrami paralelo para APC2/AS4 según referencia bibliográfica

Tal y como reflejan esas ecuaciones, para el estudio se hace preciso emplear el valor de fracción volumétrica de matriz, obtenido como indica la ecuación 4.64 a partir de su fracción másica. En la ecuación anterior, $\chi_{v c}$ representa la fracción volumétrica de cristal, $\chi_{m c}$ es la fracción másica, $P_{c}=1,4 \mathrm{~g} / \mathrm{cc}$ es la densidad de la fase cristalina y $P_{n}=1,26 \mathrm{~g} / \mathrm{cc}$ es la densidad de la fase amorfa.

$$
\chi_{v c}=\frac{\chi_{m c} P_{n}}{P_{n}-\chi_{m c}\left(P_{c}-P_{n}\right)}
$$

En la Tabla 4.22 se incluye la información de la cristalización desarrollada por el APC2/AS4 en cuatro rampas de enfriamiento distintas, en ninguna 


\begin{tabular}{|c|c|}
\hline Parámetro & $(\overline{\text { Cebe }}, \overline{1988 \mathrm{a}})^{*}$ \\
\hline \hline$w_{1}$ & 0,72 \\
\hline$C_{11}\left[s^{-1}\right]$ & 0,63 \\
\hline$C_{21}[K]$ & 1700 \\
\hline$C_{31}\left[K^{2}\right]$ & $6,3 \cdot 10^{5}$ \\
\hline$T_{m 1}[K]$ & 662 \\
\hline$n_{1}$ & 3,45 \\
\hline \hline$w_{2}$ & 0,28 \\
\hline$C_{12}\left[s^{-1}\right]$ & 1,06 \\
\hline$C_{22}[K]$ & 1650 \\
\hline$C_{32}\left[K^{2}\right]$ & $4 \cdot 10^{5}$ \\
\hline$T_{m 2}[K]$ & 662 \\
\hline$n_{2}$ & 2 \\
\hline Calculados para enfriamiento a $10 K /$ min
\end{tabular}

Tabla 4.21: Parámetros de la ecuación de doble Avrami paralelo para APC2/AS4 según referencia

de ellas se ha observado la existencia de cristalización en frío en el calentamiento posterior del material, de ahí que no sea tenida en consideración en los cálculos.

\begin{tabular}{|c|c|c|c|c|}
\hline Enfriamiento & Masa & Entalpía fusión & $\begin{array}{c}\text { Cristalización } \\
(\text { másico }) \\
{[\mathrm{K} / \mathrm{min}]}\end{array}$ & $\begin{array}{c}\text { Cristalización } \\
\text { (volumétrico) } \\
{[\%]}\end{array}$ \\
\hline 2 & 20,64 & 20,07 & 45,41 & 42,81 \\
\hline 5 & 20,77 & 19,3 & 43,67 & 41,09 \\
\hline 10 & 20,75 & 18,95 & 42,87 & 40,31 \\
\hline 15 & 22,27 & 18,23 & 41,24 & 38,71 \\
\hline
\end{tabular}

Tabla 4.22: Cristalización desarrollada en APC2/AS4 según el programa de enfriamiento dinámico

La anterior tabla, es un reflejo de que ha sido posible obtener una conversión próxima a un $43 \%$ en volumen con un enfriamiento a $2 \mathrm{~K} / \mathrm{min}$ y efectuando la medición mediante el empleo de la calorimetría diferencial de barrido. Este hecho entra en contradicción con el valor bibliográfico propuesto de un $37 \%$ como valor para la máxima conversión volumétrica cristalina (donde la obtención se ejecutó por el método de las densidades), para este trabajo se utilizará el valor $43 \%$, teniendo por tanto las conversiones mostradas en la Figura 4.122 en los 4 programas de enfriamiento considerados. 


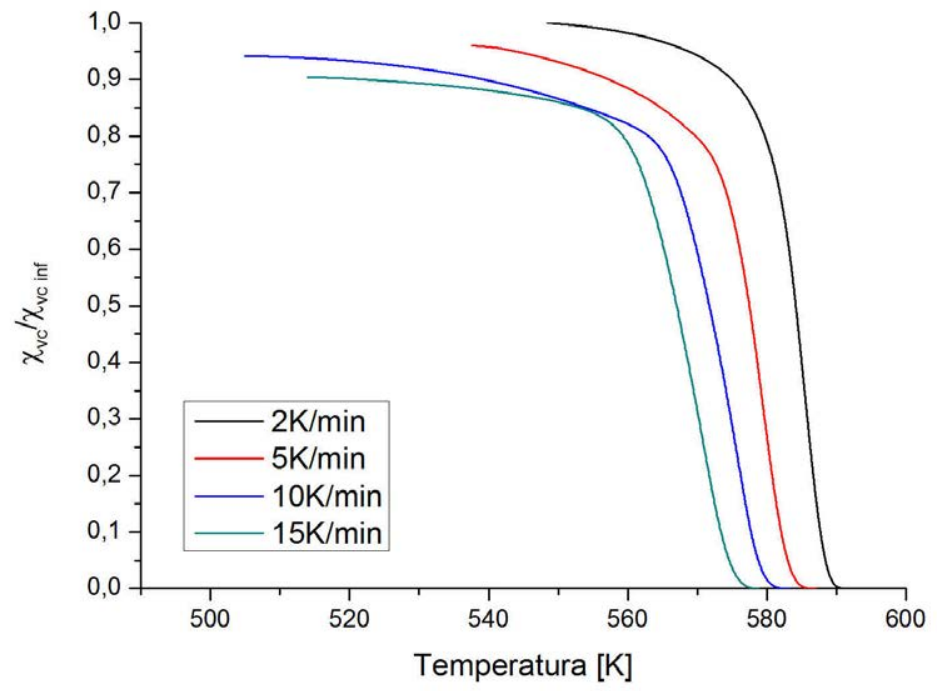

Figura 4.122: $\frac{\chi_{v c}}{\chi_{v c \infty}}$ vs. Temperatura en APC2/AS4 para distintos programas de enfriamiento dinámico

Aplicando los modelos teóricos al caso de $10 \mathrm{~K} / \mathrm{min}$, la solución obtenida refleja un mal ajuste entre las curvas experimentales y las calculadas (Figuras 4.123 4.124 y 4.125. Siendo el modelo de Tierney el más aproximado al resultado. 


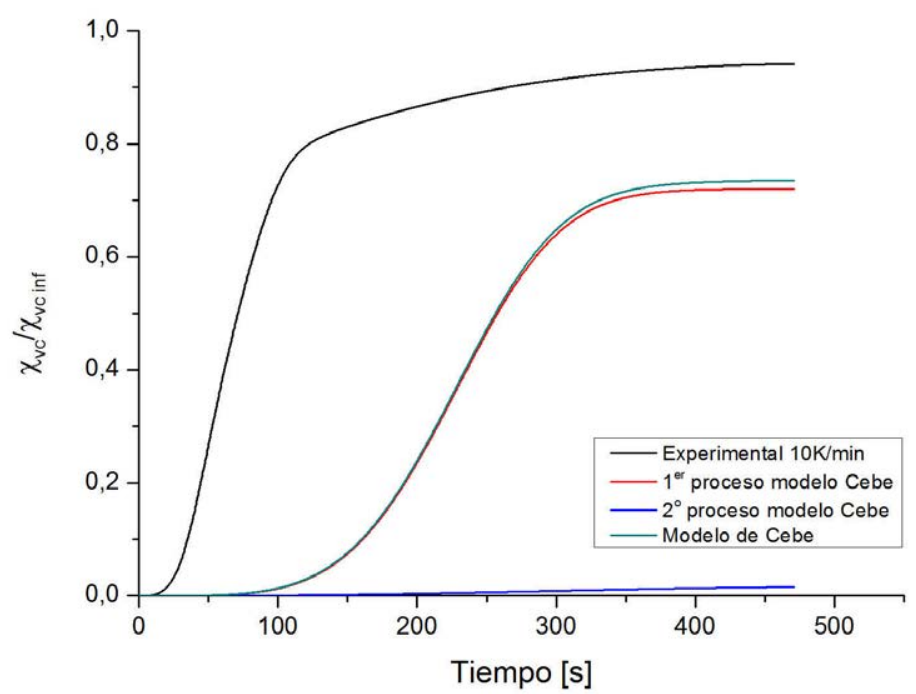

Figura 4.123: Aplicación al resultado experimental de $10 \mathrm{~K} / \mathrm{min}$ en APC2/AS4 de los modelos teóricos bibliográficos - Cebe

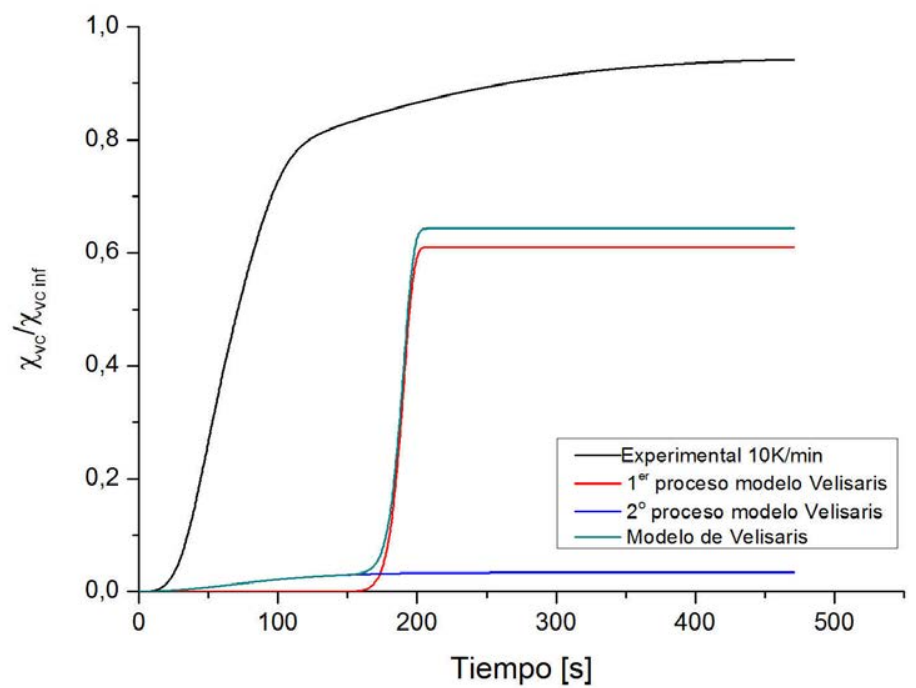

Figura 4.124: Aplicación al resultado experimental de $10 \mathrm{~K} / \mathrm{min}$ en APC2/AS4 de los modelos teóricos bibliográficos - Velisaris 


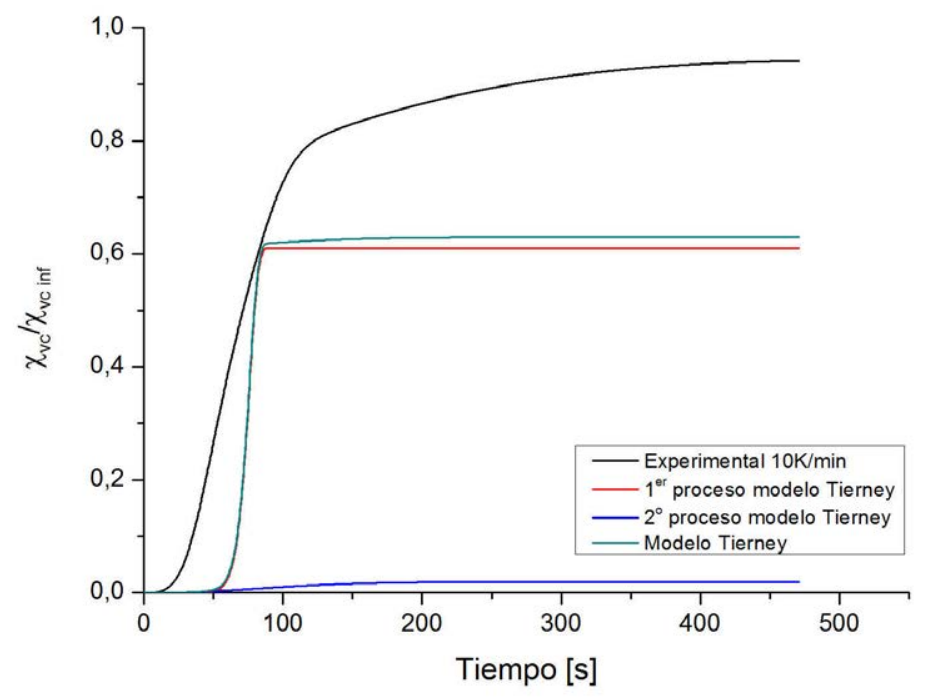

Figura 4.125: Aplicación al resultado experimental de $10 \mathrm{~K} / \mathrm{min}$ en APC2/AS4 de los modelos teóricos bibliográficos - Tierney

Buscando obtener los parámetros que mejor reproducían el comportamiento del material, se ha efectuado un ajuste no lineal por mínimos cuadrados con el software Matlab para el caso de ensayo a $10 \mathrm{~K} / \mathrm{min}$. Los parámetros obtenidos se recogen en la Tabla 4.23 bajo el empleo de la ecuación de Tierney (que proporcionó los mejores resultados). La representación del ajuste obtenido con los nuevos parámetros se ilustra en la Figura 4.126. Según el resultado, los procesos no se desarrollan de modo independiente sino solapados en el tiempo, siendo el primero de ellos el de menor contribución porcentual al total, como ya fue detectado en el desarrollo de la deconvolución de la curva experimental, donde se extrajo una contribución en peso superior.

Considerando el desarrollo del proceso de cristalización, se estima que no es posible obtener unos parámetros inequívocos para velocidades de enfriamiento muy dispares entre sí. En esos casos, no será posible estabilizar las contribuciones del primer y el segundo proceso, es decir, los valores obtenidos de los parámetros para el ensayo a $10 \mathrm{~K} / \mathrm{min}$ deberían nuevamente ajustarse para programas de enfriamiento con velocidades en el entorno del proceso de laminación automática y consolidación in-situ, imposibles de reproducir con las técnicas convencionales de laboratorio. Teniendo en cuenta un ensayo a $30 K / \min \left(\chi_{m}=37,30 \%, \chi_{v}=34,87 \%, \frac{\chi_{v c}}{\chi_{v c \text { inf }}}=81,45 \%\right)$, el ajuste de parámetros de la ecuación de Tierney en este caso arroja los resultados ob- 


\begin{tabular}{|c|c|}
\hline Parámetro & Ecuación para ajuste (Tierney y Gillespie Jr. \\
\hline \hline$w_{1}$ & 0,1023 \\
\hline$C_{11}\left[s^{-n}\right]$ & $2,08 \cdot 10^{10}$ \\
\hline$C_{21}[K]$ & 4028 \\
\hline$C_{31}\left[K^{3}\right]$ & $1,8 \cdot 10^{7}$ \\
\hline$T_{m 1}[K]$ & 611 \\
\hline$n_{1}$ & 3,41 \\
\hline \hline$w_{2}$ & 0,8977 \\
\hline$C_{12}\left[s^{-n}\right]$ & $2,08 \cdot 10^{10}$ \\
\hline$C_{22}[K]$ & 6732,5 \\
\hline$C_{32}\left[K^{3}\right]$ & $3,2 \cdot 10^{6}$ \\
\hline$n_{2}$ & 1,4 \\
\hline
\end{tabular}

Tabla 4.23: Parámetros del ajuste no lineal con el modelo de Tierney para ensayo a $10 \mathrm{~K} / \mathrm{min}$

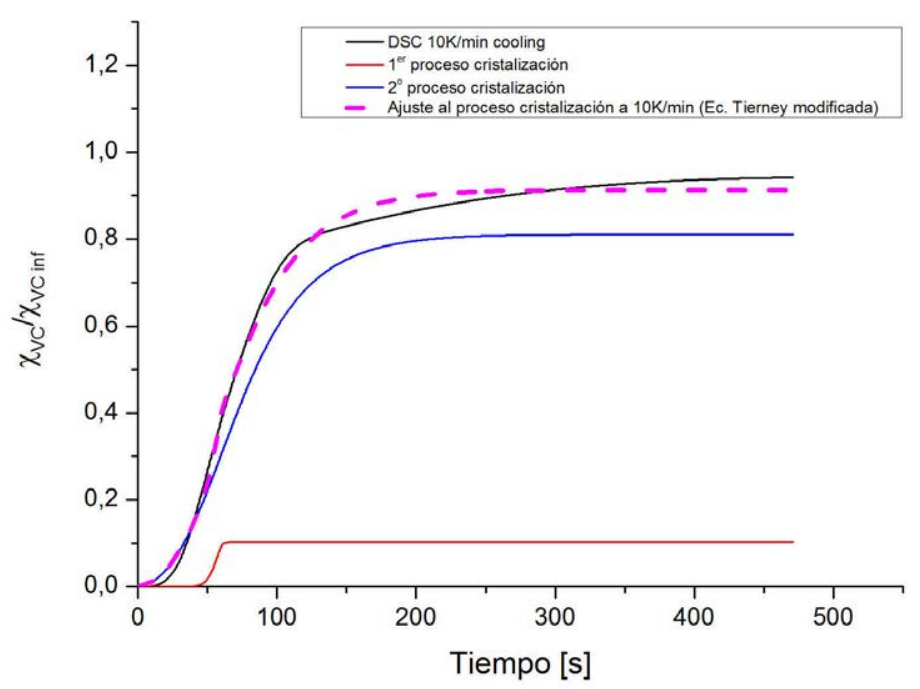

Figura 4.126: Comparativa del ensayo a $10 \mathrm{~K} / \mathrm{min}$ y el modelo de Tierney con parámetros obtenidos tras el ajuste no lineal

servables en la Tabla 4.24 y representados en la Figura 4.127. En el ajuste, se observa un crecimiento en el valor de $w_{1}$ a 0,41 frente al 0,1023 obtenido en el ajuste para $10 \mathrm{~K} / \mathrm{min}$ muestra del cambio de contribuciones entre ambos procesos. 


\begin{tabular}{|c|c|}
\hline Parámetro & Ecuación para ajuste (Tierney y Gillespie Jr. 2004) \\
\hline$w_{1}$ & 0,41 \\
\hline$C_{11}\left[s^{-n}\right]$ & $2,08 \cdot 10^{10}$ \\
\hline$C_{21}[K]$ & 5023,8 \\
\hline$C_{31}\left[K^{3}\right]$ & $1,8 \cdot 10^{7}$ \\
\hline$T_{m 1}[K]$ & 611 \\
\hline$n_{1}$ & 2,5 \\
\hline$w_{2}$ & 0,59 \\
\hline$C_{12}\left[s^{-n}\right]$ & $2,08 \cdot 10^{10}$ \\
\hline$C_{22}[K]$ & 6560,2 \\
\hline$C_{32}\left[K^{3}\right]$ & $3,2 \cdot 10^{6}$ \\
\hline$n_{2}$ & 1,5 \\
\hline
\end{tabular}

Tabla 4.24: Parámetros del ajuste no lineal con el modelo de Tierney para ensayo a $30 \mathrm{~K} / \mathrm{min}$

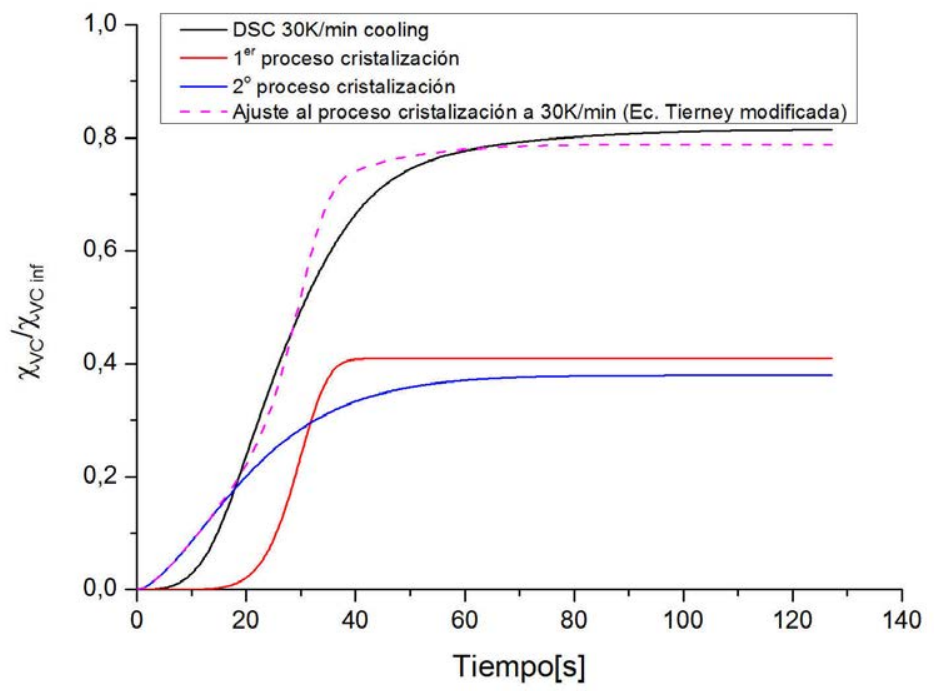

Figura 4.127: Comparativa del ensayo a $30 \mathrm{~K} / \mathrm{min}$ y el modelo de Tierney con parámetros obtenidos tras el ajuste no lineal

A la vista de las desviaciones observadas, se ha optado por ejecutar una simulación dejando que los valores de las temperaturas de fusión para el primer y segundo proceso oscilaran hasta alcanzar el parámetro más óptimo del 
ajuste, aproximando por tanto el resultado al propuesto por el modelo de Velisaris. Ese ajuste condujo a los valores de la Tabla 4.25 y a la representación de la Figura 4.128

Los dos valores de temperatura de fusión obtenidos, son muy próximos a los finales de los dos picos de fusión del ciclo de calentamiento tras un enfriamiento ejecutado lentamente. Como puede observarse, el ajuste obtenido representa con mucha precisión el comportamiento experimental, siendo la ecuación final obtenida es la codificada como Ecuación 4.65.

\begin{tabular}{|c|c|}
\hline Parámetro & Ecuación para ajuste $(\overline{\text { Velisaris y Seferis, }}, \overline{1986})$ \\
\hline \hline$w_{1}$ & 0,8 \\
\hline$C_{11}\left[s^{-n}\right]$ & $2,08 \cdot 10^{10}$ \\
\hline$C_{21}[K]$ & 6418,4 \\
\hline$C_{31}\left[K^{3}\right]$ & $1,8 \cdot 10^{7}$ \\
\hline$T_{m 1}[K]$ & 634,9 \\
\hline$n_{1}$ & 2,5 \\
\hline \hline$w_{2}$ & 0,2 \\
\hline$C_{12}\left[s^{-n}\right]$ & $2,08 \cdot 10^{10}$ \\
\hline$C_{22}[K]$ & 7223,2 \\
\hline$C_{32}\left[K^{3}\right]$ & $3,2 \cdot 10^{6}$ \\
\hline$T_{m 2}[K]$ & 626,54 \\
\hline$n_{2}$ & 1,5 \\
\hline
\end{tabular}

Tabla 4.25: Parámetros del ajuste no lineal con el modelo de Velisaris para ensayo a $30 \mathrm{~K} / \mathrm{min}$

$$
\begin{aligned}
\frac{\chi_{v c}}{\chi_{v c \infty}}= & \\
& 0,8\left[1-\exp \left[-2,08 \cdot 10^{10} \int_{0}^{t}\left(T \exp \left[-\frac{6418,4}{T-417+51,6}-\frac{1,8 \cdot 10^{7}}{T(634,9-T)^{2}}\right] 2,5 t^{1,5}\right) d t\right]\right] \\
& +0,2\left[1-\exp \left[-2,08 \cdot 10^{10} \int_{0}^{t}\left(T \exp \left[-\frac{7223,2}{T-417+51,6}-\frac{3,2 \cdot 10^{6}}{T(626,54-T)^{2}}\right] 1,5 t^{0,5}\right) d t\right]\right]
\end{aligned}
$$




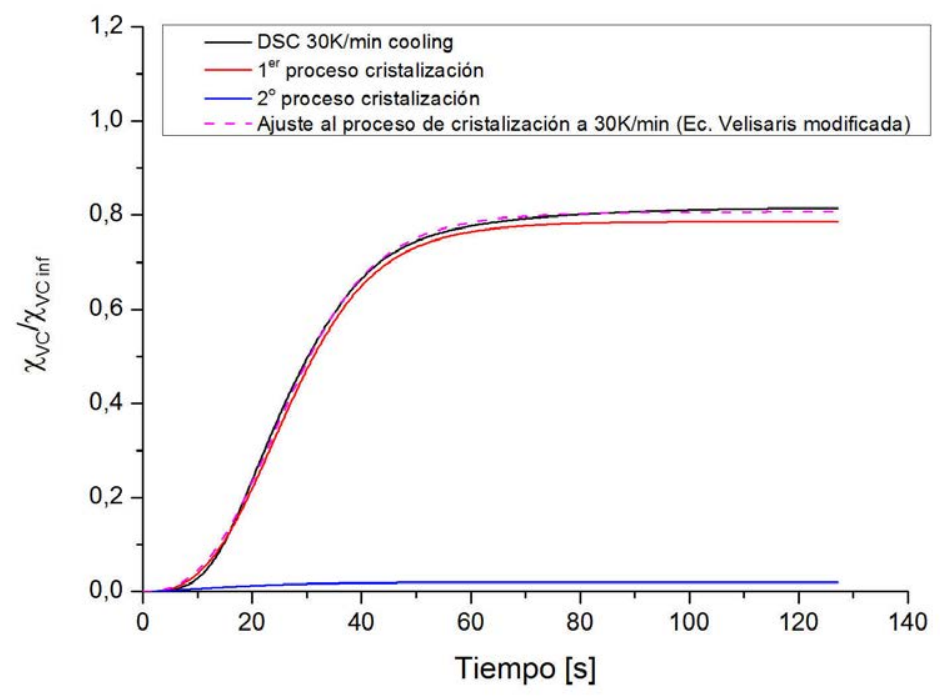

Figura 4.128: Comparativa del ensayo a $30 \mathrm{~K} / \mathrm{min}$ y el modelo de Velisaris con parámetros obtenidos tras el ajuste no lineal

Si consideramos ésta como la ecuación representativa del proceso de encintado automático y consolidación in-situ y efectuamos su integración para un perfil de enfriamiento de $10000 \mathrm{~K} / \mathrm{min}$, el resultado obtenido de la integración manifiesta cristalización nula. Utilizando la ecuación bajo la hipótesis de su aplicabilidad también en el proceso de calentamiento. Un calentamiento en mesa a $473 \mathrm{~K}$ a una velocidad de $2 \mathrm{~K} / \mathrm{min}$ (primera capa posicionada sobre mesa), daría una cristalización volumétrica relativa en el entorno del $80 \%$, equivalente a un \% másico de cristalinidad de un 36,75\%, valor próximo al obtenido en el panel procesado en mesa calefactada.

En una etapa de calentamiento, la subida en el tramo donde podría producirse la cristalización fría, está en el entorno de $200 \mathrm{~K} / \mathrm{s}$, velocidad a la cual la ecuación no manifiesta un porcentaje significativo de cristalización, de igual modo, considerando los perfiles de enfriamiento que se tendrían desde la capa 4, las velocidades siguen siendo muy elevadas y la ecuación predice valores muy pequeños de cristalización, en contra del resultado obtenido en la probeta escalón ensayada por calorimetría. El modelo podría estar fallando aquí por no tener en consideración efectos de cristalización adelantada por una mala fusión de todo el cristal existente. 


\subsection{Caracterización de laminados fabricados}

Tras el desarrollo de los modelos anteriormente incluidos en el documento, se ejecutaron dos paneles por laminación automática y consolidación in-situ con secuencias $[0]_{16}$ y $[+/-45]_{4 s}$, destinados a la elaboración de diferentes ensayos mecánicos. "Single Cantilever" en DMA, ILSS y flexión (laminados con todas las capas a $\left.0^{\circ}\right)$ e IPSS $\left([+/-45]_{4 s}\right)$. En ellos se mantuvieron como condiciones de proceso las indicadas en la Tabla 3.4 .

Idénticos paneles fueron elaborados en prensa de platos calientes con el fin de comparar sus resultados. Los paneles fueron inspeccionados ultrasónicamente tras su fabricación comprobando que eran conformes respecto al estándar considerado e indicado en la sección 3.2 .3 .

Las codificaciones otorgadas a los paneles, para que sirvan como vía de trazabilidad para futuros trabajos derivados de esta tesis doctoral, fueron las recogidas por la Tabla 4.26 .

\begin{tabular}{|c|c|c|c|}
\hline Fabricación & Panel & Secuencia & Ensayo \\
\hline Prensa & $2014-10-\mathrm{P} 16-01$ & {$[0]_{16}$} & Flexión EN2562 (A) \\
& & & DMA ISO 75-3 \\
& & & ILSS 2563 \\
& & & $D S C^{*}(39,4 \%)$ \\
\hline ISC & $2014-10-\mathrm{P} 18-01$ & {$[0]_{16}$} & Flexión EN2562 (A) \\
& & & DMA ISO 75-3 \\
& & & ILSS 2563 \\
& & & $D S C^{*}(35,3 \%)$ \\
\hline Prensa & $2014-10-\mathrm{P} 27-01$ & {$[+/-45]_{4 s}$} & IPSS (AITM 1-0002) \\
& & & $D S C^{*}(37,05 \%)$ \\
\hline ISC & $2017-76-$ P02-01 & {$[+/-45]_{4 s}$} & IPSS (AITM 1-0002) \\
& & & $D S C^{*}(38,9 \%)$ \\
\hline
\end{tabular}

Tabla 4.26: Codificacion paneles de ensayos mecánicos

\subsubsection{Caracterización termo-mecánica de laminados fabrica- dos por ISC}

La ejecución de ensayos dinamomecánicos (DMA) tenía la finalidad de extraer información sobre el comportamiento viscoelástico de este material. Considerando las diferencias en la cristalización del material, es de esperar, que la contribución de la parte amorfa pueda generar tendencias diferentes 
según el proceso de fabricación que está siendo considerado.

Las Figuras 4.129 y 4.130 recogen los ensayos ejecutados sobre 3 probetas procedentes respectivamente del panel fabricado en prensa y el panel fabricado por ISC.

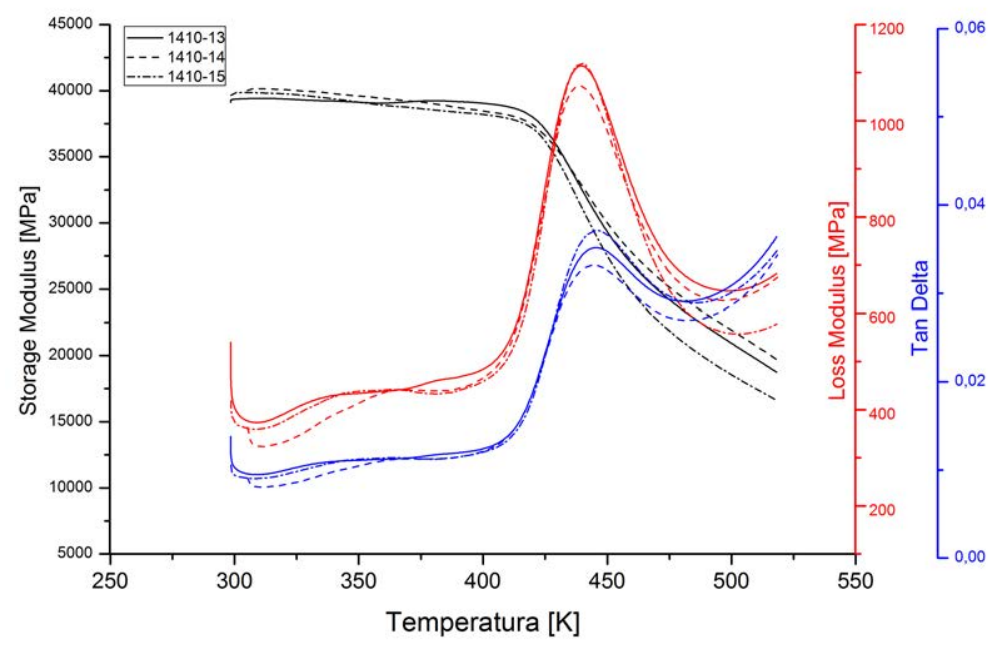

Figura 4.129: DMA Single Cantilever panel prensa

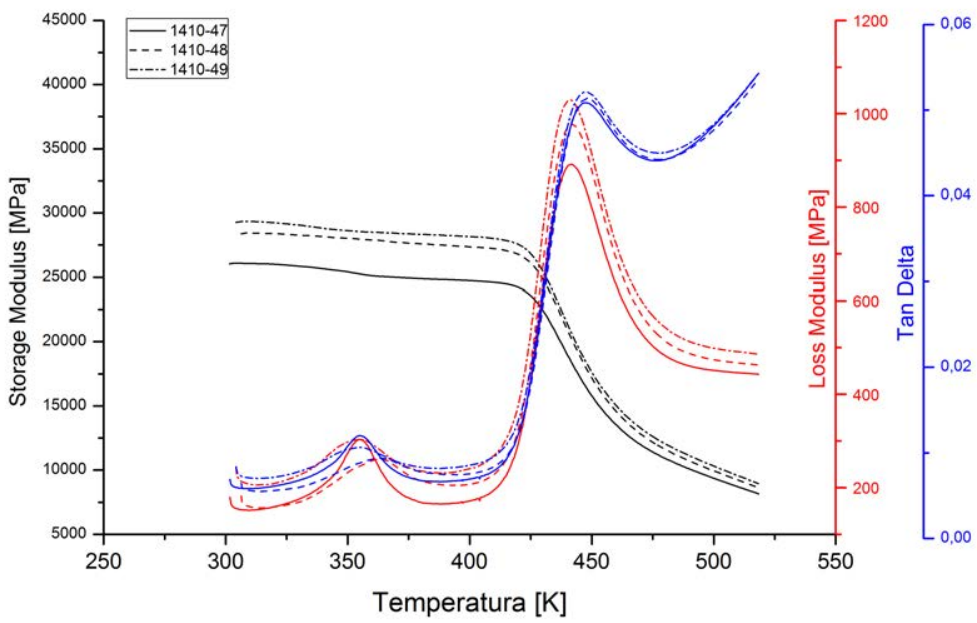

Figura 4.130: DMA Single Cantilever panel ISC 
El análisis intercomparativo de los valores de $T_{g}$ (estimada como el punto de inflexión de la curva del módulo de almacenamiento) da como resultado un valor promedio de $438,74 K$ para las probetas de prensa y $437,84 K$ para las de ISC, pudiendo considerarse despreciable la diferencia entre ellas.

La Tabla 4.27 contiene la información sobre los valores promedio obtenidos para los módulos de almacenamiento a la temperatura de inicio del ensayo y las $T_{g}$ referidas en el párrafo anterior.

Otro elemento sobre el que se prestó atención fue al ancho del pico de la curva Tan Delta, pues tal y como se recoge en la referencia bibliográfica (Thompson y Woods, 1956), dicho pico será más ancho en aquellos materiales que presenten un comportamiento más cristalino y se estrechará en los amorfos. Con objeto de visualizar de modo más sencillo ese pico en Tan Delta, se ha procesado la señal mediante una sustracción de línea base con Origin 8.6 (empleando línea base XPS) y utilizando la medida FWHM (anchura de pico a la mitad de la altura) tras ajustar la curva a una Gaussiana. Los valores cambian de $32,29 \mathrm{~K}$ para prensa frente a $25,76 \mathrm{~K}$ en ISC. Por tanto sí que existe una reducción, aunque sutil, del ancho de la curva reflejando una variación en el comportamiento cristalino.

\begin{tabular}{|c|c|c|c|c|}
\hline Panel & Storage Modulus [MPa] & Desviación & $T_{g}[\mathrm{~K}]$ & Desviación \\
\hline Prensa & 39768,85 & 330,71 & 438,74 & 1,07 \\
\hline ISC & 27946,81 & 1376,59 & 437,84 & 0,44 \\
\hline
\end{tabular}

Tabla 4.27: Promedios DMA - Storage Modulus y $T_{g}$

Dado que en todo momento se trata de correlacionar la cristalinidad con el resultado, se decidió evaluar también un grupo de probetas cortándolas en dirección contraria, quedando todas las capas orientadas a $90^{\circ}$ (Figura 4.131, siendo por tanto el polímero, el elemento fundamental respondiendo a la carga aplicada. Asimismo, se efectuaron dos acondicionamientos diferentes sobre las probetas a $323 K$ (Figura 4.132) y $378 K$ (Figura 4.133) para descartar posibles efectos de absorción de humedad por el material condicionando los resultados (aún conociéndose la baja tendencia de este material a la absorción de humedad).

En esta modificación, se ejecutó nuevamente un análisis sobre el ancho del pico de Tan Delta sobre una de las probetas de cada grupo. Para prensa se obtuvo un valor de $31,66 \mathrm{~K}$ siendo $29,30 \mathrm{~K}$ el de ISC. Como puede observarse, al cambiar la orientación de la probeta se ha reducido la diferencia indicando por tanto una preferencia en orientación de los cristales que hace que a $90^{\circ}$, 
las probetas sean posiblemente más semejantes bajo la solicitación de "Single Cantilever".

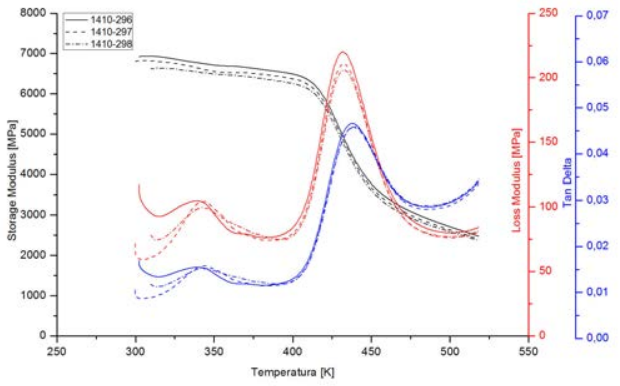

(a)

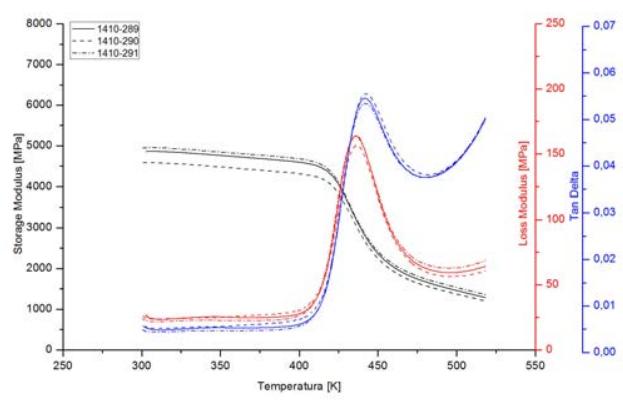

(b)

Figura 4.131: DMA fibra a $90^{\circ}$ en (a) Panel de prensa y (b) Panel de ISC sin acondicionamiento

\begin{tabular}{|c|c|c|c|c|}
\hline Panel & Storage Modulus [MPa] & Desviación & $T_{g}[\mathrm{~K}]$ & Desviación \\
\hline Prensa & 6793,67 & 128,25 & 429,67 & 0,28 \\
\hline ISC & 4802,67 & 155,00 & 432,97 & 0,38 \\
\hline
\end{tabular}

Tabla 4.28: Promedios DMA - Storage Modulus y $T_{g}$ a $90^{\circ}$

Observando los gráficos se puede obtener además otra información respecto al comportamiento de las probetas, aquéllas procedentes del procesado en prensa, manifiestan un pico a la altura de $375 K$, que podría estar relacionado con absorción de humedad en las muestras. Esa suposición parece poco probable considerando la limitada absorción de humedad en un polímero como el PEEK, no obstante se ejecutaron acondicionamientos a dos temperaturas (bajo el valor observado de esa transición y por encima del mismo), monitorizando la evolución de la masa de las probetas sin detectarse variaciones sustanciales. Tras su acondicionamiento a $323 K$, se observa una disminución de la intensidad de dicho pico, que desaparece por completo tras el acondicionamiento a $378 K$. Descartando la posible absorción de agua, la única explicación a la presencia de ese pico es una transición/relajación de la parte amorfa del material que es más visible ensayando a $90^{\circ}$ en prensa y a $0^{\circ}$ en ISC. 


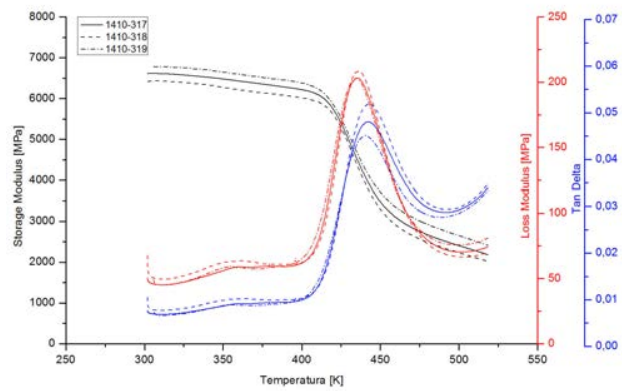

(a)

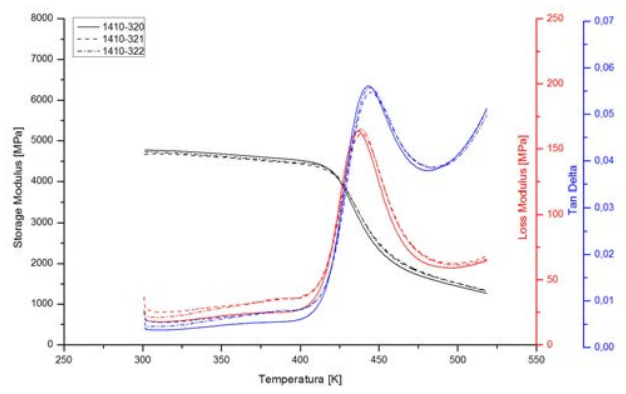

(b)

Figura 4.132: DMA fibra a $90^{\circ}$ en (a) Panel de prensa y (b) Panel de ISC acondicionados a $323 K$

\begin{tabular}{|c|c|c|c|c|}
\hline Panel & Storage Modulus [MPa] & Desviación & $T_{g}[\mathrm{~K}]$ & Desviación \\
\hline Prensa & 6609,00 & 139,26 & 431,93 & 0,44 \\
\hline ISC & 4719,67 & 36,33 & 434,58 & 0,75 \\
\hline
\end{tabular}

Tabla 4.29: Promedios DMA - Storage Modulus y $T_{g}$ a $90^{\circ}$ acondicionado a $323 \mathrm{~K}$

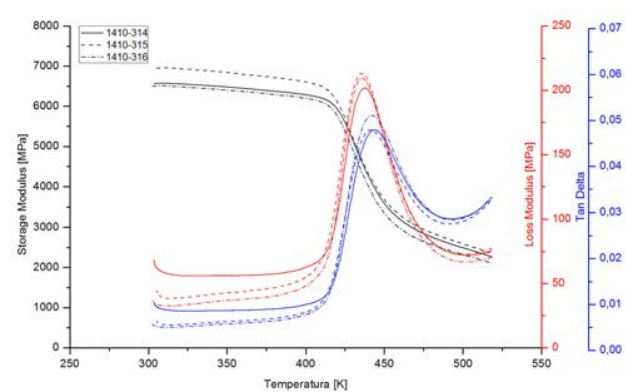

(a)

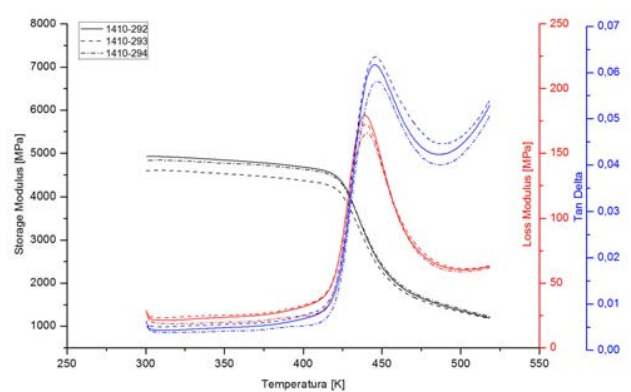

(b)

Figura 4.133: DMA fibra a $90^{\circ}$ en (a) Panel de prensa y (b) Panel de ISC acondicionados a $378 K$

\subsubsection{Caracterización mecánica de laminados}

\subsubsection{Ensayo de pelado}

Con el objetivo de efectuar un análisis de la entrecara de dos capas de material unidas mediante laminación automática y mediante prensa, se recurrió al ensayo de pelado. Para la ejecución del ensayo se efectuó un set-up sencillo incluido en el apartado del desarrollo experimental. Dicho ensayo 


\begin{tabular}{|c|c|c|c|c|}
\hline Panel & Storage Modulus [MPa] & Desviación & $T_{g}[\mathrm{~K}]$ & Desviación \\
\hline Prensa & 6677,33 & 195,00 & 430,44 & 1,10 \\
\hline ISC & 4788,67 & 136,58 & 435,06 & 0,19 \\
\hline
\end{tabular}

Tabla 4.30: Promedios DMA - Storage Modulus y $T_{g}$ a $90^{\circ}$ acondicionado a $378 K$

presenta ciertas deficiencias en la estimación del valor de carga de pelado, que han sido solventadas mediante el desarrollo de un nuevo utillaje basado en la configuración de ensayo propuesta en el trabajo de (Nicodeau, 2005).

A causa de esas desviaciones observadas en la obtención del valor numérico, no se reportarán aquí valores de carga pelado, quedando su análisis abierto a futuros trabajos mediante el empleo del nuevo utillaje desarrollado. Sin embargo, dado que fue posible separar dos capas de material consolidadas por las dos técnicas de fabricación presentadas, éstas fueron evaluadas mediante microscopia electrónica de barrido (SEM), Figura 4.134.

Ambas imágenes son una representación clara de las diferencias morfológicas entre ambas probetas, en la imagen de la entrecara de prensa se ve que las fibras están completamente recubiertas de resina, mientras que la probeta de consolidación in-situ presenta fibras prácticamente desnudas, un comportamiento típicamente dúctil, siendo una evidencia de una peor adhesión fibra/resina en los laminados de ISC.

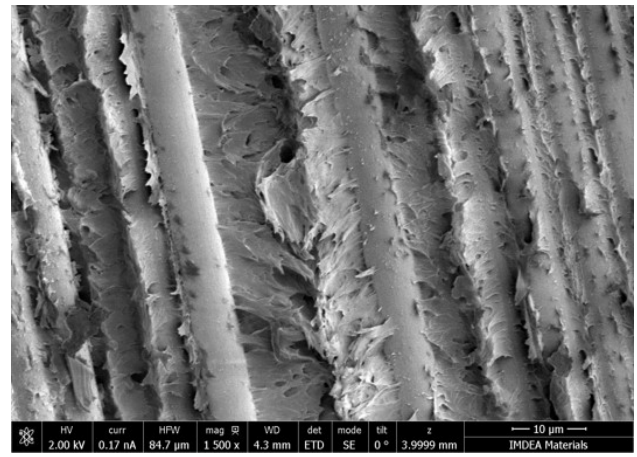

(a)

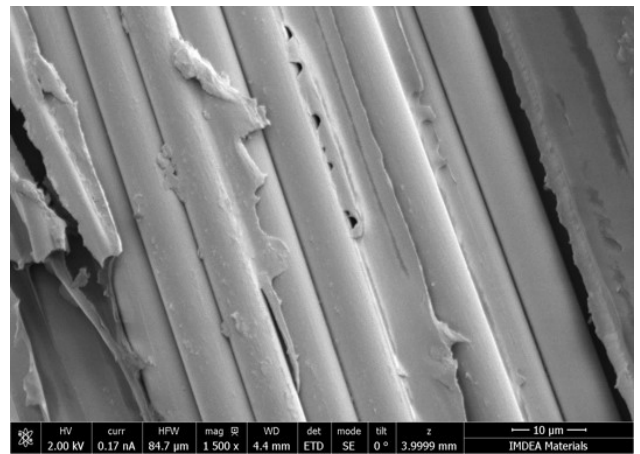

(b)

Figura 4.134: SEM entrecara pelado (a) Prensa y (b) Consolidación in-situ 
Este comportamiento no es representativo de la morfología final de la intercara final entre la capa 1 y 2 en un laminado general obtenido por consolidación in-situ. Dicha intercara se reprocesará en cada secuencia de posicionado de material. De modo que un panel de 8 capas supondrá reprocesar en 6 ocasiones dicha entrecara, modificando su estado de adhesión (contacto y healing/difusión) y causando ciertas variaciones en la cristalización final. Sin embargo, constituye una buena representación de lo alejadas que se encuentran las técnicas entre sí y el impacto que tienen sobre la morfología del material.

En las probetas ensayadas procedentes del procesado en prensa también pudo observarse que no presentaban una entrecara uniforme, existiendo zonas perfectamente diferenciadas a tramos de coloración negra y blanquecina. Dichas zonas podrían correlarse con frentes cristalinos. Se han tomado imágenes SEM de ambas áreas, la Figura 4.135 ha sido obtenida en una franja intermedia entre la zona de coloración blanquecina y la zona negra. Entre ellas es posible distinguir una zona con un comportamiento frágil en la parte superior y otra con un comportamiento dúctil en la zona inferior de la imagen.

Las zonas se amplifican de modo separado en la Figura 4.136, correspondiendo la 4.136 a con la zona de coloración blanca de la entrecara y la $4.136 \mathrm{~b}$ con la zona de color negro.

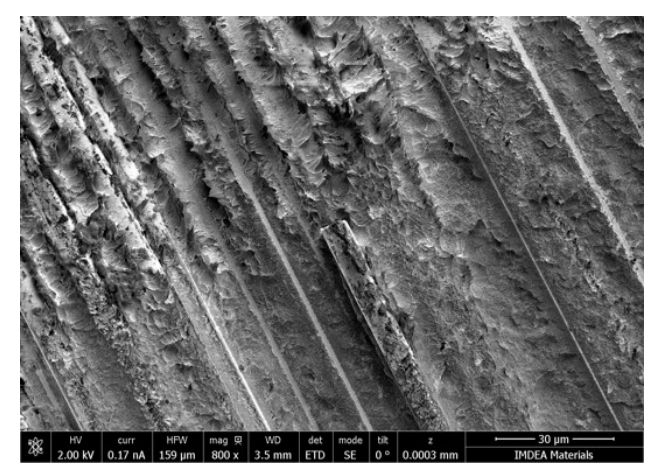

Figura 4.135: SEM entrecara prensa frontera zonas fractura 
La zona "blanca" manifiesta un estado en el que la resina se encuentra estirada, siendo un reflejo de la posible ductilidad del material en esas áreas. Teniendo en cuenta el comportamiento durante el ensayo de pelado, la curva carga-desplazamiento manifestaba ciertos picos de resistencia a la carga para luego progresar rápidamente hasta encontrar un nuevo freno a la propagación. Se considera que, las áreas negras coinciden con los momentos en los que la carga salta y las zonas blancas coinciden con la oposición a la apertura de la entrecara.

Para extraer más información respecto a este punto, es necesario una investigación más profunda en aspectos relacionados con fractografía de cristales, estudio que queda fuera del marco de esta tesis pero que se propone nuevamente como trabajo futuro derivado de este estudio.

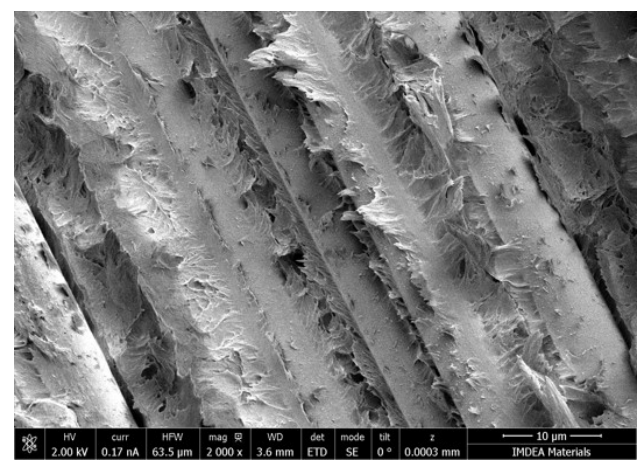

(a)

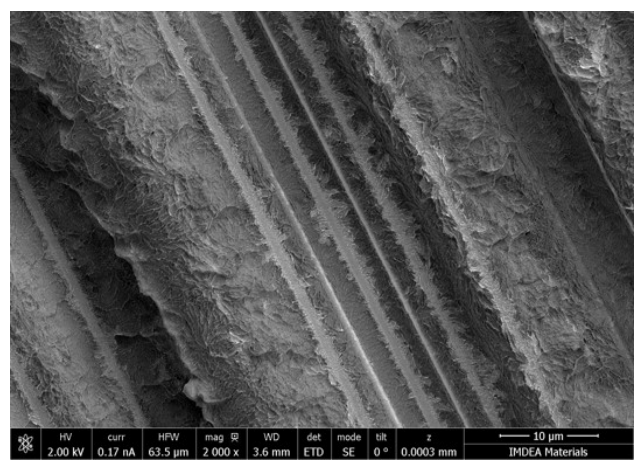

(b)

Figura 4.136: Probeta de prensa tras ensayo de pelado a) Zona blanca y b) Zona negra 


\subsubsection{Ensayo de cortadura en el plano (IPSS)}

En estos ensayos, se pretende determinar la resistencia a cortadura en el plano. El ensayo consiste en traccionar una probeta con capas orientadas a $+/-45^{\circ}$ respecto a la dirección de aplicación de la carga. El estado al que se somete al material no es una cortadura pura sino que está sometido a la combinación de tracción y compresión.

Por como se define el ensayo, se analiza fundamentalmente el comportamiento de la resina, luego todos los efectos del procesado que afecten a la misma serán detectables. Asimismo, también analiza el comportamiento de la lámina, es decir, el efecto interacción fibra/resina. La adhesión entre capas también impacta sobre el resultado, siendo por tanto significativo sobre el resultado la porosidad entre capas y el grado de unión entre ellas.

En (Campbell, 2010) se recoge información sobre que una limitada adhesión fibra-resina impactará en los resultados de tracción a $90^{\circ}$, compresión a $0^{\circ}$ y los valores de cortadura interlaminar y en el plano. Por lo que desviaciones en el resultado de cortadura en el plano también podrían asociarse con diferencias en la línea de adhesión fibra resina. Se espera que en los laminados de consolidación in-situ, esa línea se encuentre formada por numerosos cristales de pequeño tamaño, frente a un numero más limitado en prensa y de tamaño superior.

El ensayo se ejecuta de modo habitual mediante el empleo de tacones de fibra de vidrio, adheridos a la probeta mediante un adhesivo de curado a $120^{\circ}$. Por simplicidad para los trabajos de esta tesis, se han ejecutado los ensayos sin emplear tacones, mostrando la Figura 4.137 las probetas ensayadas con un modo de fallo correcto a pesar de ensayarse sin ellos.

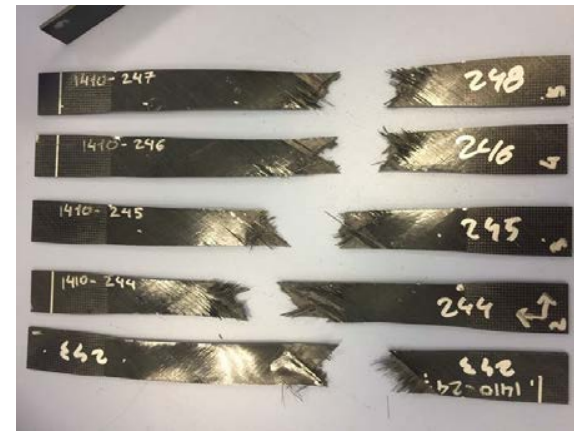

(a)

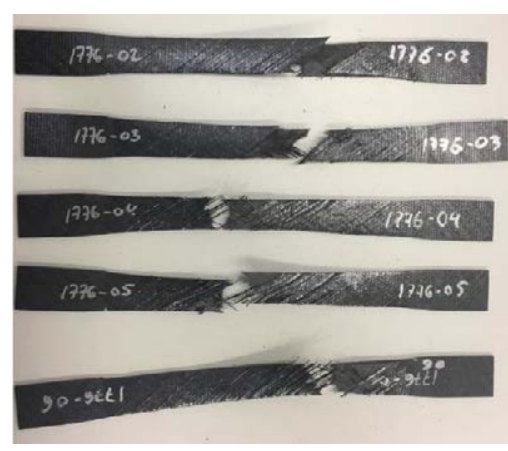

(b)

Figura 4.137: IPSS sobre paneles fabricados en (a) Prensa y (b) ISC sin tacones, modo de fallo 


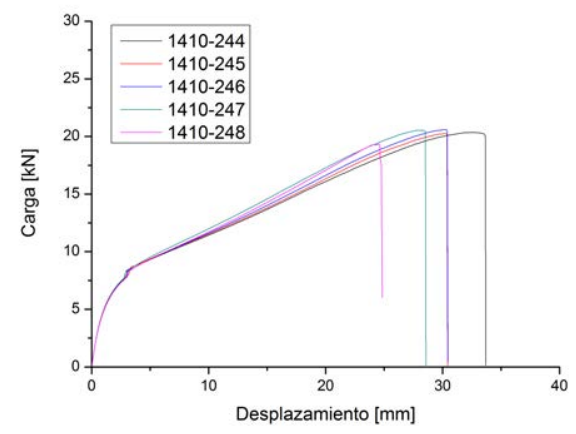

(a)

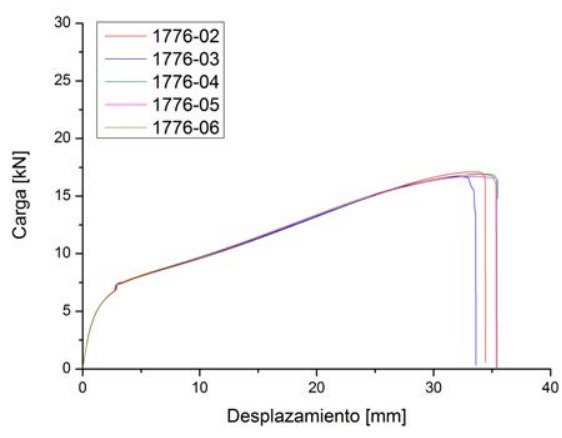

(b)

Figura 4.138: IPSS sobre paneles fabricados en (a) Prensa y (b) ISC

La Figura 4.138(b) recoge los resultados del ensayo de IPSS (sin tacones) del panel fabricado por laminación automática y consolidación in-situ. Las curvas representadas de carga frente a desplazamiento han sido incluidas porque proporcionan una información valiosa sobre el procedimiento de fabricación. En prensa es posible observar valores heterogéneos entre probetas extraídas de un mismo panel, causa posible de un efecto de presionado disimilar en la superficie del panel por el equipo empleado. Por su parte, todas las probetas extraídas del panel de consolidación in-situ presentan curvas con valores de carga inferiores pero con un comportamiento más estable, teniendo todas ellas una deformación a rotura coincidente con el máximo observable en el conjunto de probetas fabricadas en la prensa.

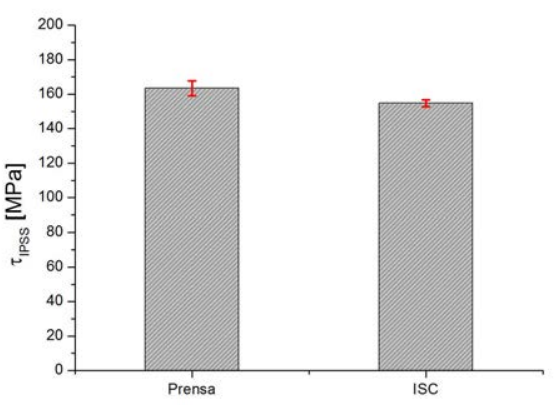

(a)

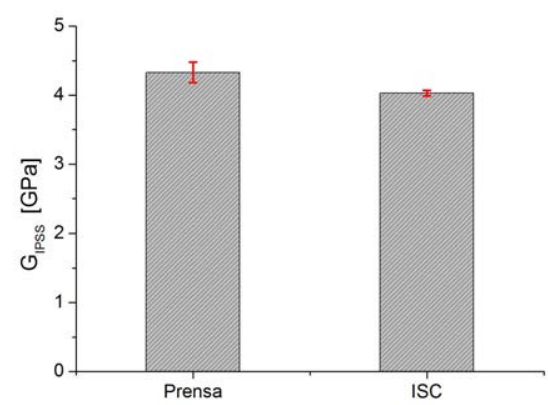

(b)

Figura 4.139: Resultado del ensayo de IPSS sobre panel fabricado en prensa y por ISC (a) Resistencia y (b) Módulo 
Las imágenes obtenidas mediante microscopia electrónica de barrido sobre las zonas de fractura de probetas procedentes del ensayo de IPSS, Figura 4.140 muestran un estado prácticamente "desnudo" de la fibra en el caso de los laminados de ISC, asociándose con una menor resistencia de la entrecara fibra-resina.

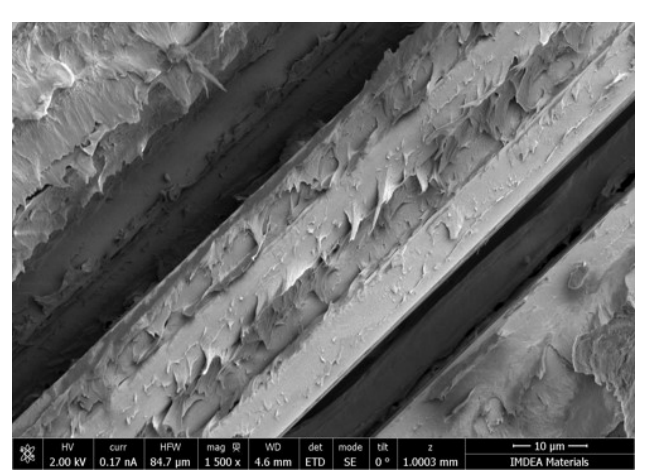

(a)

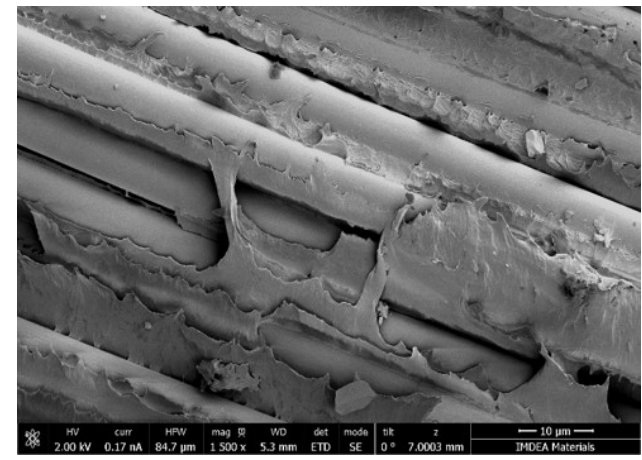

(b)

Figura 4.140: SEM en probetas de IPSS tras fallo, fabricadas (a) Prensa y (b) ISC 


\subsubsection{Ensayo de flexión}

En el ensayo de flexión, se determina la deflexión del punto de apoyo del rodillo central frente a la carga aplicada, teniendo en cuenta una velocidad de ensayo constante hasta que acontece el fallo. Este ensayo sólo es considerado válido en aquellos casos en los que la rotura tiene lugar bajo tensión o compresión, garantizándose que no existe fallo por cortadura en la muestra.

Las curvas de carga frente a deformación obtenidas para las diferentes probetas ensayadas se recogen en la Figura 4.141.

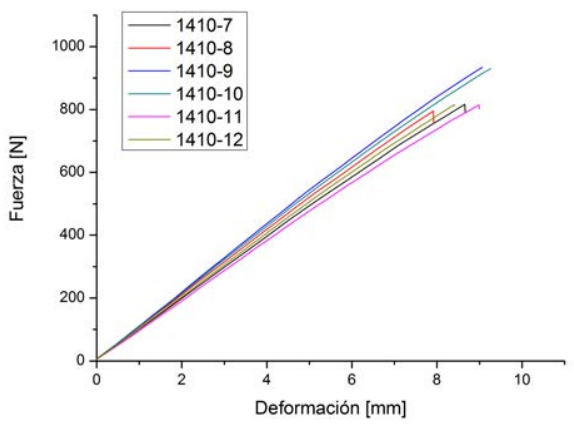

(a)

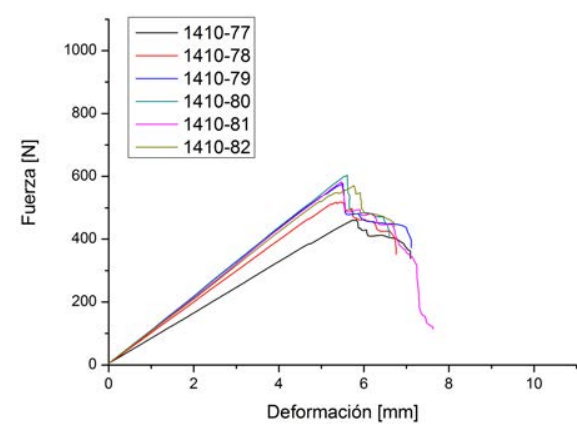

(b)

Figura 4.141: Fuerza frente a deformación en un ensayo a flexión de laminados fabricados (a) Prensa y (b) ISC

La comparativa entre los valores promedio de flexión tanto en resistencia como en módulo son representados en la Figura 4.142. El resultado manifiesta una caída superior al $40 \%$ en el laminado fabricado por ISC, con una variación inferior al $30 \%$ para el caso del módulo.

En todos los casos mostrados con anterioridad, las probetas se colocaron con la cara "útil" hacia abajo; en el caso de la prensa dicha condición no tiene ningún impacto pues ambas superficies estuvieron en contacto con los platos calientes del equipo. En la máquina de encintado, sin embargo, ambas superficies de las probetas presentan notorias diferencias, además, el efecto de las tensiones residuales tiende a revirar el laminado en una dirección preferente. A causa de la anterior afirmación, se estimó preciso ejecutar también ensayos intercambiando las posiciones de cara superior e inferior (Figura 4.143), tratando de establecer cómo de importante se hace la contribución de las tensiones residuales a los resultados. Analizando los resultados (Figura 4.144, se observa un leve incremento del valor de resistencia a rotura para el caso de tener la cara útil en contacto con el rodillo que aplica la carga. 


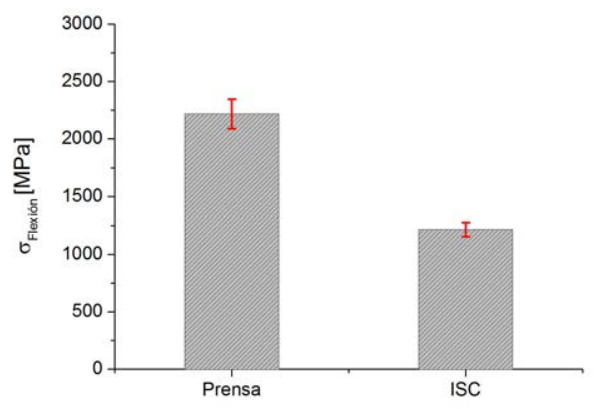

(a)

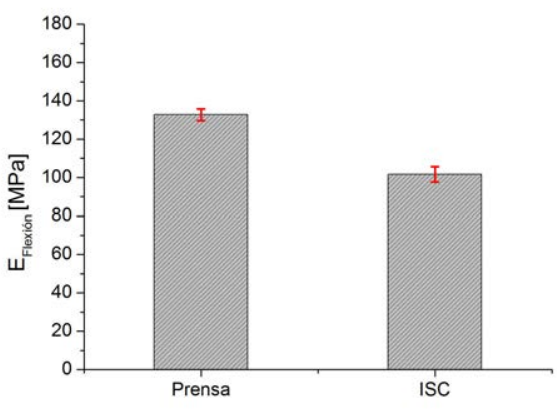

(b)

Figura 4.142: Valores de (a) resistencia y (b) módulo a flexión para paneles de prensa e ISC ensayados a flexión

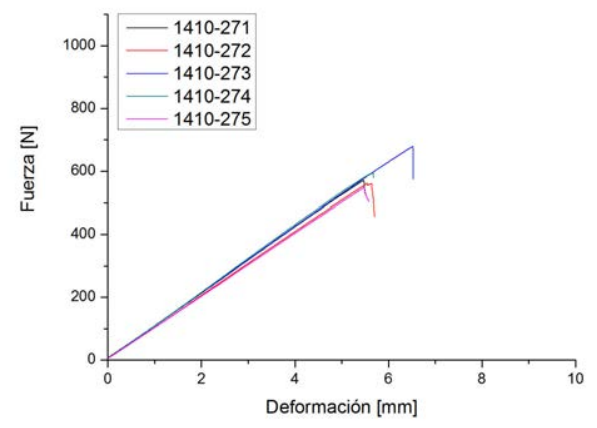

(a)

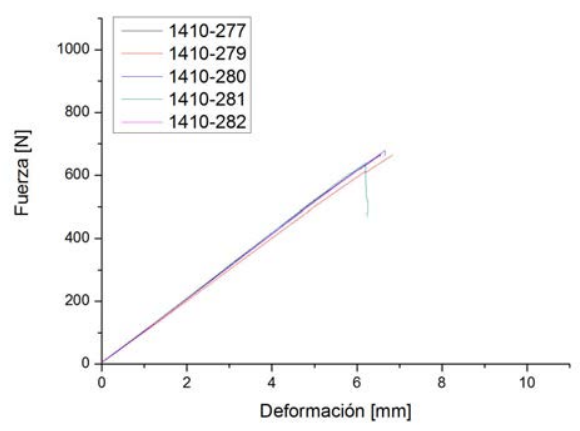

(b)

Figura 4.143: Fuerza frente a deformación en un ensayo a flexión de laminados fabricados por laminación automática y consolidación in-situ con a) Cara útil abajo y b) Cara útil arriba

El análisis mediante la microscopia electrónica, ha mostrado nuevamente, que se detecta menos polímero adherido a las fibras en la zona de fractura, siendo este un indicio de una débil adhesión fibra-resina en la superficie de la fibra.

\subsubsection{Ensayo de cortadura en el plano (ILSS)}

En los ensayos de cortadura interlaminar se determina la resistencia a cortadura interlaminar aparente por medio de un ensayo de flexión. Por la 


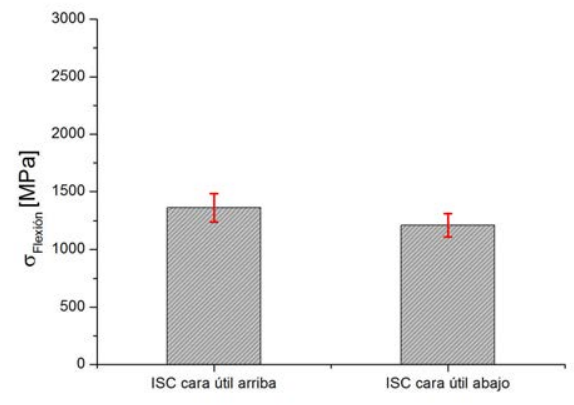

(a)

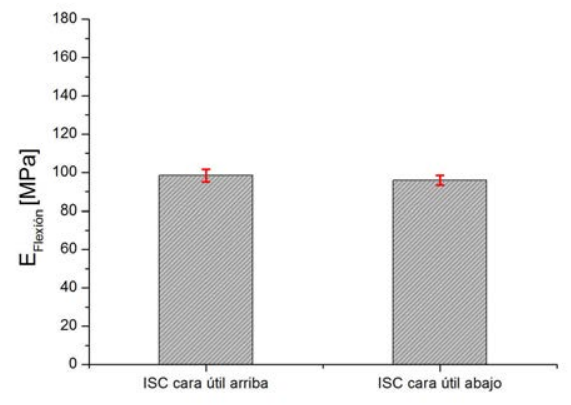

(b)

Figura 4.144: Valores de (a) Resistencia y (b) Módulo a flexión para paneles de ISC ensayados a flexión alternando la posición de la cara en contacto con el útil en el set-up del ensayo

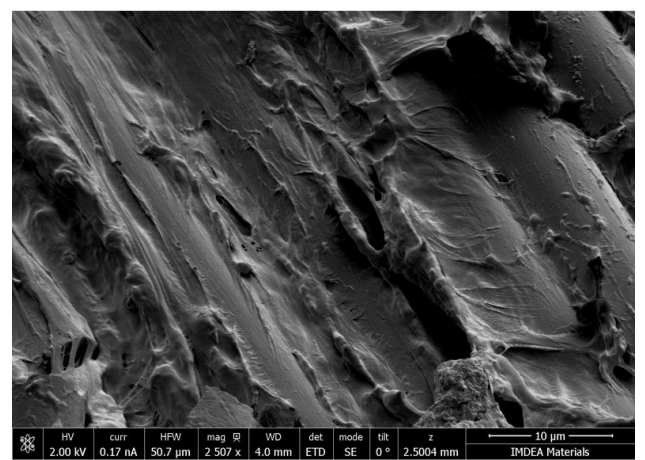

(a)

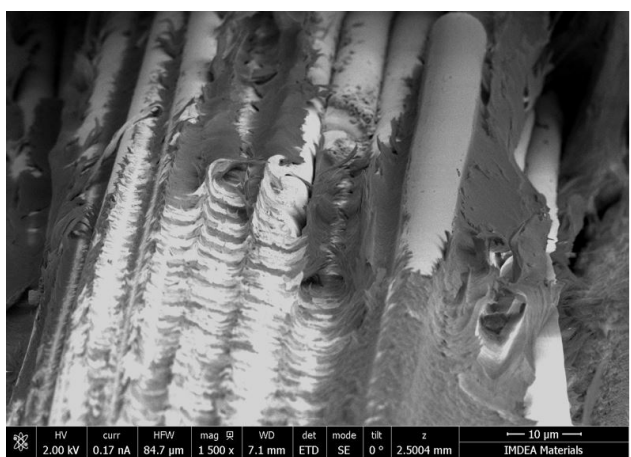

(b)

Figura 4.145: SEM en probetas de flexión tras fallo, fabricadas (a) Prensa y (b) ISC

propia definición del ensayo, las variables del proceso de fabricación que se estiman más influyentes a este respecto son: grado de unión entre las capas, así como estado de la resina (influencia de su nivel de degradación y cristalización).

La principal problemática asociada a este ensayo es el modo de fallo. Se ensayó una población superior a 12 probetas para condiciones de fabricación en prensa y consolidación in-situ, ninguna de ellas presentó un modo de fallo correcto según indicaciones de la norma EN 2563. Todas las probetas fallaron de modo plástico o por flexión. No obstante, se incluirá a continuación la comparativa de resultados entre ambos métodos de fabricación. No se aceptará cuantitativamente el valor numérico obtenido de resistencia in- 
terlaminar, pero sí será posible extraer indicativos de diferencias entre las tecnologías de fabricación.

Se considera importante tener en consideración las desviaciones en los espesores de las probetas. A pesar de que en ambos casos los paneles han sido fabricados con 16 capas a $0^{\circ}$, los paneles de prensa y de laminación automática y consolidación in-situ, presentan diferencias en su valor de espesor promedio (prensa $2,214 \pm 0,01$ e ISC 2,318 $\pm 0,018$ ). Este efecto puede ser condicionante del valor final resultante, si tal y como se referencia en (Hoang, 2015) esta variación de espesor viene ocasionada por variaciones en los volúmenes de fibra de las probetas. Sin embargo, en la referencia asociada, se reporta un efecto contrario al observado en las probetas ensayadas en esta tesis doctoral, con decrementos de espesor para probetas de tracción fabricadas por laminación automática de aproximadamente un $19 \%$ en probetas para ensayos de tracción y comparándose con una baseline de paneles en autoclave (se toma este panel como representativo por tener todas las capas a $0^{\circ}$ como ocurre con los laminados de ILSS). En este trabajo, se ha observado un incremento de espesor de un $4,7 \%$ en los paneles de laminación automática y consolidación in-situ, valor obtenido de la comparación de los valores promedio en espesor de las diferentes probetas ensayadas.

En el análisis de las curvas de carga frente a deformación, se ha efectuado una representación conjunta de una probeta procedente de cada uno de los métodos de fabricación, ambas representativas del comportamiento general del grupo de probetas ensayadas, Figura 4.146. La Figura 4.148 contiene una representación de las curvas de todas las probetas ensayadas.

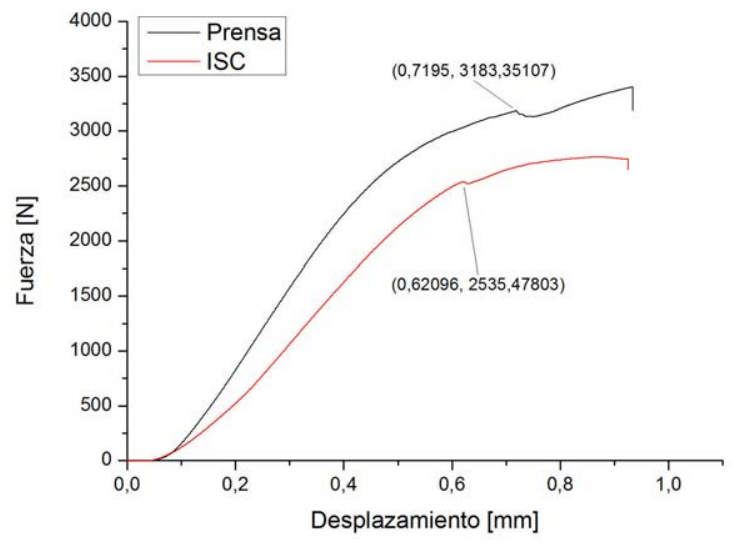

Figura 4.146: Carga vs deformación ILSS 


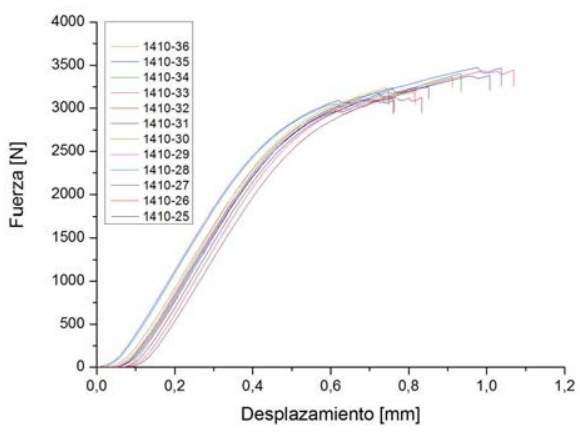

(a)

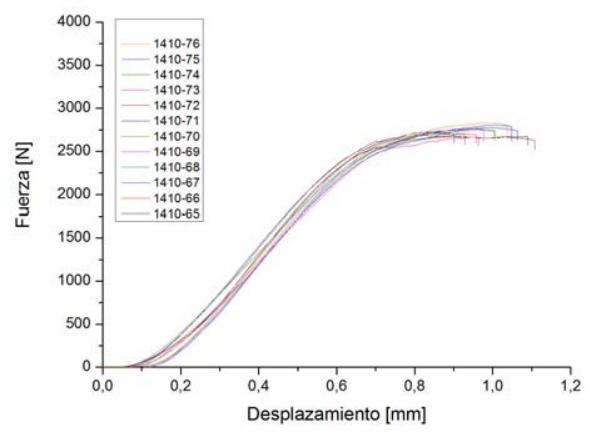

(b)

Figura 4.147: Curvas de ensayo para las probetas de (a) Prensa e (b) ISC

Tal y como puede verse en la Figura 4.146 las probetas fabricadas en prensa presentan un valor de carga de fallo superior a las de consolidación in-situ. Ambas probetas muestran un comportamiento marcadamente plástico característico de este tipo de materiales, sin embargo, prestando atención a la evolución de la curva tras la primera caída de carga, es posible afirmar una tendencia más plástica para las probetas procedentes de ISC.

Todas las probetas fueron observadas por microscopia óptica tras la ejecución de los ensayos, ninguna de las probetas procedentes de prensa permitió distinguir con claridad la presencia de las grietas típicas asociadas al fallo por cortadura, por su parte sí es notorio el efecto de fallo por compresión así como una visible deformación plástica de la probeta, como se muestra en la Figura 4.148(a). En cambio, alguna de las probetas fabricadas por laminación automática (como la incluida en la Figura 4.148(b)), sí presentaron una combinación de fallo por compresión y cortadura interlaminar. Esta combinación de modos de fallo, hace que su comparación cuantitativa no sea rigurosa y que el ensayo de ILSS, ampliamente empleado como control de proceso en materiales termoestables, no se considere una alternativa tal cual se encuentra definida la configuración de probeta por la norma.

Considerando ahora el valor de resistencia promedio obtenido de las diferentes probetas (recordando que únicamente se emplean a modo intercomparativo y no como referencia de valor de cortadura en el material), se estima que el valor obtenido en laminación automática y consolidación in-situ, supone un $82 \%$ del valor alcanzable en el laminado de la prensa (Figura 4.149).

La bibliografía referencia un número sustancial de documentos en los que se emplean ensayos de cortadura interlaminar para paneles fabricados por medio de laminación automática y consolidación in-situ, no sólo para 


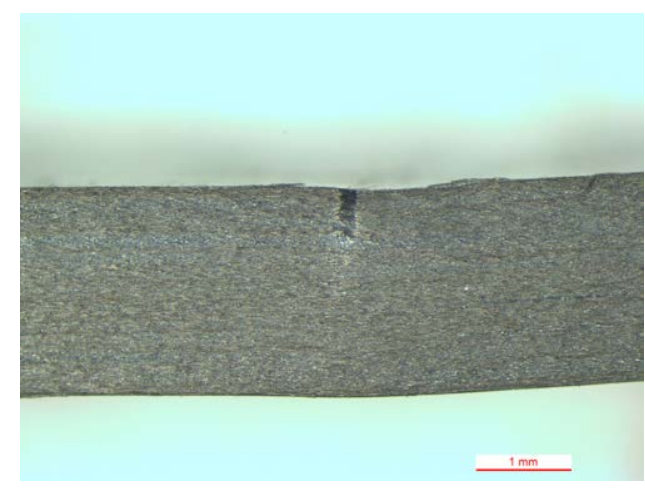

(a)

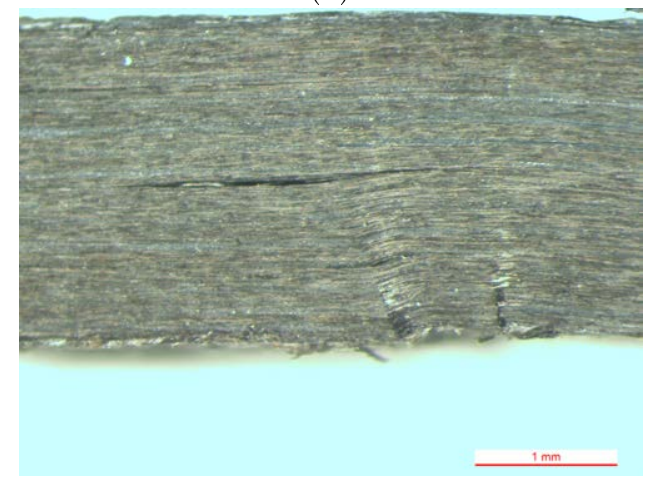

(b)

Figura 4.148: Modo de fallo ILSS (a) Prensa y (b) ISC

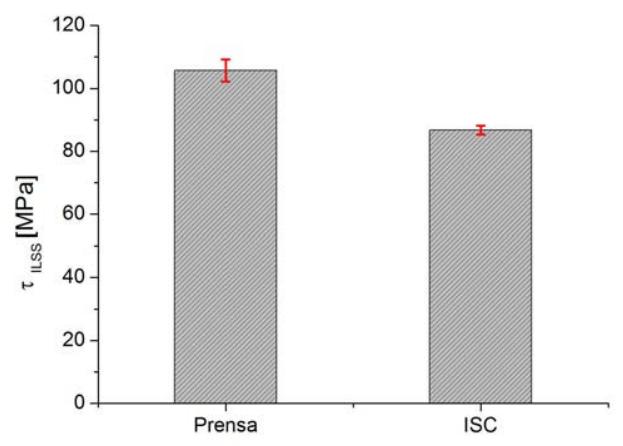

Figura 4.149: Resistencia en ILSS en laminado fabricado en prensa y por ISC

su intercomparación con otras técnicas de fabricación sino también para la definición de parámetros óptimos de encintado (como en el trabajo de (Modi et al. 2013)). De hecho, se llega a efectuar una correlación directa entre 
el grado de unión y el valor de resistencia a cortadura de modo matemático (Stokes-Griffin y Compston 2016b), aludiendo a valores de SBS (Single Beam Shear). En la bibliografía, es común encontrar alusiones a la ejecución de ensayos bajo la norma ASTM D 2344, donde el ensayo se define como SBS (Short Beam Shear), entre otras particularidades, el tamaño de la probeta es muy inferior al requerido por la EN 2563 utilizada en este estudio. Un trabajo futuro debería recoger la ejecución de una comparación con los resultados que se obtendrían bajo la aplicación de esta otra norma/configuración de probeta.

La aplicación de microscopia electrónica (SEM) no permitió extraer ninguna información relevante. 


\section{Capítulo 5}

\section{Conclusiones}

Un viaje de mil millas comienza con un

solo paso.

Lao Tse

\subsection{Conclusiones}

Después de desarrollar este trabajo, se ha adquirido un mayor conocimiento sobre las diferentes problemáticas que tiene asociadas el proceso de laminación automática y consolidación in-situ con materiales reforzados termoplásticos. En este apartado, va a incluirse una revisión de los efectos detectados así como todas aquellas vías de mejora y trabajos futuros que se consideran imprescindibles para continuar avanzando en el completo conocimiento de este proceso de fabricación.

Una primera conclusión tras todos los desarrollos elaborados pasa por clarificar que, ejecutar comparaciones entre los resultados obtenidos de diferentes equipos de encintado, procedentes de diferentes fabricantes, no es riguroso. En este proceso de fabricación interviene un número elevado de variables que deben estar completamente controladas y deben ser lo más similares posible para poder establecer una comparativa lógica. Evaluar los resultados respecto a los obtenidos por otros centros, requiere conocer todos los elementos implicados en el encintado: material exacto empleado, equipo de encintado (presión, guiado, calentamiento), sistemas de fijación de primera capa, calentamiento y materiales del utillaje de laminación, rodillos de compactación, etc. La modificación de uno solo de los elementos, altera por completo todos los resultados.

Durante los desarrollos elaborados para la determinación de la transferencia térmica en el material de modo experimental, se ha detectado la 
importancia de emplear un tipo de sonda de medida de espesor inferior al tamaño individual de capa del material, este es el único modo de permitir mediciones que se ajusten en posición dentro del laminado a los valores que se desea registrar. Estas monitorizaciones han mostrado que, una capa del laminado, bajo unas condiciones de encintado específicas $((1 \mathrm{~m} / \mathrm{min})$, consignando un valor de temperatura de encintado de (673K) en el NIP y útil frío), experimenta fusión durante los encintados de hasta 5 capas por encima. No obstante, aun experimentando valores de temperatura en el rango de fusión, solo durante el encintado de la primera capa se superará la temperatura de fusión de equilibrio y tras la cuarta, la fusión no sobrepasará el máximo del pico endotérmico registrado por calorimetría en la fusión. Este resultado es de gran utilidad para conocer hasta cuándo pueden generarse efectos de reconsolidación en el material. Asimismo, detectar una falta de superación de la fusión de equilibrio es un reflejo claro de los cambios de tendencia que se obtendrán en la cristalización del material.

Los perfiles manifiestan también, que en un laminado de bajo espesor (considerando bajo espesor, 16 capas), durante todo el proceso de encintado las capas inferiores superarán la temperatura de transición vítrea. Asimismo, es notable que los perfiles de enfriamiento de estas capas más bajas, se volverán cada vez más suaves, de modo tal que, para recuperar la temperatura del utillaje se necesitará un intervalo de tiempo superior cuanto más lejos se localice el punto respecto a la fuente de calor.

Un trabajo futuro en este aspecto, debería basarse en la ejecución de monitorizaciones también en condiciones de utillaje calefactado, con variaciones en la velocidad de encintado del equipo, con mayores espesores en los laminados considerados y con diferentes posiciones para la sonda de medida en el espesor.

La simulación térmica ejecutada, ha permitido obtener un resultado que acopla bien con el obtenido por la medida experimental con termopares, bajo la consideración de un factor que estima que el material no absorberá toda la densidad de energía suministrada por el láser. La simulación, ha facilitado valorar los efectos de la modificación de ciertos parámetros: resistividad entre capas, efecto de la velocidad de encintado, etc. Sirviendo como herramienta a la hora de efectuar una toma de decisiones sobre cambios de condiciones de encintado en el equipo. Entre la información reportada se destaca la evidencia de un requisito de potencia superior en los encintados a mayor velocidad o la relajación del requisito de potencia mediante el empleo de utillajes calefactados. Además, las observaciones realizadas sobre los efectos del calentamiento en el material de aporte, resultan de utilidad para futuras situaciones de encintado en geometrías más complejas. 
Este modelo, aunque operativo y útil como elemento predictivo, sigue presentando desviaciones respecto a los resultados reales. Esas fuentes de error podrían estar causadas por el gran número de propiedades del material en las que está basado el modelo y cuya variación respecto al valor real supone un gran impacto sobre el resultado final. Otra fuente de error en el modelo procede de considerar valores mantenidos para la potencia durante los encintados, hecho que no es real y que es detectable en las variaciones entre los perfiles tiempo-temperatura obtenidos para un punto entre capas 1 y 2 durante los encintados de 16 capas entre modelo y termopar. Para paliar esta problemática, una futura evolución del modelo debería re-alimentarlo con una subrutina que actualizara el valor de potencia bajo la premisa de obtener $673 \mathrm{~K}$ en la capa que está siendo encintada en dicho instante.

El hecho de trabajar experimentalmente con un láser de óptica variable también altera los resultados, pues supone el empleo de una fuente térmica heterogénea frente a la homogeneidad considerada en el modelizado. Trabajos futuros deberían también destinarse a efectuar simulaciones con una función en la fuente de calentamiento que pueda asemejarse a un caso más realista de encintado.

Se han localizado trabajos de investigación donde ya se han elaborado acoplamientos entre modelos térmicos y ópticos, que permiten obtener mayor precisión en la determinación de la temperatura por contemplar los efectos de las diferentes reflexiones del haz láser. Como trabajo futuro, deberán ser caracterizadas las propiedades ópticas del material de trabajo y extrapolarlas al desarrollo de modelos acoplados termo-ópticos. El empleo de Comsol Multiphysics permitirá la tarea pues consta de un módulo que permite contabilizar esos efectos.

Futuros desarrollos deberán permitir extrapolar el modelo desarrollado a un caso tridimensional. Dicha extensión del modelo posibilitará acoplar los efectos térmicos con predicciones sobre el desarrollo de tensiones residuales en el material. El caso tridimensional, será requisito para las predicciones de calentamiento en casos de encintado con geometrías más complejas.

Los diferentes análisis ejecutados tratando de estimar la degradación térmica en el material PEEK y APC2/AS4 han permitido llegar a las siguientes conclusiones.

Las medidas experimentales buscando efectos de degradación en diferentes muestras tras su calentamiento por la fuente láser, en condiciones de trabajo habituales de laminación automática y consolidación in-situ, han 
manifestado sutiles indicios de una posible degradación térmica en el material. Ésta es pequeña como para condicionar los resultados finales de pieza.

El desarrollo de los modelos de degradación por medio de los resultados de las técnicas de termogravimetría y reología han permitido generar representaciones matemáticas predictivas sobre posibles efectos en el material sometido a perfiles específicos tiempo-temperatura. Sus resultados no son idénticos, mostrando la reología un efecto de degradación adelantado respecto al obtenido por la termogravimetría, probablemente como causa de la imposibilidad de esta segunda técnica para detectar roturas en las cadenas sin que estas sean suficientemente pequeñas como para volatilizarse.

Por como tiene lugar el proceso de encintado automático, los puntos del laminado experimentan además re-calentamientos en cada estadio de laminación de una nueva capa. Las mediciones elaboradas no representan de modo estricto el estado final general en que queda el material. Respecto a las observaciones de la reología, los actos de reticulación probablemente se incrementarán con cada etapa de encintado de una nueva capa, teniéndose en cuenta el perfil térmico registrado a medida que el punto se aleja de la fuente láser, que irá decayendo progresivamente. A pesar de la anterior afirmación, los registros de la calorimetría diferencial de barrido pueden utilizarse como garantía de la inexistencia de efectos importantes sobre el laminado completo en las condiciones habituales de encintado.

Teniéndose en cuenta la información de la Figura 4.56 es posible detectar que con un programa de calentamiento de $1073 \mathrm{~K}$, transcurridos tan solo $0,2 \mathrm{~s}$ se produciría una degradación de la muestra de hasta un $9 \%$, considerándose la pérdida de masa como parámetro de control. El anterior resultado permite efectuar evaluaciones sobre los límites de incremento de temperatura en el trabajo a mayor velocidad sin impactar en degradación sobre el material.

Respecto al análisis elaborado sobre el comportamiento a unión, ha sido posible plantear ecuaciones para el análisis del desarrollo de contacto íntimo y de difusión en el material. El estudio elaborado ha arrojado información sobre la importancia del trabajo con materiales con buenos acabados superficiales para conseguir incrementos en la productividad de los encintados.

La simplificación de la superficie del material por medio de una sucesión de rectángulos ha permitido ejecutar una primera aproximación a la heterogeneidad del material. Su resultado, acoplado con las mediciones de viscosidad del material han reportado información sobre la imposibilidad de conseguir un grado de contacto total durante una sola etapa de encintado a $1 \mathrm{~m} / \mathrm{min}$. Ha sido posible plantear una evolución de dicho parámetro con mo- 
dificaciones sobre la velocidad de encintado, siendo una muestra clara de su impacto para la consecución de incrementos productivos de esta tecnología. No obstante, el trabajo se ha limitado a analizar el impacto de la variable durante la primera etapa de encintado, reportándose evidencias sobre su evolución con el incremento en el número de capa encintadas.

La viscosidad se ha presentado como un factor crítico del resultado obtenido. Su determinación ha sido posible para PEEK neto, pero su extrapolación mediante modelos teóricos al caso del preimpregnado ha resultado en valores alejados de los previamente propuestos por la bibliografía consultada. En el trabajo, han sido presentadas las variaciones causadas sobre el grado de contacto íntimo bajo la consideración de valores diferentes de viscosidad, observándose claras modificaciones en las tendencias obtenidas. En base a estos resultados, se considera necesario elaborar en un trabajo futuro una caracterización más precisa de la superficie del material, no sólo del material de partida enviado por el suministrador sino sobre su estado tras la compactación por el rodillo de la máquina de encintado. Esa etapa de compactación, dejará en unas condiciones diferentes a la entre-cara de las capas de material puestas en contacto y a la superficie exterior del material aportado. Esas modificaciones actuarán como nuevos condicionantes sobre el resultado del grado de contacto a obtener.

En línea con la determinación de la viscosidad, futuros trabajos derivados de esta tesis deberían destinarse a conocer el "shear rate" al que se somete el material durante el proceso de fabricación con la variación de la velocidad de encintado. En este trabajo, los cálculos se han efectuado bajo la suposición de un "shear rate" nulo, empleando los valores más altos de viscosidad del perfil, en la zona del primer "plateau newtoniano". Dicho efecto condiciona el valor numérico de viscosidad a emplear en los cálculos, modificando por completo la estimación del grado de contacto íntimo alcanzado al poder estimarse partiendo de valores de viscosidad muy inferiores.

La difusión de las cadenas poliméricas ha sido modelizada mediante una función de dependencia del tiempo de relajación de cadena con la temperatura. Para estimar los tiempos de relajación, se han empleado ensayos isotermos de reología y sus valores se han obtenido atendiendo a distintos criterios (que se basan en diferentes estados de relajación de la cadena). El mayor de esos tiempos de relajación de cadena, que se obtendría en el cruce de las pendientes $G^{\prime}$ y $G^{\prime \prime}$ cuando la frecuencia tiende a cero, no ha podido extraerse a causa de los efectos de degradación del PEEK para dichas condiciones de ensayo (largos tiempos). Se cree, que ese es el tiempo que mejor ajustaría el comportamiento del movimiento de las cadenas en la entre-cara de las distintas capas de material y por ello deberán ejecutarse trabajos fu- 
turos que permitan determinar su valor con soluciones que eviten efectos de degradación en el material.

Los análisis sobre la cristalización del material durante el proceso de encintado automático y consolidación in-situ han arrojado numerosa información sobre esta física en el polímero bajo estudio. Por un lado, la aplicación de la calorimetría diferencial de barrido sobre diferentes muestras de material procedentes de enfriamientos muy dispares, han manifestado variaciones principalmente asociadas con cambios morfológicos en el desarrollo de los cristales. Asimismo, la comparación de los resultados por DSC con los obtenidos mediante XRD parece un indicativo de una posible sobre-estimación de los valores de cristalinidad cuando se emplea la calorimetría.

Las anteriores evidencias sobre morfología, concuerdan también con los resultados obtenidos de la deconvolución de los picos exotérmicos de cristalización, donde se hizo necesario emplear dos picos de ajuste en PEEK y tres para el caso del APC2/AS4. Este incremento del número de picos se ha asociado con el desarrollo de una capa transcristalina sobre la fibra de carbono, que adquiere gran importancia sobre todo cuando los enfriamientos se efectúan a una gran velocidad.

Con los desarrollos elaborados, ha sido posible obtener una ecuación para la evolución de la cristalización en APC2/AS4 basada en la ecuación cinética general; no obstante, se cree que presentará una aplicación limitada a casos de alta velocidad de enfriamiento a causa del pobre ajuste obtenido en la determinación de los parámetros cinéticos y por la variación de los factores de peso que aplican a cada uno de los mecanismos de la cristalización cuando ésta se genera a altas velocidades como las de laminación automática y consolidación in-situ. Futuros trabajos deberán destinarse a la búsqueda de técnicas de ensayo capaces de reproducir programas de enfriamiento más similares a los del proceso de fabricación bajo estudio.

También se plantea en el trabajo una combinación de parámetros para la ecuación de doble Avrami, obtenida mediante un ajuste por mínimos cuadrados elaborado sobre ensayos de calorimetría. En la integración de la ecuación se ha podido observar que, bajo las condiciones de encintado automático, el valor reportado por la ecuación para la cristalización desarrollada es nulo y se aproxima a un $30 \%$ cuando se imponen condiciones de utillaje calefactado, en línea con los resultados reales obtenidos.

Futuros trabajos deberán considerar la extrapolación de los cálculos a las sucesivas etapas de calentamiento-enfriamiento en el proceso de encintado automático, así como valorar la factibilidad de aplicar esta ecuación en 
procesos de cristalización en frío del material.

Las observaciones realizadas sobre las diferencias en la cristalización entre laminados en prensa e ISC, han sido contrastadas con las imágenes obtenidas por SEM sobre las probetas sometidas a ensayos mecánicos, donde se ha detectado la existencia de fibras desnudas en los laminados procedentes de ISC en comparación con fibras completamente cubiertas de resina en las probetas ensayados procedentes de la prensa. La diferencia parece indicar la existencia de una capa transcristalina débil en las probetas de ISC, pudiendo ser ésta la causa de la gran desviación entre los resultados de flexión obtenidos entre los paneles fabricados por ambas tecnologías, con una resistencia casi un $50 \%$ inferior en ISC.

Las propiedades mecánicas de IPSS e ILSS, no parecen verse tan afectadas como la flexión, donde el efecto fundamental de rotura se asocia a la compresión. Estas probetas, con todas las capas orientadas a $0^{\circ}$, son un reflejo de otras de las problemáticas asociadas al proceso de consolidación in-situ, como efectos de desalineamiento en las fibras o tensiones residuales en los laminados.

Los análisis elaborados mediante DMA, son también una muestra de las variaciones que la cristalización puede estar generando sobre los resultados, viéndose una tendencia de comportamiento diferente cuando la temperatura alcanza valores próximos a los de $T_{g}$ durante el ensayo. Se cree que, a causa de la imposibilidad para formar geometrías tipo lamelas en ISC por el rápido choque entre las esferulitas, la parte amorfa puede estar sometida a otras restricciones en sus movimientos de lo que se encuentra en las formaciones cristalinas de la prensa.

Este trabajo ha permitido dar un paso adelante en el análisis del proceso de encintado automático y consolidación in-situ con materiales reforzados termoplásticos, no obstante, todos los desarrollos se han particularizado sobre APC2/AS4. Futuras modificaciones del material de encintado obligarán a re-calcular y obtener nuevamente los diferentes parámetros que aplican a cada una de las ecuaciones propuestas en este trabajo. Asimismo, en el trabajo no se ha podido resolver el acoplamiento entre todos los modelos ni su extrapolación al encintado de capas sucesivas, trabajos que se plantean como futuros desarrollos derivados de esta tesis doctoral. 



\section{Apéndice A}

\section{Ejecuciones de medida de temperatura con termopares}

Para la estimación de temperatura desarrollada durante el proceso, en el transcurso de esta tesis fueron elaboradas diferentes ejecuciones para embeber termopares en el conjunto laminado a diferentes alturas en el espesor del mismo. En esas ejecuciones, los termopares empleados no fueron los de menor diámetro adquiridos a OMEGA y referenciados en la sección 4.1.1 por ello, se ha prescindido de las mismas para la intercomparación con los datos simulados. El mayor espesor de los termopares puede limitar la precisión en la medida, suponiendo desviaciones al modelo directamente ligadas a ese efecto. Sin embargo, sí permiten obtener tendencias en el comportamiento durante el encintado. Se incluyen a continuación los resultados de tres ejecuciones donde los encintados presentan todas las capas a $0^{\circ}$, una combinación de capas a $0^{\circ}$ y a $90^{\circ}$ y un encintado con la interacción de doble láser.

Todas las ejecuciones que serán presentadas en lo sucesivo fueron elaboradas con el utillaje de laminación sin calefactar.

\section{A.1. Encintado con todas las capas a 0}

En una ejecución de encintado habitual con todas las capas a cero, fue embebido un termopar tipo 406-622 y varios 818-021 de TC Direct (más información de los mismos recogida en 4.1.1. Los termopares fueron colocados en diferentes alturas del espesor del laminado tal y como se esquematiza en la Figura A.1. obteniéndose los perfiles térmicos que se reportarán en esta sección. A pesar de que la representación recoge una visualización en bidimensional relativa al espesor del laminado, los termopares se localizaron en diferentes posiciones a lo largo de la longitud de la tow laminada. En con- 
diciones normales de encintado, las tows individuales no se posicionan una sobre otra en dirección del espesor en las capas sucesivas sino que se decalan entre sí unos milímetros siguiendo las reglas del "stagger index". En este caso y por claridad en la representación, se incluirán aquellos perfiles donde el punto de medida recibe la irradiación directa del láser con el número de capas que corresponda en la vertical sobre el punto. En las representaciones se obviarán las medidas cuando el termopar recibe la irradiación directa del láser.

Otra problemática localizada durante la ejecución de estas pruebas fue que dada la necesidad de desnudar los cables de los temopares, se hacía preciso posicionar kapton para proteger el cable de la conducción de la fibra de carbono. En aquellas zonas donde se producía algún efecto de degradación sobre el kapton por la irradiación láser, el termopar quedaba libre y por tanto la medida registrada por el termopar resultaba del promedio de los puntos posibles de medida, quedando invalidada.

Se incluyen a continuación los resultados de las medidas durante los encintados de las capas 6, 8, 12 y 15 .

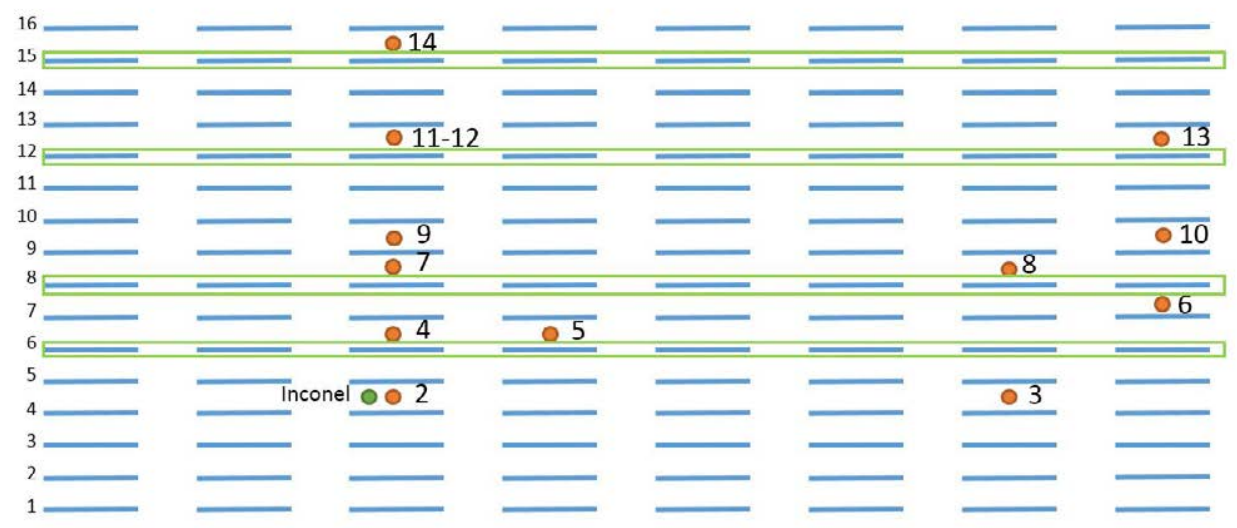

Figura A.1: Croquis de posicionado de termopares en un encintado a $0^{\circ}$

Encintado de capa 6. En el encintado de la capa 6, se ha podido monitorizar la temperatura de un punto posicionado entre las capas 4 y 5 mediante las lecturas de los termopares TC1, TC2 y TC3 (1 capa de separación con la irradiación del láser). Tal y como refleja la Figura A.2, los TC1 y TC2, de distinta naturaleza, han medido valores similares y en el entorno de $575 \mathrm{~K}$ $\left(300^{\circ} \mathrm{C}\right)$ con una capa de separación a la irradiación de la fuente láser. Un valor muy inferior al registrado en la medición con los termopares de OMEGA. Por su parte, el TC3 ha registrado un valor de temperatura de $675 K$ 
$\left(400^{\circ} \mathrm{C}\right)$, mucho más aproximado al valor real del encintado monitorizado por la termografía. Una causa probable de este efecto es el posible valor promedio de temperatura leído por el termopar al encontrarse los cables del mismo en contacto con el carbono.

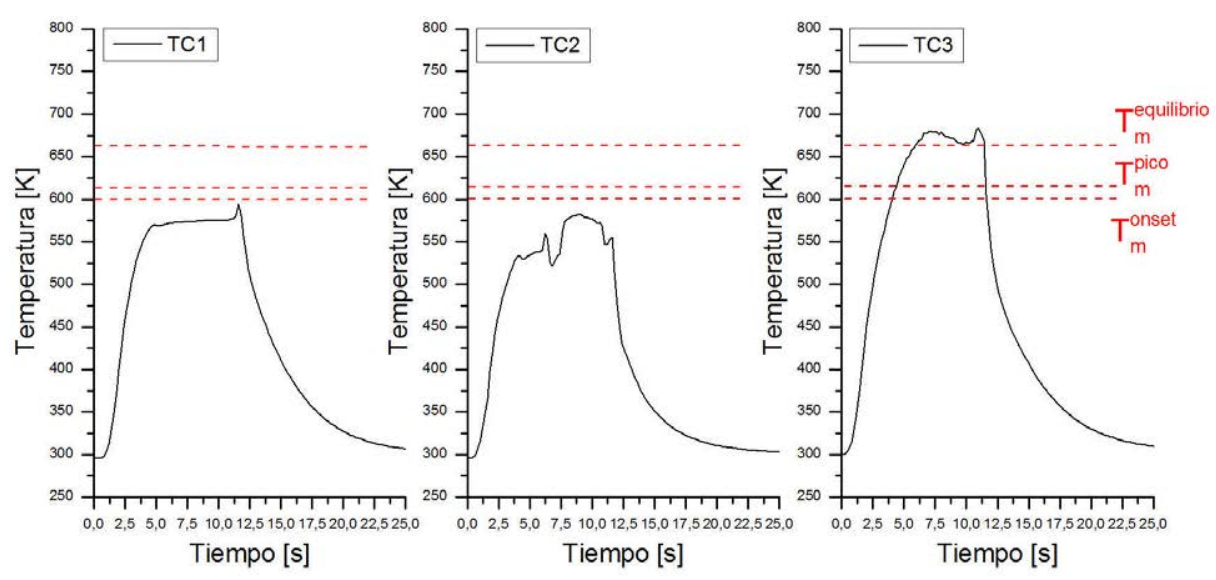

Figura A.2: Encintado de la capa 6, lecturas de los termopares TC1-TC2TC3 (entre 4-5)

Encintado de capa 8. Nuevamente, la lectura del termopar TC3, ha mostrado un valor de $100 \mathrm{~K}$ por encima de las lecturas de los termopares TC1TC2. En ambos casos de encintado, tanto para la capa 6 como para la 8 puede considerarse que la lectura del TC3 se ajusta más al caso real obtenido con una consigna de $673 \mathrm{~K}\left(400^{\circ} \mathrm{C}\right)$ en la medida de termografía sobre el sustrato irradiado por el láser. Los perfiles tiempo-temperatura se incluyen en la Figura A.3.

Durante el encintado de esta capa, los termopares TC4-TC5 con una sola capa de distancia a la irradiación del láser, presentan una desviación en la medida de unos $100 \mathrm{~K}$, como puede observarse en los perfiles de la Figura A.4. Siendo el termopar TC5, con un valor de unos $700 \mathrm{~K}\left(\sim 425^{\circ} \mathrm{C}\right)$, el más alto y con más sentido respecto a las condiciones del encintado. 


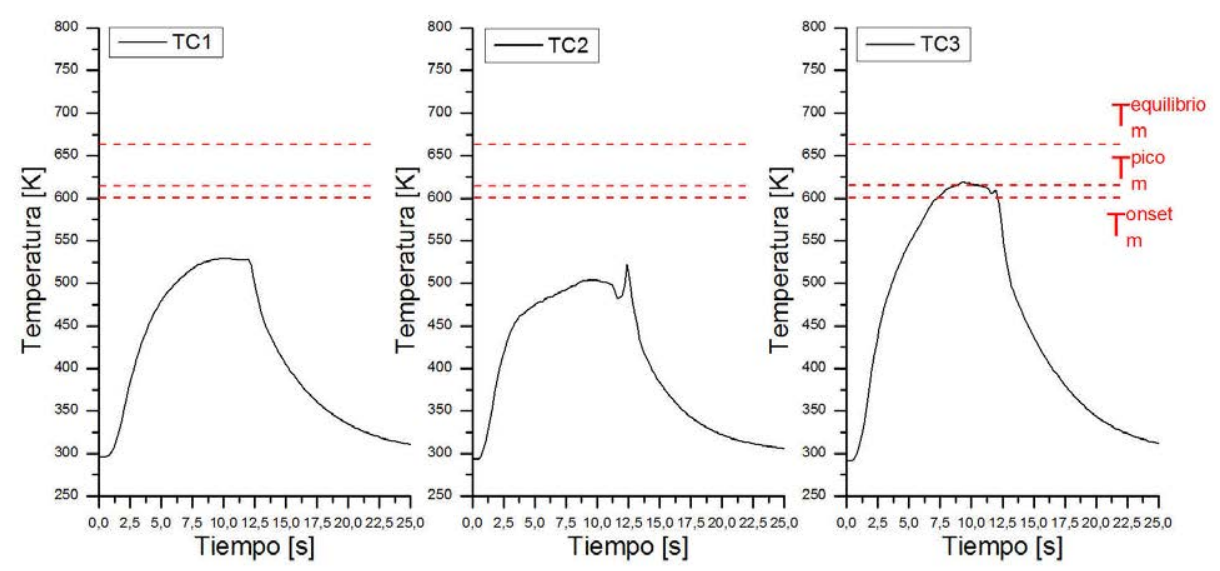

Figura A.3: Encintado de la capa 8, lecturas de los termopares TC1-TC2TC3
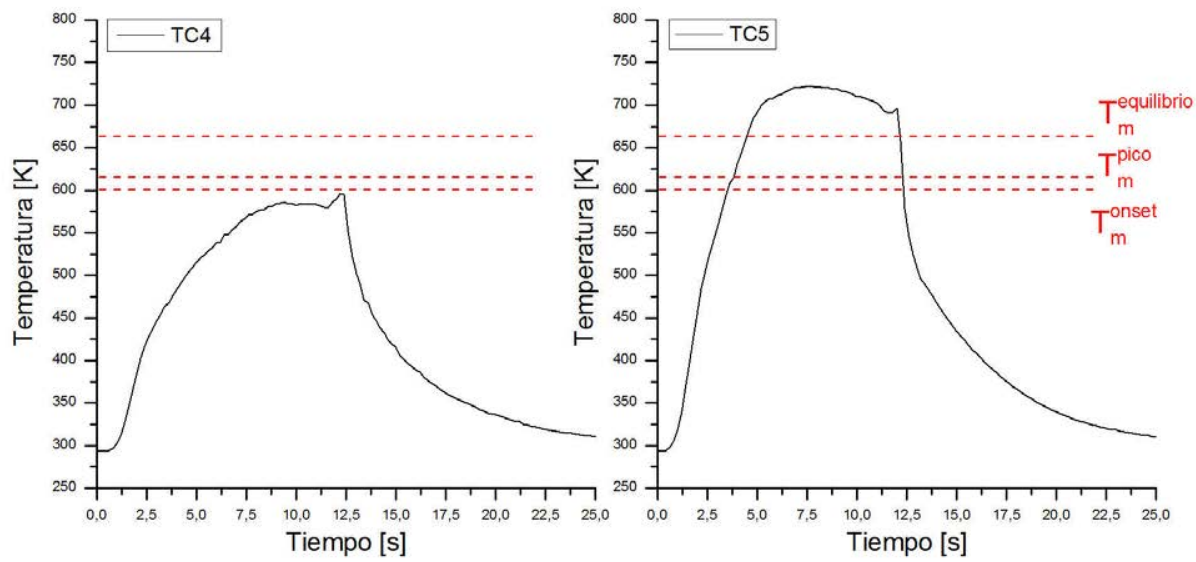

Figura A.4: Encintado de la capa 8, lecturas de los TC4-TC5

Encintado de capa 12. En el encintado de la capa 12 se ha perdido la información de los termopares TC3, TC5-TC8, luego los registros tiempotemperatura de esa ejecución se limitan a los reportados por TC1-TC2 en la Figura A.5 (7 capas de distancia a la fuente de irradiación), TC4 en la Figura A.6 (5 capas de distancia a la irradiación del láser) y TC9-TC10 en la Figura A.7 (2 capas de distancia al láser). 


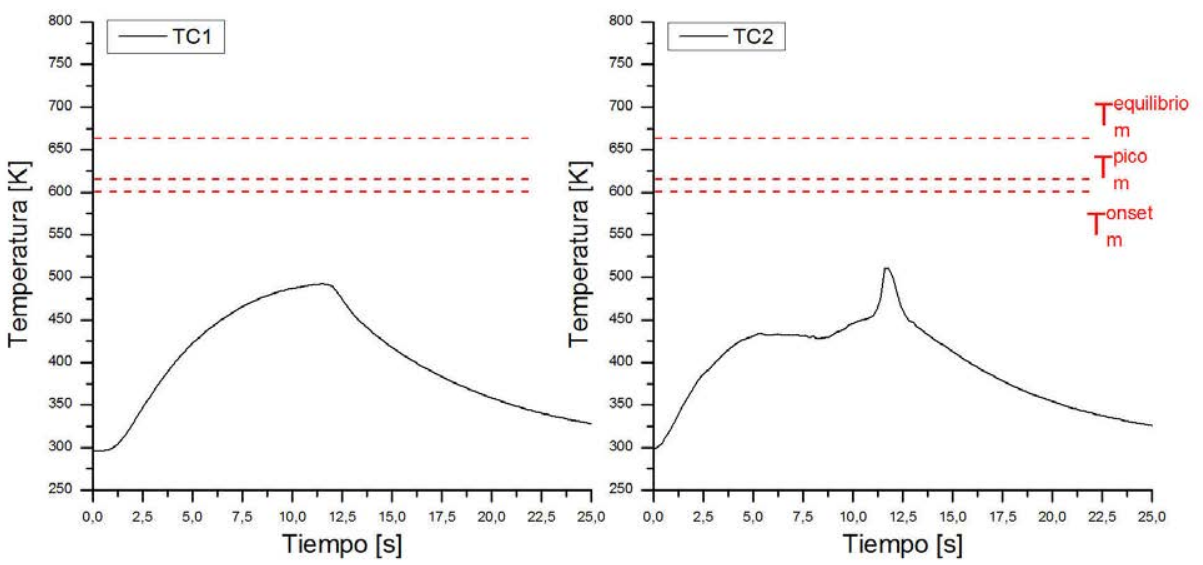

Figura A.5: Encintado de la capa 12, lecturas de los termopares TC1-TC2

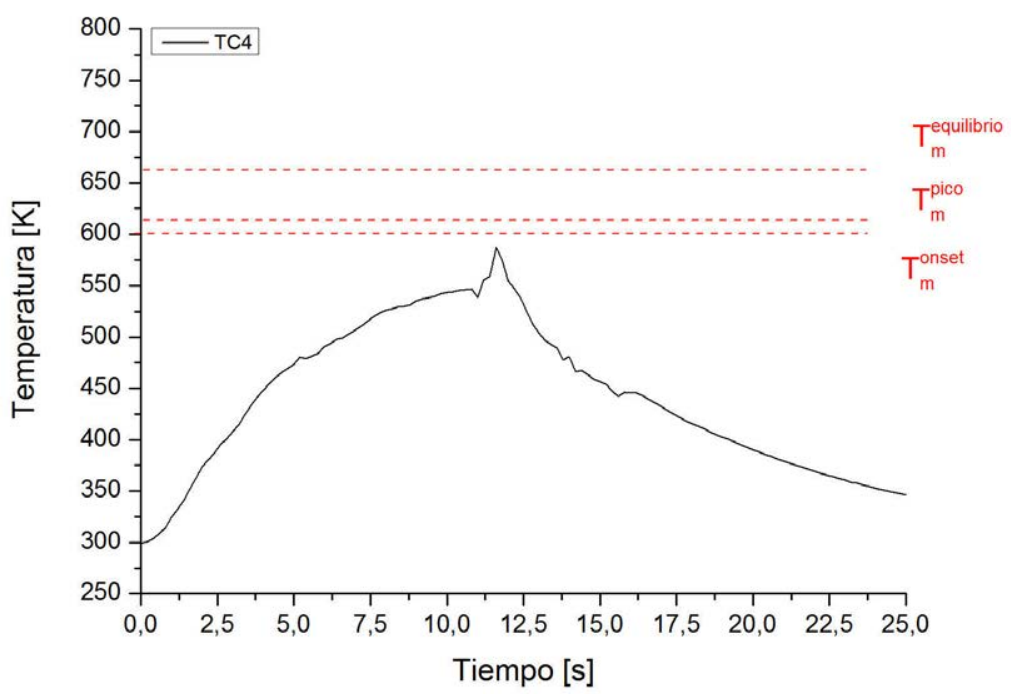

Figura A.6: Encintado de la capa 12, lectura del termopar TC4 

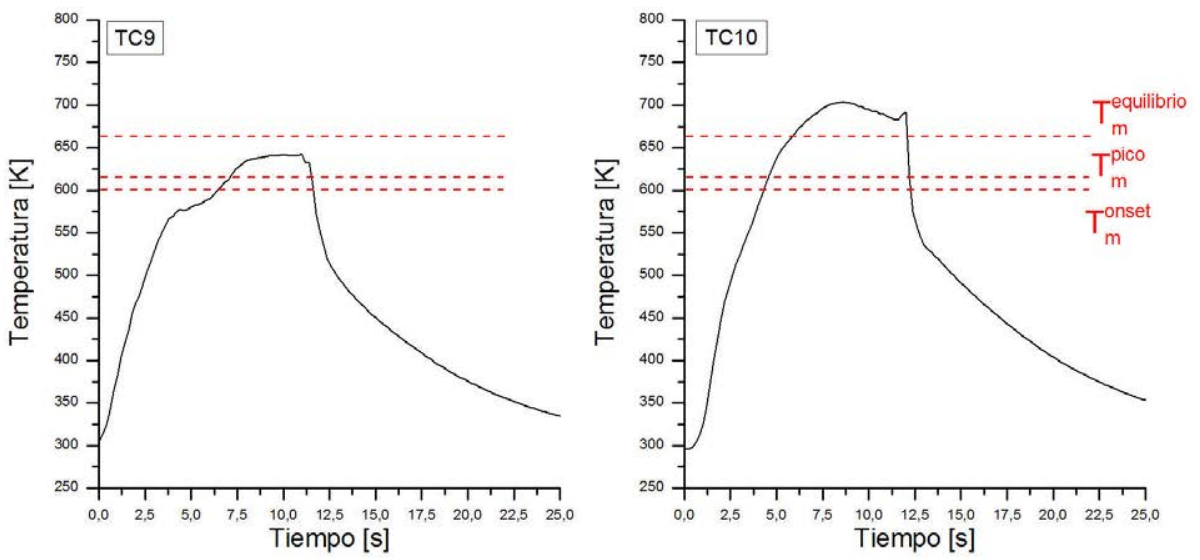

Figura A.7: Encintado de la capa 12, lectura de los termopares TC9-TC10

Encintado de capa 15. En el encintado de la capa 15, se han podido monitorizar las medidas de puntos correspondientes a zonas situadas entre las capas 4 y 5 (TC1-TC2), entre las capas 6 y 7 (TC4), entre capas 8 y 9 (TC7), entre las capas 9 y 10 (TC9) y finalmente entre las capas 12 y 13 (TC11).

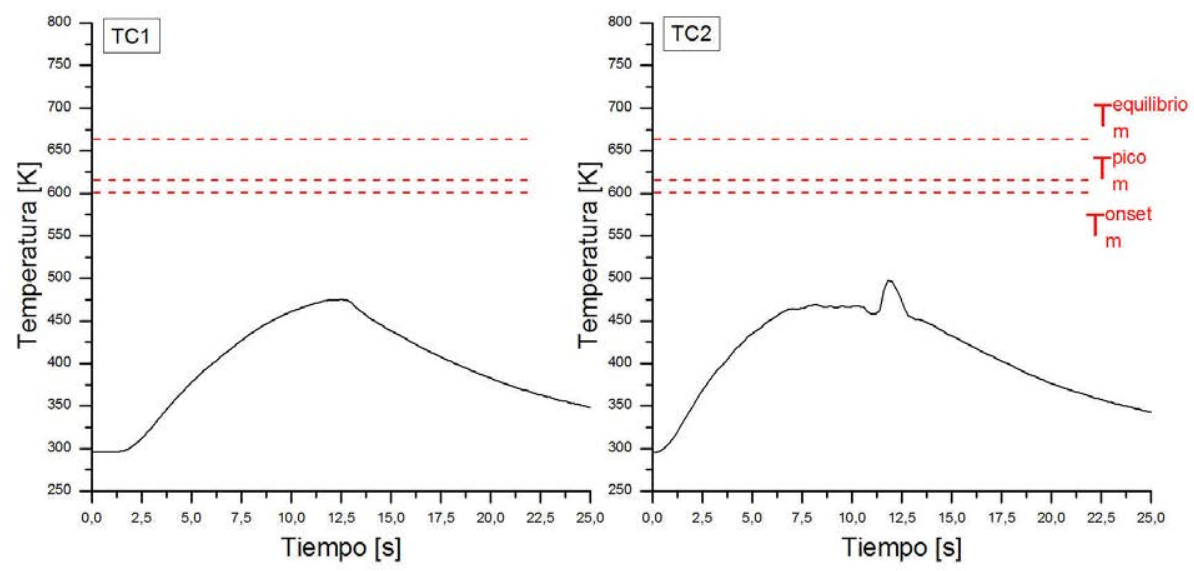

Figura A.8: Encintado de la capa 15, lecturas de los TC1-TC2-TC3 


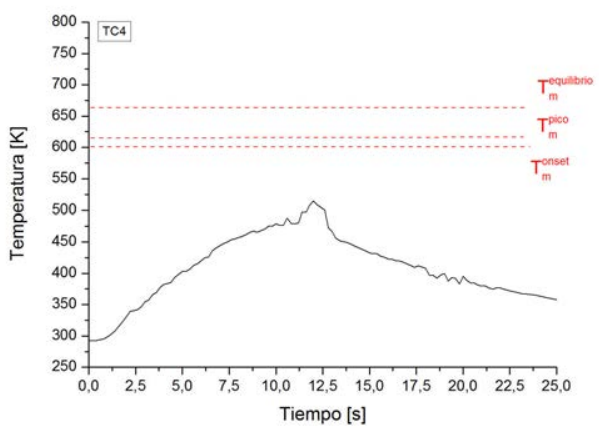

(a)

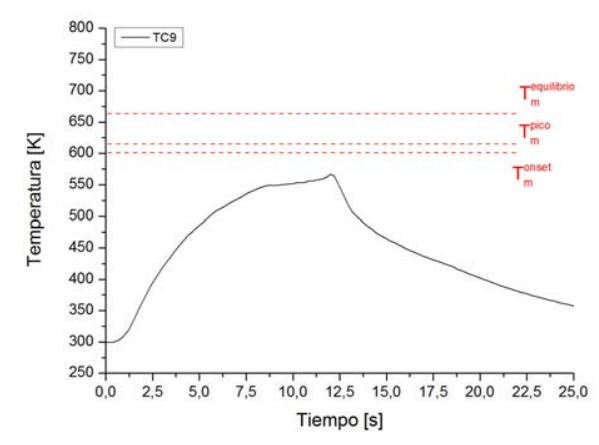

(c)

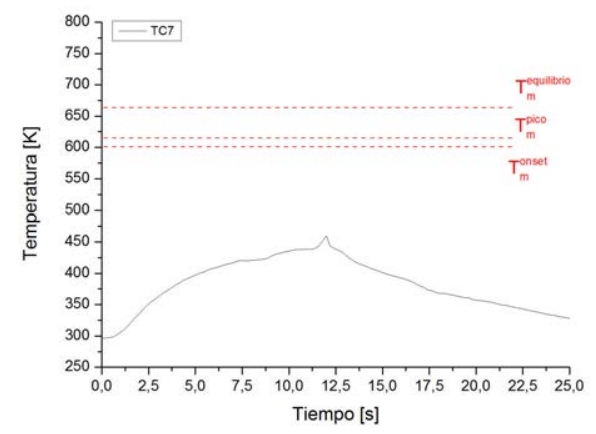

(b)

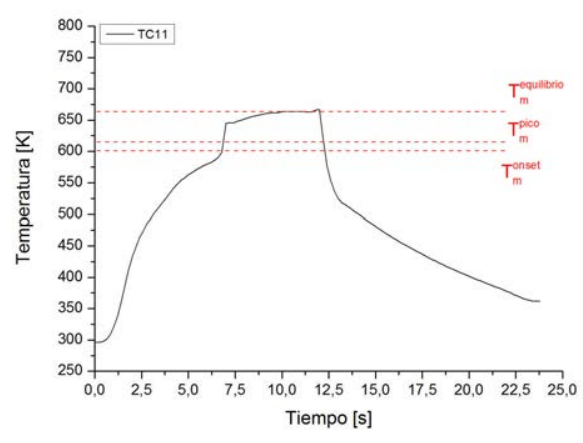

(d)

Figura A.9: Encintado capa 15 (a) TC4, (b) TC7, (c) TC9 y (d) TC11

La ejecución anteriormente incluida en el estudio refleja como, en los encintados con este proceso de fabricación, existe una fuerte heterogeneidad en el resultado medido mediante el empleo de termopares, cuyas causas posibles son desviaciones en el posicionado de los mismos o posibles daños experimentados por sobre-calentamiento impuesto por el láser. Tratando de paliar la anterior problemática, fue elaborada una prueba de encintado combinando capas a 0 y $90^{\circ}$, donde la posición de los termopares era más fácilmente controlable. 


\section{A.2. Encintado con capas a 0-90}

Esta ejecución se basó en el encintado de un laminado con 32 capas donde se intercalaban las orientaciones $0^{\circ}$ y $90^{\circ}$ (representadas en la Figura A.10. donde la línea punteada hace referencia a una capa a $\left.90^{\circ}\right)$.

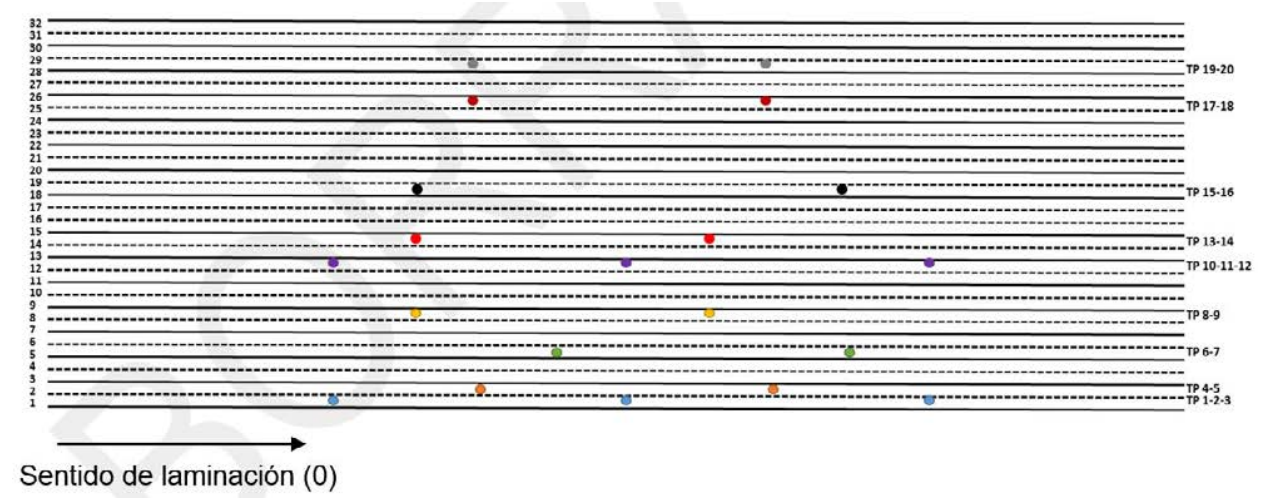

Figura A.10: Croquis de posicionado de termopares en un encintado a 0-90

Tomando como referencia un extremo del encintado, las posiciones de los diferentes termopares en distancia quedan recogidas en la Tabla A.1. Para controlar la evolución de la temperatura en el espesor se representarán en lo sucesivo los datos obtenidos en los encintados a $0^{\circ}$.

\begin{tabular}{|c|c|c|}
\hline Termopar & Posición en espesor & $\begin{array}{c}\text { Posición desde extremo del laminado } \\
{[\mathrm{mm}]}\end{array}$ \\
\hline TC1-TC2-TC3 & Entre 1-2 & $92,5-187,5-282,5$ \\
\hline TC4-TC5 & Entre 2-3 & $140-235$ \\
\hline TC6-TC7 & Entre 5-6 & $162,5-257,5$ \\
\hline TC8-TC9 & Entre 8-9 & $117,5-212,5$ \\
\hline TC10-TC11-TC12 & Entre 12-13 & $92,5-187,5-282,5$ \\
\hline TC13-TC14 & Entre 14-15 & $117,5-212,5$ \\
\hline TC15-TC16 & Entre 18-19 & $117,5-212,5$ \\
\hline TC17-TC18 & Entre 25-26 & $140-235$ \\
\hline TC19-TC20 & Entre 28-29 & $140-235$ \\
\hline
\end{tabular}

Tabla A.1: Posiciones termopares en el encintado 0-90 
Encintando capa 3. En el encintado de la capa 3, los termopares TC1TC2-TC3 son los que reciben la fuente de calor a través de una capa interpuesta entre ellos y la fuente láser. Entre los sensores es posible detectar una diferencia de temperatura máxima de $50 \mathrm{~K}$. Registrándose un valor máximo por el termopar TC1 de $770 K\left(\sim 500^{\circ} \mathrm{C}\right)$ puntual justo en el punto NIP y unos valores medios estabilizados entre 700 y $730 K$ aproximadamente $\left(\sim 425-460^{\circ} \mathrm{C}\right)$. Los valores son superiores al valor consignado de $673 \mathrm{~K}$; sin embargo, teniendo en consideración la Figura A.12 representativa de las lecturas tomadas por la cámara termográfica durante el encintado de capa 3 , es posible observar como existen puntos capaces de alcanzar incluso $720 \mathrm{~K}$ $\left(\sim 450^{\circ} \mathrm{C}\right)$ por la propia irregularidad del perfil de calentamiento.

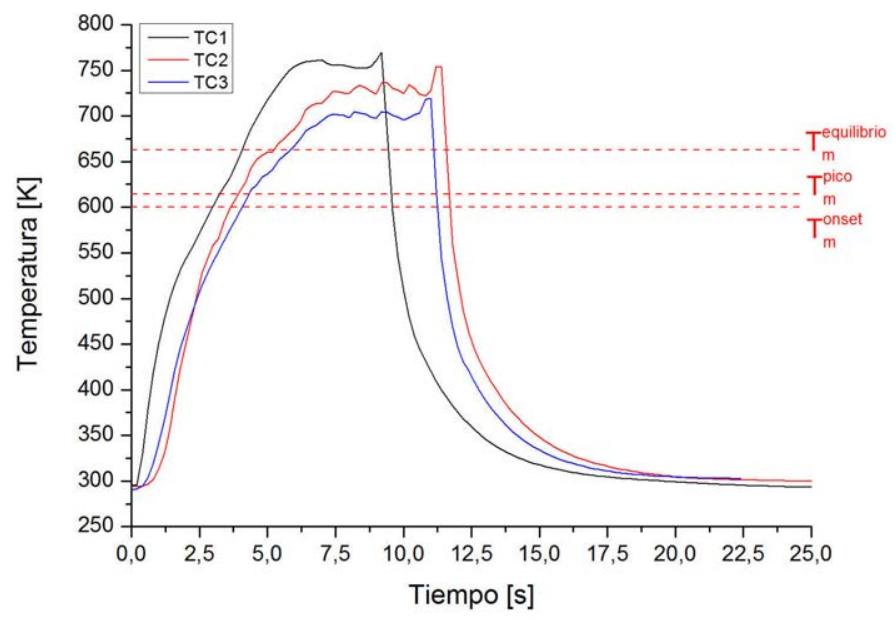

Figura A.11: Croquis de posicionado de termopares en un encintado a 0-90, encintado capa 3 - lecturas de TC1-TC2-TC3

Encintando capa 5. En el encintado de la capa 5, los termopares capaces de registrar el calentamiento láser son TC1-TC2-TC3 entre las capas 1 y 2 (3 capas de separación con la irradiación láser), y los termopares TC4 y TC5 entre las capas 2 y 3 (2 capas de separación con la irradiación láser). Durante el encintado, la lectura del termopar TC2 se pierde porque el termopar resulta dañado.

La comparativa entre los gráficos de derecha e izquierda de la Figura A.13 manifiesta como el TC1, encontrándose a 92,5 $\mathrm{mm}$ del borde de panel e inicio de la irradiación láser, experimenta un calentamiento menor en extensión temporal y en máximo, respecto a los demás termopares, que sí son capaces de registrar toda la longitud del láser durante su recorrido. A 3 capas de separación respecto de la fuente de calentamiento, existe una diferencia 
320 ApÉndice A. Ejecuciones de medida de temperatura con termopares

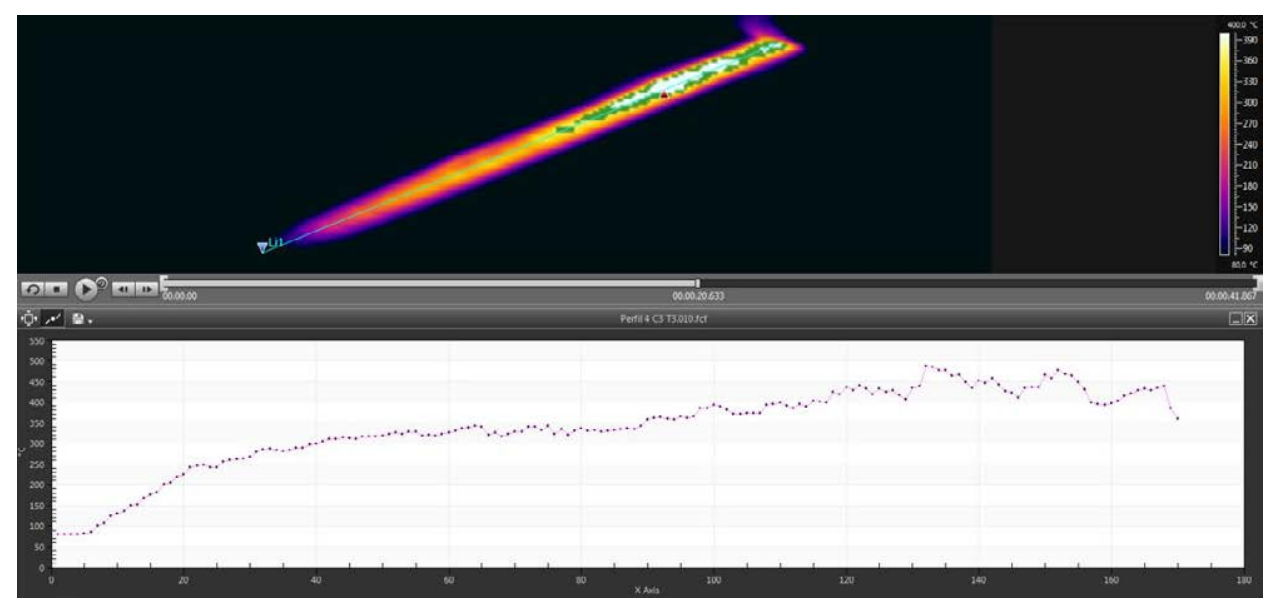

Figura A.12: Registro en un instante temporal de la termografía durante el encintado de capa 3

de temperatura de unos $60 K$ respecto al valor impuesto en superficie y observado por termografía, por su parte, 2 capas de separación manifiestan una diferencia próxima a $40 K$.

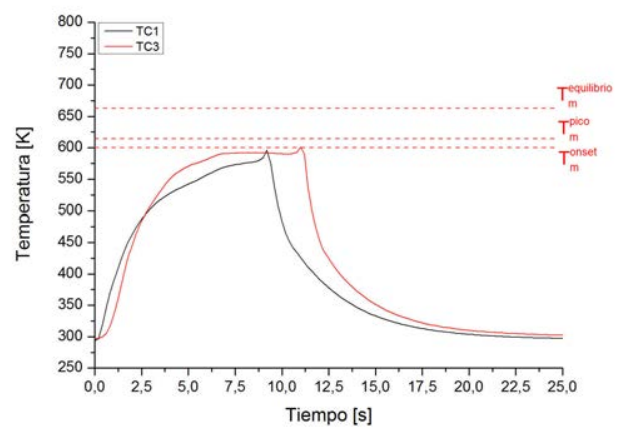

(a)

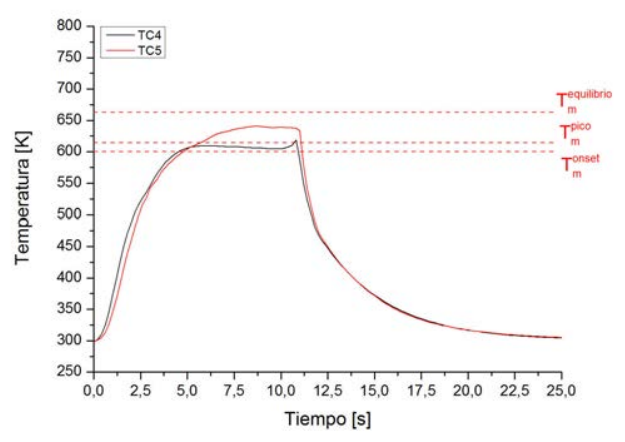

(b)

Figura A.13: Encintado capa 5 (a) TC1-TC3 y (b) TC4-TC5

Encintando capa 7. En el encintado de la capa 7, los termopares capaces de registrar temperatura son TC1-TC2-TC3 entre las capas 1 y 2 (5 capas de separación con la irradiación del láser). La lectura del termopar TC2 se descartó ya durante encintados previos al haber resultado dañado el termopar durante el calentamiento láser. También los termopares TC4-TC5 entre las capas 2 y 3 (4 capas de separación con la irradiación láser). Se hizo necesario descartar la medida del TC5 por resultar nuevamente dañado por el láser en los encintados de tows paralelas a la que era objeto de la monitori- 
zación. Asimismo, en este encintado pudieron monitorizar el calentamiento los termopares TC6-TC7 entre las capas 5 y 6 (1 capa de separación con la irradiación láser). Los perfiles tiempo-temperatura se recogen en la Figura A.14.

Con 5 capas de separación al láser, el punto registra valores de temperatura unos $120 \mathrm{~K}$ por debajo del valor de consigna en superficie y leído por termografía (valor tomado del máximo registrado por el TC3 considerando que el TC1 no es capaz de mantenerse bajo todo el perfil de encintado láser en longitud). Cuando son 4 capas de separación a la fuente de irradiación, la diferencia en temperatura es del entorno de $70 K$ y al existir sólo una capa intermedia respecto a la fuente láser, el resultado de las medidas entre TC6 y TC7 presenta una diferencia de $50 K$ indicado posibles efectos derivados de diferencias en el embebido entre los termopares. El valor registrado por el termopar que muestra la mayor temperatura (TC6) es de $667 \mathrm{~K}\left(\sim 395^{\circ} \mathrm{C}\right)$, en un encintado en el que la termografía llegó a lecturas puntuales de hasta $723 K\left(\sim 450^{\circ} \mathrm{C}\right)$ en superficie. 


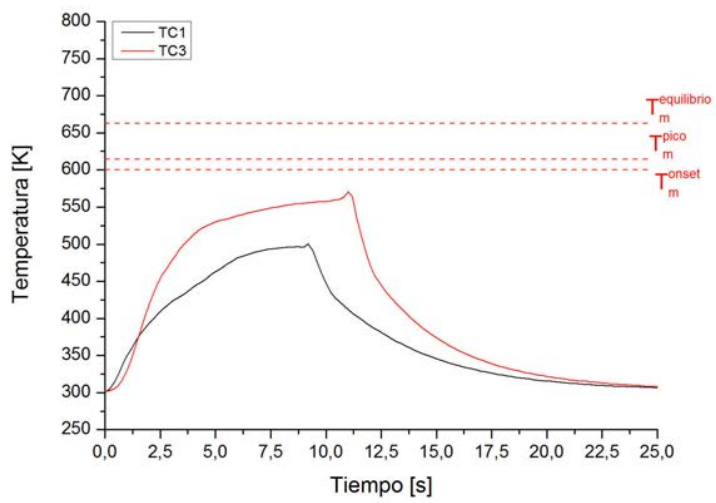

(a)

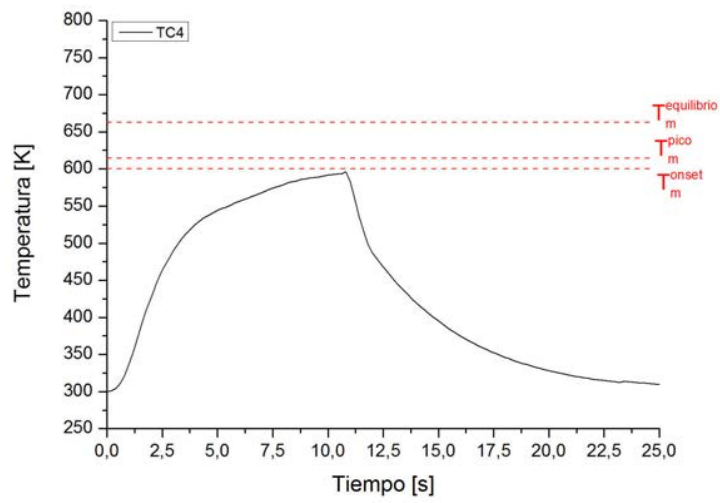

(b)

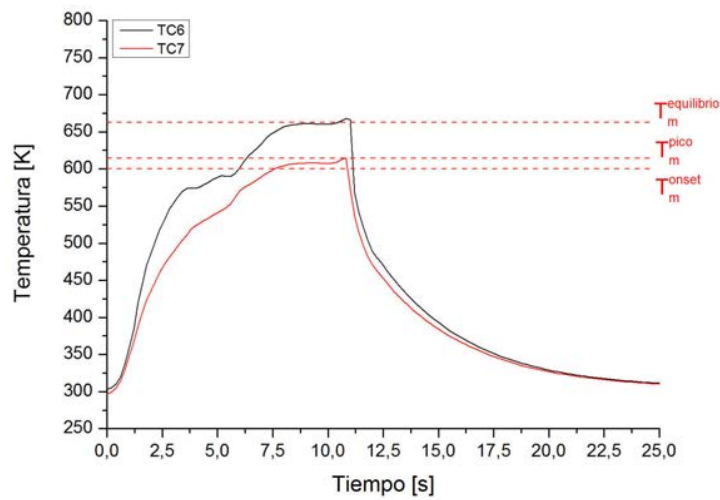

(c)

Figura A.14: Encintado capa 7 (a) TC1-TC3, (b) TC4 y (c) TC6-TC7 
Encintando capa 9. En el encintado de la capa 9, los termopares capaces de registrar temperatura fueron TC1-TC3, entre las capas 1 y 2 (7 capas de separación con la irradiación del láser), el termopares TC4 entre las capas 2 y 3 (6 capas de separación con la irradiación del láser) y los termopares TC6-TC7 entre las capas 5 y 6 (3 capas de separación con la irradiación láser). Los perfiles tiempo-temperatura se recogen en la Figura A.15.

El TC3 ha registrado un valor máximo de $510 K\left(\sim 240^{\circ} \mathrm{C}\right)$, con 7 capas de separación a la fuente de irradiación, unos $160 \mathrm{~K}$ bajo la consigna de encintado en la superficie medida por termografía. El termopar TC4, registró un valor prácticamente similar al existir 6 capas de separación. Por su parte, existe una desviación entre los dos termopares TC6 y TC7 en el calentamiento, con unos $70 K$ de diferencia entre sus medidas (ya observada con anterioridad en el encintado de la capa 7), siendo la del TC6 la más elevada y con una desviación de $120 K$ respecto a la consigna de temperatura en la superficie. 


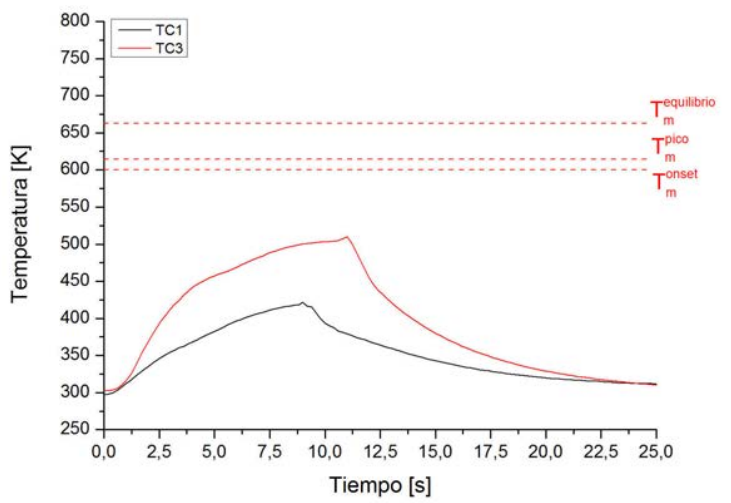

(a)

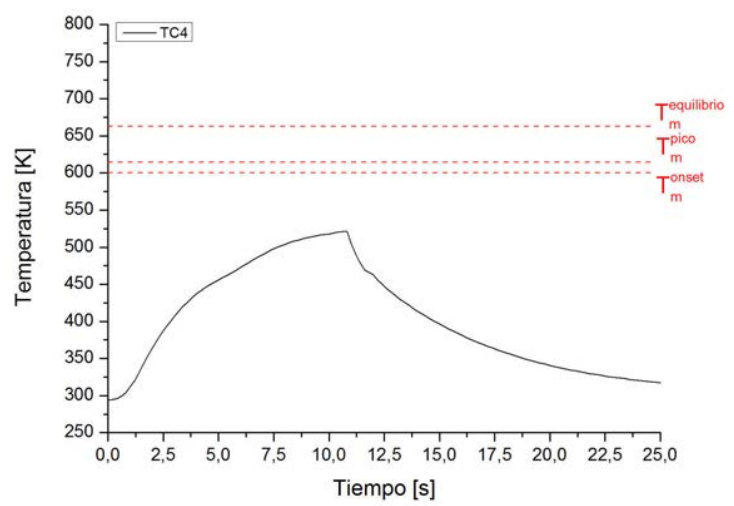

(b)

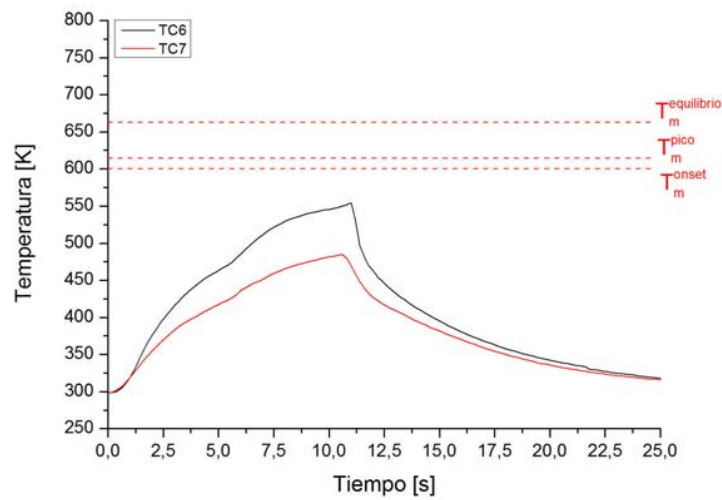

(c)

Figura A.15: Encintado capa 9 (a) TC1-TC3, (b) TC4 y (c) TC6-TC7 
Encintando capa 11. En el encintado de la capa 11, se incluyen además las lecturas de los termopares TC 8 y TC9, entre las capas 8 y 9, a las ya incluidas con anterioridad. Los termopares TC1-TC3 (9 capas de separación con la irradiación del láser), TC4 (8 capas de separación con la irradiación del láser), TC6-TC7 (5 capas de separación con la irradiación del láser) y TC8-TC9 (2 capas de separación con la irradiación del láser). Los perfiles tiempo-temperatura se recogen en la Figura A.16

Los registros manifiestan que, tomando como referencia una temperatura de $673 \mathrm{~K}$ en superficie por termografía, existen las siguientes desviaciones en función del número de capas de separación con la fuente térmica: $210 K$ con 9 capas de separación, $170 K$ con 8 capas de separación, $110 K$ con 5 capas de separación y $60 K$ con 2 capas de separación.

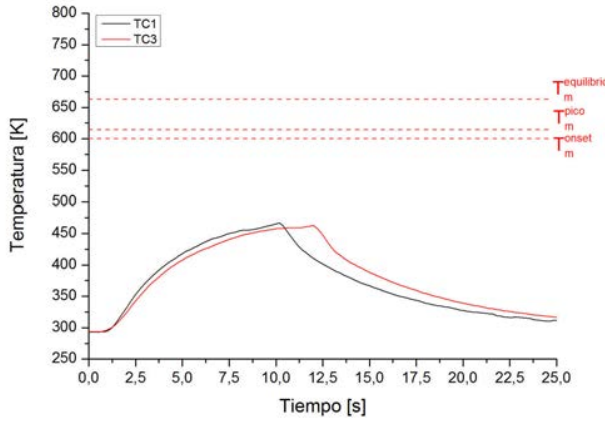

(a)

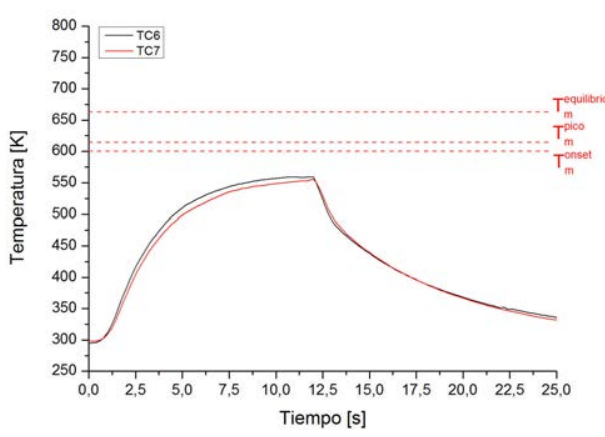

(c)

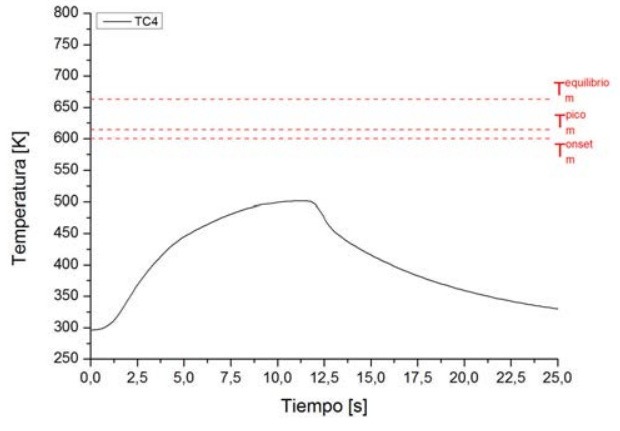

(b)

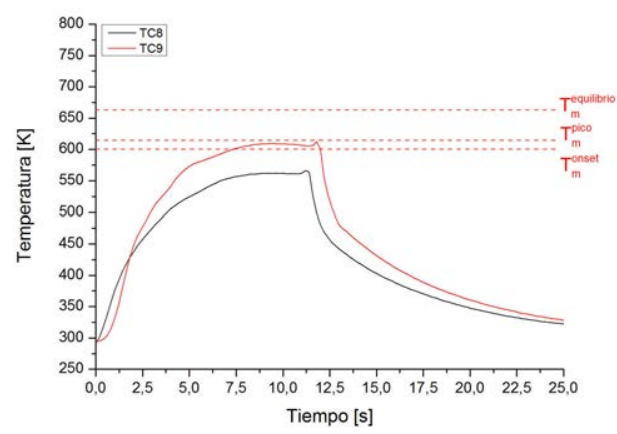

(d)

Figura A.16: Encintado capa 11 (a) TC1-TC3, (b) TC4, (c) TC6-TC7 y (d) TC8-TC9

Encintando capa 13. En el encintado de la capa 13, los termopares capaces de registrar temperatura fueron TC1-TC3, entre las capas 1 y 2 (11 capas de separación con la irradiación del láser), el termopares TC4 entre las capas 
2 y 3 (10 capas de separación con la irradiación del láser), los termopares TC6-TC7 entre las capas 5 y 6 (7 capas de separación con la irradiación láser) y los termopares TC8-TC9 (4 capas de separación con la irradiación láser). Los perfiles temperatura-tiempo se recogen en la Figura A.17.

Analizando nuevamente las desviaciones respecto a los $673 K$ de consigna para la potencia en el registro leído por la termografía en la superficie directamente irradiada, las diferencias apreciadas fueron: $210 \mathrm{~K}$ con 11 capas al láser, $160 K$ con 10 capas al láser, $120 K$ con 7 capas al láser y $70 K$ con 4 capas al láser.

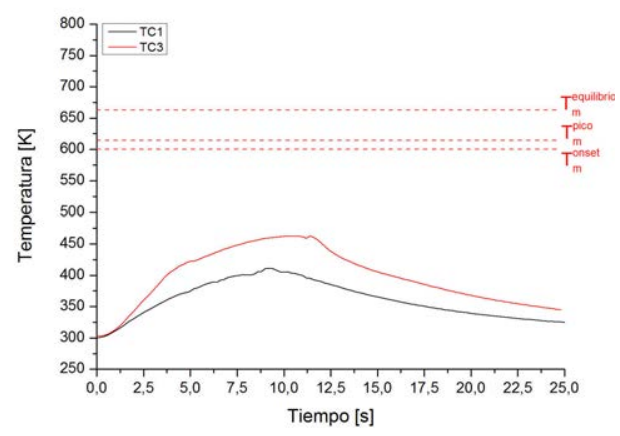

(a)

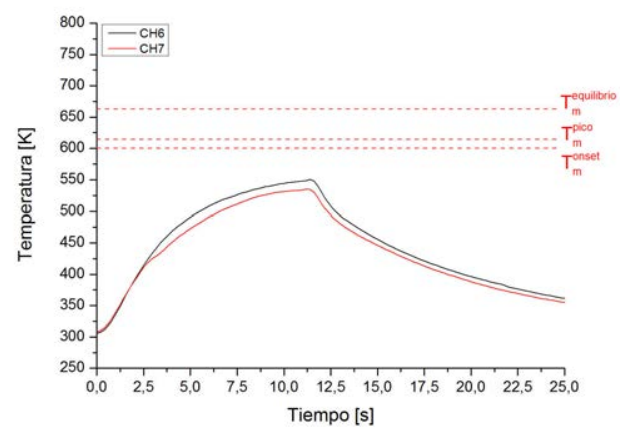

(c)

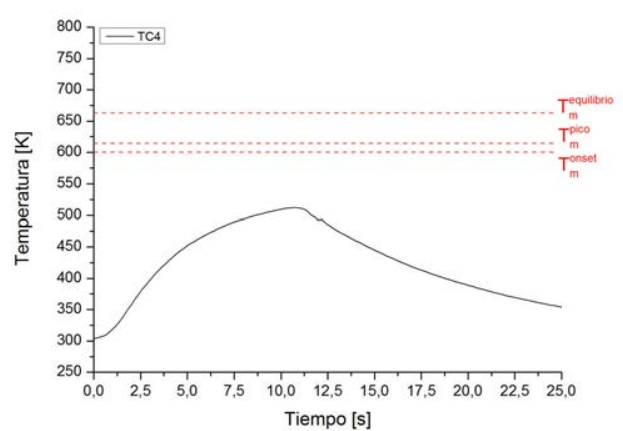

(b)

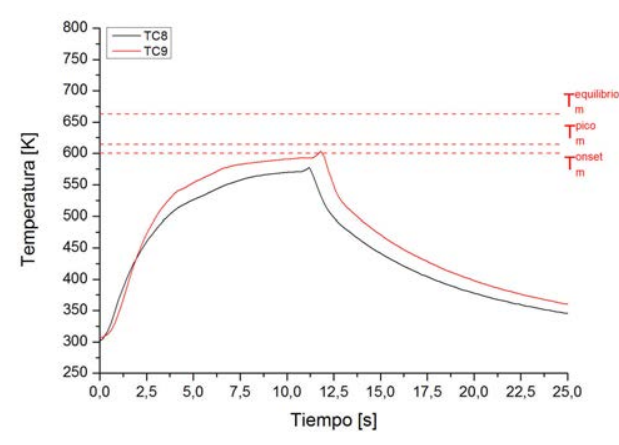

(d)

Figura A.17: Encintado capa 13 (a) TC1-TC3, (b) TC4, (c) TC6-TC7 y (d) TC8-TC9 
Encintando capa 15. En este encintado se incluyen también las lecturas de los termopares TC10-TC11-TC12, posicionados entre las capas 12 y 13 . Manifestado el termopar TC10 un efecto similar al ya observado por el termopar TC1, con un perfil de calentamiento donde no se completa toda la pasada en longitud del láser, siendo su huella de calentamiento superior en longitud a la distancia desde el inicio del laminado al posicionado del punto. Los perfiles tiempo-temperatura se recogen en la Figura A.18

Las desviaciones respecto a los $673 K$ de consigna para la potencia en el registro leído por la termografía en la superficie directamente irradiada, en este caso fueron de: $220 K$ con 13 capas al láser, $200 K$ con 12 capas al láser, $170 K$ con 9 capas al láser, $120 K$ con 6 capas al láser y $10 K$ con 2 capas al láser. 


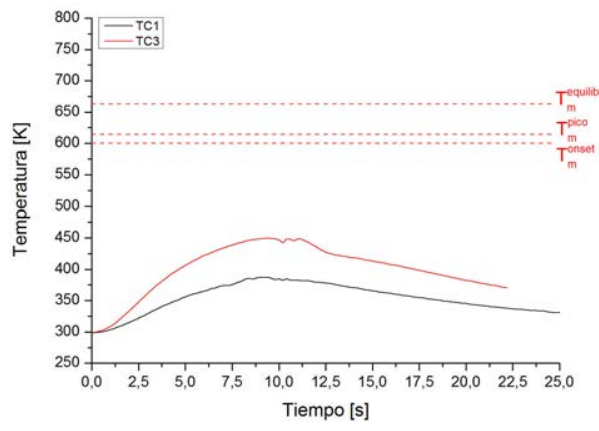

(a)

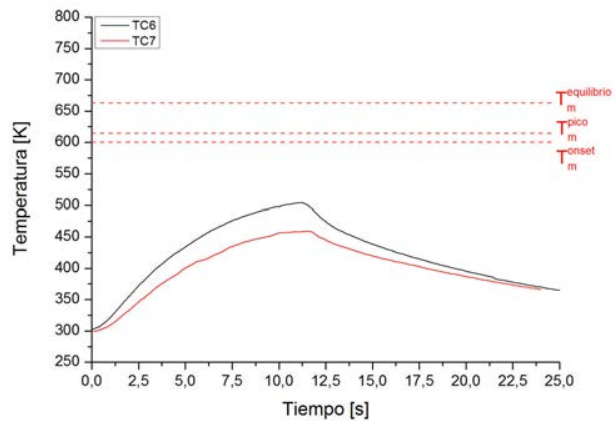

(c)

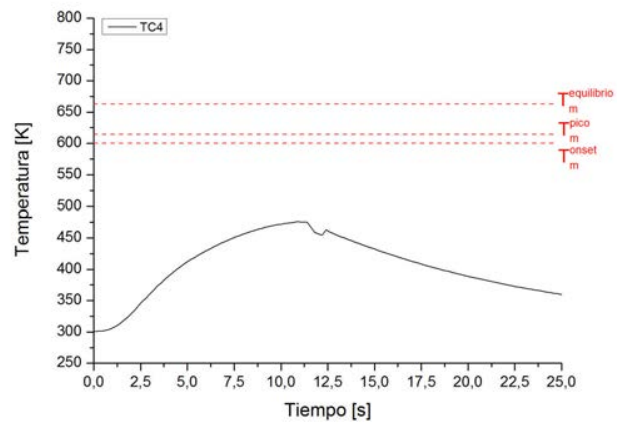

(b)

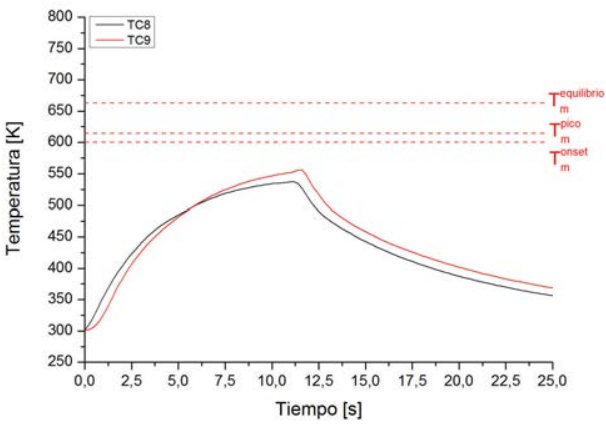

(d)

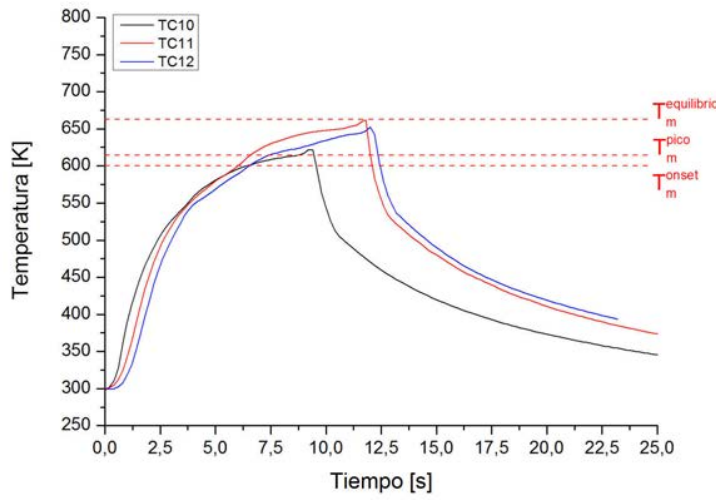

(e)

Figura A.18: Encintado capa 15 (a) TC1-TC3, (b) TC4, (c) TC6-TC7, (d) TC8-TC9 у (e) TC10-TC11-TC12

Encintando capa 20. En el encintado de la capa 20, se incluyen también las medidas de los termopares TC13-TC14 (entre las capas 14 y 15) y TC15- 
TC16 (entre las capas 18 y 19). Los perfiles tiempo-temperatura aparecen recogidos en las Figuras A.19 y A.20.

Las desviaciones respecto a los $673 K$ de consigna para la potencia en el registro leído por la termografía en la superficie directamente irradiada, en este caso fueron de: $270 K$ con 18 capas al láser, $240 K$ con 17 capas al láser, $210 K$ con 14 capas al láser, $170 K$ con 11 capas al láser, $130 K$ con 7 capas al láser, $120 K$ con 5 capas al láser y $10 K$ con 1 capa al láser. Para la última medida, ha sido tomada la medida registrada por el termopar TC16 pues la medida proporcionada por el TC15 registra un valor $127 \mathrm{~K}$ por encima de la consigna, pudiendo tratarse de un efecto causado por un ataque directo del láser sobre el termopar que hubiera quedado incorrectamente embebido en el laminado.

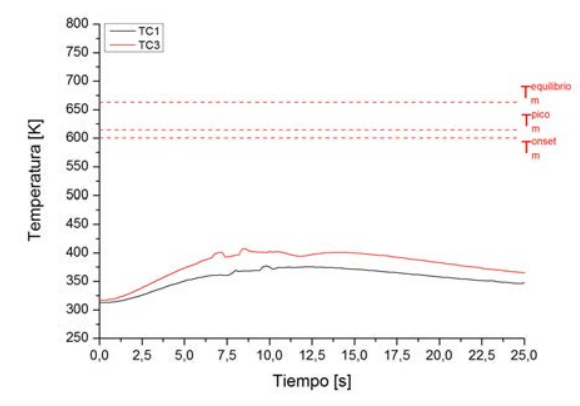

(a)

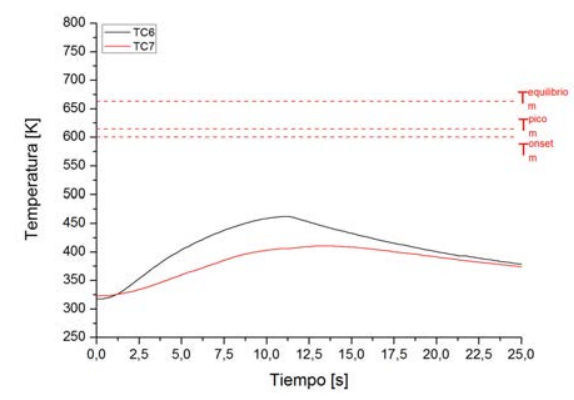

(c)

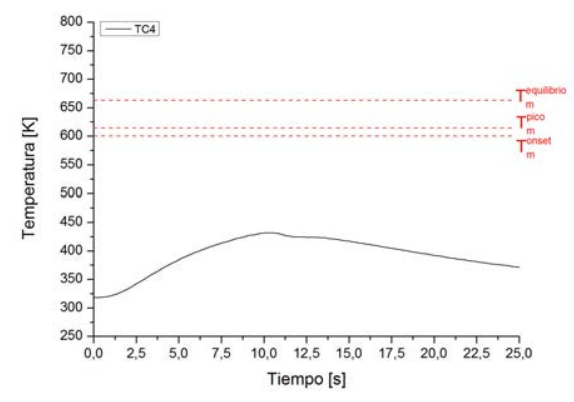

(b)

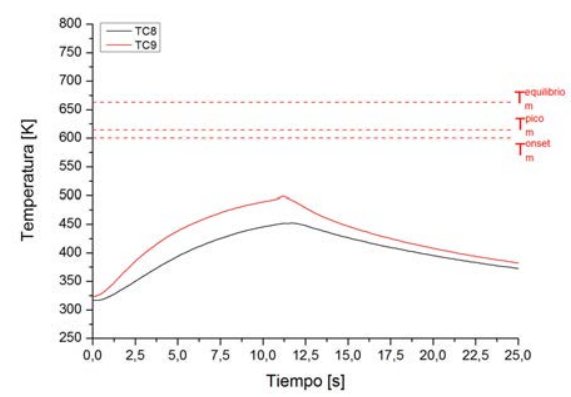

(d)

Figura A.19: Encintado capa 20 (a) TC1-TC3, (b) TC4, (c) TC6-TC7 y (d) TC8-TC9 


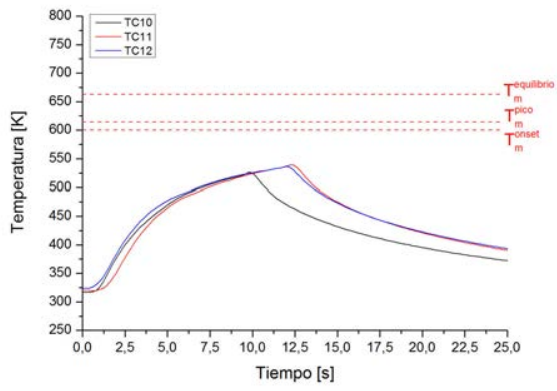

(e)

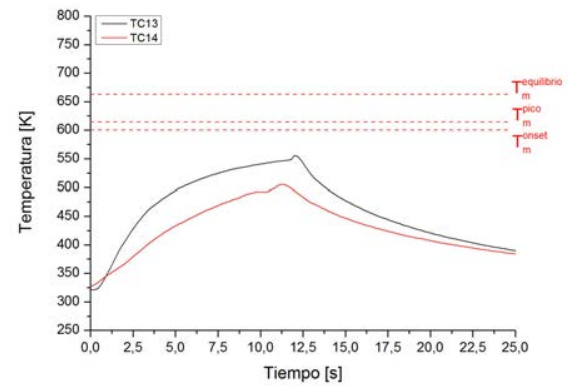

(f)

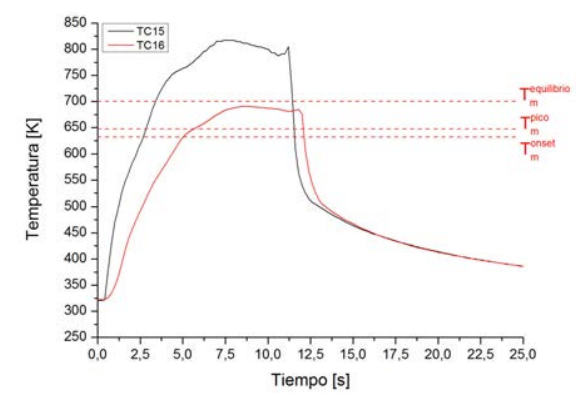

(g)

Figura A.20: Encintado capa 20 (e) TC10-TC11-TC12, (f) TC13-TC14 y (g) TC15-TC16

Encintando capa 30. En el encintado de la capa 30, se incluyen también las medidas de los temopares TC17-TC18 (entre las capas 25 y 26) y TC19TC20 (entre las capas 28 y 29).

Dadas las bajas temperaturas registradas en las capas más bajas, se ha decidido efectuar una representación de los perfiles tiempo-temperatura de los termopares posicionados en las capas más altas, TC15-TC16 (entre las capas 18 y 19), TC17-TC18 (entre las capas 25 y 26) y TC19-TC20 (entre las capas 28 y 29). Durante el encintado se perdió la información del TC16 y del TC19. Los perfiles quedan recogidos en la Figura A.21

Las temperaturas registradas por los termopares, tomando como referencia de nuevo los $673 \mathrm{~K}$ de superficie, se corresponden con variaciones de $170 \mathrm{~K}$ con 11 capas de separación al láser, $120 K$ con 4 capas de separación y una temperatura medida de unos $720 \mathrm{~K}\left(\sim 450^{\circ} \mathrm{C}\right)$ en el encintado con 1 capa de separación a la fuente de irradiación. Ese exceso de temperatura puede estar motivado por una mala lectura del termopar incorrectamente embebido o por el propio sobre-espesor generado por la presencia del termopar. 


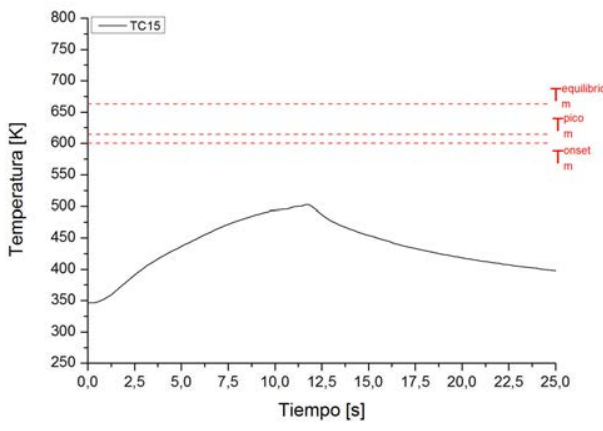

(a)

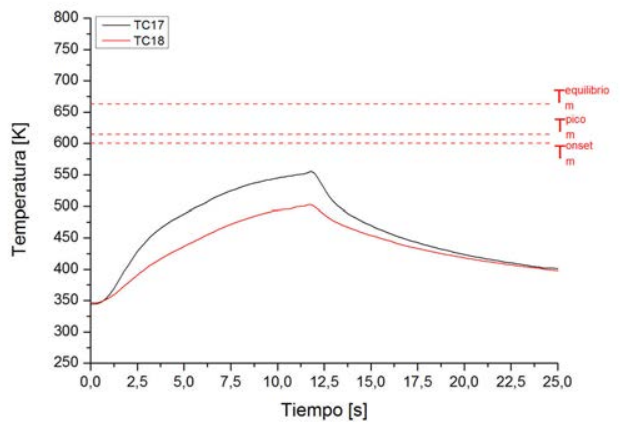

(b)

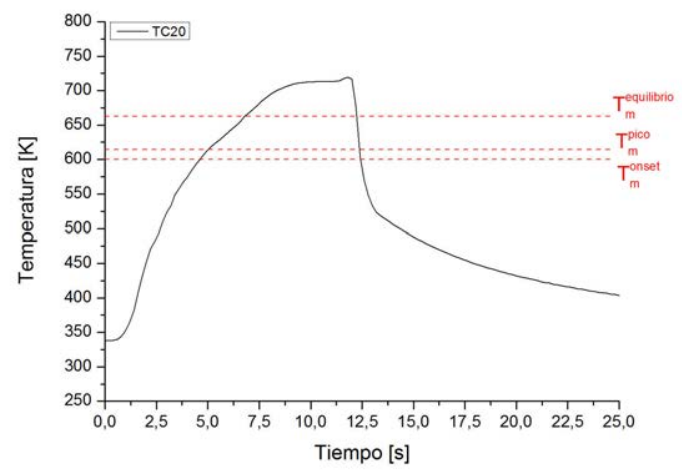

(c)

Figura A.21: Encintado capa 30 (a) TC15, (b) TC17-TC18 y (c) TC20 
En el gráfico de la Figura A.22 se muestra una representación con todas las temperaturas obtenidas por cada encintado en función de la distancia a la fuente de irradiación láser.

La ejecución anteriormente incluida en el trabajo, ha permitido extraer una representación general donde se observa una tendencia de disminución de la temperatura con la distancia a la fuente de irradiación láser. Con 4 capas de separación a la fuente de calentamiento el material comienza a no alcanzar temperaturas dentro del rango del pico de fusión del polímero y no es hasta un rango de hasta 17 capas de distancia cuando se decae bajo la temperatura de transición vítrea del material. La importancia de este hecho es notable desde el punto de vista del desarrollo de efectos de cristalización en frío en las capas más alejadas del láser en los laminados y también para los análisis de la consolidación en el material por encima y bajo su punto de fusión.

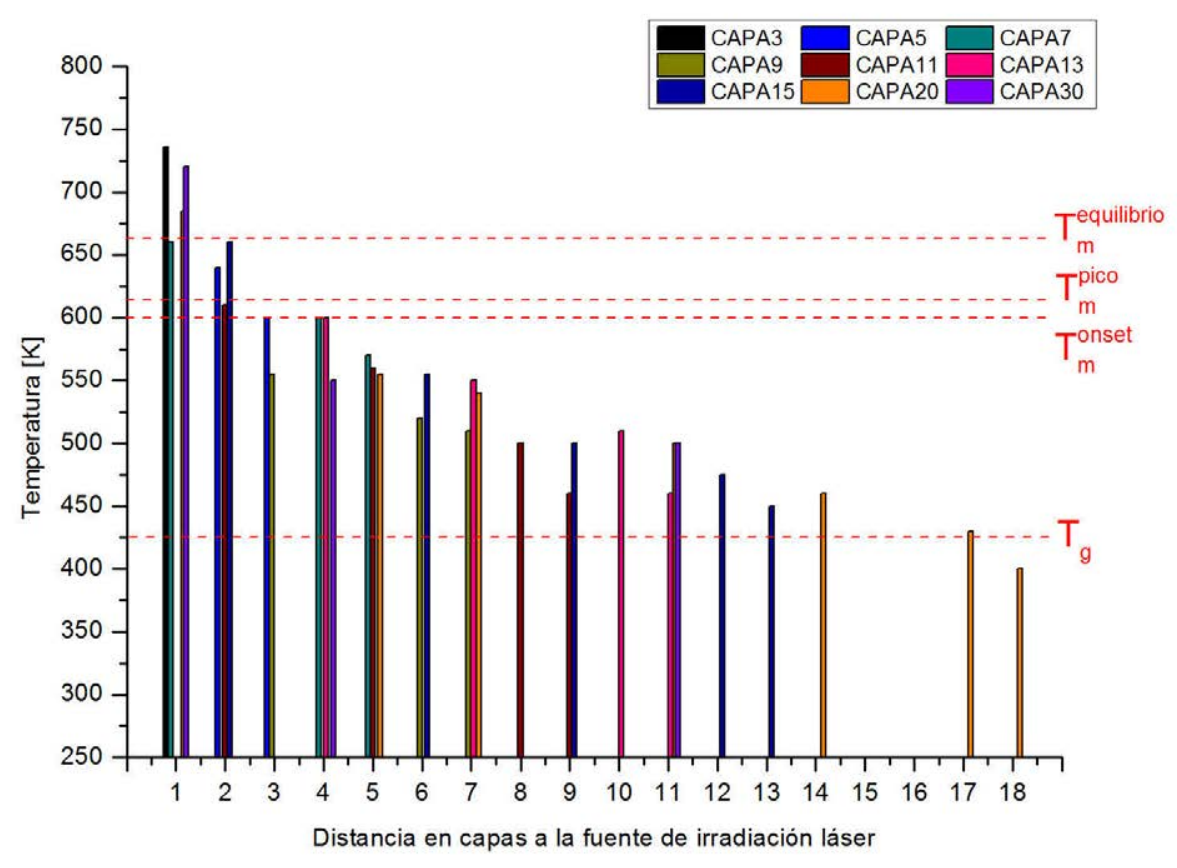

Figura A.22: Croquis de posicionado de termopares en un encintado a 0-90

Con esta ejecución, es posible detectar un efecto importante en el comportamiento de las capas más altas de los laminados, en las cuales se detectan perfiles de enfriamiento más suaves a los correspondientes en las capas inferiores, con las mismas distancias respecto a la fuente de irradiación láser. 


\section{A.3. Encintado con doble láser}

El planteamiento del doble láser en consolidación in-situ permite efectuar una etapa de consolidación secundaria durante la misma ejecución de laminación, incrementándose así el grado de adhesión entre las partes. Asimismo, podría utilizarse como vía para remontar el perfil de enfriamiento en algún punto del mismo tras la salida del primer rodillo de compactación, modificándose la cristalización en el polímero. Con el fin de establecer las lecturas registradas por un termopar cuando se emplea este sistema, se ejecutó un análisis mediante el empleo de cable de termopar K1KP-25SA de Termya y frecuencia de muestreo de $200 \mathrm{~ms}$.

Se emplearon dos termopares posicionados entre las capas 1 y 2 para observar los perfiles en los encintados de las capas 3, 4 y 5. En el encintado, por las posiciones en las que fueron situados los termopares, se consiguió el calentamiento con doble láser del termopar codificado como TC2 y con un único láser del codificado TC3.

La potencia aplicada fue tal que se perseguían lecturas de termografía de entre 623 y $673 \mathrm{~K}$ en el calentamiento efectuado por el láser 1 (potencia aproximada de $300 \mathrm{~W}$ ) y valores en el entorno de $600 \mathrm{~K}$ en el área de calentamiento del láser 2 (potencia aproximada de $150 \mathrm{~W}$ ) y controlada en este caso por un pirómetro instalado en el cabezal.

La longitud de calentamiento impuesta por el láser 2, se corresponde con unos $118 \mathrm{~mm}$ y por como se distribuyen los perfiles, existen unos $40 \mathrm{~mm}$ desde la zona de compactación del rodillo 1 a la entrada en funcionamiento del láser 2, distancia que debería ser optimizada para conseguir el propósito requerido sobre el enfriamiento a desarrollar en el primer perfil.

Por como están posicionados los láseres, en las medidas registradas bajo el segundo láser siempre habrá que considerar que existe una capa más entre el punto de medida y la fuente de calentamiento. Como ejemplo, en el encintado de la capa 3 , bajo el láser 1 , el termopar tiene únicamente una capa encima y durante el calentamiento del láser 2 hay dos capas interpuestas con la fuente láser.

\begin{tabular}{|c|c|c|}
\hline Termopar & Posición en espesor & $\begin{array}{c}\text { Posición desde extremo del laminado } \\
{[\mathrm{mm}]}\end{array}$ \\
\hline TC2 & Entre 1-2 & 300 \\
\hline TC3 & Entre 1-2 & 450 \\
\hline
\end{tabular}

Tabla A.2: Posiciones termopares en el encintado con doble láser 
Se va a obviar el primer registro de los termopares cuando son directamente irradiados por el láser pues la medición carece de sentido, se incorporarán las lecturas desde que existe un capa interpuesta entre termopar y láser, Figura A.23(a). Además, para comprobar la repetitividad de la medida, los perfiles se representarán con origen temporal en el momento en que el termopar comienza a detectar el primer calentamiento del láser. 


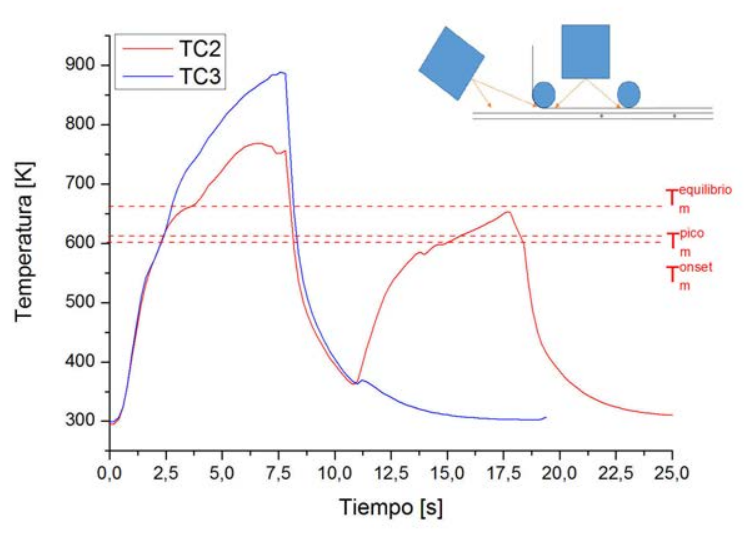

(a)

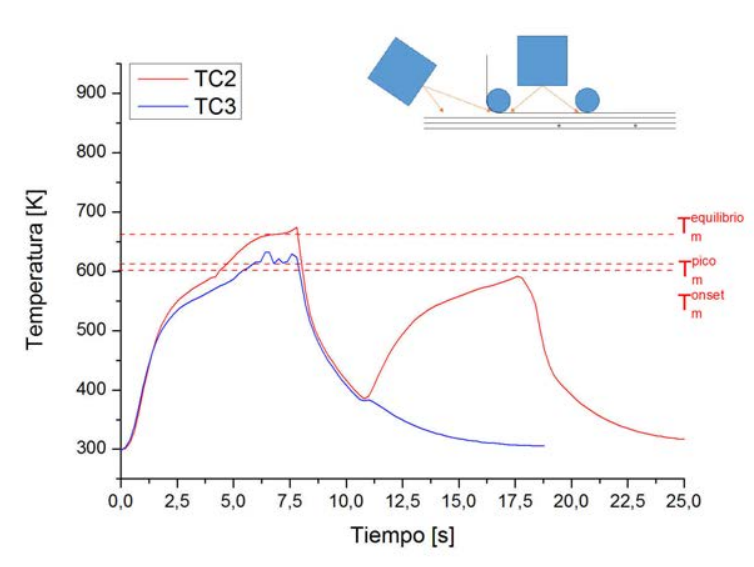

(b)

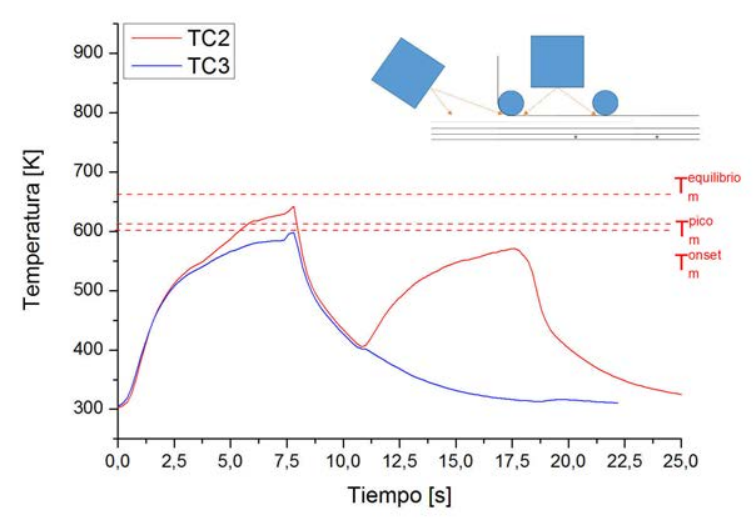

Figura A.23: Registro de termopares TC2-TC3 en el encintado con doble láser entre capas 1 y 2 (a) Laminando capa 3, (b) Laminando capa 4 y (c) Laminando capa 5 
Con los perfiles obtenidos es posible observar que, en la posición en la que se localizan los láseres en la ejecución, la entrada del láser 2 no permite recuperar el perfil del primer láser en un valor de temperatura apropiado para compensar un brusco enfriamiento del material. Respecto a la temperatura obtenida durante el encintado de la capa 3 , en el encintado de la cuarta, los termopares registran una caída de temperatura de 93 y $61 K$ (Figura A.23(b) y de 125 y $81 K$ en el encintado de la quinta (Figura A.23.(c).

Los valores obtenidos, incluso con una capa de material entre el sensor y la fuente de irradiación, muestran temperaturas muy por encima de la registrada por termografía. El espesor de los termopares utilizados es la causa más probable de este problema, esta ejecución debería desarrollarse nuevamente con termopares OMEGA de bajo diámetro para obtener perfiles térmicos más ajustados a la realidad, sin embargo, la ejecución ha permitido conocer cómo se producen la entradas de la segunda fuente láser y la longitud de las zonas no irradiadas o en sombra por el rodillo. 



\section{Apéndice B}

\section{Capacidad calorífica Zafiro}

\begin{tabular}{|c|c|c|}
\hline $\begin{array}{l}\text { Temperatura } \\
{ }^{\circ} \mathrm{C}\end{array}$ & $\begin{array}{c}\text { Temperatura } \\
\mathrm{K} \\
\end{array}$ & $\begin{array}{l}\mathrm{C}_{\mathrm{p}} \text { teórico } \\
\mathrm{J} \cdot \mathrm{g}^{-1} \cdot{ }^{\circ} \mathrm{C}^{-1}\end{array}$ \\
\hline 20 & 293 & 0,7643 \\
\hline 30 & 303 & 0,7857 \\
\hline 40 & 313 & 0,8060 \\
\hline 50 & 323 & 0,8253 \\
\hline 60 & 333 & 0,8435 \\
\hline 70 & 343 & 0,8608 \\
\hline 80 & 353 & 0,8770 \\
\hline 90 & 363 & 0,8925 \\
\hline 100 & 373 & 0,9071 \\
\hline 110 & 383 & 0,9210 \\
\hline 120 & 393 & 0,9342 \\
\hline 130 & 403 & 0,9467 \\
\hline 140 & 413 & 0,9587 \\
\hline 150 & 423 & 0,9700 \\
\hline 160 & 433 & 0,9808 \\
\hline 170 & 443 & 0,9909 \\
\hline 180 & 453 & 1,0006 \\
\hline 190 & 463 & 1,0102 \\
\hline 200 & 473 & 1,0191 \\
\hline
\end{tabular}

Figura B.1: Valor teórico de la $C_{p}$ del Zafiro 



\section{Apéndice $\mathrm{C}$}

\section{Calorimetría diferencial de barrido}

En este apéndice se incluyen los termogramas de los ensayos de calorimetría diferencial de barrido a los que se alude en diferentes puntos del texto. Se considera de importancia su incorporación al documento pues la forma de las curvas ha sido destacada como un elemento diferenciador del proceso de encintado automático y consolidación in-situ.

En el caso particular de las probetas tipo escalón, se podrá ir observando como al incrementar la capa, la exoterma de cristalización fría va perdiendo área hasta desaparecer por completo.

La calorimetría ha sido empleada con el propósito de analizar posibles efectos de degradación en las muestras, estados de cristalinidad en diferentes probetas y también para la obtención de las cinéticas de cristalización.

\section{C.1. Calorimetría en el análisis de la degradación térmica}

En este apartado se incluyen los gráficos resultantes de los ensayos de calorimetría sobre muestras procedentes de un panel fabricado en prensa y un panel fabricado por laminación automática y consolidación in-situ. De cada uno de ellos han sido ejecutados tres ensayos para comprobar su repetitividad. Los gráficos han sido separados incluyéndose de modo independiente el resultado del primer ciclo de calentamiento para las muestras procedentes de prensa C.1 y laminación automática y consolidación in-situ C.4 el ciclo de enfriamiento tras fusión de las muestras de prensa C.2 y de laminación automática y consolidación in-situ C.5 y un nuevo ciclo de calentamiento sobre 
el resultado previo del enfriamiento controlado C.3 (prensa) y C.6 (consolidación in-situ).

El método de ensayo aplicado así como las masas de las muestras (Tabla C.1) se incluyen a continuación.

- Rampa $10 \mathrm{~K} / \mathrm{min}$ hasta $663 \mathrm{~K}\left(390^{\circ} \mathrm{C}\right)$

- Isoterma $5 \mathrm{~min}$

- Rampa $5 K / \min$ hasta $303 K\left(30^{\circ} \mathrm{C}\right)$

- Rampa $10 \mathrm{~K} / \mathrm{min}$ hasta $663 \mathrm{~K}\left(390^{\circ} \mathrm{C}\right)$

\begin{tabular}{|c|c|c|}
\hline Procedencia & Probeta & Masa $[\mathrm{mg}]$ \\
\hline & $1410-93$ & 23,68 \\
Prensa & $1410-94$ & 24,73 \\
& $1410-95$ & 22,50 \\
\hline \multirow{3}{*}{ ISC } & $1410-96$ & 25,97 \\
& $1410-97$ & 28,07 \\
& $1410-98$ & 32,29 \\
\hline
\end{tabular}

Tabla C.1: Masas de las probetas ensayadas

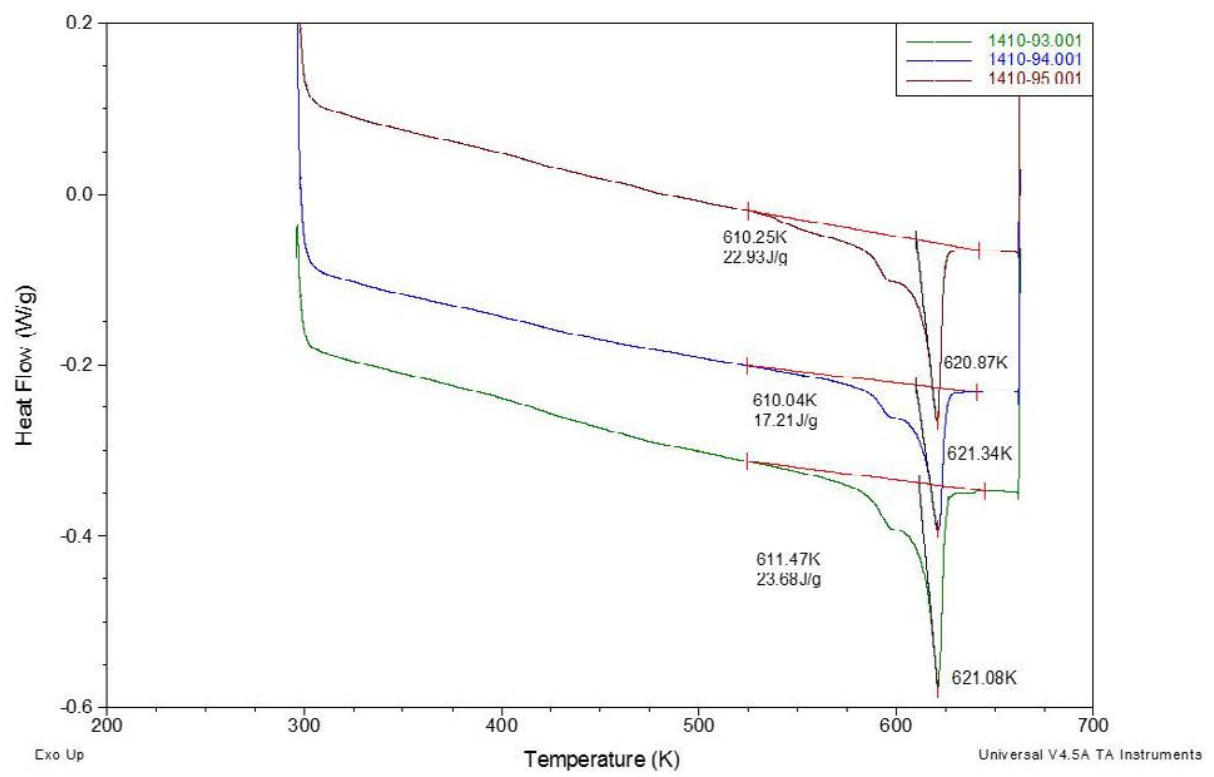

Figura C.1: DSC panel prensa ciclo 1 - estudio de degradación por intercomparación entre procesos de fabricación 


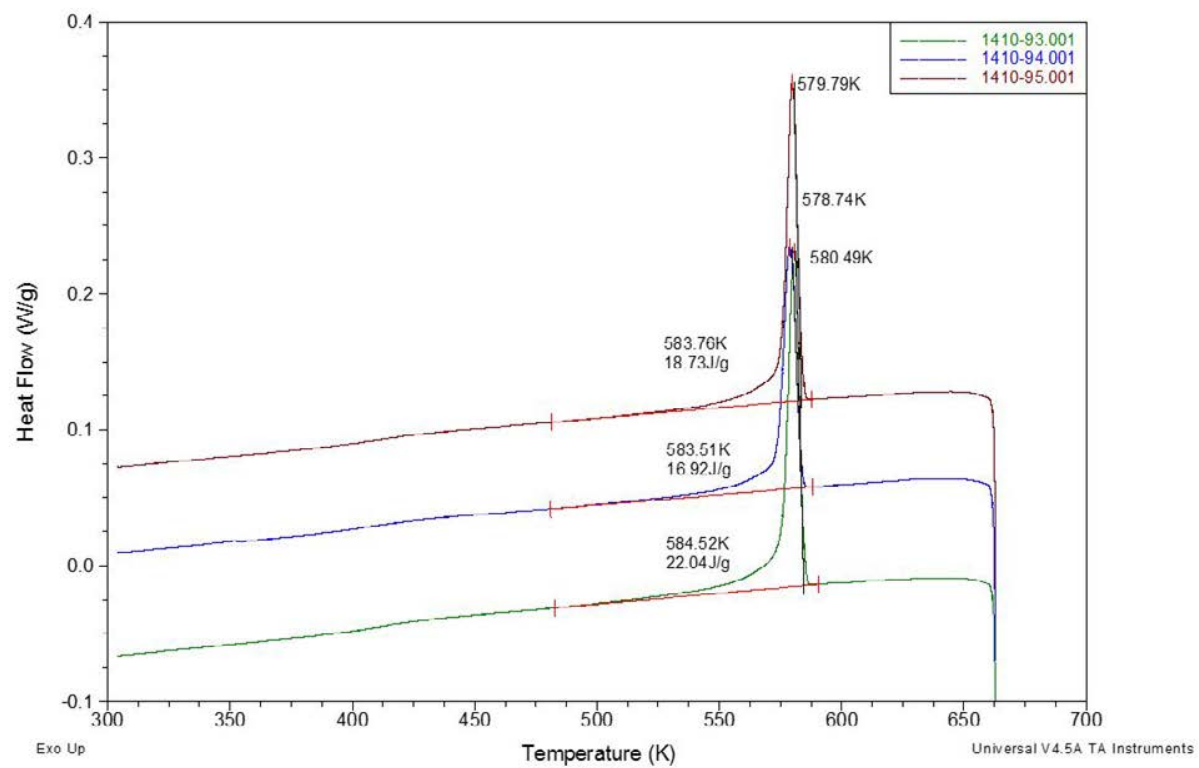

Figura C.2: DSC panel prensa ciclo 2 - estudio de degradación por intercomparación entre procesos de fabricación

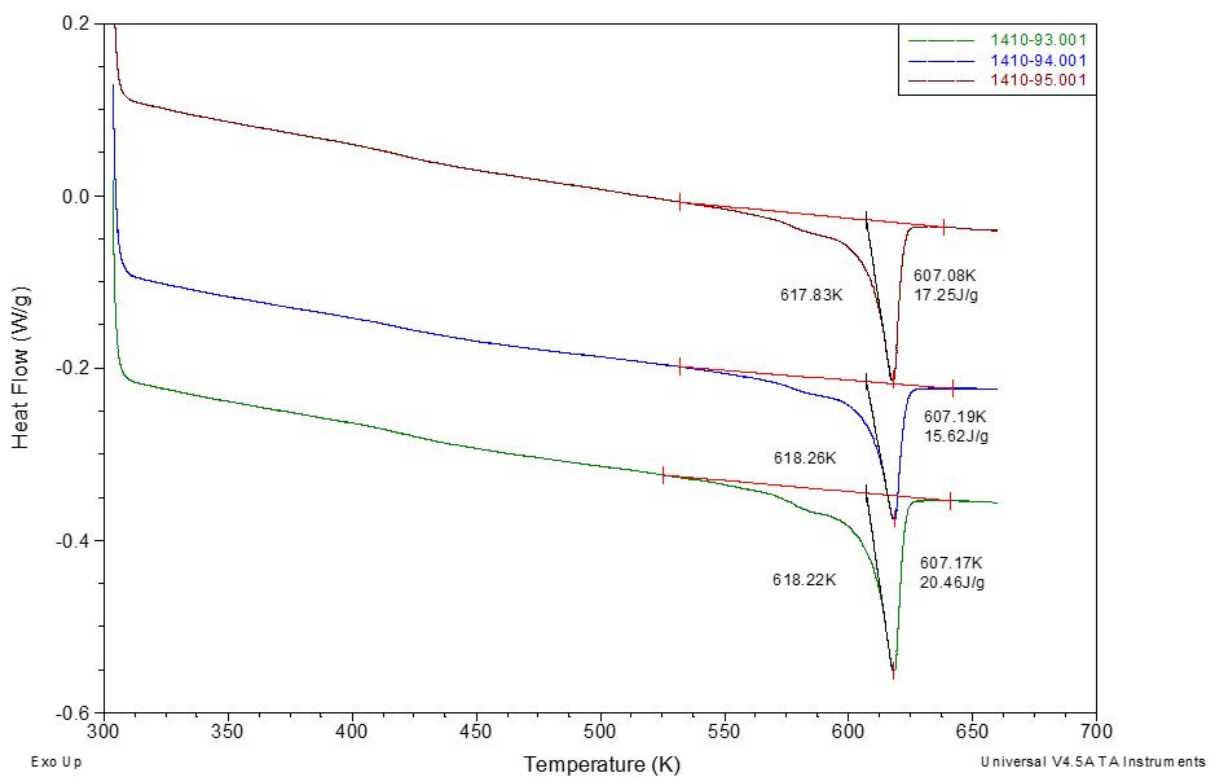

Figura C.3: DSC panel prensa ciclo 3 - estudio de degradación por intercomparación entre procesos de fabricación 


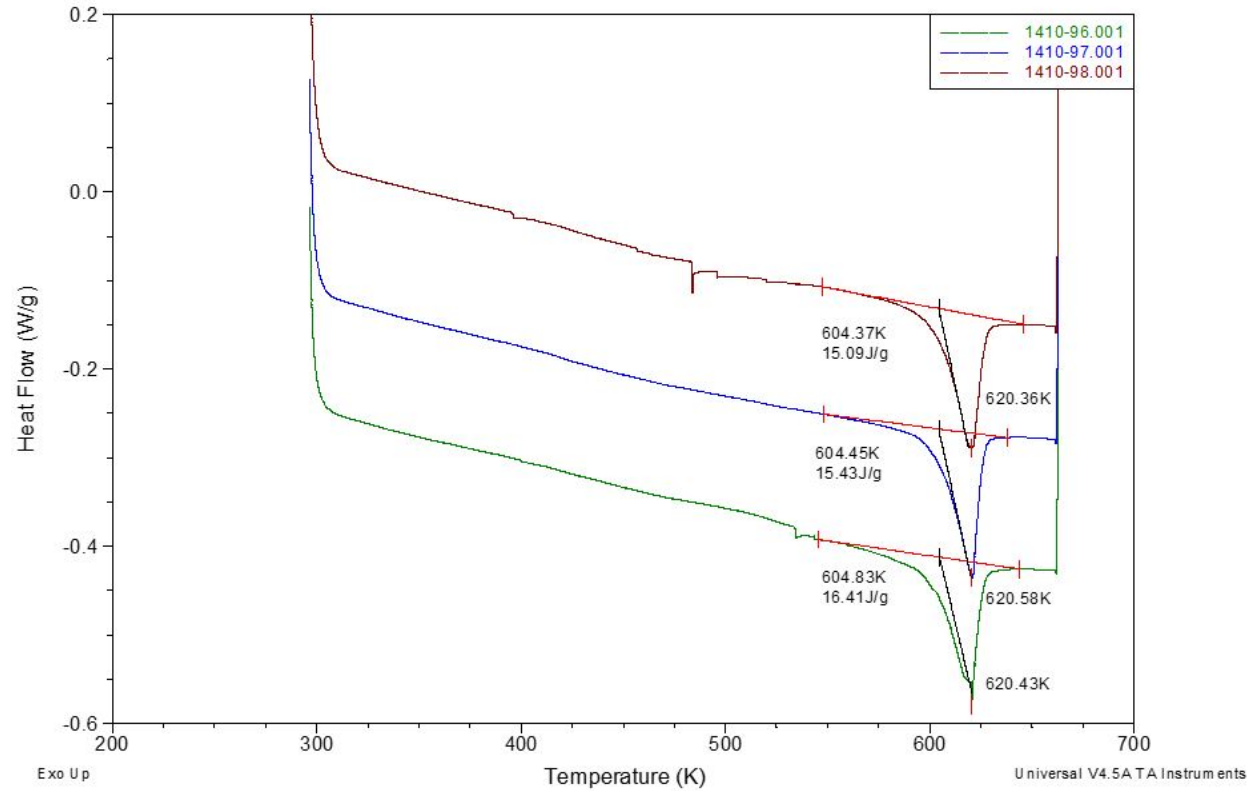

Figura C.4: DSC panel ISC ciclo 1 - estudio de degradación por intercomparación entre procesos de fabricación

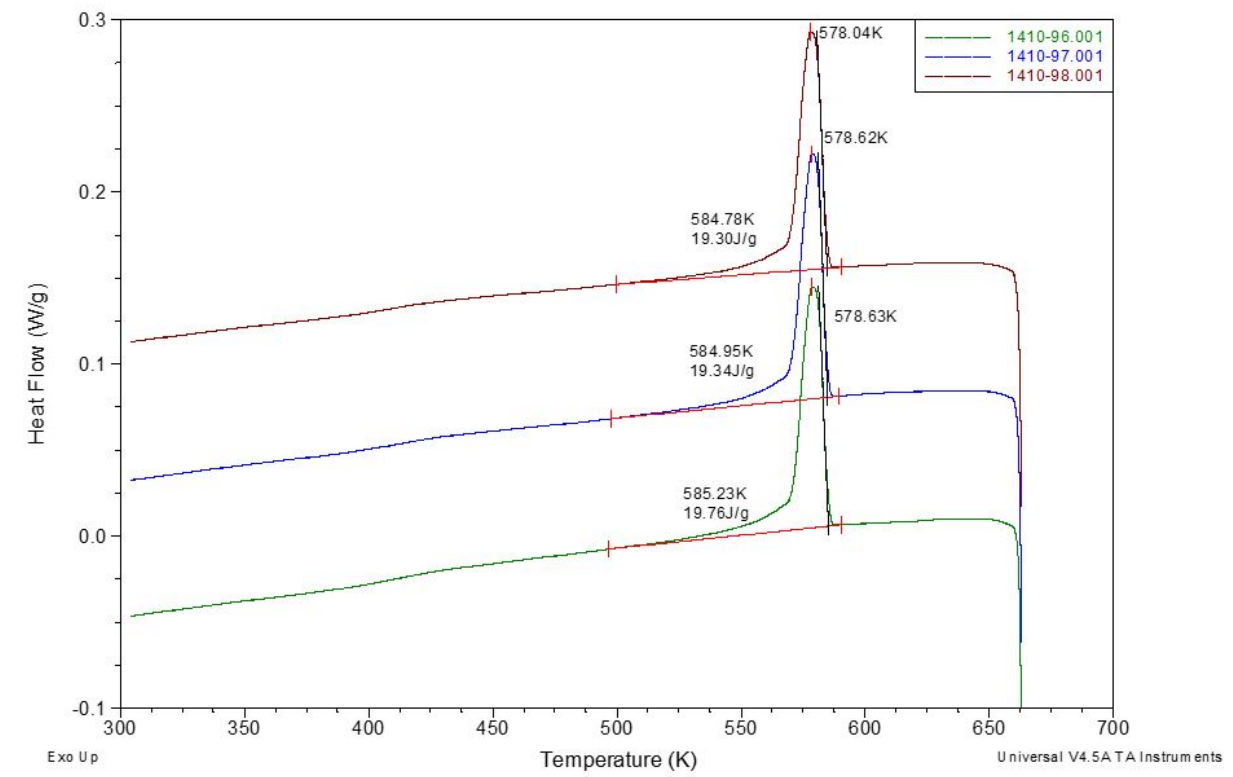

Figura C.5: DSC panel ISC ciclo 2 - estudio de degradación por intercomparación entre procesos de fabricación 


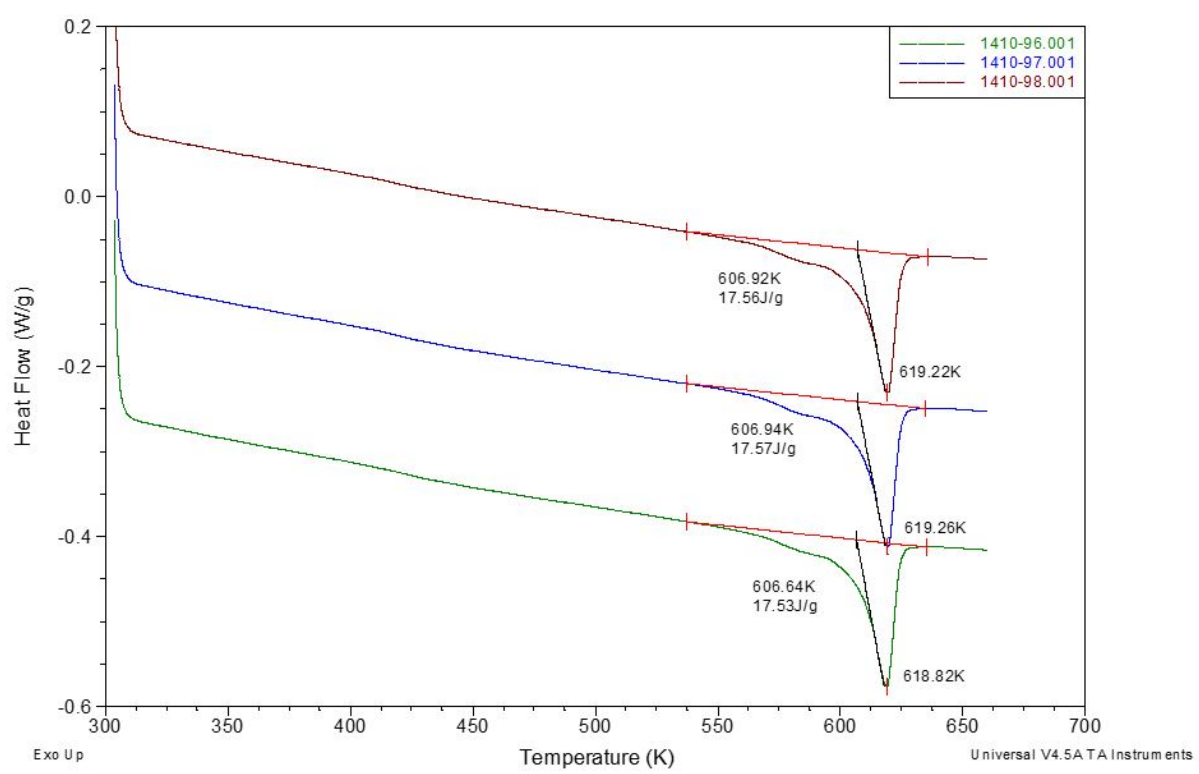

Figura C.6: DSC panel ISC ciclo 3 - estudio de degradación por intercomparación entre procesos de fabricación

\section{C.2. Calorimetría en el análisis de la estructura del PEEK}

En este apartado, se incluyen los termogramas ejecutados sobre muestras de PEEK y APC2/AS4 con diferentes estados de cristalización.

Las condiciones y las masas (Tabla C.2 de las muestras de los termogramas mostrados en C.7 C.8 y C.9 fueron:

- Rampa $10 K / \min$ hasta $663 K\left(390^{\circ} \mathrm{C}\right)$

\begin{tabular}{|c|c|c|}
\hline Procedencia & Probeta & Masa $[\mathrm{mg}]$ \\
\hline PEEK amorfo quenching & $1410-99$ & 14,18 \\
\hline PEEK cristalizado en prensa & $1410-209$ & 17,89 \\
\hline APC2/AS4 as received & 14-10-16-PREPREG-F05-07 & 20,77 \\
\hline
\end{tabular}

Tabla C.2: Masas de las probetas ensayadas 


\section{PEEK 450G:}

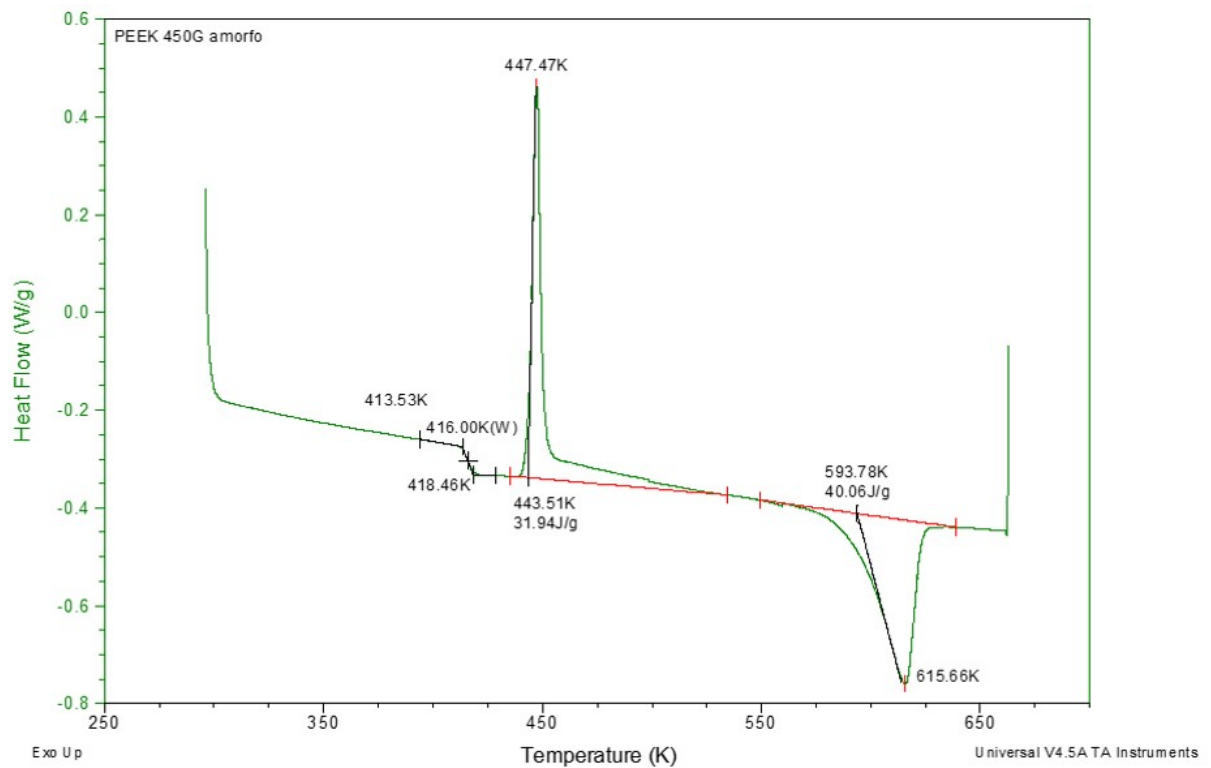

Figura C.7: DSC PEEK 450G amorfo tras quenching

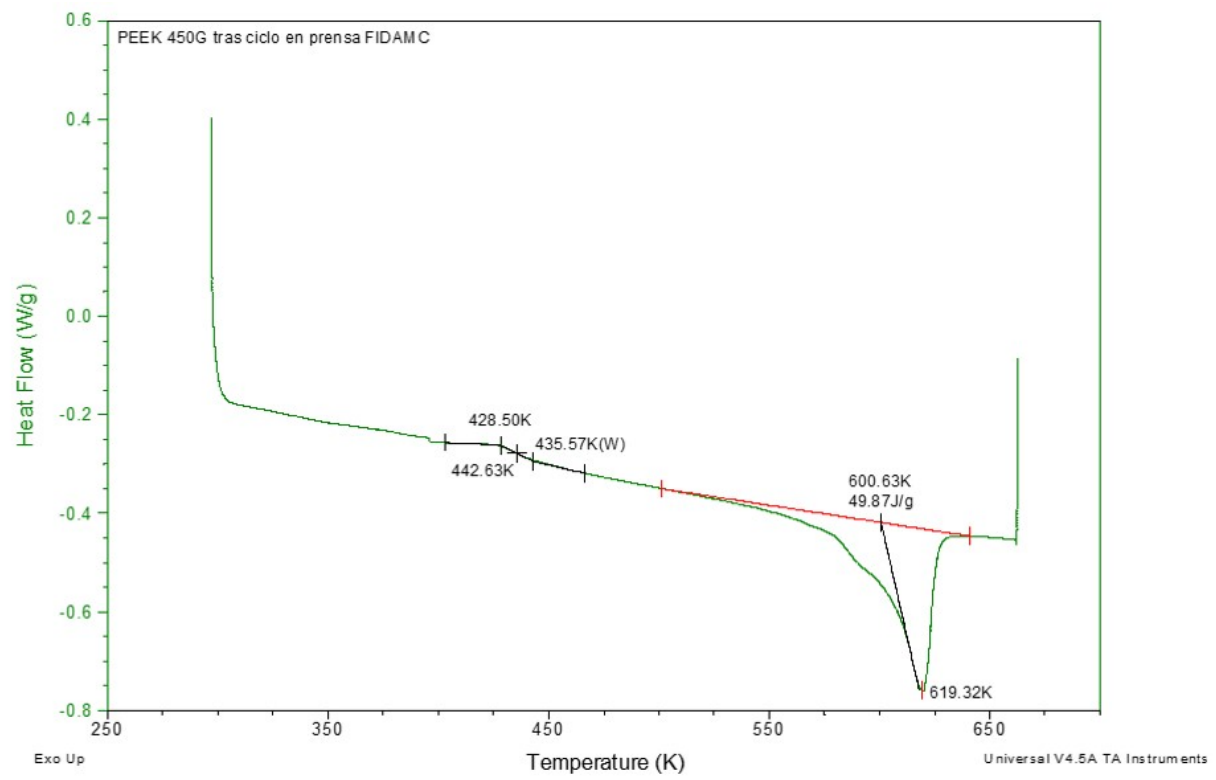

Figura C.8: DSC PEEK 450G cristalizado tras ciclo en prensa de platos calientes 
APC2/AS4:

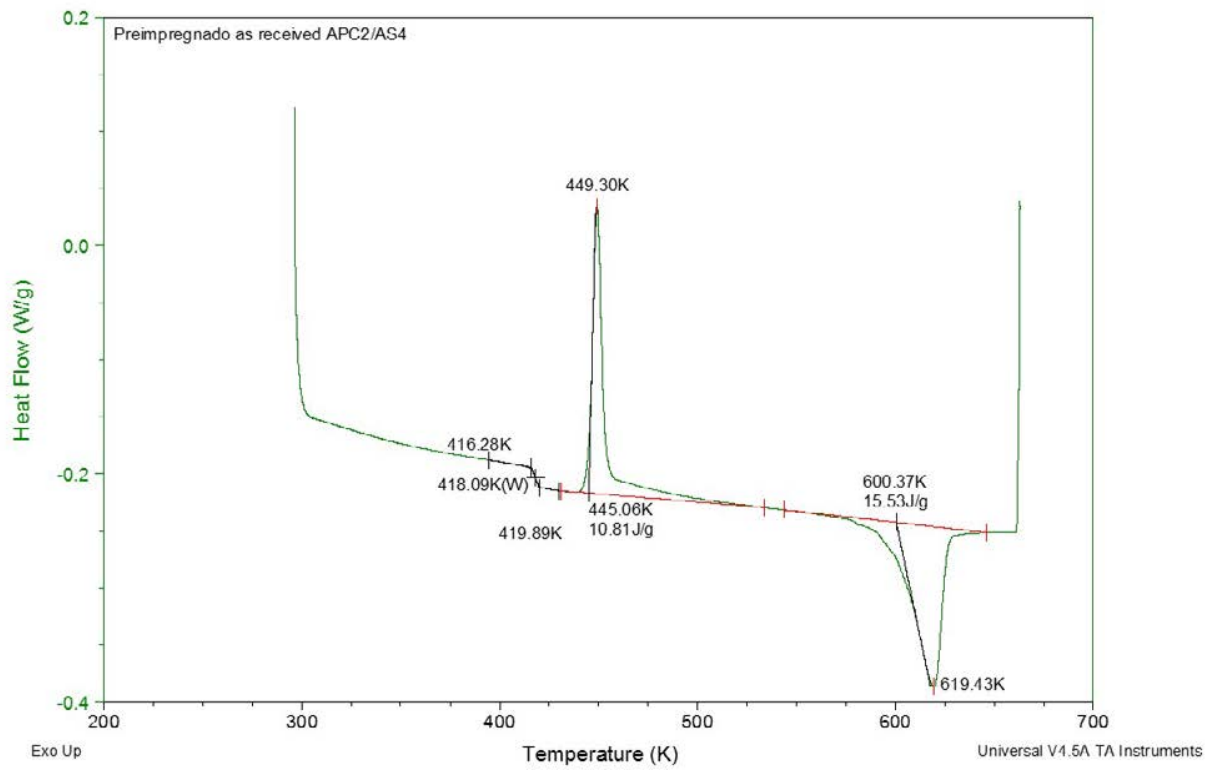

Figura C.9: DSC APC2/AS4 as received - primer ciclo calentammiento 
En base al desconocimiento sobre el peso molecular de la resina utilizada en la impregnación del APC2/AS4, fueron ejecutados ensayos sobre material PEEK 150G con la finalidad de evaluar el impacto del peso molecular sobre la cristalización. En la Figura C.10 se recoge una comparativa de las curvas en el enfriamiento de muestras de PEEK 150G y PEEK 450G con las masas indicadas por la Tabla C.3 y tras ser sometidas al siguiente ciclo de ensayo.

- Rampa $10 K / \min$ hasta $663 K\left(390^{\circ} \mathrm{C}\right)$

- Isoterma $5 \mathrm{~min}$

- Rampa $20 \mathrm{~K} / \mathrm{min}$ hasta $303 \mathrm{~K}\left(30^{\circ} \mathrm{C}\right)$

\begin{tabular}{|c|c|c|}
\hline Material & Probeta & Masa $[\mathrm{mg}]$ \\
\hline PEEK 450G & $14-10-27-P E E K 450-F 05-05$ & 15,92 \\
\hline PEEK 150G & $14-10-27-P E E K 150-F 05-05$ & 17,89 \\
\hline
\end{tabular}

Tabla C.3: Masas de las probetas ensayadas 


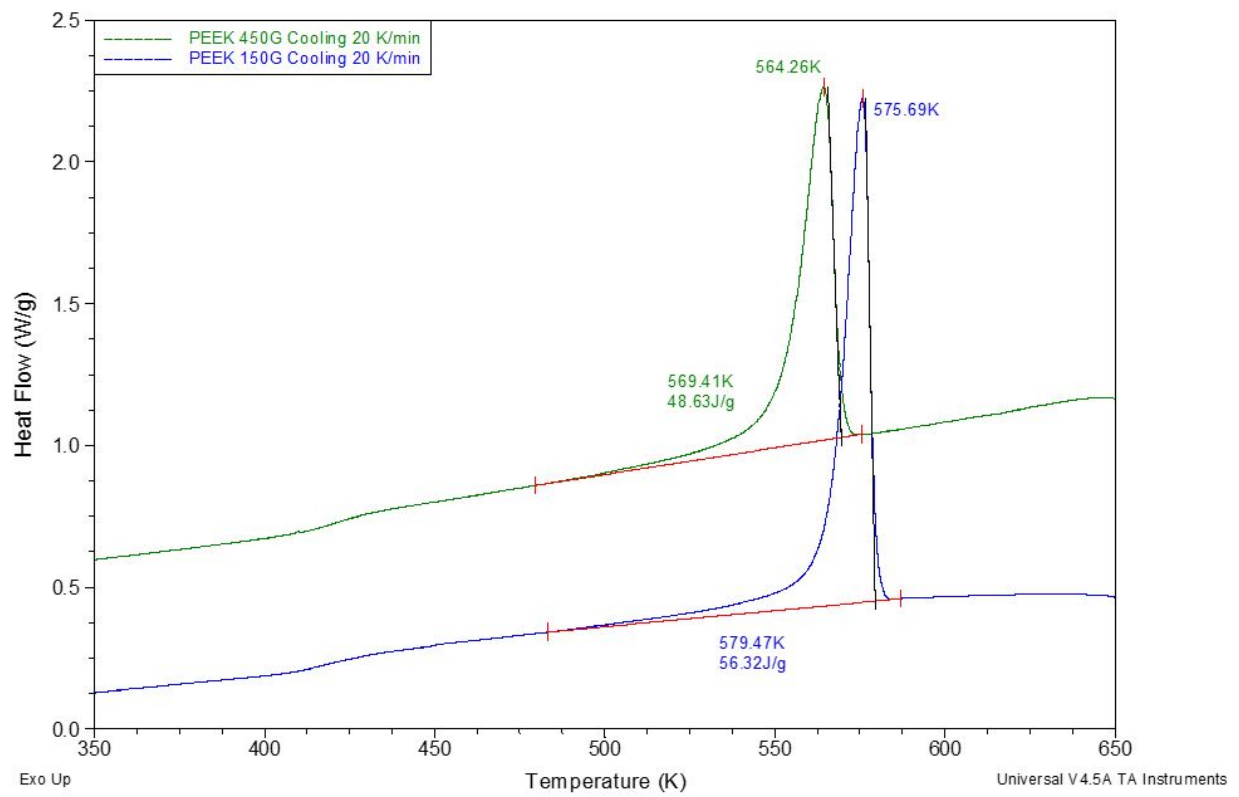

Figura C.10: DSC PEEK 150G vs 450G enfriando a $20 \mathrm{~K} / \mathrm{min}$ tras fusión completa

Para comprobar qué le ocurre al material objeto del encintado (APC2/AS4) en función del programa de calentamiento o enfriamiento al que es sometido, se ejecutaron ensayos bajo diferentes rampas de calentamiento C.11 y de enfriamiento C.12 Las Tablas C.4 y C.5 recogen la información sobre las muestras.

\begin{tabular}{|c|c|c|}
\hline APC2/AS4 (as received) & $\begin{array}{c}\text { Velocidad }[\mathrm{K} / \mathrm{min}] \\
\text { Calentamiento }\end{array}$ & Masa $[\mathrm{mg}]$ \\
\hline $1410-352$ & 2 & 22,24 \\
\hline $1410-353$ & 5 & 21,47 \\
\hline $1410-354$ & 10 & 21,23 \\
\hline $1410-355$ & 15 & 20,02 \\
\hline $1410-356$ & 20 & 22,23 \\
\hline $1410-357$ & 30 & 21,76 \\
\hline
\end{tabular}

Tabla C.4: Masas de las probetas ensayadas 


\begin{tabular}{|c|c|c|}
\hline APC2/AS4 $\left(^{*}\right)$ & $\begin{array}{c}\text { Velocidad }[\mathrm{K} / \mathrm{min}] \\
\text { Enfriamiento }\end{array}$ & Masa $[\mathrm{mg}]$ \\
\hline 14-10-16-PREPREG-F05-06 & 2 & 20,64 \\
\hline 14-10-16-PREPREG-F05-07 & 5 & 20,77 \\
\hline 14-10-16-PREPREG-F05-08 & 10 & 20,75 \\
\hline 14-10-16-PREPREG-F05-09 & 15 & 22,27 \\
\hline 14-10-16-PREPREG-F05-10 & 20 & 22,87 \\
\hline 14-10-16-PREPREG-F05-12 & 30 & 20,96 \\
\hline
\end{tabular}

* Tras calentamiento a $10 \mathrm{~K} / \mathrm{min}$ hasta $663 \mathrm{~K}$ e isoterma de $5 \mathrm{~min}$

Tabla C.5: Masas de las probetas ensayadas

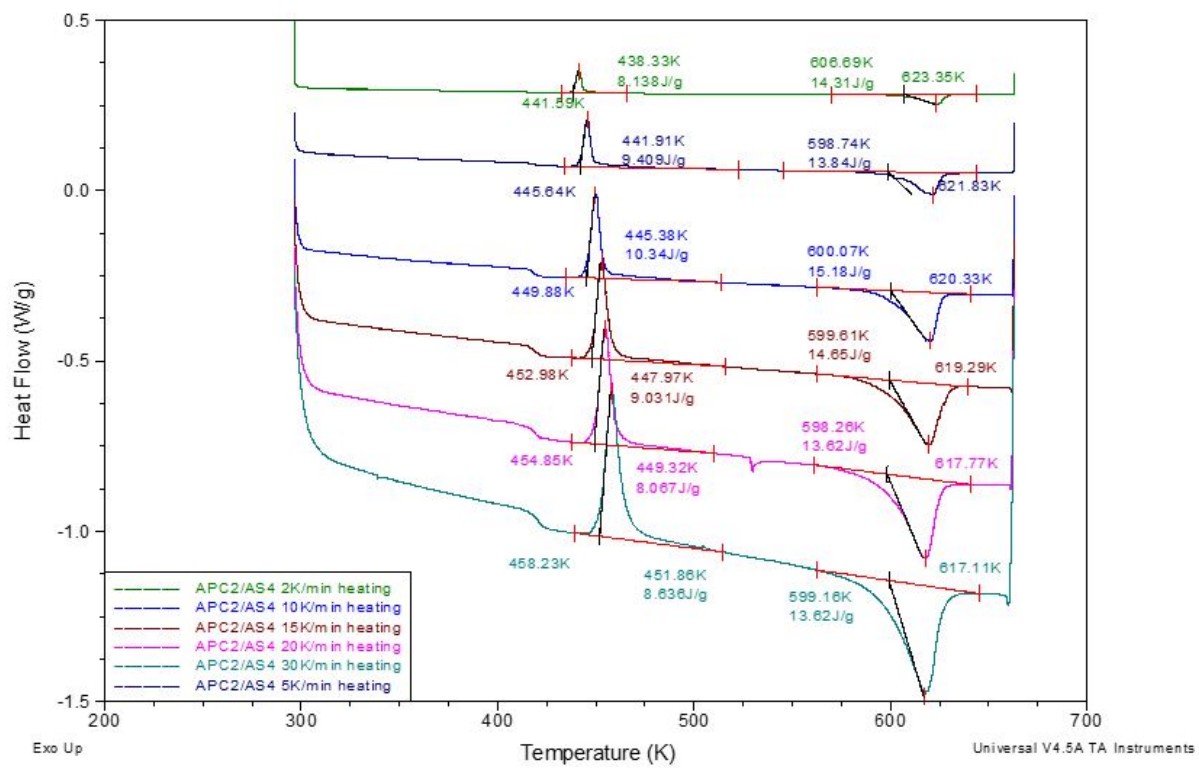

Figura C.11: DSC APC2/AS4 as received sometido a distintas velocidades de calentamiento 


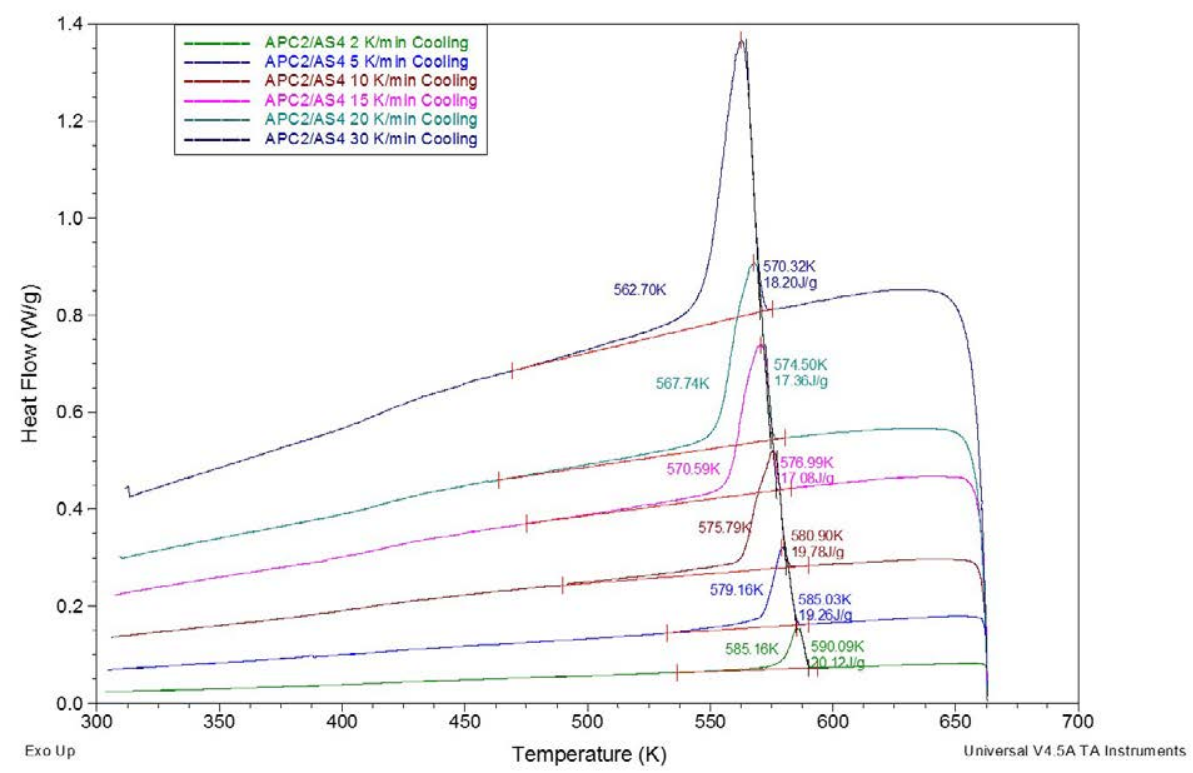

Figura C.12: DSC APC2/AS4 fundido y sometido a distintas velocidades de enfriamiento; $2,5,10,15,20,30 \mathrm{~K} / \mathrm{min}$

Para estimar el efecto de la fibra de carbono, también han sido ejecutadas las mismas rampas de enfriamiento sobre material PEEK 450G neto, los termogramas resultantes se recogen en C.13 siendo las masas de las muestras las incluidas en la Tabla C.6.

\begin{tabular}{|c|c|c|}
\hline PEEK 450G $\left(^{*}\right)$ & $\begin{array}{c}\text { Velocidad }[\mathrm{K} / \mathrm{min}] \\
\text { Enfriamiento }\end{array}$ & Masa $[\mathrm{mg}]$ \\
\hline 14-10-27-PEEK450-F05-01 & 2 & 13,74 \\
\hline 14-10-27-PEEK450-F05-02 & 5 & 14,38 \\
\hline 14-10-27-PEEK450-F05-03 & 10 & 16,06 \\
\hline 14-10-27-PEEK450-F05-04 & 15 & 14,54 \\
\hline 14-10-27-PEEK450-F05-05 & 20 & 15,92 \\
\hline 14-10-27-PEEK450-F05-07 & 30 & 13,31 \\
\hline
\end{tabular}

${ }^{*}$ Tras calentamiento a $10 \mathrm{~K} / \mathrm{min}$ hasta $663 \mathrm{~K}$ e isoterma de $5 \mathrm{~min}$

Tabla C.6: Masas de las probetas ensayadas 


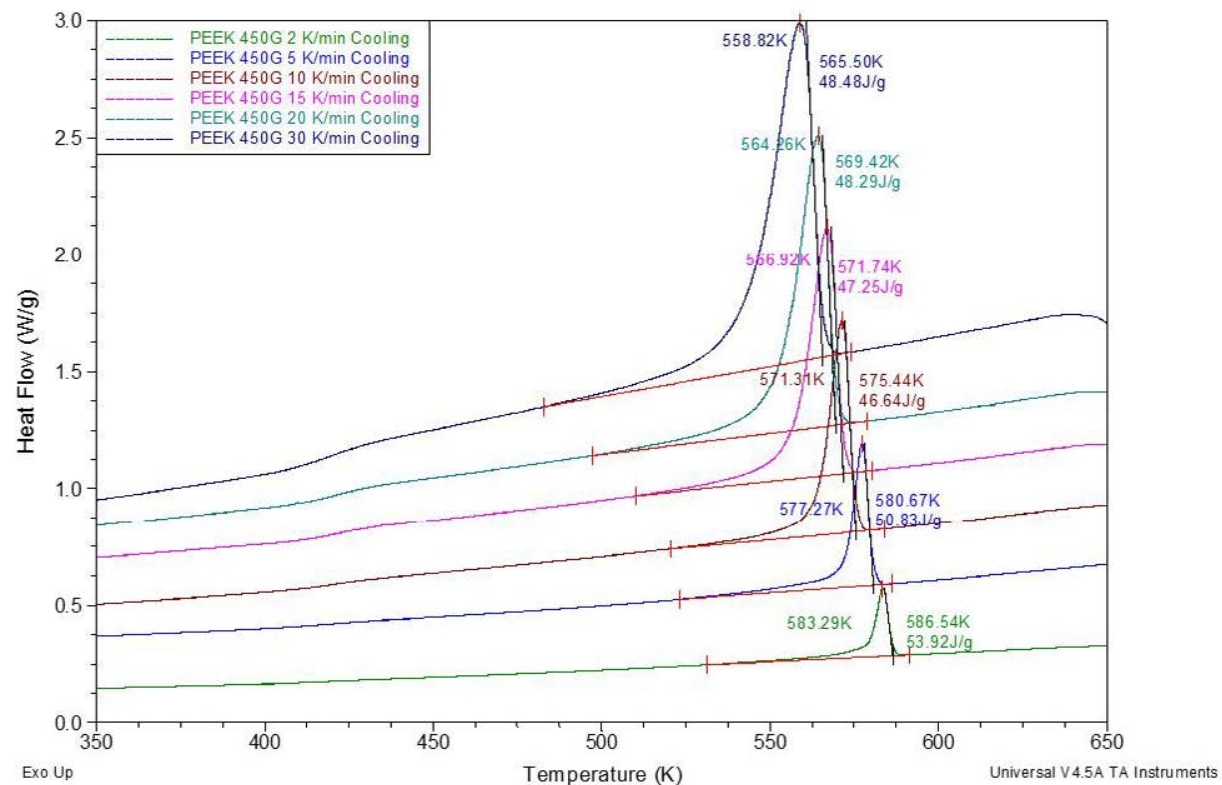

Figura C.13: DSC PEEK 450G distintas velocidades de enfriamiento; 2, 5, $10,15,20,30 \mathrm{~K} / \mathrm{min}$

\section{C.3. Morfología del pico de fusión}

En la Figura C.14 se presenta la comparativa entre los picos de fusión de paneles en prensa y paneles procedentes de la laminación automática y consolidación in-situ. También se estima preciso recoger la información de un segundo ciclo de calentamiento sobre las muestras enfriadas del mismo modo, Figura C.15.

Método de ensayo definido en C.1

\begin{tabular}{|c|c|c|}
\hline Panel & Probeta & Masa $[\mathrm{mg}]$ \\
\hline Prensa & $1410-94$ & 24,73 \\
\hline ISC & $1410-95$ & 22,50 \\
\hline
\end{tabular}

Tabla C.7: Masas de las probetas ensayadas 


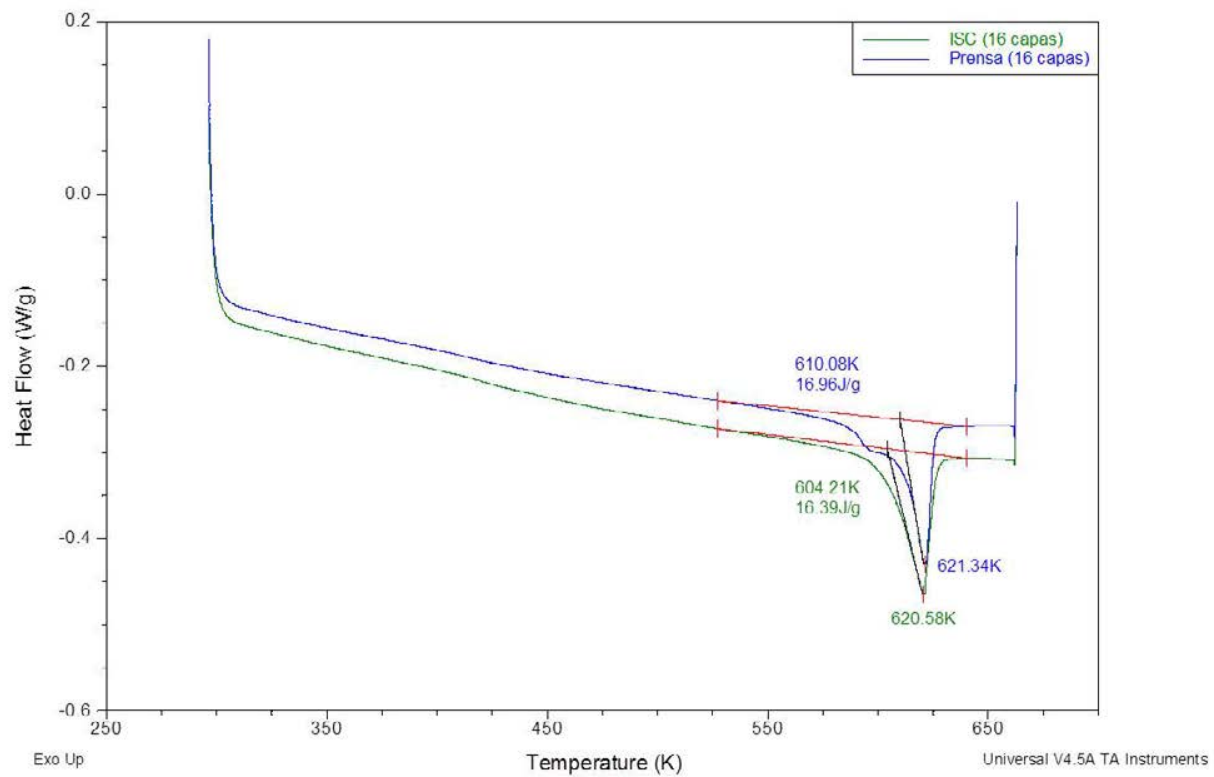

Figura C.14: Comparativa entre paneles en prensa e ISC, ciclo calentamiento 1

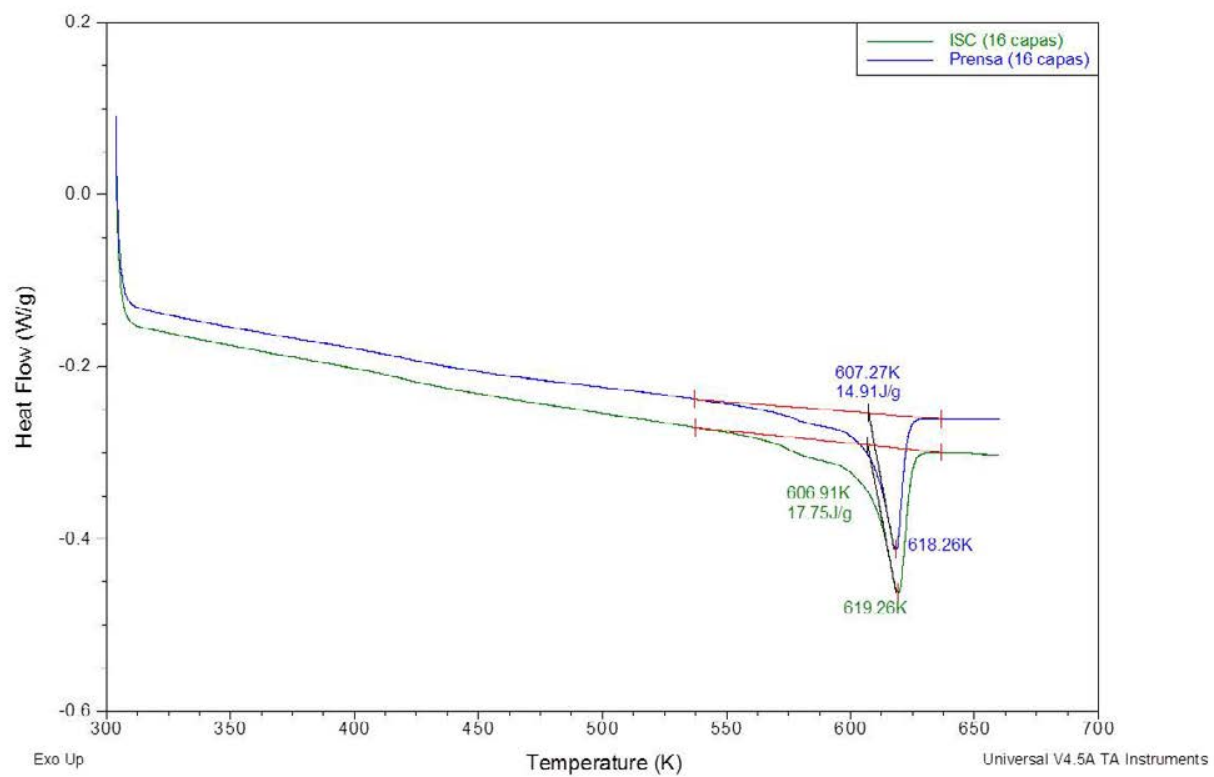

Figura C.15: Comparativa entre paneles en prensa e ISC, ciclo calentamiento 3 


\section{C.4. Efecto del utillaje calefactado}

En la laminación automática y consolidación in-situ es habitual trabajar con mesas calefactadas a temperaturas en el entorno de $473 \mathrm{~K}$. A continuación se muestra el termograma de una muestra tras colocarse el material sobre la mesa y subir la consigna a $473 \mathrm{~K}$ y un enfriamiento lento posterior C.16. Asimismo, se ha tratado de reproducir ese mismo ciclo en el calorímetro con una rampa de calentamiento C.17 y una isoterma posterior C.18

Método de ensayo sobre el APC2/AS4 de mesa calefactada:

- Rampa $10 K / \min$ hasta $663 K\left(390^{\circ} \mathrm{C}\right)$

Método de ensayo utilizado en la simulación:

- Rampa $1 K / \min$ hasta $473 K\left(200^{\circ} \mathrm{C}\right)$

- Isoterma $120 \mathrm{~min}$

- Salto a $663 K\left(390^{\circ} \mathrm{C}\right)$

\begin{tabular}{|c|c|c|}
\hline Muestra & Probeta & Masa $[\mathrm{mg}]$ \\
\hline APC2/AS4 mesa ISC & $1410-213$ & 13,93 \\
\hline Simulación APC2/AS4 en mesa ISC & $1410-267$ & 21,76 \\
\hline
\end{tabular}

Tabla C.8: Masas de las probetas ensayadas 


\section{APC2/AS4 en mesa calefactada:}

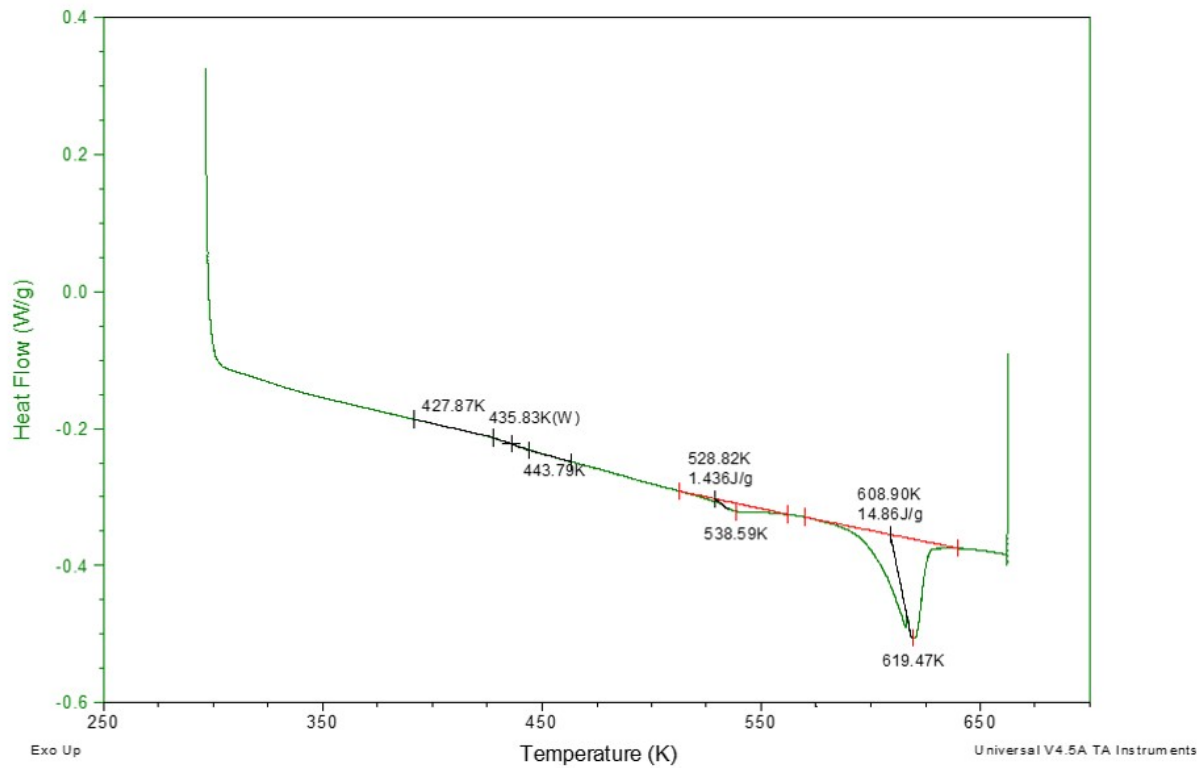

Figura C.16: DSC APC2/AS4 tras posicionarlo en mesa calefactada

APC2/AS4 simulación en DSC de su estado en mesa calefactada:

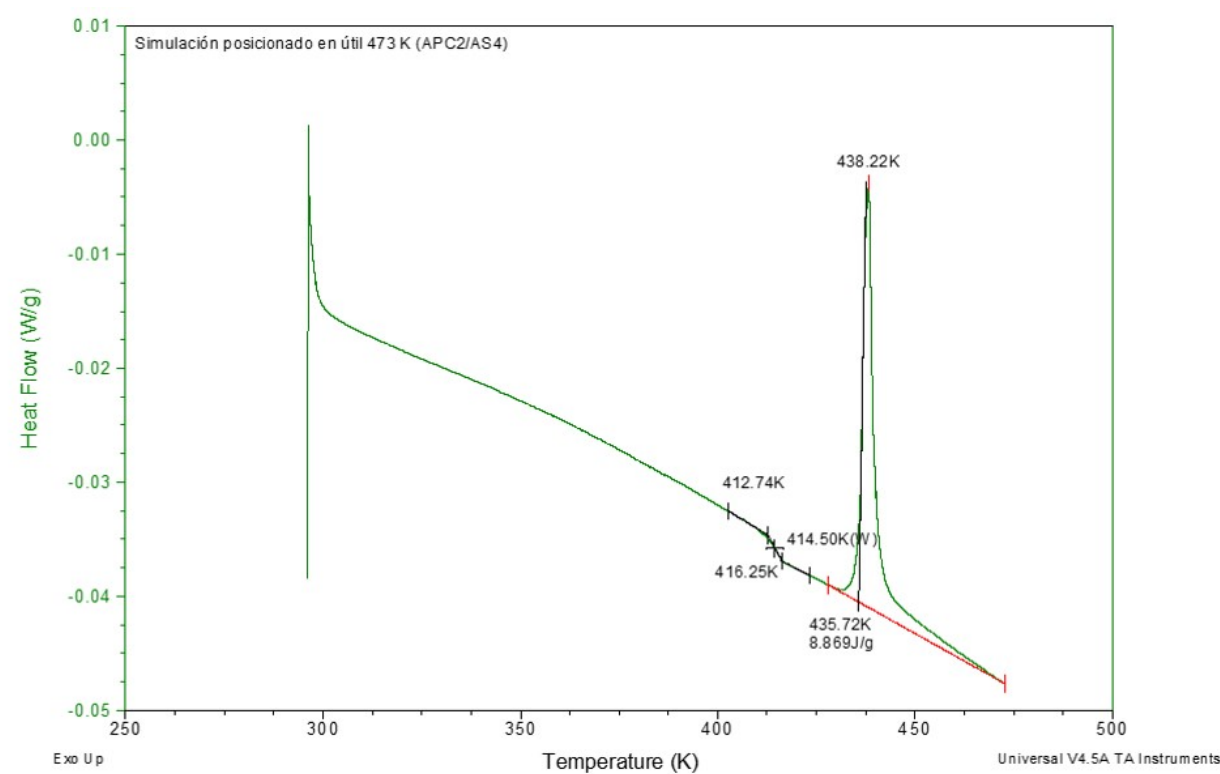

Figura C.17: DSC APC2/AS4 simulación del proceso de colocación de primera capa en útil calefactado a $473 K$ 


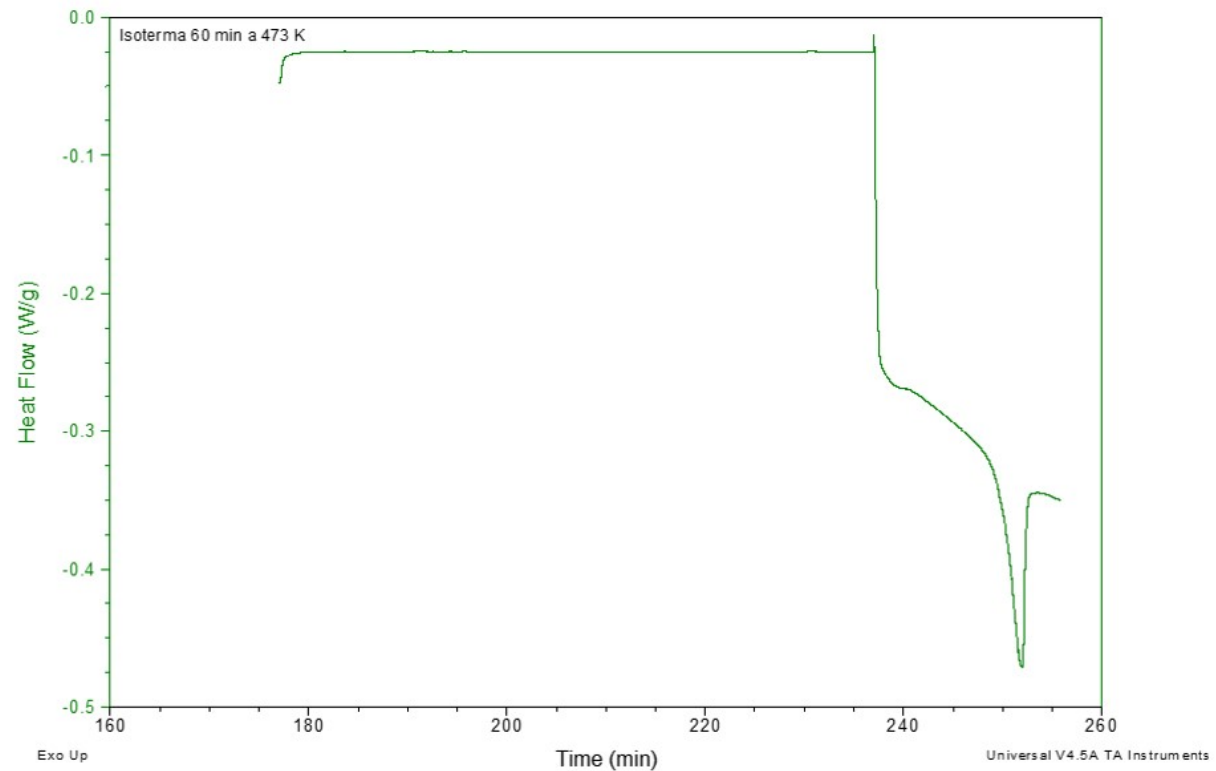

Figura C.18: DSC APC2/AS4 simulación del proceso de colocación de primera capa en útil calefactado a $473 K$ - isoterma a $473 K$

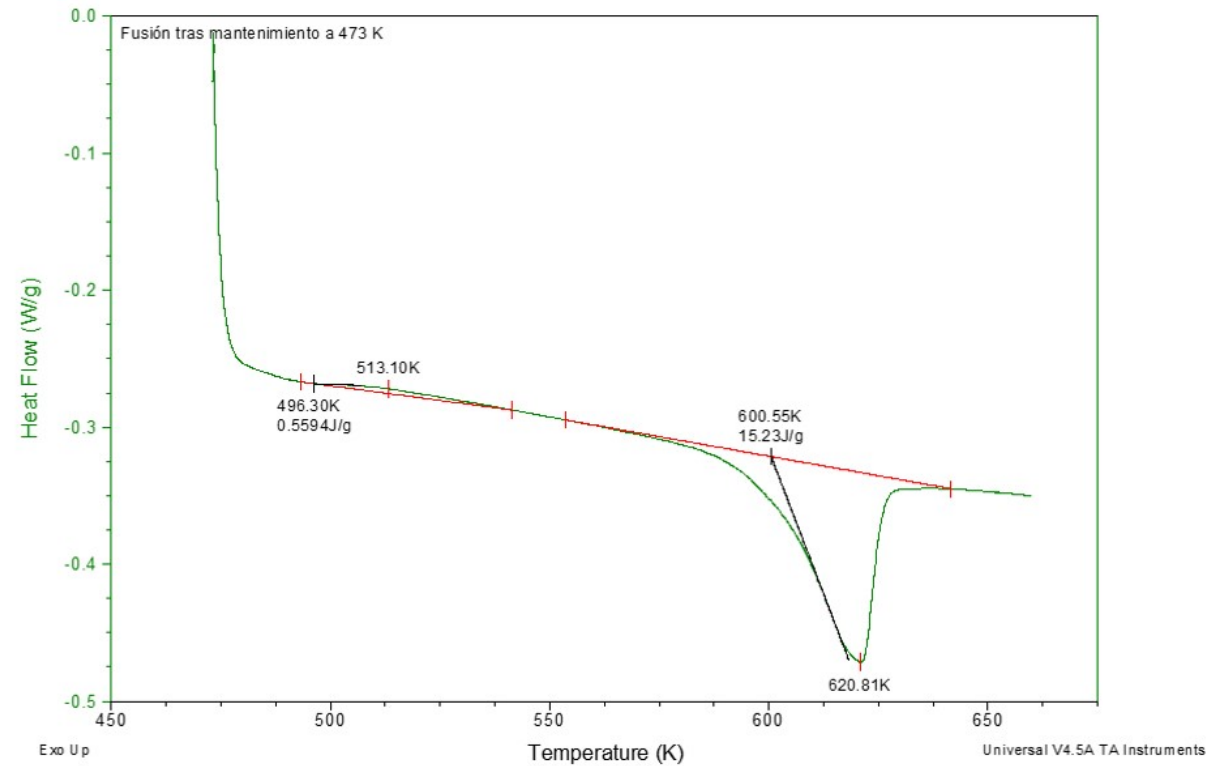

Figura C.19: DSC APC2/AS4 simulación del proceso de colocación de primera capa en útil calefactado a $473 K$ - fusión 


\section{C.5. Efecto del calentamiento secuencial en ISC}

En base a los reiterados calentamientos y enfriamientos del proceso de ISC, la cristalización irá evolucionando durante todo el proceso de encintado, se incluyen a continuación los resultados del trabajo con utillaje sin calefactar y calefactado a $473 K$.

Método de ensayo para todas las probetas:

- Rampa $10 K / \min$ hasta $663 K$

- Isoterma $5 \mathrm{~min}$

- Rampa $10 K / \min$ hasta $303 K$

- Rampa $10 K / \min$ hasta $663 K$ 


\section{C.5.1. Utillaje no calefactado - probeta escalón}

\begin{tabular}{|c|c|c|}
\hline Capa & Probeta & Masa $[\mathrm{mg}]$ \\
\hline 1 & $1776-657$ & 12,00 \\
\hline 1 & $1776-658$ & 12,19 \\
\hline 2 & $1776-659$ & 12,42 \\
\hline 2 & $1776-660$ & 17,30 \\
\hline 3 & $1776-661$ & 13,66 \\
\hline 3 & $1776-662$ & 11,62 \\
\hline 4 & $1776-663$ & 17,25 \\
\hline 4 & $1776-664$ & 17,86 \\
\hline 5 & $1776-414$ & 12,17 \\
\hline 5 & $1776-415$ & 12,51 \\
\hline 6 & $1776-416$ & 14,36 \\
\hline 6 & $1776-417$ & 14,19 \\
\hline 7 & $1776-418$ & 16,77 \\
\hline 7 & $1776-419$ & 15,66 \\
\hline 8 & $1776-420$ & 16,13 \\
\hline 8 & $1776-421$ & 18,93 \\
\hline 9 & $1776-422$ & 16,84 \\
\hline 9 & $1776-423$ & 20,50 \\
\hline 10 & $1776-424$ & 24,32 \\
\hline 10 & $1776-425$ & 20,52 \\
\hline 11 & $1776-426$ & 21,10 \\
\hline 11 & $1776-427$ & 23,51 \\
\hline 12 & $1776-428$ & 26,32 \\
\hline 12 & $1776-429$ & 27,06 \\
\hline 13 & $1776-430$ & 30,25 \\
\hline 13 & $1776-431$ & 27,13 \\
\hline 14 & $1776-432$ & 28,21 \\
\hline 14 & $1776-433$ & 29,00 \\
\hline 15 & $1776-434$ & 31,80 \\
\hline 15 & $1776-435$ & 26,43 \\
\hline 16 & $1776-436$ & 30,74 \\
\hline 16 & $1776-437$ & 30,50 \\
\hline & & \\
\hline
\end{tabular}

Tabla C.9: Masas de las probetas ensayadas 


\section{Encintado de las capas 1 y 2:}

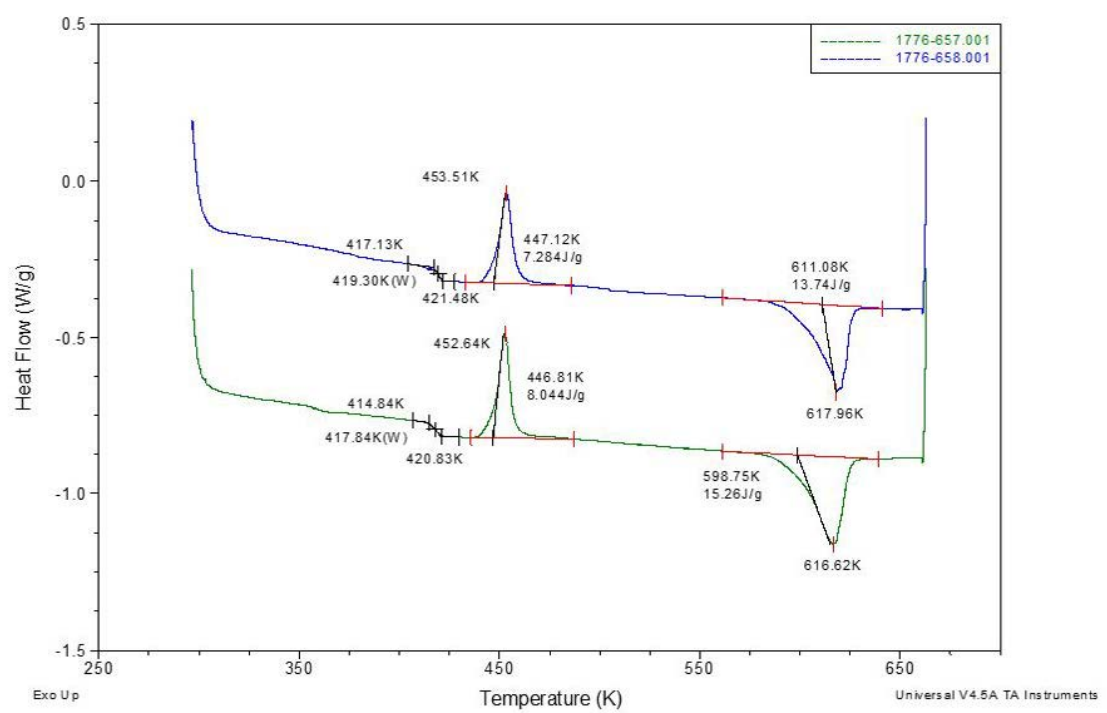

Figura C.20: DSC APC2/AS4 probeta escalón encintada sobre útil frío capa 1

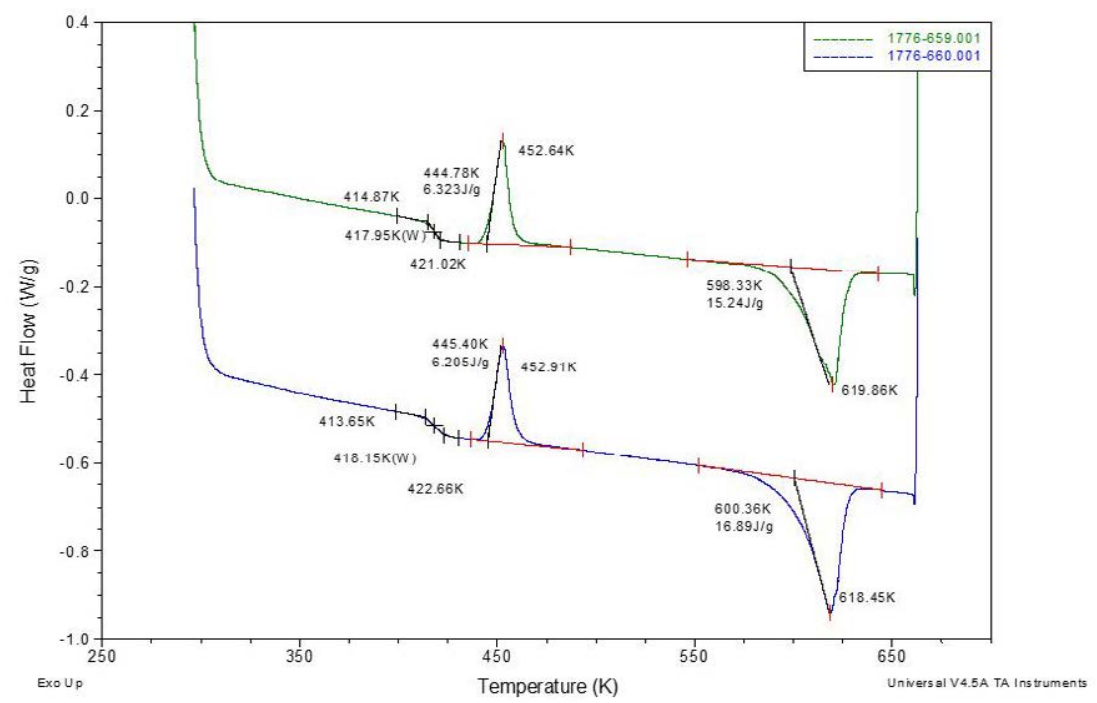

Figura C.21: DSC APC2/AS4 probeta escalón encintada sobre útil frío capa 2 
Encintado de las capas 3 y 4:

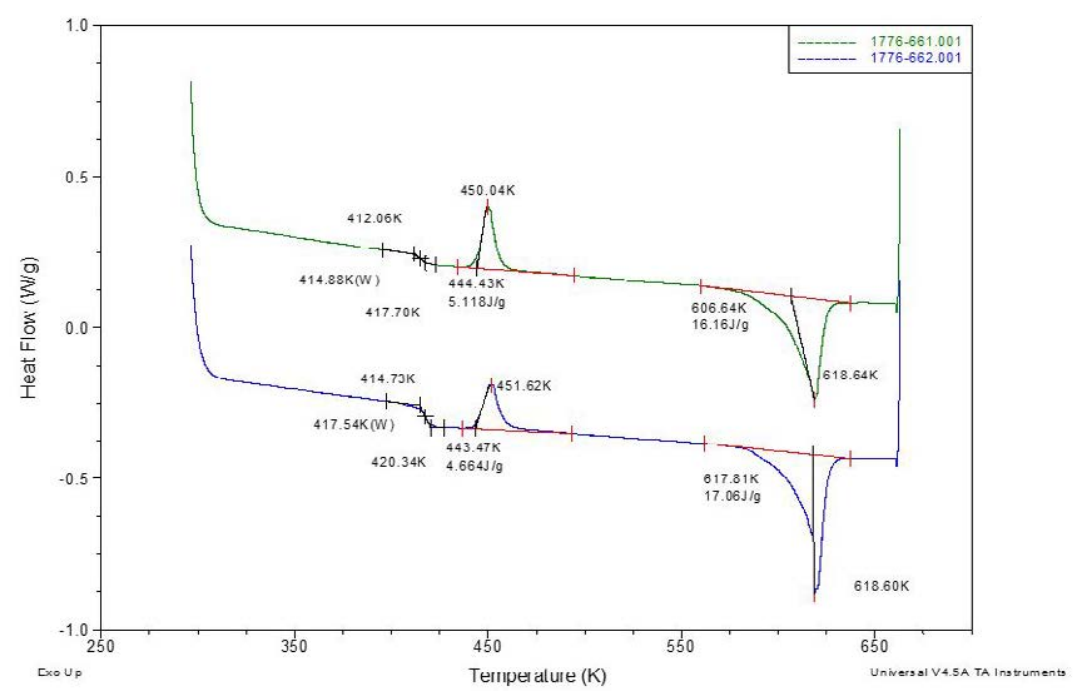

Figura C.22: DSC APC2/AS4 probeta escalón encintada sobre útil frío capa 3

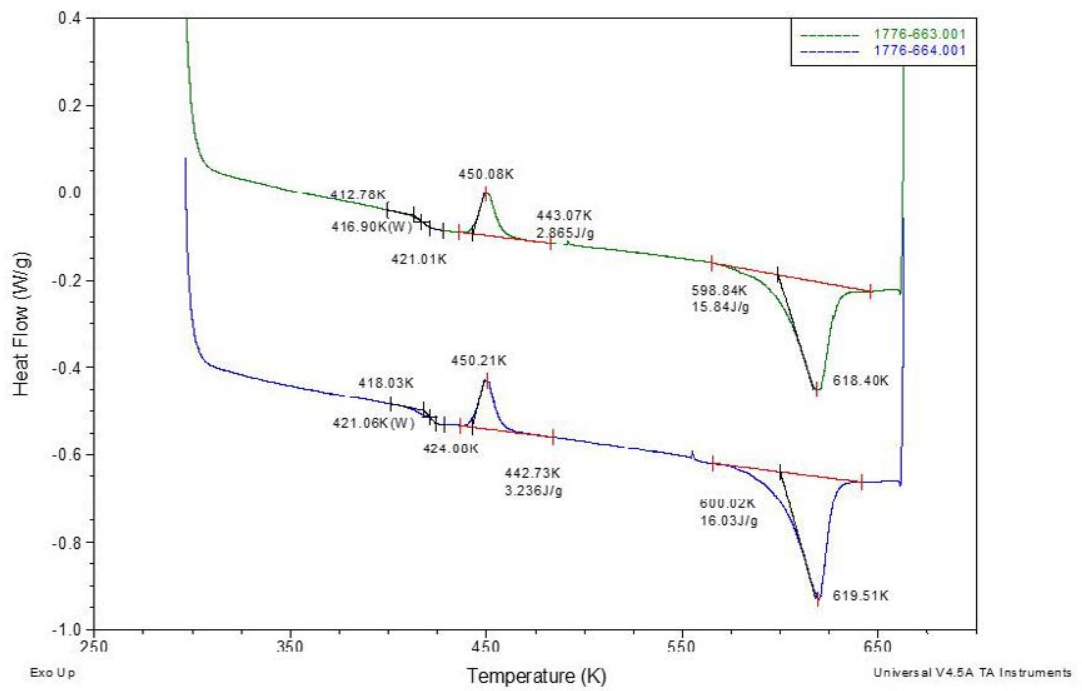

Figura C.23: DSC APC2/AS4 probeta escalón encintada sobre útil frío capa 4 
Encintado de las capas 5 y 6 :

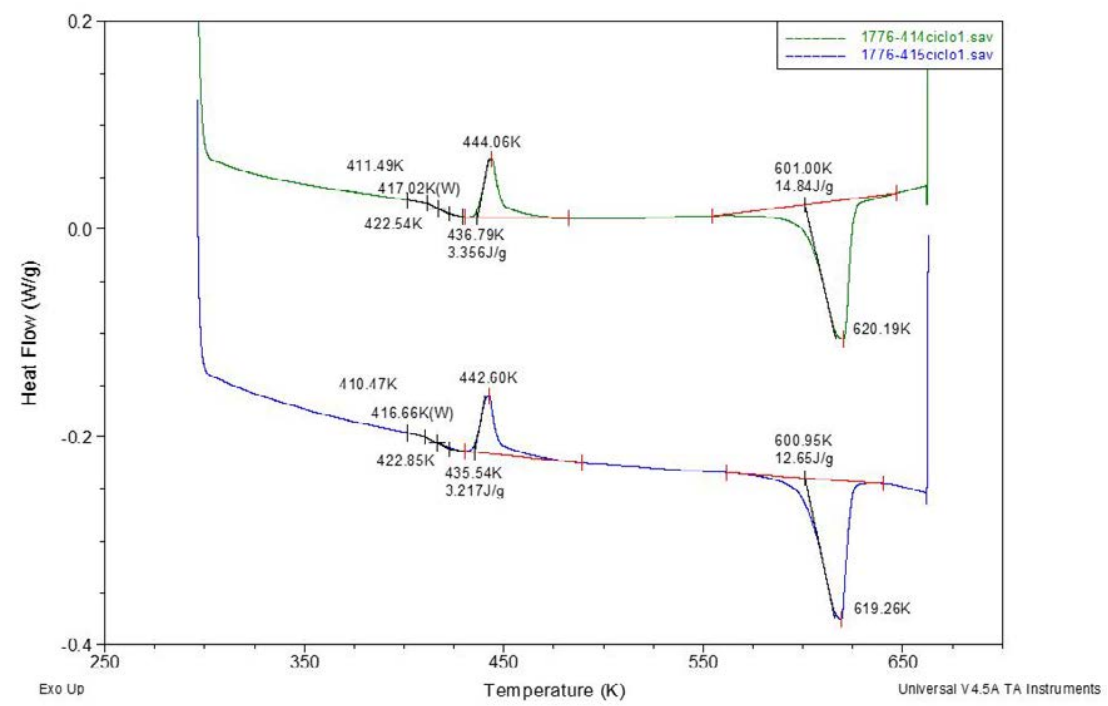

Figura C.24: DSC APC2/AS4 probeta escalón encintada sobre útil frío capa 5

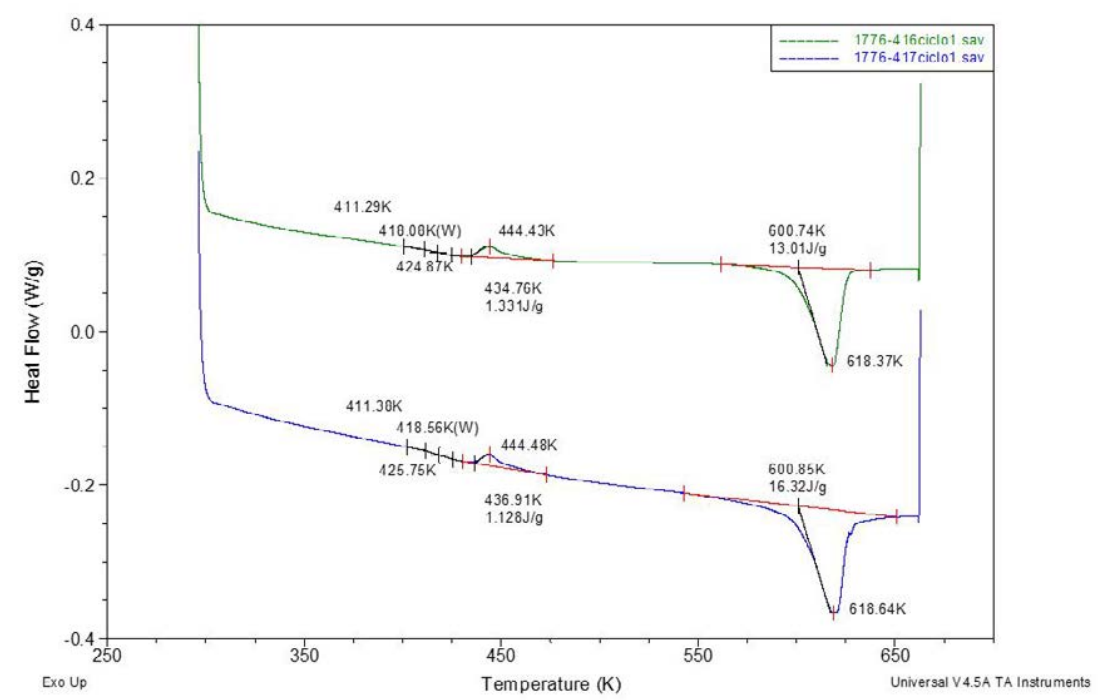

Figura C.25: DSC APC2/AS4 probeta escalón encintada sobre útil frío capa 6 
Encintado de las capas 7 y 8:

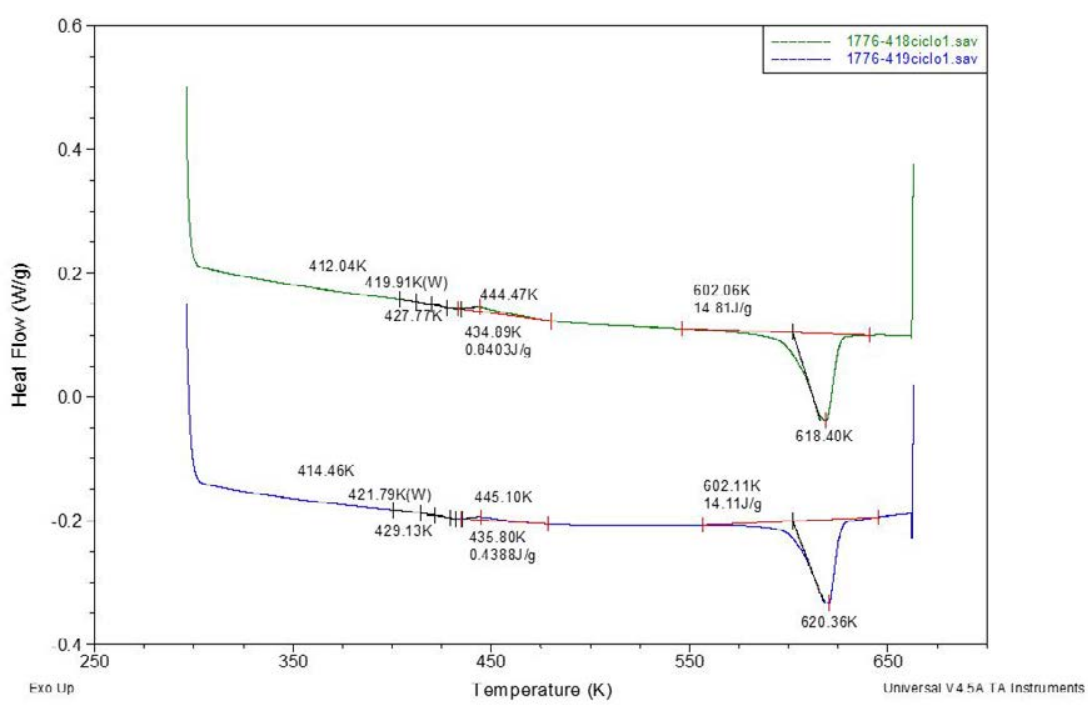

Figura C.26: DSC APC2/AS4 probeta escalón encintada sobre útil frío capa 7

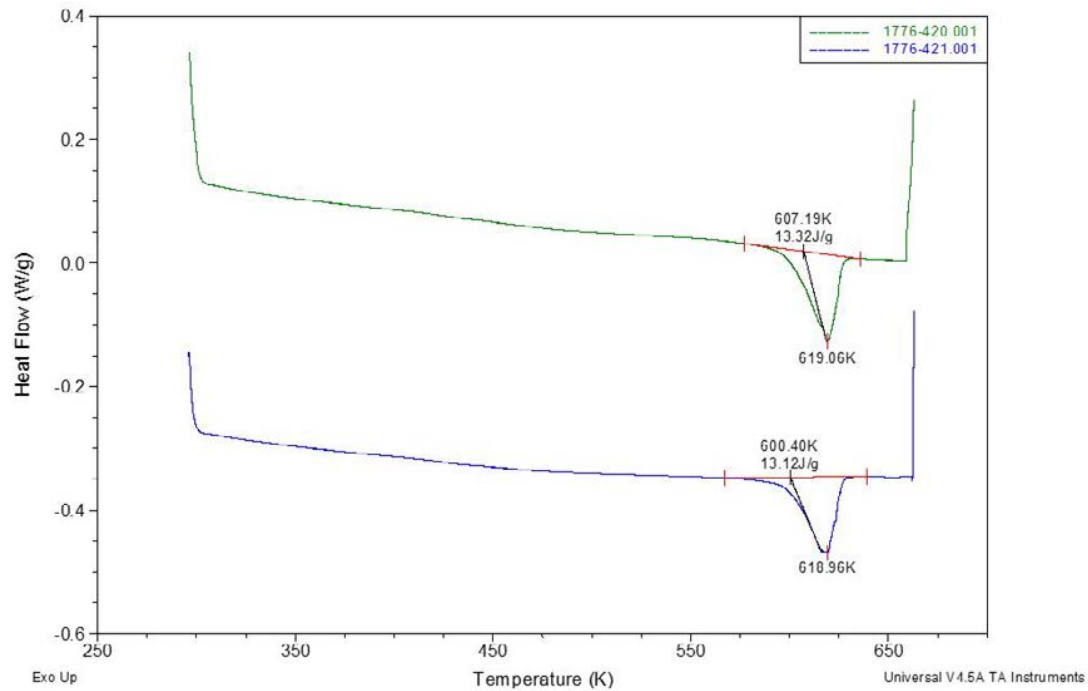

Figura C.27: DSC APC2/AS4 probeta escalón encintada sobre útil frío capa 8 
Encintado de las capas 9 y 10:

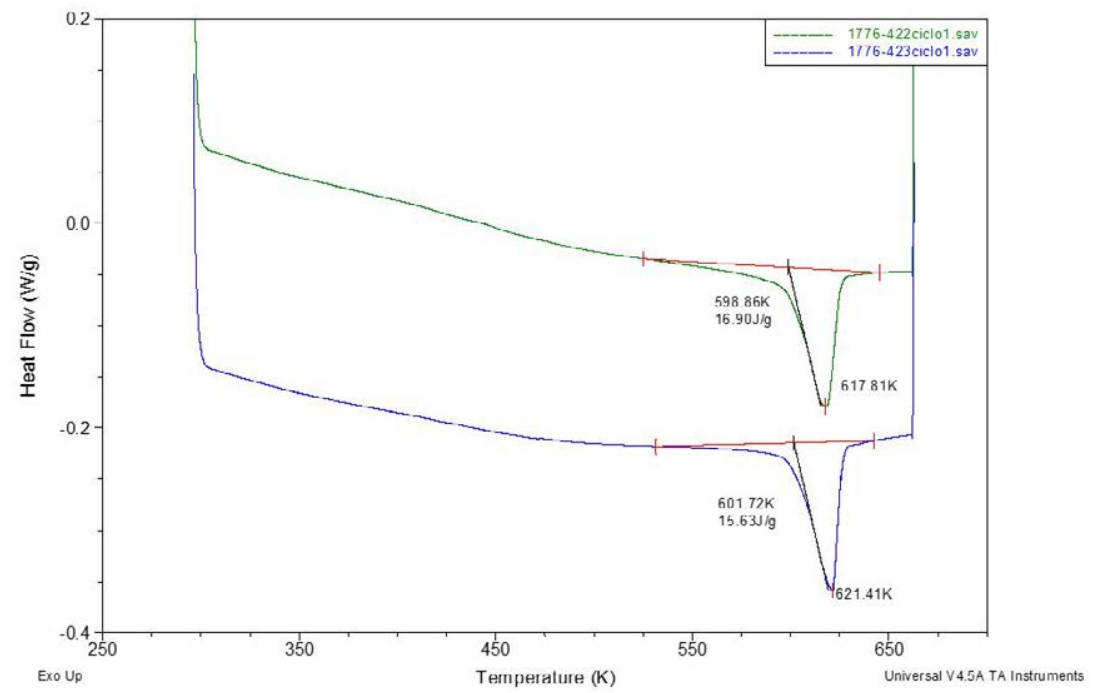

Figura C.28: DSC APC2/AS4 probeta escalón encintada sobre útil frío capa 9

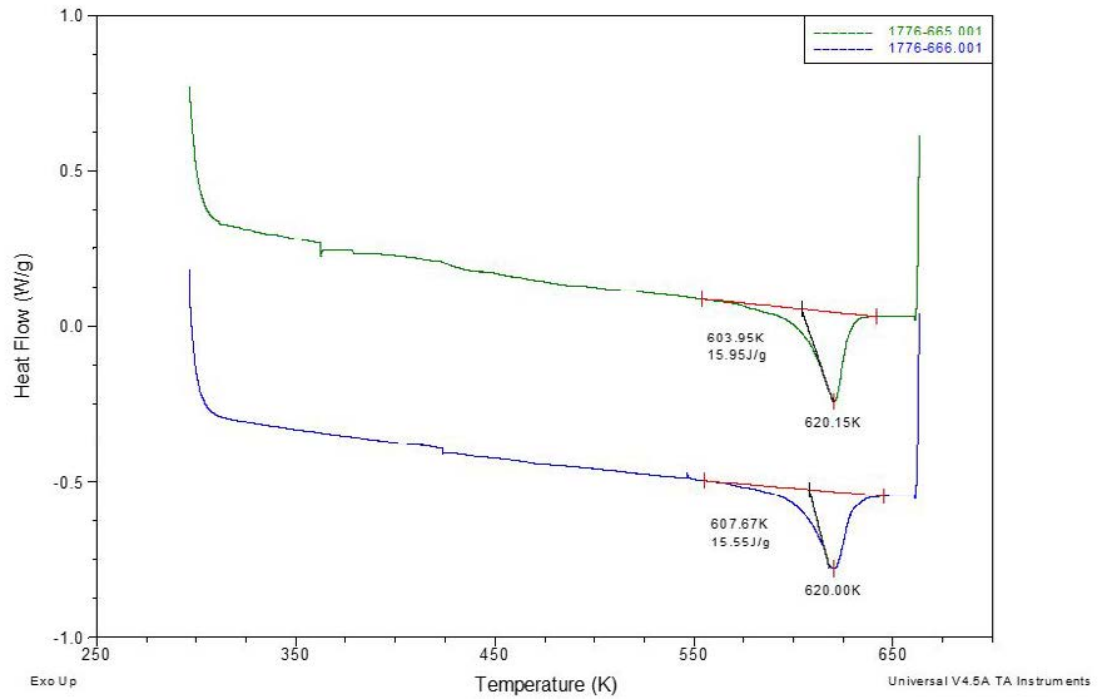

Figura C.29: DSC APC2/AS4 probeta escalón encintada sobre útil frío capa 10 
Encintado de las capas 11 y 12:

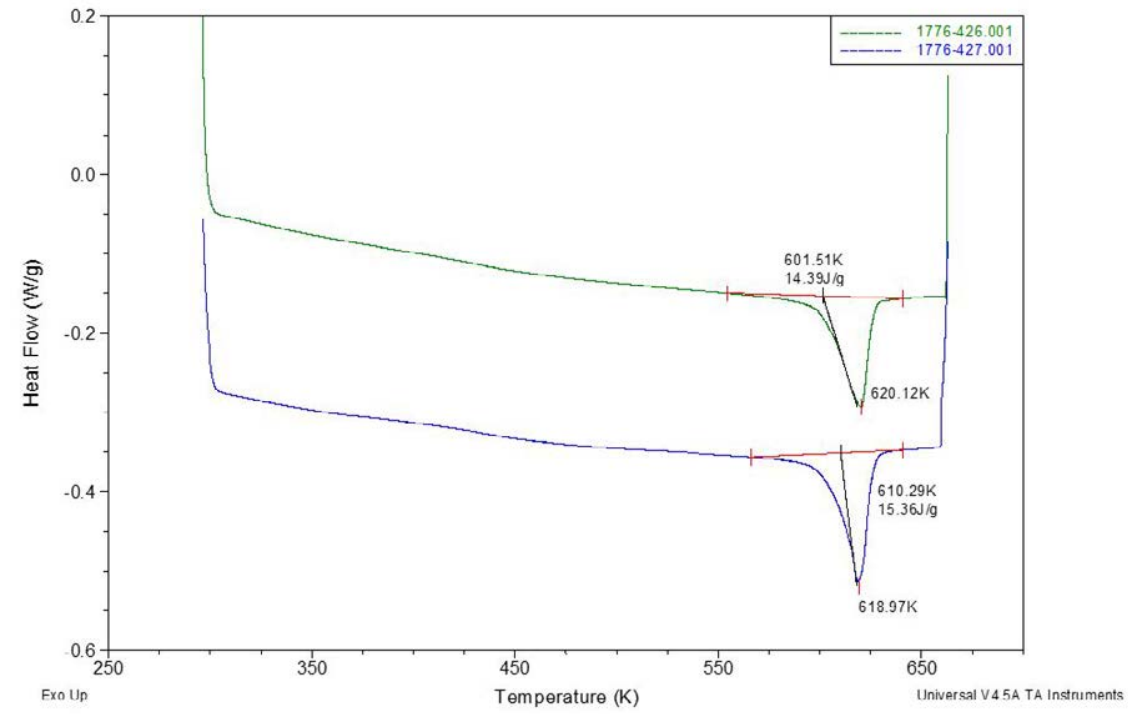

Figura C.30: DSC APC2/AS4 probeta escalón encintada sobre útil frío capa 11

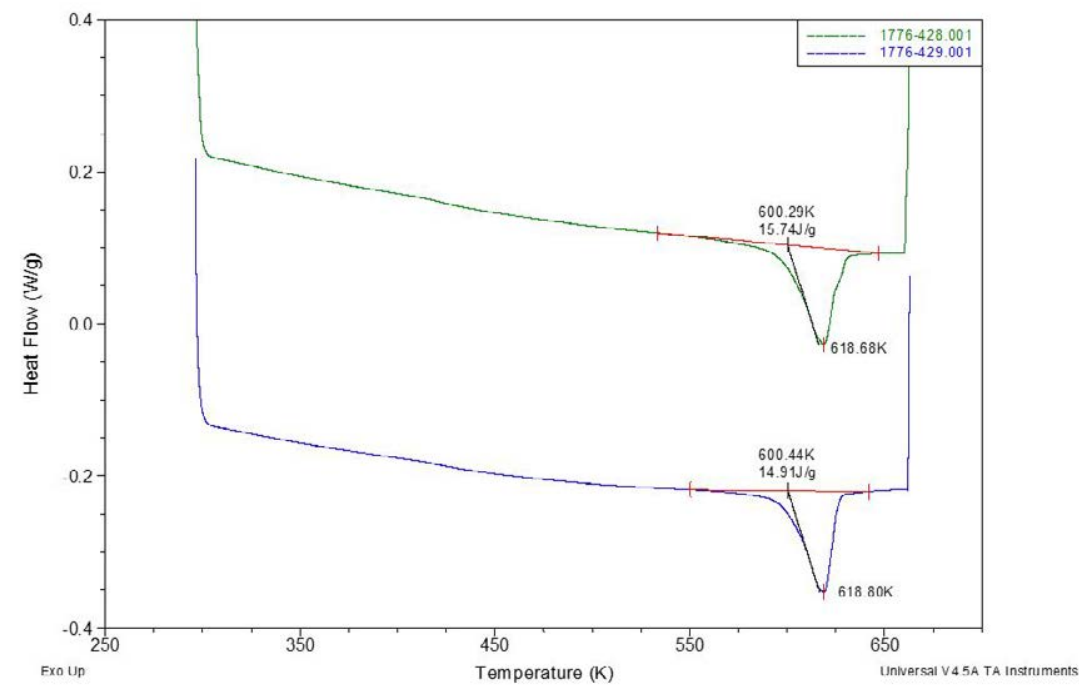

Figura C.31: DSC APC2/AS4 probeta escalón encintada sobre útil frío capa 12 
Encintado de las capas 13 y 14:

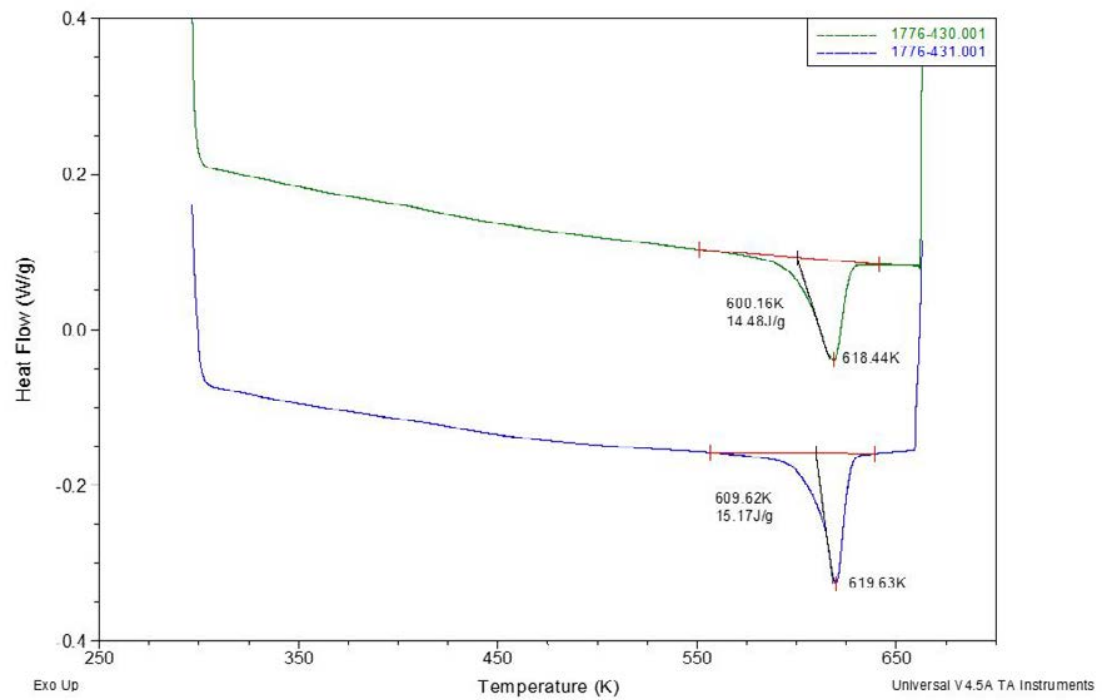

Figura C.32: DSC APC2/AS4 probeta escalón encintada sobre útil frío capa 13

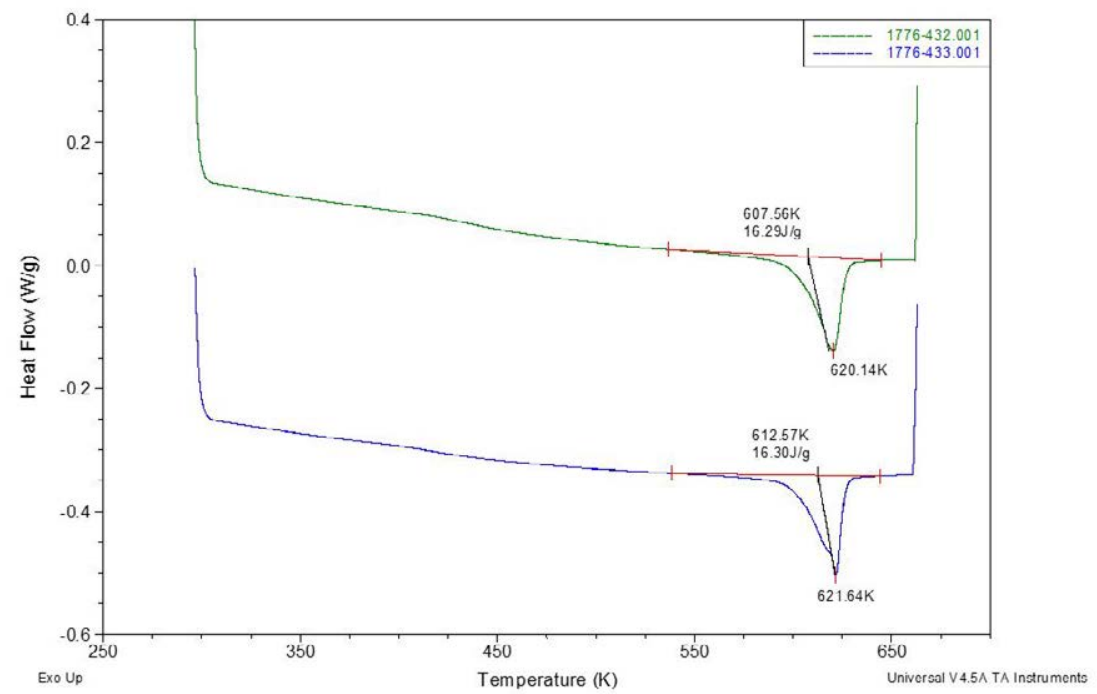

Figura C.33: DSC APC2/AS4 probeta escalón encintada sobre útil frío capa 14 
Encintado de las capas 15 y 16 :

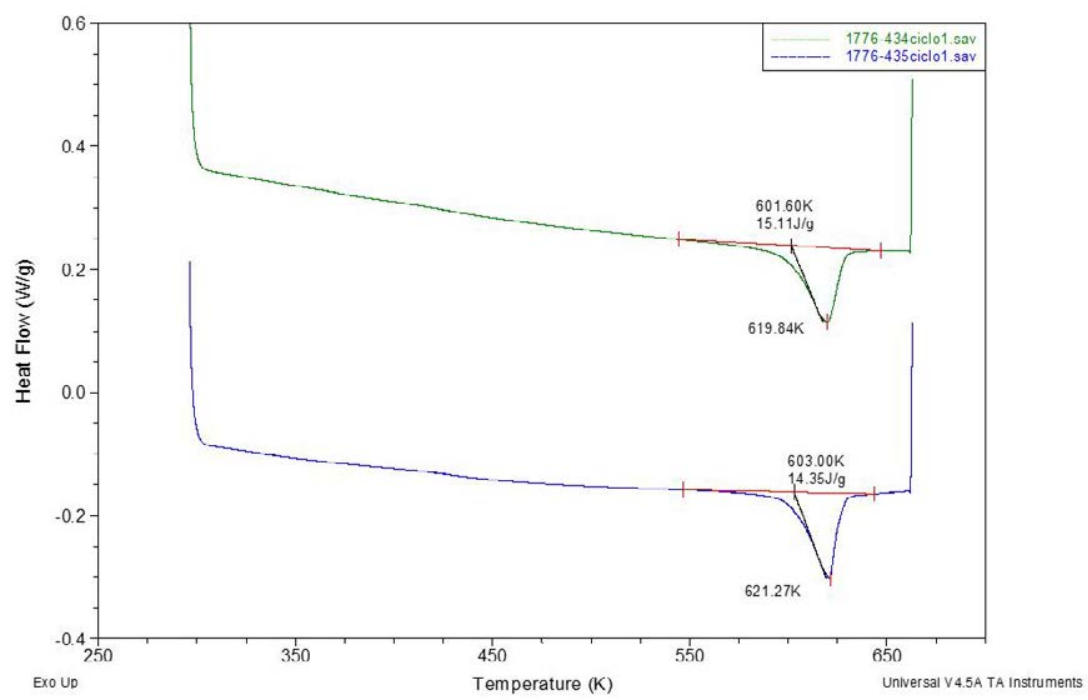

Figura C.34: DSC APC2/AS4 probeta escalón encintada sobre útil frío capa 15

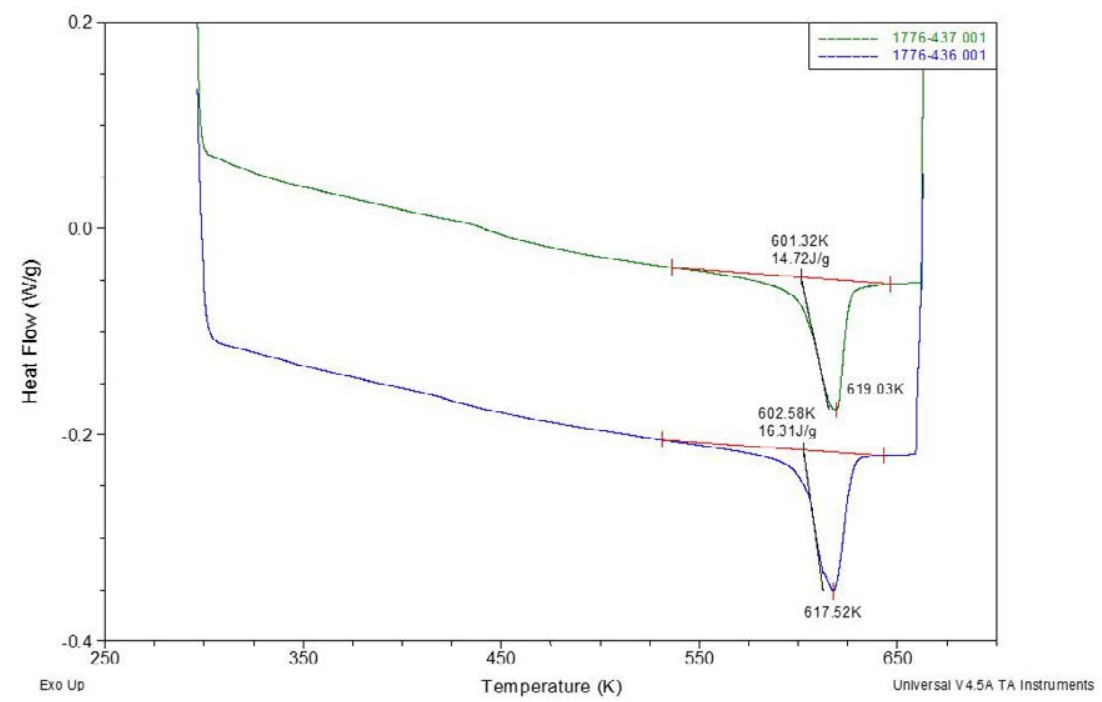

Figura C.35: DSC APC2/AS4 probeta escalón encintada sobre útil frío capa 16 


\section{C.5.2. Utillaje calefactado - probeta escalón}

\begin{tabular}{|c|c|c|}
\hline Capa & Probeta & Masa [mg] \\
\hline 1 & $1776-667$ & 10,12 \\
\hline 1 & $1776-668$ & 9,46 \\
\hline 2 & 1776-669 & 15,59 \\
\hline 2 & $1776-670$ & 12,16 \\
\hline 3 & $1776-671$ & 21,00 \\
\hline 3 & $1776-672$ & 20,20 \\
\hline 4 & - & - \\
\hline 4 & - & - \\
\hline 5 & $1776-454$ & 11,23 \\
\hline 5 & $1776-455$ & 9,84 \\
\hline 6 & $1776-456$ & 14,34 \\
\hline 6 & $1776-457$ & 11,75 \\
\hline 7 & $1776-458$ & 16,44 \\
\hline 7 & $1776-459$ & 14,28 \\
\hline 8 & $1776-460$ & 19,12 \\
\hline 8 & $1776-461$ & 14,18 \\
\hline 9 & $1776-462$ & 17,94 \\
\hline 9 & $1776-463$ & 17,01 \\
\hline 10 & $1776-464$ & 18,75 \\
\hline 10 & $1776-465$ & 16,78 \\
\hline 11 & $1776-466$ & 14,89 \\
\hline 11 & $1776-467$ & 16,19 \\
\hline 12 & $1776-468$ & 17,75 \\
\hline 12 & 1776-469 & 16,62 \\
\hline 13 & $1776-470$ & 18,78 \\
\hline 13 & $1776-471$ & 17,91 \\
\hline 14 & $1776-472$ & 22,17 \\
\hline 14 & $1776-473$ & 21,31 \\
\hline 15 & $1776-474$ & 21,47 \\
\hline 15 & $1776-475$ & 18,36 \\
\hline 16 & $1776-436$ & 21,49 \\
\hline 16 & $1776-437$ & 23,18 \\
\hline
\end{tabular}

Tabla C.10: Masas de las probetas ensayadas 
Encintado de las capas 1 y 2 :

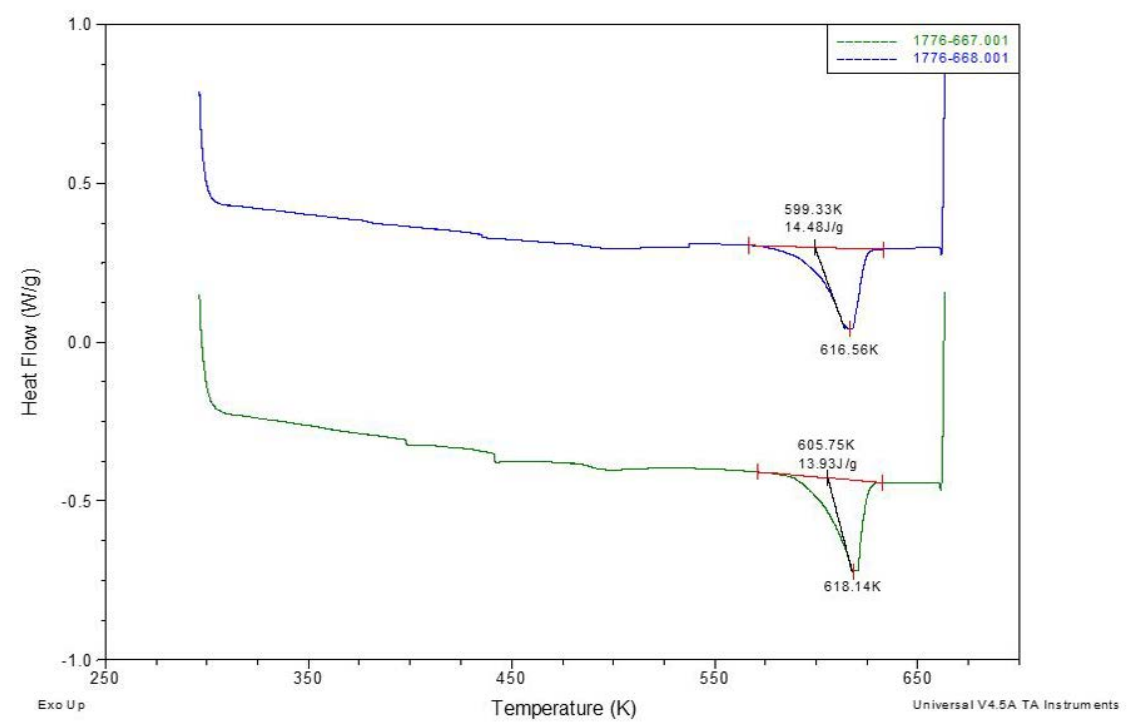

Figura C.36: DSC APC2/AS4 probeta escalón encintada sobre útil caliente - capa 1

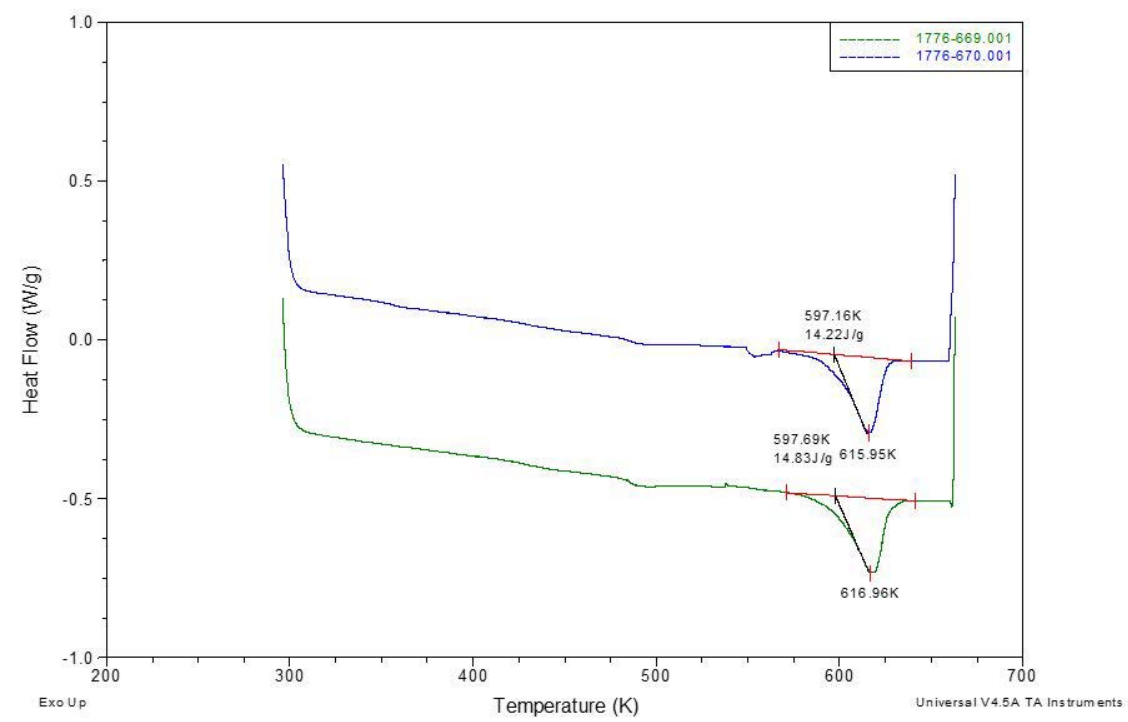

Figura C.37: DSC APC2/AS4 probeta escalón encintada sobre útil caliente - capa 2 
Encintado de las capas 3 y 5 :

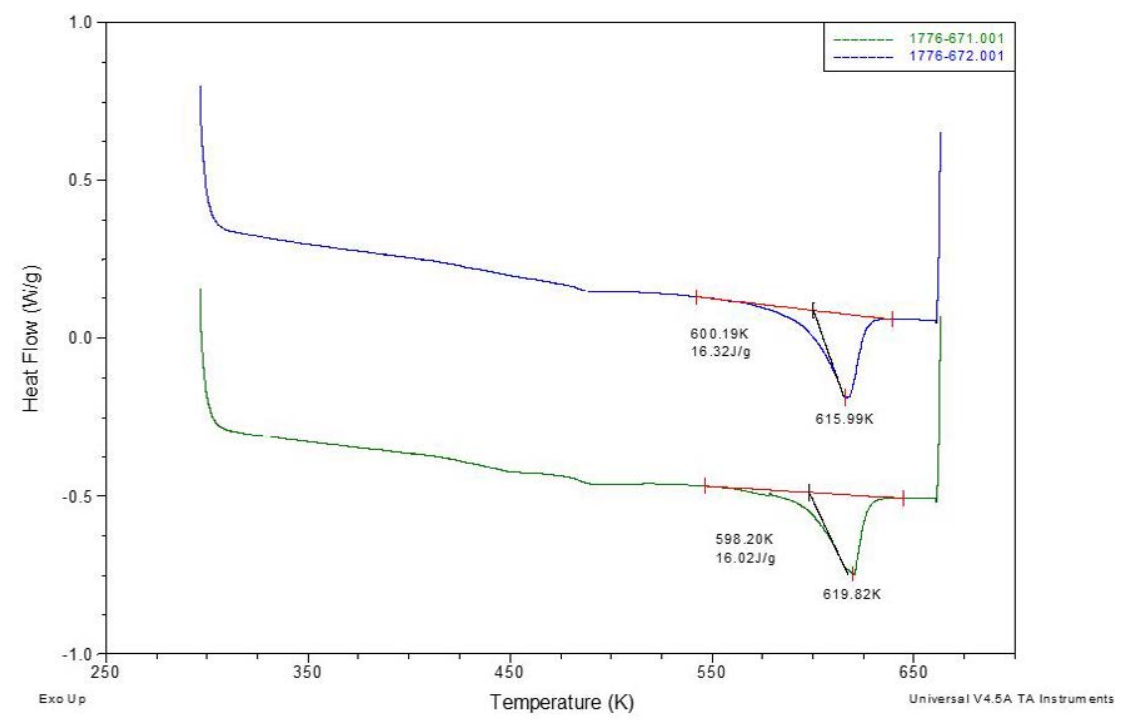

Figura C.38: DSC APC2/AS4 probeta escalón encintada sobre útil caliente - capa 3

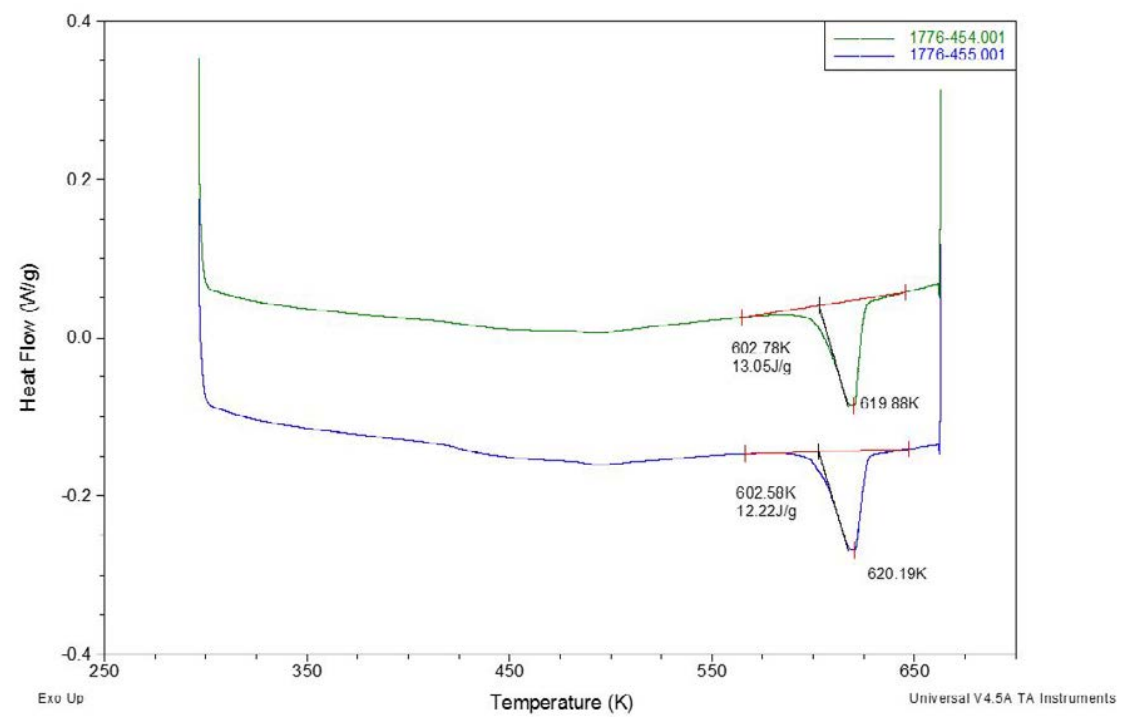

Figura C.39: DSC APC2/AS4 probeta escalón encintada sobre útil caliente - capa 5 
Encintado de las capas 6 y 7 :

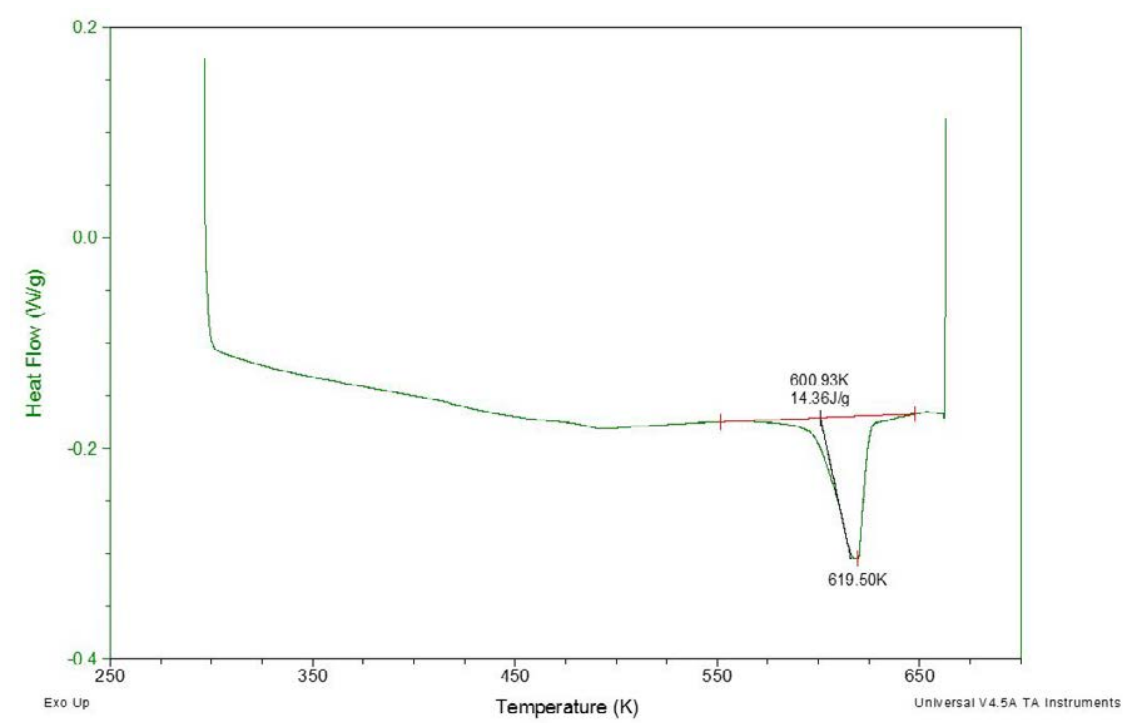

Figura C.40: DSC APC2/AS4 probeta escalón encintada sobre útil caliente - capa 6

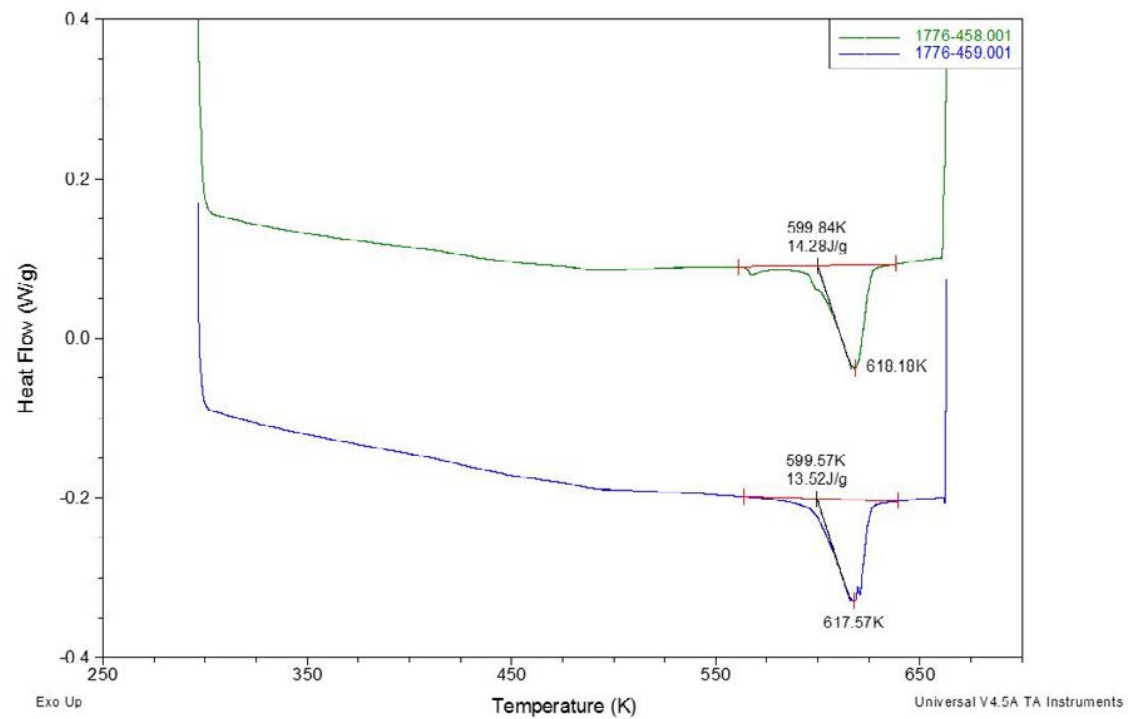

Figura C.41: DSC APC2/AS4 probeta escalón encintada sobre útil caliente - capa 7 
Encintado de las capas 8 y 9 :

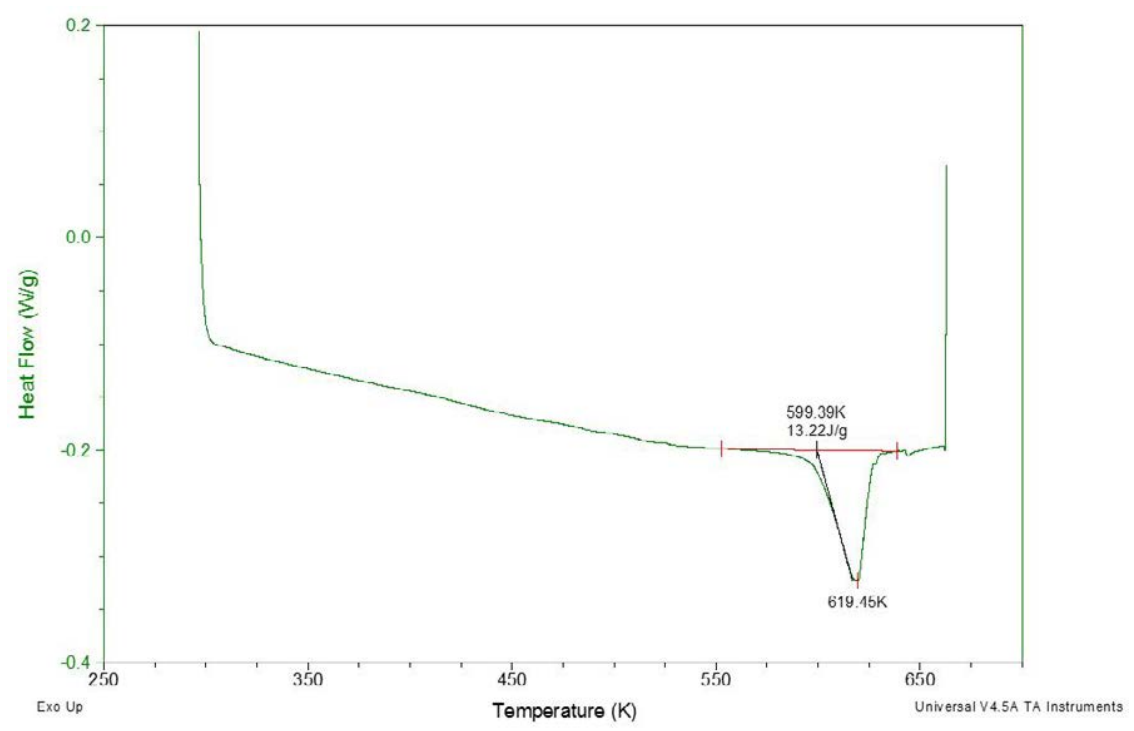

Figura C.42: DSC APC2/AS4 probeta escalón encintada sobre útil caliente - capa 8

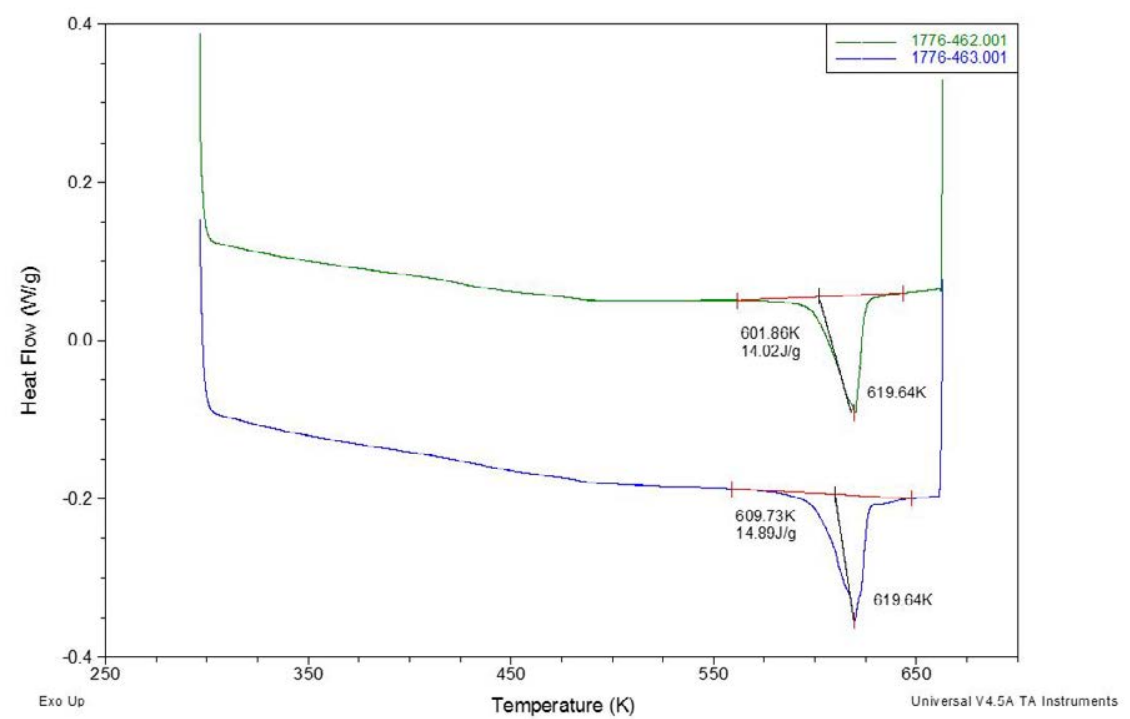

Figura C.43: DSC APC2/AS4 probeta escalón encintada sobre útil caliente - capa 9 
Encintado de las capas 10 y 11 :

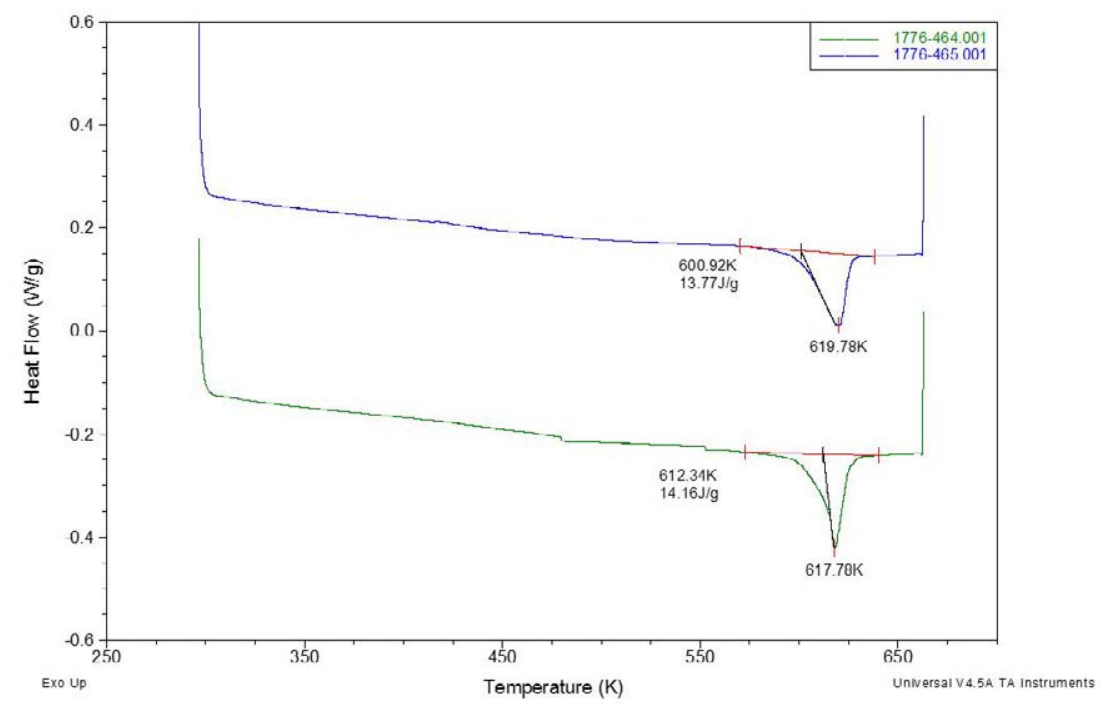

Figura C.44: DSC APC2/AS4 probeta escalón encintada sobre útil caliente - capa 10

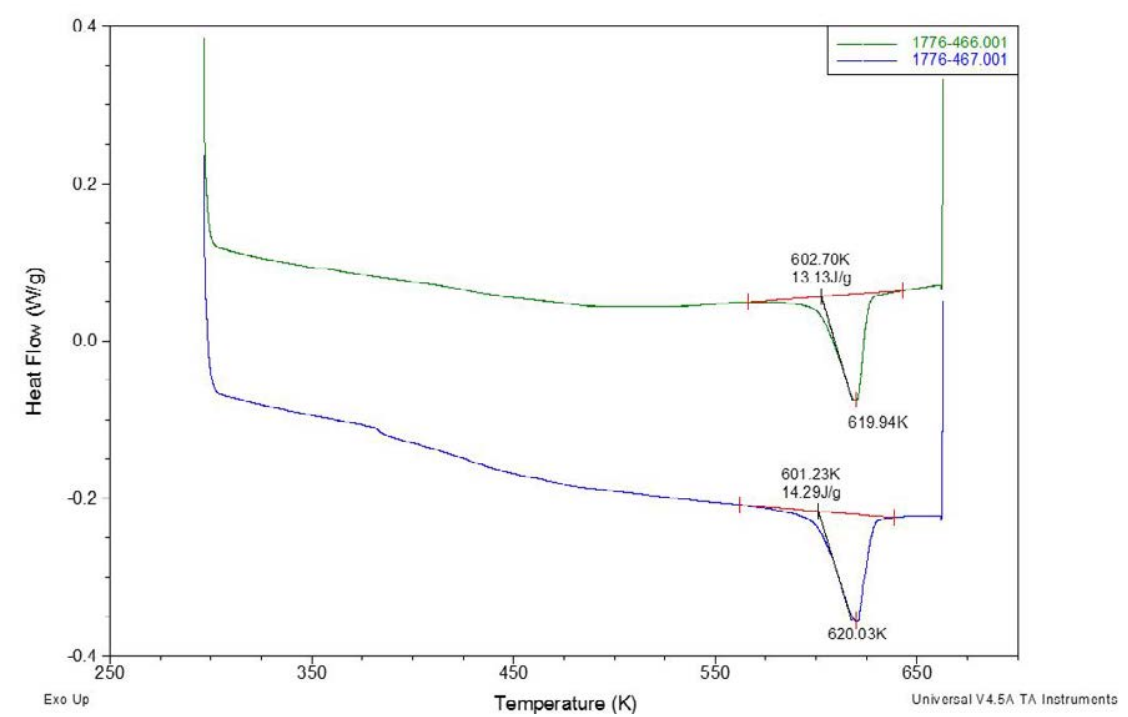

Figura C.45: DSC APC2/AS4 probeta escalón encintada sobre útil caliente - capa 11 
Encintado de las capas 12 y 13 :

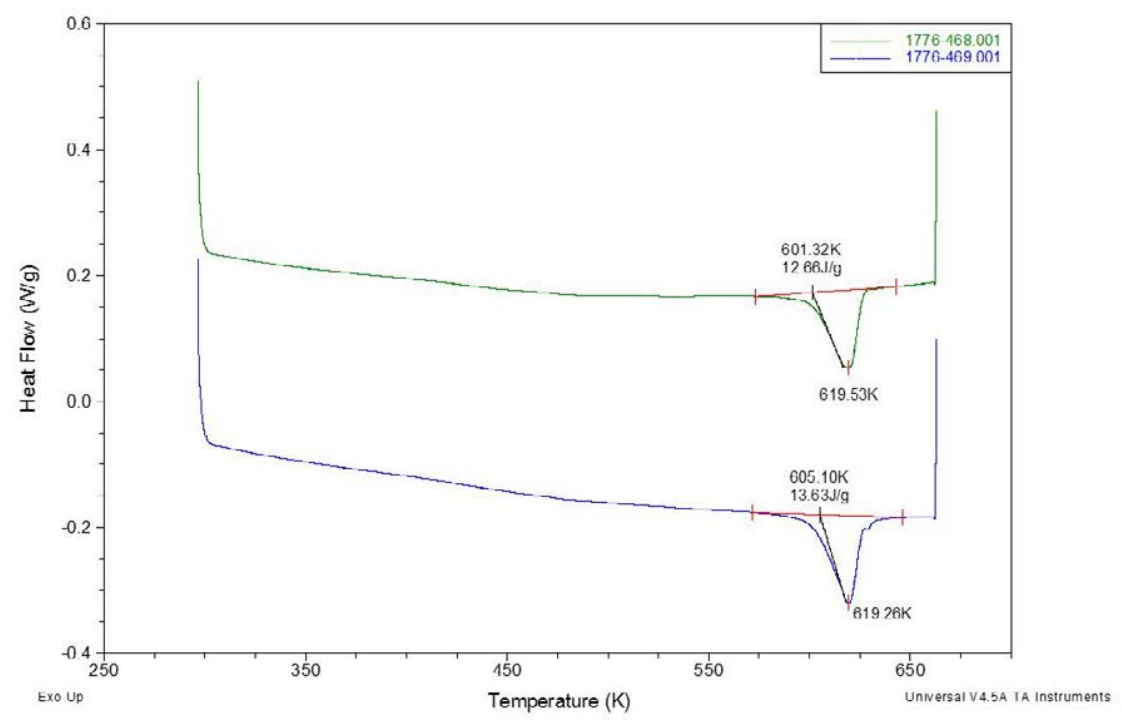

Figura C.46: DSC APC2/AS4 probeta escalón encintada sobre útil caliente - capa 12

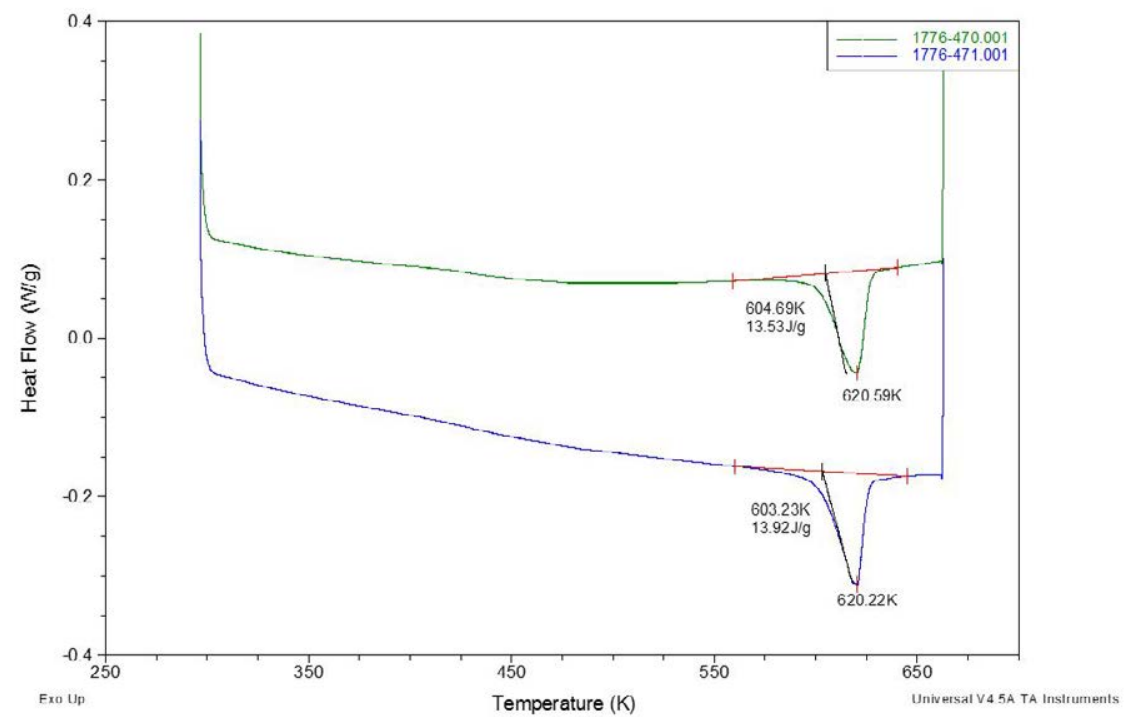

Figura C.47: DSC APC2/AS4 probeta escalón encintada sobre útil caliente - capa 13 
Encintado de las capas 14 y 15 :

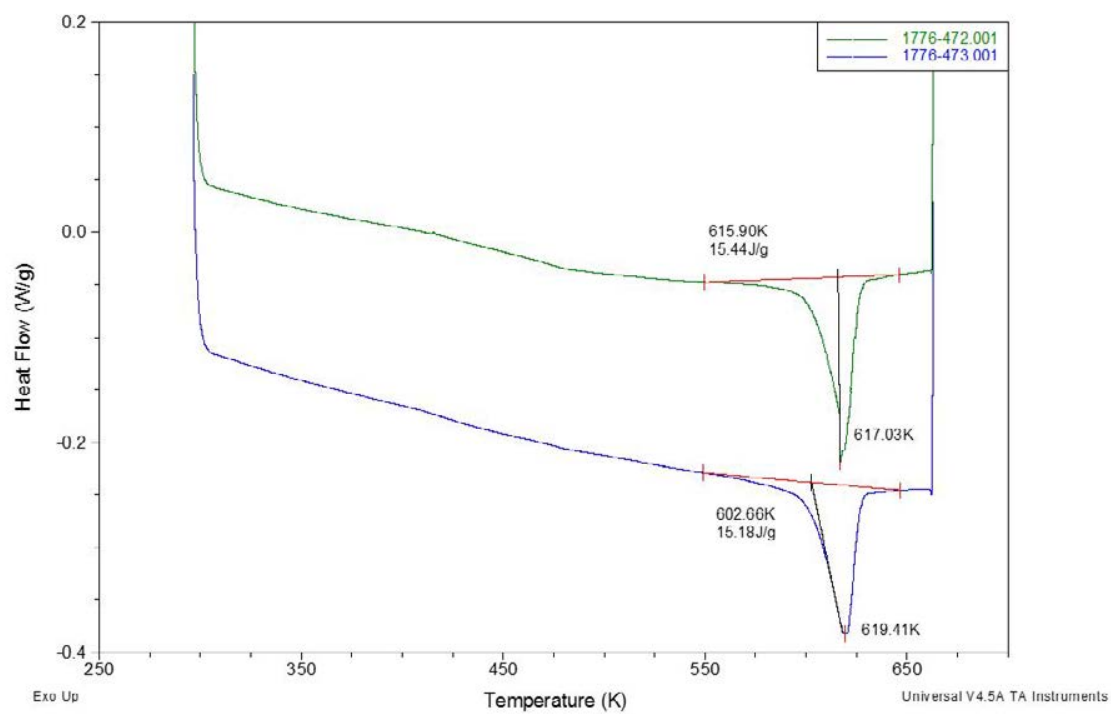

Figura C.48: DSC APC2/AS4 probeta escalón encintada sobre útil caliente - capa 14

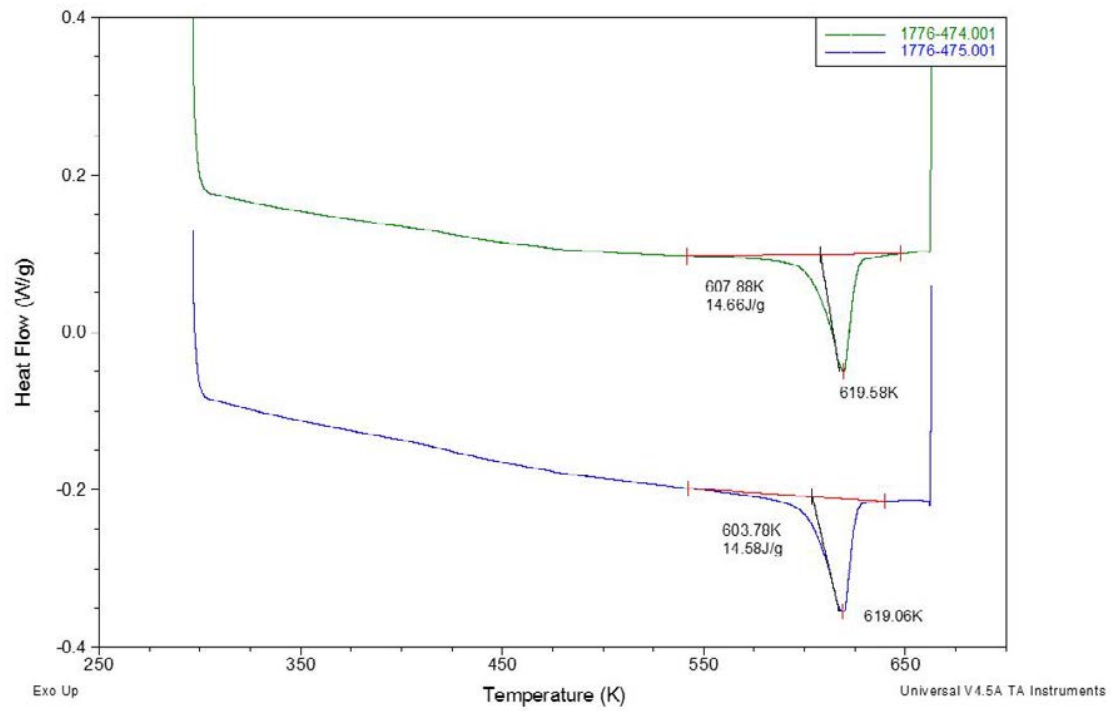

Figura C.49: DSC APC2/AS4 probeta escalón encintada sobre útil caliente - capa 15 
Encintado de la capa 16:

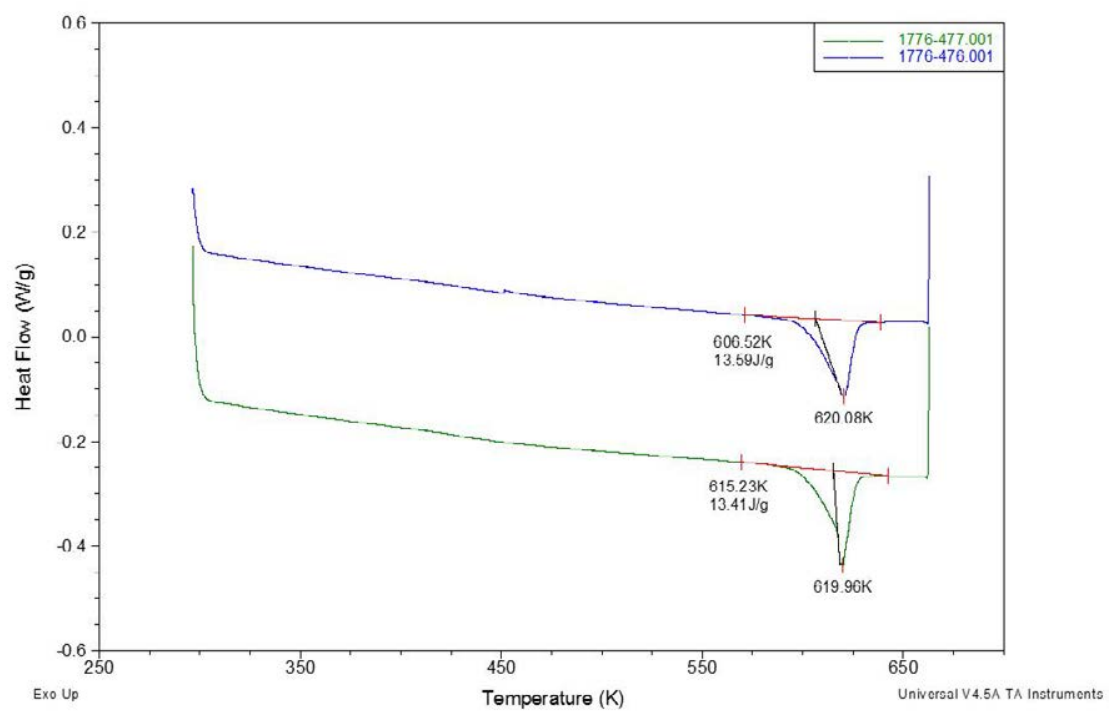

Figura C.50: DSC APC2/AS4 probeta escalón encintada sobre útil caliente - capa 16 



\section{Apéndice D}

\section{Deconvolución en cristalización: enfriamientos a mayor velocidad}

Tras las deconvoluciones de los picos exotérmicos de cristalización para el PEEK 450G obtenidos de los ensayos de calorimetría a 2, 5, 10 y 15K/min, se observó la inestabilidad en los factores de peso que marcaban las contribuciones de cada uno de los procesos.

Se ejecutaron nuevas deconvoluciones sobre ensayos donde las velocidades de enfriamiento se elevaron buscando estabilizar los factores de contribución. 
ApÉndice D. Deconvolución en cristalización: enfriamientos a mayor

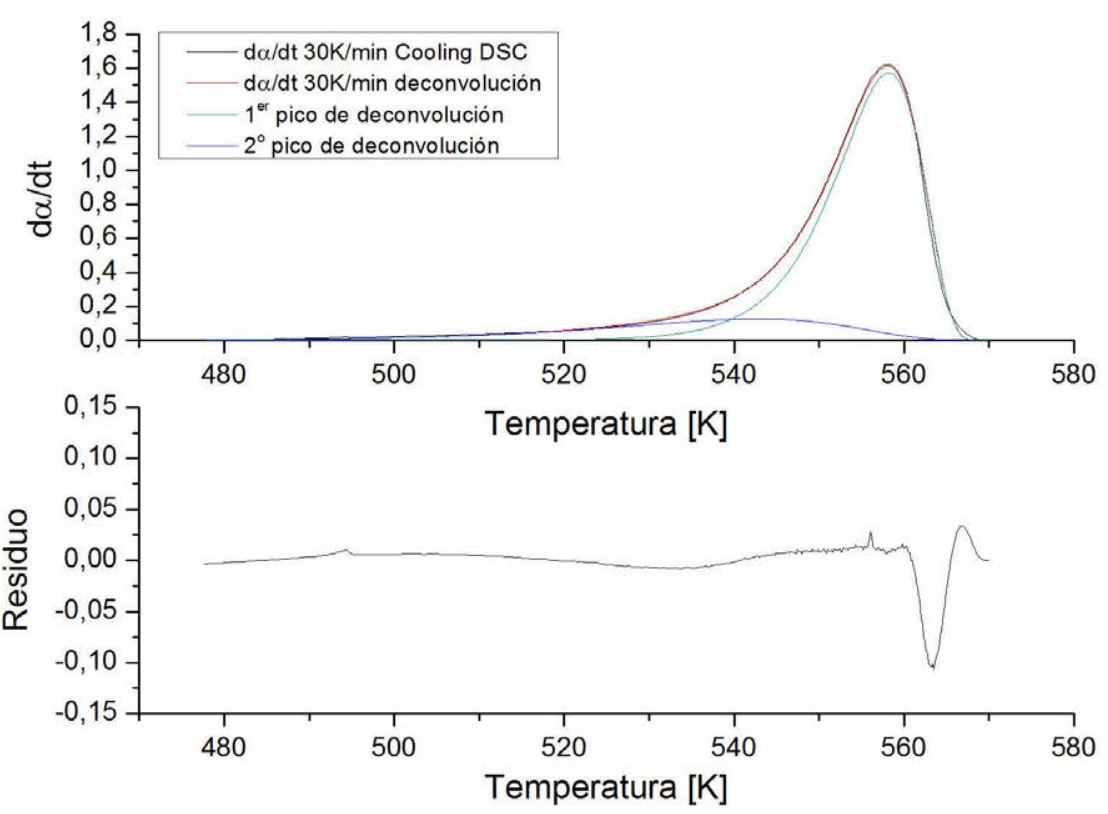

Figura D.1: Deconvolución del pico exotermo de cristalización en PEEK $450 \mathrm{G}$ enfriando a $30 \mathrm{~K} / \mathrm{min}$

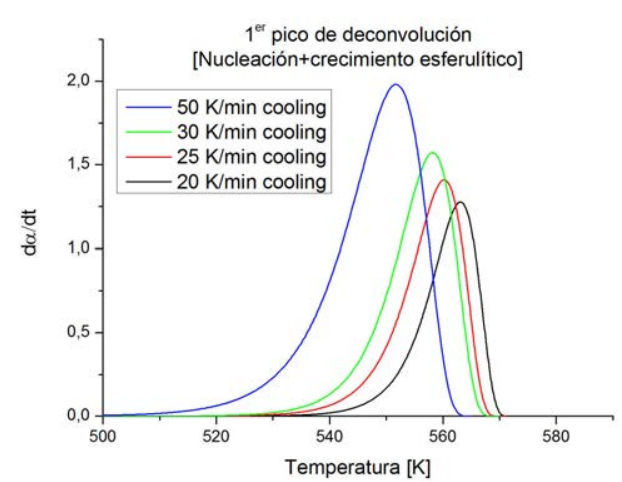

(a)

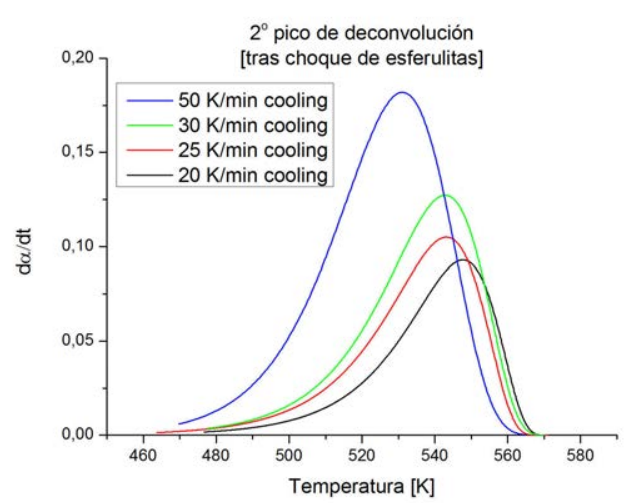

(b)

Figura D.2: Deconvolución aplicada a PEEK 450G, (a) Primer pico - nucleación y crecimiento esferulítico y (b) Segundo pico - cristalización tras el choque de esferulitas, incrementando las velocidades de enfriamiento 


\title{
Bibliografía
}

\author{
Lo que sabemos es una gota de agua: lo \\ que ignoramos es el océano \\ Isaac Newton
}

Ageorges, C., Ye, L. y Hou, M. Advances in fusion bonding techniques for joining thermoplastic matrix composites: a review. Composites Part A: Applied Science and Manufacturing, vol. 32(6), páginas 839-857, 2001. ISSN 1359835X.

AL-Mulla, A. Isothermal crystallization kinetics of poly(ethylene terephthalate) and poly(methyl methacrylate) blends. Express Polymer Letters, vol. 1(6), páginas 334-344, 2007. ISSN 1788618X.

Alvarez, M. G. ET Al. Fisicoquímica III: Química de los materiales. 2011.

Arshad, M. A. y MaAroufi, A.-K. An innovative reaction model determination methodology in solid state kinetics based on variable activation energy. Thermochimica Acta, vol. 585, páginas 25-35, 2014. ISSN 00406031.

August, Z., Ostrander, G., Michasiow, J. y Hauber, D. Recent Developments in Automated Fiber Placement of Thermoplastic Composites. SAMPE Journal, vol. 50(2), páginas 30-37, 2014.

Awaja, F., Zhang, S. y McKenzie, D. R. Autohesion of semi-crystalline PEEK near and under the glass transition temperature. Applied Surface Science, vol. 282, páginas 571-577, 2013. ISSN 01694332.

Baley, C., Kervoëlen, A., Lan, M., Cartié, D., Le Duigou, A., Bourmaud, A. y Davies, P. Flax/PP manufacture by automated fibre placement (AFP). Materials \&5 Design, vol. 94, páginas 207-213, 2016. ISSN 02641275.

Baran, I., Cinar, K., Ersoy, N., Akkerman, R. y Hattel, J. H. A Review on the Mechanical Modeling of Composite Manufacturing Processes. 
Archives of Computational Methods in Engineering, vol. 24(2), páginas 365-395, 2017. ISSN 1134-3060, 1886-1784.

Barasinski, A., Leygue, A., Soccard, E. y Poitou, A. In situ consolidation for thermoplastic tape placement process is not obvious. En AIP Conference Proceedings, vol. 1353, páginas 948-953. AIP, 2011a.

Barasinski, A., Leygue, A., Soccard, E. y Poitou, A. Identification of non uniform thermal contact resistance in automated tape placement process. International Journal of Material Forming, vol. 7(4), páginas 479-486, 2014. ISSN 1960-6206, 1960-6214.

Barasinski, A., Leygue, A., Soccard, E., Poitou, A., Chinesta, F., Chastel, Y. y El Mansori, M. An Improvement in Thermal Modelling of Automated Tape Placement Process. En AIP Conference Proceedings, vol. 1315, páginas 185-190. AIP, 2011b.

BAS, C. Crystallization kinetics of poly(aryl ether ether ketone): Timetemperature-transformation and continuous-cooling-transformation diagrams. European Polymer Journal, vol. 31(10), páginas 911-921, 1995. ISSN 00143057.

Bassett, D., Olley, R. y Al Raheil, I. On crystallization phenomena in PEEK. Polymer, vol. 29(10), páginas 1745-1754, 1988. ISSN 0032-3861.

Bastien, L. J. y Gillespie, J. W. A non-isothermal healing model for strength and toughness of fusion bonded joints of amorphous thermoplastics. Polymer Engineering and Science, vol. 31(24), páginas 1720-1730, 1991. ISSN 0032-3888, 1548-2634.

Batista, N. L., Costa, M. L., Iha, K. y Botelho, E. C. Thermal degradation and lifetime estimation of poly(ether imide)/carbon fiber composites. Journal of Thermoplastic Composite Materials, vol. 28(2), páginas 265-274, 2015. ISSN 0892-7057, 1530-7980.

Bayerl, T., Brzeski, M., Martínez-Tafalla, M., Schledjewski, R. y Mitschang, P. Thermal degradation analysis of short-time heated polymers. Journal of Thermoplastic Composite Materials, vol. 28(3), páginas 390-414, 2015. ISSN 0892-7057, 1530-7980.

Bessard, E., De Almeida, O. y Bernhart, G. Etude et modélisation de la cinétique de cristallisation du PEEK lors de refroidissements isothermes et anisothermes. En 17èmes Journées Nationales sur les Composites (JNC17), página 105. 2011.

Beyler, C. L. y Hirschler, M. M. Thermal decomposition of polymers. SFPE handbook of fire protection engineering, vol. 2, páginas 111-131, 2002. 
Biron, M. Outline of the Actual Situation of Plastics Compared to Conventional Materials. En Thermoplastics and Thermoplastic Composites, páginas 1-30. Elsevier, 2018a. ISBN 978-0-08-102501-7.

Biron, M. Thermoplastic Composites. En Thermoplastics and Thermoplastic Composites, páginas 821-882. Elsevier, 2018b. ISBN 978-0-08-1025017.

Blaine, R. L. y Kissinger, H. E. Homer Kissinger and the Kissinger equation. Thermochimica Acta, vol. 540, páginas 1-6, 2012. ISSN 00406031.

BLundelL, D. On the interpretation of multiple melting peaks in poly(ether ether ketone). Polymer, vol. 28(13), páginas 2248-2251, 1987. ISSN 00323861 .

Blundell, D. y Newton, A. Variations in the crystal lattice of PEEK and related para-substituted aromatic polymers: 2. Effect of sequence and proportion of ether and ketone links. Polymer, vol. 32(2), páginas 308-313, 1991. ISSN 00323861.

Blundell, D. J., Crick, R. A., Fife, B., Peacock, J., Keller, A. y WADDOn, A. Spherulitic morphology of the matrix of thermoplastic PEEK/carbon fibre aromatic polymer composites. Journal of Materials Science, vol. 24(6), páginas 2057-2064, 1989. ISSN 0022-2461, 1573-4803.

Brazel, C. S. y Rosen, S. L. Fundamental principles of polymeric materials. John Wiley \& Sons, 2012. ISBN 978-0470505427.

Brecher, C., Emonts, M. y Stimpfl, J. CO2-Laser-assisted production of hybrid fiber-reinforced thermoplastic composites. En ICCM19. ICCM19, Montréal, Canada, 2013.

Brown, C. L., Ashcraft, H. C., Tichenor, D. R. y Garcia, R. M. Automated tape laminator head for thermoplastic matrix composite material. 1991. US Patent 4,990,213.

Brown, M. E., Maciejewski, M., Vyazovkin, S., Nomen, R., Sempere, J., Burnham, A., Opfermann, J., Strey, R., Anderson, H. L., Kemmler, A. ET AL. Computational aspects of kinetic analysis Part A: The ICTAC kinetics project-data, methods and results. Thermochimica Acta, vol. 355(1-2), páginas 125-143, 2000. ISSN 0040-6031.

Bur, N., Joyot, P., Ghnatios, C., Villon, P., Cueto, E. y Chinesta, F. On the use of model order reduction for simulating automated fibre placement processes. Advanced Modeling and Simulation in Engineering Sciences, vol. 3(1), 2016. ISSN 2213-7467. 
Burchell, P. Method of tape laying of thermoplastic composite materials. 2011. US Patent App. 12/922,923.

Caffiau, J., Gaillard, L. y Hardy, Y. Fiber application head including a segmented compaction roller. 2016. US Patent 9,248,591.

Campbell, F. C. Manfacturing processes for advanced composites. Elsevier, New York, 2004. ISBN 978-1-85617-415-2.

Campbell, F. C. Structural composite materials. ASM international, 2010.

Campo, E. A. Complete Part Design Handbook. Hanser Germany, 2006. ISBN 978-3-446-40309-3.

Carrasco, F., Pérez-Maqueda, L., Santana, O. y Maspoch, M. Enhanced general analytical equation for the kinetics of the thermal degradation of poly(lactic acid)/montmorillonite nanocomposites driven by random scission. Polymer Degradation and Stability, vol. 101, páginas 52-59, 2014. ISSN 01413910.

Saenz del Castillo, D., Martin, I., Rodriguez-Lence, F. y Guemes, A. On-line monitoring of a laser assisted fiber placement process with CFR thermoplastic matrix by using Fiber Bragg Gratings. En 8th European Workshop On Structural Health Monitoring (EWSHM 2016), página 10. Spain, Bilbao, 2016.

CeBe, P. Application of the parallel Avrami model to crystallization of poly (etheretherketone). Polymer Engineering $\mathscr{E}$ Science, vol. 28(18), páginas 1192-1197, 1988a.

CEBe, P. Non-isothermal crystallization of poly (etheretherketone) aromatic polymer composite. Polymer composites, vol. 9(4), páginas 271-279, 1988b.

Cebe, P., Chung, S. Y. y Hong, S.-D. Effect of thermal history on mechanical properties of polyetheretherketone below the glass transition temperature. Journal of Applied Polymer Science, vol. 33(2), páginas 487503, 1987. ISSN 00218995, 10974628.

Cebe, P. y Hong, S.-D. Crystallization behaviour of poly(ether-etherketone). Polymer, vol. 27(8), páginas 1183-1192, 1986. ISSN 00323861.

Chen, M. y Chen, J.-Y. Analysis of crystallization kinetics of poly(ether ether ketone). Journal of Polymer Science Part B: Polymer Physics, vol. 36(8), páginas 1335-1348, 1998. ISSN 0887-6266, 1099-0488.

Chen, Z., Hay, J. y Jenkins, M. The effect of secondary crystallization on melting. European Polymer Journal, vol. 49(9), páginas 2697-2703, 2013. ISSN 00143057. 
Cheng, S. Z. y Lotz, B. Enthalpic and entropic origins of nucleation barriers during polymer crystallization: the Hoffman-Lauritzen theory and beyond. Polymer, vol. 46(20), páginas 8662-8681, 2005. ISSN 00323861.

Chrissafis, K. Kinetics of thermal degradation of polymers. Journal of Thermal Analysis and Calorimetry, vol. 95(1), páginas 273-283, 2009. ISSN 1572-8943.

Chu, Q., Li, Y., Xiao, J., Huan, D., Zhang, X. y Chen, X. Processing and characterization of the thermoplastic composites manufactured by ultrasonic vibration assisted automated fiber placement. Journal of Thermoplastic Composite Materials, vol. 31(3), páginas 339-358, 2018. ISSN 0892-7057, 1530-7980.

Cogswell, F. N. Thermoplastic aromatic polymer composites: a study of the structure, processing and properties of carbon fibre-reinforced polyetheretherketone and related materials. Elsevier, 2013. ISBN 9781483164762.

Cole, K. y Casella, I. Fourier transform infra-red spectroscopic study of thermal degradation in poly(ether ether ketone)-carbon composites. Polymer, vol. 34(4), páginas 740-745, 1993. ISSN 00323861.

Cope, R. D., Funck, S. B., B, G. M., Lamontia, M. A. y Johnson, A. D. Tape placement head fot applying thermoplastic tape to an object. 2008. US Patent $7,404,868$.

Criado, J. M. y Pérez-Maqueda, L. A. Sample controlled thermal analysis and kinetics. Journal of thermal analysis and calorimetry, vol. 80(1), páginas 27-33, 2005. ISSN 1572-8943.

DAI, S. C. y Ye, L. Characteristics of CF/PEI tape winding process with on-line consolidation. Composites Part A: Applied Science and Manufacturing, vol. 33(9), páginas 1227-1238, 2002. ISSN 1359835X.

De Gennes, P. y Leger, L. Dynamics of entangled polymer chains. Annual Review of Physical Chemistry, vol. 33(1), páginas 49-61, 1982.

Denkena, B., Schmidt, C., Völtzer, K. y Hocke, T. Thermographic online monitoring system for Automated Fiber Placement processes. Composites Part B: Engineering, vol. 97, páginas 239-243, 2016. ISSN 13598368 .

Derisi, B., Hoa, S. V., Xu, D., Hojuati, M. y Fews, R. Mechanical behavior of carbon/pekk thermoplastic compopsite tube under bending load. Journal of Thermoplastic Composite Materials, vol. 24(1), páginas 29-49, 2011. ISSN 0892-7057. 
Di Francesco, M., Giddings, P. F., Scott, M., Goodman, E., DeLLÁnno, G. y Potter, K. Influence of laser power density on the mesostructure of thermoplastic composite preforms maufactured by automated fibre placement. En International SAMPE Technical Conference. 2016.

Di Francesco, M., Veldenz, L., Dellánno, G. y Potter, K. Heater power control for multi-material, variable speed Automated Fibre Placement. Composites Part A: Applied Science and Manufacturing, vol. 101, páginas 408-421, 2017. ISSN 1359835X.

Di Lorenzo, M. y Silvestre, C. Non-isothermal crystallization of polymers. Progress in Polymer Science, vol. 24(6), páginas 917-950, 1999. ISSN 00796700.

Di Lorenzo, M. L., Androsch, R., Rhondes, A. M. y Righetti, M. C. Analysis of Polymer Crystallization by Calorimetry. En Handbook of Thermal Analysis and Calorimetry, vol. 6, páginas 253-299. Elsevier, 2018. ISBN 978-0-444-64062-8.

DoI, M. y EDWARDs, S. F. The theory of polymer dynamics. Oxford Univ. Press, 1988. ISBN 978-0198520337.

Dolo, G., Férec, J., Cartié, D., Grohens, Y. y Ausias, G. Model for thermal degradation of carbon fiber filled poly(ether ether ketone). Polymer Degradation and Stability, vol. 143, páginas 20-25, 2017. ISSN 01413910 .

Duhovic, M., Hümbert, M., Mitschang, P., Maier, M., CaldiChoury, I. y L'Eplattenier, P. Further advances in simulating the processing of composite materials by electromagnetic induction. En Proceedings of the 13th international LS-DYNA conference. 2014.

Dutton, S., Kelly, D. y Baker, A. Composite Materials for Aircraft Structures, Second Edition. American Institute of Aeronautics and Astronautics, Reston ,VA, 2004. ISBN 978-1-56347-540-5 978-1-60086-168-0.

El Kadi, H. y Denault, J. Effects of Processing Conditions on the Mechanical Behavior of Carbon-Fiber-Reinforced PEEK. Journal of Thermoplastic Composite Materials, vol. 14(1), páginas 34-53, 2001. ISSN 0892-7057, 1530-7980.

Feldman, D. Polymer history. Designed monomers and polymers, vol. 11(1), páginas 1-15, 2008.

Fetters, L. J. Determination of the intermolecular entanglement coupling spacings in polyisoprene by viscosity measurements. Journal of Research of the National Bureau of Standards Section A: Physics and Chemistry, vol. 69A(1), página 33, 1965. ISSN 0022-4332. 
Filippone, G., Carroccio, S., Curcuruto, G., Passaglia, E., GamBarotti, C. y Dintcheva, N. Time-resolved rheology as a tool to monitor the progress of polymer degradation in the melt state - Part II: Thermal and thermo-oxidative degradation of polyamide 11/organoclay nanocomposites. Polymer, vol. 73, páginas 102-110, 2015a. ISSN 00323861 .

Filippone, G., Carroccio, S., Mendichi, R., Gioiella, L., DintcheVA, N. y Gambarotti, C. Time-resolved rheology as a tool to monitor the progress of polymer degradation in the melt state-Part I: Thermal and thermo-oxidative degradation of polyamide 11. Polymer, vol. 72, páginas 134-141, 2015b. ISSN 00323861.

Fink, B. K., Gillespie JR, J. W. y Ersoy, N. B. Thermal degradation effects on consolidation and bonding in the thermoplastic fibre-placement process. Informe técnico, ARMY RESEARCH LAB ABERDEEN PROVING GROUND MD, 2000.

Fink, J. K. Handbook of engineering and specialty thermoplastics, Volume 1: Polyolefins and Styrenics. John Wiley \& Sons, 2010. ISBN 978-0-47062583-5 978-1-118-06275-3 978-0-470-63926-9 978-0-470-63925-2.

FLynn, J. H. y WALL, L. A. General treatment of the thermogravimetry of polymers. Journal of Research of the National Bureau of Standards Section A: Physics and Chemistry, vol. 70A(6), página 487, 1966. ISSN 0022-4332.

Funck, R. y Neitzel, M. Improved thermoplastic tape winding using laser or direct-flame heating. Composites Manufacturing, vol. 6(3-4), páginas 189-192, 1995. ISSN 09567143.

Furushima, Y., Toda, A., Rousseaux, V., Bailly, C., Zhuravlev, E. y ScHICK, C. Quantitative understanding of two distinct melting kinetics of an isothermally crystallized poly(ether ether ketone). Polymer, vol. 99, páginas 97-104, 2016. ISSN 00323861.

Furushima, Y., Yang, B., Toda, A. y Schick, C. Comment on reexploring the double-melting behavior of semirigid-chain polymers with an in-situ combination of synchrotron nanofocus x-ray scattering and nanocalorimetry by Ivanov et al. [European Polymer Journal 81 (2016) 598606.]. European Polymer Journal, vol. 94, páginas 511-516, 2017. ISSN 00143057 .

GaO, S.-L. y Kim, J.-K. Crystallinity and interphase properties of carbon fiber/PEEK matrix composites. En Proc. 12th Intern. Conf. Composite Mater. (ICCM-12). 1999. 
GAO, S.-L. y KIM, J.-K. Cooling rate influences in carbon fibre/PEEK composites. Part I. Crystallinity and interface adhesion. Composites Part A: Applied Science and Manufacturing, vol. 31(6), páginas 517-530, 2000. ISSN 1359-835X.

GAO, S.-L. y KIM, J.-K. Cooling rate infuences in carbon fibre/PEEK composites. Part II: interlaminar fracture toughness. Composites Part A: Applied science and manufacturing, vol. 32(6), páginas 763-774, 2001a. ISSN 1359-835X.

GAO, S.-L. y KIM, J.-K. Cooling rate infuences in carbon fibre/PEEK composites. Part III: impact damage performance. Composites Part A: Applied science and manufacturing, vol. 32(6), páginas 775-785, 2001b. ISSN 1359-835X.

GAO, S.-L. y KIM, J.-K. Correlation among crystalline morphology of PEEK, interface bond strength, and in-plane mechanical properties of carbon/PEEK composites. Journal of Applied Polymer Science, vol. 84(6), páginas 1155-1167, 2002. ISSN 0021-8995, 1097-4628.

DE Gennes, P. G. Reptation of a Polymer Chain in the Presence of Fixed Obstacles. The Journal of Chemical Physics, vol. 55(2), páginas 572-579, 1971. ISSN 0021-9606, 1089-7690.

Ghasemi Nejhad, M. Issues Related to Processability during the Manufacture of Thermoplastic Composites Using On-Line Consolidation Techniques. Journal of Thermoplastic Composite Materials, vol. 6(2), páginas 130-146, 1993. ISSN 0892-7057, 1530-7980.

Ghasemi Nejhad, M., Cope, R. y Güceri, S. Thermal Analysis of insitu Thermoplastic Composite Tape Laying. Journal of Thermoplastic Composite Materials, vol. 4(1), páginas 20-45, 1991. ISSN 0892-7057, 1530-7980.

Goswami, A., Srivastava, G., Umarji, A. y Madras, G. Thermal degradation kinetics of poly(trimethylol propane triacrylate)/poly(hexane diol diacrylate) interpenetrating polymer network. Thermochimica Acta, vol. 547, páginas 53-61, 2012. ISSN 00406031.

Grouve, W. Weld strength of laser-assisted tape-placed thermoplastic composites. Tesis Doctoral, Uinversity of Twente, 2012.

Grove, S. Thermal modelling of tape laying with continuous carbon fibrereinforced thermoplastic. Composites, vol. 19(5), páginas 367-375, 1988. ISSN 00104361. 
Guan, X. y Pitchumani, R. Modeling of spherulitic crystallization in thermoplastic tow-placement process: spherulitic microstructure evolution. Composites Science and Technology, vol. 64(9), páginas 1363-1374, 2004. ISSN 02663538.

HAAKE, J. High power diode laser - assisted fiber placement of composite structure. En ICALEO 2005: 24th International Congress on Laser Materials Processing and Laser Microfabrication. 2005.

Han, Z., CaO, Z., Shao, Z. y Fu, H. Parametric study on heat transfer for tow placement process of thermoplastic composite. Polymers and Polymer Composites, vol. 22(8), páginas 713-722, 2014.

Hancox, N. Thermal effects on polymer matrix composites: Part 2. Thermal degradation. Materials \&3 Design, vol. 19(3), páginas 93-97, 1998. ISSN 02613069 .

Hassan, N., Thompson, J. E., Batra, R. C., Hulcher, A. B., Song, X. y Loos, A. C. A Heat Transfer Analysis of the Fiber Placement Composite Manufacturing Process. Journal of Reinforced Plastics and Composites, vol. 24(8), páginas 869-888, 2005. ISSN 0731-6844, 15307964 .

Hauber, D. E., Langone, R. J., Martin, J. P., Miller, S. F. y PASANEN, M. J. Composite tape laying appartus and method. 2006. US Patent 7,063,118.

Hay, J. y Kemmish, D. Thermal decomposition of poly(aryl ether ketones). Polymer, vol. 28(12), páginas 2047-2051, 1987. ISSN 00323861.

Heider, D., Piovoso, M. J. y Gillespie JR, J. W. Application of a neural network to improve an automated thermoplastic tow-placement process. Journal of Process Control, vol. 12(1), páginas 101-111, 2002. ISSN 09591524.

Henne, F., Ehar, S., Kollmannsberger, A., Hoeck, B., Sause, M. y Drechsler, K. Thermoplastic in-situ fiber placement for future solid rocket motor casing manufacturing. SAMPE Europe SETEC, 2014.

HiLlier, I. H. Modified avrami equation for the bulk crystallization kinetics of spherulitic polymers. Journal of Polymer Science Part A: General Papers, vol. 3(9), páginas 3067-3078, 1965. ISSN 04492951, 15426246.

HoA, S. V. Principles of the manufacturing of composite materials. DEStech Publ, 2009. ISBN 978-1-932078-26-8.

HoA, S. V. Automated composites manufacturing and 4d printing of composites. En Composites Manufacturing, página 38. University of TorontoInstitute for Aerospace Studies, 2017. 
Hoang, M. D. Procedure for making flat thermoplastic composite plates by Automated Fiber Placement and their mechanical properties. Tesis Doctoral, Concordia University, 2015.

Holmes, S., Lawton, S. A. y HaAke, J. M. Method for heating and contorlling temperature of composite material during automated placement. 2002. US Patent 6,451,152.

Homburg, O., Bayer, A., Mitra, T., Meinschien, J. y Aschke, L. Beam shaping of high power diode lasers benefits from asymmetrical refractive micro-lens arrays. En High-Power Diode Laser Technology and Applications VI, vol. 6876, página 68760B. International Society for Optics and Photonics, 2008.

Hsiao, B. S., Gardner, K. H., Wu, D. Q. y Chu, B. Time-resolved X-ray study of poly(aryl ether ether ketone) crystallization and melting behaviour: 1. Crystallization. Polymer, vol. 34(19), páginas 3986-3995, 1993. ISSN 00323861.

Hynstová, K. The Crystallization Kinetics in semicrystalline nanocomposites. Tesis Doctoral, Brno University of Technology, Brno, 2010.

Irgens, F. Rheology and Non-Newtonian Fluids. Springer International Publishing, Cham, 2014. ISBN 978-3-319-01052-6 978-3-319-01053-3.

IVAnov, D., Legras, R. y Jonas, A. The crystallization of poly(aryl-etherether-ketone) (PEEK): reorganization processes during gradual reheating of cold-crystallized samples. Polymer, vol. 41(10), páginas 3719-3727, 2000. ISSN 00323861.

Ivanov, D. A., Legras, R. y Jonas, A. M. Interdependencies between the Evolution of Amorphous and Crystalline Regions during Isothermal Cold Crystallization of poly-ether-ether-ketone. Macromolecules, vol. 32(5), páginas 1582-1592, 1999. ISSN 0024-9297, 1520-5835.

Jain, V., Biesinger, M. C. y Linford, M. R. The gaussian-lorentzian sum, product, and convolution (voigt) functions in the context of peak fitting x-ray photoelectron spectroscopy (xps) narrow scans. Applied Surface Science, vol. 447, páginas 548-553, 2018. ISSN 0169-4332.

Janković, B., Mentus, S. y Janković, M. A kinetic study of the thermal decomposition process of potassium metabisulfite: estimation of distributed reactivity model. Journal of Physics and Chemistry of Solids, vol. 69(8), páginas 1923-1933, 2008. ISSN 00223697.

Jarrousse, G. Self adhesion of semi-crytalline polymers between their glass transition temperature and their melting temperature. Tesis Doctoral, Université Pierre et Marie Curie-Paris VI, 2004. 
Jenkins, M. Crystallisation in miscible blends of PEEK and PEI. Polymer, vol. 42(5), páginas 1981-1986, 2001. ISSN 00323861.

Jenkins, M., Hay, J. y Terrill, N. Structure evolution in melt crystallised PEEK. Polymer, vol. 44(22), páginas 6781-6787, 2003. ISSN 00323861 .

Jin, L., Ball, J., Bremner, T. y Sue, H.-J. Crystallization behavior and morphological characterization of poly(ether ether ketone). Polymer, vol. 55(20), páginas 5255-5265, 2014. ISSN 00323861.

JorAID, A. Limitation of the johnson mehl avrami (JMA) formula for kinetic analysis of the crystallization of a chalcogenide glass. Thermochimica Acta, vol. 436(1-2), páginas 78-82, 2005. ISSN 00406031.

KARACAN, I. X-ray diffraction studies of poly(aryl ether ether ketone) fibers with different degrees of crystallinity and orientation. Fibers and Polymers, vol. 6(3), páginas 206-218, 2005. ISSN 1229-9197, 1875-0052.

Kergomard, Y. D. 3D Thermo-mechanical model based simulation of the welding of thermoplastic composite tape using automated tape laying (ATL) process. 2016.

Khan, M. A., Mitschang, P. y Schledjewski, R. Identification of some optimal parameters to achieve higher laminate quality through tape placement process. Advances in Polymer Technology, vol. 29(2), páginas 98-111, 2010. ISSN 07306679, 10982329.

Khan, M. A., Mitschang, P. y Schledjewski, R. Parametric study on processing parameters and resulting part quality through thermoplastic tape placement process. Journal of Composite Materials, vol. 47(4), páginas 485-499, 2013. ISSN 0021-9983, 1530-793X.

Khan, M. A. y Schledjewski, R. Influencing factors for an online consolidating thermoplastic tape placement process. En 17th International conference on composite materials, ICCM-17. 2009.

KHAN, S. Thermal control system design for automated fiber placement process. Tesis Doctoral, Concordia University, Canada, 2011.

Khawam, A. y Flanagan, D. R. Role of isoconversional methods in varying activation energies of solid-state kinetics. Thermochimica Acta, vol. 429(1), páginas 93-102, 2005. ISSN 00406031.

Kim, H. J., Kim, S. K. y LeE, W. I. A study on heat transfer during thermoplastic composite tape lay-up process. Experimental Thermal and Fluid Science, vol. 13(4), páginas 408-418, 1996. ISSN 08941777. 
King, M. A., Blundell, D. J., Howard, J., Colbourn, E. A. y KenDRICK, J. Modelling Studies of Crystalline PEEK. Molecular Simulation, vol. 4(1-3), páginas 3-13, 1989. ISSN 0892-7022, 1029-0435.

Köhler, B., Noeske, A., Kindervater, T., Wessollek, A., Brand, T. y BiesenBACH, J. 11-kW direct diode laser system with homogenized $55 \times 20 \mathrm{~mm} 2$ top-hat intensity distribution. En High-Power Diode Laser Technology and Applications $V$, vol. 6456, página 64560O. International Society for Optics and Photonics, 2007.

Kozaczuk, K. Automated fiber placement systems overview. Transactions of the Institute of Aviation, vol. 245(4), páginas 52-59, 2016. ISSN 0509$6669,2300-5408$.

Kumar, S., Anderson, D. P. y Adams, W. Crystallization and morphology of poly(aryl-ether-ether-ketone). Polymer, vol. 27(3), páginas 329336, 1986. ISSN 00323861.

Kuo, M., Huang, J. y Chen, M. Non-isothermal crystallization kinetic behavior of alumina nanoparticle filled poly(ether ether ketone). Materials Chemistry and Physics, vol. 99(2-3), páginas 258-268, 2006. ISSN 02540584 .

Kuo, M., Kuo, J., YAng, M. y HuAng, J. On the crystallization behavior of the nano-silica filled PEEK composites. Materials Chemistry and Physics, vol. 123(2-3), páginas 471-480, 2010. ISSN 02540584.

LAMÈThe, J.-F. Etude de l'adhésion de composites thermoplastiques semicristallins; application à la mise en oeuvre par soudure. Tesis Doctoral, Université Pierre et Marie Curie- Paris VI, 2004.

Lamèthe, J.-F., Beauchêne, P. y Léger, L. Polymer dynamics applied to PEEK matrix composite welding. Aerospace Science and Technology, vol. 9(3), páginas 233-240, 2005. ISSN 12709638.

LAngone, R. J. y Becker, R. D. Methods for forming a structure having a lightning strike protection. 2015. US Patent 8,947,847.

Langone, R. J., Hauber, D. E. y August, Z. A. Thermoplastic composite prepreg for automated fiber placement. 2013. US Patent App. $13 / 718,192$.

Langone, R. J., Hauber, D. E. y August, Z. A. Thermoplastic composite prepreg for automated fiber placement. 2016. US Patent App. 14/848,637. 
Le Louët, V., Rousseau, B., Le Corre, S., Boyard, N., Tardif, X., Delmas, J. y Delaunay, D. Directional spectral reflectivity measurements of a carbon fibre reinforced composite up to $450{ }^{\circ} \mathrm{C}$. International Journal of Heat and Mass Transfer, vol. 112, páginas 882-890, 2017. ISSN 00179310 .

LeE, I.-G., Kim, D.-H., Jung, K.-H., Kim, H.-J. y Kim, H.-S. Effect of the cooling rate on the mechanical properties of glass fiber reinforced thermoplastic composites. Composite Structures, vol. 177, páginas 28-37, 2017. ISSN 02638223.

Lee, K. y Weitsman, Y. Effects of Nonuniform Crystallinity on Stress Distributions in Cross-Ply Graphite/PEEK (APC-2) Laminates. Journal of Composite Materials, vol. 25(9), páginas 1143-1157, 1991. ISSN 00219983, 1530-793X.

LeE, M. Heat Transfer and Consolidation Modeling of Composite Fiber Tow in Fiber Placement. Tesis Doctoral, Blacksburg: Virginia Polytechnic Institute and State University, 2004.

Lefebure, P. y Lang, D. DINAMIT Development and INnovation for Advanced ManufacturIng of Thermoplastics. 2007.

LeGault, M. Bulding a better tail boom. CompositesWorld, 2013.

Lemarchand, F. Étude de l'apparition des contraintes résiduelles dans le procédé démpilement par soudage et consolidation en continu de composites thermoplastiques. Tesis Doctoral, Paris, ENSAM, 2008.

Levy, A., Heider, D., Tierney, J. y Gillespie, J. W. Inter-layer thermal contact resistance evolution with the degree of intimate contact in the processing of thermoplastic composite laminates. Journal of Composite Materials, vol. 48(4), páginas 491-503, 2014. ISSN 0021-9983, 1530-793X.

Li, Y. H., Fu, H. Y. y ShaO, Z. X. The Influence of Preheating on Automated Fiber Placement Speed. Advanced Materials Research, vol. 213, páginas 136-142, 2011. ISSN 1662-8985.

LI, Z., YAng, T. y DU, Y. Dynamic finite element simulation and transient temperature field analysis in thermoplastic composite tape lay-up process. Journal of Thermoplastic Composite Materials, vol. 28(4), páginas 558573, 2015. ISSN 0892-7057, 1530-7980.

Lichtinger, R., Hörmann, P., Stelzl, D. y Hinterhölzl, R. The effects of heat input on adjacent paths during Automated Fibre Placement. Composites Part A: Applied Science and Manufacturing, vol. 68, páginas 387-397, 2015. ISSN 1359835X. 
Lionetto, F., Dell’Anna, R., Montagna, F. y Maffezzoli, A. Modeling of continuous ultrasonic impregnation and consolidation of thermoplastic matrix composites. Composites Part A: Applied Science and Manufacturing, vol. 82, páginas 119-129, 2016. ISSN 1359835X.

Lionetto, F., Pappadà, S., Buccoliero, G. y Maffezzoli, A. Finite element modeling of continuous induction welding of thermoplastic matrix composites. Materials \& Design, vol. 120, páginas 212-221, 2017. ISSN 02641275 .

Long, Y., Shanks, R. A. y Stachurski, Z. H. Kinetics of polymer crystallisation. Progress in Polymer Science, vol. 20(4), páginas 651-701, 1995. ISSN 00796700.

Loos, A. C. y DARA, P. H. Processing of thermoplastic matrix composites. En Review of Progress in Quantitative Nondestructive Evaluation, páginas 1257-1265. Springer, 1987. ISBN 978-1-4612-9054-4 978-1-4613-1893-4.

Louette, P., Bodino, F. y Pireaux, J.-J. Poly (ether ether ketone) (PEEK) XPS reference core level and energy loss spectra. Surface Science Spectra, vol. 12(1), páginas 149-153, 2005.

LyOn, R. E. An integral method of nonisothermal kinetic analysis. Thermochimica Acta, vol. 297(1-2), páginas 117-124, 1997. ISSN 00406031.

Maison, S., Meunier, S., Thibout, C., Mouton, L., Payen, H., VauTey, P., Coiffier-Colas, C. y Delbez, J. Method for making parts in composite material with thermoplastic matrix. 2003. US Patent 6,613,258.

MALLICK, V. Thermoplastic composite based processing technologies for high performance turbomachinery components. Composites Part A: Applied science and manufacturing, vol. 32(8), páginas 1167-1173, 2001. ISSN 1359835X.

Mantell, S. C., Qiuling Wang y Springer, G. S. Processing Thermoplastic Composites in a Press and by Tape Laying?Experimental Results. Journal of Composite Materials, vol. 26(16), páginas 2378-2401, 1992. ISSN 0021-9983, 1530-793X.

Mantell, S. C. y Springer, G. S. Manufacturing Process Models for Thermoplastic Composites. Journal of Composite Materials, vol. 26(16), páginas 2348-2377, 1992. ISSN 0021-9983, 1530-793X.

Marand, H. y Prasad, A. On the Observation of a New Morphology in Poly(ary1ene ether ether ketone). A Further Examination of the Double Endothermic Behavior of Poly(arylene ether ether ketone). Macromolecules, vol. 25(6), páginas 1731-1736, 1992. 
Marchello, J. M. y Messier, B. C. Langley Research Center, Hampton, Virginia. página 64, 1996.

Marsh, G. Could thermoplastics be the answer for utility-scale wind turbine blades? Reinforced Plastics, vol. 54(1), páginas 31-35, 2010. ISSN 00343617 .

Martin, J. P. Multiple tape laying apparatus and method. 2007. US Patent 7,293,590.

Martineau, L., Chabert, F., Boniface, B. y Bernhart, G. Effect of interfacial crystalline growth on autohesion of PEEK. International Journal of Adhesion and Adhesives, vol. 89, páginas 82-87, 2019. ISSN 0143-7496.

Martins, J. y Cruz Pinto, J. Non-isothermal crystallisation kinetics with instantaneous nucleation. Polymer, vol. 41(18), páginas 6875-6884, 2000. ISSN 00323861.

MatWeb. Material property data. En http://www.matweb.com. 2018.

Maurer, D. y Mitschang, P. Laser-powered tape placement process simulation and optimization. Advanced Manufacturing: Polymer \& Composites Science, vol. 1(3), páginas 129-137, 2015. ISSN 2055-0340, 20550359.

McGregor, O., Duhovic, M., Somashekar, A. y Bhattacharyya, D. Pre-impregnated natural fibre-thermoplastic composite tape manufacture using a novel process. Composites Part A: Applied science and manufacturing, vol. 101, páginas 59-71, 2017. ISSN 1359835X.

McLeish, T. C. B. Tube theory of entangled polymer dynamics. Advances in Physics, vol. 51(6), páginas 1379-1527, 2002. ISSN 0001-8732, 14606976.

Modi, D., Comer, A., O'Higgins, R. M. y McCarthy, M. A. Thermoplastic composites: in-situ consolidation or in-situ welding? En Proceedings of the 19th international conference on composite materials (ICCM 19), Montreal, Canada, vol. 28. 2013.

Modi, S. H., Dikovics, K. B., Gevgilili, H., Mago, G., Bartolucci, S. F., Fisher, F. T. y Kalyon, D. M. Nanocomposites of poly(ether ether ketone) with carbon nanofibers: Effects of dispersion and thermooxidative degradation on development of linear viscoelasticity and crystallinity. Polymer, vol. 51(22), páginas 5236-5244, 2010. ISSN 00323861.

Murray, B. R., Doyle, A., Feerick, P., Semprimoschnig, C. O., Leen, S. B. y Ó BrÁdAigh, C. M. Rotational moulding of PEEK 
polymer liners with carbon fibre/PEEK over tape-placement for space cryogenic fuel tanks. Materials \& Design, vol. 132, páginas 567-581, 2017. ISSN 02641275.

Muthukumar, M. Nucleation in Polymer Crystallization. En Advances in Chemical Physics, páginas 1-63. John Wiley \& Sons, Inc., 2004. ISBN 978-0-471-44528-9 978-0-471-48423-3.

Nakamura, K., Watanabe, T., Katayama, K. y Amano, T. Some aspects of nonisothermal crystallization of polymers. I. Relationship between crystallization temperature, crystallinity, and cooling conditions. Journal of Applied Polymer Science, vol. 16(5), páginas 1077-1091, 1972. ISSN 0021-8995.

NAm, J.-D. y Seferis, J. C. Generalized composite degradation kinetics for polymeric systems under isothermal and nonisothermal conditions. Journal of Polymer Science Part B: Polymer Physics, vol. 30(5), páginas 455-463, 1992. ISSN 08876266, 10990488.

Nandan, B., Kandpal, L. y Mathur, G. Poly(ether ether ketone)/poly(aryl ether sulphone) blends: thermal degradation behaviour. European Polymer Journal, vol. 39(1), páginas 193-198, 2003. ISSN 00143057 .

Narnhofer, M., Schledjewski, R., Mitschang, P. y Perko, L. Simulation of the Tape-Laying Process for Thermoplastic Matrix Composites. Advances in Polymer Technology, vol. 32(S1), páginas E705-E713, 2013. ISSN 07306679.

Nichelatti, E. Complex refractive index of a slab from reflectance and transmittance: analytical solution. Journal of Optics A: Pure and Applied Optics, vol. 4(4), páginas 400-403, 2002. ISSN 14644258.

Nicodeau, C. Modélisation du soudage en continu de composites à matrice thermoplastique. Doctoral dissertation, ENSAM, Paris, ENSAM, 2005.

Ning, N., Fu, S., Zhang, W., Chen, F., Wang, K., Deng, H., Zhang, Q. y Fu, Q. Realizing the enhancement of interfacial interaction in semicrystalline polymer/filler composites via interfacial crystallization. Progress in Polymer Science, vol. 37(10), páginas 1425-1455, 2012. ISSN 00796700 .

Oliveri, V., Peeters, D., Clancy, G. J., Jones, D., O’Higgins, R. y Weaver, P. M. Design, optimization and manufacturing of a unitized carbon fiber/thermoplastic wingbox structure. American Institute of Aeronautics and Astronautics, 2018. ISBN 978-1-62410-532-6. 
Oromiehie, E., Gangadhara Prusty, B., Compston, P. y Rajan, G. In situ simultaneous measurement of strain and temperature in automated fiber placement (AFP) using optical fiber Bragg grating (FBG) sensors. Advanced Manufacturing: Polymer $\& 3$ Composites Science, vol. 3(2), páginas 52-61, 2017. ISSN 2055-0340, 2055-0359.

Oromiehie, E., Prusty, B. G., Compston, P. y Rajan, G. In situ process monitoring for automated fibre placement using fibre Bragg grating sensors. Structural Health Monitoring: An International Journal, vol. 15(6), páginas 706-714, 2016. ISSN 1475-9217, 1741-3168.

P. Arrieta, M., López, J., Ferrándiz, S. y Parres. Aplicación de modelos matemáticos para el estudio de degradación térmica de polímeros. Ingeniería del agua, vol. 18(1), páginas 119-130, 2014. ISSN 1886-4996, 1134-2196.

Parlevliet, P. P., Bersee, H. E. y Beukers, A. Residual stresses in thermoplastic composites-a study of the literature-part I: Formation of residual stresses. Composites Part A: Applied science and manufacturing, vol. 37(11), páginas 1847-1857, 2006.

Parlevliet, P. P., Bersee, H. E. y Beukers, A. Residual stresses in thermoplastic composites-a study of the literature-part II: Experimental techniques. Composites Part A: Applied science and manufacturing, vol. 38(3), páginas 651-665, 2007a.

Parlevliet, P. P., Bersee, H. E. y Beukers, A. Residual stresses in thermoplastic composites-a study of the literature-part III: Effects of thermal residual stresses. Composites Part A: Applied science and manufacturing, vol. 38(6), páginas 1581-1596, 2007b.

Pascon, F., Bruyneel, M. y Cheruet, A. Simulation of the thermoforming process of thermoplastic composite parts. 2013.

PATEL, P. Investigation of the Fire Behaviour of PEEK-based Polymers and Compounds. Tesis Doctoral, University of Central Lancashire, 2011.

Patel, P., Hull, T. R., McCabe, R. W., Flath, D., Grasmeder, J. y PERCY, M. Mechanism of thermal decomposition of poly(ether ether ketone) (PEEK) from a review of decomposition studies. Polymer Degradation and Stability, vol. 95(5), páginas 709-718, 2010. ISSN 01413910.

Peeters, D., Clancy, G. J., Oliveri, V., O'Higgins, R., Jones, D. y Weaver, P. M. Thermoplastic Composite Stiffener Design with Manufacturing Considerations. En 2018 AIAA/ASCE/AHS/ASC Structures, Structural Dynamics, and Materials Conference. American Institute of Aeronautics and Astronautics, 2018. ISBN 978-1-62410-532-6. 
Perejón, A., Sánchez-Jiménez, P. E., Criado, J. M. y PérezMaquedA, L. A. Kinetic Analysis of Complex Solid-State Reactions. A New Deconvolution Procedure. The Journal of Physical Chemistry B, vol. 115(8), páginas 1780-1791, 2011. ISSN 1520-6106, 1520-5207.

Perejón, A., Sánchez-Jiménez, P. E., Criado, J. M. y PérezMaqueda, L. A. A Promising approach to the kinetics of crystallization processes: The sample controlled thermal analysis. Journal of the American Ceramic Society, vol. 100(3), páginas 1125-1133, 2017. ISSN 00027820 .

Perejón, A., Sánchez-Jiménez, P. E., Gil-González, E., PérezMaqueda, L. A. y Criado, J. M. Pyrolysis kinetics of ethylenepropylene (EPM) and ethylene-propylene-diene (EPDM). Polymer Degradation and Stability, vol. 98(9), páginas 1571-1577, 2013. ISSN 01413910.

Perez, M., Barasinski, A., Courtemanche, B., Ghnatios, C., Abisset-Chavanne, E. y Chinesta, F. Simulation du comportement thermique du procédé d'enroulement filamentaire de composites thermoplastiques assisté par chauffage laser. En Journées Nationales sur les Composites 2017. 2017.

Perez, M., Leon, A., Dedieu, C., Argerich, C., Defoort, B., DupiLlier, J. M., Soccard, R., Barasinski, A. y Chinesta, F. Keys for designing the most efficient and robust in-situ TP ATP. En 6th International Carbon Composites Conference, página 22. 2018.

Perng, L., Tsai, C. y Ling, Y. Mechanism and kinetic modelling of PEEK pyrolysis by TG/MS. Polymer, vol. 40(26), páginas 7321-7329, 1999. ISSN 00323861 .

Phillips, R., Glauser, T. y MAnson, J.-A. E. Thermal stability of PEEK/carbon fiber in air and its influence on consolidation: Thermal Stability of PEEK/Carbon Fiber. Polymer Composites, vol. 18(4), páginas 500-508, 1997. ISSN 02728397.

Phillips, R., Sunderland, P., Kim, P. y Manson, J.-A. E. Influence of processing parameters on the dimensional stability of polymer composites. 1994.

Pignon, B., Boyard, N., Sobotka, V. y Delaunay, D. Heat transfer analysis at high cooling rate on the surface of thermoplastic parts. International Journal of Heat and Mass Transfer, vol. 106, páginas 253-262, 2017. ISSN 00179310.

Pionkowska, E., Galeski, A. y Haudin, J.-M. Critical assessment of overall crystallization kinetics theories and predictions. Progress in Polymer Science, vol. 31(6), páginas 549-575, 2006. ISSN 00796700. 
Pistor, C., Yardimci, M. y GüÇERI, S. On-line consolidation of thermoplastic composites using laser scanning. Composites Part A: Applied science and manufacturing, vol. 30(10), páginas 1149-1157, 1999. ISSN $1359835 X$.

Pitchumani, R., Ranganathan, S., Don, R., Gillespie, J. y LamonTIA, M. Analysis of transport phenomena governing interfacial bonding and void dynamics during thermoplastic tow-placement. International Journal of Heat and Mass Transfer, vol. 39(9), páginas 1883-1897, 1996. ISSN 00179310.

Pérez-Cárdenas, F. C., Castillo, L. F. D. y Vera-Graziano, R. Modified Avrami expression for polymer crystallization kinetics. Journal of Applied Polymer Science, vol. 43(4), páginas 779-782, 1991. ISSN $00218995,10974628$.

Prime, R. B. y Seferis, J. C. Thermo-oxidative decomposition of poly (ether ether ketone). Journal of Polymer Science Part C: Polymer Letters, vol. 24(12), páginas 641-644, 1986.

Quan, H., Li, Z.-M., Yang, M.-B. y Huang, R. On transcrystallinity in semi-crystalline polymer composites. Composites Science and Technology, vol. 65(7-8), páginas 999-1021, 2005. ISSN 02663538.

Quinlan, E. P. Thermal and Crystallinity Profiles in Laminates Manufactured with the Automated Thermoplastic Tow Placement Process. Tesis Doctoral, McGill University Library, 2011.

Regis, M., Bellare, A., Pascolini, T. y Bracco, P. Characterization of thermally annealed PEEK and CFR-PEEK composites: Structureproperties relationships. Polymer Degradation and Stability, vol. 136, páginas 121-130, 2017. ISSN 01413910.

Regnier, G. y Le Corre, S. Modeling of Thermoplastic Welding. En Heat Transfer in Polymer Composite Materials, páginas 235-268. John Wiley \& Sons, Inc., 2016. ISBN 978-1-119-11628-8 978-1-84821-761-4.

Regnier, G., Nicodeau, C., Verdu, J., Cinquin, J. y Chinesta, F. A multi-physic and multi-scale approach to model the continuous welding of thermoplastic matrix composites. En 16th International Conference on Composite Materials ICCM-16. 2007.

Reichardt, J., Baran, I. y Akkerman, R. New analytical and numerical optical model for the laser assisted tape winding process. Composites Part A: Applied science and manufacturing, vol. 107, páginas 647-656, 2018. ISSN 1359835X. 
Rizzolo, R. H. y WALCZYK, D. F. Ultrasonic consolidation of thermoplastic composite prepreg for automated fiber placement. Journal of Thermoplastic Composite Materials, vol. 29(11), páginas 1480-1497, 2016. ISSN 0892-7057, 1530-7980.

Roberts, R. y Jones, R. Rheological characterization of continuous fibre composites in oscillatory shear flow. Composites Manufacturing, vol. 6(34), páginas 161-167, 1995. ISSN 09567143.

Romoli, L., Fischer, F. y Kling, R. A study on UV laser drilling of PEEK reinforced with carbon fibers. Optics and Lasers in Engineering, vol. 50(3), páginas 449-457, 2012. ISSN 01438166.

Sajkiewicz, P., Carpaneto, L. y Wasiak, A. Application of the Ozawa model to non-isothermal crystallization of poly(ethylene terephthalate). Polymer, vol. 42(12), páginas 5365-5370, 2001. ISSN 00323861.

Salehiyan, R., Malwela, T. y Ray, S. S. Thermo-oxidative degradation study of melt-processed polyethylene and its blend with polyamide using time-resolved rheometry. Polymer Degradation and Stability, vol. 139, páginas 130-137, 2017. ISSN 01413910.

Saliba, T. E., Anderson, D. P. y Servais, R. A. Process Modeling of Heat Transfer and Crystallization in Complex Shapes Thermoplastic Composites. Journal of Thermoplastic Composite Materials, vol. 2(2), páginas 91-104, 1989. ISSN 0892-7057, 1530-7980.

Sattari, M., Molazemhosseini, A., Naimi-Jamal, M. y Khavandi, A. Nonisothermal crystallization behavior and mechanical properties of PEEK/SCF/nano-SiO2 composites. Materials Chemistry and Physics, vol. 147(3), páginas 942-953, 2014. ISSN 02540584.

Schaefer, P., Gierszewsit, D., Kollmannsberger, A., Zaremba, S. y Drechsler, K. Analysis and improved process response prediction of laser-assisted automated tape placement with PA-6/carbon tapes using Design of Experiments and numerical simulations. Composites Part A: Applied science and manufacturing, vol. 96, páginas 137-146, 2017a. ISSN 1359835X.

Schaefer, P., Guglhoer, T., Sause, M. y Drechsler, K. Development of intimate contact during processing of carbon fiber reinforced Polyamide6 tapes. Journal of Reinforced Plastics and Composites, vol. 36(8), páginas 593-607, 2017b. ISSN 0731-6844, 1530-7964.

Schaefer, P. M. Material characterization for determining the consolidation properties of carbon fiber tapes with PA-6 matrix. En 20th International Conference on Composite Materials. 2015. 
Schell, J., Guilleminot, J., Binetruy, C. y Krawczak, P. Computational and experimental analysis of fusion bonding in thermoplastic composites: Influence of process parameters. Journal of Materials Processing Technology, vol. 209(11), páginas 5211-5219, 2009. ISSN 09240136.

Schledjewski, R. y Miaris, A. Thermoplastic tape placement by means of diode laser heating. En SAMPE '09 Spring Symposium Conference Proceedings, Baltimore. 2009.

Schlottermuller, M., Lu, H., Roth, Y., Himmel, N., Schledjewski, R. y Mitschang, P. Thermal Residual Stress Simulation in Thermoplastic Filament Winding Process. Journal of Thermoplastic Composite Materials, vol. 16(6), páginas 497-519, 2003. ISSN 0892-7057, 1530-7980.

Segal, L. y Testa, A. Lamination of highly reinforced thermoplastic composites. 1984. US Patent 4,469,543.

SHIH, P.-J. On-Line Consolidation of Thermoplastic Composites. Tesis Doctoral, Virginia Tech, 1997.

Sánchez-Jiménez, P. E., Pérez-Maqueda, L. A., Perejón, A. y CriaDO, J. M. Generalized Kinetic Master Plots for the Thermal Degradation of Polymers Following a Random Scission Mechanism. The Journal of Physical Chemistry A, vol. 114(30), páginas 7868-7876, 2010a. ISSN 1089-5639, 1520-5215.

Sánchez-Jiménez, P. E., Pérez-Maqueda, L. A., Perejón, A. y CriaDO, J. M. A new model for the kinetic analysis of thermal degradation of polymers driven by random scission. Polymer Degradation and Stability, vol. 95(5), páginas 733-739, 2010b. ISSN 01413910.

Sánchez-Jiménez, P. E., Pérez-Maqueda, L. A., Perejón, A., Pascual-Cosp, J., Benítez-Guerrero, M. y Criado, J. M. An improved model for the kinetic description of the thermal degradation of cellulose. Cellulose, vol. 18(6), páginas 1487-1498, 2011. ISSN 0969-0239, $1572-882 \mathrm{X}$.

SoAres, J. A. N. T. Introduction to Optical Characterization of Materials. En Practical Materials Characterization, páginas 43-92. Springer New York, 2014. ISBN 978-1-4614-9280-1 978-1-4614-9281-8.

Sonmez, F. O. y Akbulut, M. Process optimization of tape placement for thermoplastic composites. Composites Part A: Applied science and manufacturing, vol. 38(9), páginas 2013-2023, 2007. ISSN 1359835X.

Sonmez, F. O. y Hahn, H. T. Analysis of the On-Line Consolidation Process in Thermoplastic Composite Tape Placement. Journal of Ther- 
moplastic Composite Materials, vol. 10(6), páginas 543-572, 1997. ISSN 0892-7057, 1530-7980.

Sonmez, F. O., Hahn, H. T. y Akbulut, M. Analysis of Process-Induced Residual Stresses in Tape Placement. Journal of Thermoplastic Composite Materials, vol. 15(6), páginas 525-544, 2002. ISSN 0892-7057, 1530-7980.

Soutis, C. Fibre reinforced composites in aircraft construction. Progress in aerospace sciences, vol. 41(2), páginas 143-151, 2005. ISSN 0376-0421.

Stokes-Griffin, C. y Compston, P. A combined optical-thermal model for near-infrared laser heating of thermoplastic composites in an automated tape placement process. Composites Part A: Applied science and manufacturing, vol. 75, páginas 104-115, 2015a. ISSN 1359835X.

Stokes-Griffin, C. y Compston, P. The effect of processing temperature and placement rate on the short beam strength of carbon fibre?PEEK manufactured using a laser tape placement process. Composites Part A: Applied science and manufacturing, vol. 78, páginas 274-283, 2015b. ISSN 1359835X.

Stokes-Griffin, C. y Compston, P. Optical characterisation and modelling for oblique near-infrared laser heating of carbon fibre reinforced thermoplastic composites. Optics and Lasers in Engineering, vol. 72, páginas 1-11, 2015c. ISSN 01438166.

Stokes-Griffin, C. y Compston, P. An inverse model for optimisation of laser heat flux distributions in an automated laser tape placement process for carbon-fibre/PEEK. Composites Part A: Applied science and manufacturing, vol. 88, páginas 190-197, 2016a. ISSN 1359835X.

Stokes-Griffin, C. y Compston, P. Investigation of sub-melt temperature bonding of carbon-fibre/PEEK in an automated laser tape placement process. Composites Part A: Applied Science and Manufacturing, vol. 84, páginas 17-25, 2016b. ISSN 1359835X.

Stokes-Griffin, C. M., Compston, P., Matuszyk, T. I. y CardewHALL, M. J. Thermal modelling of the laser-assisted thermoplastic tape placement process. Journal of Thermoplastic Composite Materials, vol. 28(10), páginas 1445-1462, 2015. ISSN 0892-7057, 1530-7980.

Supaphol, P. Application of the Avrami, Tobin, Malkin, and UrbanoviciSegal macrokinetic models to isothermal crystallization of syndiotactic polypropylene. Thermochimica Acta, vol. 370(1-2), páginas 37-48, 2001. ISSN 00406031. 
Takeda, S.-I., Tsukada, T., Minakuchi, S., Takeda, N. y Iwahori, Y. Fiber-optic Sensing for Press Forming of L-shaped Thermoplastic Composites. Procedia Engineering, vol. 188, páginas 348-353, 2017. ISSN 18777058 .

Talbot, E., Yousefpour, A., Hubert, P. y Hojuati, M. Thermal behavior during thermoplastic composites resistance welding. En Anuual Technical Conference (ANTEC) of the Society of Plastics Engineers, Boston, $M A$. Citeseer, 2005.

Talbott, M. F., Springer, G. S. y Berglund, L. A. The effects of crystallinity on the mechanical properties of PEEK polymer and graphite fiber reinforced PEEK. Journal of Composite Materials, vol. 21(11), páginas 1056-1081, 1987.

TAn, S., Su, A., LuO, J. y Zhou, E. Crystallization kinetics of poly(ether ether ketone) (PEEK) from its metastable melt. Polymer, vol. 40(5), páginas 1223-1231, 1999. ISSN 00323861.

Tardif, X., Pignon, B., Boyard, N., Schmelzer, J. W., Sobotka, V., Delaunay, D. y Schick, C. Experimental study of crystallization of PolyEtherEtherKetone (PEEK) over a large temperature range using a nano-calorimeter. Polymer Testing, vol. 36, páginas 10-19, 2014. ISSN 01429418 .

Thompson, A. B. y Woods, D. W. The transitions of polyethylene terephthalate. Transactions of the Faraday Society, vol. 52, páginas 13831397, 1956. ISSN 0014-7672.

Tierney, J. y Gillespie, J. W. Modeling of Heat Transfer and Void Dynamics for the Thermoplastic Composite Tow-Placement Process. Journal of Composite Materials, vol. 37(19), páginas 1745-1768, 2003. ISSN 00219983, 1530-793X.

Tierney, J. y Gillespie, J. W. Modeling of In Situ Strength Development for the Thermoplastic Composite Tow Placement Process. Journal of Composite Materials, vol. 40(16), páginas 1487-1506, 2006. ISSN 00219983, 1530-793X.

Tierney, J. J. y Gillespie JR., J. Crystallization kinetics behavior of PEEK based composites exposed to high heating and cooling rates. Composites Part A: Applied science and manufacturing, vol. 35(5), páginas 547-558, 2004. ISSN 1359835X.

Tofт, M. The effect of crystalline morphology on the glass transition and enthalpic relaxation in poly (ether-ether-ketone). Tesis Doctoral, University of Birmingham, 2012. 
Toso, Y. M. P. Effective automated tape winding process with on-line bonding under transient thermal conditions. Tesis Doctoral, ETH Zurich, 2003.

Tregub, A., Harel, H., Marom, G. y Migliaresi, C. The influence of thermal history on the mechanical properties of poly(ether ether ketone) matrix composite materials. Composites Science and Technology, vol. 48(1-4), páginas 185-190, 1993. ISSN 02663538.

Trende, A., Åström, B., Wöginger, A., Mayer, C. y Neitzel, M. Modelling of heat transfer in thermoplastic composites manufacturing: double-belt press lamination. Composites Part A: Applied science and manufacturing, vol. 30(8), páginas 935-943, 1999. ISSN 1359835X.

Tsotra, P., Toma, M., Pascual, A., Schadt, F., Brauner, C. y Dransfeld, C. Thermo-oxidative degradation of PEEK at high temperatures. En 18th European Conference on Composite Materials, ECCM18. 2018.

Tumkor, S., Turkmen, N., Chassapis, C. y Manoochehri, S. Modeling of heat transfer in thermoplastic composite tape lay-up manufacturing. International Communications in Heat and Mass Transfer, vol. 28(1), páginas 49-58, 2001. ISSN 07351933.

VAidya, U. K. y ChaWla, K. K. Processing of fibre reinforced thermoplastic composites. International Materials Reviews, vol. 53(4), páginas 185-218, 2008. ISSN 0950-6608, 1743-2804.

VARUn, R. Crystallization, morphology, thermal stability and adhesive properties of novel high performance semicystalline polyimides. Tesis Doctoral, Virginia Tech, 1999.

Vaughan, A. y Stevens, G. On crystallization, morphology and radiation effects in poly(ether ether ketone). Polymer, vol. 36(8), páginas 1531-1540, 1995. ISSN 00323861.

Vega, J. F., Rastogi, S., Peters, G. W. M. y Meijer, H. E. H. Rheology and reptation of linear polymers. Ultrahigh molecular weight chain dynamics in the melt. Journal of Rheology, vol. 48(3), páginas 663-678, 2004. ISSN 0148-6055, 1520-8516.

Velisaris, C. N. Heat Transfer Effects on the Processing - Structure Relationships of Polyetheretherketone PEEK Based Composites. Science and Engineering of Composite Materials, vol. 1(1), páginas 13-22, 1988.

Velisaris, C. N. y Seferis, J. C. Crystallization kinetics of polyetheretherketone (peek) matrices. Polymer Engineering and Science, vol. 26(22), páginas 1574-1581, 1986. ISSN 0032-3888, 1548-2634. 
Vyazovkin, S. Isoconversional Kinetics. En Handbook of Thermal Analysis and Calorimetry, vol. 5, páginas 503-538. Elsevier, 2008. ISBN 978-0-44453123-0.

Vyazovkin, S., Burnham, A. K., Criado, J. M., Pérez-Maqueda, L. A., Popescu, C. y Sbirrazzuoli, N. ICTAC Kinetics Committee recommendations for performing kinetic computations on thermal analysis data. Thermochimica Acta, vol. 520(1-2), páginas 1-19, 2011. ISSN 00406031 .

Vyazovkin, S. y Sbirrazzuoli, N. Isoconversional Kinetic Analysis of Thermally Stimulated Processes in Polymers. Macromolecular Rapid Communications, vol. 27(18), páginas 1515-1532, 2006. ISSN 1022-1336, 15213927.

Vyazovkin, S. y Wight, C. A. Isothermal and non-isothermal kinetics of thermally stimulated reactions of solids. International Reviews in Physical Chemistry, vol. 17(3), páginas 407-433, 1998. ISSN 0144-235X, 1366-591X.

WAN, J., Li, C., FAN, H., Bu, Z.-Y. y Li, B.-G. Elucidating isothermal crystallization behaviors of nylon-11s. Influence of star-chain branching. Thermochimica Acta, vol. 544, páginas 99-104, 2012. ISSN 00406031.

Wang, H., Zhou, F., Wang, T., Zhang, H., Liu, T. y Yang, Y. Isothermal and nonisothermal crystallization kinetics of poly(ether ether ketone)/gadolinium oxide composites. High Performance Polymers, vol. 25(5), páginas 584-593, 2013. ISSN 0954-0083, 1361-6412.

WeI, C.-L., Chen, M. y Yu, F.-E. Temperature modulated DSC and DSC studies on the origin of double melting peaks in poly(ether ether ketone). Polymer, vol. 44(26), páginas 8185-8193, 2003. ISSN 00323861.

Weiler, T., Emonts, M. y Janssen, H. On the use of flexible intensity distributions for thermoplastic tape placement by means of VCSEL. En ITHEC 2016, 3rd International Conference on Thermoplastic Composites. Bremen, 2016a.

Weiler, T., Emonts, M., Striet, P., Gronenborn, S. y Janssen, H. Optical modelling of VCSEL assisted thermoplastic tape placement. En 17th European Conference on Composite Maerials, (ECCM17). 2016b.

Weiler, T., Emonts, M., Wollenburg, L. y Janssen, H. Transient thermal analysis of laser-assisted thermoplastic tape placement at high process speeds by use of analytical solutions. Journal of Thermoplastic Composite Materials, vol. 31(3), páginas 311-338, 2018. ISSN 0892-7057, 1530-7980. 
Woo Il Lee y Springer, G. S. A Model of the Manufacturing Process of Thermoplastic Matrix Composites. Journal of Composite Materials, vol. 21(11), páginas 1017-1055, 1987. ISSN 0021-9983, 1530-793X.

Wool, R. P. Diffusion and autohesion. En Adhesion Science and Engineering, páginas 351-401. Elsevier, 2002. ISBN 978-0-444-51140-9.

Wool, R. P. y O'Connor, K. M. A theory crack healing in polymers. Journal of Applied Physics, vol. 52(10), páginas 5953-5963, 1981. ISSN 0021-8979, 1089-7550.

Xu, J. Equilibrium Melting Temperature Determination of Semicrystalline Polymers through Nonlinear Hoffman-Weeks Extrapolation and Secondary Crystallization of Ethylene/Styrene Copolymers. Tesis Doctoral, Virginia Tech, 1999.

Yamada, K., Hikosaka, M., Toda, A., Yamazaki, S. y Tagashira, K. Equilibrium melting temperature of isotactic polypropylene with high tacticity:1. determination by differential scanning calorimetry. Macromolecules, vol. 36(13), páginas 4790-4801, 2003. ISSN 0024-9297.

Yan, X., Imai, Y., Shimamoto, D. y Hotta, Y. Relationship study between crystal structure and thermal/mechanical properties of polyamide 6 reinforced and unreinforced by carbon fiber from macro and local view. Polymer, vol. 55(23), páginas 6186-6194, 2014. ISSN 00323861.

Yang, C., Tian, X., Li, D., CaO, Y., Zhao, F. y Shi, C. Influence of thermal processing conditions in $3 \mathrm{D}$ printing on the crystallinity and mechanical properties of PEEK material. Journal of Materials Processing Technology, vol. 248, páginas 1-7, 2017. ISSN 09240136.

Yang, F. y Pitchumani, R. A fractal Cantor set based description of interlaminar contact evolution during thermoplastic composites processing. vol. 36(19), páginas 4661-4671, 2001. ISSN 1573-4803.

Yang, F. y Pitchumani, R. Healing of Thermoplastic Polymers at an Interface under Nonisothermal Conditions. Macromolecules, vol. 35(8), páginas 3213-3224, 2002a. ISSN 0024-9297, 1520-5835.

Yang, F. y Pitchumani, R. Interlaminar contact development during thermoplastic fusion bonding. Polymer Engineering \& Science, vol. 42(2), páginas 424-438, 2002b. ISSN 0032-3888, 1548-2634.

Yang, F. y Pitchumani, R. Nonisothermal healing and interlaminar bond strength evolution during thermoplastic matrix composites processing. Polymer Composites, vol. 24(2), páginas 263-278, 2003. ISSN 0272-8397, 1548-0569. 
Yao, F., Zheng, J., Mingbi, Q., Wang, W. y Zongneng, Q. The thermal decomposition kinetics of poly (ether-ether-ketone) (PEEK) and its carbon fiber composite. Elsevier, vol. 183, páginas 91-97, 1991. ISSN 0040-6031.

Yu, T., Shi, Y., He, X., Kang, C. y Deng, B. Modeling and optimization of interlaminar bond strength for composite tape winding process. Journal of Reinforced Plastics and Composites, vol. 36(8), páginas 579-592, 2017. ISSN 0731-6844, 1530-7964.

Yu, T., Wu, C. M., Chang, C. Y., Wang, C. Y. y Rwei, S. P. Effects of crystalline morphologies on the mechanical properties of carbon fiber reinforcing polymerized cyclic butylene terephthalate composites. Express Polymer Letters, vol. 6(4), páginas 318-328, 2012. ISSN 1788618X.

Zaffiro, P. A. Control of radiant heating system for thermoplastic composite tape. 1993. US Patent 5,177,340.

Zhang, M., BaO-HuA, G. y Xu, J. A review on polymer crystallization theories. Crystals, vol. 7(1), página 4, 2016.

Zhao, P., Shirinzadeh, B., Shi, Y., Cheuk, S. y Clark, L. Multi-pass layup process for thermoplastic composites using robotic fiber placement. Robotics and Computer-Integrated Manufacturing, vol. 49, páginas 277284, 2018. ISSN 07365845 . 

